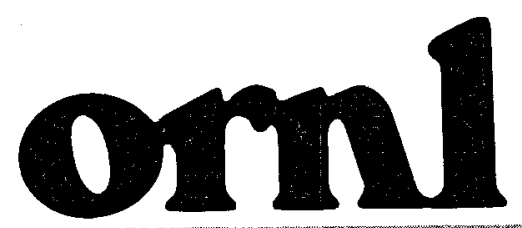

OAK RIDGE

NATIONAL

LABORATORY

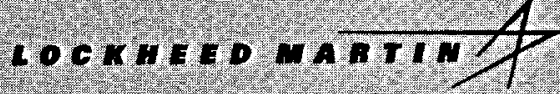

\section{RECEIVED}

JAN 291997

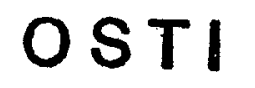

\section{NATTVE HAWAIIAN ETHNOGRAPHIC STUDY FOR THE HAWAI' I GEOTHERMAL PROJECT PROPOSED FOR PUNA AND SOUTHEAST MAUI}

\author{
by \\ Jon K. Matsuoka, \\ Davianna Pomaika i McGregor, \\ Luciano Minerbi \\ Cultural Advocacy Network for Developing \\ Options (CANDO) \\ Pualani Kanahele, \\ Marion Kelly, \\ Noenoe Barney-Campbell \\ L. D. Trettin \\ J. W. Saulsbury \\ Energy Division \\ ORNL Subcontract Managers
}

RSTHETIU, OF THS JOOUIJT IS UNLRITED

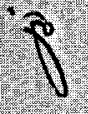

MANAGED AND OPERATED BY LOCKHEEO UARTIN ENERGY RESEARCH CORPOBATION FOR THE UNTED STATES DEPARTIENT OF ENERGY 


\section{DISCLAIMER}

This report was prepared as an account of work sponsored by an agency of the United States Government. Neither the United States Government nor any agency Thereof, nor any of their employees, makes any warranty, express or implied, or assumes any legal liability or responsibility for the accuracy, completeness, or usefulness of any information, apparatus, product, or process disclosed, or represents that its use would not infringe privately owned rights. Reference herein to any specific commercial product, process, or service by trade name, trademark, manufacturer, or otherwise does not necessarily constitute or imply its endorsement, recommendation, or favoring by the United States Government or any agency thereof. The views and opinions of authors expressed herein do not necessarily state or reflect those of the United States Government or any agency thereof. 


\section{DISCLAIMER}

Portions of this document may be illegible in electronic image products. Images are produced from the best available original document. 
This report has been reproduced directly from the best available copy.

Available to DOE and DOE contractors from the Office of Scientific and Technical Information, P. O. Box 62. Oak Ridge. TN 37831; prices available from (423) 576-8401, FTS 626-8401.

Available to the public from the National Technical Information Service, U.S. Department of Commerce. 5285 Port Royal Road. Springfield. VA 22161.

This report was prepared as an account of work sponsored by an agency of the United States Government. Neither the United States Government nor any agency thereof, nor any of their employees, makes any warranty, express or implied, or assumes any legal liability or responsibility for the accuracy, completeness, or usefulness of any information, apparatus, product, or process disclosed, or represents that its use would not infringe privately owned rights. Reference herein to any specific commercial product, process, or service by trade name. trademark, manufacturer, or otherwise, does not necessarily constitute or imply its endorsement. recommendation. or favoring by the United States Government or any agency thereof. The views and opinions of authors expressed herein do not necessarily state or reflect those of the United States Government of any agency thereof. 


\title{
NATIVE HAWAIIAN ETHNOGRAPHIC STUDY FOR THE HAWAI'I GEOTHERMAL PROJECT PROPOSED FOR PUNA AND SOUTHEAST MAUI
}

\author{
Jon K. Matsuoka, Ph.D. \\ Davianna Pomaika'i McGregor, Ph.D. \\ Luciano Minerbi, Dr. Arch., AICP \\ Cultural Advocacy Network for Developing Options \\ (CANDO) \\ Pualani Kanahele \\ Marion Kelly, MA \\ Noenoe Barney-Campbell, MA \\ L. D. Trettin* \\ J. W. Saulsbury \\ Energy Division \\ ORNL Subcontract Managers
}

University of Tennessee* 6154000

May 1996

Prepared for:

U.S. Department of Energy

Oak Ridge Operations Office

by

OAK RIDGE NATIONAL LABORATORY

Oak Ridge, Tennessee 37831

managed by

LOCKHEED MARTIN ENERGY RESEARCH CORP.

for the

U.S.DEPARTMENT OF ENERGY

under contract DC-AC05-960R22464 


\section{TABLE OF CONTENTS}

PREFACE.

LIST OF TABLES viii

CHAPTER 1: INTRODUCTION ...........................................................................................1

PURPOSE AND GUIDEL INES........................................................................................................................................ 1

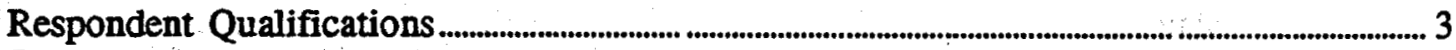

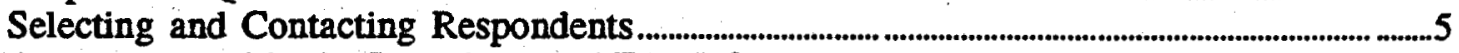

Areas Assessed in the Interviews and Focus Groups ............................................................. 7

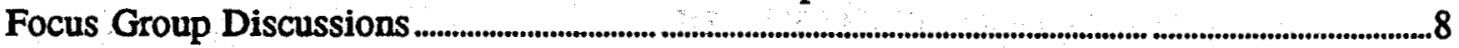

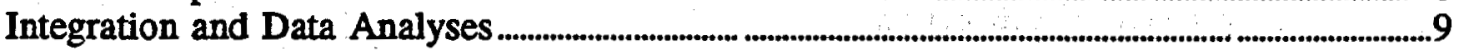

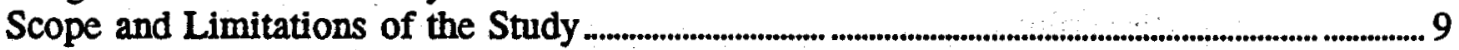

Contemporary Political Status of Hawaiians: Why an Ethnography on Hawaiians............... 10

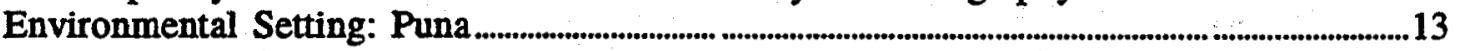

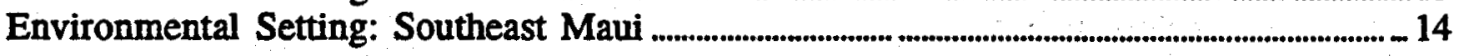

CHAPTER 2: THE ETHNOHISTORY OF PUNA AND SOUTHEAST MAUI................................ 17

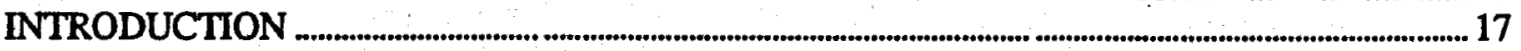

Land/Nature: The Foundation of Hawaiian Customs, Beliefs, and Practices ............................ 17

Cultural Kipuka: A Framework for the Ethnography of Puna and South Maui ......................... 18

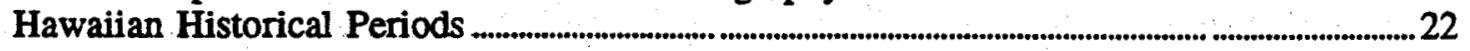

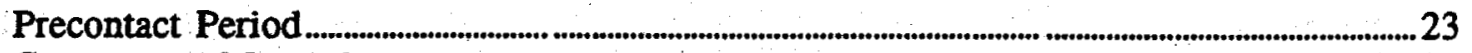

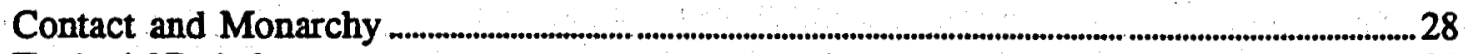

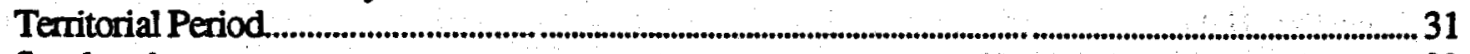

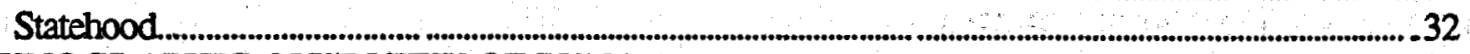

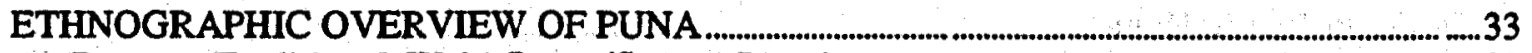

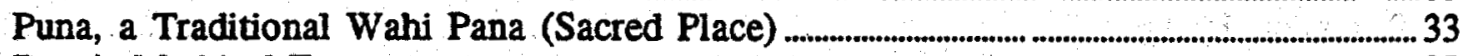

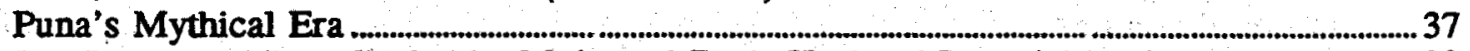

The Legend of Pele, Waka the Mo'o and Their Husband Puna-'ai-koa'e.................................. 38

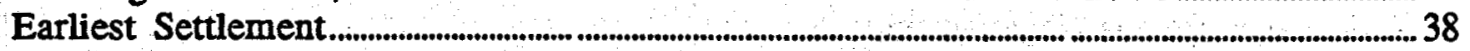

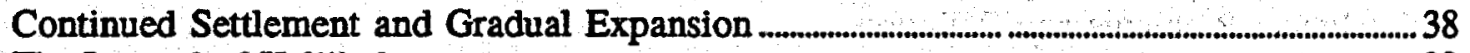

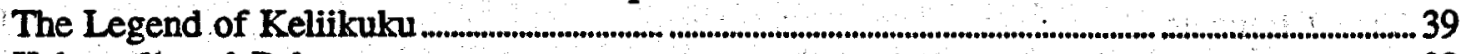

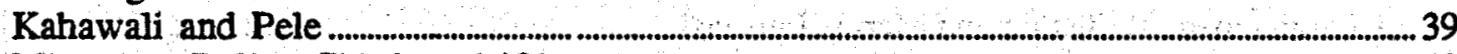

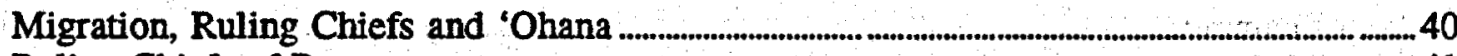

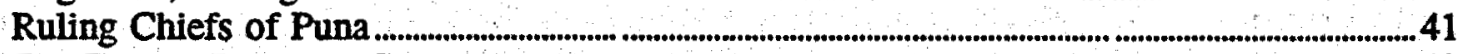

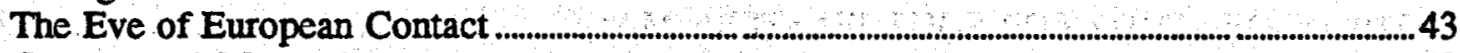

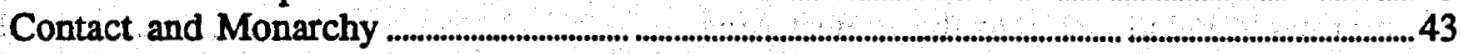

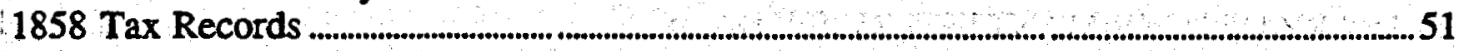

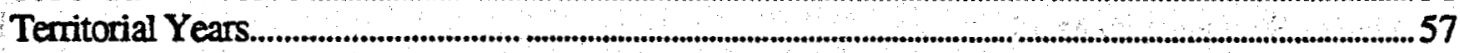

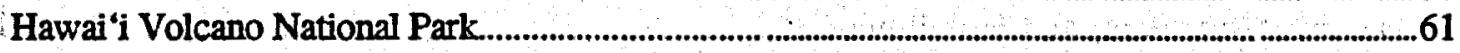

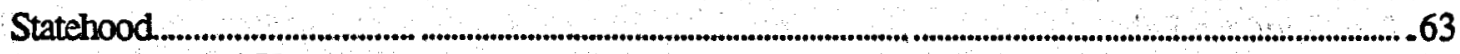

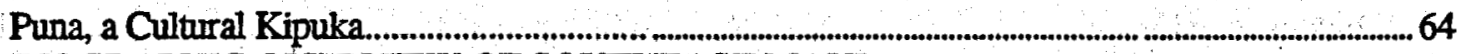

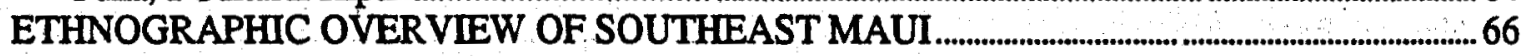

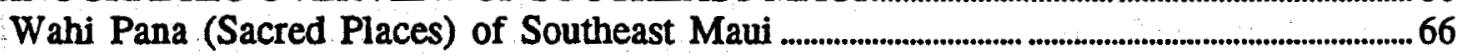

The Mythical Era of Southeast Maui ..................................................................................................6 69 


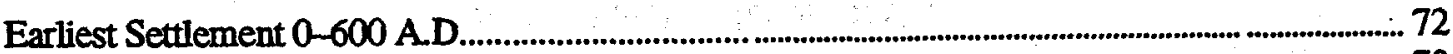

Continued Settlement and Gradual Expansion 600-1100 A.D........................................................ 73

Migration, Ruling Chiefs and 'Ohana 110-1400 A.D....................................................................... 75

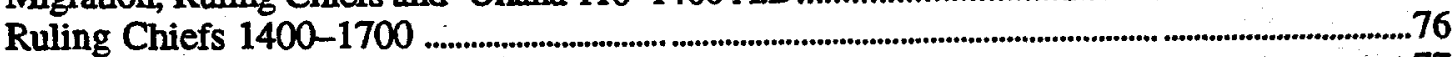

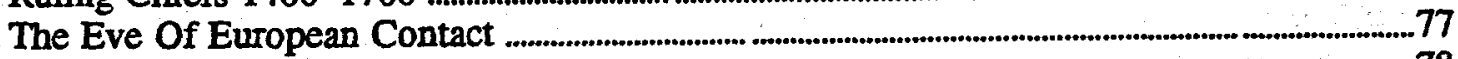

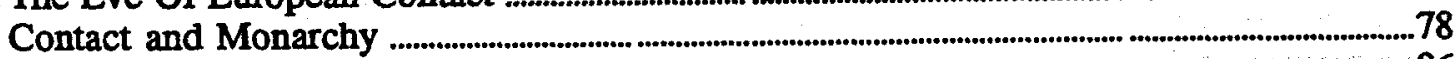

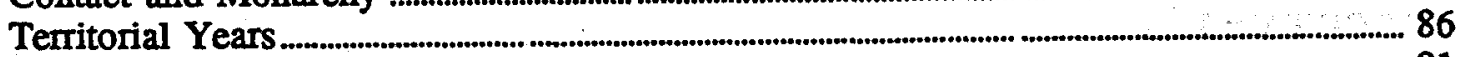

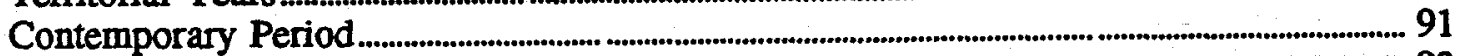

Ahihi-Kina' $u$ and Kanaio Natural Area Reserves (NAR) ......................................................93

ASSESSMENT OF SITE AND DISTRICT SIGNIFICANCE FOR NOMINATION TO

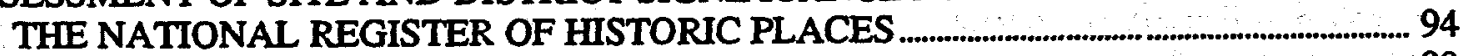

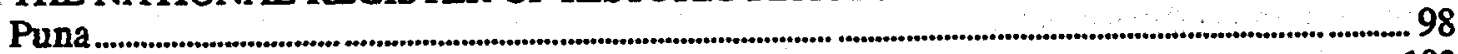

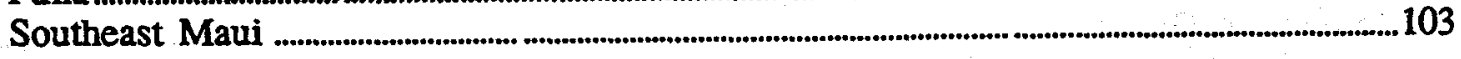

CHAPTER 3: ETHNOGRAPHIC FIELDWORK

COMPARING PUNA AND SOUTHEAST MAUI...................................................................................107

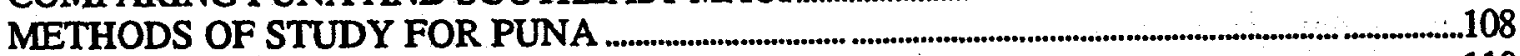

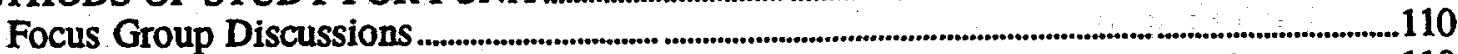

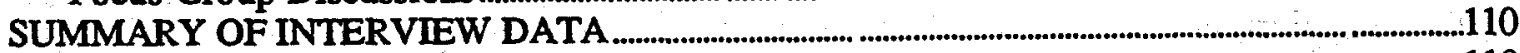

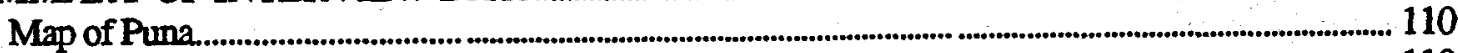

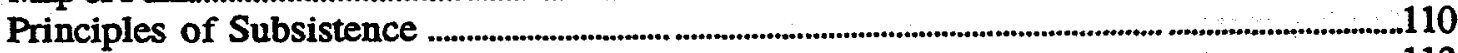

Spiritual Beliefs and Practices ...................................................................................................................... 113

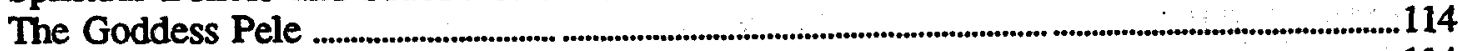

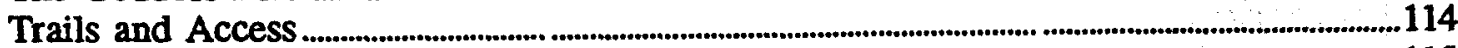

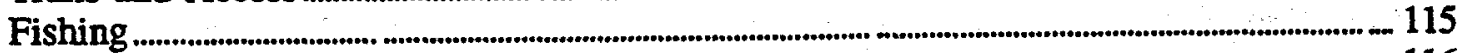

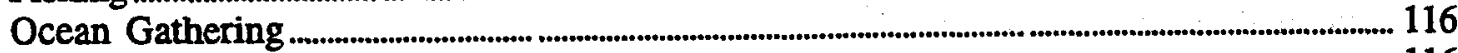

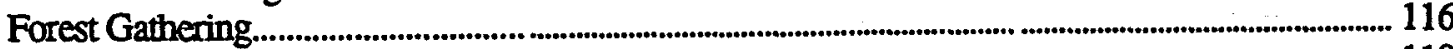

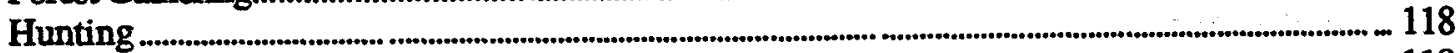

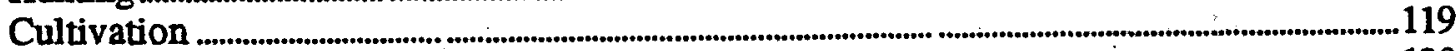

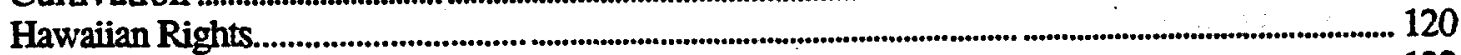

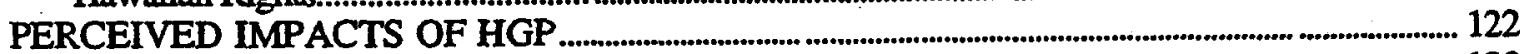

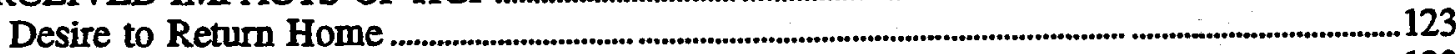

Perceptions by Age........................................................................................................................................... 123

Impacts on the Forest...................................................................................................................................... 124

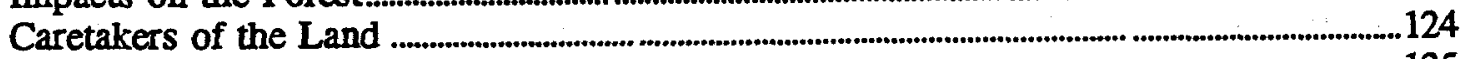

Advantages Versus Negative Impacts ..........................................................................................................125

Technical Problems and Pollution .....................................................................................................125

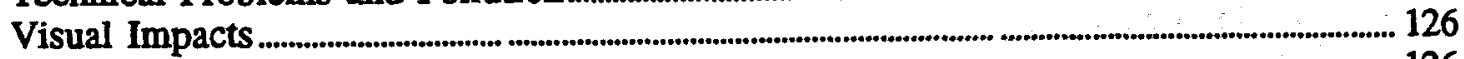

Electromagnetic Radiation and Marine Impacts........................................................................... 126

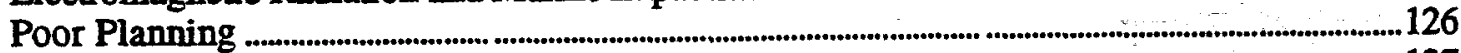

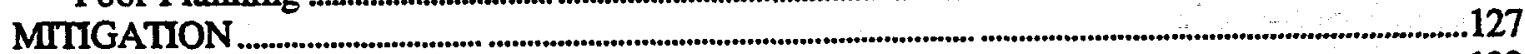

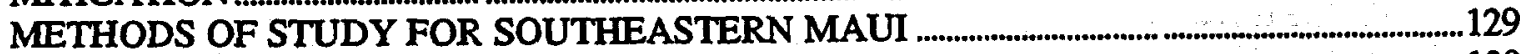

Informants Relationship to the Project Area ................................................................................130

SUMMARY OF INFORMANT INTERVIEW DATA

Map of Southeastern Maui............................................................................................................... 130

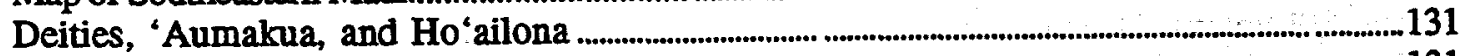

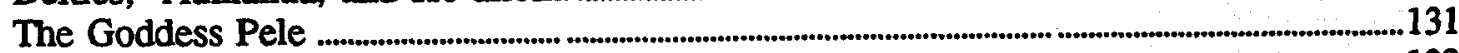

Religious Practices........................................................................................................................ 132

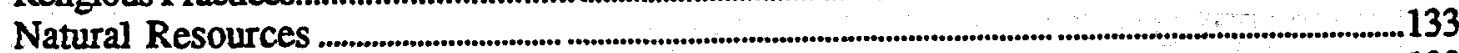

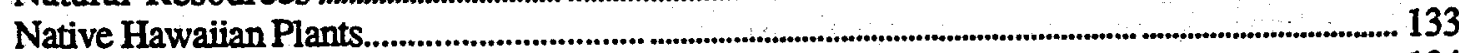

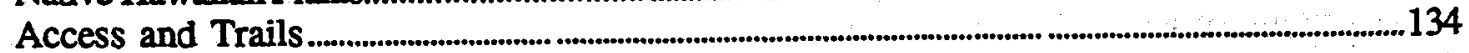




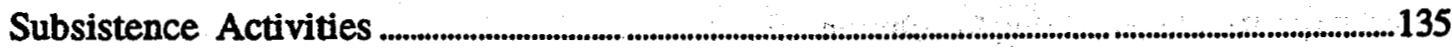

Fishing and Ocean Gathering

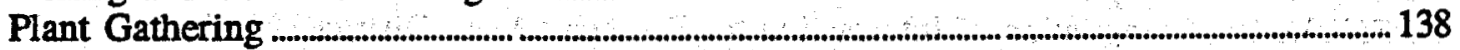

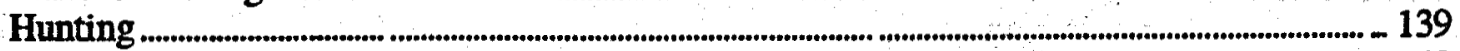

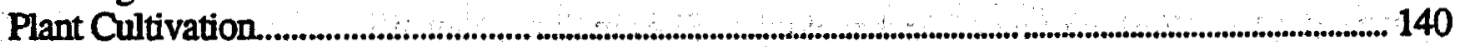

PERCEIVED IMPACTS OF HGP

Native Hawaiian Rights and Intended Use of the Area................................................................. 140

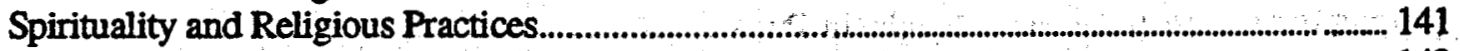

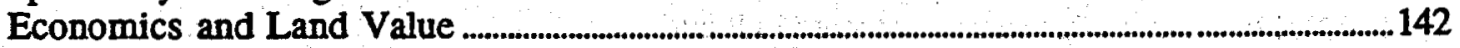

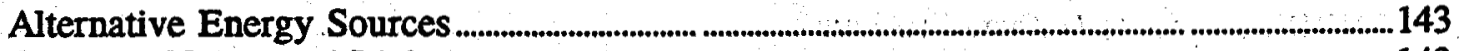

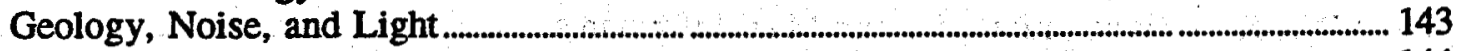

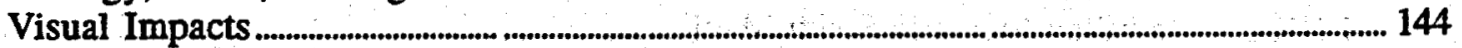

Electromagnetic Radiation and Concerns about Health................................................................ 144

Marine Life and Ecology, and Fishing Grounds.................................................................................. 145

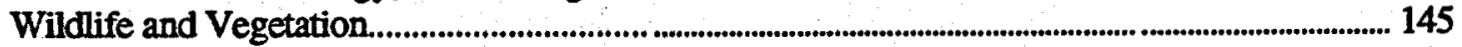

Construction, Maintenance, Traffic and Population Growth........................................................ 146

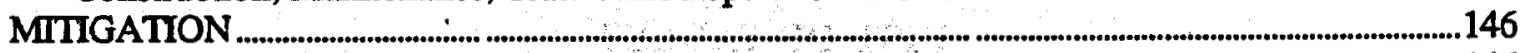

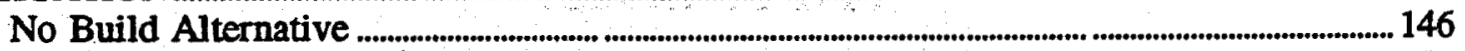

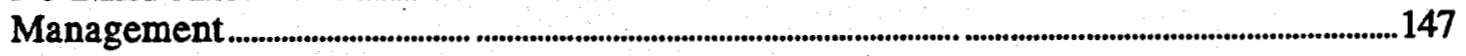

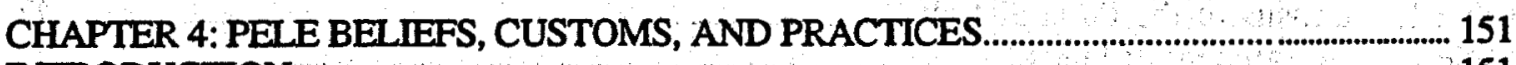

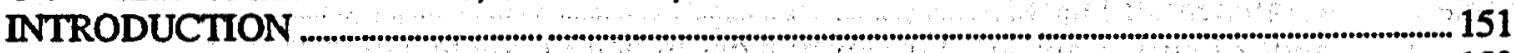

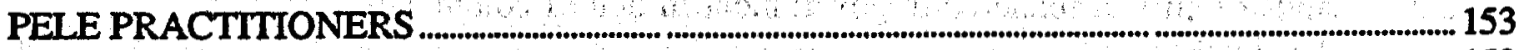

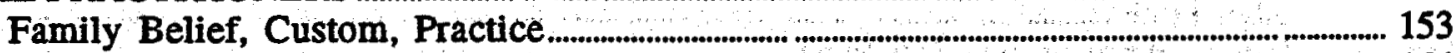

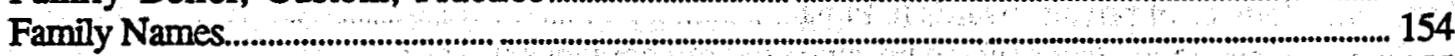

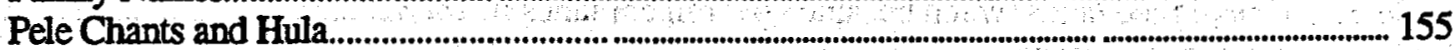

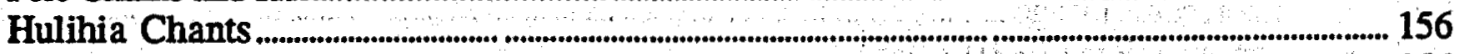

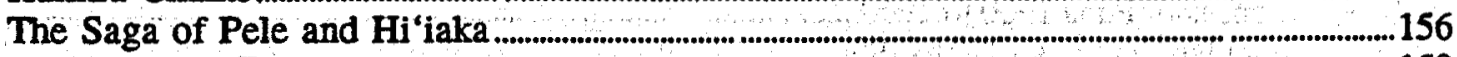

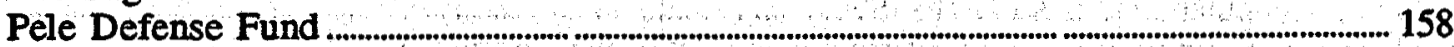

Pele Acknowledged and Worshipped as Hawaiian Akua

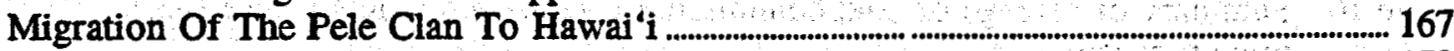

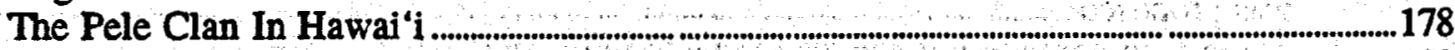

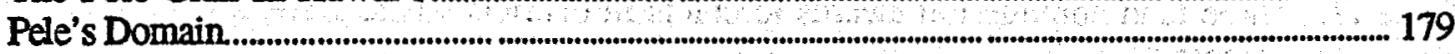

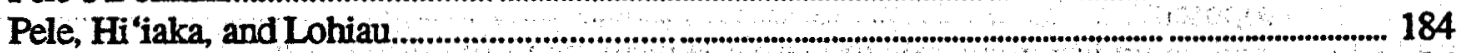

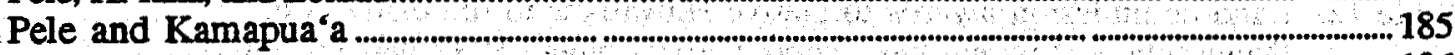

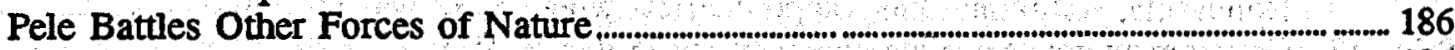

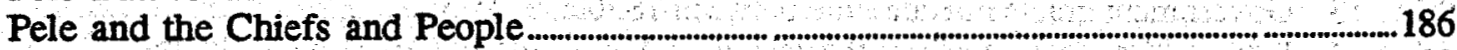

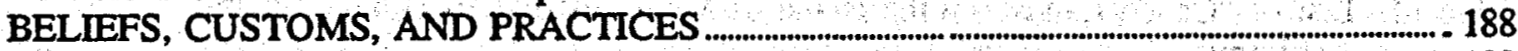

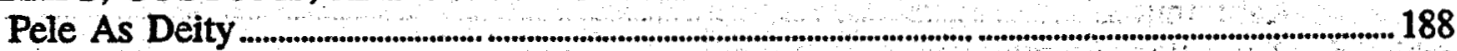

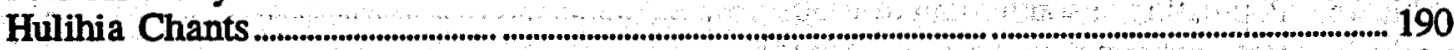

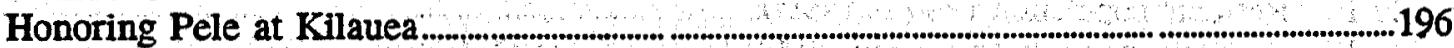

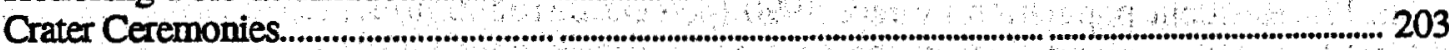

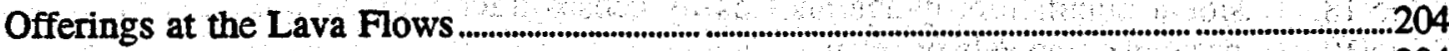

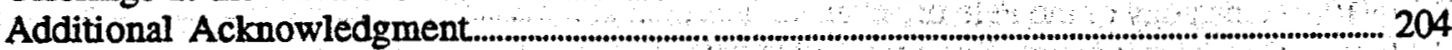

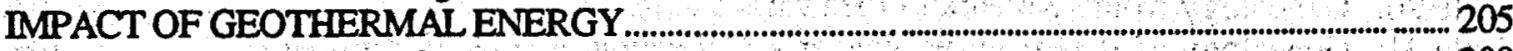

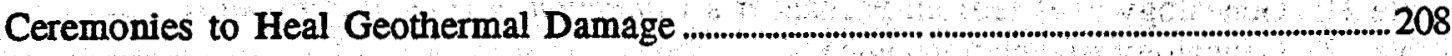

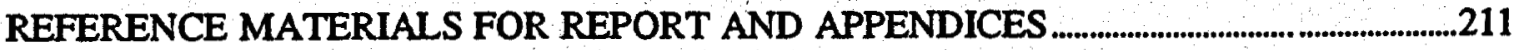

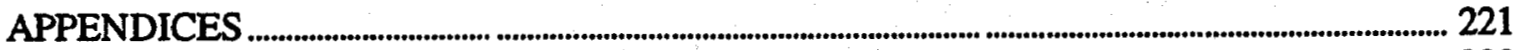

APPENDIX A: Materials Used During Informant Interviews ..................................................................223 
APPENDIX B: Senate Joint Resolution 19.................................................................................................239

APPENDIX C: Compilation of Information for Puna ............................................................. 245

APPENDIX D: Compilation of Information for Southeast Maui District Honolua'ula Land Section ............................................................................................................283

APPENDIX E: Working List of Archaeological Sites in Puna, Hawai 'i...................................... 303

APPENDIX F: . Wao Kele 'O Puna Natural Area Reserve ................................................................311

APPENDIX G: Classification of Puna Informants ....................................................................... 349

APPENDIX H: Fish Species Caught in Puna ........................................................................................ 351

APPENDIX I: Ocean Resources Gathered in Puna................................................................................. 353

APPENDIX J: Plants Gathered in Puna ................................................................................................ 355

APPENDIX K: Classification of South Maui Informants...................................................................... 357

APPENDIX L: Hawaiian Plants in South Maui ....................................................................................... 359

APPENDIX M: Interview with Renee Silva ...................................................................................................363

\section{LIST OF TABLES}

Table 1. Census of the Puna district........................................................................................................................... 47

Table 2. Assignment of lands ..............................................................................................................................48

Table 3. Lands of ali' $i$ surrendered to government in lieu of commutation due on other lands

Table 4. Indices of private awards in Puna.................................................................................................... 49

Table 5. Unassigned lands which became government lands in 1888........................................... 51

Table 6. Tax records by age.................................................................................................................................... 52

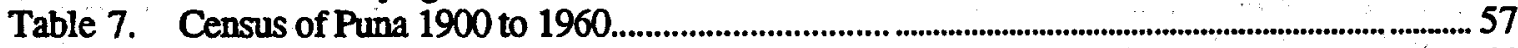

Table 8. Population trends 1970 to 1990 ...............................................................................................6 64

Table 9. Government lands in districts where HGP was proposed.......................................................82

Table 10. Summary of acreage of land commission awards in districts where HGP was proposed

Table 11. Three land commission awards to chiefs in districts where HGP was proposed

Table 12. Land commission awards to Native Hawaiians in the districts of Honua'ula, Kahikinui and Kaupo districts where HGP was proposed .............................84

Table 13. Government grants in Kahikinui between 1856 and 1965 .................................................85

Table 14. List of "Ceded Lands" on the island of Maui, districts of Honua 'ula and Kahikinui

Table 15. Population of south Maui in 1930 ................................................................................................99

Table 16. Resident population 1980 and 1990............................................................................................... 92

Table 17. Resident population by race 1990 (percent distribution)..............................................92

Table 18. Resident population by age and sex by census tract 1990 ..................................................92

Table 19. Genealogy of the Pele fire clan................................................................................................ 161

Table 20. Genealogy from " $\mathrm{Ka}$ Hoku O Hawai $\mathrm{i}$ "

Table 21. Genealogy of Pele from Fornander's Collection of Hawaiian Folklore..................... 164

Table 22. Genealogy of Pelehonuamea .................................................................................................................. 165 


\section{LIST OF FIGURES}

Figure 1. General locations of use areas and cultural and historic sites in Southeastern Maui.

Figure 2. General locations of subsistence activities, trails, and ancient sites in Puna. 


\section{CHAPTER 1}

\section{INTRODUCTION}

This Native Hawaiian ethnographic study is comprised of 4 chapters. Chapter 1 , which was written by Jon $\mathbf{K}$. Matsuoka, Davianna Pomaika'i McGregor, and Luciano Minerbi, provides background information on the framework of the study and a description of federal guidelines and Native Hawaiian political status which was used in the design of the study. This chapter includes a description of the study objectives and major tasks, respondent qualifications, research methodologies, and a description of the environmental settings of Puna and Southeastern Maui. Chapter 2 is a report on the ethnographic fieldwork conducted for the two study areas. Each section (Puna and Southeastern Maui) includes a description of the research methodologies, sample description, a map of subsistence areas and practices, and a summary of the interview and focus group data. Jon $\mathbf{K}$. Matsuoka, Davianna Pomaika' $i$ McGregor, Pualani Kanahele, and Noenoe Barney-Campbell coauthored the Puna section and Luciano Minerbi and Marion Kelly co-authored the Southeastern Maui section. Chapter 3 is an ethnohistory of Puna and South Maui. Each section includes an historical overview of events and figures from the mythical era to the contemporary period. Included in this chapter are extensive appendices for Puna and South Maui which are compilations/descriptions of place names, natural and other features, and legendary and historical figures and events. Davianna Pomaika'i McGregor and Noenoe Barney-Campbell co-authored the Puna ethnohistory and Luciano Minerbi and Marion Kelly co-authored the Southeastern Maui section. Finally, Chapter 4 is a description of Pele beliefs, customs, and practices. This chapter is coauthored by Native Hawaiian religious authorities Pualani Kanahele and Davianna McGregor. It is in tended to contribute to an understanding of Native American religions as mandated by the American Indian Religious Freedom Act. This chapter discusses broad impacts of geothermal development from the viewpoint of practitioners. The research project team was comprised of numerous individuals who assisted in data gathering, transcribing, contacting informants, organizing focus groups, site visitations, etc. ${ }^{1}$

\section{PURPOSE AND GUIDELINES}

The purpose of this study was to gather information on Hawaiian ethnographic resources in the regions of Puna and Southeast Maui, particularly traditional cultural properties, as described in and in conformance with: The National Register Bulletin \#38 "Guidelines for Evaluating and Documenting Traditional Cultural Properties", and The National Register Bulletin \#30 "Guidelines for Evaluating and Documenting Rural Historic Landscapes." The concept of traditional cultural properties refers to those beliefs, customs, and practices of a living community of people that are associated with natural resources and prehistoric or historic sites. These aspects of culture have been passed down through the generations, usually orally or through practice. Properties to which traditional cultural value is ascribed often take on a vital significance, so that any damage to or infringement upon them

\footnotetext{
${ }^{1}$ Luana Busby was the on-site coordinator for Puna and Leslie Kuloloio was the on-site coordinator for Southeastern Maui. Malia Ka'ai was a graduate research assistant for the Southeastern Maui area and Wisma Manuar was a graduate research assistant for the general project. Mark Luning was the project's accountant.
} 
is perceived to be deeply offensive to, and even destructive of, the group that values them (National Register Bulletin \#38).

This ethnographic study was originally intended as part of a larger environmental impact statement (EIS) that was being prepared by the U.S. Department of Energy (DOE) to identify and assess the potential environmental impacts of the Hawai'i Geothermal Project (HGP). However, on May 17, 1994, DOE published a notice in the Federal Register (Fed. Regis. 59 25638) withdrawing its Notice of Intent (Fed. Regis. 57 5433) of February 14, 1992, to prepared the HGP EIS. Since the State of Hawai' $i$ is no longer pursuing or planning to pursue the HGP, DOE considers the project to be terminated. The ethnographic study was completed, however, because DOE intends to archive and make available information developed for the EIS project. The EIS would have requested DOE's compliance with the National Environmental Policy Act of 1969 (NEPA), the National Historic Preservation Act of 1966 (NHPA) (as amended through 1992), the American Indian Religious Freedom Act of 1978 (AIRFA), the Native American Graves Protection and Repatriation Act of 1990 (NAGPRA), and other federal and State legislation pertaining to the protection of cultural resources and Native Hawaiian rights and beliefs.

These statutory requirements and policies served to guide the study design in terms of the use of particular research methodologies, sample selection, and processes. The study was designed to identify and thoroughly assess Native Hawaiian cultural resources, particularly significant sites and traditional cultural properties, with regard to potential impacts of the HGP in the two proposed project areas. The information sought was related primarily to Native Hawaiian resources in terms of ecological (atmospheric/terrestrial/aquatic) impacts, subsistence impacts, cultural impacts, and spiritual/religious impacts.

The objectives of the study were to:

1. Describe sites and areas of cultural and historical use and significance in the Puna and Southeast Maui areas;

2. Identify and describe the known natural and cultural resources in Puna and Southeast Maui;

3. Describe Native Hawaiian beliefs and customs as they relate to culture, religion, and subsistence;

4. Describe and assess Native Hawaiian concerns about the potential affects of HGP on the aforementioned aspects of culture and the requisite natural resources; and

5. Develop recommendations and suggest mitigation efforts related to the proposed HGP.

The major tasks of the study were to:

1. Conduct literature searches at the following locations: the University of Hawai' $i$ Hamilton Library, Bernice Pauahi Bishop Museum, Lyman Museum, Volcano National Park Museum, Maui Historical Society Museum, Hawai ${ }^{\prime} i$ Mission Children's Library, and the Hawai'i State Archives. This activity provided a foundation for 
ethnohistorical and ethnographic information on Native Hawaiian cultural, religious, and subsistence customs, beliefs, and practices as it related to the two project areas.

2 Review Pele chants and chants for South Maui to identify significant sites, wahi pana (sacred areas), and cultural and religious use areas.

3. Extract place names from historical maps found in museums and archives for interpretation by tradition bearers and practitioners. There is a broad range of meanings for many Hawaiian place names and there is extensive speculation over meanings that may have been obscured over generations. The intent of this aspect of the research was to clarify the location, geographic extent, and possible pronunciation and cultural meaning.

4. Contact Native Hawaiian ohana (extended family) and cultural groups that were likely to be affected by the proposed HGP and consult with them in order to develop: (a) a list of community informants, and (b) a list of cultural experts and practitioners for indepth interviews and for focus group discussions.

5. Create a map of subsistence use areas as identified by informants. Native Hawaiians who actively engage in subsistence practices identified places where the activity occured and the types of resources obtained. This exercise provided critical information on subsistence regarding its range, frequency, type of resource, etc.

Native Hawaiians with close ancestral ties and traditional knowledge of natural and cultural resources in Puna and South Maui were the primary participants in this study. However, a wide range of Native Hawaiians are involved in or seek to revive and reestablish traditional cultural, religious, and subsistence customs and practices in the two project areas. The sampling strategy involved contacting and engaging groups and individuals from the two project areas who represented the broad range of concerns and viewpoints.

\section{Respondent Qualifications}

In order to acquire information relevant to the study objectives, individuals were sought for both in-depth interviews and focus group discussions. Several terms have been used in past ethnographic efforts to describe individuals who have been identified as experts whose knowledge is worthy of documenting for the purposes of advancing indigenous knowledge, decision-making, or policy/program development. Such terms have included: tradition bearer, kama'aina witness, kupuna, cultural informant, and practitioner. These terms are not mutually exclusive and it is difficult to make exact distinctions between the populations they are intended to tepresent. They refer to a broad range of individuals who may be scholars who have researched aspects of Hawaiian culture, individuals who practice traditional customs as a way of everyday life, those who possess traditional knowledge of places they may no longer visit, those who have a deep understanding of customs they no longer practice, educators and proprietors, etc. Respondents for this study included all of the above although a major emphasis was placed on identifying those persons with traditional knowledge of places, customs, and practices in the two project areas. Those who were chosen for interviews or focus groups were principal individuals who had a deep and vested knowledge of Hawaiian culture and practices.

Native Hawaiians are not today organized as a nation. Efforts are underway to reconstitute a government for a sovereign Native Hawaiian nation and there are many 
organizations who are involved at different levels in the process. In the absence of a national government, 'ohana (extended family) networks also survive as significant social organization units in rural Native Hawaiian communities.

Consultation with interested and affected Native Hawaiians was therefore approached at different levels-from the 'ohana networks in the rural areas included in the HGP to the Native Hawaiian organizations (e.g., Puna Hui 'Ohana, Pele Defense Fund, Ka. 'Ohana O Kahikinui, Malama I Na Kupuna) as well as groups concerned with the broader issues relating to sovereignty, redress, and reparations (e.g., Office of Hawaiian Affairs, Ka Lahui Hawai' $\left.{ }^{i}\right)$.

Native Hawaiians who live closest to the project areas may have a different interest and stake in their natural and cultural resources compared to those who live at a distance. The availability of natural and cultural resources for traditional Native Hawaiian customs, beliefs, and practices are important to individuals and 'ohana as part of maintaining their subsistence livelihoods, mutual support networks, and family heritage. At the broader societal level, maintaining natural and cultural resources for traditional customs, beliefs, and practices are often viewed as being essential to the perpetuation of Native Hawaiians as a distinct and unique people. The interests are different and equally important to acknowledge.

National Register Bulletin \#38 provides guidelines on how to evaluate and document traditional cultural properties which were instructive to the design of this ethnographic study. It defines culture as the traditions, beliefs, practices, lifeways, arts, crafts, and social institutions of any community, be it an Indian tribe, a local ethnic group, or the people of the nation as a whole. It notes the importance of consulting with groups and individuals who have special knowledge about and interests in the history and culture of the area to be studied. It cautions that the interests of the contemporary sources should be carefully considered be cause individuals who have economic interests in the potential development of an area may be motivated to deny its cultural significance. More subtly, individuals who regarded traditional practices and beliefs as backward and contrary to the best contemporary interests of the group that once ascribed significance to a property, may feel justified in saying that such significance has been lost, or was never ascribed to the property.

The following categories of people, placed in order of significance, provided operational definitions of those who qualified as respondents for the study:

A Members of Native Hawaijan 'ohana who lived in close proximity to the natural /cultural resource area and who frequently use the area for cultural, religious, or subsistence purposes. In some cases, these 'ohana were seeking to reestablish and revive cultural, religious, or subsistence uses of the area. These persons had ahupua'a tenant gathering rights under Article XII, Section 7 of the Hawai'i State Constitution.

Also included were members of 'ohana who may be non-residents but whose genealogies trace their origin or some family connection to these districts even though no family member resided there. These are individuals who have maintained close ancestral ties to the major study areas and those who wish, particularly from a distance, to maintain an opportunity to exercise particular religious or gathering rights. These persons can claim ahupua'a tenant gathering rights under Article XII. Section 7 of the Hawaj'i State Constitution through their 'ohana ties to the area being considered. 
B. Non-Hawaiians who were part of a Hawaiian ohana through intermarriage or hanai (raised as part of the ohana) were included in the above categories. As members of 'ohana who were resident of a district, these persons could also claim ahupua'a tenant gathering rights under Article XII, Section 7 of the Hawai' $i$ State Constitution.

C Hawaiian individuals or groups who lived outside of the natural/cultural resource area but have established or seek to re-establish and revive religious, cultural, or subsistence practices in those districts. This would include traditional Hawaiian healers

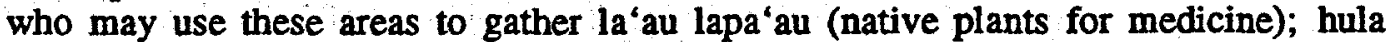
halau whose chants and dances honor deities associated with the natural/cultural resource area who may need to gather certain native plants from these districts; and fishermen, hunters, gatherers, taro planters, etc. who have accessed and used the natural/cultural resource area for subsistence. Access for this group is covered under Hawai'i Revised Statutes 1-1 "Hawaiian usage" but if they are not residents of the area they are not included under ahupua'a tenant gathering rights under Article XII, Section 7 of the Constitution.

D. Non-Hawaiians who may frequent the area in the company of Hawaiians who are in the above categories were also included. Access for this group is covered under HRS 1-1 "Hawaiian usage."

E Native Hawaiian groups/organizations who have established or seek to revive and re establish cultural, religious, or subsistence customs, beliefs, and practices. Proposed amendments to the American Indian Religious Freedom Act (AIRFA) provide a useful basis for defining the term "Native Hawaiian organizations." They state that Native Hawaiian organization means, "any organization which is composed primarily of Native Hawaiians, serves and represents the interests of Native Hawaiians and whose members (a) practice a Native American (Hawaiian) religion or conduct traditional ceremonial rituals, or (b) utilize, preserve, and protect Native American (Hawaiian) religious sites." The Native American Graves Protection and Repatriation Act (NAGPRA) definition of Native Hawaiian organization is "any organization that 1) serves and represents the interests of Native Hawaiians; 2) has as a primary and stated purpose the provision of services to Native Hawaiians; and 3) has expertise in Native Hawaiians affairs. Such organizations shall include the Office of Hawaiian Affairs and Hui Ma lama I Na Kupuna 'O Hawai'i Nei”' (43 CFR Part 10.2, Definitions):

For the purposes of this study, the Native Hawailan groups/organizations sought included interests beyond religion. Such groups include those organized for the purposes of subsistence and cultural perpetuation.

F. In the case of Hawaiian Homelands (Kaohe-Maku' $u$, Puna, Kahikinui, South Maui), individuals and their 'ohana who were seeking to become established on those lands as stewards, curators, settlers, or license holders.

\section{Selecting and Contacting Respondents}

A list of key informants was compiled after extensive discussions with researchers who had conducted previous studies in the two districts, discussions with community leaders, 
a review of lists or registries of meetings and organizations related to the subject of geothermal development, and names suggested to us by those who were interviewed. ${ }^{2}$ Upon contact ing individuals to request interviews, we also requested the names of other potential key informants. This broad-based "snow-ball" sampling procedure provided a means for crosschecking the names of individuals as qualified key informants and provided representation from most, if not all, relevant sectors of the communities under study. Interestingly, it became apparent that given the criteria that were used for selecting respondents, the community of those deemed to be cultural experts was generally small and well-known. In other words, the same names were mentioned repeatedly. A number of individuals in a Hawaiian community may possess different kinds of knowledge, backgrounds, and life experiences that qualifies them as a "cultural expert" and they are acknowledged by the community for their particular expertise.

The preliminary lists of potential respondents (individuals, groups/organizations, 'ohana) were delivered to representatives of the State Historic Preservation Division (SHPD) and Oak Ridge National Laboratory who reviewed them and recommend additional informants for in-depth interviews and focus groups. This process ensured that the recommended list was as representative and exhaustive as possible.

Press releases discussing the study project were delivered to and published in the Hilo Tribune Herald, Maui News, West Hawai' $i$ Today, and Office of Hawaiian Affairs news paper (KaWaiOla O O.H.A.) as a primary means for publicizing the study. The same press releases were used to solicit names of organizations or individuals interested in reviewing a draft version of the study prior to its general release and its citation in the EIS. However, to expedite completion of the final study and wrap-up activities on the terminated EIS project, the draft study was not distributed for review to anyone other than study participants and SHPD staff. Newspaper articles also served as a way to contact potential respondents whose names did not arise through other means. This assured that a broad range of individuals were at least offered an opportunity to participate.

Other criteria used to select the individuals for in-depth interviews were related to the breadth of an informant's knowledge; the clarity of his/her ideas or recollections; the risk of losing this information due to old age or ill health; the enthusiasm of the informant to participate; and the representativeness of a particular kind of knowledge or experience. The articulateness of the respondent was not to be a major consideration although it was important that most of what she/he verbalized was discernible. Although many of the informants were bilingual (Hawaiian and English), all interviews were conducted in English.

Several of the interviews were audio-taped and, as a back-up, hand-written notes were taken by a research assistant. Note-taking was important because some of the interviews occurred in environments that were comfortable for respondents, but not always condu cive to a clear tape-recording (e.g., near the ocean or highway, during a rainstorm).

\footnotetext{
2In developing a list of potential informants, the investigators consulted with numerous persons who provided suggestions and ideas. Those who provided assistance included Dr. Jerry Johnson, Psychology Department, UH Hilo; Dr. Charles Langles, Department of Anthropology, UH Hilo; Dr. Larry Kimura, Hawaiian Language Department, UH Hilo; Mr. Sonny Kinney, who conducted an earlier study in Puna; and the Pele Defense Fund. The list of names was reviewed by Holly McEldowney and Nathan Napoka with the State Historic Preservation Division, and Dr. Lillian Trettin with Oak Ridge National Laboratory.
} 
The on-site coordinator for Southeast Maui assisted in making contacts and arranged interviews with informants. In most cases, he was present during the interviews and focus group sessions. Because he was a well-known and respected member of the Hawaiian community on Maui, his presence appeared to provide a basis for developing rapport and trust among informants. Trust is essential in this type of research because many Hawaiians are reticent about sharing cultural information for fear of it being misused or misinterpreted.

The investigators proceeded in Puna by directly contacting prospective informants. First contacts were made in person with key "ohana groups. After spending time "talking story" and describing our study, a request was made to conduct an interview on a future date. In other cases, efforts were made to network through friends and acquaintances residing in the Hilo and Puna areas to gain access to prospective informants. This process was extremely useful in reaching those who may have been skeptical about the research or not accustomed to the process of scientific inquiry. In other words, it was prudent to have a confidant or family member explain to the informant what the study was about. The first interviews were crucial to the success of the study because of the interrelatedness of the ohana residing in Puna and the velocity at which news traveled. In many instances, prospective informants were well aware of the investigators prior to the initial contact.

\section{Areas Assessed in the Interviews and Focus Groups}

The Health Environmental Risk Ranking Report (HERR) (Minerbi, McGregor, Matsuoka, 1993) identified aspects of Hawaiian and local culture that should be assessed in a socio-cultural impact study. Drawing from this report, the investigators developed openended questions that were used in a semi-structured interview format (see Appendix A for interview materials). The emphasis on each of these constructs/variables varied in the interviews according to their relevance and appropriateness to the location and expertise of the informant. Descriptions of relevant variables were tailored to solicit as much specific information as possible on the perceived range of beneficial and adverse impacts from the HGP. Informants were asked to assess the extent or level of impact HGP would have and suggest ways to mitigate the impacts. included:

The major areas/issues defined in the HERR report that were applicable to this study

1. Community Life - Refers to the cohesion and integrity of "cultural kipuka"; the continuity of life cycle events and social evolution of an aggregate of residents sharing a common locale, culture and lifeways; the potential for disruption, displace ment, or dissolution.

2. Family Life-Refers to the cohesion and integrity of the ohana or extended family system; the continuity of dynamics, structure, and traditions as they relate to such features as child-rearing networks, psychological and resource support, sharing, exchange, and housing.

3. Human Well-Being and Spirituality-Refers to physical, mental, and spiritual health and how they may be affected by development and social change, cultural distuption, or displacement.

4. Human Ecosystem-Refers to the individual in the context of a physical or social environment. In terms of the ethnographic study it relates to a sense of place, a 
particular locale to which individual/family has genealogical and/or spiritual ties, where life forces are experienced, a place of healing, or where subsistence practices including hunting, fishing, and gathering occur.

5. Natural Environment and Ecological Resources-Refers to the differential resource zones (e.g., ocean, forest) within a particular district that offer various types or species of resources necessary to maintain a livelihood and cultural practices.

6. Customs and Practices-Refers to subsistence practices and the methods used to obtain natural resources; spiritual beliefs and associated customs and practices; behaviors and beliefs that reflect genealogical or intergenerational linkages to ancestral lands; and the significance of cultural/historic sites.

7. Rights-Refers to the exercise of rights defined in the Hawai'i State Constitution, the Hawai' $i$ Revised Statutes, the American Indian Religious Freedom Action, and common law which was incorporated into the Hawaiian legal system in 1892.

8. Economics-Refers to rates and types of employment, rates of taxation, cost-ofliving (e.g., income in relation to expenses; housing costs, quality, and availability), local employment opportunities and preferences, public opinion surrounding proposed economic development, and community-based and culturally appropriate development initiatives.

Whenever necessary, interviewers used a mitigative approach. That is, they solicited sensitive cultural information on the most general level that still allowed adequate assess ment of potential impacts. Under appropriate circumstances, they determined whether avoiding an area described as culturally sensitive could substantially reduce potentially adverse impacts.

\section{Focus Group Discussions}

The focus group format was particularly useful for assessing intracultural variations on Hawaiian customs, beliefs, and practices; perceptions of HGP impacts across groups; and ideas for mitigation. Participants were guided through questions and presented with the map in a manner similar to the in-depth interviews.

The agenda for the focus groups was as follows:

a. A brief presentation of data from the in-depth interviews, a synopsis of the HGP implementation plan, and maps indicating site and use areas. The maps were also used to identify sites or use areas not previously mentioned.

b. A semi-structured discussion of the aforementioned topics in order to assess, affirm, and review related issues.

c. A semi-structured discussion of anticipated/perceived socio-cultural impacts, both positive and negative.

d A discussion of mitigation/prevention measures, distinguishing which are appropriate and acceptable from those that are not. 


\section{Integration and Data Analyses}

Most of the data collected were qualitative in nature. The information gathered from the in-depth interviews, focus groups, and on-site visits was integrated and evaluated by the investigators along with the information derived from the literature and chant searches in order to produce a complete description of the ethnographic resources of the study areas. Integration and evaluation involved the selective abstraction of transcripts of interview tapes, organizing field notes, and integrating information collected in the literature-search phase with that collected during fieldwork.

As previously mentioned, all interview and focus group participants had the opportunity to review their contributions for accuracy and completeness and to determine whether the material contained any sensitive information that should not be released in a public document. If concerns were expressed about the release of sensitive information, then the consultants prepared two versions of the survey report, one for public release and one for restricted access to key decision makers and support staff. Individuals who participated in the study and SHPD staff reviewed the draft study report for accuracy, thoroughness, and adequate maintenance of confidentiality.

The report includes the following components:

1. A narrative description of areas of cultural and historical use and significance and known natural resources used for cultural, religious, and subsistence purposes in the project areas;

2. A narrative description of Native Hawaiian cultural, religious, and subsistence practices in these areas;

3. A map indicating the known natural and cultural resources used for cultural, religlous, and subsistence purposes in the project areas;

4. A list and summary of Native Hawailan concerns about the potential affects of the HGP on Hawaiian cultural, religious, and subsistence beliefs, customs, and practices in the project areas; and

5. Recommendations concerning future development and proposed mitigation to address anticipated negative impacts.

\section{Scope and Limitations of the Study}

The scope of work was determined by Oak Ridge National Laboratory (ORNL). This study is limited to the proposed project areas in Puna on the island of Hawai' $i$, and Southeast Maui. However, as originally proposed, the HGP would extend far beyond these two areas. The proposed transmission route would traverse other districts on the island of Hawai' $i$ along a corridor from Puna through Pohakuloa and to Upolu Point. The HGP's proposed submarine cable would also affect Hawaiian cultural, religious, and subsistence practitioners who use the channels between Maui, Kaho'olawe, Moloka'i, and Lana'i. There are also Hawaiian communities on Moloka' $i$ and in Waimanalo which may be affected. Given the limited resources available for this study, the consultants were unable to gather information beyond the two districts described in this design proposal. 
The description of tasks outlined by ORNL specified that the study would focus on an assessment of impacts on traditional "cultural resources" and "cultural and religious practices" consisting of all customary and traditional values, practices, and beliefs associated with natural resources and prehistoric sites located in the two project areas. The study was not designed to involve a poll or large survey, random or otherwise, from the general public.

The study was specifically designed to examine the beliefs and practices of Hawaiians with close ancestral ties and traditional knowledge of natural and cultural resources in Puna and Southeast Maui. The sampling strategy was applied successfully and the most qualified individuals were selected for interviews. However, it is important to note that a wide range of Hawaiians are involved in or seek to revive and re-establish traditional cultural religious, and subsistence customs and practices in the two project areas. The sampling approach served to delimit the range of respondents and exclude virtually anyone who did not have ancestral ties to these areas. The process of respondent selection was consistent with the study design, although it may have eliminated highly qualified individuals who possessed expertise in areas relevant to the study.

There were numerous issues concerning geothermal development that were beyond the scope of the study. The investigators became aware of a variety of health and environmental issues, often shared in a more scientific or technical manner. Because of the source of this information (not qualified as respondents), these issues were generally not included in the analysis. It is important to note, however, that Hawaiians may be directly impacted by health and environmental changes described by non-Hawaiians.

The limited time frame for the study presented many disadvantages. In rural Hawaiian districts like Puna and Southeast Maui, investigators require a great amount of time observing landscapes and getting a "feel" for the place. This means exploring areas through site visits, observing cultural activities (e.g., hunting, gathering, luau), and developing community ties and cultivating relationships with key individuals and 'ohana. Although the investigators relied heavily on informal networking and made numerous pre-interview contacts with prospective informants, cultivating trust can be a challenging process. Some of the initial difficulties, especially those experienced in focus group settings, could be attributed to the short amount of time spent developing trust and rapport which were seen as essential to data gathering.

\section{Contemporary Political Status of Hawaiians: Why an Ethnography on Hawaiians}

Hawaiians today are not organized as a nation and efforts are underway to reconstitute a government for a sovereign Hawaiian nation. There are many organizations who are involved at different levels in the process. ${ }^{3}$ In the absence of a national government, "ohana

\footnotetext{
${ }^{3} \mathrm{Ka}$ Lahui Hawai'i, claiming to represent 20,000 members, has already held 4 constitutional conventions which have established their own national legislature, governor, and council of elders. The Office of Hawaiian Affairs is a state department which has 60,000 Hawaiians enrolled as voters for special elections to select the Hawaiian trustees who govern the agency. The office is committed to supporting a process for the Hawaiian community to vote for delegates to a convention that will draft a constitution for approval by a broad spectrum of Hawaiians. The State Council of Hawaiian Homes Associations claims to represent 30,000 Hawaiians who are settled on Hawaiians Homelands. They seek immmediate and direct control over the homestead lands they live on and use. They are willing to participate in a convention process, but really seek homerule over the Hawaiian Homelands. There are several organizations which seek to totally decolonize Hawai ${ }^{\prime}$.
} 
(extended family) networks survive as the primary traditional social unit of organization, particularly in rural Hawaiian communities.

The indigenous Hawaiian people, unlike Native Americans, Aleuts, and Eskimos, are not yet recognized as a nation by the United States government. Nevertheless, Congress has included Hawaiians in the definition of Native Americans in federal legislation which recognizes the distinct social condition and cultural beliefs, customs, and practices of the indigenous peoples within the United States. The definition currently being used in Congress for "Native Hawalian" is, "any individual who is a descendent of the aboriginal people who, prior to 1778, occupied and exercised sovereignty in the area that now constitutes the State of Hawaii." Federal laws relevant to this ethnography because they relate to the protection of cultural resources include the following:

1. American Indian Religious Freedom Act (AIRFA) of 1978. [42 U.S.C. 1996, P.L. No. 95-341, 1978] ensures that actions taken or licensed by federal agencies do not interfere with the inherent right of individual Native Americans (including American Indians, Eskimos, Aleuts, and Native Hawaiians) to believe, express, and exercise their traditional religions. These rights include access to religious sites, use and possession of sacred objects, and the freedom to worship through traditional ceremonials and rights. When a federal agency finds, upon consultation, that its proposed action would deny the free exercise of religion and yet determines that there is a compelling need for the action, the decision to proceed may be made, but appropriate mitigation measures to reduce interference with traditional religious practice to the low est possible level must be included.

2 National Historic Preservation Act of 1966, as amended [16 U.S.C. 470; 80 Stat.. 915; P.L. No. 89-665 (1966), and amendments thereto]. Regulations: Protection of Historic Properties (Advisory Council on Historic Preservation) 36 CFR Part 800, as amended. Pertinent addition in the 1992 amendments include: Section 304(a)-(b) on withholding from disclosure and Section $101(d)(6)(A)-(C)$ on traditional cultural properties of religious significance; and on State consultation with Native Hawaiian groups during the Section 106 Review process.

3. Archaeological Resources Protection Act of 1979, as amended [16 U.S.C. 470 aa$470 \mathrm{~mm}$; P.L. No. 96-95 (1979), and amendments thereto]. To protect archaeological resources on public lands and Indian lands; requires that American Indian tribes be notified prior to any negative impact on cultural and spiritual sites located on fed eral lands; substantially increases the severity of civil and criminal penalties imposed on unqualified and unpermitted looters; assures that information concerning the nature and location of any archaeological resource may not be made available to the public. This act's provisions do not specifically include Native Hawaiians; however, by implementing ARPA federal agencies have adopted various policies and guidelines that encourage early consultation with concerned Native Americans.

Smaller in number than the advocates of nation-within-nation status, they nevertheless comprise a vocal and determined sector of the community. Included among the organizations seeking total independence from the U.S: are the Institute for the Advancement of Hawaiian Affairs, the 'Ohana Council, Ka Pakaukau, the Pro-Hawaiian Sovereignty Working Group, the Sovereign Kingdom of Hawai' $i$, and the Kamehameha Probate Trust of Hawai' $i$. 
4. Archaeological and Historic Preservation Act of 1974, [16 U.S.C. 469-469c; PL. 86-532 (1960), and amendments thereto]. To provide for the preservation of historical and archaeological data which might otherwise be lost as the result of the construction of a dam (or any alteration of the terrain caused as a result of federal construction or federally licensed activity). This law applies if a federal project requires placement of dredged or fill materials along a coast.

5. National Environmental Policy Act of 1969, as amended [42 U.S.C. 4371 et. seq., P.L. 91-190 (1970), and amendments thereto]. Regulations of the Council on Environmental Quality, 40 CFR 1500-1517. To promote conditions under which "man and nature can exist in productive harmony," federal agencies may take practicable measures to help the Nation "preserve important historic, cultural, and natural as pects of our national heritage, and maintain, wherever possible, an environment which supports diversity and variety of individual choice."

6. Native American Graves Protection and Repatriation Act of 1990 [25 U.S.C. 3001-3013; P.L. 101-601 (1990)]. NAGPRA Regulations; Proposed Rule (Fed. Regis. May 28, 1993), 43CFR 10. To provide direction on how Native American remains and burial artifacts are to be treated. The statute deals with museum collections receiving federal funds and with ongoing archaeological investigations. NAGPRA encourages in situ preservation of archaeological sites that include burials and requires federal agencies to consult with affiliated, or potentially affiliated, Native Americans concerning the treatment and disposition of cultural remains. Native Hawaiian organ izations and Native Hawaiian Home Lands are specifically cited.

The Constitution and Hawai'i Revised Statutes of the State of Hawai' $i$ also recognize the unique status of the Native Hawaiians and affords protection of traditional Hawaiian beliefs, customs, and practices. ${ }^{4}$ The recognition of Hawaiian as an official language of the State of Hawai' $i$ and the acknowledgment that the State of Hawai' $i$ has a responsibility to perpetuate Hawaiian culture lay an important foundation for state protection of Hawaiian culture. In addition, Article XII, Section 7, of the Hawai' $i$ State Constitution states:

The State reaffirms and shall protect all rights, customarily and traditionally exercised for subsistence, cultural and religious purposes and possessed by ahupua'a tenants who are descendants of native Hawaiians who inhabited the Hawaiian Islands prior to 1778 , subject to the right of the State to regulate such rights.

Throughout over 200 years of continuous contact with Europe, America, and Asia beginning in 1778, Hawaiian customs, beliefs, and practices have undergone uneven processes of change, continuity, and revitalization. The reign of King David Kalakaua from 1874 through 1891 is distinguished as a period of a renaissance of the Hawaiian culture. Hawaiian culture again went through a period of revival and renaissance in the 1970s and 1980s. A decade after Hawai'i became a state in 1959, the consciousness and practice of Hawaiian cultural and spiritual customs and beliefs heightened. This renewal was manifested in such things as the establishment of Hawaiian language pre-schools and Hawaiian language

\footnotetext{
${ }^{4} \mathrm{~A}$ comprehensive compilation and analysis of laws and court cases affecting Native Hawaiians was published as the Native Hawaiian Rights Handbook in 1991 by the Native Hawaiian Legal Corporation (edited by M. Mackenzie, esq.)
} 
immersion classes, an increase in the number of hula halau or schools which teach traditional Hawaiian dance and chant, and the development of Hawaiian studies from the elementary to university level. Traditional navigational arts and skills were revived with the transpacific voyages of the Polynesian Voyaging Society on the double-hulled canoe, Hokule' $a$. The traditional practice of aloha 'aina gained prominence and rural Hawaiian communities, strongholds of traditional Hawaiian subsistence lifestyles, gained a new prominence.

At present, there are numerous Hawaiian organizations working for the re-establishment and recognition of a sovereign Hawaiian nation. Hawaiians involved in these organizations seek to improve Hawaiian health, education, and standards of living. Hawaiians also seek to protect and perpetuate the natural and cultural resources essential for religious, cultural, and subsistence custom, belief, and practice. Hawaiians are seeking redress for past injustices; restitution of all of the territory of the Hawaiian nation; compensation for misman agement and destruction of national lands and natural resources; and the re-establishment and recognition of a government to exercise sovereignty and self-determination (Hawaiian Sovereignty Advisory Commission, 1994).

It is significant to note that in November 1993, after 100 years, the U.S. Congress passed and President Bill Clinton signed a joint resolution (P.L. 103-150) offering a formal and official apology to the Hawaiian people for the U.S. role in overthrowing the Hawaiian monarchy on January 17,1893 and suppressing the sovereignty of the Native Hawaiian people (see Appendix B).

\section{Environmental Setting: Puna}

The Hawai' $i$ Geothermal Project was originally planned for three Geothermal Resource Subzones within Puna-Kilauea Middle East Rift, Kama'ili, and Kapoho. However, current state law permits drilling for geothermal energy outside of these subzones so the literature search and informant interviews were not limited to information regarding the three subzones but included information for the entire district.

Puna lies partly on the lower slopes of Mauna Loa, but is located mostly on the undissected lava shield of Kilauea. The east rift zone traverses 28 miles from the Kilauea Cal dera and Halemaumau across lower Puna to Cape Kumukahi. The landscape of Puna today is still dominated by the seismic and eruptive phases of the Kilauea volcano. No part of Puna is entirely free of volcanic activity. The climate varies from the rocky shoreline, to barren lava fields, cultivated orchards, grassy plains, and dense rainforests. Puna includes part of the Hawai 'i Volcanoes National Park, large undeveloped non-conforming subdivisions, unsettled Hawaiian Homelands, forest reserves, diversified agricultural farms, and small concentrations of population. The district is subject to heavy rainfall and periodically experiences severe flooding. The rocky coastline, which is comprised of sheer cliffs in many sections, is subject to tsunami inundation and subsidence.

Puna is primarily an agricultural district. Until 1984, when Puna Sugar Company ceased operating its sugar plantation, sugar was the principal crop grown in Puna. The towns of Pahoa, Kea'au, and Mountain View were created as a result of that industry. Now that sugar production has shut down, there is still diversified agriculture in the district. The volcano area has small truck farms. Kapoho has papaya groves and flower farms. Flowers, primarily anthuriums and vanda orchids, are also cultivated in the Mountain View and Pahoa 
areas. Hawaiian communities, traditionally strung out along the coastline, engage in fishing, agriculture, and hunting.

The Kilauea Middle East Rift Geothermal Resource Subzone is part of the Kilauea volcanic lowland rainforest. It is a mosaic of ecosystems of varied ages and development, shaped by periodic lava flows and rapid forest regeneration. The Kamaili Geothermal Resource Subzone encompasses agricultural subdivision tracts interspersed with forest and lava and tunneled with lava tubes. The Kapoho Geothermal Resource Zone is primarily agricultural interspersed with lava craters, springs, and flows. Many of the residents in the Kamaili and Kapoho Geothermal Resources Subzones moved into the district after 1965 from $0^{\prime}$ ahu and the U.S. mainland. Most of the Hawaiians in Puna live in lower Puna. However, these families have customarily utilized the areas now zoned for geothermal resource development for hunting of pigs or cattle; gathering of maile, fern, ' $i e^{\text {' }} \mathrm{ie}$ and medicinal plants; and cultivating taro and other food plants. In addition, some of the families were displaced from the Kaimu-Kalapana area and have temporarily relocated into subdivisions near Pahoa and in the Kamaili Geothermal Resource Zone.

\section{Environmental Setting: Southeast Maui}

Proceeding from east to west, the proposed HGP transmission route on Maui would traverse the moku (land sections) of Kaupo, Kahikinui, and Honua'ula. According to original plans, the HGP submarine cable would surface at a land transition point along Huakini Bay, in Kaupo, just west of the primary canoe landing site at $\mathrm{Nu}^{\prime} \mathrm{u}$ Bay. From here, the electricity would be transmitted through overhead transmission lines and continue to follow the highway between the elevations of 500 and 1,800 feet. Going mauka (mountainward) from Huakini Bay, the transmission lines would cross Pi'ilani Highway at an elevation just below 200 feet. The transmission line would follow the highway and cross it again going makai (seaward) at an elevation of about 500 feet. The route of the overland transmission line would then paral lel the island's south shore for a distance of approximately 20 miles, along the makai side of the Pi'ilani Highway at between the 500-foot and 1,800-foot elevations. The route, east to west, would cut along the scenic grasslands of Kaupo, the scenic lava outcrops of Kahikinui, through the Kahikinui Cultural Management Zone of the Department of Hawaiian Home Lands, and intersects the lower Kanaio Homesteads. It would be situated east of the Kipahulu Forest Reserve, makai of the Kahikinui and Honua'ula Forest Reserve (elevation above 2,600-3,700 feet) and makai of the upper Kanaio Homesteads (elevation 2,800-3,400 feet).

It was proposed that the overhead transmission line would connect to another segment of submarine cable at a land-sea transition point located at "Ahihi Bay on the South shore at Kanahena. This is west of the Natural Area Reserve of Cape Kina' $u$ and the tradi: tional landing at Keone'oio, or La Perouse Bay, in the Honua'ula district of Maui (USGS, 1993).

The southeastern coast of Maui consists of the southeastern slope of the Haleakala crater and descends from the rim at 10,000 feet elevation down to sea level. It is an unspoiled scenic district of forests, pastoral grassland, lava outcrops, and indigenous Hawaiian plants which survive in the ravines and gulches.

On modern maps, southeast Maui is shown as being located within the large districts of Makawao and Hana (DBED\&T, 1992). Older maps divided the area into the several smaller moku (also called kalana, or okana), of Honua'ula, Kahikinui, Kaupo, Kipahulu, and 
Hana (Handy, Handy and Pukui, 1972; Wall, 1922). King (1935) discussed the history of land divisions throughout the islands and noted that the Maui land designations lack the simplicity observed in the other islands. An experienced surveyor, Robert King, also identified these land sections as districts. In another account, Curtis J. Lyons, an early surveyor for the Hawaiian government, wrote the following in 1876:

On East Maui, the division [of land] in its general principles was much the same as on Hawaii, save that the radial system was better adhered to. The fact there is pointed out, to this day, on the sharp spur projecting into the east side of Haleakala crater, a rock called the "Pohaku oki aina,"-land-dividing rock, to which the larger lands came as a centre. How many lands actually came up to this is not yet known (Lyons, 1875:111).

Within the districts of Honua'ula, Kahikinui, and Kaupo, are located smaller land divisions, or ahupua'a. These sub-district land divisions usually extended from the sea to the uplands. Some extended inland only as far as the forest. Others swept up to the top of the mountain. A few went into the crater to meet ahupua'a from other districts at the piko (umbilical) stone, known as Pohaku Palaha, on the northern rim of Haleakala crater. 


\section{CHAPTER 2}

\section{THE ETHNOHISTORY OF PUNA AND SOUTHEAST MAUI}

\section{INTRODUCTION}

\section{Land/Nature: The Foundation of Hawailan Customs, Beliefs, and Practices}

Aloha 'aina, aloha i na akua, aloha kekahi i kekahi / love the land, love the gods, and love one another, expresses the three precepts which form the core of traditional Hawaiian philosophy, world view, and belief system. Culturally, it was important for Hawaiians to sustain supportive, nurturing, and harmonious relations with the land, the gods, and each other, particularly their 'ohana or extended family. Moreover, the Hawaiian, the land, and the gods were believed to be spiritually, culturally, and biologically united as one-lokahi by lineal descent. In their mo'oku auhau / family genealogy chants, Hawaiians traced their lineal ancestry to historical figures and ultimately, through them, to various deities and gods of the land, ocean, forest, and nature (Handy \& Pukui, 1958; Johnson, 1981).

The land and all of nature is the source of existence for the Hawaiians-not only as the origin of humanity, but also as the source of natural resources for day-to-day subsistence. Traditionally, the Hawaiian did not possess or own the land or its abundant resources. Instead, they maintained stewardship over it-planting and fishing according to the moon phases and the changes from rainy to dry seasons. The traditional Hawaiian land system evolved to provide Hawaiians access to the resources they would need for subsistence and to allow for stewardship over the land.

Throughout history, the Hawaiian people maintained a deep abiding faith in the land and its power of providing physical sustenance, spiritual strength, and political empowerment.

Hawaiians who petitioned King Kamehameha III in 1845 not to sell land to foreigners reflected this viewpoint when they wrote:

If, perhaps, the land is covered over and crowded with the dollars of those who purchase land, from Hawai'i to Kauai. Ten, perhaps a hundred thousand million. Will most of these dollars be for the land if we agree to its sale? We will not have anything at all to say about this money. Very few indeed will be the dollars in the hands of the true Hawaiians, and in the land. The land strives [kulia] for revenue every day. The earth continues to receive its wealth and its distinction every day. There would be no end of worldly goods to the very end of this race. But, the money from the sale of land is quickly ended, by ten years time.

The historian Samuel Kamakau who wrote of the drastic changes to Hawaiian lands and ohana in the 1850 s and 1860 s made the following observation about how Hawaiians related to the land: 
You foreigners regard the winds, the rain, the land, and sea as things to make money with, but we look upon them as loving friends with whom we share the universe. We adjust our lives to them. You try to bludgeon them to your will. That is why we do not like this civilization you are trying to thrust upon us. It is not rich and sweet to our taste nor satisfying to our hearts.

Members of the Aha Hui Pu'uhonua O Na Hawai 'i (Hawaiian Protective Associa tion) reflected their trust and reliance upon the land and its power to heal the Hawaiian people when they worked to establish the Hawaiian Home Lands Program in 1920. The following is an excerpt from a memorial that they sent to the U.S. Congress:

The soil is a redeeming factor in the life of any race, and our plan for the rehabilitation of the Hawaiians is futile unless the question of returning to mother earth takes precedence to all other considerations in such a plan. ... In so far as experience has proven and as much as science has revealed, physical health and vigor, the power to propagate the race, eradication of diseases, the restoration of normal domestic living conditions, the elimination of poverty and pauperism, the establishment of business relationship with the business world, the deepened appreciation of the soil and of the material wealth-all of these benefits come, not by the fashionable [sic] life of this century, but, by the intimate acquaintance with the life and the possibilities of the soil.

A contemporary practitioner of Hawaiian religion who has been instrumental in establishing recognition of native Hawaiian religious beliefs by the U.S. courts explains the relationship of the Hawaiian people to land and the nature deities as follows:

At its root, Aloha "Aina is the belief that the land is the religion and the culture. Native Hawaiians descend from a tradition and genealogy of nature deities: Wakea, Papa, Ho'ohokulani, Hina, Kane, Kanaloa, Lono and Pelethe sky, the earth, the stars, the moon, water, the sea, the natural phenomena such as rain and steam; and from native plants and animals. The native $\mathrm{Ha}$ waiian today, inheritors of these genes and mana [spiritual power], are the kino lau or alternate body forms of all our deities (Aluli, 1988).

Historically, the special relationship of Hawaiians to the land and their spiritual ancestors remained strongest where foreign penetration and the market economy was the weakest. These districts include the districts of $\mathrm{Ka}^{\prime} \mathrm{u}, \mathrm{Kona}$, and Puna as well as Waipi 'o Valley on the island of Hawai' $\mathrm{i}$; the Hana district (from $\mathrm{Ha}$ 'iku to Honua' 'ula) and Kahakuloa Valley on Maui; parts of the Leeward and Windward districts on $\mathrm{O}^{\prime}$ ahu; the districts of Anahola and Kekaha on Kaua' $i$, the entire island of Moloka' $i$, and the entire island of Ni ihau. 5

\section{Cultural Kipuka: A Framework for the Ethnography of Puna and South Maui}

The social significance of traditional Hawaiian rural communities for the perpetuation of native Hawaiian society may be compared to a phenomenon in nature. Botanists who

\footnotetext{
${ }^{5}$ For example, the 1884 Census by the Kingdom of Hawai' $i$ showed particularly high concentrations of native Hawaiians as follows: Puna with 95 percent; South Kona with 92 percent, North Kona with 94 percent and Ni'ihau with 98 percent.
} 
study the natural rainforest in the area of the active Kilauea volcano have observed that eruptions which destroy and cover up large areas of forest lands leave little oases of native trees and plants in their wake which are called kipuka. From these natural kipuka come the seeds and spores for the eventual regeneration of the native flora upon the fresh lava. For contemporary Hawaiians, the traditional Hawaiian rural communities are cultural kipuka from which Hawaiian culture can be regenerated and revitalized in tho contemporary setting.

Referring to the 17 rural districts where Hawaiians were still predominant in 1930, Andrew Lind, in his book An Island Community: Ecological Succession in Hawaii, wrote of the significance of these areas for the continuity of Hawaiian culture:

These racial havens-small-population islands still relatively secure from the strong currents which have swept the archipelago as a whole into the worldcomplex of trade-are strikingly similar to those which appear in the census of 1853. The dry and rocky portions of Kau, Puna, and the Kona coast, the deep valley of Waipio, the wild sections of Hana, Maui, portions of lonely Lanai and Molokai where industrial methods of agriculture have not succeeded, the leper settlement, and Niihau, the island of mystery-these are the places of refuge for some 4,400 or nearly one-fifth, of the native Polynesians. ...

The old fish and poi company, with its accompaniment of tutelary deities, taboos, religion, and magic, still persists in modified form within many of these isolated communities. A small plot of taro and access to the sea and the mountains are apparently all that is required for the satisfaction of their material wants. The wage from an occasional day's work on the government road enables them to purchase the necessary supplies which the old economy cannot now provide. ... The natives themselves have found these rural havens where the economy of life to which they are best adapted can survive (Lind, 1938: 102-103).

Examining the history of Puna and South Maui as cultural kipuka is a useful framework of analysis for understanding the historical trends of social, political, and cultural change and continuity within these districts. Davianna McGregor, in her doctoral dissertation Kupa'a I Ka Aina: Persistence On The Land (McGregor, 1989), studied rural Hawaiian communities and provided summary of the features and historical trends which were common to these areas and distinguished them as cultural kipuka. The following sections describe these historical features and trends in order to establish the framework for discussing the ethnography of Puna and South Maui.

Cultural kipuka were traditional centers of spiritual power. In traditional Hawaiian chants and mythology, major akua (gods) and Hawaiian deities were associated with the areas. The districts were isolated and difficult to access over land and by sea. Due to the lack of good anchorage and harbors, early traders often bypassed these districts in favor of more accessible areas. The missionaries entered these areas and established permanent stations during a later period than in other parts of Hawai' $i$. Thus, traditional Hawaiian spiritual beliefs and practices persisted there, without competition, for a longer period of time. As Christian influences entered these areas, they co-existed with traditional beliefs and practices. 
The geography of these districts discouraged the widespread or long-term development of sugar plantations. In the arid areas, the lack of water resources made development of sugar plantations unfeasible. In the areas with sufficient rainfall, the terrain was too steep or rugged for plantation agriculture. Where plantation agriculture failed in Moloka $i$ and the Hana district, ranches were able to succeed. The ranches employed Hawaiian men as cowboys and allowed them to live with their families in these isolated districts and pursue traditional fishing, gathering, and hunting activities to supplement their wages.

Where neither plantations nor ranches were established, traditional subsistence acti vities continued to be pursued, undisturbed by modern economic development, through World War II. In the wetland areas taro continued to be farmed, often in conjunction with rice. In the arid areas, sweet potatoes, dryland taro, and other traditional and introduced crops suited to the dry soil and climate were cultivated. The undeveloped natural resources in these areas provided an abundance of foods for the native Hawaiians who lived in these districts. Forested lands provided Hawaiians with fruits to eat; vines, plants, and woods for making household implements and tools; and herbs to heal themselves. They provided a natural habitat for animals that were hunted for meat. Marine life flourished in the streams. The ocean provided an abundance of food. Subsistence activities continued to be the primary source of sustenance for the native Hawaiians. Production in these districts was primarily oriented around home consumption. In some areas small stores provided the Hawaiians access to some basic modern amenities such as kerosene, lanterns, tools, flour, crackers, and sugar. However, for the most part, rural Hawaiians were not consumer oriented. Money to purchase these basic provisions came from selling taro or fish or an occasional day's labor for a local entrepreneur or the government road crew.

Rural Hawaiians who lived in these districts were able to acquire the basic necessities for their families through subsistence activities upon the land by employing traditional knowledge and practices passed down to them from their kupuna (elderly). Family knowledge about prime fishing grounds and the types of fish which frequent the ocean in their district at different times of year usually assured Hawaiian fishermen of successful fishing expeditions.

Many Hawaiians in rural districts continued to cultivate fish in ponds and the open ocean by regularly feeding the fish in conjunction with making offerings at the ku'ula shrines that marked their ocean fishing grounds. Taro and other domestic crops were planted by the moon phase to assure excellent growth. Rural families took advantage of seasonal fruits and marine life for their regular diet. Native plants were utilized for healing of illness by traditional methods which involved both physical and spiritual cleansing and dedication. Cultural knowledge attached to the traditional names of places, winds, and rains of their district informed rural Hawaiians about the affect of the dynamic forces of nature upon the ocean and the land in their area and activities were planned accordingly. Legends and chants informed them about how their ancestors coped with such elements.

Thus, in these rural communities, Hawaiian custom, belief, and practice continued to be a practical part of every day life, not only for the old people, but also for the middle aged and the young.

Very few haole (Caucasians) settled in these districts and there was very little interaction of Hawaiians with the outside community. Chinese who completed their contracts on the plantation and did not return home or move to the mainland leased or rented lands from the Hawaiians. Some served as middlemen marketing whatever taro and fish Hawaiians 
desired to sell in the towns and bringing back consumer goods for sale or barter in the rural communities. Where there was a small rural store in these districts, it was invariably owned by a Chinese, who in some cases was married to a Hawaiian woman.

Hawaiians in these rural districts maintained their large extended family networks. The practice of hanai, or the raising of adopted children, continued to be commonly practiced. Ties with family who moved to another island, especially $O^{\prime}$ ahu, continued to be maintained. While some of the children moved away to the city, one or two would remain behind to care for parents and the family kuleana lands. Often those who moved away would send children home to be raised by the extended family. They would periodically visit their families in the rural areas.

Hawaiians in these districts continued to trace unbroken lineal descent to the original Hawaiians who had settled the districts as well as to the 'uhane (spirits), 'aumakua (ancestral deities), and other deities of the land itself. These Hawaiians continued to acknowledge the presence of their spiritual ancestors in the surrounding land through the passing on of chants and legends; maintained respectful practices in the use of the land, streams, ponds, and ocean, perpetuating usage of the particular place names of the district; and retained knowledge of the mythical and historical events and deities associated with the area.

Rural Hawaiians today descend from those who were content to remain in the isolated districts while many others moved out during the first three decades of the twentieth century. For those who stayed behind, life in those districts was filled with interesting natural phenomena and forces which challenged them as they sought out their subsistence needs. They patterned their economic activities around the life cycles of the various fish, animals, and plants that they depended upon for food. Thus, from month to month, as the seasons shifted from wet to dry, their food sources changed in accordance with the type of fish, fruits, and plants that were in season. This knowledge of the environment and natural life forces was often the substance of Hawaiian traditions, beliefs, and practices as the Hawaiians chose to personify the forces of nature and create legends and myths to describe and remember the dynamic patterns of change that they observed. According to Mrs. Pukui:

We have not been taught Hawaiian in schools. We have been taught Hawaiian by our makua and our kupuna. And now they're gone and we are the kupuna today. In the future, the children will not get the same old way of life and they must understand that when they read the books. We must write the books. We must present the Hawaiian side, because sometimes other writers write of us too critically, not understanding our ways. They write too critically of us. They don't understand why we did certain things. But we had a reason to everything we did. And when they write of us as superstitious people-are we? Are they sure we are superstitious? We had a reason for doing things. Sometimes our people couldn't explain, so that the malihini would understand. But their explanation suited our own people. You can't eat a certain thing because that's you 'aumakua. Well when you look for the other side, you can't eat a certain thing because you are allergic. Your system won't accept it. 6

\footnotetext{
${ }^{6}$ Mary Kawena Pukui, during interview with Dolly Mahalo, Josephine Marciel and Francis Marciel, November 30, 1961, Kaupo, Maui, Bishop Museum Audio-Recording Collection \#86.03.1,2,3.
} 
Folk beliefs and legends contain, in a story form, traditional knowledge accumulated by Hawaiian ancestors in utilizing the natural resources of these areas. They provide rural Hawaiians with information they need to understand and adapt to the qualities and character of the landscape in which they live-the climate, the variations of rain and wind, soil conditions, flora, fauna, and seasonal changes. The folklore also provide a profound sense of identity with the 'aina as well as responsibility to provide stewardship of the area where they live.

\section{Hawaiian Historical Periods}

The ethnohistories for Puna and South Maui are organized in relation to the major historical periods in Hawai' $i$. The subsections describe what is recorded to have taken place in Puna and South Maui during the designated historical period.

Each of the ethnohistories begin by examining the traditional cultural significance of the district. The place name for the district and the 'olelo no'eau or descriptive proverbs and poetic sayings for which the area is famous are interpreted; and selected descriptive chants for the area are translated and interpreted. These provide valuable insights about the cultural resources and features for which the area was known and thus the role of this area overall in the traditional cultural practices and customs of Hawaiians.

This is followed by a discussion of traditional mo'olelo or myths and legends for places within the respective districts. These myths record what the Hawaiian people observed as the primal natural elements and the important natural and physical features and natural resources of the districts. They provide, in a story form, a description of the natural environmental setting in which the early Hawaiians settled and established themselves. The primal natural elements were depicted as manifestations of Hawaiian deities. The myths and chants relate which natural elements dominated the landscape and the lives of the early Hawaiians.

In his introduction to Ancient Sites of $O^{\prime} a h u$, Edward Kanahele explained the relationship of myths about various deities to wahi pana or sacred places throughout the islands. He also explained why the understanding of a place, its place names, and the reason for its designation as wahi pana or sacred area is essential to understanding the area's function and cultural significance to Hawaiian society:

As a native Hawaiian, a place tells me who I am and who my extended family is. A place gives me my history, the history of my clan, and the history of my people. I am able to look at a place and tie in human events that affect me and my loved ones. A place gives me a feeling of stability and of belonging to my family, those living and dead. A place gives me a sense of well-being and of acceptance of all who have experienced that place.

The concept of wahi pana merges the importance of place with that of the spiritual. My culture accepts the spiritual as a dominant factor in life; this value links me to my past and to my future, and is physically located at my wahi pana.

Where once the entire native Hawaiian society paid homage to numerous wahi pana, now we may give wahi pana hardly a cursory glance. Only when a native Hawaiian gains spiritual wisdom is the ancestral and spiritual sense 
of place reactivated. Spiritual knowledge and the wahi pana are ancestrally related, thus spiritual strength connects to the ancestral guardians, or 'aumakua. My aumakua knew that the great gods created the land and generated life. The gods infused the earth with their spiritual force or mana. The gravity of this concept was keenly grasped by my ancestors: they knew that the earth's spiritual essence was focused through the wahi pana (James, 1991).

Reviewing the traditional proverbs, chants, and legends for Puna and South Maui at the beginning of their respective sections allows the reader to understand the overall cultural significance of the districts and important places within the districts.

\section{Precontact Period}

Research by archaeologists, anthropologists and ethnographers over the past thirty years suggest that the pre-contact period be looked at in five distinct eras. ${ }^{7}$ The first period dates between 0 and 600 A.D. Based on current subsurface archaeological research on each of the islands, the dates for settlements being established on the various islands are continually being adjusted to reflect evidence of settlement earlier and earlier within this period.

Migrations from Polynesia, particularly the Marquesas, continued through the second era. Between 600 and 1100 A.D. the population in the Hawailan islands primarily expanded from natural internal growth on all of the islands. Through the course of this period the inhabitants of the Hawaiian islands grew to share common ancestors and a common heritage. More significantly, they had developed a Hawaiian culture and language uniquely adapted to the islands of Hawai' $i$ which was distinct from that of other Polynesian peoples.

During this period, the social system was communal and organized around subsistence production to sustain 'ohana, large extended families. Hawaiian spiritual beliefs, customs, and practices focused on maintaining harmonious and nurturing relationships to the various life forces, elements and beings of nature as ancestral spirits who were honored as deities. Land and natural resources were not privately owned. Rather, the Hawaiian people maintained a communal stewardship over the land, ocean and all of the natural resources of the islands. The kupuna (elders) provided leadership and guidance to the makua (adults) who performed most of the daily productive work of fishing, cultivation, and gathering. Between the islands of Hawai' $i$ there was some variation of language dialect and names for plants, animals, rains and winds. There were also variations in physical structures, subsistence techniques and art forms. Origin myths varied according to the particular migration and genealogical line from which families descended. The prominence of akua and kupua also varied

${ }^{7}$ These periods are discussed and summarized by Kirch, Patrick V. in Feathered Gods and Fishhooks: An Introduction to Hawaiian Archaeology and Prehistory. Honolulu: UH Press, 1985. It is also discussed by Malcolm Naea Chun and Matthew Spriggs in "New Terms Suggested For Early Hawaiian History," Ka Wai Ola O OHA, February 1987, p. 4. Other sources for dating these periods are Fornander, Abraham, Fornander Collection of Hawaiian Antiquities and Folk-Lore. Honolulu: T.G. Thrum (ed.), BPBM Memoirs 4, 5, 6, 1916-1920; Beckwith, Martha W., Hawaiian Mythology. Honolulu: UH Press, 1970, Kamakau, Samuel, Ruling. Chiefs of Hawaii. Honolulu: Kamehameha Schools Press, 1961; Kamakau, Samuel, Ka Po'e Kahiko: The People of Old. BPBM Spec. Publ. 51., 1964; Kamakau, Samuel, The Works of the People of Old. BPBM Spec. Publ. 61, 1976. Kalakana, David, King of Hawaii, The Legends and Myths of Hawait: The Fables and Folklore of a Strange People. Tokyo \& Rutland: Charles E. Tuttle, 1973. 
by island. For example, as discussed above, the volcanic deity Pele was prominent in Puna and $\mathrm{Ka}^{\prime} \mathrm{u}$. Qualitatively, the language, culture, social system and spiritual beliefs, customs and practices were common among all the inhabitants of the islands. Oral traditions indicate frequent transmigration and even intermarriage among families from different islands.

This third period, between 1100 and 1400 A.D., also marks the era of the long voyages between Hawai' $i$ and Tahiti and the introduction of major changes in the social system of the Hawaiian people's nation. The chants, myths and legends record the voyages of great Polynesian chiefs and priests, such as the high priest $\mathrm{Pa}^{\prime}$ 'ao, the ali' $\mathrm{i}$ nui $\mathrm{Mo}$ 'ikeha and his sons Kiha and La'amaikahiki, and high chief Hawai'i Loa. Traditional chants and myths describe how these new Polynesian chiefs and their sons and daughters gradually appropriated the rule over the land from the original inhabitants through intermarriage, battles and ritual sacrifices. The high priest $\mathrm{Pa}^{\prime}$ ao introduced a new religious system that used human sacrifice, feathered images, and walled-in heiau. The migration coincided also with a period of rapid internal population growth. Remnant structures and artifacts dating to this time suggest that previously uninhabited leeward areas were settled during this period.

The fourth period dates from 1400 through 1600 . Voyaging between Hawai' $i$ and Tahiti ended. As a result of the external influences introduced by the migrating Polynesian chiefs and priests and internal developments related to the geometric growth of the population, sophisticated innovations in cultivation, irrigation, aquaculture, and fishing were implemented. These innovations were applied in the construction of major fishponds, irrigation systems, and field cultivation systems. Such advances resulted in the production of a food surplus which sustained the developing stratification of Hawaiian society into three basic classes-ali' $i$ the chiefs, kahuna the priests, and maka'ainana the commoners. Oral traditions relate stories of warring chiefs, battles, and conquest resulting in the emergence of the great ruling chiefs who controlled entire islands, rather than portions of islands. These ruling chiefs organized great public works projects that are still evident today. For example, 'Umi-A-Liloa constructed taro terraces, irrigation systems, and heiau throughout Hawai' $i$ island, including the Pu'uhonua at Kealakekua.

Although the common people provided food, barkcloth, and household implements to the chiefs, Hawaiian society remained predominantly a subsistence agricultural economy. There is no evidence of a money system or commodity production. A system of barter in essential goods between fishermen, mountain dwellers, and taro cultivators existed within the framework of the extended family unit called "ohana. In general, this exchange within the 'ohana functioned primarily to facilitate the sharing of what had been produced upon the 'ili or extensive land grant that the 'ohana held and worked upon in common.

Mary Kawena Pukui and E.S. Craighill Handy in The Polynesian Family System in $K a-{ }^{\prime} u, H a w a i{ }^{~} i$ describe this as follows:

Between households within the 'ohana there was constant sharing and exchange of foods and of utilitarian articles and also of services, not in barter but as voluntary (though decidedly obligatory) giving. 'Ohana living inland (ko kula uka), raising taro, bananas, wauke (for tapa, or barkcloth, making) and olona (for its fibre), and needing gourds, coconuts and marine foods, would take a gift to some 'ohana'living near the shore (ko kula kai) and in return would receive fish or whatever was needed. The fisherman needing poi or 'awa would take fish, squid or lobster upland to a household known to have taro, and would return with his kalo (taro) or pa' $i{ }^{\prime} a i$ (hard poi, the steamed 
and pounded taro corn).... In other words, it was the 'ohana that constituted the community within which the economic life moved (Handy \& Pukui, 1958).

Cultivation of taro and fishing were the centerpieces of the material culture. The sys tem of irrigation, fishing and aquaculture was highly developed and produced a surplus that sustained a relatively developed and unified social structure that was embraced throughout the whole archipelago. All the basic necessities of life came from plants. Even fishing relied on plants - the canoe was made from a hardwood tree; the net was woven out of olona or some other vine; spears were carved out of a hardwood tree; ropes were woven from the coconut husk or a vine; the sails were usually made of lauhala (pandanus leaves). Hawaiians could not have survived without plants, and Hawaiians were expert planters and cultivators.

In the fifth period, during the century preceding the opening of Hawai'i to European contact in 1778, the Hawaiian economy expanded to support a population between 400,000 and 800,000 people. 8 The social system consisted of the 'ohana who lived and worked upon communally held portions of land called 'ili within the ahupua'a natural resource system. These families-the building blocks of the Hawaiian social system-were ruled over by the stewards of the land - the chiefs along with their retainers and priests.

Even during this period of chiefly rule, land in Hawai' $i$ was still not privately owned. The chiefly class which provided stewardship over the land, divided and re-divided control over the districts of the islands among themselves through war and succession. A single chief could control a major section of an island, a whole island or several islands depending upon his military power. Up until the time of Kamehameha I, however, no one chief was ever paramount over all of the islands. ${ }^{9}$

The chief divided his landholdings among lesser ranking chiefs who were called konohiki. The konohiki functioned as supervisors on behalf of the chief over the people that lived on the lands and cultivated them. The tenure of a konohiki was dependent upon his benefactor, the chief. Konohike were often related to the chief and were allocated land in recognition of loyal or outstanding service to him. However, unlike elsewhere in Polynesia, the konohiki were rarely related to the maka 'ainana or commoners on the land under his supervision (Ralston, 1984). Thus, the konohiki represented the collective interest of the ali' $\mathrm{i}$ class over the maka'ainana as well as the individual interest of his patron chief.

The lands allocated to the konohiki were called ahupua'a. Ahupua'a boundaries coincided with the geographic features of a valley. They ran from the mountain to the ocean, were watered by a stream, and were bounded on both sides by mountain ridges. It afforded the 'ohana who lived in the ahupua'a access to the basic necessities of life-marine foods from ocean reefs and streams, low lying wetlands for taro, fresh water, timber, and medicinal plants from the forest. The use rights of the konohiki including fishing rights over shoreline fishponds and reefs.

${ }^{8}$ Estimate from Cook's voyage was 400,000. See Schmitt, Robert C., Demographic Statistics of Hawaii, Honolulu: UH Press, 1968. Recent studies by David Stannard place the pre-contact population as high as 800,000. See Before the Horror. Honolulu: UH Press, 1989.

${ }^{9}$ At the time of Cook, Kalaniopu'u controlled Hawai'i island, Kahekili controlled Maui, O'ahu, Moloka 'i, Lana'i, Kaho'olawe, Kava'i and $\mathrm{Ni}^{\prime}$ 'ihau. 
The konohiki supervised all productive communal labor within the ahupua'a monthto-month and season-to-season. He collected the annual tribute and determined if it was sufficient in relation to the productivity of the land. He regulated the use of land and ocean resources, administering the kanawai applying to the use of irrigated water as well as to fishing rights in the ocean. The konohiki was responsible for organizing communal labor for public works projects such as roads, fishponds, and irrigation systems.

The ahupua'a of the konohiki were further divided into strips of land called 'ili which were allocated either by the chief or konohiki to the commoner Hawaiians called maka'ainana. However, these land grants were given to specific extended family units of maka'ainana called 'ohana. These 'ili either extended continuously from the mountain to the ocean or were comprised of separate plots of land located in each of the distinct resource zones of the ahupua'a. In this way an 'ohana was provided access to all of the resources necessary for survival-vines, timber, thatch from mountain areas; sloping land for sweet potatoes and crops that require higher altitudes; low lying lands irrigated by stream waters; and ocean areas for fish, limpids, crustaceans and seaweed, the principal source of protein for Hawaiians (Handy, Handy \& Pukui, 1972). ${ }^{10}$

The tenure of the maka'ainana on the land was stable, unlike that of the ali' $i$ and the konohiki. There were two Hawaiian sayings that illustrated this principle. The first saying "Ko luna pohaku no ke ka'a i lalo, 'a'ole hiki i ko lalo pohaku ke ka'a" translates as "A stone that is high up can roll down, but a stone that is down cannot roll" (Pukui, 1983, \#1833). In other words, the chief and his retainers including the konohiki could be overthrown and lose their positions of influence. A chief could be defeated in war and lose his lands. When a chief died and a new chief succeeded him, the lands were re-distributed and the

${ }^{10}$ The traditional Hawaiian land divisions according to Malo (1951:16-18) consist of the following district, subdistricts, land divisions and land parcels:

- island: Moku-puni (cut off surrounded).

- Large District: Apana (pieces) or Moku-o-loko (interior division), e.g. Hana.

- Sections: 'Okana or Kalana, e.g. Honua'ula. ['Okana is also a district or sub-district and usually comprising several ahupua "a; Kalana is smaller than a district (Pukui \& Elbert 1971: 113, 258).]

- Subsection within 'Okana: Poko. [Dividing a District, or ahupua' a into two or more sections, e.g.: Hamakua Poko; Hamakua Loa]

- Ahupua'a (running mauka-makai, from the mountains to the sea) [a sub-district land division, some contain a few hundred acres, others 10,000 acres, or more]

- 'Ili-'aina ['Ili-'aina, a sub-division of an ahupua'a; 'ili lele, a discontinuous 'ili-'aina, consisting of two or more parcels of land in the same ahupua' $a$ and having the same name]

- Mo:o-'aina [mo'o-'aina is a cultivated garden within an 'ili-'aina or 'ili-lele]

- Pauku-'aina (joints of lands) [pauku-'aina is a land section smaller than a mo'o-'aina]

- Kihapai (patches or farms) [dry land garden]

- Ko'ele [ko'ele, a cultivated garden, the produce of which went to the ali' $i$ of the district or island]

- Hakuone (land cultivated by 'ohana with crops going to konohiki) [produce of which went to chief of the ahupua' $a$ ]

- Kuakua (broad kuauna or kuaauna, an embankment) [embankments between wet taro gardens, usually cultivated] (Malo 1951: 16-18). Information in brackets [ ] added. 
previous chief's konohiki could be displaced. However, the common people who lived on the land from the days of their ancestors were stable on the land. They were not displaced when the chief or konohiki over them changed. They continued to live on and cultivate the land of their 'ili from one chief to the next.

The second saying illustrating the stable tenure of the maka'ainana on the land, "I 'aina no ka "aina i ke ali' $\mathbf{i}$, a i waiwai no ka 'aina i ke kanaka" translates as "The land remains the land because of the chiefs, and prosperity comes to the land because of the common people" (Pukui, 1983, \#1149). In other words, the chiefs held the land, but the common people worked the land and made it valuable.

While the tenure of the maka'ainana was stable, they were not tied to the land and did have the option to move away if they chose to. There is little evidence, however, that moving off the land of one's birth was ever a common practice.

The maka'ainana produced all the necessities of life for their extended families from the 'ili that was allotted to them. In addition to cultivating plots for the subsistence of their 'ohana, the maka'ainana were obligated to keep the plots of land set aside for the konohiki and chiefs cultivated in food crops. These plots were called haku one and koele, respectively. The common people were also required to provide the chiefs and konohiki with an annual ho'okupu or tribute that included food and all types of household needs, such as tapa cloth and woven mats to stone and wooden containers and implements as well as feathers to make cloaks and helmets that were symbols of the ali' $i$ rank. In addition to the annual requirements; the maka'ainana were obligated to provide labor service and products from the land upon the request of the chief or konohiki. It was the labor of the maka ainana that supported the entire society; however the ali' $i$ enjoyed full appropriation rights over all that was produced upon his land grants.

Among the maka ainana there was cooperative labor and sharing of the fruits of the labor. Most of this sharing was done within the context of the ohana as the primary unit of production. The 'ohana lived in dispersed clusters of households called kauhale on the illi land granted to them. They did not congregate in villages as is common in other areas of the Pacific. Between the 'ohana there was also cooperative enterprise and reciprocal exchange of labor service called kokua. This was practiced in the undertaking of major projects such as the chopping down, hewing out, and hauling of a $\log$ for a canoe or the construction and thatching of a house structure. These type of projects required the labor of more people than comprised one single ohana. In addition, all of the "ohana within an ahupua 'a could be organized to do massive public works projects under the supervision of the konohiki. This included construction and maintenance of the irrigation systems and the fishponds.

Although the chiefs and their konohiki had full appropriation rights over the land and the people, in the main this was a system of mutual obligation and benefit between the chiefs and the people. The chiefs controlled the land and distributed it among the maka'ainana. The chief was required to manage and oversee the production on the land. He regulated the use of scarce resources; apportioned these resources among the people according to principles of fair usage; regulated the use of the water which was the most valued resource of the land; assured that the irrigation system was properly maintained; conducted proper rituals to the gods who controlled nature; and conserved the resources of the land through restriction and replacement policies. In return, the maka'ainana were obliged to provide labor service and products of the land to the chiefs and konohiki. 
While Hawaiian tradition records cases of arbitrary, irresponsible, and self-serving chiefs who abused the people, they were clearly exceptional cases and were quickly replaced with responsible chiefs who cared for the well-being of the people (Kamakau, 1961; Kelly 1980).

The Hawaiian proverb, "I ali'i no ali'i no na kanaka," or "A chief is a chief because of the people," reflects the Hawaiian attitude that the greatness of a chief was judged according to the welfare of the people under him (Pukui, 1983).

The Hawaiian historian David Malo wrote, "In former times, before Kamehameha, the chiefs took great care of their people. That was their appropriate business, to seek the comfort and welfare of the people, for a chief was called great in proportion to the number of his people ..." (Malo, 1839). In his book, Hawaiian Antiquities, Malo described the type of training given to young chiefs who were destined to rule:

It was the policy of the government to place the chiefs who were destined to rule, while they were still young, with wise persons, that they might be instructed by skilled teachers in the principles of government, be taught the art of war, and be made to acquire personal skill and bravery. The young man had first to be subject to another chief, that he might be disciplined and have experience of poverty, hunger, want and hardship, and by reflecting on these things learn to care for the common people, and at the same time pay due respect to the ceremonies of religion and the worship of gods to live temperately, not violating virgins ... conducting the government kindly to all (Malo, 1971).

The fragile system of checks and balances between the common people and ruling class which developed during the latter stage of Hawai' $i$ 's pre-European contact history functioned efficiently so long as the interest and values of both classes remained in basic harmony. However, to the extent that Hawaiian society had evolved into a socially and economically stratified system by 1600 , there was always inherent in this system the threat of dissolution of the bonds that tied commoners and ruling chiefs together.

\section{Contact and Monarchy}

The responses of the Hawaiian people to contact and change after 1778 were divergent and largely influenced by the individual social and economic role they played in the society. The acceptance or rejection of Western culture was largely the prerogative of the ruling class of ali'i. The common people did not play a major role in determining the political and economic future of Hawai' $i$. Instead, the Hawaiian social system assigned the ali' $i$ the lead role. In exercising this role, their response to foreign interests and foreign powers further distanced them from the common people, who were left with the problem of trying to survive the burdens of contact-war, disease, and depopulation.

Periodically, the common people also suffered from the famines which gripped the land, as the chiefs gave priority to meeting the needs of the fur and sandalwood traders:

As the desires of the chiefs and the pressure of the trading captains grew, more and more people were put to the task, fewer and fewer were left for the normal duties of everyday living; in many areas planting and fishing virtually ceased, and for a season thereafter there would be little harvested beyond the 
needs of the ali'i and their konohiki (supervisors). It was the people who went hungry. 11

Upon the death of King Kamehameha I in 1819 , those chiefs who were closely allied to him feared a rebellion from rival traditional chiefs. As a means of undermining their tivals, the Council of Chiefs, under the leadership of Mo'i Kamehameha II, Kuhina Nui Ka'ahumanu, and High Chief Kalanimoku instituted the "Ai Noa or abolition of the state religion. 12 By abolishing the traditional chiefly religion under which rivals could claim rank, prestige, and position, the Kamehameha chiefs consolidated political power under their control.

Although Native Hawaiian religion ceased to have the official sanction of the royal government, Hawaiian spiritual beliefs and customs continued to be honored and practiced in most of the rural communities and settlements of the kingdom. Families continued to honor their 'aumakua (ancestral deities). Traditional kahuna la'au lapa'au (herbal healers) continued their healing practices using native Hawaiian plants and spiritual healing arts. Family burial caves and lava tubes continued to be cared for. The hula and chants continued to be taught, in distinctly private ways. Among the deities who continued to be actively honored, worshipped, thought of and respected, even to the present, was Pele and her family of deities. Every eruption reinforced and validated her existence to her descendants and new generations of followers (Kanahele, 1992).

In 1820 , the year following 'Ai Noa, American missionaries began to settle Hawai' $i$ and convert Hawaiians to Christianity. In that same year commercial whaling began to attract increasing numbers of foreign settlers who demanded rights of citizenship and private ownership of land. 13

By 1840 , King Kamehameha transformed the government into a constitutional monarchy, having signed a Bill of Rights in 1839 and a Constitution for the Kingdom of Hawai' $i$ in the following year. In 1845, despite petitions of protest signed by 5,790 Hawaiians, foreigners were allowed to become naturalized citizens and to hold public office. Ka Mahele (The Land Division) in 1848 established a system of private land ownership which concentrated 99.2 percent of Hawai'i's lands among 245 chiefs, the Crown, and the Government. Less than one percent of the lands were given to 28 percent of the people, leaving 72 percent of the people landless. In 1850, over the protests of Hawaiians, foreigners were given the inght to own land. From that point on foreigners, primarily Americans continued to expand

\footnotetext{
11 Handy, 1976, p. 234-235.

12Kamakau, 1961, pp. 219-228. David Kalakaua, King of Hawaii, The Legends and Myths of Hawaii: The Fables and Folklore of a Strange People (New York: Charles L. Webster and Co., 1888; reprint Tokyo: Charles E. Tuttle Co., Ltd., 1973), pp. 429-446. Marshall Sahlins, Historical Metaphors and Mythical Realities: Structure in the Early History of the Sandwich Islands Kingdom (Ann Arbor: University of Michigan, 1981), pp. 55-64. William Davenport," "The Hawaiian 'Cultural Revolution': Some Economic and Political Considerations." American Anthropologist, LXXI, 1969, pp. 1-20. A.L.Kroeber, Anthropology, (New York: Harcourt, Brace, 1948).

${ }^{1}$ Kamakau, 1961; Ralph S. Kuykendall, The Hawaiian Kingdom Volume 1, 1778-1854. Foundation and Transformation, Honolulu: University of Hawai'i Press; 1938; reprint Honolulu: The University Press of Hawai' $i, 1980$.
} 
their interests, eventually controlling most of the land, sugar plantations, banks, shipping, and commerce of the islands. ${ }^{14}$

In 1887, American planter interests organized a coup d'etat against King David Kalakaua forcing him to sign the Bayonet Constitution which took away his sovereign powers as king and the civil rights of Hawaiians. In 1889,8 men were killed, 12 wounded, and 70 arrested in the Wilcox Rebellion which attempted to restore the Hawaiian Constitution. By 1890, non-Hawaiians controlled 96 percent of the sugar industry and Hawaiians were reduced to only 45 percent of the population due to the importation of Chinese, Japanese, and Portuguese immigrant laborers by the sugar planters.

In the year 1893, the United States Minister assigned to the Kingdom of Hawai ${ }^{~} i$, John L. Stevens, conspired with a small group of non-Hawaiian residents of the Kingdom, including citizens of the United States, to overthrow the indigenous and lawful Government of Hawai'i. ${ }^{15}$ On January 16, 1893, U.S. military forces invaded Hawai 'i. On January 17, 1893, a Provisional Government was declared and was immediately recognized by the U.S. minister plenipotentiary to Hawai'i.

In 1898, the United States annexed Hawai' $i$ through the Newlands Resolution without the consent of or compensation to the indigenous Hawaiian people or their sovereign government. Hawaiians were thereby denied the mechanism for expression of their inherent sovereignty through self-government and self-determination, their lands and ocean resources (Littler, 1929). ${ }^{16}$

Through the Newlands Resolution and the 1900 Organic Act, the United States Congress received 1.75 million acres of lands formerly owned by the Crown and Government of the Hawaiian Kingdom and exempted the lands from then existing public land laws of the United States by mandating that the revenue and proceeds from these lands be "used solely for the benefit of the inhabitants of the Hawaiian Islands for education and other public purposes," thereby establishing a special trust relationship between the United States and the inhabitants of Hawai 'i. 17 .

${ }^{14}$ Kuykendall, 1980. Davianna McGregor, "Voices of Today Echo Voices of the Past" in Malama Hawaiian Land and Water, edited by Dana Naone Hall, Honolulu: Bamboo Ridge Press, 1985.

${ }^{15}$ U.S. Congress. House. Report No. 243 "Intervention of United States Government in Affairs of Foreign Friendly Governments." 53rd Congress, 2d Session. December 21, 1893. Washington: Government Printing Office, 1893. U.S. Congress. Senate. Committee on Foreign Relations. "Hawaiian Islands." Report of the Committee on Foreign Relations With Accompanying Testimony and Executive Documents Transmitted to Congress from January 1, 1893 to March 19, 1894. Volumes I and II. Washington: Government Printing Office, 1894. Also referred to as "The Morgan Report." U.S. Congress. Senate. Committee on Foreign Relations. Report No. 227. "Report from the Committee on Foreign Relations and Appendix in Relation to the Hawaiian Islands, February 26, 1894." 53d Congress 2d Session. Washington: Government Printing Office, 1894. U.S. Department of State. "Papers Relating to the Mission of James H. Blount, United States Commissioner to the Hawaiian Islands." Washington: Government Printing Office, 1893.

${ }^{16}$ Littler, Robert M.C. The Governance of Hawaii: A Study in Territorial Administration. Stanford: Stanford University Press, 1929.

${ }^{17}$ U.S. Congress. 56th Congress, 1st Session 1899-1900. “Congressional Debates on Hawaii Organic Act, Together With Debates and Congressional Action on Other Matters Concerning the Hawaiian 


\section{Territorial Period}

From 1900 through 1959 Hawai'i was governed as a Territory of the United States. The official U.S. policy was to Americanize the multi-ethnic society of the Hawaiian Islands, beginning with the children through the American public school system. Hawaiian and other languages except English were banned as official languages or as a medium of instruction. An elite group of Americans who were the owners and managers of what was called the Big Five factors had monopoly control over every facet of Hawai'i's economy. ${ }^{18}$ They controlled the sugar plantations, shipping, banking and commerce.

In the realm of politics, Hawaiians held the plurality of votes and controlled the legislature and the delegate to U.S. Congress up through World War II. Immigrant plantation workers and their descendants comprised the majority of the population, but first generation Asians were excluded from becoming naturalized citizens under U.S. law. It was not until after World War II that second generation Asian descendants matured to voting age and became a major political force in the islands. Hawaiian leaders allied with the Big Five under the banner of the Republican Party during the Territorial years. Due to political patronage, Hawaiians held a majority of the government jobs and dominated certain private sector jobs such as cowboys on ranches, longshoremen on the docks, and in the electric and telephone companies. In 1927, Hawaiians held 46 percent of the appointive executive government positions, 55 percent of the clerical and other government jobs, and over half of the judgeships and elective offices. Through 1935, Hawaiians held almost a third of the public service jobs and dominated law enforcement although they comprised only 15 percent of the population of the islands (McGregor, 1980).

Despite these obvious advantages, close to half of the Hawaiian population did not assimilate and mainstream into the developing economy. Instead they remained in remote valleys and isolated rural pockets providing for their large families through subsistence farming and fishing. During this period a major distinction internal to the Hawaiian community evolved between the urban Hawaiians who assimilated and accommodated to the socio-economic system dominated by the American elite and the rural Hawaiians or kua'aina who remained in the back country areas maintaining a traditional Hawainan way of life. 19

During the Territorial period a "local" culture combining Hawailan with the cultures of the various immigrant groups who settled in Hawai' $i$ began to evolve. Most of the immigrants who were imported to work on Hawai' $i$ 's plantations were peasant farmers in their countries of origin. With the majority of Hawaiians who were planters and fishermen, they shared a respect for the land and a strong reliance on extended family relations. Loyalty, respect, and caring for family elders and the overall well-being of all family members were

Islands." Washington, (photostat reproduction from the Congressional Record, v, 33, pts. 1-8), 1899-1900.

${ }^{18}$ The Big Five are C. Brewer, Theo H. Davies, Castle \& Cooke, AmFac, and Alexander and Baldwin. Fuchs, Lawrence, Hawaii Pono: A Social History. San Diego: Harcourt, Brace \& World, Inc., 1961; Kent, Noel. Hawaii, Islands Under the Influence. New York: Monthly Review Press, 1983; Lind, Andrew, An Island Community: Ecological Succession in Hawaii. Chicago: The University of Chicago, 1938; reprint New York: Greenwood Press, 1968.

${ }^{19} \mathrm{Kua}$ aina is translated in the Pukui/Elbert Hawaiian Dictionary as person from the country. It means the back of the land. These are the people who bent their back, toiled and sweated to care for the land. 
important values that came to characterize "local" people. In rural plantation communities, the immigrant workers shared the common experience of oppressive working conditions, living in plantation camp housing, and being in constant debt to the plantation store. Children of immigrant workers and Native Hawaiians alike attended Hawai ' $i$ 's common public schools. There they were socialized by the American school system. The children learned together, ate and shared meals together, and communicated across cultural barriers in pidgin dialect. They learned to hunt for pigs and gather fruits in the forest. They caught fish or gathered marine life from common fishing grounds. Between Hawaiians and immigrant groups, particularly the second and third generations, the rate of intermarriage was very high.

World War II ushered in major changes in the social, economic, and political life of the islands. Many Hawaiians left their rural enclaves to join the service or to work in high paying military jobs in Honolulu. The military were also stationed in rural areas throughout the islands. The war experience broadened the social horizons and raised the expectations and aspirations of all of Hawai' $i$ 's people for a higher standard of living. Raising the age for compulsory education to 18 also forced rural families out of the most remote areas in order to comply with the law and send their children to intermediate and high school. There was also a large exodus of people from Hawai' $i$ to the U.S. mainland in search of better job opportunities.

Labor unions successfully organized workers and gained collective bargaining contracts on the docks, plantations, utility companies, transportation, hotels and restaurants, and the public sector. Leaders of the Japanese community joined ranks with labor to reorganize the Democratic Party and defeated the Republican Party in 1954. Gradually Hawaiians were replaced in government jobs by Japanese. The Democratic Party led the movement to gain statehood for Hawai'i.

\section{Statehood}

Statehood stimulated unprecedented economic expansion in Hawai' $i$. The number of hotel rooms more than tripled and the number of tourists increased fivefold within the first ten years. Pineapple and sugar agribusiness operations were phased out and moved to cheaper labor markets in Southeast Asia. The prime agricultural lands which remained were developed into profitable subdivision, condominium, and resort developments. Left jobless, former plantation and cannery workers had few employment options. They obtained lower paying and less stable jobs in the expanding tourist industry. An excerpt from a social impact statement concerning the effects of new freeway connecting rural $O^{\prime}$ ahu to urban Honolulu offered an insight on the frustrations and social pressures that Hawaiian and local people began to associate with development:

Some long-time residents have the feeling that they are being dispossessed of their traditional access to the beauties and bounties of nature around them. Anxieties arise as open space is filled up by newcomers and the taxes on land keep going up. Frustration is felt as the future character of their shrinking world is being decided by landowners and developers, government planners, and elected officials in offices and meeting rooms far away. And there is a problem of the carry over of these insecurities to the younger generation. There are indications of social breakdown as reflected in the rate of unemployment, the growing incidence of family separations, the heavier welfare loads and the increase in juvenile delinquency and adult crimes (Dean, Eckbo, Austin, and Williams, 1973). 
Changes to the rural and agricultural areas concerned all of Hawai' $i$ 's local people. However the Hawaiian community, because of its traditional concentration, in the rural pockets were especially affected.

\section{ETHNOGRAPHIC OVERVIEW OF PUNA}

Puna, a Traditional Wahi Pana (Sacred Place)

"Puna, mai "Oki"okiaho a Mawae".

"Puna from "Oki'okiaho to Mawae"

This traditional 'olelo no'eau or proverb describes the boundaries of Puna as going from 'Oki'okiaho on the Ka'u side to Mawae on the Hilo side (Pukui, 1983, \#1777). Comprising 311,754 acres, the island of Kaua'i (354,112 acres) could almost fit within the district.

Traditionally, Puna is one of the most sacred areas in all of Hawai'i. Located in the easternmost part of Hawai' $i$ island, the easternmost island of the Hawaiian chain, the day and all of life springs forth in Puna. The northeast trade winds with its cloud formations and rainfall first encounter Hawai' $i$ in Puna. The following Hawaiian proverb speaks of how these winds grow fragrant as they travel over Puna, luxuriant with maile, lehua, and hala (Pukui, $1983, \# 1458$ ).

\section{"Ka makani hali "ala o Puna" \\ "The fragrance-bearing wind of Puna":}

Puna means well-spring. Hawaiians observed how the forests of Puna attract the clouds to drench the district with its many rains, such as " $\mathrm{ka}$ ua moaniani lehua o Puna" / "the rain that brings the fragrance of the lehua of Puna" (Pukui, 1983, \#1587). The rains refresh and enrich the Puna water table and sustain the life cycle of all living things in Puna. The recharge cycle in the Puna district is important to the water table of the entire island.

The waters of the newest and easternmost district of Puna are believed to originate with Kaneikawaiola, the Hawaiian god of fresh water springs and streams. His domain is traditionally in the east. Kaneikawaiola is guardian of the Pele fire clan, the family of deities who migrated from the south to Hawai $i$ and are manifest in the various volcanic activities in the Puna district. Kaneikawaiola protects the subsurface waters, main source of the volcanic steam which forms the bloodstream of the volcano deity, Pelehonuamea.

The steam is believed to be the mana, the life force and the energy of Pele. When Pele does not actively erupt, the steam is the main form in which she manifests herself. When there is steam in the forest, Pele is thought to be there. That is her identity, her imagery and her manifestation. Throughout the district of Puna, traditional chants tell of warm pools in caves and under the ground, such as Kaukala and Punahakeone. These are sacred bathing places of Pele. Pele practitioners believe that the waters of the Puna district are sacred to Kaneikawaiola and that the steam generated by the heat of Pele are sacred to Pele. 
Puna is also where new land is created and new growth and new life sprouts. The land is sacred, fresh, clean, untouched, and after vegetation regenerates upon it, then it is ready for human use. ${ }^{20}$

The following chant "Ke Ha'a La Puna I Ka Makani," translated by Pualani Kanahele, elaborates the primal elements and features associated with Puna that Hawaiians celebrate in legends, chants, and hula. ${ }^{21}$ It describes how and why Puna is regarded as a wahi pana or sacred area by Hawaiians.

\section{Ke Ha`a La Puna I Ka Makani}

1. Ke ha'a la Puna i ka makani

Puna is dancing in the breeze

2 Ha'a ka ulu hala i Kea'au

The hala groves at Kea'au dance

3. Ha'a Ha'ena me Hopoe

Ha'ena and Hopoe dance

4. Ha'a ka wahine

The woman dances

5. 'Ami i kai o Nanahuki

(She) dances at the sea of Nanahuki

6. Hula le'a wale

Dancing is delightfully pleasing

7. I kai o Nanahuki

At the sea of Nanahuki

8. 'O Puna kai kuwa i ka hala

The voice of Puna resounds

9. Pae i ka leo o ke kai

The voice of the sea is carried.

10. Ke lu la, i na pua lehua

While the lehua blossoms are being scattered.

11. Nana i kai o Hopoe

Look towards the sea of Hopoe

\footnotetext{
${ }^{20}$ Pualani Kanaka'ole Kanahele, lecture to student body of Kamehameha Schools, May 2, 1990.

${ }^{21}$ Pualani Kanaka'ole Kanahele, Ka Honua Ola (The Living Earth), Part I An Introduction to Pele and Hi'iaka, unpublished manuscript for the State Foundation on Culture and the Arts, 1992, available in Hawaiian-Pacific Collection of Hamilton Library. The following translation and interpretation of the chant is excerpted from the report by Ms. Kanahele with her permission.
} 
12. Ka wahine 'ami i kai o Nanahuki

The dancing woman is below, towards Nanahuki

13. Hula le'a wale

Dancing is delightfully pleasing

14. I kai o Nanahuki

At the sea of Nanahuki

Pualani Kanahele has provided the following interpretation of this chant which expounds upon the qualities of Puna which distinguish it as a singularly sacred area because it is where the ha'a form of hula originated.

"Ke Ha'a La Puna" is the first recorded hula in the Pele and Hi'iaka saga. Hi'iaka performed a hula to this mele to please her older sibling. The motif of this mele focuses on ha'a or hula; therefore discussion of this mele concentrates upon the subject of hula. Also included in this discussion are place names, weather phenomena, movements of nature, and natural imagery.

Ha'ena, Hopoe, Kea'au, Nanahuki, and Puna are the land sections or land features mentioned in this mele. Puna is the district in which these places are found. Puna is also the land section that inspires hula creation because of the natural movements of wave, wind, and trees.

Puna is the source of regenerative power. Some examples are the rising of the sun, volcanic creation of new land, and the growth of new vegetation on this new formed land. Puna is described as, $\mathrm{Ka}$ aina $\mathrm{i} \mathrm{ka}$ houpo a Kane or the land in the heart of Kane. Kane is one of the four major Gods of the Hawaiian pantheon and Puna is affected by all of the manifestations of Kane.

Puna is the easternmost land section of the Hawailan archipelago and Kane represents the east. Kane represents the sun and Kumukahi and $\mathrm{Ha}^{\prime} \mathrm{eha} \mathrm{e}^{\prime} \mathrm{e}$, the gateway to the sun, are located in Puna. Literally the word puna means well-spring and fresh water is represented by Kane. The northeast side of the island chain is known as the ko'olau or windward. The windward sides of the islands are the rain sections.

The Moa'e, or trade wind, brings the rain clouds. In our story line the easternmost point or Puna receives the rain first. The rain together with the sun in the Puna area are the nurturing substances which induce incubation and growth of vegetation on the new land. The other agent vital to this growth is land itself and the processes through which new land develops. Lava flow which creates new land is credited to the creative power of Pelehonuamea and her siblings.

Kanehoalani, the father of Pele, is a Kane form. At the end of her migration Pele finds herself in the eastern district of Hawai 1 island and acknowledges his presence by calling out a greeting to him in the east.

"E Kanehoalani, e Kanehoalani aloha kaua"

"Kanehoalani, Kanehoalani greeting to us" 
Pele establishes residency here and along with her sister' Hi'iakaikapoliopele gains the reputation of the women of the east. Ho mai Pele is one of the many chants associating Pele with the east.

"Holo mai Pele mai ka hikina"

"Pele travels from the east"

Pele is the manifestation of the out-pouring of magma and the primary causation of new land. The Hawaiian word for lava is pele, whether the lava takes the form of pahoehoe, ' $a$ ' $a$ or fountaining it is still called pele. The phenomenon of Puna alludes to the impression of newness, birth, creation, incubation, reproduction, genitals, and the concepts related to an earthly or cosmic creation. The regenerative elements of Puna includes Kane and Pele and their manifestations of fresh water, sunlight, and land.

1. Ke ha'a la Puna i ka makani

Puna is dancing in the breeze

Hi 'iaka, the youngest sister of Pele, is asked by Pele to do a ha'a and a mele. She satisfies her older sister's request with "Ke ha'a la Puna i ka makani." The ha'a or dance which she exhibits is a creative exposition in praise of the environment around her and a celebration of the regenerative power of the coupling of land and flora.

Hi'iaka's kinolau or body forms are the flora which readily grows on new lava flows. Therefore it is Hi'iaka's place to celebrate this newly made land upon which her body forms are given life.

The poetic mind of the Hawaiian saw the wind as a dramatic character with many faces. For instance, when the wind blows on your back in certain situations it is the element of support and encouragement. When the wind is accompanied by the rain it can be interpreted as destructive and piercing such as the Kipu'upu'u wind and rain. The Ka'ilialoha wind has a reputation of snatching away your love never to return. The Malanai wind is so comfortable and pleasant it is able to entice and encourage love making. In association with Hi'iaka the wind is the primary component which aids Hi'iaka in the dispersal and distribution of flora. However, the phrase, is ka makani, or in the wind, gives movement to Puna, and this flowing movement created by the wind is worthy of imitation and thus a basic and primal form in ha'a is born.

2. Ha'a ka ulu hala i Kea'au

The hala groves at Kea'au dance

The abundance of hala in the Puna district gives birth to this saying and the bounteous supply of hala in Puna is credited to Pele.

The hala is valuable because the leaves are woven into mats, baskets, and other usable items. The ripe yellow and orange fruit are often compared to the glow of a lava flow. The ripe fruit is also made into a lei and on Hi'iaka's journey to Kaua'i to fetch Lohi'au she wore a hala lei. Kapo'ulakinau, another protector and champion of the Pele clan, wore hala leis often. Kapo was the female deity of 'ana'ana and 'ana'ana practitioners wore hala leis often to ward off evil influences. 
The ulu before hala is the qualifier which simply means grove; however ulu indicates the abundance in growth of hala in Puna. The name of Kea'au gives one a sense of place. Kea'au is an ahupua'a in the district of Puna close to the Hilo-Puna borders.

Lines $2,3,4,5,6,7$, and 8 have patterns with definite emphasis: a) words of dance such as ha'a, 'ami, and hula; b) place names associated with hula as Kea'au, Ha'ena, Hopoe; c) elements of land, sea, air and their movements and finally; d) the woman, Hopoe.

The natural choreography allow us to appreciate the visual movements of nature and begin to develop imagery associated with the aural interpretation of poetry.

Puna produces sounds with the beating of the sea on the cliff. This sound is magnified through the groves of hala. The hala grove becomes the resonator. The sea movements of, as it heaves, rolls, dashes, splashes, sprays and vibrates, produces various distinct sounds and chords. The various sounds emanating from the hala grove are symbolic of the sounds re produced by the hula implement which excites and provokes movement for the dancer.

The mele (song) explains the role of the deities in hula. They provide the means and the arena and one must be ingenious and create the dance by imitating the things around us. Imitation of nature gives praise to those Deities responsible for different aspects of nature. Pele's energy, her explosive, dramatic creative tactics of land birth deserve praise. The dualistic nature of Hi'iaka and her procreative powers of vegetable growth also deserve praise. The land and vegetable manifestation of these sisters provides initial movement and energy in creating hula. The hula associated with these deified sisters are pure original movement and pure sound.

Having generally reviewed the way in which the Puna district is regarded in Hawai ian tradition by the Hawaiians of old and by the contemporary Hawaiians who continue to cherish and honor those traditions, we will examine the history of change and continuity in the district.

\section{Puna's Mythical Era}

In the myths of Hawaiian oral tradition, the islands were first inhabited by akua (gods) and deities. These deities represented the natural elements of nature which shaped the landscape and remained as features of the land. The myths and legends of Puna are domi nated by Pelehonuamea, Hawaiian goddess of the volcano, and the members of her fire clan who migrated from their distant homeland through the northwest 1slands of Hawai'i until they settled in Puna, Hawai' $i$. These are discussed in Chapter 4 of this report, "Pele Beliefs, Customs, and Practices."

"Ke one lau"ena a Kane"

"The rich, fertile land of Kane"

This Hawaiian proverb was interpreted by Mary Kawena Pukui as a reference to how Puna was a beautiful and fertile land loved by the god Kane. According to Pukui, Pele changed it into a land of lava beds, cinder, and rock when she settled there from Kahiki (Pukui, 1983, \#1777).

The legends, myths, and chants which describe the early development of the Puna district relate the dynamic interplay between the deities of the Pele fire clan and the deities 
honored by other Hawaiian families as their ancestors. Each of the deities represent different elemental forces in the natural landscape of the Puna district. Throughout all of the folklore for Puna, Pele and her family of deities emerge as the natural primal elements which dominate and shape the lives of the chiefs and the people of Puna. The cosmology, beliefs, customs, and practices sacred to Pele, which are honored by the generations of descendants who trace their genealogies to the fire clan of Puna and $\mathrm{Ka}{ }^{\prime} \mathrm{u}$ will be discussed in a special section of this ethnographic study. However, here are two traditional mo'olelo (historical accounts) which relate the conflict between Pele of the volcanic fire and deities representing other natural elements in Puna, the mo'o or dragon lizards who dwelt in mountain pools and shoreline ponds before the Pele clan came to Hawai' $i$, and the pig god which dwelt in the older growth forests. The volcanic deity conquers the mo'o but reaches a compromise with the pig god. The mo'o dwell in both fresh water mountain pools and in brackish shoreline ponds but they are not associated with the major Hawaiian god Kaneikawaiola in any chants, legends, or myths.

\section{The Legend of Pele, Waka the Mo'o and Their Husband Puna-'ai-koa'e}

It is said by the ancients in their legends that $\mathrm{Ka}-{ }^{-} \mathrm{u}$ and Puna were beautiful lands without lava beds, and that there was only earth from one end to the other .... It was said that a very long sandy stretch called Ke-one-lau-ena-a-Kane (Kane's great sand stretch) was found in the district of Puna. That was before the lava destroyed and changed Puna and Waiakea into a land of lava rocks.

Waka-ke-aka-i-ka-wai and Puna-'ai-koa'e were destroyed by Pele of the eternal fires. It was said in this legend by the ancients that this fight between these wondrous supernatural beings went on from Punalu' $u$ in Ka-' $u$ to Puna and to Waiakea in Hilo. This caused the long, long stretch of sand which extended from Waiakea, Hilo to Panau in Puna, called Keone-lau'ena-a-Kane, to be covered with lava. Because Waka ran thither, most of the land of Puna became covered with rough and smooth lava to this day. Thus did this famous stretch of sand disappear but traces of it can be seen through small holes here and there all the way from Waiakea to Puna. 22

\section{Earliest Settlement}

The companion archaeology report for this study by Greg $C$. Burtchard sets the dates for the earliest settlement of Puna between 300 A.D. and 600 A.D. (Burtchard and Moblo 1994). However, as the report notes, very little subsurface excavation has been conducted in the Puna district. As study of the area expands, it is possible that the date for earliest settlement could be revised. Settlements in Puna would have first developed along the shoreline where families would have access to the ocean, fresh water springs, as well as arable lands.

\section{Continued Settlement and Gradual Expansion}

Legends, possibly set in this era, between 600 A.D. and 1100 A.D. document the trials of Puna chiefs and their followers with Pele, the fiery tempered volcano goddess. Chief Kanuha of Kona shared the legend of Puna chief Keliikuku with French explorer Jules Remy.

\footnotetext{
2Excerpt from: A Legend told by Moses Manu, Ka Loea Kalai'aina, May 1899-Feb. 1900, translated by Mary Kawena Pukui, in Dorothy Barrere, "Political History of Puna," manuscript for Archaeology Reconnaissance of the Kalapana Extension by Bishop Museum, 1959.
} 
(Remy, 1868). The event was believed by Kanuha to have occurred two centuries from when he lived, in the 1600s. The legend provides a description of Puna prior to 1600, when the district was being settled. The legend of how the young chief Kahawali and his hula students perish after rebuffing a challenge from Pele to compete at holua (mountain surfboard) sledding is also related in many sources and probably occurred around the same time. ${ }^{23}$

\section{The Legend of Keliikuku}

According to Chief Kanuha, the common tradition for the district of Puna was that, before 1600 , it was a magnificent country, possessing a sandy soil very favorable to vegetation and with smooth even roads. The Hawaiians of the time of Kanuha in the nineteenth century held a tradition from their ancestors that their great grandparents beheld the advent of volcanic floods in Puna.

This high chief reigned in Puna. He journeyed to the island of Oahu. There he met a prophet of Kauai, named Kaneakalau, who asked him who he was. "I am," replied the chief, "Keliikuku of Puna." The prophet then asked him what sort of country he possessed. The chief said: "My country is charming, everything is found there in abundance, everywhere are sandy plains which produce marvelously." "Alas!" replied the prophet, "go, return to your beautiful country, you will find it overthrown, abominable. Pele has made of it a heap of ruins; the trees of the mountains have descended towards the sea, the ohia and pandanus are on the shore. Your country is no longer habitable." The chief made answer: "Prophet of evil, if what you now tell me is true you shall live; but if, when I return to my country, I prove the falsity of your predictions, I will come back on purpose and you shall die by my hand."

Unable, in spite of his incredulity, to forget this terrible prophecy, Keliikuku set sail for Hawaii. He reached Hamakua and, landing, traveled home by short stages. From the heights of Hilo at the village of Makahanaloa, he beheld in the distance all his province overwhelmed in chaotic ruin, a prey to fire and smoke. In despair, the unfortunate chief hung himself on the very spot where he first discovered this sad spectacle.

This tradition of the mountain of Keliikuku and Kaneakalau continued to be told and retold among Hawaiian storytellers. It was reduced to meter and sung by the ancients. According to Chief Kanuha, whether the prediction was made or not, the fact that Puna had been ravaged by volcanic action had come to pass.

\section{Kahawali and Pele}

The handsome young chief Kahawali lived near Kapoho in Puna district on Hawai' $i$ in the days of Kahoukapu the chief. He had a wife and two children named Paupoulu and Kaohe, a mother living at Kuki'i, and a sister Koae at Kula. His father and another sister named Kane-wahine-keaho lived on Oahu. Kahawali was an expert in the hula dance and in riding the holua. At the time of the Lono festival, when the hula pupils gathered for a public appearance, a sled race was arranged with his friend Ahua. Pele in the guise of an old woman offered to compete with him. Angry at the chief's rebuff, she pursued him down the

${ }^{2}$ William Ellis, A Narrative of a Tour Through Hawaii ... With Remarks on the History, Traditions, Manners, Customs, and Language of the Inhabitants, London, 1827; reprint 1963. His Hawaiian Majesty King David Kalakaua, The Legends and Myths of Hawai' $i$ : The Fables and Folk-Lore of a Strange People, New York: 1888, reprint Tokyo: 1973. Mary K. Pukni, and C. Curtis, Pikoi and Other Legends of the Island of Hawaii. Honolulu, Kamehameha Schools Press, 1949. 
hill in fire form. He fled first to the hill Pu'ukea, then went to bid good-by to his wife and children, paused to say farewell to his favorite pig Aloi-pua'a, and had just time to greet his sister at Kula before he escaped to the sea in a canoe which his brother had opportunely brought to land. Lava rocks are said to mark the fate of members of Kahawali's family and of his favorite pig. The famous tree-molds (Papa-lau-ahi) above Kapoho are said to be a group of hula pupils caught in the trail of Pele's wrath (Beckwith, 1976: 190-192).

\section{Migration, Ruling Chiefs and 'Ohana}

For the period of the Tahitian migration and ascendancy in Hawai' $i$ island between 1100 and 1300 A.D., Puna is prominent in legends as the district where the high priest $\mathrm{Pa}^{\prime}{ }^{\prime} \mathrm{ao}$ made his first landfall and built the heiau (temple) for his god which is today called Wahaula. Hawaiian historian Samuel Kamakau provides the following brief account:

Puna on Hawai' $\mathrm{i}$ island was the land first reached by $\mathrm{Pa}$ 'ao, and here in Puna he built his first heiau for his god Aha'ula and named it Aha'ula [Waha'ula]. It was a luakini. From Puna, Pa'ao went on to land in Kohala, at Pu'uepa. He built a heiau there, called Mo'okini, a luakini (Kamakau, 1991: 100).

$\mathrm{Pa}^{\prime}$ ao, according to Hawaiian oral tradition, was a powerful priest and prophet. According to Kamakau he originated from Wawau and 'Upolu, lands of the mythical Polynesian homeland, Kahiki. ${ }^{24}$ In Hawai' $i$ he established a new order of religious priesthood and practices which included human sacrifices at the luakini heiau which form of construction he introduced into Hawai' $\mathrm{i}$. The priesthood of $\mathrm{Pa}^{\prime}{ }^{\prime} \mathrm{oo}$ 's served the ruling chiefs of Hawai' $\mathrm{i}$, until the time of Hewahewa, high priest of King Kamehameha I and II who collaborated with. Kamehameha II in the abolition of the traditional chiefly kapu (system of sacred rituals and restrictions) in 1819.

Abraham Fornander in An Account of the Polynesian Race, gives the following description of Waha'ula heiau:

It was built in the quadrangular or parallelogram form which characterized all the Heiaus built under and after the religious regime introduced by Paao, and in its enclosure was a sacred grove, said to have contained one or more specimens of every tree growing on the Hawaiian group, a considerable number of which, or perhaps their descendants, had survived when last the author visited the place in 1869 (Fornander, 1880: 35-36).

According to Kamakau, Hawai' $\mathrm{i}$ island was without a chief when $\mathrm{Pa}^{\prime} \mathrm{a}$ o arrived in Hawai' $i$. Evidently the chiefs of Hawai' $i$ were considered ali' $i$ maka'ainana or just commoners, maka'ainana during that time (Kamakau, 1991: 100). $\mathrm{Pa}^{\prime}$ ao sent back to Tahiti for a

${ }^{24}$ Martha Beckwith, 1976 , p. 370 wrote, Tradition ascribes to Paao the introduction of human sacrifice into the temple ritual, the walled heiau, and the red-feather girdle as a sign of rank; all typical, says Handy, of late Tahitian culture and not found in Samoa. Other institutions ascribed to him are the puloulo'u tapu sign, the prostrating tapu (tapu moe or -0 ), and the feather god Kaili; some would call Paao rather than $\mathrm{La}^{\prime} \mathrm{a}$-ai-kahiki the introducer of image worship ... That Paso took his ideas from Tahiti is further indicated by reference to "Vavau" and "Upolo" as places where he owned land, probably in districts so named in northern Tahiti in the Aha-roa division of that island, and the name Aha-ula (later called Waha-ula) for the first heiau erected by his party on Hawai'i suggests such a connection. 
new ruler for Hawai' $i$, thereby ushering a new era of ruling chiefs and kahuna (priests) in Hawaiian archipelago. The new ruler was Pili-ka'aiea from whom King Kamehameha I eventually descended. Kamakau, Fornander and Thrum placed $\mathrm{Pa}$ 'ao in the 11th century, sixteen generations from Heleipawa. Bruce Cartwright in "Some Aliis of the Migratory Period" places Pili, the chief brought to Hawai'i by Pa'ao, in the 25 th generation before 1900 , i.e. 1275 A.D. (Barrere, 1959; Cartwright, 1933).

In the migration legend of Mo'ikeha to Hawai'i his party first touched at the easternmost point of Hawai'i, cape Kumukahi, and the younger brothers of Moikeha, Kumukahi and $\mathrm{Ha}^{\prime}$ eha'e remained in Puna. Among the others in his family, the kahuna Mo'okini and Kalua-wilinau made their home at Kohala; Honua-ula landed in Hana on Maui; the sisters Makapu'u and Makaaoa landed on $O^{\prime}$ ahu. The rest of the party went on to Kaua'i.

In the Kumuhonua legend which records the migration of Hawai' $i$-loa, also known as Ke-kowa-i-Hawai' $i$, his grandson is born in Puna. Hawai ' $i-l o a$, his family, and his followers migrate to Hawai' $i$. He alone takes his wife and children and are ascribed as being the ancestors of the Hawaiian people. He named the island of Hawai' $i$ after himself, the other islands after his children, and various land divisions after his navigators who sailed with him. From time to time he voyages south to bring back mates for his children out of the family of his brother $\mathrm{Ki}$. He brings Ki's oldest son Tu-nui-ai-a-te-atua as husband for his favorite daughter Oahu. Their son Tu-nui-atea is born at Keauhou on Hawai'i. Hawai' $i$ Loa names the district of Puna for the birthplace of his nephew Tu-nui-ai-a-te-atua, Puna-auia, in Tahiti (Beckwith, 1976: 363-370).

\section{Ruling Chiefs of Puna}

"Hilina'i Puna, kalele ia Ka'u" I "Puna leans and reclines on $\mathrm{Ka}$ 'u" refers to the common origin of the people of Puna and $\mathrm{Ka}^{\prime} \mathrm{u}$. The ancestors of these two districts were originally of one extended family. The time came when those of each district decided to have a name of their own, without breaking the link entirely. Those in $\mathrm{Ka}{ }^{\text {' }} \mathrm{u}$ referred to themselves as the Makaha meaning fierce, savage, ferocious. Those in Puna called themselves Kumakaha or standing fierce, savage, ferocious. Both names are related in chants of the chiefs of Puna and Ka'u (Pukui, 1983, \#994). Again referring to the common origins of the Makaha of $\mathrm{Ka}^{\mathrm{u}} \mathrm{u}$ and the Kumakaha of Puna is the rallying call, " $\mathrm{E}$ ala $\mathrm{e} \mathrm{Ka}$ ' $\mathrm{u}$, Kahiko o Makaha; e ala e Puna, Puna Kumakaha; e ala e Hilo na'au kele!" / "Arise, O Ka'u of ancient fierce descent; arise o Puna stand fierce; arise, $O$ Hilo of the water-soaked foundation" (Pukui, 1983, \#260). The distinction among the families of Ka' $\mathrm{U}$ and Puna possibly occurred during this period.

Puna's political history throughout this period is bound up with the fortunes of the ruling families of Hilo and Ka' $\mathrm{U}$. No one single family emerges upon whose support one $\alpha$ another of the chiefs seeking power had to depend upon for his success. Thus, the political control of Puna did not rest upon conquering Puna itself, but rather upon control of the neighboring districts of $\mathrm{Ka}^{\prime} \mathrm{u}$ and Hilo (Barrere, 1959: 15).

Nevertheless, there are two notable Puna chiefs in this era, Hua'a and 'Imaikalani, who are identified as enemies of high chief 'Umi-a-Liloa and are killed by him and his warriors.

During the time of high chief Liloa, approximately 1475 A.D., the chiefs of the six districts of Hawai' $i$, including Puna, were autonomous within their own districts, but they 
acknowledged Liloa as their paramount chief. Hakau, son of the sacred wife of Liloa succeeded him. According to Kamakau, Hakau failed to look after the well-being of the people under him.

But in the later years of his rule he was lost in pleasure, mistreated the chiefs, beat those who were not guilty of any wrongdoing, and abused the priests of the heiaus of his god and the chiefs of his own government Kamakau, .1992).

The chiefs and priests conspired with 'Umi-a-Liloa, Hakau's half-brother, and killed Hakau. Hakau's death left 'Umi in possession of Hamakua. The chiefs of the remaining districts of Hawai' $i$ declared themselves to be independent of 'Umi. 'Umi conquered those chiefs who resisted him and reunited the districts of the entire island under his rule. According to Kamakau, Hua-'a, the chief of Puna was conquered by 'Umi-a-Liloa.

Hua-'a was the chief of Puna, but Puna was seized by 'Umi and his warrior adopted sons, Pi' $i$-mai-wa'a, 'Oma'o-kamau, and Ko'i. These were noted war leaders and counsellors during 'Umi's reign over the kingdom of Hawai' $i$. Hua-'a was killed by Pi'i-mai-wa'a on the battlefield of Kuolo in Kea'au, and Puna became 'Umi-a-Liloa's (Kamakau, 1992: 17).

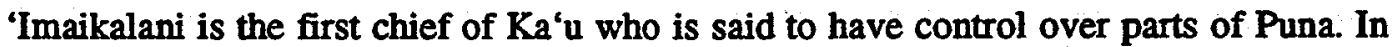
the time of 'Umi-a-Liloa, circa 1500 A.D. he reconditioned the heiau of Waha'ula. This is an indication that he held supreme authority over the ahupua'a of Pulama in Puna. He was a chief of power and prestige, found on several chiefly genealogies, including that of Queen Emma. According to Barrere, 'Imaikalani may well have been one of the chiefly ancestors of the Makaha and Kumakaha lines of $\mathrm{Ka}{ }^{\prime} \mathrm{u}$ and Puna (Barrere, 1959).

Kamakau provided the following account of the conquest of chief 'Imaikalani by 'Umi warrior, Pi'imaiwa'a:

'Umi-a-Liloa feared I-mai-ka-lani. Although he was blind and unable to see, his hearing was keen. He had pet ducks that told him in which direction a person approached, whether from in front, at the back, or on either side. All depended on the cries of the birds. In former days I-mai-ka-lani was not blind, and 'Umi was never able to take $\mathrm{Ka}$ ' $\mathrm{u}$. The war lasted a long time. 'Umi went by way of the mountains to stir up a fight with I-mai-ka-lani and the chiefs of Kona ... I-mai-ka-lani was never taken captive by 'Umi, but Pi'i-mai-wa'a was crafty and studied the reason for his great strength and skill with the spear ,... all these men were destroyed by $\mathrm{Pi}^{\prime} \mathrm{i}$-mai-wa' $\mathrm{a}$, and the blind man was at a loss for the lack of helpers. Well could Pi 'i-mai-wa'a say in a boast, "Death to him from Pi'i-mai-wa'a." After I-mai-ka-lani's death Ka'u became 'Umi-a-Liloa's (Kamakau, 1992: 18-19).

Kahalemilo, son of 'Imaikalani, and Lililehua, son of Hua-'a, were both killed by 'Umi's son, Keawe-nui-a-'Umi, who gained control of Hawai' $i$ island in the next generation. According to Barrere, this seems to have extinguished both their lines as autonomous chiefs of $\mathrm{Ka}^{\prime} \mathrm{u}$ and Puna. $\mathrm{Ka}^{\prime} \mathrm{u}$ is ruled by the Kona chiefs which stemmed by Keawe-nui-a-'Umi and all of Puna is linked with $\mathrm{Ka}^{\prime} \mathrm{u}$ until the time of Keawe-i-kekahi-ali'i-o-ka-moku, when the 'I family of Hilo controlled parts of Puna. The other part is not mentioned specifically, but the inference is that it was still linked with $\mathrm{Ka}^{4} \mathrm{u}$ (Barrere, 1959: 17-18). 


\section{The Eve of European Contact}

On the eve of European contact, Puna seemed to have enjoyed a brief resurgence of semi-autonomous rule. Two generations after Keawe, in the time of Kalani'opu' $u$, I-makakoloa became powerful enough to warrant the wrath of high chief Kalaniopu'u.

'Imakakoloa was probably a descendant of 'Imaikalani through the 'I family of whom he was an ancestor. Kalaniopu' $u$, having gained control of all Hawai' $i$, found his latter days troubled by suspected rebellion in Puna and $\mathrm{Ka}^{\prime} \mathrm{u}$. Kamakau gave the following account:

Meanwhile rebellion was brewing. It was I-maka-koloa, a chief of Puna, who rebelled, I-maka-koloa the choice young awa [favorite son] of Puna. He seized the valuable products of his district which consisted of hogs, gray tapa cloth ('eleuli), tapas made of mamaki bark, fine mats made of young pandanus blossoms ('ahu hinano), mats made of young pandanus leaves ('ahuao), and feathers of the "o'o and mamo birds of Puna.

Nu'u-anu-pa'ahu, chief of $\mathrm{Ka}^{\prime} \mathrm{u}$, was also in the plot to rebel, but he was at this time with Ka-lani-opu'u, and Ka-lani-opu'u feared Nu'u-anu-'opu'u (Kamakau, 1992: 106).

Kalaniopu 'u first disposed of Nu'uanupa'ahu by conspiring with his kahuna to have a shark devour him. Although Nu'uanupa'ahu successfully killed the attacking sharks, he died from the mortal wounds that he sustained in the struggle with them (Kamakau, 1992). After disposing of Nu'uanupa'ahu, Kalani'opu'u hunted down 'Imakakoloa. Kamakau, again, offers an account:

Ka-lani-'opu'u the chief set out for Hilo with his chiefs, warriors, and fighting men, some by land and some by canoe, to subdue the rebellion of I-makakoloa, the rebel chief of Puna ... the fight lasted a long time, but I-makakoloa fled and for almost a year lay hidden by the people of Puna ... 'Go with your god,' said the chief. Puhili went until he came to the boundary where Puna adjoins $\mathrm{Ka}$-'u, to 'Oki'okiaho in 'Apua, and began to fire the villages. Great was the sorrow of the villagers over the loss of their property and their canoes by fires. When one district (ahupua'a) had been burnt out from upland to sea he moved on to the next ... thus it was that he found Imaka-koloa where he was being hidden by a woman kahu on a little islet of the sea ... I-maka- koloa was taken to Ka-lani-'opu'u in $\mathrm{Ka}$ - $\mathrm{u}$ to be placed on the altar as an offering to the god, and Kiwala'o was the one for whom the house of the god had been made ready that he might perform the offering ... Before he had ended offering the first sacrifices, Kamehameha grasped the body of I-maka-koloa and offered it up to the god, and the freeing of the tabu for the heiau was completed. (Kamakau, 1992: 108-109).

The stage was therefore set for the usurpation of Kiwala'o as heir to his father, high chief Kalani 'opu' $u$, by Kamehameha, in the period after European contact.

\section{Contact and Monarchy}

David Samwell, a surgeon, and Lt. King, British officers on the Cook voyage, provided the first written accounts of Puna. King wrote: 
On the southwest extremity of Opoona the hills rise abruptly from the sea side, leaving but a narrow border, and although the sides of the hills have a fine verdure, yet they do not seem cultivated (Cook/Beaglehole, 1967: 606).

Samwell observed:

Many people collected on the Beach to look at the Ship ... many canoes came off to us ... [with] a great number of beautiful young women.

Soon after Kalani 'opu'u died in 1782, Kiwala'o was killed by the forces of Kameha meha in the battle of Moku'ohai. For the next 10 years, Kamehameha fought the chiefs of Hawai' $i$ for control of the island. The districts of Kona, Kohala, and portions of Hamakua acknowledged Kamehameha as their ruler. Hilo, the remaining portion of Hamakua and a part of Puna acknowledged Keawemauhili as their ruling chief. The lower part of Puna and the district of $\mathrm{Ka}^{4} \mathrm{u}$ supported their chief Keoua. The battles among these three chiefs culminated in the triumph of Kamehameha (Barrere, 1959: 19).

\section{"He moku ‘aleuleu" \\ "District of ragamuffins"}

This was a descriptive saying of the followers of Kamehameha I for the people of $\mathrm{Ka}^{\prime} \mathrm{u}$ and Puna. According to Hawaiian scholar, Mary Kawena Pukui, this was said because the people of these two districts were hard-working farmers, who lived most of the time in old clothes (Pukui, 1983, \#826). This saying indicates that the people of Puna were not among those who prospered under the reign of King Kamehameha.

"Lawe li'ili'i ka make a ka Hawaii, lawe nui ka make a ka
haole."
"Death by Hawaiians takes a few at a time; death by
foreigners takes many."

This proverb meant that diseases known in the islands before the advent of foreigners caused fewer deaths than those that were introduced (Pukui, 1983, \#1960). One of the most serious impacts of foreign contact was widespread deaths from epidemics. While the epidemics hit the port towns most severely, no district of the islands was spared, including Puna. Kamakau reports on the epidemic in 1804 of ma' $i$ oku' $u$, (either cholera or bubonic plague) in which half of the population was reported to have succumbed; in 1826 when thousands died of "cough, congested lungs, and sore throat;" in 1844 of colds;; in 1848 of measles which carried away a third of the population; in 1853 of smallpox (Kamakau, 1992: 236-237).

The first missionary to journey through Puna was William Ellis in 1823. In his published journal he described the natural resources available to the residents of the district and some of their living conditions, subsistence, and exchange practices. He estimated that there were approximately 725 inhabitants at Kaimu and another 2,000 Hawaiians in the immediate vicinity along the coast. At Kauaea, about $31 / 2$ miles from Kaimu, he reported that 300 people gathered to hear him preach (Ellis, 1825). The following are excerpts from his journal which describe the diversity of conditions he observed traveling through Puna, from Kilauea through Kealakomo toward Kalapana and over to Kapoho and to finally Keaau: 
Leaving Kearakomo [Kealakomo], we travelled several miles ... The popula tion of this part of Puna, though somewhat numerous, did not appear to pos sess the means of subsistence in any great variety or abundance; and we have often been surprised to find the desolate coasts more thickly inhabited than some of the fertile tracts in the interior; a circumstance we can only account for, by supposing that the facilities which the former afforded for fishing, induce the natives to prefer them as places of abode; for they find that where the coast is low, the adjacent water is generally shallow.

We saw several fowls and a few hogs here, but a tolerable number of dogs, and quantities of dried salt fish, principally albicores, and bonitos. This latter article, with their poe [poi] and sweet potatoes, constitutes nearly the entire support of the inhabitants, not only in this vicinity, but on the seacoasts of the north and south parts of the island.

Besides what is reserved for their own subsistence, they cure large quantities as an article of commerce, which they exchange for the vegetable productions of Hiro [Hilo] and Mamakua [Hamakua], or the mamake and other tapas of Ora [Olaa] and the more fertile districts of Hawaii.

When we had passed Punau, Leapuki, and Kamomoa [Panau, Laeapuki and Kamoamoa], the country began to wear a more agreeable aspect. Groves of cocoa-nuts ornamented the projecting points of land, clumps of kou-trees appeared in various directions, and the habitations of the natives were also thickly scattered over the coast...

Shortly after, we reached Kupahua, a pleasant village, situated on a rising ground, in the midst of groves of shady trees, and surrounded by a wellcultivated country...

Kaimu is pleasantly situated near the sea shore, on the S.E. side of the island, standing on a bed of lava considerably decomposed, and covered over with a light and fertile soil. It is adorned with plantations, groves of cocoanuts, and clumps of kou-trees. It has a fine sandy beach, where canoes may land with safety; and, according to the houses numbered to-day, contains about 725 inhabitants...

Leaving Kehena, we walked on to Kamaili, a pleasant village, standing in a gently sloping valley, cultivated and shaded by some large cocoa-nut trees.

A most beautiful and romantic landscape presented itself on our left, as we travelled out of Pualaa. The lava was covered with a tolerably thick layer of soil, and the verdant plain, extending several miles towards the foot of the mountains, was agreeably diversified by groups of picturesque hills, originally craters, but now clothed with grass, and ornamented with clumps of trees. The natives informed us, that three of these groups, Honuaura, Malama and Mariu [Honua'ula, Malama \& Maliu], being contiguous, and joined at their base, arrested the progress of an immense torrent of lava .... We soon left this cheerful scenery, and entered a rugged tract of lava, over which we continued our way till about two p.m., when we reached Kapoho. 


\begin{abstract}
A cluster, apparently of hills three or four miles round, and as many hundred feet high, with deep indented sides, overhung with trees, and clothed with herbage, standing in the midst of the barren plain of lava, attracted our atten tion ... on reaching the summit, were agreeably surprised to behold a charming valley opening before us. It was circular, and open towards the sea. The outer boundary of this natural amphitheater was formed by an uneven ridge of rocks, covered with soil and vegetation. Within these there was a smaller circle of hills, equally verdant, and ornamented with trees. The sides of the valley, which gradually sloped from the foot of the hills, were almost entirely laid out in plantations, and enlivened by the cottages of their proprietors...
\end{abstract}

We reach Kaau [Keaau], the last village in the division of Puna. It was extensive and populous, abounding with well-cultivated plantations of taro, sweet potatoes, and sugar-cane; and probably owes its fertility to a fine rapid stream of water, which, descending from the mountains, runs through it into the sea. (Ellis, 1825).

It was not until 1836 that the next missionary, Rev. Titus Coan, traveled through Puna. He preached the word of God to villages throughout the district creating a Christian re vivalist atmosphere wherever he went. Following his visit, some of the Puna Hawaiians formed Christian congregations. In the 1840 Annual Station Report for Hilo it was noted that six new "meeting houses" had been built and fifteen congregations were meeting in houses in the districts around Hilo. When Rev. Chester Lyman toured Puna with Lyman in 1846 he described visiting a meeting house in Kamoamoa and a "church" in Kalapana (Langlas, 1990).

In 1840, a Catholic priest, Father Walsh, was assigned to the island of Hawai' $i$ and in 1841 he baptized Hawaiians in Puna and $\mathrm{Ka}^{\prime} \mathrm{u}$. Soon thereafter a resident priest was assigned to $\mathrm{Ka}^{\prime} \mathrm{u}$ and he made periodic visits to Puna. However, it was not until a Belgian priest, Father Damien de Veuster, was assigned to Puna in 1864 that more Hawaiians were baptized into the Catholic faith and regular services were held. During the year that he spent there, Father Damien increased the number of Catholics in Puna from 350 to 450 and he built several thatched grass churches. Since the time of Father Damien there was a resident priest in Puna and a strong Catholic congregation.

In 1841, Rev. Titus Coan estimated the Hawaiian population of Puna at 4,371 . He wrote that most of the inhabitants of Puna lived along the shore, although there were hundreds also scattered inland (Holmes, 1985). In that same year, Capt. Charles Wilkes of the U.S. Exploring Expedition explored the Kilauea volcano and the East Rift Zone in Puna. He observed agricultural activities in the Puna Forest Reserve in the vicinity of Kahauale'a. He wrote:

We left Panau after half-past eight o'clock, and passed on towards the east. After traveling about three miles, we came in sight of the ocean, five miles off. Our course now changed to the northeast, and before noon we reached an extensive upland taro-patch ... (Wilkes, 1845: 181).

In 1846, Chester Lyman traveled through Puna with Rev. Coan and reported on agricultural activity in what was probably the interior of the Puna Forest Reserve near Kahauale'a. He wrote: 
Our route from Kahauale'a [village] lay northerly, gradually rising. By half past 2 p.m. we had reached a plantation in an unsettled region where a good old man had been at work all day putting up a small neat house of ti leaves, in expectation that we would stop here for the night. Plantains, pawpaws, taro, etc. were growing around ... we went on about 5 miles further, or 10 miles from Kahauale'a [village] over an exceeding rough and jagged path an through a dense miry thicket to a small grass shanty (Lyman, 1924: 19).

Puna is distinguished as a district with a very small number of private land awards from the 1848 Mahele and Kuleana Act. Only 19 awards of private land was made in the entire district (Table 4). Of these, 16 awards were made in large tracts to 10 chiefs who lived outside of Puna and three small parcels were granted to commoners, Baranaba, Hewahewa and Haka. Baranaba was a school superintendent. Given his position, he was probably aware of the process and had the money needed to conduct the survey. Hewahewa filed for a coffee patch in Hapaiolaa which he had received in 1842. Haka received 6 fields in the 'ili of Pakalua (Allen, 1979). In 1854, four years after the Kuleana awards were granted, the estimated population for Puna was 2,702 (Table 1).

An examination of the possible reasons why almost the entire population of Puna did not enjoy the benefits of the Mahele and Kuleana Act lends an understanding of why Hawaiians living in the district remained outside of the mainstream of Hawai' $i$ 's economic and social development. First, Puna was isolated from the mainstream of economic, social and political developments. It is possible that the Hawaiians in Puna were not aware of the process or did not realize the significance of the new law. Second, it is possible that the Puna Hawaiians did not have a way to raise the cash needed for the land surveys which cost between $\$ 6$ to $\$ 12$. Wages at the time were normally between $121 / 2$ cents and 33 cents a day. However, there were few wage earning jobs in Puna. Cash would have to be raised from selling extra fish or other products, which was difficult given their subsistence level of living. Third, at least some of the Puna Hawatians filed their land claims after the deadline. In an 1851 petition to the legislature, several Puna residents asked to be issued land grants without penalty as they had filed their claims after February 14, 1848 (Allen, 1979).

Table 1. Census of the Puna district ${ }^{\mathrm{a}}$

\begin{tabular}{lcl}
\hline Year & Population & \multicolumn{1}{c}{ Source } \\
\hline 1832 & 12,755 & Jarves (North Hilo \& S. Hilo included) \\
1834 & 4,000 & ABCFM \\
1835 & 4,807 & Ke Kumu, April 13, 1836 \\
1854 & 2,702 & Lyman, letter to Armstrong, Jan, 14, 1854 \\
1860 & 2,158 & Anderson, Hawailan Islands, p. 278 \\
1866 & 1,932 & Jarves, Hist of the Hawn Islands, 1872,(202) \\
1872 & 1,228 & Thrum's, 1876 \\
1878 & 1,043 & General Suptd. of the Census, 12-27-1878 \\
1884 & 944 & Gen'l Sup. of the Census, 12-27-84 \\
1890 & 834 & Bureau of Pub Instruction, GSP, Census, 1890 \\
1896 & 1,748 & DPI, GSP, 1896 \\
\hline
\end{tabular}

a1823 Estimate, 142,050 (Missionary Censuses of Hawai'i, Robert Schmitt) 
Table 2. Assignment of lands

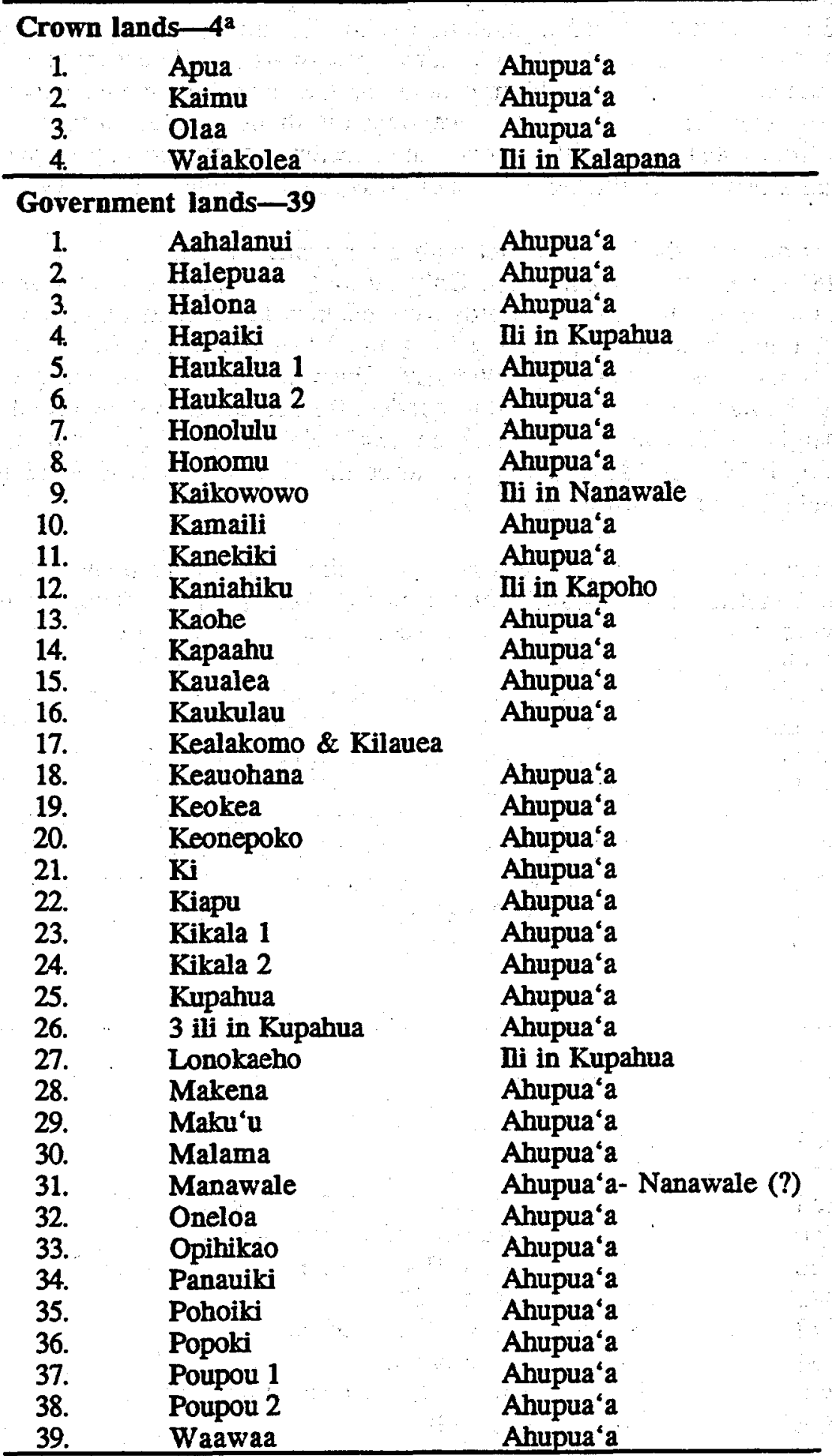

a Crown, Government and Fort Lands, Enumerated. L. 1848, p. 22, C.C., p. 374. 
Table 3. Lands of ali' $i$ surrendered to government in lieu of commutation due on other lands

\begin{tabular}{|c|l|l}
\hline 1. & Kalapana & Lunalilo \\
\hline 2 & Kamalomalo & Lunalilo \\
\hline 3. & Koae 1 & Lunalilo \\
4. & Koae 2 & Lunalilo \\
5. & Laeapuiki & Lunalilo \\
\hline 6 & Laepaoo & Lunalilo \\
\hline
\end{tabular}

Table 4. Indices of private awards in Puna

(1) Kahaualea Lunalilo, W.C.

King of Hawai'i, 1873-1874

L.C.A. 8559-B B 10 p 479 / RP 8030 B 32 p $43 / 26,000$ acs

(2) Keahialaka Lunalilo, William C.

L.C.A. $8559-B$ B 10 p. 479 / RP 8094 B 35 p. $1 / 5562$ acs

L.C.A. $8559-$ B B 10 p. 479 / RP 8088 B 32 p. 55

(3) Keaau, Halauloa Lunalilo, William C.

L.C.A. 8559-B B 10 p. $480 /$ RP 7223 B 25 p. $149 / 64.275$ acs

(4) Kapoho Kanaina Charles

Father of the King, William C. Lunalilo

L.C.A. 8559 B 10 p. 633 / RP 4497 B 18 p. 487 / 4060 acs

L.C.A. 8559 B 10 p. 634 / RP 8177 B 35 p. 329

(5)

Kauaea

Kamamalu, Victoria

Sister of Alexander Liholiho (Kamehameha IV), Lot Kamehameha (V),

Moses Kekuaiwa and half-sister of Ruth Keelikolani

L.C.A. 7713 B 10 P. 437 / RP 8200 B35 p. 425 / 1568 acs

Native Register v. 5 p. 443

(6)

Kauwalehua

Kamamalu, Victoria

L.C.A. 7713 B. 10 p. 437 / RP 8199 B 35 p.417/ 1822 acs

Native Register v. 5 p. 443

(7) Kahuwai Kamamalu, Victoria

L.C.A. 7713 B 10 p. 437 / RP 6884 B 25 p $81 / 2869$ acs

Native Register v. 5 p. 443

Puia, Puna

Keohokalole Ane

Mother of King Kalakaua, Queen Lili'uokalani, Miriam Likelike

Cleghorn, and William Pitt Leleiohoku 2nd.

L.C.A. 8452 B 9 p. 431 / RP 7788 B 29 p. $125 / 4919$ acs

(9)

Puna

Keohokalole Ane

L.C.A. 8452 B 9 p. 431 / RP 4386 B 18 p. 97 / Ahp 
Table 4 (continued)

(10) Panau Kekauonohi, Miriam

Great grandaughter of Kekaulike (High Chief of Maui), wife of

Kealiihonui (died June 23, 1849). Also wife of Levi Haalelea.

L.C.A. 11216 B 9 p. 661 / RP 8095 B 35 p. 5/ Ahp (Ap4)

(11)

Waiakahiula

Kekauonohi, Miriam

L.C.A. 11216 B 9 p. 661 / RP 8095 B 35 p. 5 / Ahp

Puna (Kula)

Kalama, Hazaleleponi

Wife of 'Kauikeaouli (Kamehameha III). Exempted from commutation.

L.C.A. 4452 B 9 p., 467 / RP 7483 B 25 p. $231 / 2902$ acs

Waikahekahe

Kale Davis

Sister of G.D. Hueu and Peke; daughter of Isaac Davis, British military advisor to Kamehameha $I$.

L.C.A. $8522-B$ B 10 p. 465 / RP 2236 B 9 p. 605 / Ahp (Ap3)

Waikahekahe

Lahilahi, Gina M.

Daughter of John Young, Sr. British military advisor to Kamehameha I.

L.C.A. 8520-B B 10 p. 6 / RP 1668 B 6 p. 279 / Ahp

v.10 p. 185 Gina Lahilahi inherited land.

They have given to the government, the ahupuaa's Kealia, Waikahekahe 1 and Pahoehoe, the remaining land for them fee simple with the approval of the Privy Council. (A.G. Thurston, Secretary K.K.)

Leleiohoku, William P.

Husband of Nahienaena (sister of Liholiho and Kauikeaouli). After Nahienaena died (December 30, 1836) he married Ruth Keelikolani. L.C.A. 9971 B 10 p. 609 / RP 7714 B 29 p. 53 / 1110 acs v. 4 p. 502

Kamoamoa

Kaoanaeha, Mary

Mother of Kuhina Nui Keoni Ana, James Young Kanehoa, Kamaikui, Gina Lahilahi and Fanny Young. Daugher of Keliimaikai, the brother of Kamehameha I.

L.C.A. 8515-B B 10 p. 297 / RP 1665 B 6 p. 267 / Ahp (Ap 1)

Native Register v. 3 p. 709 / Native Testimony v. 10 p. 169

Listed as "inherited lands"

*(17)

Kalaihina

Barenaba

School Superintendent for District 1 of Hawai' $i$

An early convert to Christianity and Rev. Titus Coan's first Hawaiian language teacher. Given position, aware of process and had money to conduct the survey (Coan, 1882, 27).

L.C.A. 2327 B 5 p. 390 / RP 7602 B 28 p. 345 / 11.32 acs

*(18)

Hewahewa

Keaau, Halauloa

filed for a coffee patch in Hapaiolaa which he had received in 1842.

L.C.A 8081 B 5 p. 389 / RP 4360 B 17 p. 717 / 13.64 acs 
Table 4 (continued)

*(19) Kehena
possibly the former house servant of Mr Coan who kept a "small, snug
house" ready for him at Keekee, just $11 / 2$ miles north of Kehena
(Lyman, 1846, July 10).
L.C. A. 1 - M B 7 p. 677 / RP 8029 B 34 p. $293 / 7.37$ acs
6 fields in the 'ili of Pakalua

(* indicates award to commoner)

Table 5. Unassigned lands which became government lands in 1888

\begin{tabular}{|c|l}
\hline 1 & Kahue \\
2 & Huluna-nai \\
3 & Iililoa \\
4 & Aunaloa \\
5. & Ki-B \\
6 & Keekee \\
7 & Keonepoko 2 \\
\hline
\end{tabular}

The bulk of the Puna lands were designated as public lands to either the monarchy, as "crown" land or to the government of the Hawaiian Kingdom ${ }^{25}$ (Territory of Hawai' $i$, 1929). Between 1852 and 1915, 526 land grants and patents were issued in Puna. Out of this number, over half, 275 were issued for the ahupua' $a$ of Ola'a. It is possible that these grants represent kuleana claims which were not awarded. Eventually more public lands were opened for homesteading in Puna. However, large tracts remained in the public domain and continued to be openly accessed for hunting, gathering and spiritual practices.

\section{Tax Records}

The 1858 tax records for Puna shows how many men over 20 and how many men under 20 were living in each ahupua'a and paid taxes (Table 6 ). There were a total of 894 males over the age of 20 who paid poll taxes in Puna in 1858. One hundred and thirty males under the age of 20 paid taxes.

With the break up of the traditional land and labor system by the establishment of private property, Hawaiians were pushed into the market economy to earn cash to purchase, lease, or rent land and to pay taxes. In Puna the primary resources for commercial sale were the coastal fisheries, salt, pulu (the hairy fibers from the hapu'u fern), 'ohi'a timber, and open land for cattle and goat grazing. Isaac Davis traveled around Hawai' $i$ to conduct an assessment of the Crown lands. Of the Crown land in Puna he wrote:

${ }^{25}$ Seven lands in Puna were left unassigned during the Mahele-Kahue, Huluna-nai, Iililoa, Kaunaloa, $\mathrm{Ki}$ (B), Keekee, and Keonepoko 2 . In 1888 it was decided that these would be government lands (Allen, 1979). 
Table 6. Tax records by age

\begin{tabular}{|c|c|c|}
\hline $\begin{array}{l}1 . \\
2 \\
3 . \\
4 . \\
5 . \\
6 \\
7 . \\
8 . \\
9 . \\
10 . \\
11 . \\
12 . \\
13 . \\
14 . \\
15 . \\
16 . \\
17 . \\
18 . \\
19 . \\
20 . \\
21 . \\
21 . \\
22 . \\
23 . \\
24 . \\
25 . \\
26 . \\
27 . \\
28 . \\
29 . \\
30 . \\
31 . \\
32 . \\
33 . \\
34 . \\
35 . \\
36 . \\
37 . \\
30\end{array}$ & $\begin{array}{l}\text { Apua } \\
\text { Kealakomo } \\
\text { Panau Nui } \\
\text { Paunau Iki } \\
\text { Laepuki } \\
\text { Kamoamoa } \\
\text { Pulama } \\
\text { Kahaualea } \\
\text { Kapaahu } \\
\text { Kupahua } \\
\text { Kalapana } \\
\text { Kaimu } \\
\text { Ua Kona } \\
\text { Kehena } \\
\text { Keekee } \\
\text { Kamaili } \\
\text { Kaueleau } \\
\text { Kanane } \\
\text { Opihikao } \\
\text { Iililoa } \\
\text { Kauaea } \\
\text { Malama } \\
\text { Kaukulau } \\
\text { Keahialaka } \\
\text { Pohoiki } \\
\text { Oneloa } \\
\text { Ili kipi kaa Inaina Papoi_kou } \\
\text { Laepaoo } \\
\text { Pualaa } \\
\text { Kapoho } \\
\text { Kula } \\
\text { Puua } \\
\text { Koae 1 } \\
\text { Koae 2 } \\
\text { Kanekiki } \\
\text { Halepuaa } \\
\text { Kahuai } \\
\text { Waawaa } \\
\text { Honolulu } \\
\text { Waiakahiula } \\
\text { Keonepoko } \\
\text { Halona } \\
\text { Popoki } \\
\text { Makuu } \\
\text { Keaau } \\
\text { Olaa }\end{array}$ & 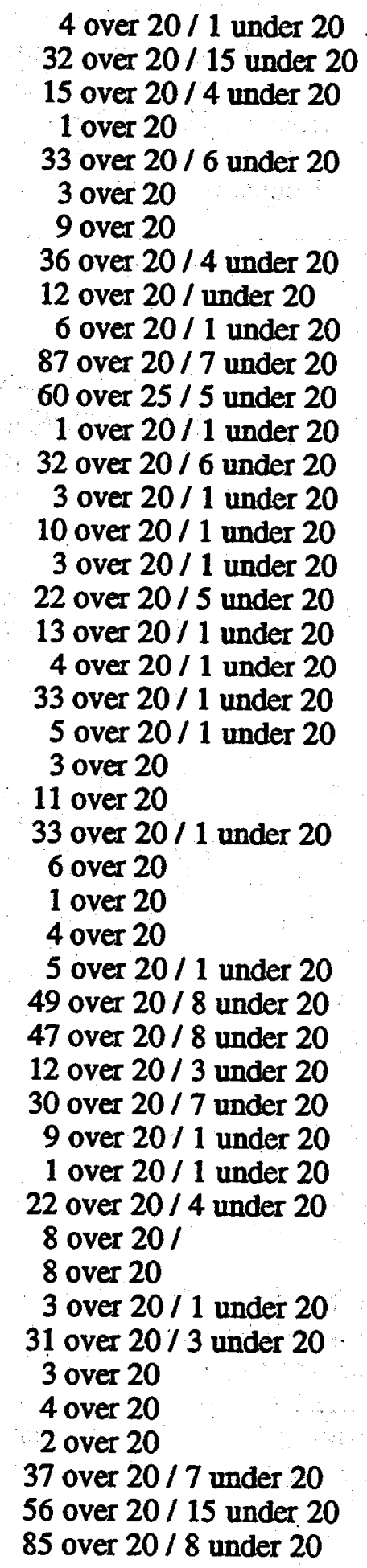 \\
\hline
\end{tabular}


Kaimu ahupua'a in Puna, was the first land that I saw. Cocoanuts and pandanus are the only things growing, there is sand on the sea shore, and rocks are the most. Waiokolea, and $\mathrm{ni}$ in Kaimu, is of the same quality, but there is a fish pond in Waiokolea, it is a good pond, and I have leased it for $\$ 909.00$, and R. Keelikolani has it.

Apua, Ahupuaa in Kau, I do not know the extent of this land, not at the sea shore, but, on making observation, there is a lot of stone on that land, Kapaakea's man told me that salt is the only product on this land, but it is very little. And I called the natives to lease it, but there was no one wanted it, and no one made a reply (Int. Dept. Letters, 1857, March 26).

Pulu processing became an industry in Puna in 1851. Pulu is the soft downy material which covers the shoots of the hapu'u (tree fern). It was used for mattresses, pillows, and upholstery. At its peak, in 1862 , Hawai' $i$ exported 738,000 pounds of pulu worldwide to San Francisco, Vancouver, Portland and Australia. It sold for 14 to 28 cents a pound.

In 1860, Abel and C.C. Harris and Frank Swain leased the ahupua'a of Panau for the hapu'u on the land. Kaina and Heleluhe requested government leases on Lae'apuki and Panauiki. Kaina maintained two pulu picker camps, one near Makaopuhi Crater and the other near the present Keauhou Ranch Headquarters. Pulu was collected, processed, and dried at these camps and then hauled down the pali to Keauhou Landing on mules.

In an article about pulu in 1929;. Thomas Thrum suggested that the pulu industry broke up homes and dispersed the Hawaiians:

The sad part of the story lies in the fact that the industry caused homes in various sections to be broken up, the people moving up into the forests to collect the pulu. In many cases whole families were employed, who provided themselves with rude shelter huts meanwhile, to live long periods at a time in damp, if not actually rainy quarters, without regular and proper food, that resulted in colds and illness.

H.L. Lyman surveyed the unsold government lands of Puna and filed his report in 1865. He described those lands as follows:

1. Makuu to Kaohe, a large tract mauka, rocky land, worth little.

2 Kalapana, about 200 acres, mauka, rocky land.

3. Kaapahu, about 300 acres or 400 , mauka, rocky land.

4. Laeapuki, about 200 acres, mauka, rocky land (Holmes, 1985).

Holmes quotes a Dr. Russell's description of the Ola'a area which provides an insight into the changes in the Hawaiian population and their way of life in the late nineteenth century:

Some fifty years ago about 1,000 natives were living on the margin of the virgin forest and Pahoe-hoe rock along the trail connecting Hilo town with the crater of Kilauea, island of Hawai' $i$, in a spot corresponding to the present 22-mile point of the Volcano road. Making of 'kapa' [native bark] out of 'mamake' bark [pipturus albidus], of olona fiber for fishing nets out of Touchardia latifolia, and capturing ' $\mathrm{O}-\mathrm{U}$ ' birds for the sake of the few 
precious yellow feathers under the wings, of which luxurious royal garments were manufactured-those were the industries on which they lived.

For the reasons common to all the native population of the islands, viz, the introduction of new germs of disease-syphilis, leprosy, tuberculosis, smallpox, etc.- this settlement gradually dwindled away and in 1862 the few surviving members migrated to other localities. At present only patches of wild bananas, taro, and heaps of stones scattered in the forest indicate the places of former habitation and industry. I have heard, however, that as late as the seventies Kalakaua still levied a tax on olona fiber from the natives of Puna and Olaa districts, which fiber he sold at high prices to Swiss Alpine clubs, who valued it for its light weight and great strength (Holmes, 1985: 17).

Throughout this period, subsistence fishing, ocean gathering, hunting, and forest gathering were still the primary livelihood for the Hawailans living in the Puna district. Despite strong economic and social forces pushing to disperse the 'ohana, Hawaiians still maintained strong family ties and obligations. They continued to look after the welfare of their relatives and friends. Hawaiians who had to move away to earn a living were periodically able to return to visit and find refuge among relatives and solace from the drudgeries and alienating social conditions of wage-labor. Some left their children to be raised by grandparents in the traditional rural setting rather than in a port town. An article in the Ka Nuhou of 1873 described the 'ohana as a source of support and comfort:

The kanaka has no need to be very constant; and does not suffer if he has neglected accumulation and aprovision [sic] for old age. The bounty of the whole race affords a sure refuge to any bankrupt, cripple, or pauper among their number. A kanaka can never become dead broke and dread the poor house, because he will always be welcome to fish and poi in any native hut that he enters. And so it is hard to get plantation hands out of such easy going, spending, mutually helping people. ${ }^{26}$

In June 1873, The Boundary Commission conducted hearings to settle the boundaries of the privately held lands in the ahupua a of Keaau in the district of Puna. Uma, a native Hawaiian who was born at Keauhou in Keaau "at the time of the return of Kamehameha Ist from Kaunakakai, Molokai," provided testimony which included descriptions of the natural features and resources in the area and the activities of Hawaiians in the district. The follow ing are relevant excerpts from his testimony showing that the inland forest of Puna was used for birdcatching, the gathering of sandalwood and olona, and that the lava tubes were used for shelter during war:

I have always lived there and know the boundaries between Keaau and Waikahekahe. My parents pointed them out to me when we went after birds and sandalwood. Waikahekahe Nui joins Keaau at the sea shore at Kaehuokaliloa [sp.], a rock that looks like a human body, which is between two points, the point on Waikahekahe is called Kaluapaa and the one on Keaau Keahuokaliloa, thence the boundary runs mauka to place called Koolano, the pahoehoe on the North side is Keaau and the good ground where cocoanut trees grown is on Waikahekahe. In past days there was a

${ }^{25} \mathrm{Ka}$ Nuhou, May 23, 1873. 
native village at this place. Thence mauka to Haalaaniani (Ke Kupua) when the old road from Kalapana, used to run to Keaau thence the boundary runs to Wahikolae, two large caves, the boundary runs between them thence mauka, to another cave called-Oliolimanienie, where people used to hide in time of war ... Keaau on the Hilo side of the road running mauka, thence to Kikihui, an old Kauhale [living compound] for bird catchers, thence to Hoolapehu, another old village, thence to Alaalakeiki, which is the end of Waikahekahe iki and Kahaualea joins Keaau. This place is at an old Kauhale manu [birdcatcher's compound]. ... from the Hilo Court House to the Government School house, thence mauka to KeeKee; Kauhale kahi olona [olona fiber combing compound] in Olaa, the boundary is a short distance from the Government road, on the South East side ... the sea bounds Keaau on the makai side Ancient fishing rights, including the Uhu which was konohiki fish extending out to sea. ${ }^{27}$

Puaa was another native who testified on the boundaries of Keeau. His testimony reveals more information on resources and activities in the interior of Puna as he identifies places with breadfruit trees, cultivation plots, marshy areas, springs, and banana trees:

The boundary between Keaau and Waikahekahe is the land of, or place Keahuokaliloa, thence mauka along Waikahekahe to pahoehoe, on Hilo side of a place called Kukuikea (where the natives cultivate food, and where bread fruit trees grow, thence to Hilo side of Waiamahu a large place that fills with water in the rainy season, thence to Koolano, the pahoehoe on the Hilo side of it is Keaau the soil is on Waikahekahe nui thence mauka along the road to Halaaniani, Keaau on the Hilo side of road; Halaaniani is a puupahoehoe, in a grove of ohia trees, called Keakui. ... below Kahopuakuui's houses, to a place called Kilohana where Oranges are growing there the boundary of Keaau and Olaa leaves the Volcano road, and runs mauka above these Orange trees, thence to an ohia grove called Puaaehu, thence to Waiaele .... a water spring with banana trees growing near it used to be an old kauhale.

Kenoi, originally from Kapapala in Kau provided testimony on the boundaries, as he had learned them from companions with whom he went gathering in the forests. He spoke of going after the $\mathrm{Oo}$ bird in Keauhou; after sandalwood in Kahauale'a and at Pu'ukea; and catching the Uwao at Namamokale, opposite to Kauanahunahu. He also spoke of two ponds, Nawailoloa and Kilohana, on the road to Panau from Palauhulu. Nailima, a native Hawaiian from Ola'a, also provided testimony. He verified the accounts of those who went before him and also identified in his descriptive testimony a hill covered with puuhala by Kilohana; an old village at a place called Kaaipuaa; and a pond of water with aweoweo growing in it at Waiaele on the old road from Olaa to Pooholua. Waipo, a native Hawaiian from Waiakea, identified a small cave where natives worshipped idols at a place called Kawiakaawa and of a place called Naauo between Mawae and Waiaele where people used to flee and live in time of war.

${ }^{2}$ Hawai'i State Archives. Boundary Commission Hawai' $i$, 3rd \& 4th Circuits. Petitioner's Exhibit B, "The Ahupuaa of Keaau, District of Puna, Island of Hawaii, 3d, J.C. Before the Commissioner of Boundaries, Fourth Judicial Circuit. Territory of Hawai'i. In the Matter of the Boundaries of Waiakahekahe-'iki. upon the petition of W.H. Shipman, owner. Carl S. Carlsmith, attorney for petitioner. I.M. Stainback, Attorney General, Hilo, June 18th, 1914. 
A description of the land use pattern and practices in Kapoho and Keahialaka in the late nineteenth century was recorded in a brief filed by Hitchcock and Wise and filed with the Boundary Commission for the 3rd and 4th Circuits of Hawai'i on March 20,1897. Of significance is the fact that where two ahupua'a were owned in common by the same family, the boundaries between the two lost significance. The brief also speaks of an isolated section of land which belonged to no one, and was therefore open to all, as was similar to the "Kamoku" in Hamakua. In part it stated:

The two ahupuaas of Kapoho, and of Keahialaka, were practically held by one family. By the great Mahele, Kapoho was confirmed to 0 . Kanaina, while Keahialaka was confirmed to his son W.O. Lunalilo. The influence remains that the laws and customs which in the case of adjoining ahupuaas under different owners would have held as trespass, the one to the other thereby enjoined, were in this instance permitted to lapse. It is furthermore probable, and the presumption is given force by the subsequent isolation of Kaniahiku so-called that it was an Okana "a no man's land," similar to the Kamoku of Hamakua. This trend of the Puna coastline on both sides of the East Point with ahupuaas extending back rectangularly from the sea coast, would naturally bring about an irregular shaped remnant in the interior similar to those in the North Kohala District, and the upper Keauhou lands of Kona. 28

In Puna, Joseph Nawahi, a founder of the Hui Aloha Aina (Hawaiian Patriotic League), had a strong following of royalists. On May 23, 1893, four months after the overthrow of the Hawaiian monarchy, Reverend Rufus A. Lyman, patriarch of the Lyman Estate which now owns substantial landholdings in Keahialaka and Kapoho, wrote to his colleague M. Whitney in Honolulu suggesting that the Provisional Government open up government and crown lands for homesteading by Hawaiians as a means of winning the support of Hawaiians and undermining the influence of Nawahi in the district:

Here in Puna there are only three Crown Lands Ola'a, Kaimu and Apua next to the Kau boundary. The Govt. lands are scattered all through District, and large tracts near the villages especially Opihikao, Kamaili, Kehena, and not under lease. And there are quite a number of young men there with families who own no land, who will probably remain in Puna and cultivate coffee, kalo, oranges, etc., if you get them settled on land they can have for homes for themselves.

Nine of them have commenced planting coffee on shares for me. Puna has always been Nawahi's stronghold, and I want to see his hold on natives here broken. And I think it would help do it, if we can show natives here that the Govt. is ready to give them homes, and to improve the roads. ${ }^{29}$

In 1894 , the Provisional Government set up the Republic of Hawai'i which instituted a program of opening up government lands for homesteading under the Land Act of 1895 . In Puna, as Lyman had predicted in his letter to Whitney, homestead grants were quickly

\footnotetext{
${ }^{28}$ Hawai'i State Archives, Boundary Commission Hawai'i 3rd \& 4th Circuits, In Re-Boundaries, Ahupuas of Keahialaka, Puna, Hawai' $i$, Brief of Hitchcock \& Wise, filed March 20, 1897, 2:10 pm.

${ }^{29}$ Hawai'i State Archives, Place Name file for Puna.
} 
purchased and cultivated in coffee. Coffee acreage expanded from 168 acres in 1895 to 272.5 in 1899 (Thrum 1895c, 1899) in Ola'a and Pahoa.

\section{Territorial Years}

Economic development in Puna centered around the scarcely populated inland forest areas around the towns of Pahoa and Ola'a. A multi-ethnic plantation community also developed in and around these towns as immigrant Japanese, Puerto Rican, and Filipino laborers were imported to work on the developing sugar plantations. Hawaiian families continued to live along the coastal areas in lower Puna, particularly around Kalapana.

Table 7. Census of Puna 1900 to 1960

\begin{tabular}{ccc}
\hline Year & Population & \multicolumn{1}{c}{ Source } \\
\hline 1900 & 5,128 & Twelfth Census of the United States: 1900 \\
1910 & 6,834 & Thirteenth Census of the United States: 1910 \\
1920 & 7,282 & Bureau of Health Statistics, BOH, Pop. Est. \\
1930 & 8,284 & Fifteenth Census of the United States: 1930 \\
1940 & 7,733 & Sixteenth Census of the United States: 1940 \\
1950 & 6,747 & Seventeenth Census of the United States: 1950 \\
1960 & 5,030 & Eighteenth Census of the United States: 1960 \\
\hline
\end{tabular}

The Puna Sugar Company was established in 1900 in Kapoho. The lowland forest was cleared for cane fields and railroads were built. Puna Sugar expanded around Pahoa and Ola'a.

At the turn of the century coffee was still an important agricultural industry in Puna. The Shipman family, a major landowner in the district, ran the Shipman Ranch in Kea'au. Pineapple was started for export to California. In 1908, the Hawaiian Mahogany Company erected a lumber mill in Pahoa and sent out its first shipment of 20,000 ohi'a log ties to the Santa Fe Railroad. In 1910, the company became the Pahoa Lumber Mill and obtained cutting rights to 12,000 acres of Territorial Forest in Puna. 30

In 1911 the Territorial Government designated 19,850 acres as the Puna Forest Reserve. In 1928 , the forest reserve was expanded to include a total of 25,738 acres. ${ }^{31}$

A book called Geography of the Hawaiian Islands by Charles Baldwin and published in 1908 provides a glimpse of the Puna district at the turn of the century. The following are excerpts from the section about Puna:

The rainfall is so great in parts of the district that this lava has been rapidly decomposed, and the heaviest of forests are to be found, as in Olaa and the region about Pahoa [the Puna Forest Reserve] A large part of the soil of

\footnotetext{
30Skolmen, Roger, "Hawaii's Forest Products Industry," Proceedings of the 18th Annual Hawaii Forestry Conference held November 18-19, 1976, Honolulu.

${ }^{31}$ Governor's Proclamation, June 29, 1911; Governor's Proclamation, December 22, 1928, in Hawai'i State Archives file of Governor's Proclamations.
} 
upper Olaa is ash which probably came from Kilauea; the great fertility of this soil is due to the decayed vegetable matter which has been added to it ...

The Olaa section of Puna is a fine agricultural region, but, owing to the want of a market, small-truck farming does not pay. However, vanilla, tobacco, pineapples, and bananas grow well; and the rubber industry is destined to be an important one, as the climate is particularly well adapted to the growth of rubber trees. The cultivation of coffee in Olaa has been abandoned, as the trees did not thrive there.

All the lower lands of Olaa are planted with the cane of the Olaa Sugar Company. This is one of the largest plantations on Hawaii, and occupies nearly all of the available cane land of the Puna district, including the Kapoho and Pahoa tracts ...

A long section of the Puna coast, thirty or forty miles, shows evidence of having sunk: coconut trees are found below the tide level, or their dead stumps stand out in the sea.

At Kapoho there is a warm spring ... Other interesting features of Puna are: the lava tree casts found in the forest above Kapoho; the bowlders strewn along the coast near Pohoiki by the great 1868 tidal wave; the heiau of Wahaula in farthest Puna (Baldwin, 1908: 78-79).

In 1913, the Hilo Board of Trade published a book by Henry Walsworth Kinney to guide visitors around the island called The Island of Hawai ${ }^{\prime} i$. The book provided an extensive description of the Kilauea Volcano area, its spectacular sites, trails, and forested areas. It described Puna as follows:

The district of Puna may, for the sake of clearness, be divided into two sections, the Olaa region, the north half, and Puna proper. The former consists in the main of the great Olaa sugar plantation, and forest which has been partially cleared, while some tracts are used for cattle. The middle part of the district, with Pahoa as the center, is used for extensive lumber operations. The remainder, Puna proper, is covered by forest and old lava flows, most of them covered with vegetation. In spite of its exceptional beauty and the fine opportunity it offers for seeing the typical Hawai' $i$, which is so rapidly disappearing in the march of progress, it is comparatively little known (Kinney, 1913).

Economic development in the district during the Territorial years centered at Olaa with a ranch and a sugar plantation and around Pahoa with the ohia and koa lumber operations. Lower Puna was described as remaining predominantly as a traditional Hawaiian subsistence area. Kinney provided the following descriptions of Kaimu and Kalapana:

At the beach the road enters first the village of KAIMU, exclusively Hawaiian, with a large grove of cocoanut trees surrounding a fine semi-circular sand beach. Care should be exercised in bathing on account of the undertow. Less than a mile further on, westwards, lies the village of KALAPANA, one of the largest Hawaiian villages in the Islands. There are no white 
inhabitants, and only a couple of Chinese stores ... KALAPANA still supports quite a large population, and is a very pretty village, having like all the Puna coast villages, a fine growth of cocoanuts, puhala and monkeypod trees. The landing is so rough that it is used now only for canoes.

In the section on Kalapana, Kinney also described Pu'u o Hakuma, a cave used as a place of refuge during war, the Niukukahi heiau, the ranch and Hawaiian village at Kahaualea, a mineral bathing pool called Punaluu and the Wahaula Heiau.

Kinney also described significant sites in Kapoho. He described the Waiapele crater, famous as the first residence of Pele in Puna and the three craters mauka of that which were created as Pele searched for suitable home until she reached Kilauea. The "Green Lake" was said to be situated within a ring of five craters. Kukii heiau and the hot springs of Puna were also described as well as a pretty Hawaiian village called Koae. Along the coast between Kapoho and Kaimu Kinney provided descriptions of Cape Kumukahi, the almost deserted Pohoiki village, Opihikao with its hot spring cave, and the small villages of Kamaile, Kehena, and Kaueleau.

The Kalapana Oral History Project, finished in 1990 by UH Hilo anthropologist Charles Langlas and student researchers, is a primary source of information about the life of Hawaiians in Lower Puna during the territorial period. This section summarizes the descriptions of life in the district as recorded in the manuscript for the project.

Throughout the Territorial years the majority of the food of the Hawaiians in Puna was home-produced. Uala (sweet potatoes), kalo (taro), and 'ulu (breadiruit) were the made staples. Seafood especially fish, opihi ( limpet), and limu (seaweed) was the main protein. Chickens, pigs, and cattle were raised. Pigs and goats were hunted and the meat was usually smoked. Some households kept cows for milk and even made butter. When cash was earned special items from the store such as flour, sugar, tea, coffee, and rice could be bought.

Sweet potato was usually grown around the home. Families also grew chili pepper, onion, and sometimes pumpkin, watermelon; tomato or cucumber. Families in Kalapana usu ally had a taro patch up in the hills, sometimes three or more miles from their houselots. E.S. Craighill Handy wrote that in 1935 when he toured Puna to appraise the old native horticulture, "one energetic Hawaiian of Kapa"ahu had cleared "ohi"a forest, at a place called Kaho'onoho about 2.5 miles inland, and had a good stand of taro, bananas, and sugar cane in two adjacent clearings" (Handy, 1972: 541).

Pigs were allowed to run free, but to keep them tame and near the home, they were fed sweet potato vines and tubers after harvesting, papayas, mangos, or breadfruit. Each family had its own way of marking its pigs by notching or slitting the ears or cutting the tail. Some pigs went wild and wandered up the Kilauea mountain, even above the zone where the families cultivated taro. These were hunted with dogs.

The Hawaiians in Kalapana utilized many methods of fishing during this period. Net fishing for 'opelu (mackerel) was the highest-yielding method. It was usually dried for later consumption or for sale. Aku was also caught for subsistence and for sale in season. The Kalapana Oral History provides the following account about "opelu fishing in Kalapana during the twenties and thirties: 
The 'opelu season began in the summer months, after a first-fruits sacrifice: a fish from the first catch was placed on the ku'ula rock at the beach. The ku'ula rock was kept by a guardian, who brought it out for the ritual, and then took it away for safe-keeping. Traditionally the year was divided into two seasons, a period from approximately February to July, when aku could be caught and "opelu was taboo, and a period from approximately August to December, when 'opelu could be caught but aku was taboo. The opening of the 'opelu season was marked by a fish sacrifice (Langlas, 1990: 35-36).

'Opelu fishing went from daybreak to evening. The canoes from a village generally went out together and kept each other in sight in case one should get into trouble. When they returned, people would be waiting to help carry the canoe up and everyone would get a share of fish. Later in the day or at night the canoes might go out for ' $u^{\prime} u$ or kawele'a. On dark nights, if the fishermen went out, children would gather at the beach and keep bonfires of coconut leaves going as a guide to the fishermen back to shore. Until 1926 the nets were made of olona from the wet uplands of Puna. After that they were replaced by store-bought cord.

A one-room house, with a separate cookhouse, was the usual style in Kalapana around 1900. By the twenties several families still lived in such dwellings, but the majority of the families were already living in sizable multi-room board houses built in the Western style. Many families had also installed kerosene stoves in their houses. Since there was no running water in the Kalapana area, families had outhouses for toilets. Water-barrels were used to collect water from the roof for drinking and cooking. In times of drought, they had to drink brackish water from the ponds. Brackish ponds were used for bathing, for doing laundry, for rinsing off saltwater after coming from the ocean, and for watering stock.

Through the twenties and the thirties, families still made their own poi from breadfruit or the taro they grew in the uplands. They usually made enough poi to last the whole week. After this, there was only a limited amount of daily cooking to do, mostly broiling fish on the fire or salting shellfish to eat with the poi. Sometimes the family might cook a pig in the imu, stew dried meat, or make rice over the fire or kerosene stove.

Weaving lauhala mats for home-use and for sale was a major part of a woman's work during this period. Lauhala grew all along the coast, but women often went to Kehena to gather good quality leaves.

Luaus continued to be held for family gatherings to celebrate special occasions and life cycle events-birthdays, weddings, anniversaries, funerals, etc. The lu'au for Christmas usually lasted through New Year's. :Ohana relationships remained strong. Even the practice of hanai (adoption between family members) continued in Kalapana.

Through the twenties and early thirties, relations with the outside were limited by the distance and difficulty of travel. The outside world was represented in Kalapana by school teachers, ministers from Hilo, Chinese stores which sold goods from the outside, and campaigning political candidates. Automobiles were introduced and most families eventually had a car by the late 1930s. Still, most people went to town only once or twice a month to shop for cloth, kerosene, and food items they didn't grow. Rice and flour were purchased in big bags. Since they seldom went to town, the people of Kalapana did not go to Western doctors and hospitals. Hawaiians in Kalapana relied on Hawaiian medicine, using herbal remedies for sickness and broken bones. 
Even as cars became common in the thirties, it was impractical to commute to work every day. Those who got a job outside usually moved there, even if it was as close as Pahoa. A few men stayed outside through the week and came back for the weekend. The men who lived in Kalapana usually combined subsistence farming and fishing for food production for the family with part-time work for cash-roadwork for the county and small-scale selling of vegetables, fish or pigs. The county road from Kapa'ahu through Kaimu and up to Pahoa was a one-lane gravel road. Nearly all the Kalapana men did road work for the county, breaking up rock into gravel. Each man worked an eight-hour day for two dollars, four or five days a month. The crew rotated so that all of them had a chance to work the same amount. Additional cash could be made by selling extra "opelu to the Chinese store-owners to dry, or fresh in Pahoa. Some grew 'awa in the uplands which was cut and dried and sold to a buyer from Hilo for export to Germany. Some husked and dried coconut to sell as copra to Chinese store owners. Sometimes Chinese drove from Hilo to buy pigs in Kalapana. As mentioned above, the women sold lauhala, weaving mats to fill orders from Hilo and Honolulu. They also sold smaller items such as hats and fans to tourists. Children sometimes sold coconuts to tourists and posed for pictures. In 1918, the movie Bird of Paradise was filmed at Kaimu beach. Grass huts were built and the Kalapana people were paid to wander around in sarongs.

In the Kalapana Village there were three churches-Catholic, Hawaiian Congregational, and Mormon. The first Kalapana Hawaiians were baptized as Catholics in 1841. In 1864, Father Damien de Veuster was assigned. During his assignment Father Damien directed the construction of several grass churches and began to build a mortar church with a thatched roof, originally called St. Joseph's but generally known as "Father Damien's Church." Since the time of Father Damien there has been a resident priest in Puna and a strong Catholic congregation. During the term of Father Loots (1881-1898) a small Catholic church was built at Kalapana village. In the twentieth century the main church and rectory was at Pahoa and the priest went to Kalapana to hold weekly services (Langlas, 1990). In the 1840 s the Congregationalists built a church at Kalapana and a meeting house in Kamoamoa. The first minister for the Kalapana under the Hawaiian Evangelical Association was Reverend Papapa Barenaba from 1869 to 1873. After the 1868 earthquake and subsidence the Kalapana Church was rebuilt. By 1905 a third church had been constructed on the same location. It was called Mauna Kea. It was again rebuilt in 1930 . During the nineteenth century and through the present the Hawaiian Congregational churches held periodic conferences at the island level and the all-island level for discussion of church business. By the 1880 s a feature of the conference was a song competition between the choirs of the various churches. The story of how the Kalapana congregation won the competition in 1886 and was presented with a silver pitcher and goblet by Queen Lili'uokalani is one which has been proudly passed down from one generation to the next. The Mormon church was built in Kalapana some time before 1910.

\section{Hawai'i Volcano National Park}

In 1932 a new force entered the lives of the Kalapana people. The Hawai' $i$ Volcano National Park, urged on by the Governor's office, the Hawai 'i County Board of Supervisors, and prominent citizens, proposed expanding the park to include all of the land from Apua over to Kaimu Black Sand Beach. The people in Kalapana strongly opposed the proposal. Russell Apple interviewed Edward G. Wingate who served as superintendent of the Hawai' $i$ Volcano National Park at the time of the proposed acquisition. Wingate said that he supported the Hawailans in Kalapana and felt it was wrong of the Federal Government or the park service to dispossess the Hawailans of their homes, their land, and their traditional way of life. A compromise was reached. The Hawai'i Volcano National Park would expand to 
include the six ahupua'a of 'Apua, Kahue, Kealakomo, Panaunui, Lae'apuki and Kamoamoa, parts of Pulama and Poupou, and Keauhou in the $\mathrm{Ka}{ }^{\prime} \mathrm{u}$ district. However, the lands from Kalapana over to Kaimu were deleted from the extension proposal.

Wingate was still concerned about negative impacts on the way of life of the Kalapana Hawaiians of the road that was to be built to link the Chain of Craters road to Kalapana, all the way to Kaimu. He believed that the road would put pressure on the Hawaiians to sell their homes in Kalapana to developers or others and their livelihoods which were still dependent on the land and sea would be destroyed. To make it possible for the Kalapana Hawaiians to continue their way of living, it was proposed that homesites be made available to them in the park extension so that the villagers could move into the park as they saw the need. In addition a fishing provision was added which allowed only Kalapana residents and those accompanied by a local guide to fish within the park extension. No Hawaiian was precluded from fishing in that area provided that there was a local guide. This provision, according to Wingate, was "to protect the fishing for the people who lived from the sea and who lived from the land, to have some food source from the sea as some areas have been fished out." He also noted that serving as a guide provides jobs and a source of a little cash income for the Hawaiians in the district. Apple summarized Wingate's thinking as follows:

A new village inside the Kalapana Extension was foreseen. The idea was a subsistence-type arrangement, with Hawaiians living in a traditional manner-fishing offshore and along the coast, houses near the shore and agricultural plots inland. Exclusive fishing rights for those still living in Kalapana and for those living within the Extension were included. 32

In 1938, the U.S. Congress passed the Kalapana Extension Act (52 Stat. 781 et seq.) which set an important precedent by including a provision to lease lands within the extension to Native Hawaiians and to permit fishing in the area "only by native Hawaiian residents of said area or of adjacent villages and by visitors under their guidance." The special traditional subsistence lifestyle of the Hawaiians in Kalapana was acknowledged by the U.S Congress and measures were passed to protect it. 33

Under the New Deal, federal programs created new jobs for the Kalapana men. The federal government funded a county project to improve Kalapana Park and various roadbuilding projects in Puna. The Civilian Conservation Corps (CCC) established a camp for young single men at the Volcano. They cut trails, built stone walls, and were trained in carpentry skills. As military construction expanded in Honolulu in preparation for potential war with Japan, Honolulu became a boom town, attracting workers from the mainland and from the neighbor islands. Many from Kalapana moved there on the eve of the war (Langlas, 1990: 92-94).

World War II had a profound effect on Hawai'i. In Puna, those who remained behind were made to fear a Japanese invasion by sea. The coastline were watched and guarded by soldiers stationed in the Kalapana area. Observation points were set up at Panau and at

${ }^{32}$ Documents in the Hawai'i Volcano National Park Headquarters Library, "Transcriptions of a 1974 interview by Russell Apple with former superintendent Wingate concerning the Kalapana Extension" and "Homesite Provisions of the 1938 Kalapana Act" by Russell Apple, January 5, 1971.

${ }^{33}$ Act of June 20, 1938 ( 52 Stat. 781 et seq.) 
Mokuhulu. The beach at Kaimu and Kalapana was strung with barbed wire to stave off an enemy landing. Initially the Kalapana people were not supposed to go through the wire, but eventually the soldiers let the people crawl through to fish or collect seafood at the beach. There was a nightly curfew and blackout curtains were used because not a single glimmer of light was supposed to be seen.

There were 100 to 150 soldiers stationed in Kalapana and they were rotated every three months. Some camped in tents on Kaimu beach and Kalapana beach, some lived in the school cafeteria, and others in the gym and the priest's house at the Catholic Church.

During the war there were still men growing taro, but many of them were in their sixties. With the end of the war, they were getting too old to grow taro and make poi. Many younger men had left during the war, and many still left in Kalapana got jobs on the outside which left little time for taro. During the thirties fewer canoes went out to catch opelu. The last canoe which went out from Kaimu was that of Simon Wai'au Bill. When he got too old, in the late thirties, no more went out. Younger men were busy going to school or going out to work to learn the technique of catching 'opelu. A couple canoes from Kalapana continued going out even after the war. Eventually a boat ramp was constructed at Pohoiki, east of Kalapana, and the canoes were replaced by motorboats.

Other forms of subsistence production continued after the war, such as pole-fishing from shore, gathering limu and opihi and crab and raising stock. Hunting of wild pigs remained an important source of meat. Native plants were gathered for herbal teas and medicine.

Statehood

In 1958, on the eve of statehood, the Puna district began to be parceled out in nonconforming subdivisions of raw land. Tropic Estates bought 12,000 acres of land between Kurtistown and Mountainview and cut it up into 4,000 lots which was put on the market for $\$ 500$ to $\$ 1000$. The project was named Hawailan Acres (Cooper, 1985: 259).

Royal Gardens was opened in Kalapana in the early 1960s. One acre lots were sold for \$995. The brochure for the development read in part:

Along the southern shores of the Big Island, Hawaii, largest of the Hawaiian chain lies the historic and legendary lands of Kalapana. This site the setting for Royal Gardens, a fertile area directly adjacent to the Hawai'i Volcano National Park with its spectacular attractions, yet only walking distance away from lovely beach and shore areas. Royal Gardens lots are all one acre in size, making it possible for the owners to have a small orchard or truck garden, or a magnificent garden, as well as a home and a haven for retirement (in Cooper, 1985: 262),

By contrast, the Bishop Museum study for the Kalapana Extension in 1959 described the coast nearest to Royal Gardens as follows:

Shoreline of low, black, lava cliffs, battered continuously by windward waves. This coast bears witness to the great volcanic forces underlaying it through numerous earthquake-opened fissures, and to the violence of tidal 
waves through huge blocks of lava which have been ripped from the ocean cliffs and hurled inland (Cooper, 1985: 265).

Actually, Royal Gardens land was 40 percent a'a (rough and broken lava rocks in tumbled heaps), 20 percent pahoehoe (solid thick sheets of lava, hard and smooth-surfaced with no soil covering), and 40 percent opihikao (extremely rocky muck with pahoehoe underneath. Water was scarce with just a few widely scattered waterholes (Cooper, 1985: 263).

Like Hawaiian Acres and Royal Gardens, other non-conforming subdivisions developed in Puna prior to adoption by the County of a Comprehensive Zoning Ordinance. Gradually, these subdivisions attracted an in-migrant population of retirees, ex-military, and persons seeking an alternative lifestyle to urban centers in the United States. These included Eden Roc, Fern Forest Vacation Estates, Hawaiian Paradise Park, Hawai ‘i Beaches Estates, Aina Loa Estates, Orchid Land Estates, Leilani Estates, Nanawale Estates, Vacation Lands, Kalapana Black Sands Subdivision, Kalapana Gardens and Kalapana Sea View Estates.

\section{Puna, a Cultural Kipuka}

The landscape of Puna today is still dominated by the seismic and eruptive phases of the Kilauea volcano. The climate varies from the rocky shoreline, to barren lava fields, culti vated orchards, grassy plains and dense rainforests. It includes part of the Hawai i Volcanoes National Park, large undeveloped non-conforming subdivisions, unsettled Hawaiian Homelands, forest reserves, and small concentrations of population. The district is subject to heavy rainfall and periodically experiences severe flooding (County of Hawai ' $i, 1989$ ).

The Puna district of the island of Hawai ' $i$ as a whole, and Lower Puna in particular, has been a rural area of Hawaiian cultural continuity. Out of 452 Hawaiians who lived in the Puna district in 1970 (Table 8), 77 percent or 350 lived in Lower Puna. In 1980, 1,334 Hawaiians lived in Puna, out of which 75 percent or 1,001 resided in Lower Puna. Between 1980 and 1990 the number of Hawaiians in Puna increased by 296 percent, to 3,953. For the first time, the majority of Hawaiians who lived in Puna resided outside of Lower Puna. Only 38 percent lived in Lower Puna, while 62 percent lived elsewhere. This was due to migration of Hawaiians into Puna from Hilo and other islands and the displacement of Hawaiians from Lower Puna by volcanic flows out of the Kupaianaha lava lake.

Table 8. Population trends 1970 to 1990

\begin{tabular}{lrrr}
\hline Ethnic group & 1970 & 1980 & 1990 \\
\hline Hawaiian & 452 & 1,334 & 3,953 \\
Caucasian & 1,237 & 5,078 & 9,515 \\
Other Non-Caucasian & 3,465 & 5,339 & 7,313 \\
\hline Total population & 5,154 & 11,751 & 20,781 \\
\hline
\end{tabular}

Source: (State of Hawai'i, 1991).

A modern infrastructure for households and farm lots such as electricity, piped water, and sewage is still not available in many parts of Puna. Puna residents must therefore rely on 
generators, water catchments, centralized county water stands, and outhouses for their households.

There are four major water systems in the district: Olaa-Mt. View, Pahoa, Kapoho, and Kalapana. Hawaiian Beaches has a privately owned water system. Glenwood and Volcano are not serviced by any water system and depend on roof catchment systems. There are no municipal sewerage systems in Puna. Most residents use cesspools and individual household aerobic treatment units. Aside from the primary routes in the Puna district, the majority of roads throughout the district are substandard, and many are only cinder-surfaced. Puna has thousands of non-conforming residential lots which lack the basic improvements necessary for development or are being kept vacant for future speculation. Construction with the nonconforming subdivisions has increased. Strip residential development exists along the highways. There are three public school complexes in the Puna District in the communities of Keaau, Mt. View, and Pahoa.

Economically, Puna is primarily an agricultural district. Diversified agriculture prospers in the form of truck farming of lettuce, flowers, and cabbage in the Volcano area; papaya groves in Kapoho; and flowers, principally anthuriums and vanda orchids, in the Mountain View, Pahoa and Kapoho areas. Factors inhibiting the growth of these industries are the shortage of labor, housing, processing requirements, and plant disease. Vegetables and a variety of fruits, primarily oranges and tangerines, are grown throughout the district. Macadamia nuts are planted on the Hilo side of Kea'au and additional acreage became available with the closing of the Puna Sugar Company in 1984. The former sugar lands will also be planted in papayas, bananas, alfalfa, and trees for biomass. There are 197,900 acres zoned for agricultural use in Puna, but less than 50,000 acres is actively used for agriculture. The majority of agriculturally zoned areas have been subdivided for large lot residential purposes.

The major industrial activity in Puna is a large macadamia processing plant northeast of the sugar mill. Other industrial activities include a kimchee factory, quarrying of lava materials, slaughter houses, bakeries, flower packaging, papaya processing and packing and several cottage industries. These are primarily located around Kea'au and Pahoa, outside of lower Puna. There are no major government installations in the district (County' of Hawai' $i$, 1989).

The rocky coastline which is comprised of sheer cliffs in many sections is subject to tsunami inundation and subsidence. Inland areas are vulnerable to volcanic and seismic activity. These natural phenomena have discouraged the development of major resorts or hotels in the district. There are now some modest Bed and Breakfast establishments in Puna and the ecotourist Kalanihonua retreat and conference center.

Native Hawaiian residents in the district supplement their incomes from jobs or public assistance by engaging in subsistence fishing, hunting, and gathering for the households of their ohana or extended family. The fishermen, hunters, and gatherers utilize and exercise their traditional access to the ocean offshore of the Puna district and the adjacent mauka (upland) forest lands. This forest area afforded access to middle elevation plants and resources for Hawaiians who lived in each of the ahupua 'a of the Puna district.

Native Hawaiians of the district utilized the forests of Puna from generation to generation to gather maile, fern, 'ie'ie, 'ohi'a and other such native plants for adornment, 
weaving, and decoration. They also gathered plants such as kookolau, mamaki, and noni for herbal medicine.

Due to the alteration and degradation of low and middle elevation forests in other parts of Hawai' $i$ island and the public status of the forests in Puna, Hawaiians from other parts of the island and from $O$ 'ahu also regularly gathered liko lehua, maile, fern, awa, and other native plants for hula (traditional Hawaiian dance) and la'au lapa'au (traditional Hawaiian herbal healing) purposes from this forest.

A survey of the role of hunting in the Kalapana-Kaimu Hawaiian community under the University of Hawai'i departments of Geography, Anthropology and School of Public Health in 1971 revealed that hunting in the forests mauka of Kalapana-Kaimu, which would be the Puna Forest Reserve, was an important part of subsistence for the Hawaiian households of the area. Despite the fact that there were not hunters in every household, many households benefited from the hunting activities because the meat was shared among extended family members and friends (Burdette, 1971).

In 1982, the U.S. Department of Energy commissioned a study by the Puna Hui 'Ohana, an organization of Hawaiian families in Puna. The 1982 survey by the Puna Hui 'Ohana of 85 percent of the adult Hawaiians in lower Puna ( 351 out of 413 adult Hawaiians) showed that 38 percent of those surveyed engaged in traditional subsistence hunting in the adjacent forests. It also showed that 48 percent of those surveyed gathered medicinal plants and 38 percent gathered maile in the nearby forests for household use.

Today, the Hawaiian community of Puna, particularly the lower part, remains dis tinct-geographically, culturally, and socially. There is still a significant group descended from the first families who migrated to and settled in the district. They have a strong tradition of perseverance in a district that has been constantly changing and evolving. There is also a growing number of young Hawaiian families moving into Puna from Hilo, Honolulu, and other neighbor islands. Most have moved into the non-standard subdivisions which opened up in the district beginning in 1958. Informant interviews, conducted in 1994 with older and younger Hawaiian families in the district reveal the ongoing continuity of subsistence farming, fishing, and gathering and the associated cultural customs and beliefs.

\section{ETHNOGRAPHIC OVERVEW OF SOUTHEAST MAUI}

\section{Wahi Pana (Sacred Places) of Southeast Maui}

The coastline of this section of Maui, much like Kaho'olawe, is windswept and relatively barren. Most of the mo'olelo (oral tradition) for southeast Maui date back to the era of the great migration from Tahiti and the long voyages between Hawai'i and Tahiti. In this, the mo'olelo of Kaupo, Kahikinui, and Honua'ula are also intertwined with that of the island of Kaho'olawe, which was originally dedicated to Kanaloa, the great Polynesian god of the ocean and of seafaring, and its Kealaikahiki Channel (pathway to Tahiti). Thus, the wahi pana or sacred storied places of southeast Maui reveal a history of the settlement of the islands of Hawai' $i$ by the high chiefs of Tahiti as they were guided to Hawai' $i$ by their great navigators (see Figure 1).

Nu'u means the high place, or second platform in a temple. It is a place of sacred ness and it is a village site. The bay was so named because it was the landing place of $N u^{\prime} u$, a great kahuna navigator who was an ancestor twelve generations from the beginning of the 
NATIVE HAWAIIANS ETHNOGRAPHIC SURVEY HAWAII GEOTHERMAL PROJECT - EIS

$$
\text { CANDO } 1994
$$

University of Hawaii, Manoa

Honolulu, $\mathrm{HI}$ 96822

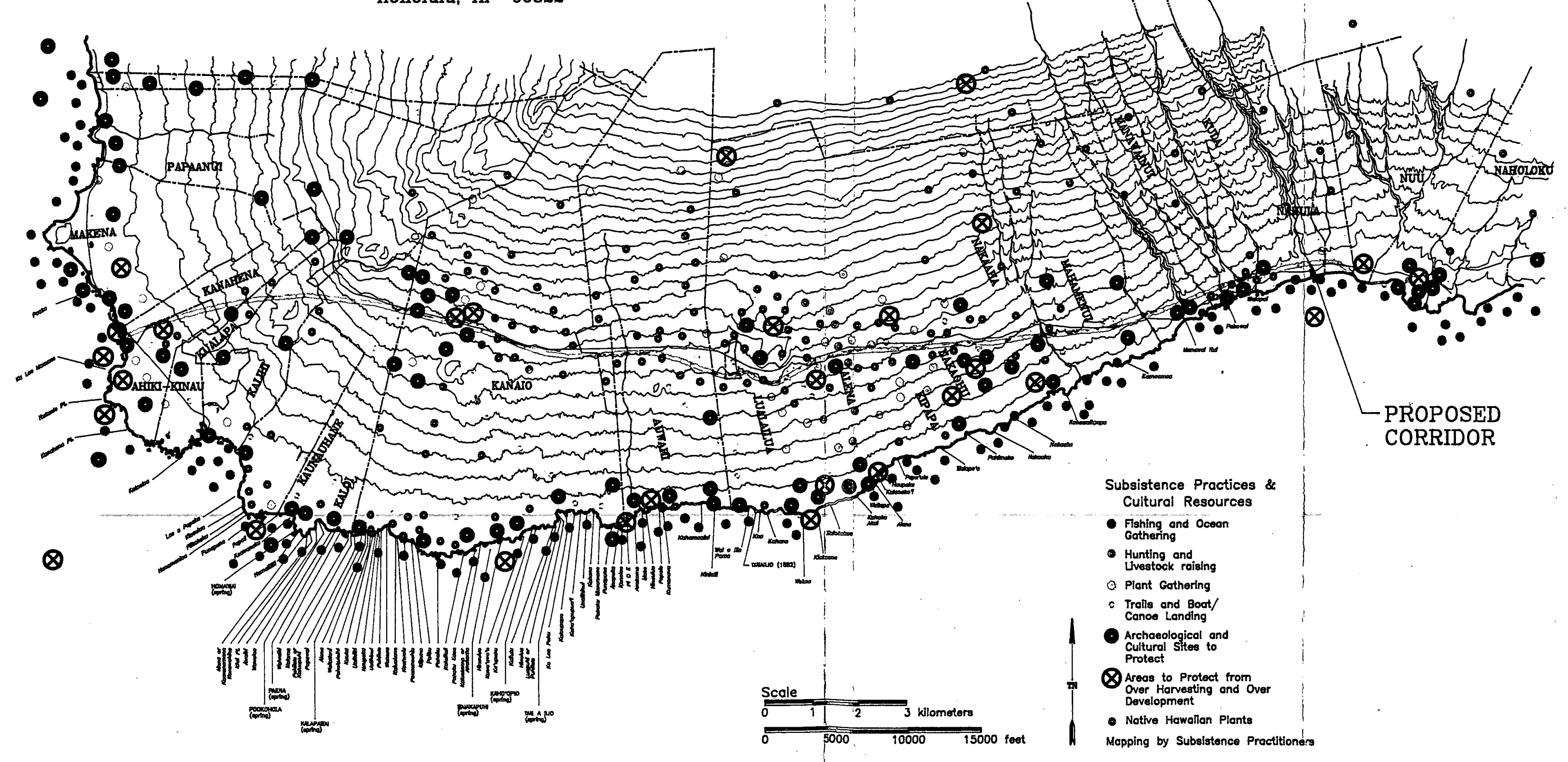

Figure 1. General locations of use areas and cultural and historic sites in Southeastern Maui. 

Southeast Maui 
Hawaiian people in the genealogy of Kumuhonua (Beckwith, 1970). Kaupo means landing by canoe in the night. As the name attests; the bay of $\mathrm{Nu}^{\prime} \mathrm{u}$ was a noted landing for the entire South-East Maui.

Honua'ula means ted earth. The sacred red color was restricted to the chiefly and priestly classes. Honua'ula was liked by the ali' $i$ (chiefs) for its productive soil, climate and expansive views. It was a sacred land of the ali' $i$.

It is reported that Kahikinui was named for the beloved homeland, Kahiki, of the earliest settlers who came to Maui from the South (Handy, Handy and Pukui, 1972). Luala'ilua Hills in Kahikinui means the place of double enjoyment, resting place for peace. Most of the Hawaiians in the Hana districts are said to trace their ancestry to Hawaiians who lived in Kaupo and Kahikinui before Captain James Cook's arrival in the Hawaiian Islands in 1778.

\section{The Mythical Era of Southeast Maui}

The legends associated with the places of south and east Maui help explain in a symbolic and poetic way how the basic elemental forces of nature shaped the landscape of the remote district and how humans adjusted to those elemental forces. The activities of Maui, the demigod, in southeast Maui metaphorically explain the gradual quest of humans to understand the mysterious essence of the elemental life forces of nature in order to improve the condition of their life in the islands. The beauty of the stories and the poetry of Hawaiian legends and chants associated with the study area must be taken into account, even if they do not appear in the abbreviated narratives contained in this document.

The ocean along the shoreline of southeast Maui has abundant marine life and is a source of sustenance for many people. Fresh water seeps into the ocean at the shore and creates a productive ecosystem for a large array of sea life. The gods Kane and Kanaloa are credited with going about all of the islands providing fresh water. Kane and Kanaloa are also attributed with providing springs of fresh water springs along the southeast coast of Maui. It is said that they landed at Pu'u-o-Kanaloa (Hill-of-Kanaloa), a small hill just north of Keone'o'io, when they first came from Kahiki. They dug a water hole by the beach and found the water brackish. So they went about 200 yards inland and dug another hole and created the spring called $\mathrm{Ka}$-wai-a-ka-la ${ }^{\circ} \mathrm{o}$. These gods also opened the Kanaloa fishpond at Luala'ilua-kai providing the brackish water that the need for spawning (Beckwith, 1970: 64). From here, they went on to Nu'u and dug another spring (Handy, 1972).

19 Maui is the Hawaiian demi-god attributed with fishing the islands of Hawai'i up from the ocean, slowing the sun to make the days longer during the summer months, lifting the sky, and discovering the secret of how to make fire. He set out to accomplish his great feats from Kaupo, the district in which he lived with his mother Hina. It was from Kaupo, above the Ko'olau Gap, that Maui was able to snare the sun and force it to make a commitment to slow down during the summer months (Walker, 1931; Beckwith, 1970).

Maul fished up the islands of Hawai' $i$ when he went fishing with his brothers in the fishing ground called Po'o directly seaward from Kipahulu and in a line with the hill called $\mathrm{Ka}$-iwi-o-Pele near Hana. He used the magic hook Manaiakalani (Made Fast to the Heavens) and caught the big ulua of Pimoe. For two days they pull at it before it comes to the surface and is drawn close to the canoes. The brothers are warned not to look back. They do 
so. The cord breaks, and the fish vanishes. That is why the islands are not united into one (Beckwith, 1970). Pu'u Pimoe is a remnant of the ulua fish.

Sometime in the mythical period, a particular species of wauke or mulberry plant is believed to have originated in Kaupo, according to the legend of Maikona, banished son of Konikonia and Hina'aikamalama. In the story, he wandered around and finally died at Kaupo. Out of his body grew a wauke plant (Broussonetia papyrifera) of a hairy kind like the hairy Maikona and useful for beating out bark cloth.

The practice of establishing ko'a to honor $\mathrm{Ku}$ 'ula as patron of fishing, together with his wife Hina, were introduced in Hawai'i by his son 'Ai'ai. The $\mathrm{Ku}^{\prime} \mathrm{ula}$ and ' $\mathrm{Ai}$ 'ai traditions related to Hawaiian fishing customs and practices originate in Hana and spread along the coast through Kipahulu and on to Kahiki'ula and to the other islands. Martha Beckwith offered the following account of the Ku'ula practice as it related to south Maui:

The god lived as a man on earth on east Maui in the land called Alea-mai at a place called Leho-ula (Red-cowry) on the side of the hill Ka-iwi-o-Pele (The bones of Pele). There he built the first fishpond; and when he died he gave to his son ' $\mathrm{Ai}$ 'ai the four magic objects with which he controlled the fish and taught him how to address the gods in prayer and how to set up fish altars. ... His son ' $\mathrm{Ai}$ 'ai, following his instructions, traveled about the island establishing fishing stations (ko'a) at fishing grounds ( $\mathrm{kO}^{\prime} \mathrm{a}$ 'aina) where fish were accustomed to feed and setting up altars (ku'ula) upon which to lay, as offerings to the fishing gods, two fish from the first catch (Beckwith, 1971: 19).

Leaving Hana, he establishes fishing stations and altars along the coast all around the island as far as Kipahulu. At the famous fishing ground (Ko'a-nui) in the sea of Maulili he meets the fisherman Kane-makua and presents him with the fish he has just caught and gives him charge of the grounds, bidding him establish the custom of giving the first fish caught to any stranger passing by canoe. Another famous station and altar is at Kahiki-ula (Beckwith 1971: 22).

Walker added more details to the legendary accomplishments of 'Ai'ai. According to him, ' $\mathrm{Ai}^{\prime} \mathrm{ai}$ raised the large stone $\mathrm{Ku}^{\prime} \mathrm{a}$-lanikila at Puhele near Hamoa, and it became a $k{ }^{\prime}$ 'ula stone with the power to attract fish. The first $\mathbf{k o}^{\prime} \mathrm{a}$, or fishing station, was established near 'Aleamai South-East of 'Alau Island a few miles out at sea. The second was so far out that can be located only by taking bearings from points ashore. 'Ai'ai taught people how to make nets and lines and showed them how the giant octopus could be caught by using a cowry shell. He then moved to Kipahulu, Kaupo, Kahikinui and so on around the island establishing ko'a and ku'ula everywhere (Walker, 1931). The Kanahena Heiau is reputed to have been built by 'Ai'ai in commemoration of his noted father Ku'ula-kai.

Pele and her family of the volcano fire clan lived on the southern slopes of Haleakala during Maui's mythical era. Pele made her first home on Maui in Pu'u Keka'a. When that crater was inundated by the ocean waters of her fiercest enemy, her sister Namakaokaha'i, Pele climbed Mauna Kahalawai and left her footprint there as Pu'u Laina (Ashdown, 1963-1977). 
When the goddess Pele moved to Haleakala, the mountain enlarged it to its present size. Again, Namakaokaha'i found her. A great fight ensued in which the physical body of Pele was killed and her bones were scattered along the South and East coast of Maui at places known as Na-iwi-o-Pele (the bones of Pele) (Walker, 1931: 37). In her apotheosis, the spirit of Pele lived on in the more powerful form as a deity who could take on many physical body forms, and she and her family moved on to Hawai' $i$ island and settled in the Puna district.

About two centuries ago, Pele visited Maui and completed her Lalanipu' $u$, or row of foot hills in Honua'ula-Pu'u Naio, Pu'u Kalu 'Ola'a, Pu'u Lua Palani and Pu'u Pimoe. In 1736, Pele was still at Pimoe and she helped to herald the birth of Kamehameha the Great. Although Haleakala remains dormant, there is still a lot of seismic activity from Pu'u Pimoe and over to Pu'u Ola'i, Earthquake hill, at Ku-Makena.

The latest eruptions of Haleakala run down the Southwestern corner of East Maui. One story explains that this eruption was due to a family who incurred Pele's wrath. The goddess swept down and consumed them and their whole village (Walker, 1931). The $\mathrm{Pa}$ 'ea flow from 'Olapa and Palani is linked to one of the love affairs of the volcanic goddess. Pele fell in love with a married man who remained true to his wife rather than giving in to Pele's advances. Angered, Pele raged down from Palani, caught the man and turned him into a stone near Pu'u Mahoe at Ana Muki, the Twin Hills, just below the cave called Ke Kua Muki (Whispering of God). A lava stone there resembles a man's head and shoulders and it is shaped like a map of Maui. It is called Po'o Kanaka or Man's head stone. The lower part of the man's body is Pohaku Pa'ea in the sea of Keone'o'io at Ku-Makena. The 'Olapa hill is the wife.

The Wai'ola Flow begins with a kind woman named Wai'ola, or water of life. There was a drought and the people of Kahikinui were hoarding water. An old woman came and the people laughed and told her she was old, and that it was time for her to die. Only Wai'ola, the kind one, gave her last ipu wai, her water gourd to the old woman who drank the water. Later, lava rolled over the people, leaving only Wai'ola's land and home safe. Then a big dog came. Wai'ola followed him to a beautiful pool of water, sparkling in the sunshine with kalo (taro), hala (Pandanus odoratissimus), mai'a (banana) and other fine plants. Wai'ola gave thanks, drank, and then she realized that the dog was Poli, the black dog of Pele. She named the water Wai-a-ka- Ilio, the Water of the Dog, in thanksgiving to Pele. There are now three springs in the lava flow named water of the dog. One of them is pumping water to the old Kahikinui House.

At Pu'u Ola'i, Earthquake Hill, Pele was jealous of the Mo'o Maiden of Kaho'olawe, Inaina, whose parents where Hele and Kali. Pele accused Inaina of trying to steal Lohi“au from her. In a fit of anger, Pele transformed the three into hills named after them. Kamohoali'i scolded her and pronounced the Kanawai Inaina there, meaning you must not say or do unkind things to others. From that time the people of Honua ula observed that law. They named the area as Ku-Makena meaning you stand courageously, accepting the joys. and sorrows of life bravely, even while mourning or rejoicing.

In another legend, Pele and Hi'iaka journeyed to Haleakala from Molokai'i. Upon their arrival at this place they began digging a pit which they left open on the top of the mountain. The rocks at Hanaka'ie'ie, at Kahikinui, are those that were dug up by Pele and Hi'iaka. These are a noted cluster of rocks in an 'a'a rubble lava in the uplands (Sterling, 1968). 
Earliest Settlement 0-600 A.D.

Hawaiian cultural sites said to be built by the menehune were structures and features constructed by the original settlers of Hawai' $i$ prior to the Tahitian migration to Hawai' $i$ sometime between 1200 and 1250 A.D. Lo'alo'a is a very ancient heiau that was said to have been built by the Menehune in the Manawainui ahupua'a to honor the ancient gods. It is the longest heiau on Maui.

Apparently, this southeastern section of Maui which is less hospitable than the waterabundant windward districts of the island was settled as the population gradually expanded and eventually moved into the leeward districts.

Some Hawaiian cultural sites are said to have been built by menehune. One such site is Heiau Lo'alo'a in Kipahulu. Because such sites are not associated with the name of a particular chief, it has been assumed that they may have been built in the early settlement period.

Menehune are often characterized as the "mythical little people of the Hawaiian Islands" (Luomala, 1955). They are sometimes described as diminutive, hard working and generally good hearted mythical people, similar to goblins, elves, and gnomes of Western society.

In much of the described behavior of the menehune are found the work ethics of the Hawaiian commoners. For example, on big projects large numbers of menehune are said to have worked together (kokua, laulima). They transported stones great distances by forming a long line and passing the stones from hand to hand to the construction site. They worked at one project at a time and completed it between sundown and sunup in one great effort (ukupau). In return they asked only for a little poi (pounded kalo, or taro), and a few 'opae (shrimp). The sites most often attributed to them are heiau (temples) and kuapa o loko-i'a (fishpond walls), works that required the cooperation of large numbers of people working together harmoniously.

Luomala (1955) pointed out that the term menehune is similar to and may have been taken from the Tahitian word, manahune, meaning the commoner(s) or the common people. Thus, it is sometimes asserted that the menehune of Hawai' $i$ were perhaps the earliest inhabitants of the Hawaiian Archipelago and were the builders of some of the earliest cultural sites in the Islands. What, or who were the menehune in Hawaiian culture was summarized by Luomala:

Menehune ... are the glamorized common people of the Hawaiian Islands. Into the stories about them have been woven beliefs about the myriad spirits of the forests and about human beings who have escaped into the hills away from the dangers that threatened them in the settled areas (Luomala, 1955: 136).

While the construction of many heiau (temples) and lokoi'a kuapa (walled fishponds) are attributed to Hawaiian chiefs, others are attributed to menehune. It is sometimes said that the oldest heiau or loko kuapa are attributed to menehune. Perhaps the heiau were built in a time when the community, acting in concert, was responsible for the construction of large community works, instead of a single person, such as a chief. Alternatively, the explanation for some heiau or loko kuapa not being associated with the name of a chief is 
because they were built so long ago that the chief's name has been long forgotten. However, menehune legends are still told today as well as modern experiences of menehune sightings.

\section{Continued Settlement and Gradual Expansion 600-1100 A.D.}

Throughout southeast Maui, the Hawaiians lived along the coast where the offshore ocean was abundant with marine resources and fresh water percolates seaward along the rocky shore or from springs in shallow bays. At the higher elevations, where the clouds daily cling to the slopes of Haleakala, the mountain forests are lush with native vegetation. In the uplands, just below the forest zone, the soil was excellent for dryland taro, sweet potatoes, medicinal plants, wauke trees for tapa making, all sorts of forest trees including mamane, kamani, koa, and other indigenous growth (Ashdown, 1969-1977).

In dry areas the wiliwili and nene-leau trees provided light weight wood for canoe outriggers and poles for buildings. The pretty red seeds of the wiliwili were used for making lei. The hau trees along the beach provided wood for building and bast for making cordage rope and certain hula skirts. Koa and kukui trees in the upper forest and kukui trees in forest and in villages, such as Nahawale and Moanakala, provided hard wood, lighter wood, dyes, medicine, cordage and oil for lamps and polishing. The hala and halapepe used for matting (moena) and other purposes are gone and few remain in the upper forest today. The 'auhuhu plant was pounded and mixed with chewed bait to stun fish so that they could be taken by hand.

Hawaiian mauka-makai use of the ahupua'a in southeastern Maui was linked to the planting cycle which was dependent upon the variations in rainfall according to elevation and seasons. In the uplands, where it usually rains daily, planting was done the year around. In the lowlands, planting was usually done in conjunction with the rainy season. When the rains moved down to the lowlands, each family cultivated plants at habitation sites along the coast. This important seasonal cycle is documented in the interviews with Sam Po (Chapman, 1966). According to him, even up through the latter half of the 19 th century, the Hawaiians in the district continued to live mauka or makai and plant in accordance with the annual rains. About one month before the rainy season began, they would carry dirt down from the mountains to the coast in lauhala baskets and fill holes in the lava in preparation for planting. Children also helped to carry some dirt in lauhala bags. While on the coast, the Hawaiians would subsist on fishing and various vegetable foods that they cultivated in soil placed in the pockets of lava and nurtured by the rain. When the vegetables matured (Hawaiian watermelon, Ipu oloolo, Ipu nuhou-lani, pumpkin, and Poha or Ipu ala) they were consumed. After a period of about six months, just when the climate became dry, the families would make the return journey to their upland habitation sites (Chapman, 1966).

The ocean along the entire district from Ko'olau to Kaupo provided Hawaiians with various sources of food, including numerous varieties of fish, crab, shellfish, and seaweed. They would gather shellfish and limu along the shore; go deep-water fishing in canoes; lay nets, including the large hukilau nets in the bays; dive; line fish; cultivate fish in ponds, and develop fishing grounds by feeding the fish at ko'a or designated spots in the open ocean.

Salt for the Hana district was gathered at $\mathrm{Nu}^{\prime} \mathrm{u}$, where there were kaheka (natural hollows) in the rocks in which salt ( $\mathrm{pa} \cdot \mathrm{a}-\mathrm{kai}$ ) accumulated when sea water was deposited in depressions in the rocks during rough seas and evaporated by the sun. People would travel to $\mathrm{Nu}$ ' $u$ in the summertime to gather salt. Nu'valo'a, in Kaupo, had several veins of 'alae, the 
red earthen mineral that is rich in iron. The Hawaiians commonly ground their salt together with alae to enrich it with iron (McGregor, 1989).

Fishing and ocean gathering was based on observation of moon phases and stars. When the stars were numerous and bright that was the time to go and look for the shellfish such as Kupe'e (Nerita polita) which usually hide during the day. This gathering was done in the utmost silence, lest the shellfish drop off the rocks and burrow in the sand to hide themselves. Salt was gathered in the summer from the hollow stones along the shore. Families would gather an entire year's supply during the summer, dry it, and store it in caves. Summer was the spawning time for the Manini, the Humuhumunukunukuapua'a, the Mullet, and the Aholehole. The Humuhumunukunukuapua'a could be used as substitutes for the pig in religious ceremonies (Chapman, 1966).

Most of the families living in Kaupo and Kipahulu were related, and exchanging and sharing among them was common and expected. There was an Hawaiian riddle for Kaupo and Kipahulu that linked the two districts together. It noted the importance of coping with famine during drought times by eating the sprouting potatoes that had been left in the old mounds to grow to maturity (McGregor, 1989).

In the drier areas of Kaupo, Hawaiians planted sweet potatoes, pumpkins, and dry taro for home consumption. The sweet potato was the staple food for the Kaupo families. They made poi out of sweet potatoes.

The Hawaiians of Kaupo obtained fresh water from numerous springs in the area such as Punahoe and Waiu. In Manawainui Valley, there were several large springs until landslides covered them and broke the pipelines carrying water to households.

Kahikinui was arid along the coast but well-forested above the cloud line. Fishing was good along its rugged shores. Hawaiians lived in isolated communities on the broken lava, scattered from one end of the district to the other, close to the sea or slightly inland, wherever potable water was found in a brackish well or a submarine spring offshore. The Hawaiians of Kahikinui also developed garden holes, but their primary cultivation area was upland just below the forest zone and where the rainfall was plentiful. There they developed upland plots of dry taro, sweet potato, and other edible plants (Handy \& Handy, 1972).

In the lower uplands of Honua'ula, above the inhabited area and where the rains fell daily, was the main cultivation zone. The eastern and coastal portion of Honua 'ula was thickly populated by Hawaiian planters (Handy \& Handy, 1972). The entire area of Honua 'ula was highly cultivated. Handy writes of sweet potato cultivation extending from Kula to $\mathrm{Nu}^{\prime} \mathrm{u}$, and in the Honua'ula area of Maui from Keawakapu to $\mathrm{Nu}$ ' $\dot{\mathrm{u}}$. It is important to note that later, when lava flows covered the land, people did not move away. Instead, they dug deep holes in the lava and transported soil from the uplands to fill them up. The earth was dug up and the soil passed in baskets from hand to hand along a row of people to fill the "garden holes" in the lava. In Honua "ula, structures of all sorts can be found where such farming was done after a lava flow. Today called "footprints," there are garden holes of all sizes that can be found in the lava flows of Honua "ula, Luala'ilua, and at Pu'u-o-kali. High chief Kiha-a-Pi'ilani is said to have planted sweet potatoes for the starving people, doing the work of eighty men in one day. Even the gulches were planted with certain types of vines suited to that type of terrain. 


\section{Migration, Ruling Chiefs and 'Ohana 110-1400 A.D.}

Puaniani is the hill in Kahikinui where the Santa Ynez church ruins now stand. This place is also called Pu'u Aniani. The great navigator Hawai'iloa-ke-Kiwa is said to have named this hill for his father, the great navigator Anianikalani, and the surrounding area for his homeland across the horizon, Kahiki Ku, "Tahiti over the horizon" or Kahikinui, the "Great Tahiti." Kahikinui is also the name of a navigational star, said to be named for one of the eight steersmen of Hawai 'iloa.

Aniani can mean a number of things. For example, it can mean mirror, shining like glass, clearness, or travel swiftly. It also is a person and a place, named by Hawai'iloa, the noted navigator, after his father, Anianikalani. Pohakea literally means the white stone, also means fading night.

The navigator, Hawai'i Loa, is credited with naming the Ke-ala-i-Kahiki sea at the southwest end of Kaho olawe. He utilized a system of triangulation, or what is today being called the "navigational triangle" to get a bearing for the long voyage to Hawai' $i$ from Tahiti. The land points for the triangle are Ukumehame and Mauna Hoku'ula on West Maui; Pu'u Aniani in Kahikinui on East Maui; and 'Upolu Point on the Big Island. Hawai'i Loa is said to have returned across from Kahikiku or the horizon from whence he came, and brought settlers with him and remained there. Many of the temples and the fishponds in southeast Maui are attributed to this period of history.

He then returned to his homeland and brought others from Kahiki, and at this time named the area of Kahikinui on Maui, and the Guide Stars for his eight helmsmen, or navi'gators. These crewmen were Makali'i for whom the Pleiades are named; I'ao, name of Jupiter as a morning star; Hoku'ula, which is Alderbaran; Mulehu which is one name for Venus. Mulehu, Polo'ula and Poloahilani are three stars in a triangle, said by some to be Vega.

In the migration legend of Mo'ikeha to Hawai'i his party first touched at the easternmost point of Hawai $i$, cape Kumukahi, and the younger brothers of Moikeha, Kumukahi and Ha'eha'e remained in Puna. Among the others in his family, the kahuna Mo'okini and Ka-lua-wilinau made their home at Kohala; Honua-ula landed in Hana on Maui; the sisters Makapu' $u$ and Makaaoa landed on $O^{\prime} a h u$. The rest of the party went on to Kaua'i. His son, La'amaikahiki, came from the South at a later time and settled for a while on Kaua'i. He then moved over to Kahikinui on Maui, which, some say, is so named in his honor. But finding it too windy, he moved on to Kaho'olawe and finally sailed from there back to Tahiti (Walker, 1931). Fornander offered the following translation of part of the La'amaikahiki history:

As the place [Kahikinui, Maui] was too windy, Laamaikahiki left it and sailed for the west coast of the island of Kahoolawe, where he lived until he finally left for Tahiti. It is said that because Laamaikahiki lived on Kahoolawe, and set sail from that island, was the reason why the ocean to the west of Kahoolawe is called "the road to Tahiti" (Fornander, 1916-1919; 514519).

$\mathrm{Nu}^{\prime} \mathrm{u}$ and his wife Nu'umea or Nu'umealani, or the Female who propagates from heaven, amived at Nu'u on Maui with their canoe called the canoe of Kane. Nu' $u$ was the great kahuna, the priestly one who offered sacrifices who was associated with the era of overturning and the time of the great flood. His legend has a biblical analogy to Noah and 
the Ark. In the genealogy of Kumuhonua, Lu-a-nu'u son of $\mathrm{Nu}^{\prime} \mathrm{u}$, also called Kanehoaani, was the ancestor of the $\mathrm{Mu}$ and the Menehune people. Nu'u came after the first Hawaiian from a foreign place and after him came Hawai'i Nui or Hawai 'iloa (Beckwith, 1970).

The ancestors of the ali'i nui (kings) of Maui were Paumakua, a southerner voyager, possibly a Tahitian (975 $\mathrm{AD}$ or $1200 \mathrm{AD})$, and Haho $(1,000 \mathrm{AD}$ or $1225 \mathrm{AD})$. But the dis tricts of Ko'olau, Hana, Kipahulu and Kaupo were often under different ali' $i$ nui not closely connected with the rulers of West Maui (Walker, 1931).

La'akapu of Honua'ula married Kahoukapu who was a chief of Hawai'i in the 12th. century A.D. The prayers of the kahuna $\mathrm{Pa}$ 'ao saved her son, whom she named Kauholanuimahu, meaning like a beautiful flower, or a dream unfolding. When her husband died she returned to Maui where she gave her Honua'ula lands to her beloved son. When his beautiful wife proved unfaithful to him, Kauholanuimahu left the Big Island and went to Maui and took up residence. He ruled from Makena to $\mathrm{Nu}$ ' $\mathrm{u}$. He helped the people of the villages, particularly at Maonakala where his mother dwelt by Keone'o'io. Kauhola rededicated the family fishponds there. He also built the heiau temple mauka of Keawala'i Hawaiian Church at Makena.

\section{Ruling Chiefs 1400-1700}

The history of the Hana District in East and South Maui involves many chiefs of the island of Maui and the island of Hawai'i. The Hana District can be characterized as a territory over which there has been contention for centuries between the chiefs of Maui and Hawai'i. A series of notable events and battles by chiefs are associated with various localities in the Hana District.

The earliest war between the island of Maui and the island of Hawai' $i$ is attributed to Hua'akapuaimanaku, high chief of Maui, probably a descendent of the southerner Hua family from which Paumakaua and Haho came. Hua'akapuaimanaku resided at Hana. He built a heiau at Honua'ula. After his successful war on Hawai ${ }^{\prime} i$ he returned and built another heiau, Kuawalu (Walker, 1931).

High chief Kaka'alaneo often sent 'Ele'io, a famous runner, to get some 'awa for him at Hana and return to Lahaina before dinner time. On one of his trips he met the ghost $\mathrm{Ka}^{\prime}$ ahuali'i, who gave him chase, but 'Ele'io outran him. Another time he saw a beautiful girl near Olowalu, and he pursued her around the Southeastern point of Maui to Hanamanuloa in Kahikinui. At the entrance to a pu'o'a, or bamboo tower on which the bodies of the dead of the higher classes are exposed to the elements, 'Ele'io caught the girl and learned she was only a spirit. She sent him to her home to procure a hog, kapa, fine mats and an unfinished feather cloak from Hawai'i. This he does, and he goes to Hana for 'awa near $\mathrm{Ka}$ 'eleku. He returned, and after much effort he restored the girl, Kanikaniaula, to life. During a feast, the feather cloak, a fathom and a half square long is completed to two fathoms and 'Ele'io set off with the girl to Lahaina. He escaped death by telling high chief Kaka'alaneo his story, who pardoned him and married the girl (Walker, 1931).

Kiha-Pi'ilani is believed to have reigned in the last half of the 15th and the beginning of the 16th century. He undertook the project of connecting the entire island with a network of trails on the advice of his sister's husband, 'Umi-a-Liloa, high chief of Hawai'i, who developed the network of trails on that island. The completed trail, he was advised, would aid his people in their travels, particularly across dangerous roads that led down into and out 
of steep valleys, and it would be a work that would give the chief a prominent place in history, as indeed it has. The improved roads also gave Kiha-a-Pi'ilani quick access to all parts of his kingdom should any dissident group take action against his rule. Southeast Maui was accessed in ancient times by a system of trails. Long distance trails run laterally along the shoreline and across the uplands. Short distance trails run mauka-makai within and between ahupua 'a. The Pi 'ilani paved road, built by Kiha-a-Pi'ilani, a son of High chief Pi'ilani, still exists along portions of the impacted southern coastline of east Maui from Keone'oi'o to Nu'u.

The original Kiha-a-Pi'ilani trail is approximately four feet wide between curbstones. It was paved with water-worn stones and is, therefore, "user friendly." The trail that Kiha-aPi 'ilani caused to have built would be between 350 and 450 years old today. ' $O$ 'io'aina are the terraced resting places along Ke-alaloa (the long trail), or other old trails. The Pi'ilani trail is marked on the earliest maps of Maui as having circled the entire island.

Branching trails extended from the Pi ${ }^{\prime}$ ilani trail in the Honua $u l a$ area, from Keawakapu to $\mathrm{Nu}^{\prime} u$, up to $\mathrm{Pu}$ 'u Ninole and $\mathrm{Pu}$ 'u Palani, through Kanaio and up to $\mathrm{Pu}$ 'u Pane, and so on. A trail named Kekua-waha'ula derives its meaning from Pele's Smiting Red Mouth. She smites people who speak evil from her listening "blow hole". in the waiting Hill, Pu'uokali in the Keokea "Ili (land division) in Honua 'ula. Near the church in Kanaio the trail entered the area known as $\mathrm{Ma}^{-}$ahi and into the forest of upper Auwahi where such plants as the 'akalea grew. It was used to make heavy tapa cloth. The old road is located mauka of the government road at Kahikinui. Two trails crossed from Kanaio to Keone'o'io. The upper, or mauka one, was through Pu'u Pane and down toward Luala'ilua hills and across to Kaupo. The makai trail went among the sea connecting the coastal villages. Lines of stones six feet apart mark the trail on grassy areas and finer cinders and pebble make up the road bed on 'a'a lava flows. A trail from Kaupo went up into the Haleakala Crater through the Kaupo Gap. The 1929 maps by Walter Wall show additional trails around Kanaio northwest to Keokea and Southeast to Manawainui. Mauka-makai trails are also at Hokukano and Luala'ilua and at Wai'opai (Ashdown, 1963-1977).

\section{The Eve Of European Contact}

The chief Kekaulike (1700 AD) resided at Kaupo where he built the great heiau of Pu'umaka'a at Kumuni and Kanemalohemo (Keakala'auae) at Popoiwi near Mokulau in Kaupo The heiau was used as a Pu'uhonua (place of refuge) (Walker, 1931). The Lo'alo'a Heiau on Kaupo Ranch is thought to have been rededicated by King Kekaulike about 1730. Kekaulike left his youngest son, Kamehamehanui, as ruler when he died in 1736 at Lelekea near Kaupo:

Alapa'inui, King of Hawai'i, landed a large force at Mokulau near Kaupo to raid Maui, but he concluded peace when he discovered that his own nephew Kamehamehanui (1736 AD) was the new ali'i nui (king) of Maui (Walker, 1931).

Honua ula was the residence of Queen Kalola, a daughter of high chief Kekaulike, who ruled Maui until 1736. She was the last ali'i to pronounce the kapu of the Burning Sun. 
Only the Maui ali'i had the Kapu of the Burning Sun, hence Haleakala, or Maui in the Pathway of the Sun. 34

In Honua'ula, high chief Kahekili (1765 if Kahekili II; 1475 if Kahekili I) gave permission to a chief named $\mathrm{Ku}$-Keawe to run pigs in the uplands. This chief also stole his neighbors pigs. He was killed in a battle raging through the region. His body was propped up facing the sea of Palauea, between Wailea and Makena as a warning, and peace was restored. Theft then ceased on Maui (Ashdown, 1969-1977).

When high chief Kalani'opu'u came from Hawai' $i$ to invade Maui in 1775 , his canoes lined up on the beaches from Honua'ula to $\mathrm{Ka} \mathrm{Ma}$ 'alaea Bay. His warriors ravaged the coast from Kaupo to Kama'alaea Bay. Kahekili rushed two detachments in support of the Kaupo people and in the bloody battle near the point of Ka-lae-o-ka-'ilio routed the forces of Hawai'i. Kamehameha was one of the heroes of this battle (Walker, 1931). This campaign was called "Kalaehoho"oa" because the natives where unmercifully beaten on their heads by the war clubs of the warriors from Hawai'i. At Kanahena his warriors are said to have beaten and broken the backs of the people. Alalakeiki is a burial cave at $\mathrm{Nu}^{\prime} \mathrm{u}$ which was still in use when it was partially destroyed by road builders, as were the beautiful petroglyphs in it. During the raid of Kalani 'opu'u the Maui men could hear the weeping of old folks, women, and children from the cave of $\mathrm{Nu}^{\prime} \mathrm{u}$. By the time they came back from the battle, their people had died in the cave, and that it is how it came to be called Alalakeiki (crying child) and became a burial cave. Kalani'opu'u captured the Ka'uiki Hill fortress and held Hana and Kipahulu until he was finally repulsed.

The third invasion by Kalani'opu'u took place in 1776. First landing in Honua'ula, he ravaged it from Keone'o'io to Makena, then sailed to Kihei (Walker, 1931).

\section{Contact and Monarchy}

After contact (post-1778) and throughout the nineteenth century, the Hawaiian population in the remote and arid southeast Maui districts gradually moved into Hana. Most of the Hawaiian people in the Hana district are said to trace their ancestry to Hawaiians who originally lived in Kaupo and Kahikinui prior to Cook's arrival.

Kahekili, the last ruling chief of Maui, was tattooed on one side of the body to show that he belonged to the family of the thunder god, Kanehekili. This god was an "aumakua on the island of Maui for certain families (Beckwith, 1970). In 1781 Kahekili marched on Hana by way of Ko'olau and Kaupo and laid siege to Ka'uiki Hill. By cutting off the supply of water from surrounding streams and springs, the Hawai' $i$ garrison was forced to surrender in 1782. The district of Hana was thus restored to the control of Maui (Walker, 1931).

Kamehameha, the high chief of Hawai' $i$, in 1786 sent an expedition under his younger brother, Kalanimalokulokuikapo'okalani, to retake the districts of Hana and Kipahulu. Kamohomoho was sent by Kalanikupule to drive out the invader and a fierce battle was fought on the Kipahulu side of Lelekea Gulch and at Ma'ulili, until the Maui warriors prevailed (Walker, 1931).

\footnotetext{
${ }^{34}$ When referring to that time the name Mauna $\mathrm{Ka}$ 'uiki is used because it means the First Fire Glimmering. Even when Pele moved to Halema 'uma'u on Hawai'i this kapu did not go with her because the prophecies said that Pele would return to punish wrong doings.
} 
The French explorer, La Perouse, anchored off Honua 'ula at Keone'oi'o Bay on May $28,1786$. He described a large village there.

In 1790 high chiefess Kalola, the sister of Kahekili, ali'i nui of Maui, was living in Honua'ula at Nahawale village with her husband, the chief Kaopuiki, near Keone' 0 'io. This is the chief who was mistreated by Metcalf and the crew of the Eleanora. In retaliation the chief stole the longboat and broke it up for its iron parts. His men also killed the crewman who was in the boat. Seeking vengeance, Metcalf killed over one hundred natives at Olowalu. The high chiefess Kalola, in 1790 pronounced for the last time the Kanawai Mau'u Mae, or the Withered Grass Law. The penalty for violating this proclamation was burning to death. In the aftermath of the Oluwalu Massacre, in order to prevent any further misery, high chiefess Kalola issued a kapu that no one should be seen abroad; everyone must remain in their homes; there was to be no talking, no animal noise, no association with travelers or visitors.

Kahekili and his brother Kaeo, King of Kaua'i, waged war against Hawai'i. Kaeo stopped at Hana to recruit warriors. Kahekili went to Kaupo and they launched their offensive from those two places. They lost to Kamehameha in 1791 (Walker, 1931).

Kamehameha is said to have landed at Ka-lae-0-ka'Ilio in Kaupo on a raid from Hawai'i. There was some kind of skirmish when he landed, and he put up an oar to save his face. The act finished the tapu which prevented men and women from traveling together on the road. At the place called 'Aiali' $i$ (where the chief eats) in Kaupo, the Hawai'i chiefs ate their first meal (Walker, 1931).

Pamano was a noted chanter. He was born in the village of Kaipolohua in Kaupo. Lona was the father, Kanio the mother, and Waipu his brother.

Some sections of the Maui trail system are also called the Hoapili trail after Gov ernor Hoapili of Maui who died in 1840. Hoapili's connection with the Maui trail system along this coastline was made when Hawaiians, who became Catholics in the 1820 s and ' 30 s, were persecuted as image worshipers, jailed, and made to work building roads. From Honua'ula to Kahikinui and Kaupo the road was built by convicts, under the Lua'ehu Laws of Hoapili ma. This road was built without sledge hammers or other tools. All that was used were bare hands and the '0'0 (digging stick) (Ashdown 1969-1977). Hoapili even made his own son, Kaukuna Kahekili, and other chiefs to cut down trees in Kahikinui for having broken a law. Beginning at Keone'o'io and going east for several miles over a large lava flow, the Hoapili trail is twelve to fifteen feet wide between curbstones. Much of it covers the original Pi'ilani trail. In contrast with the original Pi 'ilani trail, the Hoapili trail is very straight for miles, is wider, and is paved with rough a'a lava rubble, rather than water-worn stones. Whenever King Kamehameha III went traveling on horseback on his routine visits around Maui, probably in the 1830 s, Governor Hoapili had the trail covered with thick layers of pili grass: Much of the original Pi'ilani trail remains between Keone'oi'o and Hana and beyond, although a great deal of it was incorporated into modern road construction.

A sense that the Southeastern Maui District in the 1800 s was well populated can be presumed by the letters of missionaries who estimated the number of missionaries needed on the basis of the level of the population in a given area. The missionary Green described the need for missionaries based on an assessment of the extent of the population in each district in 1834. The conclusion was that Kula, Hana, Honua'ula, Kaupo, and Kipahulu were well 
populated districts while Kahikinui had only a few inhabitants. The following is how Green assessed the population in southeast Maui:

Kula district continuous country, not densely populated, but containing many inhabitants. Two missionaries needed here.

Honua ula district: warm but populous, need two missionaries.

Kahikinui district: small and poor few inhabitants, and scanty means of living. One vast bed of lava, few inhabitants are obliged to go far into the country to cultivate their food.

Kaupo district: similar in appearance to the Kipahulu district, but larger and more populous. Small vessels frequently anchor here. Missionaries are needed here.

Kipahulu district: rough country, fertile, and populous. In need of a two missionary families and a missionary station.

Hana district: large populous densely inhabited in need of four missionaries (Green, Dec. 1835).

The Honua 'ula District had 215 readers attending the Missionary School in 1834. A permanent mission station was established in Hana in 1837. Mission schools were established in 1850 and churches were built in the 1850 s and 1860s. The first sugar mill in Hana was established in 1849.

Insect pests, venereal diseases, and epidemic diseases were brought by sailors on foreign ships. These diseases decimated the population of Hawaiians, particularly in the rural districts, because of lack of Western medicine to cure the Western diseases. Many Hawaiians were sick, in need of assistance, and dying because of lack of immunization to newly introduced diseases in east Maui (Green, 1835). In 1844, there was a severe epidemic of colds. In 1848, a measles epidemic wiped out a third of the population of Hawaiians. In Kipahulu, in a family of 13 members, 9 died. In 1853, a smallpox epidemic swept through the Hana District, including Kipahulu and Kaupo and many people died, according to Hawaiian historian Samuel Kamakau. In Kipahulu in 1857 a woman gave birth to ten children, but lost all them in childhood to foreign diseases (Kamakau, 1961).

The establishment of ranches in the area contributed to the dislocation of Hawaiians from these areas. The ranches bought, leased, or adverse possessed the lands in the districts for raising their cattle. The cattle destroyed the native vegetation and contributed to the erosion of topsoil into streams and the ocean, undermining the agricultural quality of the land and reducing the productivity of the ocean.

Santa Ynez Catholic Church dates back to the voyage of I'olani Liholiho, Kamehameha II, to Europe and the conversion to Catholicism of a courtier named Joseph Kanui who studied in France and then returned to Maui to teach Catholicism. 
A shipwrecked Spaniard or Portuguese, Antone Pico, married a Hawaiian chiefess and built the Kahikinui House. Vierra Marciel arrived on Maui by shipwreck and married the sister of Pico's wife who owned what became Kaupo Ranch.

In 1837, Catholics who did not convert to Protestantism were pa'a kaula (tied up with ropes) at Santa Ynez Church, arrested, and force-marched to Hana and on to Wailuku for trial. Judge Mahune could not try them because by the time they reached the courthouse in Wailuku the crowd traveling with them had swelled to include 2,000 people. Kamehameha III granted religious freedom under the first Bill of Right in 1839.

Ka Mahele in 1848 and the Kuleana Act in 1850 established a system of private property ownership of all the lands in Hawai' $i$. The Board of Commissioners to Quiet Land Titles, which was set up under a law passed by the Hawaiian Government in December 1845 , began hearing testimony on selected claims registered by non-Hawaiians early in 1846 . The division of lands between the King and about 250 chiefs took place between January 27 and March 7, 1848, and resulted in what is known as The Mahele Book, in which is recorded the names of the lands belonging to King Kamehameha III and the names of the chiefs and the lands that they claimed. At the end of each mahele (division), a phrase was added that protected the rights of the hoa'aina, who were the farmers living on the lands (ahupua'a and 'ili) taken as private property by the king and the chiefs.

On March 8, 1848, the King separated his privately owned King's Lands (approximately 980,000 acres) from the Hawailan Government Lands (approximately 1,500,000 acres). The lands that went to the chiefs were approximately 1,600,000 acres. Their claims; however, were subject to application to the Board of Commissioners for a Land Commission Award.

In the Districts (moku) of Honua ula, Kahikinui or Kaupo when the lands were divided in the Mahele (division) of 1848, there were a number of ahupua a (sub-district land divisions) designated as "Government Lands" within these Districts, as indicated in the Indices of Awards (Office of the Commissioner of Public Lands, Territory of Hawai' $i, 1929$ ). Table 9 shows the government lands which are located in area where the Hawai'i Geothermal Project sea-land transfer stations and transmission line were proposed.

Lands were not awarded to Hawaiian farmers until two and a half years after the February 14, 1848, deadline for farmers (hoa'aina) to register their claims, and approximately one month short of two and a half years after the mahele, or division of lands between the King and the Chiefs had been completed. When the Kuleana Act was passed in August 1850, only then did the Board of Commissioners begin to hear testimony on claims registered by Hawaiian farmers. Based on the claims and testimony, the Commissioners awarded or denied awards of lands directly to Native Hawaiians. A summary of awarded land for each of the impacted ahupua' $a$ is shown in Table 10 Summary of Acreage of Land Commission Awards in Impacted Ahupua'a. These kuleana (privately owned) lands, their acreages, and the ahupua'a in which they are located are listed in Table 10 "Land Awards to Native Hawaiians in the Impacted Districts."

Most of the parcels of lands awarded to Native Hawaiians were very small, containing only a few acres, or even fractions of an acre. The notable exceptions to this were the awards to chiefs which were as follows (Table 11): 
Table 9. Government lands in districts where HGP was proposed

\begin{tabular}{|c|c|c|}
\hline Names of lands & Type of land division & District \\
\hline Kahikinui & Ahupua'a & Honua'ula \\
\hline Kalihi $1^{\mathrm{a}}$ & Ahupua'a & Honua 'ula \\
\hline Kalili $2^{\mathrm{a}}$ & Ahupua'a & Honua 'ula \\
\hline Kaloia & Ahupua'a & Honua ula \\
\hline Kanaio a & Ahupua'a & Honua 'ula \\
\hline Kaunuahane ${ }^{a}$ & Ahupua'a & Honua 'ula \\
\hline Kualapa a & Ahupua'a & Honua ula \\
\hline Maluaka & Ahupua'a & Honua ula \\
\hline Mohopilo 1 & Ahupua‘a & Honua'ula \\
\hline Mohopilo 2 & Ahupua'a & Honua 'ula \\
\hline Mooikia & Ahupua'a & Honua'ula \\
\hline Mooloaa & Ahupua'a & Honua 'ula \\
\hline Moomukua & Ahupua'a & Honua'ula \\
\hline Onau ${ }^{2}$ & Ahupua'a' & Honua 'ula \\
\hline Paeahu 1 & Ahupua'a & Honua'ula \\
\hline Paeahu 2 & Ahupua'a & Honua 'ula \\
\hline Papaa & Ahupua‘a & Honua ‘ula \\
\hline Papakaa & Ahupua'a & Honua 'ula \\
\hline Waipao & Ahupua'a & Honua'ula \\
\hline Kaupo & 66 Ahupua'a Ka Moku & Kaupo \\
\hline Kaupo & $\begin{array}{l}\text { Na ku o Kaupo i koe i keia } \\
\text { Mahele ana }\end{array}$ & Kaupo \\
\hline
\end{tabular}

${ }^{a}$ Government lands likely to be affected by HGP and its transmission line and sea-land transfer stations.

Source: Office of the Commissioner of Public Lands of the Territory of Hawaii (1929). Indices of Awards made by the Board of Commissioners to Quite Land Titles in the Hawaiian Islands, Honolulu Territorial Office Building.

Note: There are no "Crown Lands" in Kahikinui Moku, Honua ula or Kaupo.

Table 10. Summary of acreage of land commission awards in districts where HGP was proposed

\begin{tabular}{ll}
\hline District & Acreage \\
\hline Honua'ula & $1,320.95$ \\
Kahikinui & $5,292.32$ \\
Kaupo District & $12,475.70$ \\
\hline Total & $18,988.97$ \\
\hline
\end{tabular}


Table 11. Three land commission awards to chiefs in districts where HGP was proposed

\begin{tabular}{llr}
\hline Ahupua'a or district & Chief/Awardee & Acreage \\
\hline Keauhou & Mai & 853 \\
Auwahi/Kahikinui & Ruth Ke'ekikolani & 5,280 \\
Nu'u/Kaupo & Kalaimoku & 12,140 \\
\hline Total & & 18,273 \\
\hline
\end{tabular}

Subtracting the Land Commission Awards to chiefs (Table 11) from the total number of awards in the impacted ahupua'a of the three impacted Districts (Table 10), the remaining acreage for awards to the hoa aina, or Hawaiian farmers, totaled 715.97 acres.

Regardless of the parcel size granted to them, Native Hawaiians, tenants of an ahupua 'a, retained their traditional mauka-makai access and gathering and fishing rights. These rights are spelled out in the Kuleana Act of 1850 and are sustained in the Revised Laws of Hawai' $i$. They are as follows:

Where the landlords have obtained, or may hereafter obtain, allodial titles to their lands, the people on each of their lands shall not be deprived of the right to take firewood, house-timber, aho cord, thatch, or ki leaf, from the land on which they live, for their own private use, but they shall not have a right to take such articles to sell for profit. The people shall also have a right to drinking water, and running water, and the right of way. The springs of water, running water, and roads shall be free to all, on all lands granted in fee simple; provided that this shall not be applicable to wells and watercourses, which individuals have made for their own use" (Haw. Rev. Stat. Section 7-1 (1985).

The following lands were surrendered to the government by the Native Hawaiian chiefs who had participated in the Mahele of 1848 , in lieu of a commutation fee to the government for the purpose of clearing their titles to the remainder of their awarded land parcels:

Kanahena lands, in Honua'ula surrendered by R. Ke'elikolani

Kukuolu lands 1 \& 2; Pualaea and Waiohole in Kaupo surrendered by $M$.

Kekauonohi

Kahikinui lands surrendered by Lot Kamehameha.

These land commutations explain in part the large land holdings in the area owned by the government. When the entire district of Kahikinui was turned over to the Hawaiian Homes Commission, the Commissioners elected to lease large acreages to non-Hawaiian entrepreneurs for ranching, instead of providing land leases to the Native Hawaiians, as was the primary intention of the Act. These leases to non-Hawaiians were intended to provide a source of funds for the intended beneficiaries. 
Table 12 summarizes the acreage awarded in each ahupua'a of each of the districts where HGP was proposed.

Between 1856 and 1865 government lands were auctioned off and many who had not received any land were able to purchase land, if they had enough cash. Table 13 lists Government land sales (Grants) in Kahikinui between 1856 and 1865.

In the area designated District of Makawao, Honua'ula, there were over 150 government grants. Today, many are still owned by descendants of the families that originally bought the land from the Hawaiian Government.

Table 12. Land commission awards to Native Hawaiians in the districts of Honua'ula, Kahikinui and Kaupo where HGP was proposed

\begin{tabular}{lc}
\hline Location & Acres \\
\hline & Honua'ula district \\
\hline Ka'eo & 57.13 \\
Kalihi & 0.77 \\
Kanahena & 75.81 \& Ap 7 \\
Kanaio & 43.89 \\
Keauhou & 923.37 \\
Keopuili & 0.25 \\
Mo'oiki & 27.54 \\
Mo'oloa & 30.32 \\
Mo'omuku & 25.53 \\
Na'u & 0.11 \\
Na'ulalo & 0.25 \\
Na'uluna & 3.64 \\
Paeahu & 50.72 \\
Palauea & 73.18 \\
Papa'anui & 0.12 \\
Wahikuli & 0.22 \\
Waipao & 8.10 \\
\hline Total & $1,320.95$ \\
\hline
\end{tabular}


Table 12 (continued)

\begin{tabular}{lc}
\hline & Kaupo district \\
\hline Hikiaupea & 10.00 \\
\hline Kahawai & 2.48 \\
Kalimaowili & 2.00 \\
Kualaea & 2.37 \\
Kukoae & 4.85 \\
Kumunui & 164.15 \\
Lole & 30.00 \\
Lolei & 7.32 \\
Ma'alo & 8.64 \\
Manawanui & 13.50 \\
Maniniau & 3.56 \\
Niumalu & 35.06 \\
Nu'anu'aloa & 6.40 \\
Nu'u & $12,140.00$ (Ahupua'a) \\
Papauhauiki & 7.20 \\
Popiwi & 10.65 \\
Pu'alaea & 13.55 \\
Pukeauhulu & 6.37 \\
Pu'ulani & 7.60 \\
\hline Total & $12,475.70$ \\
\hline
\end{tabular}

Source: Office of the Commissioner of Public Lands of the Territory of Hawaii. (1929). Indices of Awards made by the Board of Commissioners to Quite Land Titles in the Hawaiian Islands, Honolulu Territorial Office Building.

Table 13. Government grants in Kahikinui between 1856 and 1965

\begin{tabular}{clllll}
\hline Grant No & Grantee & Locality & Area in acres & Date \\
\hline 1978 & Kawahalama & Alena & 10.00 & 1856 \\
2743 & Needham \& & Manawainui & $2,394.00$ & 1861 \\
& Cook & & & \\
2746 & Maluhia & Louluapu & 19.96 & 1861 \\
2794 & Kawahinekuewa & Kipapa/Waiapea & 96.64 & 1861 \\
2805 & Kailo'ilo'i & Kaohu-iki & 24.75 & 1861 \\
2824 & Kelekunihi & Kamuku/Kalihi & 119.00 & 1862 \\
2888 & Kamaka'ole & Luala'ilua & 11.00 & 1862 \\
2901 & Kamaka'ole & Kipapa/Kaohu & 75.37 & 1863 \\
2986 & Allen & Manawainui & 792.75 & 1865 \\
2988 & Kuahine & Luala'ilua & 11.50 & 1865 \\
\hline
\end{tabular}

Source: Index of Grants, Territory of Hawai 'i, 1916:94. 


\section{Territorial Years}

Control over the Hawaiian Government Lands and the Crown Lands was taken by the Provisional Government that was established in 1893 when the Hawaiian monarchy was overthrown with the assistance of U.S. military forces. When the Republic of Hawai' $i$ was declared in 1894, these two categories of lands were combined and collectively called "Public Lands." In 1898, "Public Lands" that had not been sold by the Republic of Hawai' $i$ were "ceded" to the United States of America at time of Annexation.

In 1900, under the Organic Act, most of these "Ceded Lands" were turned over to the Territory of Hawai'i to administer; however, some of the "Ceded Lands" were retained by the United States Government, primarily for use of the U.S. military and Coast Guard. Table 14 lists the Ceded Lands on the Island of Maui in the Districts of Honua 'ula and Kahikinui, as reported by the Governor of the Territory of Hawai' $i$ in 1901 to the Secretary of the U.S. Department of Interior.

Table 14. List of "Ceded Lands" on the island of Maui, districts of Honua'ula and Kahikinui

\begin{tabular}{cr}
\hline Districts and Ahupua'a & Acres \\
\hline Honua'ula: & \\
Kanaio & 7,600 \\
Papaka & 300 \\
Kualapa & 400 \\
Kanahena & 1,000 \\
Onau & 600 \\
Papa'anui & 4,500 \\
Kahikinui & 25,000 \\
\hline
\end{tabular}

Source: Report of the Governor of the Territory of Hawai'i, 1901.

The Governor's report described the Honua ula lands as "Rocky grazing," and the Kahikinui lands as "Grazing land." There had already been one lease (Lease No. 430) on Kanaio that had expired. The District of Kahikinui was under a lease as of Sept. 1, 1900, at the time of the report. Annual rental was $\$ 3,010$, and the lease was due to expire in February 1906. It is obvious that the Governor's Report is incomplete.

In 1959, the lands that had not been sold by the Territory of Hawai'i were turned over to the new State of Hawai' $i$ by the U.S. Government, with the exception of those lands that were retained by the U.S. Government, including land occupied by U.S. military, Coast Guard. and the U.S. National Parks.

At the turn of the century, Honua 'ula was described as being rich with pili-grass, tobacco, cotton, 'ilima, native plants, and trees, such as noni and kukui, in the early 1900 s (Ashdown, 1969-1977).

E.S. Craighill Handy did his field study of southeast Maui in 1934 and described the following ecological changes due to cattle ranching: 
In Honua'ula (red earth), as in Kaupo and Kahikinui, the forest zone was formerly much lower and rain more abundant before the introduction of cattle. The usual forest zone plants were cultivated in the lower uplands above the inhabited area. Despite two recent lava flows, which erupted in about 1750 , the eastern and coastal portions of Honua'ula were thickly populated by Hawaiian planters until recent years. A number of families whose men are employed at 'Ulupalakua Ranch have homes near the ranch house. About these native homes a little dry taro is cultivated.

Ulupalakua Ranch was started in the mid-nineteenth century by Charles McKee. The ranch was originally called Rose Ranch because of the roses Makee had planted on the terraced gardens around his house. Ownership of the ranch passed through many hands and in 1963 was sold to the current owner, C. Pardee Erdman, for $\$ 3.5$ million. Comprising 30,000 acres, the ranch stretches from the sea at Makena up to the 6,500-foot level of Haleakala. The main landing for the ranching operations was at Makena. At Makena there was a small landing and visiting ships used to moor offshore. King Kalakaua went almost every year with a whole entourage and spent two to three weeks. At that time shopping was done in Kihei via horse and buggy or horse and wagon, as there was just a trail before the road was built. The estimated population from Kanahena and Keone' 0 'io was 10,000 people at the beginning of the century.

A reporter with the Hawaiian Gazette who traveled to Kaupo in 1910 wrote the following description of life in the area:

At Kaupo are to be found Hawaiians living industriously and contentedly, as they do in the few places on the Islands which one has to go off the beaten track to reach. Sweet potatoes are largely grown and they have to take the place of poi, of which there is none here. There are plenty of fish, however, and some of the finest opihis procurable anywhere. There are several grass houses here and the garden of every house is overrun with geraniums, carnations and beautiful roses. A fine new schoolhouse is being built here to provide for the large number of children in the district. This evening a single party, gaily decorated with leis, is going from house to house serenading (Hawaiian Gazette, September 6, 1910: 6).

The reporter also sent his story to the Pacific Commercial Advertiser which ran the report as a series of articles on September 5 and 9, 1910. The September 9 article carried a description of the living conditions of Hawailans who lived between the new schoolhouse and the Kaupo Gap. It described the traditional houses that the reporter observed along the way, as well as the types of foods cultivated and animals raised by the native Hawaiians of the district. Problems that the native Hawailans had with marketing the fruit were also identified in this article:

It is nearly two miles from the school-house to Marciel's house, the trail running past several pohaku houses, grass thatched, and all-grass houses. The occupants raise pigs and sweet potatoes and working a little and resting a great deal, appear to drift in from day to day happily enough.

All take a turn at fishing at times and the toothsome aweoweo is so abundant hereabouts that it helps out the commissary problem materially during the moonlight season. 
Excellent oranges and limes are grown at Kaupo, the former being sweet and finely flavored. The Kaupoans could earn many a dollar by shipping their fruit to Honolulu, could they rely on a regular steamer. As it is impossible tell when a steamer is going to call. The steamer Claudine used to call here regu larly once a month but the service was discontinued last July, the steamer now going direct from Hana to Hawai' $i$ and return.

Several shipments of limes and oranges from here have rotted on the wharf waiting for a steamer to call. The Kaupo people suffer in another way by lack of a regular steamer service. Many of them order their household supplies from Honolulu and are often reduced to famine rations as far as some of the necessities of life are concerned (P.C.A., September 9, 1910: 9).

This account provided some background on the way of life for Kaupo Hawaiians. The men worked on the ranch but also engaged in subsistence farming and fishing to supplement their wages. In 1922, Maunupau and Emory made the following observations about Kaupo:

Kaupo is indeed a green land and so is Hana. They look so open and pleasant to live in because the wind is always blowing. The coast is good to look at and fine for inshore fishing. The whole of Kaupo faces West Hawaii. Looking upward one sees the majestic Haleakala mountain, the Kaupo Gap and many small waterfalls (Kuoko'a, June 1, 1922).

In 1934, almost the entire area was ranch land. Hawaiians who lived in Kaupo at that time worked for the ranch yet still raised sweet potatoes for home consumption (Handy, 1940).

$\mathrm{Nu}^{\prime} \mathrm{u}$ was also an ahupua'a of Kaupo. It had a sandy beach and a landing from which cattle were shipped. The ranch also used the landing to transport horse feed. The residents also kept their canoes there for fishing. In 1922, Maunupau and Emory observed five Hawaiian households in the area and reported:

When we came to level land, that was Nu'u proper. It is a seaport and cattle is shipped from here. This was a landing place for fishermen in the olden days and even down to the present. There are about five houses at Nu' $\mathrm{u}$ and the inhabitants are all Hawaiians (Kuoko'a, June 20, 1922: 24).

Mrs. Marciel, an informant to Mary Kawena Pukui in the 1960 s, was born and raised in Kaupo, near $\mathrm{Nu}$ ' $u$. She explained that her family planted sweet potatoes there during the rainy season when the earth was soft. They used the planting enclosures left behind by the ancient Hawaiians. They planted the piko variety which bore potatoes in four, five, or six months, and the mohiki variety which took several months to bear but lasted for several months out of the ground. Her family also planted the ipu 'awa'awa (calabash gourds) and pumpkins at Nu'u. The sweet potato, gourd, and pumpkin plants bear well in dry land and flourished at Nu'u. The people of the district also wove hats, using the nanaku sedge as well as the iwa stalk for material. 35

35 Josephine Marciel, interviewed by Mary Kawena Pukui, May 3, 1960, Kaupo, Maui, AudioRecording Collection, Anthropology Department, Bishop Museum. \#85.7. 
Mrs. Marciel related that the ocean off of Kaupo was famous for sharks. She also explained that when the wiliwili blooms one has to watch out for sharks. The sharks bite. It is mating season. That is the time when the sharks chase the females. When the wiliwili blooms, the sharks become fierce. At Nu'u, the wiliwili is plentiful (McGregor, 1989).

The King's ship used to come to Nu'u to obtain fish. People used to fish for the King in the pond, probably for mullet. The pond had an opening toward the ocean. This opening is now blocked off. There are old Hawaiian petroglyphs, house sites, and many unmarked gravesites at $\mathrm{Nu}^{4} \mathrm{u}$. Nu'u used to be a big Hawaiian village in ancient times. There were graves in the area. When the canoes came in, some wouldn't make it and the fishermen were buried at $\mathrm{Nu}^{6} \mathrm{u}$ Landing. Respondents gathered opihi and did pole fishing at Nu' $u$.

There was an active Hawaiian community at $\mathrm{Nu} u$ and Kaupo involved in fishing, making salt, and planting. Later, some worked on the ranch. The Marciel family once owned Kaupo Ranch and during a great drought they sold it to the Baldwin Estate. Prior to 1946, there were 5 boat houses and 2 canoe houses at Nu' $u$. There was a medicine house in a small hale at Kaupo Landing. Lapa'au (medicinal plants) are everywhere in the area and they were tied in bundles and kept in the medicine house. This was also the salt house. Great akule schools frequented the bay and the salt was used to dry the akule. Right against the pali, where the landing and the medicine house was, there was a canoe house that had Hawaiian canoes in it.

People gathered salt at Nu'u. All the stones with small hollows were put on the edge of the pond, then people would put ocean water in them. The sun would evaporate the water, leaving the salt. They used wooden spoons to scoop out small amounts of salt. Behind $\mathrm{Nu}^{\prime} \mathrm{u}$ Bay there was a nice pond which is now all overgrown. People used to keep it clean of hau trees. The Navy people used kahili hau for rope on an almost daily basis and this kept the hau in check.

$\mathrm{Nu}^{\prime} \mathrm{u}$ Bay has a black-stone beach. The Hawaiians used the stones for weighting their nets with palu (bait). It was a flat weight placed in a bag and wrapped in such a way that it had the sweet potato peelings inside the bag and, covered the bag, rolled and twisted it and laid it in the net. They also used pumpkin, squash, ipu, and sweet potato as bait. They would make sour potato mash which looked like a big pudding. They kept the liquid part, fermented it, and drank it as liquor. There was a cave with a water well in front if it. There was also a Hawaiian house there. Beach equipment was stored there.

Photos record that Hawailans in malo (loincloth) launched canoes in the bay. The fishing houses consisted of Japanese-style skiffs with long nets. People that lived there were part of a hui (cooperative). They fixed nets, made floaters, and made salt $\mathrm{Nu}^{\prime} \mathrm{u}$ was also famous for holoholo he' $e$, which is a very big squid that has short legs and a large body. The uhu would come in schools turning the sea red beyond the bay, and everybody would just hook them. As many as 30 people would go out fishing at a time. Someone on shore would start a fire and make coffee. It was a very happy time. Uhu is a fish that Hawaiians like to eat fresh. It also meant that, even before the fishing was over, they would start loading these fish on donkeys and trying to get mauka and literally just give the fish away. That is the way they lived. When there was something, everybody shared. There was more use of hukilau nets in those times. In Kaupo, the population was about 480. Afterward, there was a mass evacuation of young people. By 1942, all the young men were drafted. Once they were in the service, they had habits that could not be taken back to Kaupo. 
In the 1930s Kahikinui was described as an arid land, scarred by the most recent flow from Haleakala in 1750. As early as 1922, Maunupau and Emory described the district as cattle raising country. They wrote:

Many cattle roamed from the plains to the places near the beaches. Here and there were the drinking troughs made for the cattle. The water came here from Kula in pipes. The road we took was winding, going this way and that, up hill and down, sometimes on the edges of the cliffs along the coast with the sea dashing up against the base of the cliff and down into a valley with a stream bed but no water (Kuoko'a, July 6, 1922: 24).

By the time that Handy visited Kahikinui in 1934, it was uninhabited due to the impact of cattle ranching in the district. He noted that, "Now the district is almost wholly ranch land. In the lowlands of Kaupo Hawaiians were still planting sweet potato in 1934."

The population of the Hana district in 1930 was 2,436 of which 1,177 people were Hawaiians, accounting for $48 \%$ percent of the population. In Kaupo and Kahikinui the total population was 185, of which 160 people were Hawaiian, accounting for a percentage of $86 \%$ (U.S. Bureau of the Census, 1930).

Table 15. Population of south Maui in 1930

\begin{tabular}{lccc}
\hline District Hawaiian & Total Population & Number Hawaiian & Percent \\
\hline Hana Town & 1,585 & 536 & 34 \\
Kipahulu & 147 & 118 & 80 \\
Kaupo/Kahikinui & 185 & 160 & 86 \\
\hline
\end{tabular}

Source: United States Bureau of the Census, Fifteenth Census of the United States: 1930, Occupation Statistics Hawaii.

It has long been acknowledged that the United States of America has, since 1898, owed a trust responsibility to the people of Hawai' $i$ for having accepted approximately 1.8 million acres of their lands with the understanding that these lands were to be held in trust for the beneficiaries, the people of the Hawaiian Islands, including the Native Hawaiians. Since statehood in 1959, the State of Hawai'i has been the trustee, a responsibility that it took on when the "Ceded Lands" were given to the new State of Hawai'i by the U.S. Government.

In 1920, homesteading for Native Hawaiians was proposed because of the fact that Hawaiians have strong, long-standing legal rights to lands that had been illegally taken from them and "ceded" to the United States of America by the illegal Republic of Hawai' $i$ as an inducement for the United States to annex the Hawaiian Islands. Among the lands selected to be included for the purpose of homesteading by Hawaiians under the Hawaiian Home Lands Act were 22,809 acres in the Kahikinui District. However, instead of settling Hawaiians on this land, it was leased to non-Hawaiians for cattle ranching. 


\section{Contemporary Period}

Although there have been major changes in population size and composition over the past 50 years in many parts of Maui, change has been relatively slow in certain parts of South Maui (e.g., Hana). Most of the changes have occurred within the last 10 years, especially in the Makawao district (makai and mauka) due to tourism and subdivision development. These changes have accounted for demographic shifts related to a decline in the percentage of Native Hawaiians and an increase in the Caucasian population. The population of the Hana district in 1930 was 2,436, of which 1,177 or $48 \%$ were Hawaiians. In Kaupo and Kahikinui the total population was 185 , of which 160 or $86 \%$ were Hawaiian (U.S. Census Bureau, 1930).

There were 1,895 people (683 in Hana town) and 589. households in the Hana census division in 1990 (U.S. Census Bureau, 1990) (Table 16). The median age of Hana residents was 31.1 years. Between 1980 and 1990, Hana experienced an increase of $33.2 \%$ in its resident population. This was less than that experienced in the Makawao district (43\%) and less than the county-wide rate of $45 \%$, but much higher than the statewide growth rate of 15\% (Office of State Planning, 1992). Residents living within the Hana district were predominantly Hawaiian. In 1990, the Hawaiian population accounted for $47.8 \%$ (about the same level as in the 1930), the Caucasian population $38.9 \%$, and the Filipino $4.0 \%$ (Table 16). In the Makawao-Mauka census division, the Hawaiian population was $8.2 \%$, and in Makawao-Makai the Hawaiian population was 4.9 in 1990 (Table 16). In 1990, Hawaiians in Maui County comprised $13.5 \%$ of the population.

The land area in Hana is 467 square kilometers $\left(\mathrm{km}^{2}\right)$ and the gross population density per $\mathrm{km}^{2}$ in 1990 was a low 4.1 persons. The land area in Makawao-mauka is $448 \mathrm{~km}^{2}$ and the population density was 12.3 persons per $\mathrm{km}^{2}$. The land area in Makawao-makai is $234 \mathrm{~km}^{2}$ and the population density was 10.7 persons per $\mathrm{km}^{2}$.

Most of the South Maui District does not have municipal water service. Municipal water service is available in the resort coastal area from Kihei to Makena and in the uplands from Keokea in Kula to 'Ulupalakua Ranch in Honua'ula. Hawaiians at Kanaio and Kahikinui use rainwater catchment systems or haul in water and ice from other areas. Kaupo is rich of stream water. Electricity is available in Honua 'ula, but serves only some parts of Kanaio. It is not available at Kahikinul. There is only one road across the South Maui District-the Pi'ilani Highway connecting 'Ulupalakua Ranch to Kaupo, all the way to Hana. This road is not considered a viable commuter traffic alternative because it is a combination of A.C. pavement, gravel and unpaved sections, and narrows to a single lane in various places (Office of State Planning, 1992). However, the highway is being improved with new concrete bridges across gulches. Hana is served by a small airport and is provided with basic infrastructure.

Major conservation areas include the Haleakala National Park; the Kula, Makawao, Kahikinui, Kipahulu, and Hana Forest Reserves; and the 'Ahiki-Kina'u, La Perouse BayKanaloa Point and Kanaio conservation areas. The rest of the South Maui District is zoned agriculture with ranching as the predominant activity. Major tourist resorts are located in the nearby urban districts of Wailea and Makena and to a smaller extent in Hana. Hawaiians find work in all the employment sectors in town. Employment opportunities are in the areas of ranching, tourism, commercial fishing, government, and construction. Retirees often supplement fixed incomes by engaging in subsistence fishing, hunting, planting, and gathering activities. Some are homesteading on their own lands. 
Table 16. Resident population 1980 and 1990; land area and density, 1990

\begin{tabular}{lccccc}
\hline Census tract & 1980 & 1990 & $\begin{array}{c}\text { Percent } \\
\text { change }\end{array}$ & $\begin{array}{c}\text { Land area } \\
\left(\mathbf{k m}^{2}\right)\end{array}$ & $\begin{array}{c}\text { Population } \\
\text { density }\left(\mathbf{k m}^{2}\right)\end{array}$ \\
\hline Hana 301 & 1,423 & 1,895 & 33.2 & 467.31 & 4.1 \\
$\begin{array}{l}\text { Makawao } \\
\text { Mauka }\end{array}$ & 3,850 & 5,525 & 43.5 & 448.37 & 12.3 \\
$\begin{array}{l}\text { 303.01 } \\
\text { Makawao }\end{array}$ & 1,227 & 2,496 & 103.4 & 234.08 & 10.7 \\
$\begin{array}{l}\text { Makai } \\
303.02\end{array}$ & & & & & \\
\hline
\end{tabular}

Source: U.S. Census Bureau, 1990.

Table 17. Resident population by race 1990 (percent distribution)

\begin{tabular}{lcccccccccc}
\hline $\begin{array}{c}\text { Census } \\
\text { tract }\end{array}$ & $\begin{array}{c}\text { All } \\
\text { races }\end{array}$ & White & Black & $\begin{array}{c}\text { Amer. } \\
\text { Indian }\end{array}$ & Chin & Filip & Jpn & Haw & $\begin{array}{c}\text { All } \\
\text { others }\end{array}$ \\
\hline Hana 301 & 100 & 38.9 & 0.4 & 0.8 & 3.3 & 4.0 & 3.4 & 47.8 & 1.4 \\
$\begin{array}{l}\text { Makawao } \\
\text { Mauka }\end{array}$ & 100 & 34.7 & 0.2 & 0.4 & 2.8 & 3.4 & 18.0 & 8.2 & 2.2 \\
303.01 & & & & & & & & & \\
$\begin{array}{l}\text { Makawao } \\
\text { Makai }\end{array}$ & 100 & 81.0 & 0.6 & 0.5 & 1.0 & 5.2 & 4.9 & 4.6 & 2.2 \\
303.02 & & & & & & & & & \\
\hline
\end{tabular}

Source: U.S. Census Bureau, 1990.

Table 18. Resident population by age and sex by census tract 1990

\begin{tabular}{lccccc}
\hline Census tract & Total & $\begin{array}{c}\text { Under } 18 \\
\text { years }\end{array}$ & 18 to 64 years & 65 years and over & $\begin{array}{c}\text { Males per } \\
100 \text { females }\end{array}$ \\
\hline Hana 301 & 1,895 & 641 & 1,079 & 175 & 111.3 \\
$\begin{array}{l}\text { Makawao } \\
\text { Mauka }\end{array}$ & 5,525 & 1,507 & 3,348 & 670 & 100.6 \\
$\begin{array}{l}303.01 \\
\text { Makawao }\end{array}$ & 2,496 & 468 & 1,727 & 301 & 104.6 \\
$\begin{array}{l}\text { Makai } \\
303.02\end{array}$ & & & & & \\
\hline
\end{tabular}

Source: U.S. Census Bureau, 1990. 
Ranching has been blamed for many of the district's environmental problems. In Kahikinui, two ranch owners raised as many as 10,000 cattle and 3,000-5,000 goats for 60 years which have been blamed for causing damage to native flora as well as to ancient Hawaiian temples and gravesites. Ranching operations took over land previously owned by Hawaiian families. Some Hawaiians left the area and were not aware of it when the ranchers took their lands through the process of "quiet title" or "adverse possession."

A number of Hawaiians living in the district are tied to ranching activities. Some have been employed as paniolo (cowboys) or are children of former ranch employees. As employees, they received ranch housing and lived in communities dominated by this sector of the economy. Although large tracts of land belonging to the ranches were off-limits to Hawaiian residents and settlers, a number of Hawaiian families lived around them and gravi tated towards employment opportunities provided by the ranches. Seasonal community activities and feasts brought families from various localities; all the way from ranches in Kaupo and Kipahulu to 'Ulupalakua Ranch. People across regions, generations, and lineages had the opportunity to meet and intermingle during the long weekend events in June or July. Activities included a rodeo, nightly feasts, hula dancing, singing, and music. Food was brought in and cooked on wood stoves.

Many place names in the South Maui District are associated with mythology, deities (such as Pele), legendary ancestors, ancient navigators, and noted events and kings. Place names describe the geomorphologic character of places, significance, sacredness and mana (spiritual power), subsistence resources available in the area, and habitations and settlement characteristics. Names of temples and other man-made structures reveal their purpose and use, such as cultivation and fishing. Place names are also used to recognize landmarks for orientation and finding off-shore fishing grounds.

\section{'Ahihi-Kina'u and Kanaio Natural Area Reserves (NAR)}

The "Ahihi-Kina'u Natural Area Reserve encompasses 2,052 acres in Honua'ula, Makawao. It runs from 'Ahihi Bay to La Perouse Bay and includes all Cape Kina' $u$ and is intersected by the Makena Keone'o'io Government Road. Part 1 of the Reserve includes portions of the Government Land of Onau, Kanahena, Kualapa and Kalihi and encompasses a gross area of 1245.50 acres. Part 2 of the Reserve includes submerged lands fronting Moomuku, Onau, Kanahena, Kualapa and Kalihi containing an area of 807.40 acres (Department of Accounting and General Services, 1973).

The Natural Area Reserve includes the following significant coastal reserve subareas (Maciolek, 1973):

1. Marine Reserve. Pristine and representative shallow water ecosystem with dense and diverse bottom community, particularly the stony corals and the slate pencil urchins. Because of the many water rock contacts, inter-tidal fauna is rich. The protected inshore system of the bay and cape with their diversity of flora and fauna can act as a gene pool reserve in which reproduction and development can occur.

2. Lava Flow Reserve. Cape Kina'u represents the last incident of active volcanism on Maui, formed around 1790. It contains native vegetation in kipuka (open areas surrounded by lava) such as Hawaiian caper, Naio, Wiliwili, Nehe, Pili grass. 
3. Tidepool and Pond Reserve. Irregular porous lava provides another class of aquatic ecosystems intermediate between open seashore and freshwater. Biota in these systems varies with the degree of salinity. Near-shore ponds are marine-like, showing algae, invertebrates and fishes. Progressing inland, fewer and more unusual species are present. Fishes and marine algae disappear and two species of crustaceans, the endemic small red shrimp or 'Opae'ula (Halocaridina Rubla) and an alphaeid shrimp (Metabetaeus lohena), known only from three other localities in the Pacific, appears. Many ponds contain the bleu, a green alga Microcoleus vaginatus, and the aquatic phanerogam, Ruppia maritima. The Cape Kina'u ponds represent the only extensive habitat for this uncommon species on Maui. Water birds such as the Ae'o (Hawaiian stilt), sanderlings, curlews, plovers, turnstone, and migratory ducks have been observed in the larger open ponds.

Forty-two acres of La Perouse Bay/'Ahiki-Kina'u Natural Area Reserve are proposed to be rezoned from agriculture to conservation to be consistent with the NARs designation. The proposed transmission line will cut through the northern side of the 'Ahihi-Kina' $u$ Natural Area Reserve at Kanahena on government lands and will be within close proximity of several government grants on the northern side of the transmission line (Office of State Planning, 1992).

The Kanaio Natural Area Reserve includes 876 acres of land in Kanaio and Makawao on both sides of the Pi 'ilani Highway. The mauka section, or Parcel A, includes 595 acres and the makai section, or Parcel B, includes 281 acres. It contains a 50 -foot road right-of-way in favor of the State of Hawai'i located on the mauka side of the Pi'ilani Highway. This area is designated a reserve because it contains many rare and endangered native plants. It is also in the state conservation district. The proposed transmission line would cut through the Kanaio Natural Area Reserve running along the makai side of the Pi'ilani Highway.

Natural Area Reserves are unique areas that are designed to be protected from encroachment, alteration, and development. They are under the control and management of the State of Hawai' $i$, Department of Land and Natural Resources. Permitted activities are restricted to hiking, nature study, bedroll camping without tent, and hunting of game mammals and birds subject to hunting rules. Prohibited activities are those that affect plant and animal life; the introduction of plant and animal life; actions that impact any geological, paleontological feature, or substance; any historic or prehistoric remain; and those activities that damage existing notice, markers or structure. Special-use permits may be issued to conduct activities, otherwise prohibited for research, education, management, or for any other purpose consistent with Chapter 195, Hawai ${ }^{\prime} i$ Revised Statutes (Department of Land and Natural Resources, 1981).

\section{ASSESSMENT OF SITE AND DISTRICT SIGNIFICANCE FOR NOMINATION TO THE NATIONAL REGISTER OF HISTORIC PLACES}

The assessment of the significance of a site or a district is based upon guidelines developed to be consistent with the criteria listed in 36 CFR, Part 60, of the NHPA and published in a number of documents produced on the National Park service including the following: 
- National Park Service. n.d. Guidelines for Evaluating and Documenting Traditional Cultural Properties National Register Bulletin No. 38. U.S. Department of the Interior, and

- National Park Service. n.d. Guidelines for Evaluating and Documenting Rural Historic Landscapes National Register Bulletin No. 30. U.S. Department of the Interior.

Eligibility to the National Register involves the following steps and assessments (NRB No. 38, n.d.:9-16):

Step 1: Determine whether the entity is a tangible property (district, site, building, structure, or object.

Step 2: Determine whether the property exhibits integrity of location, design, setting, materials, workmanship, feeling, and association (integral relationship to tradi tional cultural practices or beliefs and integrity of conditions of the property such that the relevant relationship survives).

Step 3: Evaluate the property with reference to the National Register criteria. The criteria for eligibility for nomination to the National Register of Historic Places are NRB No. 8, n.d.: 11-12):

Criterion (a): Association with events making a significant contribution to the broad pattern of our history.

Criterion (b): Association with the lives of persons significant in our past.

Criterion (c-1): Embodiment of distinctive characteristics of a type, period, or method of construction.

Criterion (c-2): Representative of the work of a master.

Criterion (c-3): Possession of high artistic values.

Criterion (c-4): Representative of a significant and distinguishable entity whose components may lack individual distinction.

Criterion (d): History of yielding, or potential to yield, information important in prehistory or history.

Additionally the nomination to the Hawai'i State Register of Historic Places includes:

Criterion (e): Historical and cultural value to a particular ethnic group (e.g. Native Hawaiians).

Step 4: Determine whether any of the National Register Criteria considerations (36 CFR Part 60.4) makes the property ineligible. The intent here is to eliminate ethnocentric bias (NRB, n.d.: No. 38:12-16). 
Consideration A: Ownership by religious institution or use for religious purposes (avoid historical significance on the basis of religious doctrine).

Consideration B: Relocated properties.

Consideration C: Birthplaces and graves (of famous persons).

Consideration D: Cemeteries.

Consideration E: Reconstruction (reconstructed properties).

Consideration F: Commemoration (properties constructed to commemorate a traditional event or person.

Consideration G: Significance achieved within the past 50 years.

The guidelines of National Register Bulletin No. 38 also point out that the Western distinction between religion and culture does not exist among indigenous societies. Thus, many indigenous properties and sites may still be eligible even if they are properties which are characterized by considerations " $A$ " to " $G$ ". The following are additional factors to consider in determining that a site is, in fact, eligible for consideration:

- Properties used for seeking supernatural visions, collecting medicinal plants, or carrying out ceremonies are not only religious but are also intrinsic to the continuation of the culture of a people.

- Association of properties with religious history or religious persons when there is scholarly and secular recognition.

- Retention of intrinsic value even when relocated: canoes, petroglyph stones, totems, etc.

- Birthplaces and burial places which have assumed significance as centerpieces of cultural identification.

- A cultural property left unused for a lengthy period of time may again be used or reconstructed within the last 50 years.

In addition, such properties will qualify if they are integral parts of districts that do meet the criteria or if they fall within certain additional categories such as architectural, artistic, historic distinction; association with historical persons or events; uniqueness of the site; reconstructed structure as part of a restoration master plan; symbolic value or historic significance; and has exceptional importance (if developed within the past 50 years) (NRB No. 30, page 20).

The National Register Bulletin No. 30 provides guidelines for evaluating and documenting rural historic landscapes. A sample survey form (page 11) proposed a format by which panoramic pictures and site specific pictures are keyed to their geographical location 
in a topographic map. The form lists information on land use category by percentages of use and land use activity by type and boundary demarcation. include:

Bulletin No. 30 suggests that the documentation of landscape characteristics should

- land use activities and their features

- patterns of spatial organizations

- response to the natural environment

- cultural traditions

- circulation networks

- boundary demarcation

- vegetation related to land use

- building, structures, and objects

- clusters, such as villages, ranches and harbors

- archaeological sites, and

- small scale elements.

In July 1993, the Hawai'i State Legislature established a task force to develop specific criteria for designating certain sites, scenes, and landscapes as cultural landscape districts; specify activities and uses that are consistent with the designation of certain sites, scenes, and landscapes as cultural landscape districts; and develop specific procedures to define certain sites, scenes, and landscapes as cultural landscape districts. The report, submitted in January 1994, developed initial descriptions and definitions of cultural landscapes within the context of Hawai'i. According to the report, cultural landscapes are geographically definable areas possessing a significant concentration, linkage or continuity of landscape components (i.e., vegetation, buildings and structures, archaeological sits, roads and trails, waterways, religious and natural features and resources) which are united by human use and past events and/or aesthetically by plan or physical development. These landscapes clearly show the results of human occupancy and transformations of the hand or mind. Examples of such landscapes included:

1. Abandoned Native Hawaiian villages or agricultural systems such as at Kaunalu on Lanai or Ohikilolo-Kea'au on O'ahu;

2. Taro producing areas such as Hanalei on Kaua'i, Waipi'o Valley on the island of Hawai' $i$, Ke'anae or Honokohau, both on the island of Maui;

3. Expanses of land devoted to sugar cultivation such as the Hamakua Coast on the island of Hawai' $i$ or the south shore of Kaua' $i$; 
4. Ranches such as Ulupalakua and Hana ranches on Maui, the Parker and Greenwell ranches on the island of Hawai' $i$;

5. Areas related to fishing activities such as the village of Miloli'i or KaLae on the island of Hawai' $i$;

6. Religious and legendary sites such as Mokapu Peninsula and Mount Olomana on $O$ 'ahu, Iao Valley on Maui, and Kilauea on the island of Hawai' $i$;

7. Fishponds, such as those which line the southern shore of Moloka'i;

8. Traditional gathering areas, such as mauka and valley areas which contain native plants, and shoreline areas, including reefs and beyond, that support traditional ocean resources;

9. Entire islands, such as Moloka'i.

The County of Maui is currently conducting a study of the $\mathrm{Ke}^{\text {canae-Wailua district to }}$ develop an initial typology of the features, activities, and components that make up a Hawaiian cultural landscape.

In the present study, the details of historical and contemporary cultural significance and uses of the sites and cultural landscapes identified for consideration for nomination to the Historic Sites Register is contained in the ethnohistories and summaries of informant interviews for each district. Exhibits are on file in the Deparatment of Urban and Regional Planning, University of Hawai' $i$, care of Dr. Luciano Minerbi. They depict panoramic pictures and U.S.G.S. topographic maps 1:24,000 for each change of landscape scenery and district in the study area.

A detailed study for the actual compilation of National Register Forms goes beyond the funding and scope of this study and requires greater coordination in a subsequent research phase between cultural experts, archaeologists, and botanists. It also requires an expansion of the study area to the entire district, particularly for the archaeologists and the explicit funding of a physical-cultural landscape field study assessment.

Such a study for nomination of the sites in Puna and Southeast Maui to the National and State Registers for Historic Places should include additional input from Native Hawaiian groups and organizations, in addition to input from experts and line agencies. Native Hawaiians can establish the significance for their own culture, the type and level of protection they find appropriate in consideration to outside encroachment and development pressure, and their own need to use and access the site for cultural and subsistence practices.

Puna

Historic Sites

The National and State Registers of Historic Places already list the following sites for the district of Puna: 
10-62-5503 Puna-Ka'u Historic District, Hawai'i Volcanoes National Park, District with multiple sites

10-46-2529 MacKenzie Petroglyphs

10-46-2530 King's Highway

10-55-7384 'Opihikao Evangelical Church Residence

10-55-10,922 Ala Loa (Puna District)

10-55-11,333 Keauohana Ahupua'a Archaeological District, District with multiple sites

The companion archaeological report (Burtchard and Moblo 1994) provides a listing of known archaeological sites in the three Geothermal Resource Subzones in Kapoho, Kamaili, and Kilauea (Table 2, pp. 15-18 of that report).

(3)

(9) Site 5245

(23) IARII 945

(24) IARII 94-15

(26) IARII 94-7

(27) IARII $94-10$

(28) IARII 94-13

(29) IARII 94-14
Kapoho Petroglyphs

Kuki'i Heiau

Pu'u Kuki'i Cyst

Kaholua o Kahawali holua slide

holua slide

lava tube sinkhole

Wilke's Trail of 1840

Heiheiahulu Mounds

Kaimu Trail

Middle Lava Tube Cave

Southern Lava Tube Cave

Northern unnamed trail

Pu'ulena Crater

Malama Burial Cave

Halekamahina Crater

Bryson's Cinder Kit kipuka

'I'ileaw Lava Tube

Upper Kaimu Cave

Pu'u Kauka Kipuka
Kapoho

Kapoho

Kapoho

Kapoho

Kapoho

Kapoho

Kilauea

Kilauea

Kilauea

Kilauea

Kilauea

Kilauea

Kapoho

Kapoho

Kapoho

Kamaili

Kamaili

Kilauea

Kilauea

Dr. Greg Burtchard emphasized that the archaeological survey of the three subzones was inadequate because of limited resources, limited time, limited scope of the survey, and lack of access to certain private lands within the subzones. No subsurface excavation was conducted.

Puna informants in our survey (Chapter 3) identified important historic sites which are marked on the Map of Puna (Figure 2). The sites which were identified within one of the three geothermal resource subzones were referred to the archaeology team of International Archaeological Research Associates for examination. The other sites, outside of the geothermal subzones, would deserve examination and assessment should there be plans to exploit a geothermal resource outside of the geothermal resource subzones. 
A "Working List of Archaeological Sites in Puna, Hawai' $i$ " was provided to our research team by Holly McEldowney of the State Historic Preservation Division. She explained that the list is a print-out of sites that are currently entered into the Division's computerized inventory for Puna. It only includes sites that were in the hanging inventory files and those compiled for McEldowney's 1979 report which covered those portions of Puna north of Kapoho. A number of sites in the hanging inventory files which have since been destroyed by lava are not indicated on the list. The list does not include the numerous sites recorded in Hawai' $i$ Volcanoes National Park, sites located during contract studies south of Kapoho, and most sites located during contract studies after 1978. The list is attached as Appendix E.

\section{Historical Cultural Landscape}

The 25,700 acre Puna Forest Reserve, including the 6,500 acres of the former Wao Kele $O$ Puna Natural Area Reserve, qualifies for consideration as a historic cultural landscape.

Extensive historical and contemporary subsistence and cultural uses including hunting, gathering, and cultivation were revealed in the literature reviewed and in the informant interviews which were conducted. There is an unbroken continuity in hunting and gathering in this forest for subsistence and cultural use. The uses are indicated on the Map of Puna (Figure 2).

The Puna Forest Reserve is the largest remaining expanse of lowland tropical rainforest in Hawai' $i$. Other lowland forest areas in Puna have been displaced by the timber industry at the turn of the 20th century, sugar plantations, and the commercial cultivation of coffee and papaya. The fact that it is one of the few remaining forest areas in Puna where subsistence hunting and gathering can be conducted increases its current cultural use value.

There are specific sites situated within the Puna Forest Reserve which would need to be further excavated. One of the most significant historic properties are lava tubes which were used for refuge during times of war, as burial places, and as places of worship. The 1991 report, "Survey of Lava Tubes in the Former Puna Forest Reserve and on Adjacent State of Hawai'i Lands" by Holly McEldowney and Fred Stone documents the features and artifacts discovered in lava tubes within the Puna Forest Reserve. It further substantiates the basis for qualifying the Puna Forest Reserve as a historic cultural landscape.

The Wao Kele O Puna was set aside as a Natural Area Reserve by the Board of Land and Natural Resources in 1978 until 1987. We have attached the documentation which was submitted to qualify the area as a Natural Area Reserve as Appendix F This provides additional information about the resources of the forest which are available for subsistence and cultural purposes.

The Puna Forest Reserve is part of the Kilauea ecosystem. It is dominated by four species of the 'ohi'a lehua tree. It has evolved in the midst of continuous volcanic activity. The result is that the Kilauea volcanic forest is a mosaic of ecosystems of varied ages and development, shaped by periodic lava flows and rapid forest regeneration. Typically, a lava flow, associated with the Hawaiian volcanic goddess Pele, will cover over much of a given area, but leave small islands of forest life known as "kipuka" which serve as seed banks to the new lava flows. Within days of the new lava cooling, the healing process, associated with the Hawaiian deity Hi'iaka, will begin with a light rain of seeds and spores from the 
NATIVE HAWAIIANS ETHNOGRAPHIC SURVEY HAWAII GEOTHERMAL PROJECT - EIS

Universtty of Hawail, Manoa

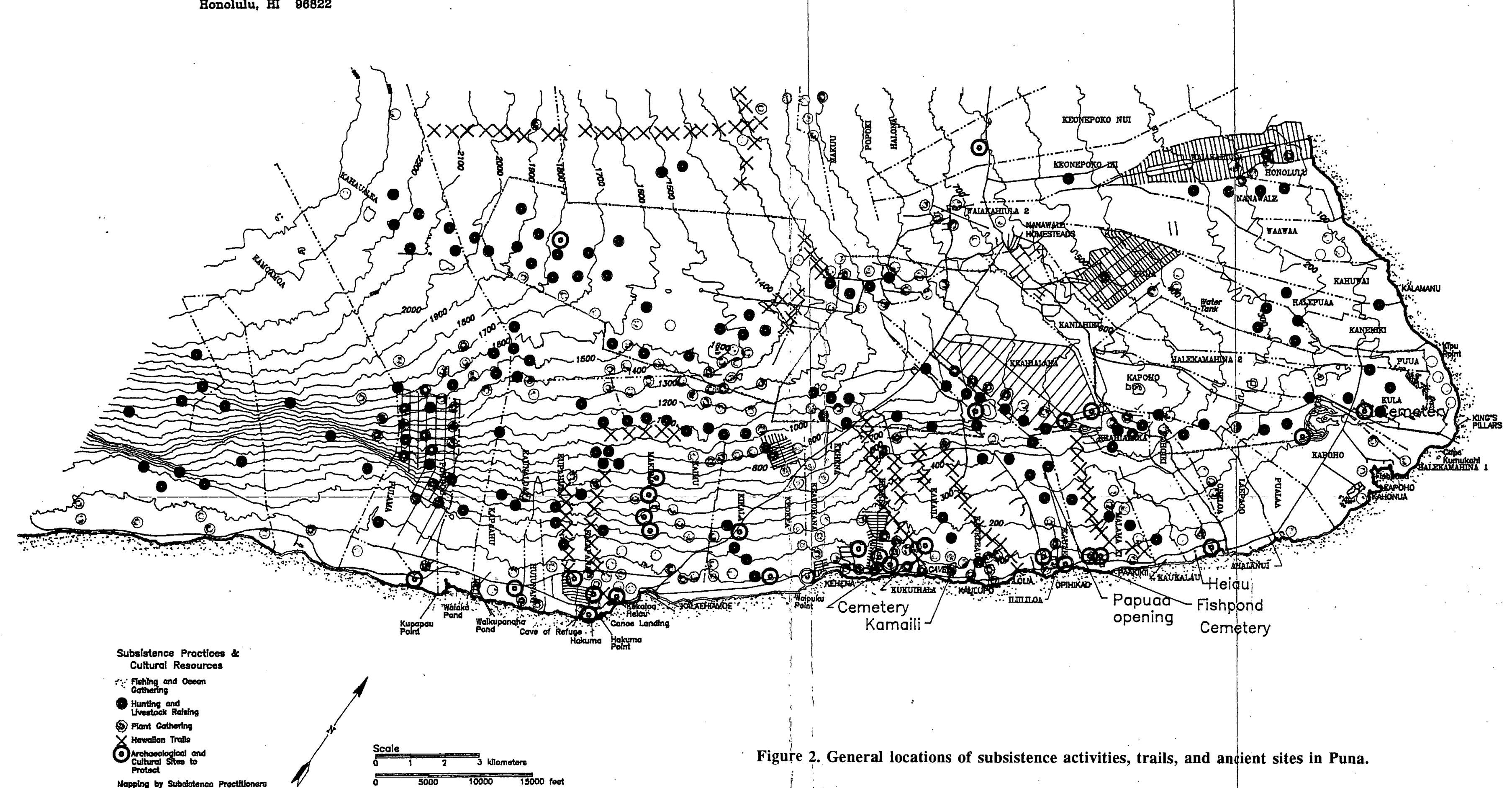


adjacent forest and kipuka. Primary succession on fresh lava is a process nearly exclusively reserved to native species. The first plants to take hold are lichen, ferns, shrubs, and most importantly the 'ohi'a which is the ecologically pivotal species, the primary link between the Kilauea lavas and the living landscape. The wet nature of Wao Kele $O$ Puna diminishes the extent of disturbances due to lava-spawned fires and favors a rapid establishment and recovery of life. In the last 200 years more than 60 percent of Hawai' $i$ 's native rainforests have been destroyed by humans. Hawai'i's lowland rainforests have been hardest hit. Once extending over as much as half of the island's surface, Hawai' $i$ 's lowland forests are reduced to remnants covering between a mere 5 and 10 percent of its original expanse.

\section{Southeast Maui}

The National and State Registers of Historic Places already list the following sites in the study area of Southeast Maui:

\section{Quad 14 Makena:}

Wahene Platform, Cave of Seven Coffins, Keone'oio Archaeological District.

Quad 15 Luala'ilua Hills:

Alena Habitation Site, Luala'ilua Heiau, Kaluakakalioa Cave, Papakea Petroglyphs, Hanamau'uloa Complex, Kipapa Archaeological District, Luala'ilua Terrace Complex, Kahikinui House.

\section{Quad 16 Kaupo:}

Lo'alo"a heiau.

Preliminary evaluation and recommendations to assess archaeological site significance and suggestion for additional archaeological investigation is provided in the report by Conrad Erkelens, August 1994. Phase I. Archaeological Investigation Cultural Resource Survey, Hawai' $i$ Geothermal Project Makawao and Hana District South Shore of Maui, Hawai ' $i$. These recommendations are based on the sample survey of a narrow corridor along the geothermal overheard transmission line route. The considerations of the following pages address a broader geographical area running mauka-makai for the entire comidor length.

The following are districts and sites which should be considered for nomination to the Federal and State Register for Historic Sites. Their name and detailed description is in the text narrative and the South Maui District Compilation of Information:Honua ula District

- The pu'u chain and the last lava flow at Ahihi-Kina'u for their association with the Goddess Pele who created them, their association to other gods and chiefs of long ago, and related legends (Criteria a, b, and e):

- The ancient fishponds and sea caves at Ahihi Bay, Lae Kina'u, Ku Makena, Keone'o'io for their association with sea gods, guardian spirits, dead chiefs, and legendary figures (mermaid, man-shark), and Hawaiian cultural practices (Criteria b and e). 
- Offshore fishing grounds and the ko'a shrines and the landmarks associated with these fishing grounds for their value as examples of cultural and fishing subsistence practices (Criteria a, b, and e).

- Kanahena a rich of fishing, recreational coastal sites, Ahiki-Kinau, rich of archaeological sites, native Hawaiian coastal plants and sites, and Kalihi rich of pu'u and geomorphological configurations, should be nominated as a scenic district to further protect-at its boundary - the Ahiki-Kinau Natural Area Reserve (Criteria a, b, d, and $e$ ).

- Dry caves for their cultural and subsistence use as underground trail networks, refuges, shelter, school, burial, especially all the cave system in Kanaio (Criteria a, b, d, and $\mathrm{e}$ ).

- Several individual heiau at Makena, Kanahena, Keone'o'io, Kanaio, and Kaloi for their religious, historical, and architectural significance (Criteria a, b, c-1, c-4, c-e).

- Ancient Hawaiian villages at Nahawale near Pu'u Ola'i, at Nahawale near Keone'o'io, and at Kanaio as settlement complexes (Criteria a, b, c-1, c-d, and c-e).

- The following are very significant scenic and cultural districts and should be protected: scenic view corridor of Kanahena-Kaloi; the scenic view corridor of Kaloi-Kanaio; the scenic view corridor Kanaio-Luala'ilua Hills (Criteria a, b, c-3, d, and e).

\section{Kahikinui Land Section}

- Offshore fishing grounds, associated ko'a systems and landmarks for their value as examples of cultural and fishing subsistence practices (Criteria a, c-1, d, e).

- Lava tubes and burial caves: large cave complex at Hanalmauuloa village and caves below Luala'ilua Hills, burial caves at Naka'aka as example of cultural and religious uses (Criteria a, b, d, and e).

- Heiau complexes at Alena, Luala'ilua and Kahikinui for their archaeological and cultural value (Criteria a, b, c-1, c-4, d, e).

- Petroglyphs at Pahihi Gulch for their artistic and historical value (Criteria a, c-3, d, e).

- Astronomical rock complexes at the crater summit and below Luala'ilua Hills for their cultural and scientific value (Criteria a, b, c-2, c-4, d, e).

- Ancient Villages and sites at Make'e, Luala'ilua, Waia'Mio, Halnamaunloa, Halena, Kipapa, Papaula, Waiapea, Nakahaka. Villages of Kahikinui at Malahohu, village of $\mathrm{Ka}-\mathrm{Lae}-\mathrm{0}-\mathrm{Ka}$-Pulou, village of Uliuli at Kahawaipapa Point, village of Kamoamoa, Kalamiana at Mahamenui, and village at Manawainui Gulch. All these villages have high archaeological and cultural values. Villages represent clusters of structures and patterns of spatial organizations, some of these villages have features for special use 
such as canoe shed, ko'a, temples, and burial platforms, in addition to house sites (Criteria a, b, c-1, c-4, d, and e).

- The entire Kahikinui district is most significant as an archaeological and cultural scenic district for the system of ancient village ruins above St. Inez Church of midlevel elevation, spanning prehistoric and historic times, and the system of ancient coastal villages and related trails all along the coast (Criteria a, b, c, d, e).

- Kahikinui is also spectacular for its scenic beauty and unspoiled landscape features. Kahikinui should be a scenic and cultural district which includes: the scenic view corridors of Luala ilua-St. Inez Church; the scenic view corridor of St. Inez ChurchManawainui; the scenic view corridor of Manawainui-Nakaahaka; and the scenic view corridor of Manawainui-Huakini Bay. Huakini Bay is most important for its scenic and recreational and subsistence values due to its accessibility from the road and cultural value for his visual proximity to $\mathrm{Nu}^{\prime} \mathrm{u}$ Bay. (Criteria $\mathrm{a}, \mathrm{b}, \mathrm{c}-4, \mathrm{~d}, \mathrm{e}$ ).

- Native Hawaiian plants are particularly abundant along the coast at Cape Hanamanioa and at mid-level elevation at Kanaio, Auway, Luala'ilua on both sides of the road. This is an added reason to protect this area as a scenic and cultural district (Criteria a, $d$ and $e$ ).

\section{Kaupo Land Section}

- The salt pond, the bay with the canoe landing place (later cattle ranch landing), the fishing village, the burial cave, the seven heiau, the petroglyphs, planting enclosures, the wiliwili wood for canoe outrigger, the Nanaku sage for woven hats, the association with famous navigators, queens and chiefs make Nu'v an ahupua' $a$ of great historical, cultural, archaeological and scenic importance (Criteria a, b, c-1, c-3, d, and e).

- The entire Kaupo district is most significant as an ancient Hawaiian place because of its many temples and structures, as a district of continuous Hawaiian village habitation, with well recorded and live Hawailan traditions, and as a significant agricultural landscape as a ranch (Criteria a, b, c1, c3, d, and e). 


\section{CHAPTER 3}

\section{ETHNOGRAPHIC FIELDWORK}

This chapter presents the data that was collected during fieldwork in the Puna and South Maui sites. Although the authors attempted to refer to as many of the thoughts and ideas shared by informants, the major themes (those that were commonly shared) were discussed at greater depth. Analyzing and processing field notes/tape recordings began with the verbatim documentation of interviews (i.e., transcribing tape recordings), extracting major themes, comparing themes across informants and with other documents, and finally, describing in this report the themes (activity, belief) that were composites of what several informants had expressed.

Informants in Puna and Southeastern Maui were presented with similar interview formats; however, the information derived from the two sites was somewhat different in terms of content. The first section of this chapter provides an explanation for these variations by geography.

\section{COMPARING PUNA AND SOUTHEAST MAUI}

Although there are numerous similarities between Puna and Southeast Maui (e.g., nural, Hawaiian past), major differences can also be drawn which accounted for variations in the types of data that were collected in the two districts. The districts of South Maui which include Kahikinui, Kanaio, and Kaupo may have once supported large, thriving Hawaiian populations, but economic changes and subsequent changes to the environment led to a major decline in these populations. At present, there are no permanent establishments at Kahikinui or persons that live there throughout the year. Many of the subsistence practitioners are from outside the district and are considered daytime or weekend users.

Between the era of major settlement by Hawaiians and until about two years ago when Hawaiians have attempted to reestablish a steady presence, there were no permanent residents. The long period of non-occupancy by Hawaiians has sociopolitical implications which determine how the area is perceived. In an attempt to reestablish ties to the district, Hawaiians have sought to identify significant historical sites, develop traditional economies, etc. Their focus, and perhaps preoccupation, is to look for connections between the past and the present. This accounts for particular themes reflected in the interview data.

Unlike Kahikinui, Kanaio sustains a few families that are permanent residents. There are symbols of an historical or ancient settlement including a church, burial grounds, and other archeological sites. Kanaio families are dependent upon subsistence resources derived from fishing and hunting activities. The area is experiencing some growth as some people with 'ohana ties are moving back. Much of the land was designated King's Lands under the Mahele and was later opened for homesteading since it was not private land. ${ }^{36}$

${ }^{36}$ The legislature of the Kingdom of Hawai'i in 1884 passed the Homestead Act, the primary purpose of which was to provide land for persons who would come to Hawai'i to live and work for a minimum of three years. In return they would be given a piece of land for a nominal fee which could 
Kaupo also maintains a small, continuous population that has been supported by ranching. Some families are turning towards tourist-related operations to accommodate hikers in the area. Much of the land is privately owned ranch land. As a rule, the major land-owner controls the local economy and settlement patterns. This, of course, determines patterns of historical and social development which is reflected in the oral histories of long-time residents.

In some respects, because of the continuity of Hawaiian communities, the situations in Kanaio and Kaupo may be more similar to Puna than to Kahikinui; albeit on a much smaller scale. There are numerous 'ohana residing in lower Puna that have strong genealogical ties to the area. The pattern of continuous settlement has meant a greater transmission of traditional practices, values, and folklore. The psychology among Puna Hawaiians may be different in terms of wanting to preserve things Hawaiian by keeping quiet about them. The tendency was to speak very generally about places and activities of significance so as to not invite people to these places. Many of the areas were still in use and public knowledge about them might lead to interference by insensitive people. On the other hand, some Southeastern Maui respondents were compelled to discuss significant areas in order to justify their presence and desire to stake their claims.

\section{METHODS OF STUDY FOR PUNA}

The investigators had originally planned to conduct approximately 20 in-depth interviews and 4 focus groups discussions of informants representing Puna. 37 As the investigators began the process of field work and data collection, it became apparent that the design needed to be adjusted according to the format or context desired by prospective respondents and the schedules and availability of those informants originally identified and those added to the list. For example, despite efforts to build trust and rapport and describe the intent and scope of the research, the investigators encountered some difficulties in eliciting information from focus groups at the beginning of the study process. It was apparent that in a group setting, more work was needed to inform and reassure participants about the study and the role of the investigators. Cultivating ties was even more critical given the controversial nature of geothermal development in Puna. The investigators modified their plans to involve more indepth interviews and fewer focus groups that were comprised of community or politically-

be paid anytime within ten years. Homestead land was seen as an added incentive to provide Hawai'i with a reliable source of labor, particularly for the sugar plantations. Lands were selected from Government Lands and set aside for the 1884 homestead program. From time to time the Homestead Act was amended by the Legislature (1888, 1890, 1892, 1898).

Previously, during the process of preparing for the "Great Mahele" in December 1847, various chiefs provided Kamehameha III with lists of lands that were said to have been Lands of Kamehameha I. The list submitted by Kekau'onohi, granddaughter of Kamehameha I, included the land of Kanaio, District of Honua'ula, Maui. Hawaiians presently living on the land of Kanaio feel particularly indebted to Kekau'onohi for having preserved this land which could then be used by Hawaiians in the latter part of the nineteenth century. When they refer to Kanaio as "The King's Land" they mean it once was the land of Kamehameha I.

${ }^{37}$ With few exceptions, respondents signed a consent form indicating that they were not concerned about anonymity or confidentiality. In the following report, there are no names used to identify sources of interview data. The project's original interviews for both Puna and Southeastern Maui will be deposited in the archives of the Hawaiian Collection, Hamilton Library, University of Hawai' $i$ at Manoa. Only those interviews for which there are signed consent forms will be available to the public. 
based organizations. However, focus groups involving 'ohana were generally successful. In these cases, the 'ohana representative usually requested that interested family members be invited to participate in the discussion.

Throughout the process, 52 individuals were contacted and interviews were requested (the investigators requested focus groups from two others representing Hawaiian organizations). Two of the individuals refused to be interviewed and three were generally unavailable during the times the investigators visited Puna. Two others, who were members of large 'ohana in Puna, requested an interview or focus group format that involved multiple family members. A total of 45 interviews were conducted. Thirty-nine of the interviews could be considered in-depth; that is, they were between 1 and 5 hours in length and the interviewer completed the semi-structured interview. Six of the interviews were less than 1 hour. Many of the interviews exceeded 3 hours in length and it created some logistical problems because they ran into the time of the next scheduled interview. ${ }^{38}$ In most cases, the interviewers completed the on-going interview and rescheduled with the waiting party. In a few cases, the informant did not show up at a scheduled interview and efforts were made to reschedule. Almost all of the interviews occurred at the residence of the informant.

Although most of the informants had 'ohana ties to the lower Puna area, many of them were not residing there at the time of the interview. Some informants had been displaced by the volcanic flows, others had moved voluntarily to subdivisions within Puna. Twenty-one informants were residing in Pahoa or nearby subdivisions (e.g., Aina Loa, Leilani Estates); 17 were residing in lower Puna (e.g., Kalapana, Kaimu, Opihikao, Pohoiki); 5 were from Hawai 'i communities outside of Puna (e.g., Hilo, $\mathrm{Na}$ 'alehu, Hamakua), and 2 were from off-island ( $\left.O^{\prime} a h u, M o l o k a ' i\right)$ (see Appendix $G$ for broader description of respondents).

A packet of information related to the HGP design was presented to respondents in both in-depth and focus group interviews. The packet included maps and diagrams of the project design so that the information presented to respondents was uniform and consistent. Informants were advised of the study process and purpose, their rights as respondents, allowed to ask any questions, and signed a consent form which verified their agreement to participate. The form served as verification that each informant understood and agreed to the use of their information and that they were given the opportunity to review and edit their contribution before it was released to the general public.

The interviews involved a number of activities aimed at eliciting information from the informant. The beginning phase generally focused on getting to know each othersometimes over food or drink (this process was especially important to the informant) and explaining to the informants who the investigators were and the purpose of the study. Near the beginning and generally throughout the interview, a large map of the district was used to enable the informants to locate subsistence areas and culturally significant sites. Places on the map were identified by using color-coded dots. This process proved to be a very useful means for collecting data, not only because it was relevant to the aims of the study, but because it offered a visual tool that informants could relate to, served as an "ice-breaker", and offered a way to indirectly ask what might be considered sensitive questions.

${ }^{38}$ The investigators conducted the interviews between Thursdays and Mondays for approximately 10 successive weeks. The scheduling of interviews was very tight because of the study time frame and the required traveling between O'ahu and the Big Island. 


\section{Focus Group Discussions}

The focus group method of information gathering was intended to allow for group interaction between informants and lead to insights into relevant issues and why certain opinions were held. It was designed to obtain perceptions on a defined area of interest in a permissive and informal environment. The four focus groups were comprised of 5-15 participants who represented 'ohana or community-based organizations. ${ }^{39}$ The total number of individuals involved in the focus groups was 34. There was no cross-over between those involved in the focus groups and in-depth interviews. The two samples were comprised of separate sets of individuals. One focus group was comprised entirely of young residents, but the others were represented by a heterogeneous mix of ages.

\section{SUMMARY OF INTERVIEW DATA}

\section{Map of Puna}

The map of Puna represents the general locations of subsistence activities, trails, and ancient sites (Figure 2). Each dot or symbol (see legend) represents a location identified by an informant during their interview. They do not reflect rates of subsistence. The dots were intentionally large relative to the size of the map in order to not reveal specific locations where subsistence occurred. The map is useful for determining important economic and cultural areas that require protection and to document Native Hawaiian use patterns throughout the lower Puna district.

As indicated on the map, fishing occurred along the district's entire coastline. Hunting occurred primarily in the mauka, forested areas, although some informants reported that pigs came down to the coastline at the east end of the district. The gathering of plants occurred throughout the district; some plants and trees were common in coastal areas, others were found in the forested mountain regions. Ancient trails were still in use by subsistence practitioners. Most of them connected mountain and ocean areas. A variety of archeological and cultural sites were identified by informants. These included heiau, grave sites, housing sites, fishing ko'a, rock walls, and natural features that were referred to in chants, folklore, and olelo noeau (poems).

\section{Principles of Subsistence}

The findings from the in-depth interviews with informants who were primarily Puna residents revealed that traditional subsistence activities were an integral part of their existing lifestyle and a viable aspect of the economy. The information provided in this section was presented in past tense, which reflects the writing style of the authors. It is important to note that this does not imply that the activity occurred only in the past or that it has ceased to exist. During the interviews, informants were asked to describe the activities they presently engage in.

Several principles and aspects of subsistence were discussed which served to regulate resources and reinforce family and community cohesion. A critical guiding principle

${ }^{39}$ The size of some focus groups, especially those involving 'ohana, was difficult to determine because participants were coming and going during the course of the discussion. The number of participants reflects all that were at one time present. 
was to never take more of a resource than was needed. Families engaged in subsistence when supplies (fish, meat) were running low or for special occasions (e.g., luau, graduations). The amounts taken depended upon family size. Obviously, a larger family required a larger quantity of a resource. The bulk of the food consumed by families came from some form of subsistence, although staples such as rice and other miscellaneous food items had to be purchased in Hilo or other nearby towns. The traditional diet was comprised of carbohydrates which came from the cultivation of kalo (taro), uala (sweet potato), and ulu (breadfruit), and sources of protein which came from fish and seafood, pigs, goats, and wild cows. Wild donkeys were also hunted at one time.

The availability of certain varieties or species of flora and fauna varied according to seasons or cycles. For example, certain species of fish (' $u$ ' $u$, ahi) were more abundant during the summer months, the pig population was cyclical according to roaming and reproductive patterns, and maile underwent periods of dormancy and regrowth according to the cycle of rain. Traditionally, when resources in a particular area dwindled because of overuse, that area was kapu or restricted to further usage or harvesting in order to allow for regeneration.

The resources were always abundant and readily accessible to those who possessed the knowledge about their location and skills required to obtain them. 40 Knowledge about subsistence was passed down intergenerationally. Subsistence areas were understood in terms of boundaries and used by "ohana who lived within close proximity to an area. These 'ohana were traditional stewards who had jurisdiction and inalienable rights in that particular resource domain. Others who wished to use the area exercised good manners and respect by asking their permission. Respect for other peoples' subsistence domains appeared to the more prevalent among hunters and gatherers. Fishermen, on the other hand, generally said they traveled the coastline in search of fish and other ocean resources. If one stop along the coast did not furnish a catch, they would move to the next place. Some informants, however, who lived along the ocean said that they watched for trespassers and warded off fishermen who entered their property without permission.

Traditional knowledge regarding techniques used for obtaining resources was based on an intimate understanding of the behaviors and predilections of animals, fish, and plants. Hawaiians were taught by their elders how to read the natural conditions (e.g., clouds, moon, water, animal behavior) to determine the best times to go fishing. The life cycle of mountain plants were also correlated to particular ocean conditions (e.g., wiliwili in bloom determined that sharks were feeding in nearshore waters).

Some informants subsisted according to traditional protocols that were tied to a "right" state of mind or spirit that placed them on a plane that was acceptable to the spirits and increased the potency of the resource. One informant stated:

When I pick flowers or medicine, I take the knowledge that my father taught me. What hand to pick with, the whole process of knowing. There's a oneness - the whole mind and body has to be centered on the medicine and how its gonna be used. You cannot think about anything else. It opens the channel, what you give out to that source. Be focused only on one thing,

${ }^{4}$ Most informants reported that over recent years they had observed a relative decline in the amount of resources. Although they were aided by new technologies (e.g., faster boats, 4 wheel drive trucks) informants believed they had to put in time and effort to obtain the desired or comparable amounts of a particular resource. 
even making leis is the same concept. The whole time, while picking flowers, I was thinking about it ... that's how my ancestors did it. That spiritual ness is carried on from generation to generation.

Subsistence was an activity that bonded ohana and communities. The activity required collective action and resulted in mutual economic gain. Subsistence served as a basis for sharing, gift-giving, and trade. Informants described a process where, after a successful hunting or fishing expedition, the young men would make stops at the homes of family or friends, dropping off meat or fish along the way. By the time they reached home, they had only enough to feed their immediate family. Older people who were unable to engage in strenuous subsistence activities were especially reliant upon this process of communal sharing. In earlier years, they were the benefactors in the same process. One older respondent said that he taught his children how to hunt and fish and now they supply him with all that he needs.

Most of the informants we talked to expressed concerns about the decline in subsistence resources for reasons related to population growth in Puna, the onslaught of newcomers who violated traditional conservation practices, and the destruction of natural ecosystems caused by housing developments and clearing the forest for agriculture (e.g., papayas). The diminishment of natural ecosystems and resources confined Hawailans to smaller areas for subsisting, increased competition and placed a higher premium on the resources, and contributed to a general attitude described as "I better take all I can because the next guy is gonna take it all." One person explained the process:

When new people came in, some were hippies, some were regular haoles. They learned how to subsist because we taught them how. That's the aloha spirit. We gave to them because we were taught to. We respected them, but they didn't respect us. They used and abused us. The same thing happened with hunting. People came in and shot the pig and left it. It hurt us very much because that is our food.

Many of the informants discussed differences between Hawaiian and western culture. For example, one informant said that living off of the land was the Hawaiian way of life. Westerners, on the other hand, tend to destroy their natural environment and have to seek meaning in life by returning to nature. She cited the example of Outward Bound programs that used to be held at the National Park. In this program, young people had to prove themselves by surviving the elements of nature for one night. To Hawaiians, nature was not perceived as a threat but as a provider, and these programs were based on a foreign understanding of how humans relate to the environment.

The commercialization of resources was cited as a primary cause for the decline in the availability of resources. Both locals from outside of Puna and newcomers were held accountable for taking too much and making a profit from sales which came at the expense of long-time subsistence practitioners.

Many Hawaiians also described how sites or areas (e.g., steam bath, beaches) had been taken over by hippies or Rastafarians who had recently moved into the district and were generally insensitive to the cultural significance of traditional places. Some informants expressed a strong desire to keep sacred sites secret because of fears that the newcomers would misuse them and apply wrong interpretations to their meaning. 
Those who engaged in subsistence never talked openly about their plans prior to going. Hawaiians believed that everything around them in nature had the ability to hear and would therefore wam the intended victims (e.g., pig, fish). To talk openly in planning a subsistence activity would bring bad luck. Even when driving along the coastline during a reconnaissance, informants said they never verbalized to others in their group when they saw a place that might be good for gathering or fishing. They would return during the night or at a good tide to try their luck. Hawaiians would use code words such as "holoholo" which meant they were going fishing or hunting. Other beliefs concerning behaviors that would bring bad luck included taking maia (banana) fishing, to not let the first catch go (i.e. one should return the first fish caught to the ocean guardians), taking more than was needed, and not expressing gratitude to the deities after a successful subsistence expedition. It was believed that the deities loathed those who appeared to be greedy or ungrateful and punished them by ensuring that their successive activities would end in failure.

\section{Spiritual Beliefs and Practices}

Most of the informants in our survey identified themselves as Christians, yet held another set of beliefs that was consistent with traditional Hawaiian spiritual beliefs. For example, although they regularly attended Christian church, most informants mentioned that prayer to a Hawaiian god or deity was a ritual part of their subsistence. They prayed for good luck before an activity and they prayed to express gratitude for a successful catch. Some informants were more deeply involved in Hawailan spiritual beliefs. They regularly acknowledged the presence of deities and asked permission to enter or take resources from their domain. With a few exceptions, all of the informants in our survey said that they believed in and respected Pele. Natural elements that were considered manifestations of the deities included: Moana (ocean), La (sun), Ua (rain), Ao (clouds), and Honua (land). Prayer to the deities was used to protect them from the elements and help them when they were lost or stranded. The concept of reciprocity was an important part of this general belief system. The land or "aina was the provider, and the tenants who were beneficiaries of these resources were obliged to "malama" or take care of the land. On some occasions, users would offer chants, "ho"okupu," or a symbolic offering to pay respect to the deities; or in other cases, they would clean an area or even encourage the growth of a wild resource (e.g., maile) by providing food and water to insure its continued health and regeneration.

Some of the informants expressed maintaining a relationship through prayer or direct interactions with their aumakua or ancestral god. These family gods were long-departed ancestors who offered protection and assistance to Hawaiian families in Puna. The aumakua took the form of animals, plants, or even inanimate objects (e.g., rocks). The aumakua that were identified by informants in our survey included the mano (shark), mo 'o (lizard), and pueo (owl). Family members were expected to learn their aumakua, their functions, dwellings, and "kino lau" or different form. An 'aumakua had the ability to change from an animal to a corresponding plant form. There were noted associations between plant and animal forms which were different attributes of the same life force.

Other supernatural beliefs that were expressed by informants concerned the night marchers who were ancestral ghosts that frequented the old Hawaiian trails in Puna. Night marchers were generally encountered at night as a procession of torch bearing spirits accompanied by the sound of drums or music. Those that happened upon them had to jump off the trail and hide or bury their face in the ground to avoid being hurt or killed. If you were recognized by a night marcher who identified you as family, you were spared. One informant mentioned that when he would go night fishing in an area now within Volcano National Park, 
they would see a series of torch lights along the coastline, although they knew they were the only people camping in the area.

There were other spirits described that were devious and intended to do harm to the unwary. There were spirits in the forest that called your name and tricked you into following them. If you followed them you would get lost. For this reason, Hawaiians were taught to never call each other in the forest. Other spirits or ghosts would roam around people's yards with the intention of causing them harm. Some informants said they would throw salt around their yards to ward off these evil spirits.

\section{The Goddess Pele}

References to Pele occurred throughout the interview process. Beliefs in Pele fell on a continuum from active worship to no belief at all. In general, informants did not actively worship Pele but held a high reverence for her. Some informants believed that transgressions against Pele would lead to punishment. For many, the force and spirit of Pele was undeniable because it was so visible through the frequent volcanic eruptions in the area. There were many stories about Pele that were shared by informants who related direct or second hand experiences. One informant shared:

When the 1977 flow came, our house is here (shows on map). There's people that drove by and when they came close to the church they saw, right by the end of the road, a lady who was dressed in red. They asked her if she needed a ride. She said no. She lives just on the mountain. At this time it was all for est. As they drove and looked back in the mirror she wasn't there. When they came to the church, they looked up and it [lava] was flowing. They saw the lady walking on the lava. They got excited-told everyone in the village.

Pele was also a deity that many gatherers and hunters acknowledged before entering the forest and thanked after a successful expedition. Some reported taking offerings of food into the forest for Pele. Her spirit was there to protect and nurture those who demonstrated respect for her, or possibly harm those who showed disrespect or acted inappropriately. Some believed that the lava flows represented her way of telling people that they were not properly caring for the land. A few informants believed that her "taking" of Queen's Bath was the result of too many people going there to use it and not giving anything back. If people did not malama the 'aina, then Pele had a way of cleansing it by restoring it to its most primal form.

\section{Trails and Access}

Informants mentioned a number of trails in the Puna District that generally extended from mauka to makai (see Figure 2). These trails provided access to traditional subsistence or recreational areas. One trail was said to begin in the west end of the district and extend all the way to Hilo. In the old days, residents would ride horses back and forth to get supplies. Other trails that ran from east to west were generally hunting trails. Although numerous trails were identified by informants on the map, very few were referred to by an exact name (many were referred to by the ahupua'a name). One exception was the Malama Trail. A couple of informants described it as starting by the crater in Kapoho and running to the ocean. The older people used it to go to the beach. Although some of the trails apparently crossed over privately-owned lands, access to hunting and gathering areas was not identified as a problem. A common way of accessing an area was to use a four-wheel drive vehicle to get to a 
particular point on a road, and then hiking in the rest of the way. Many trails, however, were not large enough to accommodate vehicles.

\section{Fishing}

Virtually every informant in the survey engaged in fishing, or in the case of older informants, had at one time fished and still benefited from the catches of younger family or community members. Although many informants had their own special or favorite fishing spots, most said that they fished the entire coastline from the east at Paradise Park or Kea'au, to the west well within the existing National Park boundaries. ${ }^{41}$ With the exception of those with boats who could fish the deeper waters, most of the fishing occurred along the relatively shallow areas off of the rocky coastline. The techniques included throwing net, laying net, whipping (casting), and dunking (still fishing). Some informants stated that they went diving for fish on calm water days.

Those informants who had boats and fished either for subsistence or commercially, fished 1 to 2 miles offshore for ahi and aku primarily in the spring and summer, or closer to shore at about 600 feet for bottom fish. They primarily used hand lines to catch fish from the boat.

Fishing occurred throughout the year (when the water was calm), although some species of fish are more common during the summer months, generally when they are spawning. For example, akule, which schooled together in bays, were more abundant during the spring and early summer months. 'U'u were more commonly caught during the summer and at night during a dark moon.

Some of the fishing grounds, especially west of Kaimu, were affected by the lava flows. Areas that use to have excellent moi holes were destroyed by the lava which altered the contour of the ocean floor. The changes have also contributed to decreased visibility which made it difficult to dive for fish in those areas. Some informants, however, said that ulua fishing was still very good in the areas affected by the lava.

In general, the fish caught were eaten raw, perhaps mixed with Hawaiian salt and limu, or cooked a variety of ways (wrapped in ti-leaf and steamed or puleu, or fried). A common way to prepare fish that were caught in abundance was to dry them for future use. When fishing in remote areas (e.g., National Park), Hawaiians would quickly clean, salt, and dry their fish to avoid spoiling during their long journey home. One informant reported that he only ate fish with white flesh because he was a descendant of ali'i (chief).

41 Approximately 150 lower Puna Hawaiian families that were displaced by the creation of Volcano National Park have fishing and hunting rights within the park boundaries. Those using the park for subsistence purposes are required to have a permit. 
The types of fish that informants generally caught were (see Appendix $\mathbf{H}$ for description of each species):

\begin{tabular}{llll} 
Akule & Ehu & Manini & Uhu \\
Aholehole & Enenue & Moi & Oouoa \\
Ahi & Kala & Opakapaka & Uu \\
Aku & Kole & Opelu & Weke \\
Aweoweo & Kumu & Papio/Ulua & \\
\hline
\end{tabular}

\section{Ocean Gathering}

Fishing was an activity that generally involved multiple family members or an entire 'ohana. Some 'ohana went fishing exclusively (especially if the method was labor intensive), while others engaged in a variety of subsistence activities, including ocean gathering. Ocean gathering involved prowling the waters edge in search of limpids and other shellfish, or wading the shallows in search of limu (seaweed). Generally, the best time to gather these ocean resources was during low tide and/or during a dark moon phase.

Gathering along the rocky shoreline was very hazardous because one tended to be preoccupied with their activity and oblivious to the errant, large waves that came crashing on the rocks. As a rule, Hawaiians were taught to never turn their backs to the water because of this threat. Some informants mentioned that they always threw their first catch (e.g., opihi) into the ocean as an offering and a way to gain protection from the waves.

There was a lot of concern expressed about diminishing shoreline resources. The decline was attributed to over-harvesting, especially by those who were from outside of Puna and insensitive to traditional conservation practices. For example, outsiders or newcomers who often gathered for commercial purposes were said to employ harvesting techniques that did not allow for rejuvenation (e.g., picking limu by the roots instead of cutting at the bottom) or taking undersize juveniles that were too young to reproduce (e.g., taking dimesize opihi).

The types of ocean resources that informants reported gathering included (see Appendix I for description of each species):

$\begin{array}{ll}\text { A'ama Crab } & \text { Opihi } \\ \text { Kupe'e } & \text { Ula } \\ \text { Limu } & \text { Wana } \\ \text { Opae Ula } & \end{array}$

\section{Forest Gathering}

Hawai'i's conditions regarding soil, climate, competition with plants and animals, and isolation by mountain ranges or bodies of water served to produce a highly unique environmental situation for the evolution of plant life (Degener, 1975). Consequently, Hawaiian flora consists of plants that have been so changed by local conditions from the ancestral structure that they are now recognized as being endemic or peculiar to these islands. According to gatherers, the same plant species also varied between the Hawaiian Islands and even between certain districts of the same island. The plants in Puna were believed to be special 
because of their colors, shapes, and fragrance, and they grew in an expansive rainforest that was fed by unique natural and spiritual elements. 42 For this reason, Puna was a favorite gathering area for hula halau on the Big Island and throughout Hawai'i.

Plant gathering occurred throughout the year, although some species had cyclical qualities regarding dormancy and regrowth. Maile had periods of regrowth according to the rains; yet if one picked its leaves throughout the year it would continue to provide new growth. It was important to not pick all of leaves so as to not kill the vine. The various fruits were gathered seasonally according to when they ripened. Some respondents reported that they altered existing environmental conditions in order to create a habitat that was ideal for a particular plant to grow. For example, one respondent reported that maile thrived in wet places where it was not constrained by competing plants and he encouraged maile growth by clearing away other plants.

The gathering of plants served many important cultural purposes. Plants were consumed for food and medicine (e.g., the bark of the root of the uhaloa was used for sore throat), used as tools and building materials, art, and adornments. Informants generally had distinct areas or secret places where they gathered plants; others who wished to venture into these areas were obliged to ask permission.

Maile was often picked for special occasions like birthday parties or graduations. One had to journey to the higher regions because it didn't commonly grow in the lower elevations and more people were picking it commercially. It was picked in numerous areas including the Kaimu forest and in Wao Kele O Puna. One informant wasn't sure how far she ventured into Wao Kele $O$ Puna because there weren't any boundary markers, but knew she was there because of the density of the forest and changes in temperature. Some of the pickers said that they often gathered plants such as maile or lama because of requests by other Hawaiians from outside Puna who wanted to use it for dedications, festivals, temples, or "ho'okupu" (offering).

Herbs were once gathered from all along the sea coast of Puna. One informant mentioned that they were no longer as plentiful because of recent land developments, but they were still plentiful in the forest reserve area. Those who engaged in la'au lapa'au (herbal medicine) were dependent upon a healthy forest where they could gather native herbs and plants. They reported that the plants gathered in Wao Kele O Puna were essential to their practice and possessed a quality and potency unlike that found anywhere else.

Large tracts of forest had vanished under recent lava flows or been plowed over in favor of subdivision development. The disappearance of forested areas or the loss of access to traditional grounds placed a higher value on remaining areas. Those displaced by the loss of plant resources, who were seeking new areas, and the intrusion of those from outside Puna placed greater strains on not only the resource but on traditional protocols regarding an understanding and respect for tenant rights. Wild animals were also blamed by some gatherers for some of the damage. Pigs were not known to eat maile but sometimes dug them up by the roots. Wild cows ate maile when they were desperate but became ill because of

\footnotetext{
${ }^{42}$ One informant said that the $a^{\prime a}$ ali' $i$ that grew in Puna had larger capsules and was not as tightly packed as in other places. There was also a type of laua 'e that didn't have dots on its underside and others that had round and stubby leaves. The maile found in Wao Kele O Puna was said to have longer leaves.
} 
the sticky residue. Many informants suggested that hunting was the most viable means to control the wild animal population and maintain a healthy rainforest.

The types of forest resources that informants reported gathering included (see Appendix $\mathrm{J}$ for description of each species):

\begin{tabular}{llll} 
A'ali'i & 'Ie'ie & Niu & Palapalai \\
Awa Kolo & Laua'e & Noni & Pink Opiko \\
Forest Flowers & Lauhala & Ohia Lehua & True Koli \\
Guava & Maile & Orange & \\
Hapu'u & Mamake & Pa'iniu & \\
Ko'oko'olau & Mango & Pala'a & \\
\hline
\end{tabular}

Hunting

The hunting range of Puna residents was very broad. It extended from well within the National Park (for those with permits) to the shoreline areas of Nanawale. The hunters were primarily after pigs but also hunted wild goats and cows. Some informants also reported hunting wild donkeys in the past. All of the animals hunted were, at some point in history, introduced to Hawai'i generally as domesticated livestock and eventually escaped or were turned loose and became feral. Hunting occurred year round and was the primary means for obtaining meat for families. Although there were reports of some hunters selling pig meat commercially, the threat of trichinosis dissuaded many from doing so.

Some informants reported going hunting as often as every day or every other day. They were responsible for and expected to provide meat for their 'ohana or extended family. One or two young men would hunt pigs and divide the meat up between the 'ohana. Some hunters also mentioned that they shared the meat with neighbors and other community residents who were older and unable to hunt. Sharing the meat was tied to a belief that if one were generous with their catch, the supply would always be there. Even if the catch was low, the hunters still shared with others. Greed was believed to be punishable by poor hunting or bad luck. When the hunt was successful, the hunters generally thanked the 'aina.

The methods used in hunting varied from guns to knife and dogs. Larger animals such as wild cows, which were considered dangerous, needed to be shot and killed. Many pig hunters used a method of trained dogs who chased and pinned down a pig. The dogs were trained to catch the pig and only attack the head and rear of the animal so as not to damage the meat. The hunter would follow the dogs and stab the immobilized pig in the heart. This method was an efficient way to hunt although it took a toll on the dogs. Hunting dogs were often injured by pigs, lost in the fissures or in the dense rainforest. Some hunters said that they spent days looking for a lost dog.

Animals were cleaned and dressed in the area where they were killed. In most cases, the meat was packed up and loaded onto the hunters back who then had to hike a long distance to a four-wheel drive vehicle. Because of the heavy load, hunters were cautious to not kill large animals (wild cows) or more than they could carry a long distance unless there were several men.

The meat was prepared a variety of ways. One of the most common preparation methods was smoking the meat which was also thought to be a way to kill trichinosis. Some 
hunters had smoke houses in the back of their property and they used wood gathered from the forest or lava flows to smoke their meat in a process that took several hours. Another traditional method was to use imu or underground ovens. The imu was comprised of hot rocks (heated by fire for 2-3 hours) placed in a pit and covered with crushed banana stumps; the pig was.placed on top of the stumps, covered with ti and banana leaves, and cooked for several hours depending on the size of the pig.

The pigs were said to roam in packs throughout the Puna district foraging different areas and evading hunters. Hunting was at times sporadic because the pigs migrated to places outside of one's traditional hunting area. In such cases, hunters waited until the pigs moved into their hunting domain or often captured live pigs, raised them to a desired size, and slaughtered them for food. Some hunters claimed that when the waiwi (small, guava-like fruit) ripened, the pigs were found in areas where they grew. During the dry season, the pigs stayed near the watering holes.

Although only a few hunters ventured into the area of Wao Kele $O$ Puna, it was considered an essential place for animals, especially pigs, because it served as a refuge and place to bear their young. Consistent with the Hawaiian concept of refuge, pigs and other organisms that were being pursued required time and safe haven to rest and rejuvenate. Because the upper Wao Kele $O$ Puna was remote and difficult to access, pigs were offered safety from hunters. One hunter described the arduous hike through the lower part of the district as "walking over soft, brittle lava and dropping one foot with every step to get to the place where the pigs stayed." For many, hunting in the area wasn't worth the effort because pigs were available in other places. But some respondents stated that in order to ensure a future supply of pigs, this area that was seen as an essential breeding grounds for pigs needed protection from development.

\section{Cultivation}

Many informants cultivated plants for food and materials in areas surrounding their house or, in some cases, on tracts of land that required a long hike or travel by four-wheel drive. The types of plants or trees that were grown around the yard included kalo (taro), 'uala (sweet potato), maia (banana), ulu (breadfruit), kukui (candle nut tree), niu (coconut), papaya, lauhala (screwpine), noni, ti, etc.

Some respondents used tracts of land they owned inside Kamaili to cultivate dry-land kalo. The planting, harvesting, and preparing of kalo was a family effort and a way to provide families with poi. About every three weeks the 'ohana would get together to plant, harvest, and make poi. Each family would go home with a generous supply of fresh poi which was becoming more expensive in the stores. Another reason for growing kalo was to teach younger ohana members about traditional cultivation techniques of Hawaiians.

Traditionally, the kalo was a staple in the Hawaiian diet and symbolic of the culture. For example, from the corm of the plant, which represented the parent, grew off-shoots which represented children. The entire plant system represented the ohana. The kalo grown today are descendants of those brought over by the progenitors of the Hawaiian race. The propagation of the plant is symbolic of how Hawaiians came to the islands and spread over the land.

The entire kalo plant furnished food. The root was cleaned and baked in the imu or boiled, peeled, and sliced; or it was made into poi using a papakuiai (wooden trough) and 
pounded with a pohakukuiai (stone pestle). ${ }^{43}$ Kulolo was a pudding made of grated raw kalo and the juice from grated coconut meat. The leaves of the kalo were wrapped around meat or fish, covered with ti leaves, tied with string, and steamed to make laulau.

Ulu was eaten in much the same way. It was cooked in the imu, peeled and sliced, or mashed into a gruel-like paste. 'Uala was often baked in the imu, peeled, mashed, and mixed with coconut milk.

Ti was a plant that had multiple uses and was of great value to Hawaiians. The leaves were used to package food for travel, to contain and buffer food during cooking, and to made into skirts for hula. The ti was considered sacred to the god Lono. It was a symbol of high rank or divine power and was often worn around the neck of the kahuna (priest). It was considered a charm against evil spirits. Because of the superstition that those partaking of cooked opelu would otherwise suffer from a rash, some ti leaves were customarily tied around the tail of the fish. Ti was also used to wrap ho'okupu which was delivered as offering to various gods or deities.

The kukui was used in many different ways. The oil from the kukui was used in candles to illuminate houses and used as torches for fishing and other night time activity in the olden days. The nut was roasted and mixed with sea salt to make a relish. The sap had medicinal qualities when rubbed over the infected or cut areas of the mouth and other parts of the body. The shells were used as necklaces and other adornments.

Much of the good, cultivable land was used by the plantations to grow sugar. Since the decline of the plantations, land suitable for agriculture has been covered by lava flows, developed into subdivisions, became private property without access, or was used to grow papaya. The prospect of using broader parcels of land for growing traditionally used plants is weak and relates to the reason why most of these plants were mainly grown around the homes of informants.

\section{Hawaiian Rights}

Numerous Native Hawaiian rights are guaranteed under state and federal law, and with regard to their national land base-the Hawaiian Home Lands and the Ceded Public Lands Trust. Any development or change in the uses of natural resources must take into account the potential impact upon the free exercise of Native Hawaiian rights. The rights of Hawaiians residing in Puna may be at risk with the development of geothermal in the region. The following is a list of rights that may be in dispute.

Ahupua'a Tenants Rights - these rights, which were expanded in 1978, affirm and protect all rights, customarily and traditionally exercised, for subsistence, cultural, and religious purposes and possessed by ahupua'a tenants who are descendants of native Hawaiians who inhabited the Hawaiians Islands prior to 1778 , subject to the right of the State to regular such rights.

Access Rights-ancient Hawaiian ahupua'a tenants needed access to the mountains and sea and along shorelines in order to fish, gather, and cultivate crops and to

\footnotetext{
${ }^{43}$ Although some Hawaiians still pound their poi the traditional way, most of the poi made today is processed by machine.
} 
communicate with neighboring ahupua'a tenants. In general, there were two kinds of trails to meet these needs. One kind of trail ran vertically from the mountains to the sea and the other ran horizontally, mostly along the shorelines. Hawaiian ahupua'a tenants can assert constitutional claims to the use of ancient Hawaiian trails under Article XII, Section 7, of the state constitution which protects Hawaiian customary practices exercised for subsistence, cultural, and religious purposes.

Fishing Rights -aside from the rights Hawaiians can claim as members of the general public to the use of fisheries, Hawaiian ahupua'a tenants have a unique constitutional claim to the use of fisheries adjacent to their ahupua'a under general language of this section protecting rights customarily and traditionally exercised for subsistence and cultural purposes.

Freedom of Religion - both the State and the United States constitutions have a provision which forbids the enactment of laws prohibiting the free exercise of religion. Another constitutional claim to freely exercise ancient Hawaiian religious beliefs can be asserted by Hawaiian ahupua'a tenants. The American Indian Religious Freedom Act of 1978 ensures that actions taken or licensed by federal agencies do not interfere with the inherent right of individual Native Americans, including Hawaiians.

Burials-the Hawai'i constitution provides a general guarantee protecting cultural and religious practices of Hawaiians and Hawai 'i's historic preservation law offers a comprehensive and detailed scheme for specifically protecting ancient Hawaiian cultural and religious sites, such as burial sites and heiau.

Act 306, enacted in 1990, amended the existing preservation law to uphold the common law rule that a private land owner does not have the right to possession of human skeletal remains found on his private property. Instead, the landowner will be treated under the statute as holding the remains "in trust" for cultural descendants who have the right to possession for purposes of proper cultural preservation or reinternment.

Water Rights - Hawaiians who want to cultivate taro and engage in other subsistence practices requiring the use of substantial amounts of water can assert three different kinds of rights to water. All three are based on customary use and common law doctrine and all three are guaranteed under the state constitution and the state water code found in the Hawai'i Revised Statutes. Two of these water rights are based on tradition and customary use and common law doctrines known as "appurtenant rights" and "riparian rights." Hawaiians who qualify for Hawaiian Home Lands under the Hawaiian Homes Commission Act of 1920 have a unique third claim to water and homestead land recipients.

Ceded Lands - In 1959, Hawai'i became a state under the Hawai'i Admission Act. Section 5(b) of the Act provides for the return of land supposedly acquired by the United States at the time of annexation from the Republic of Hawai' $i$. Approximately 1.275 million acres became the property of the State of Hawai' $i$, to be administered as a public trust for the following purposes: support public schools and educational institutions, improve conditions for Native Hawaiians, develop farms and home ownership, make public improvements, and provide lands for public use. Another 200,000 acres set aside for Hawailan Homelands in 1921 was also transferred to the State of Hawai'i. 


\section{PERCEIVED IMPACTS OF HGP}

There existed a general belief that Puna should not be responsible for other peoples' energy needs. Residents in this district felt that they had to bear the brunt of the impacts so that those living in other areas, even other islands, would have their energy needs met. Some informants believed that, in effect, they had to pay the price for overdevelopment and fueling a tourist-based economy that they had misgivings about.

The perceived impacts of geothermal development on the practices and beliefs of Puna residents were numerous and varied. It is important to note that the impact issues that were discussed by informants were from a sample of residents who fit the criteria for sample selection. That is, they were members of established Hawaiian 'ohana from Puna, subsistence practitioners, cultural bearers, etc. The perceived impacts were, therefore, most pertinent to the activities that comprised their lifestyle. There were numerous other issues that the investigators became aware of that were not reported to us directly from the informants and were often outside the range of their direct experiences. Many of these issues related to con cerns that tended to be more technical in nature or based on a western scientific perspective.

Most of the informants, especially those who were subsistence practitioners, believed that the development of a 500-megawatt geothermal project would have severe impacts on Puna's environment and the way of life for their 'ohana. Using the existing 25-megawatt Puna Geothermal Venture (PGV) as a frame of reference, some informants imagined that the impacts of the proposed 500-megawatt development would be devastating to the rainforest and spell an end to Hawaiian subsistence activities that were already being hampered by diminishing environments and resources. The loss of subsistence and other cultural activities would mean the loss of "hands-on" learning for Hawaiian children. One informant believed that the classroom would become the only place to learn how to be Hawaiian-and that was a major problem because knowledge would be taken out of context.

A few informants who believed that the impacts would be minimal were not as actively involved in subsistence activities, had family members employed at PGV, and welcomed the idea of cheap geothermal generated electricity and other modern amenities in their homes. These proponents of HGP believed that the steam from the vents was not toxic but actually good for peoples' health. Some mentioned that, as children, their parents would take them to the rift zones and have them inhale the steam in order to cure colds and other respiratory ailments.

It is important to note that the volcano naturally emits sulfur dioxide which is relatively innocuous, while the substance emitted from geothermal drilling contains hydrogen sulfide which is highly toxic in large doses. One informant believed that the gases released by geothermal drilling was too raw and potent because it was not allowed to filter naturally through the rocks before reaching the earth's surface.

Proponents of HGP also believed that those Puna Hawaiians who opposed the HGP were less worldly and too attached to old ways, exaggerated or over-romanticized the role and meaning of subsistence, and were unwilling or unable to accept the advantages offered by modern technology. The positive impacts cited by informants included cheap or free electricity provided to Puna families, employment for family members in the future, and a general trend towards modernization throughout the district. 


\section{Desire to Return Home}

An issue that was raised by lower Puna residents who were displaced by recent volcanic lava flows was that they had every intention of returning to their home when it was declared safe to do so or when the infrastructure was created to allow them to regain access to their property. Some homes were destroyed; others lost their access routes to the lava flows. Those who were displaced believed that their situation was temporary and they would someday return and resume their traditional way of life. The fact that they did not actually reside in Kalapana at the time should not be used as a reason to assume that the landscape and resources could be altered without having a negative impact. One informant who lost access stated:

People don't believe we want to go back home. You'd be surprised at the amount of families that want to go back to Kalapana, Kapa'ahu, Kaimu. This isn't my home (subdivision near Pahoa). I'm a malihini here (foreigner). I'm ashamed to be here. I want to go home. I want to be able to live without hav ing anybody bothering me. People don't understand what it means to take away a community. I would rather die than have to live someplace else.

\section{Perceptions by Age}

There were discrepancies between the perspectives and opinions of some older informants and some younger informants. Some of the older informants believed that HGP would provide jobs for younger Hawaiians in Puna. Because there wasn't much economic activity in the region outside of agriculture and subsistence, younger people who wanted to remain in the area would be provided a new employment option. Most of the younger informants, however, rejected the idea of geothermal development. It was not their "economy of choice" and they generally preferred living according to a subsistence-based economy and lifestyle. Some younger informants stated that their peers who had gone away to college planned to return to Puna after receiving their degrees and some job training. Younger people who had an aptitude for a formal western education wanted to leave Puna temporarily to gain new experiences and to see the world-but their commitment to Puna was very strong and they would eventually return. Informants claimed that the out-migration of talented youth should not be interpreted as a permanent loss of this sector, but as a means to ultimately bolster the technical "know-how" of the community as they would return with new skills.

Some believed that it was unfair for older residents to make a decision about the future of Puna because their time had passed and younger people would have to live with the consequences of geothermal development. A number of the younger informants, some of whom were not living in Puna, stated that they wanted to raise their children in Puna and ex pose them to the same community and subsistence practices that they experienced growing up.

Even though it had been surmised that geothermal development would provide more jobs for Puna residents, many informants felt that the best jobs would go to outsiders who had specialized engineering skills and local Puna people would be left with the lowest-paying menial labor positions (e.g., maintenance, security). Some believed that these jobs were also the most hazardous and workers would be prone to injury. 


\section{Impacts on the Forest}

A primary concern among hunters was how the clearing of the rainforest would destroy the habitat of the pigs. A few informants expressed specific concerns about the impacts of geothermal development on the pigs in Wao Kele $O$ Puna. They believed that the destruction of the rainforest in this area caused by developing drilling sites, access roads, and even the leakage of harmful chemicals would mean the loss of a critical food source and cultural activity. Some hunters believed that noise and human activity at the existing geothermal sites served to drive pigs away from the immediate area. This was an indication that geothermal and wild game would not co-exist and that the more expansive proposed devel opment would have devastating affects on this resource.

When discussing the issue of HGP impacts on the resources, practices, and beliefs of Hawaiians in Puna, many informants referred to what could be described as a cycle of change or an entire system that becomes vulnerable because one part of it is damaged. These informants claimed that it was difficult to predict or assess impacts as separate aspects because natural and cultural phenomenon were integrally related. Changes in one part of the system would have reverberating affects throughout the system and affect each element and organism, including humans. For example, if the rainforest were damaged, the clouds carrying rain would disappear, thus the water that nourishes the plants and trees would cease; the animal life that depends on the forest and water for sustenance would perish along with subsistence activities. From another perspective, many informants believed that if humans exploited or did not malama the 'aina (take care of the land), the gods would no longer provide for them.

Concerns were also expressed about the decline in the native bird population which was thought to indicate that the forest was under duress.

\section{Caretakers of the Land}

Environmental impacts were difficult to assess without considering the cultural and spiritual impacts as well. Some informants believed that they were sanctioned to be the caretakers of their ancestral lands in Puna. Part of this notion was tied to a sense of responsibility they had to their kupuna (elders) who had taught them how to live as Hawaiians. The kupuna had passed onto these younger informants an ancestral knowledge that emphasized co-existence between humans and other natural elements. As the latest generation to possess this knowledge, they viewed themselves as the proprietors of Hawaiian culture. One informant stated:

What I believe is, $I$ live in this area and anything that happens above me [in Wao Kele O Puna] will affect me. Spiritually as well. There's more to it than just picking plants. Its more than what you can see. There is a spiritual aspect to it-a reason to leave certain areas the way it is, not abuse and taken away by man. Some areas have to exist the way they are, in order for the culture and people to remain alive. When ancestors die, they leave something behind, whether its visual or spiritual. I believe my ancestors put it [knowledge] into us so that the land would be able to survive. And we would still be able to keep in touch with being human.

Other informants took a more apocalyptic view. If their beliefs and practices were to be eradicated by geothermal and other "irreverent" forms of development, the culture and 
people would follow a similar path of decline. One informant who inherited the beliefs of his forbears and was a Pele worshipper felt that it was his filial duty to continue this line of spiritual belief. If geothermal development detracted from the manifestations of Pele, then it might sunder the beliefs that he hoped to pass onto his children. He believed that the loss of that critical link between active worship and a living god would spell doom for Hawaiians.

\section{Advantages Versus Negative Impacts}

Some of the informants rejected the idea that geothermal development would provide a cheap source of energy. Even if it did, the cultural price they would pay would not be worth the advantages it might bring. One informant believed that the traditional way of life without electricity offered many advantages. She said:

If somebody told me it will benefit you and give you electricity, we have generators, we have solar energy. The sun provides for us. When I was little we made sure we did our homework before it was 4:00, before it got dark. Orr chores were done. There's no such thing as T.V. being on just because it was there. We hardly ever watched T.V. We listened to the radio during the day time. At night, after you eat, you had family time. You'd pray and then you'd talk story about the day.

Even when they offered us geothermal energy, we didn't hook up. We stayed with the generator. Only the people close to the highway went with electri city. They didn't have to pay extra. You grow accustomed to how the generator sounds. If geothermal was to happen, we would not have peace.

\section{Technical Problems and Pollution}

The technical problems experienced by previous efforts to harness geothermal energy also raised a great deal of concern among informants. The feeling was that if they couldn't master the situation on a small-scale then why proceed to develop geothermal on a larger scale. Some informants mentioned that geothermal projects that have been successful at other locations on the American continent never had to contend with the type of force lying beneath Puna. They believed that existing technologies could not match up with the magnitude of the energy from Hawai'i's volcano. One informant shared:

There is all kinds of things down there that comes out of the drilling. After 56 months the pressure and chemicals eat through the equipment and they. have leaks. They do patch up work that doesn't really help. Ours [volcano] is so powerful, they don't know how to control it.

A major concern related to how chemicals released from leakage or blow-outs would impact wild and cultivated plants. Some informants expressed concerns about how flower growers would be affected in the long term. If the gases released were colorless and tasteless, and humans were manifesting symptoms of illness, then they deducted that plants were also being negatively affected. One fisherman who was at sea at the time of the latest blowout said that from offshore he noticed that the ohia forest that lay downwind from the geothermal site had turned a dull grayish color. After about a week the foliage appeared to have recovered. 
There were also concerns expressed about how possible contamination of the underground freshwater system would ultimately affect marine life that thrived in the places where cool, fresh water entered and mixed with ocean water. For example, opae ula, a minute red shrimp, required fresh and salt water conditions. They lived in anchialine ponds along the shoreline or in offshore areas where fresh water entered the ocean. They attracted fish that fed on them and were caught in fine nets and used as palu or chum in order to bring fish around. Some fishermen expressed concern about how these rather fragile organisms would survive if the underground water system were contaminated by chemicals released during geothermal development. And if these small creatures near the bottom of the food chain were affected, then the entire marine system might ultimately be affected.

Blow-outs at the geothermal plants were a primary concern among informants. A massive blow-out that could not be contained would mean the evacuation of everyone living in the district. One informant speculated that such a catastrophe would mean long-term displacement and more law suits than the state or federal government could cope with. Lower Puna informants were especially concerned because they were downwind from the drilling sites. The wind carrying toxic fumes would not be constrained or filtered because of the clearing of the forest for roads and drilling sites. One informant said that every night the wind comes down from the mountain and, during the day, the trade winds start blowing from the ocean. Symptoms resulting from exposure to chemicals released by geothermal were described as headaches, muscle aches, irritability, nausea, spontaneous abortions among pregnant women, and even having a metallic taste in the mouth. Although lower Puna residents expressed the most concern about the wind bringing noxious chemicals their way, informants residing in subdivisions upwind towards Pahoa expressed similar concerns about contamination. The winds could always shift direction and those living above the drilling zones also believed they were endangered. A great deal of concern was expressed about the close proximity of the geothermal subzones to Pahoa School.

\section{Visual Impacts}

The visual impacts were also raised as a concern by informants. Some speculated that utility poles and power lines would mar the scenic roads and view planes around Puna and, if the power were transmitted through the Saddle Road, it would have a negative visual impact there as well.

\section{Electromagnetic Radiation and Marine Impacts}

There were concerns about the cable line that was projected to enter the ocean near Kawaihae Harbor. Fishermen were unsure, yet concerned, about how the cable lines emitting electromagnetic radiation might disrupt fishing and impact migrating whales.

\section{Poor Planning}

One informant described the process of development in Puna as an exercise in poor planning. He believed that the development of the rainforest provided planners justification for allowing more development. to go on. He said:

We have a lowland rainforest that is being impacted daily. Not just by geothermal but by the influx of new people coming into the area. The land is no longer pristine because of all the subdivisions and papaya groves. That gives 
the State the idea that it is not worth saving. There is poor planning in letting people develop this area and also wanting to develop geothermal.

\section{MITIGATION}

The concept of mitigation was a foreign one to many informants and based on the belief that natural or spiritual phenomenon existed as separate entities without regard for parallel or successive systems. A number of informants discussed natural and spiritual phenomena in terms of one, holistic form. If one were to misuse the resources that were provided for humans by the gods, it would incur a negative impact throughout the entire natural order. Such an affect could not be mitigated by reducing the amount of the activity or through some other means of compensation. Wahi pana (sacred areas) were the source from which natural elements emanated, and disturbance of these areas would spell an end to the resource. For example, some informants mentioned that the rain and wind that were generated from the wahi pana from within the volcanic rift areas and essential to the perpetuation of life in Puna would cease to exist if disturbed and thus lead to a major decline in the range and quality of life.

Every informant in the Puna sample was posed with the question about how to mitigate the potential negative impacts of geothermal development. In general, the response to this question was "nothing." Some informants were not totally against geothermal development but had concerns about its safety record. If the quirks or difficulties could be worked out at the existing plants, the HGP should expand at a less ambitious level (than the 500 megawatts) and assessed in terms of its benefits to the community. None of the informants, even the proponents of HGP, believed that wholesale geothermal development should occur without some restrictions or profits returned to the community.

A variety of suggestions were made that dealt with prevention, mitigation, or the general management of natural resources in Puna. Informants provided the following responses when questioned about the mitigation/management of HGP:44

- Everyone within a 15-mile radius of the geothermal wells should get free electricity-especially if they had to suffer the consequences and $O$ 'ahu got most of the benefits.

- Hawaiians with genealogical ties to lower Puna should receive royalties of $10-20 \%$ from the profits made off of geothermal development.

- There should be a buffer zone between the drilling sites and where people live. In Puna there was no buffer zone because there wasn't room for one.

- The range and number of wells should be limited. Instead of opening the vast range throughout the three sub-zones for exploratory drilling, HGP should focus on one subzone and the number of wells should be limited to an acceptable level-according to what residents believe is appropriate.

\footnotetext{
${ }^{44}$ Some of the points were themes or composites derived from various responses that had related content.
} 
- There should be strict monitoring of all aspects of the HGP. Air and water quality should be assessed regularly at designated points in time. Socio-cultural assessments should occur in phases following development. Development should occur in increments, not all at once.

- The State should encourage the development of solar energy for all homes in Puna and throughout Hawai' $i$. One informant reported that there were over 1,000 homes in the district that were solar powered and this should be a requirement for the entire state. It was viewed as an unlimited and natural resource that would lessen the need for projects like HGP.

- The State should encourage self-sufficiency in Puna and stop getting involved in projects that encourage dependency. Development should be consistent with Hawaiian culture and values. The modern way was too expensive. Alternative community economic projects would benefit everyone in the long run.

- The state/federal government should provide informational opportunities to Puna Hawaiians that address the proposed design of HGP and factual information regarding the extent to which the forest will be impacted.

- The state or federal people who are promoting geothermal should explore drilling possibilities on Lo'ihi. The Big Island was moving west, off of the hot spot. If it is too technologically challenging at this point to drill for energy underwater, then government officials should wait until Lo'ihi became an island.

- Geothermal development should not occur in areas where there was rainforest. If the proponents of geothermal were so adamant about developing this energy source, it should occur in Volcano National Park in areas where there was no forest or native residents.

- The management of natural resources should be done by native Hawaiians, or they should at least serve as primary consultants in developing programs and policies. The people who have genealogical ties to lower Puna know best how to manage the re sources. "We take only what we need." Management includes teaching about the moon phases and how it affects the ocean and planting. There should be a return to the old kapu system. That way Hawaiians could regulate their resources.

- There should be more effective management and education of tourism. Every tourist should be required to have a 1-hour class on culture when they arrive in Hawai' $i$. Tourism development and activities in Puna should be regulated and limited.

The Puna Hui 'Ohana was formed in 1971 to provide community-based management of social and economic issues for Hawaiians residing in the district. In terms of geothermal development, the group has advocated for hiring local residents, job training; and corporate mechanisms for providing resources and services to the community. It also served to educate Puna residents about geothermal impacts as they related to other places (e.g., New Zealand) and mineral rights.

Some of the recommendations made by members of this organization included: 
- Investors/developers should provide on-the-job training and opportunities for advancing/promoting local employees. This would serve to elevate Puna residents beyond the low-paying menial levels to high-tech or managerial levels which were mainly filled by out-of-state workers.

- Investors/developers should contribute monetary resources to community agenciesparticularly the schools and hospitals. Small, rural facilities were largely neglected by the state, and monies could be used to purchase equipment, supplies, art materials, fund special educational programs, etc. They suggested that some programs should be modeled after those in New Zealand that benefited Maoris after geothermal development.

- Some of the royalties from HGP should be used to set up a community trust fund for Puna Hawaiians. Grants can be provided to native entrepreneurs and for scholarships. It can also be used to develop programs aimed at protecting native fishing, hunting, and gathering rights.

\section{METHODS OF STUDY FOR SOUTHEASTERN MAUI}

The investigators originally planned to conduct approximately 20 in-depth interviews and 3 focus group discussions of informants representing Southeastern Maui. As was the case with Puna, the number of in-depth interviews exceeded what was planned and the number of focus groups was slightly less.

Informants for the Southeastern Maui portion of the HGP study were selected from a list of individuals and/or 'ohana who were known to be associated with the project area. In this case, the proposed geothermal transmission line was projected to run from the East portion of Honua'ula, across Kahikinui, and into the Western portion of the district of Kaupo. The list of Native Hawaiian informants was compiled to reflect either residents or those who had genealogical ties to these areas. The investigators received assistance from the State (e.g., State Historic Preservation Office), county agency representatives (e.g., Planning Department), and Native Hawaiian residents of Maui. A site coordinator, who had genealogical ties to Southeastern Maui, assisted the investigators in making contacts with prospective informants and conducting site visitations.

Thirty-nine informants were contacted and 26 of them were interviewed. Sixteen participated in in-depth interviews (2-3 hours); and 10 informants participated in interviews that were less than 1 hour. All interviews were conducted at either the informant's place of residence or at the location where cultural or subsistence activities were undertaken. The informants represented the following districts within Southeastern Maui: Kahikinui, Kanaio, Makena, Ulupalakua, Kaupo, and $\mathrm{Nu}^{\prime} u$ (see Appendix $\mathrm{K}$ for broader description of informants).

Similar to the Puna survey, a packet of information related to the HGP design was presented to informants in both the in-depth and focus group interviews. The intent of this exercise was to assess informants' opinions regarding impacts after they had a clearer understanding of what the project entailed. Informants were also shown a map and asked to identify sites related to subsistence and Hawaiian culture. 
The same set of interview questions were used at both Puna and Southeastern Maui. Informants were asked about their ties to the areas of Southeastern Maui, natural resources, religion, subsistence and cultural practices, HGP impacts, and mitigation measures.

Two focus group discussions of 4-5 hours were conducted with the organizations $\mathrm{Ka}$ 'Ohana $\mathrm{O}$ Kahikinui and Kanaio 'Ohana.45

\section{Informants Relationship to the Project Area}

The relationship informants had with the project area fell into the following categories: (1) born or raised in the area; (2) went to school, church, or work in the area; (3) had genealogical ties to the area; (4) family burials were in the area; (5) owned land and/or lived in the area and were caretakers of the land; (6) were on the waiting list of the Department of Hawaiian Home Lands (DHHL) to obtain pastoral or homestead leases in the area; (7) planned to build houses for themselves and their children on Hawaiian family lands; (8) used the area for subsistence practices (hunting, fishing, gathering, and planting); (9) visited the area for recreation; (10) visited the area for spiritual or cultural purposes.

Some informants had genealogical ties to the project area and were knowledgeable about past and present culturally-related activities. These informants were able to trace their ancient family lineage to a particular district within Southeastern Maui (e.g., Kanaio, Kaupo, Makena, Nu'u). In most of the cases 'ohana ties could be traced to the post-contact period when churches, schools, and ranching were established in the district. In other cases, informants were tied to the area through subsistence activities. ${ }^{46}$ Many of those who fell into this category used the area from the time they were children and were taught traditional Hawaiian subsistence practices by their parents or grandparents. These were practices that they hoped to pass on to their own children.

\section{SUMMARY OF INFORMANT INTERVIEW DATA}

\section{Map of Southeastern Maui}

The map of Southeastern Maui indicates the various use areas and cultural and historic sites (Figure 1). This information was derived from informants during interviews. As indicated on the map, fishing and ocean gathering occurred along the entire coastline. Hunting and plant gathering occurred primarily in the mauka regions. Native Hawaiian plants, many of which were endangered, were found along the coastline or in the mauka areas where foraging animals could not reach them. Many of them could be found in steep gullies within close proximity to the highway. Archaeological and cultural sites were concentrated along the coastal areas and in ancient settlements along the slopes of Haleakala. The trails that were identified generally extended from mauka to makai or ran along the coastline to

\footnotetext{
${ }^{45}$ The Ka 'Ohana o Kahikinui focus group was held on January 7, 1994, at St. Ynez Church. The group was comprised of Native Hawaiian beneficiaries who were on the Department of Hawaiian Homelands waiting list for pastoral and/or homestead leases. About ten members participated in the discussion. The Kanaio 'Ohana focus group was held on February26, 1994, at a Kanaio homestead. This group was comprised of Native Hawaiians who own land or live in the Kanaio homestead area which were from old King's Grants. Eleven individuals attended the focus group.

${ }^{46} \mathrm{Many}$ of the subsistence users frequented mauka-makai (mountain to ocean) trails or the King's Trail to gain access to coastal fishing grounds.
} 
accommodate fishermen. Informants identified a number of significant areas that for various reasons warranted protection from over-harvesting or development.

\section{Deities, 'Aumakua, and $\mathrm{Ho}^{\prime}$ ailona}

Informants who acknowledged having aumakua referred to their beliefs as a private family matter. For the informants from Southeastern Maui, the 'aumakua was represented in marine life such as great fish, mano (shark), puhi (moray eel), mo'o (lizard), honu (turtle), and land animals such as pueo (owl). Places associated with 'aumakua can be inferred from the species behaviors and habitats. For example, some aumakua dwell in the sea. Coral reefs are the special places for the eel; bays and caves are the dwelling places of the shark; the bays are where the honu live; and the natural fishponds along the coastline are habitat for the mo'o. The pueo can be seen flying throughout the study area both at mauka and makai locations.

Many of them looked for appearances of their 'aumakua. For example, one informant shared that at a family funeral, his aumakua, the pueo, appeared to lend support to his family. The family knew where their 'aumakua could be found and always made efforts to nurture or never harm them. For example, mano caught accidentally in a net were released. Some informants said that they looked for ho'ailona (omens). Particular natural phenomenon, such as clouds, thunder, rainbows, and the sighting of rare birds, were interpreted as ho'ailona. Rainbows were believed to be the herald of the porthole to other life dimensions and the clouds at night were believed to be the active, inner force of the goddess Hina. The appearance of ho'ailona was interpreted as an omen that some event was forthcoming. One informant shared information regarding a ho'ailona, the manu'iwa bird:

This black birds-it looks like an eagle. It flies here sometimes and you very seldom see it. It flies so high, a big black bird. My father used to say that whenever that bird comes, good things happen. Last year I saw him.

\section{The Goddess Pele}

Pele was represented in Southeastern Maui by various symbols. For example, in Kanaio the commonly found maidenhair represented Pele's hair. Some informants believed that the presence of Pele, as indicated by these symbols, would serve to protect them from projects that were harmful to the aina. Pele had a way of taking care of things or cleansing the landscape when it was being used inappropriately. Geothermal development showed a disrespect which would incur the wrath of Pele. Her wrath might be displayed in the form of volcanic eruptions or movements deep within the earth that would damage geothermal facilities. One informant believed that teaching hula was one way he was able to pay homage to Pele. The chants and movements involved in hula were intended to honor her spirit. Another informant believed that Pele took care of those who respected her and loathed those who did not. Geothermal was considered a sacrilege and perpetrators, it was believed, would be punished by the goddess Pele. One informant shared:

When you are tapping geothermal, you are playing with our Goddess Pele, which in my eye is not good. Spiritually, and being Hawaiian, you are playing with one of our goddesses which is not right. Leave Pele alone! Leave the geothermal alone and leave Kahikinui to people coming back on the land. 
Some of those who believed in Pele identified with Hawaiians in Puna who were committed to safeguarding her from geothermal development over there. One informant who held strong Christian beliefs was not opposed to HGP on the basis of spirituality but respected those who were. He stated:

Well, I go to church. I have one God. So I don't believe in Pele. Maybe Hawaiians believe in her. Its okay. Geothermal is going into the earth; to me it's just a volcano. People have their beliefs. I just respect what their beliefs are and I don't understand it. All I know is, its traditional that Pele is believed to have certain powers to do certain things. Some may be coincidental, some of it may not.

\section{Religious Practices}

Persons intending to resettle the area of Kahikinui have begun reinstituting ancient cultural and religious practices. The investigators witnessed the opening of Makahiki by a group of Hawaiians (Ka 'Ohana O Kahikinui) in November 1993 and its closing in February 1994. Participants believed that this ceremony may have been the first of its kind in about 127 years. The ceremonies involved food offerings, hula, and the launching of a small canoe which contained a food offering. The canoe represented the ka wa'a o Lono (the canoe of the god Lono) which was being sent back to Tahiti (Malo, 1951).

The group had elaborate plans to conduct more religious and cultural activities at Kahikinui because of its sacredness and historic significance, and it remained one of the last untouched areas on Maui. Place names at Kahikinui represented links to ancient navigators including Hawai'iloa (believed by some to have been the discoverer of the Hawaiian islands), Anianikalani (his father), and Hualalai (mother of Hawai 'iloa and Nu' $\mathrm{u}$, another noted navigator). Halau hula were known to travel to this area to enact chants and dances honoring Hawai'iloa and the others. One kumu hula (hula master) discussed the importance of this place and future plans to rebuild their culture:

So Kahikinui has gone beyond my anchoring of being raised in this area, because now it takes me beyond to mythology of Hawai'iloa. In the near future, probably summer, we would pass Pohaku (rock) from one person to another, like ancient times, to build a structure. So that, just the touching of the Pohaku to document in their minds, their 'ohana, that they were part of rebuilding a prolific element of Hawaiian culture. Because of the geographical location and the name places, it would be great to facilitate the Makahiki with and opening and closing ceremony. Any kind of ceremony for me is an offering to the gods, offering to participants, giving land and ocean. When you open, there were different activities, food offerings were always very important: Its part of this land, almost everything that was there. I anticipate this land to become more fruitful and abundant. And we need more people out here to work this land, so they can receive the reward aesthetically, or physi cally or whatever. It's willing to give back, if we are willing to come and give.

Kahikinui was described by some as "away but not away." This meant that it was usually within an hour's reach from home and was a place that provided a spiritual uplift for those who wanted a dose of nature and culture. For many informants, subsistence activities were considered ways to gain spiritual rejuvenation and a religious rite. 


\section{Natural Resources}

It has been said by some older informants that, at one time, the forest line extended all the way down to the ocean. The different elevations had different types of trees. The vast watershed system created by the forest provided Hawaiians with a supply of freshwater. In the last 100 years the forest in the lower elevations (to the 5,000 feet level) has been largely destroyed. The loss of the indigenous and native trees and watershed, as a result of the introduction in historic times of goats and cattle and the ranching practice of "chaining", has greatly diminished the land's ability to hold water. Thus, the area has become dry.

The mountain and forest as a whole were perceived by some informants as being a natural resource. The natural elements operated in concert to provide the resources required for the sustenance of endemic organisms, including humans. The daily occurrence of long cloud formations and moisture at mid-elevation on the slopes of Haleakala ensured the permanence and expansion of the forest and rare endemic plants. For many, revegetation with native forest and plants was critical to the establishment of a watershed system that would ultimately allow for the resettlement of Hawaiians.

The availability of freshwater is essential to repopulating the area and to subsistence and cultural activities. Some informants discussed ways they had adapted to the chronic water shortage in order to maintain an activity or livelihood. In the arid region of lower Kahikinui, for example, fishermen have learned to find fresh drinking water by reading natural signs along the shoreline. The appearance of opae ula or minute red shrimp in the tidal areas or on certain seaweeds indicated the presence of freshwater. After heavy rains, fishermen were also aware of places where they could dig wells by hand. One fisherman from Kanaio mentioned that ancient Hawaiians used dogs to find freshwater springs along the beach in Wa-i-a-ka'ilio.

\section{Native Hawaiian Plants}

Endemic and/or endangered plants were found in protected areas at Ahihi-Kina' $u$ and Kanio Natural Area Reserves, along the coastline at Kanaio, and in Kahikinui at Auwai, Alena, and Manawainui. The greatest concentration of rare plants was at Kahikinui below St Inez Church. Some informants spoke of plans to restock rare endemic plants throughout Kahikinui.

The Auwahi ahupua'a has a unique concentration of rare and endangered Hawaiian plants (see Appendix M, response by Renee Silva). These plants were essential to the survival of Hawailans who were tied to a subsistence economy. Hawaiians learned how to survive in an environment that was characterized by extreme heat, lack of surface water, and a harsh ocean condition. Materials derived from plants were used for making canoes, nets, spears, ropes, and sails. Although fishing and boating technologies have progressed to the point where most of these materials are no longer used, plants are still being used for food, medicine, adornments, and craft and building materials. A critical reason for protecting native plants was that they were such an integral part of the culture-so it was believed that the culture does not exist without its plants. Informants expressed concerns about the endangered status of many native plants in the Auwahi forest. One plant expert who studied the area explained:

This concentration of plants is famous. It crosses the road on both sides. It flourished because of the cloud cover, being fed by the clouds. Its one of the 
best dry forests in Hawai'i. Rock [scientist from a 1910 plant study] said that it is still a good forest, if we leave it alone. But if we keep putting power lines and houses and goats and cattle, then that's not compatible with the na tive forest. We'll lose it.

From the hill [Luala'ilua Hill], there is a big colony of ' $A$ 'ali'i. A rare fern, and Sandalwood, and all kinds of Hawaiian trees. Ha'a, olopua, are all in this area. The hill might be slowing down the clouds, there is moisture there. There's a species of Ko'oko'olau at Wai'opai, right on the beach. 'Ahakea, Koa, are trees for canoe-building. There is few Koa trees. The best elevation is about 2,600 feet, way up in the clouds. There's a small colony right behind Luala'ilua Hills. Kupimoi, a nice healthy colony. The Natural Area Reserve is there because of the Kupaoa plant.

\section{Access and Trails}

Mauka-makai trails linked the Pi'ilani Highway to the shoreline at Keauhou, Kanaio, and Kahikinui. Trails leading to traditional use areas were viewed as very important to the continuance of subsistence activities. Informants mentioned that trails were critical to gaining access to hunting and fishing areas and served to reduce the amount of effort it took to obtain resources. For example, one informant stated that he hunted or fished all day using one trail. Trails reduced the amount of time and effort it took to access an area, fish and game were generally within close proximity of the trail, and trails allowed for an easier return with a heavy catch. He further explained:

To me, yes [trails are important]. Trails go mauka (mountain) and makai (ocean), go everywhere. Trails connect for fishing and [hunting]. There's one trail. You hunt. First, put in a bag, hang 'em on a tree. Go down to the ocean and get you fish, opihi, limu. Then you come home and pick them up. All in one day, 6 hours. All on one trail.

Maintaining and gaining access to traditional subsistence and cultural areas was a primary issue of concern for many informants. Traditional access routes that extended from mauka to makai were threatened by changes in ownership and control of lands over the years. Big corporations and government agencies either owned or had jurisdiction over large tracts of land which made it difficult, if not impossible, for Hawaiians to cross over them on their way to traditional subsistence grounds. Lack of access was believed to be a major obstacle in the continuance or re-establishment of Hawaiian customs and practices. Some properties were gated or fenced to deny passage to any unauthorized persons. In other cases, informants knowingly exercised their indigenous rights to access subsistence resources by crossing over underdeveloped private property.

Other informants mentioned that permission and/or keys to gates were required to enter into some areas. However, one informant said that the process of obtaining a permit was generally not worth the effort. For some areas, persons were required to stand in line to get keys from the Department of Land and Natural Resources-and there was a limited number of keys issued. The process served as a deterrent to prospective users.

Informants identified the following traditional access trails:

- An old horse trail from Makena to 'Ulupalakua. 
- A trail in Keahu.

- A trail from La Perouse Bay to Kanaio.

- A trail in Kano'i.

- A mauka-makai trail at Cape Hana Manioa.

- A trail to the beach in Wailea that was once easy to use, but is now cumbersome because of the resort.

- A trail from Kanaio to the beach that is difficult now because of the ranch.

- A trail to Cape Kina'u that was used to pick limu, 'opihi, fish or even to pick cat eye. It is now restricted because of the Nature Reserve Area. Some felt that the reserve, which was a famous fishing area, should be open on a seasonal basis to Native Hawaiians for subsistence use.

\section{Subsistence Activities}

Until about 30 to 40 years ago those residing in Southeastern Maui were required to rely on subsistence activities because Hawaiian families had limited incomes and lived a long distance from stores. Families, which were believed to be larger back then, were easier to feed through a subsistence rather than a cash economy. Necessity was the driving force behind learning subsistence practices and honing one's skills in order to catch enough to feed the family. Subsistence in Southeastern Maui was thought to require a higher degree of innovation because of the difficulties related to a dry and desolate environment. Resources were more difficult to identify, somewhat more wary because of a lack of cover or refuge, and less abundant because of the lack of water and food sources. One informant explained his feelings about the situation:

To live here you have to have the background or you won't make it. This place will eat you up, because you gotta know the land, the ocean, what you can survive with in the mountain, in case anything happens. Survival is the main thing here. There is a lot of things you can survive off of. I cannot starve living here. And if I do, its my own fault, nobody else's, because everything is here.

From an insider's perspective, the 'aina was believed to be productive and fruitful. There were ample resources to carve out a living and the wisdom handed down from their kupuna provided an understanding of how to harness the resources without exploiting them. Hawaiian subsistence practices were compatible with the perpetuation of a finely balanced, self-regulating ecosystem. The balance changed with the onslaught of westerners and different approaches to land utilization. The introduction of new economies spelled disaster for the already vulnerable landscape and associated lifeways. One informant lamented:

It wasn't until the white culture came in and decided that we had to change the way we lived-that we needed to have telephones, toilets, electricity, this and that. You don't need to destroy the land to live a good life, which is basically what western culture has done. 
Despite the adverse effects of a changing economy, subsistence practices were maintained over the years. Fishing, hunting, and gathering in Southeastern Maui provided a basis for food, recreation, exercise, and culture for many area residents.

Informants believed the Honua'ula, Kahikinui, and Kaupo districts possessed many pristine sites where subsistence activities occurred or could be reinstituted. Of particular interest was the possibility of providing access to medicinal plants in the Natural Area Reserves of Kahikinui and Ahihi-Kina'u. Replanting and La'au Lapa'au (traditional Hawaiian use of medicinal plants) was a strong possibility. Native Hawaiian botanists and La'au Lapa'au practitioners had previously surveyed the area, collected seeds and plants, and were in the process of restocking native plants.

\section{Fishing and Ocean Gathering}

Fishing and ocean gathering occurred along the coastal areas throughout the region (from Makena to Kaupo). The techniques used to catch fish differed according to the particular locality. For example, fish traps were found in Makena and Kanahena where moi and weke were caught. Akule were found in abundance in La Perouse Bay at Kalihi and Nu'u Bay at Nakula. Ahi and ono were caught in the deeper waters near Mamalu Bay at Naholoku. Mullet, ulua, manini, and uhu were caught at various spots along Kahikinui. Popular fishing areas, especially for those from outside of the region, were the bays which had easy access (e.g., Maknea, Kanahena, Huakini, and Nu'u). Other areas were visited less frequently because they were a distance from the road and had rugged and difficult coastlines. Experienced and/or resident fishermen visited these areas because they were familiar with them and often had ahupua'a tenant rights and other types of privileges.

Ocean gathering occurred along the shoreline where 'opihi (limpet), limu (seaweed), and kupe'e (ocean snail) were picked and 'a'ama (crab) was caught; he'e (octopus) was speared when walking the shoreline or diving; ula (lobster) and crabs were caught while diving; and some species of crab were caught in traps as far as 2 miles from shore.

As mentioned in the previous section, some areas were more difficult to access be cause of restrictions. Informants said they would go fishing at Kanahena and Keone'o'io before the Natural Area Reserve designation prevented access. This was one of the best fishing grounds on the island. Uncle Harry Mitchell (well-known Kupuna) was arrested at Kanahena for.picking medicinal herbs. One person felt that Hawaiians should have been allowed to use the reserve in a way similar to the arrangement in Kalapana when the National Park took over the area. Over there, long-time Hawaiian 'ohana members were allowed to continue to use the area that fell within the Volcano National Park's new boundaries for subsistence.

Disputes over access to fishing grounds was a constant and deep concern for many informants. One person described a problem between his family and a ranch over who owned or had jurisdiction over a road that provided access to the shoreline. He said it was difficult to concentrate because you were always aware that the ranch might come down on you when you were using the road.

Methods of fishing that were reportedly used included nets (throw and surround nets), pole fishing (whipping and dunking), harpoon, and spearing fish while diving. The techniques used to catch fish varied according to location. For example, at Nu'u in Kaupo the water was nice and safe for landing boats. When the Akule came into the area, people would go and 
surround them with nets and haul them in. Fishing practices were also tied to the direction of the ocean currents. At Nu'u the current went out to sea. At Kanaio, the current came in towards the shore and fewer people were needed to lay net. Experienced fishermen felt that this was an important distinction.

Hukilau was a traditional fishing practice used by Hawaiians in the area. It became less common because of regulations imposed by the state. One informant described this method:

You take a rope and you put ti leaves every so many feet and you take rocks and tie them. Then you use the Wiliwili tree floater. When you go through an area, you can surround the whole reef without a net getting tangled up in the rocks. So it misses the bottom of the ocean. What you do with this floater, the fisherman would be swimming ... as you go along, you roll the rope out over the floater. As it gets shallow, you bring it in here. Once you get it to the bay, you can surround the whole bay with that. This kind of fishing is not very selective, so you take all of that fish that you don't eat, you throw it back in the ocean. The tragedy now is that you cannot go in there and show how to do it, because of today rules and regulations. We try to get around that any way. We did the hukilau with the children, but they can get into the water only up to the waist. Now there are regulations against the hukilau, but you can get an exemption, if it's for family or cultural things. In 1988 we had a hukilau in Kanahena.

The fish house was another traditional technique that was used by fishermen at Makena and Kanahena to catch fish such as a'alea (Hawaiian hog fish). The informants who described this technique believed that it was an effective, yet uncommon practice. One informant stated:

To build the fish houses in the ocean, make an ahu (pile) of stones, with the limu facing up, never put the rock upside down. When the tide come up all the mali ' $i$ goes into the space between the stones. What you do is cover the pile of stones with the throw net, take the stones away, one by one, and then you have all the fish inside the net. This is a method of fishing that not too many people do know. It's a rare way of fishing.

A recurring theme among fishermen was to take only what was needed and to only go fishing when the family's fish supply was down. Many informants spoke proudly about carrying on this traditional approach to ocean conservation. They believed that if they were not sensitive to the marine ecology, then nature would impose its own sanctions by not providing food. One informant mentioned that he was taught by his elders to not go fishing during the months of October to December. If he disobeyed this rule, fishing would be unsuccessful during the other months of the year.

Some fishermen expressed concerns about the inappropriate practices of outsiders or foreigners who were taking too much and often selling their catches. Some non-Hawaiians were thought to lay too much net and catch too much fish, thus violating the traditional rules of subsistence. One informant said: 
I have nothing against Filipinos or immigrants but they come here and they fish this place out-everything. And I tell them, why don't you leave some fish for me?

There were complaints about outsiders using nets that were illegal because they had small eyes which didn't allow smaller fish to escape. One informant believed that the eye of the net should be 3 inches so that juvenile fish could escape and grow to adult size.

Most fishermen were aware that fish were a valuable commercial resource, yet were more inclined to follow old ways by fishing only for personal or 'ohana use. They were also aware that store-bought fish were becoming very expensive, and the ability to fish was a way to save money and maintain a traditional diet that was healthy and otherwise beyond their means.

The types of fish that informants reported catching included the following:

$\begin{array}{ll}\text { A'alea } & \text { Manini } \\ \text { Aholehole } & \text { Moi } \\ \text { Akule } & \text { Opelu } \\ \text { Aku } & \text { Uhu } \\ \text { Blackfish } & \text { 'Ula'ula } \\ \text { Kumu } & \text { Ulua/Papio }\end{array}$

Other types of ocean animals and plants that were gathered by informants included:

Crabs (Kona and Kuhono)
He'e
Kupe'e
Limu
'Opihi
Ula

\section{Plant Gathering}

The gathering of plants occurred in a scattered fashion along the Pi'ilani Highway and along the coastline. There were several gathering spots in Kahikinui below Luala'ilua Hill and St. Inez Church. Plant gathering has declined through the years because of deforestation and the privatization of land. Knowledge about plants and their traditional uses that were specific to Southeastern Maui has declined because of depopulation and changes in the economy. The introduction of foreign species of flora and fauna also took a toll on endemic species whose numbers and habitat were in serious decline. There were active efforts by groups of younger Hawaiians to restore the vegetation through planting and watering. The ultimate goal of native forest revegetation was to bring back the rains to the lower elevations which were requisite to resettlement. Increased amounts of water would also enhance the forests and revitalize rare and endangered flora that were once an integral part of culture and lifestyle.

Informants reported gathering a number of plants for food and other purposes (See Appendix L). Many of these plants were gathered in the dry coastal areas while family 
members engaged in other subsistence activities. Subsistence involving multiple family members meant obtaining everything that was useful and generally not limited to a particular resource. One informant mentioned that his family went fishing at Keone 'oi'o for o'io (bonefish) and ula (lobster); but at the same time picked mango at the site of an old house. The 'auhuhu plant found at Cape Kina'u was traditionally used to stun fish. The reddish wiliwili (Hawaiian leguminous trees) seeds were found in Makena. These seeds were used for making lei (necklaces) and other adornments used in hula. Noni, whose fruits had numerous medicinal qualities including the treatment of stomach problems and diabetes, were found near $\mathrm{Pu}$ 'u Ola'i. Kauanoa, an orange, creeping vine-like plant that was woven into leis, was found in the sandy coastal areas. Another informant mentioned that he was treating his asthma by using certain plants found in Kanaio.

Other plants were gathered in the higher, cooler mauka areas. Mamake was gathered by informants who journeyed to the higher elevations on the slopes of Haleakala. The leaves which had medicinal qualities were used for making tea. A variety of medicinal herbs used in la'au lapa'au were also found in the higher forested areas.

\section{Hunting}

Hunting practices were not limited to particular areas but based on the movement of game. There was goat hunting in Kanaio and Kahikinui along the shoreline, and all along the Pi'ilani Highway on both sides of the road.

A common sentiment regarding wild animals in Southeastern Maui was that their population was too large and needed to be reduced or eradicated. The goats, that roamed freely throughout the district, and pigs, that were mainly. found in the upper forested areas, were believed to be responsible for the destruction of native plant life. These animals ate seedlings of young plants or uprooted them, thus preventing them from becoming established or expanding their range. Efforts were underway to control the number of animals in order to allow for plants to rejuvenate.

Some Hawaiians (i.e. Ka 'Ohana O Kahikinui) had detailed plans for controlling animals. These plans called for goat eradication through hunting and trapping, the elimination of cattle by moving them to other areas, and fencing areas to limit the range of pigs to allow for the expansion of the forest to the lower elevations.

The animals that were caught were not wasted. Younger Hawaiians engaged in trapping pigs and goats and selling them to those who would use them for food. One informant stated that some young people sold live pigs to Filipino families who slaughtered them or raised them to a more desirable size. Other means of preparing goat meat included drying or grinding it to make hamburgers. Pigs were often prepared in the imu and used for ohana or group functions. One informant described this process:

We do kalua pig. We have more ti leaves, bananas and sweet potatoes. The tree we use for kalua pig is guava, kiawe, hardwoods, softwoods. ... those woods that don't smell. We do kalua pig sometimes once a year, sometimes six times a year. Last year we did it 5 times. We get the stones from $\mathrm{Nu}$ 'u, nearby the river. If I do not have enough bananas and ti leaves I go mauka for that. One pig for a large family may be last one week. 


\section{Plant Cultivation}

Although the district was generally perceived as desolate and dry, informants contended that with some water and care the land became very fertile and productive. Kaupo was known for its very large potatoes. As many as 10 varieties were grown and they were as large as 5-7 pounds. Sugar cane and vegetables were also grown at Kaupo. At one time Kahikinui was famous for its 'uala patches (sweet potato) that extended for 3 to 4 miles along the road. The area was also good for growing squash.

Families in Kanaio were planting a variety of trees and plants on their homesteads that were intended for consumption and other uses. A number of trees and plants were mentioned: a variety of fruit-bearing trees, bananas, papayas, 'uala, ti, taro, flowers, and herbs. Plants were also grown to decorate, maintain an environment, and prevent erosion. For example, one informant grew 'ilima around the family grave and another cultivated pohuehue (beach morning glory) to hold down the sand during windy periods.

Plans were in store to cultivate endemic plants, particularly Hawaiian herbs that could be used for la'au lapa'au. One goal among a community group was to establish an herbal medicine school to educate young Hawaiians on the uses of plants that grew in Hawai'i. Kahikinui was considered an ideal place because of the availability and/or potential for growing plants that were essential to these traditional practices. The same group had a seedling project underway and planned to plant and propagate endemic trees in order to restore the watershed.

\section{PERCEIVED IMPACTS OF HGP}

\section{Native Hawaiian Rights and Intended Use of the Area}

For many informants, the concept of HGP was considered incompatible with their image or plans for Southeastern Maui. General concerns were raised over how HGP would fit with efforts to restore a sovereign Hawaiian nation, efforts to obtain land leases from the Department of Hawaiian Homelands (DHHL) to resettle the Kahikinui district, and homestead plans for Hawaiians who hoped to settle on kuleana or private land parcels held by 'ohana members in Kanaio. The concern was related to an assumption that Southeastern Maui was generally unpopulated and therefore suitable for HGP development. This assumption was thought to preempt or alter plans and efforts to resettle Hawaiians in this area. For example, the power lines which would run parallel to the highway require a buffer zone, within which housing development could not occur. If Hawaiians were granted lands for resettlement, they would have to live away from the highway. This would increase housing and infrastructural costs and place a heavier financial burden on DHHL and lessees who might have limited cash resources.

The Kahikinui area that is under the jurisdiction of DHHL encompasses an area of roughly 2,500 acres, and pastoral lots are 10 acres each. One informant calculated that about 250 families or 1,000 persons would be settled in the area when all of the lots are awarded. Envisioning all of these families with children living under or within close proximity to the power lines was worrisome to one informant who believed that HGP would defeat the purpose of resettlement.

The idea of HGP appeared contrary to efforts by the state and federal governments to advance the welfare of Hawaiians through recent acts and policies. One informant believed 
geothermal development flew right in the face of the recent apology by President Clinton for the overthrow of the Hawaiian monarchy. He said:

They talk about returning the lands of the Native Hawaiians and now they want to take some of it back with the Geothermal. How they gonna explain that to the Native Hawaiians after they signed the agreement and after they apologized to them and said the Native Hawaiians will be returned to their original status of 1778 , as it was before, to live in harmony with the land but yet now they're gonna come back and gonna take more land to complete this project.

A number of informants also questioned the purpose and benefits of HGP. Many felt that the project would benefit Honolulu and offer nothing to those residing in or using Southeastern Maui. This new energy source would also be a way to promote growth and development which was antithetical to the interests of Hawaiians. A limited energy supply was one way to control further growth. The idea that HGP would lower energy costs to consumers was also questioned. Some believed that energy costs would rise and used examples of other utilities (e.g., water) where increased supply did not translate into declining costs.

Environmental concerns focused on the impact of power lines and electromagnetic fields on humans, how power lines and towers would impair the scenic landscapes, and how increased lighting would affect marine life. Changes in the natural environment would affect the behavior of animal and plant life and ultimately impair one's ability to subsist.

\section{Spirituality and Religious Practices}

Some informants expressed how the general concept of HGP was sacrilegious to Hawaiians who had ties to the area. Analogies were made between HGP and desecrating a church. Westerners were not inclined to destroy the serenity of their own places of worship but paid little respect to the spiritual symbols of other people. Kahikinui was considered one of the last intact ahupua'a and a spiritual place, and the HGP was thought to jeopardize the serenity, aesthetics, and living culture of the area. A 200-foot corridor beneath the power lines would disrupt mauka-makai trails, impact traditional travel patterns, and consequently impede traditional practices.

Some informants referred to an understanding that returning to the land was a means towards spiritual rehabilitation for Hawaiians. Most of their social problems were caused by disenfranchisement and displacement. The loss of connection to the aina was akin to severing the aha (umbilical cord) which meant losing mana (spiritual power). Returning to Kahikinui was a major step towards developing a spiritual foundation that was critical to well-being. One informant stated:

Anything that is introduced to our ahupua'a [such] as geothermal will definitely play a big damaging role in what we just talked about. Because what we want to do is come back here as a community, living parts of our ancestors ways, and of course permitting into our lifestyle part of modern technology, such as solar energy. But geothermal will be one more genocidal step toward the death of all Hawaiians. In other words, why give Hawaiians land to rehabilitate themselves, and in the same time put up something that is going to kill them spiritually? That is what we are talking about. A lot of this is our spirituality, because we have to feel something that is there, that is seen 
but unseen, something that makes you do what you do. ... because the place is pristine.

A related issue of concern was the desecration of burial sites that exist in the area. Informants with genealogical ties to the area believe that they were the caretakers or protectors of these sites and their destruction or disturbance would be the ultimate impropriety. The final resting place of one's ancestors was not to be tampered with. Disturbance of these sites would be another way of disrupting genealogical ties and continuity between Hawaiians and the 'aina. Informants explained the risks and probabilities of disturbance with HGP development:

One of the first places where the native Hawaiians on Maui landed was right here, in $\mathrm{Nu}^{\prime} \mathrm{u}$. This is the landing area. This is where they first came. They settled this area. They were over 8,000 Hawaiians in Kahikinui alone. In the back side, Hana, there were over 80,000 . So there's a lot of cultural value in Kahikinui itself.

Over 1,000 burials in Kahikinui. So, this is their sacred land. This is Hawaiian Homelands for the Hawaiians. And not to mention, most of the historical sites are on the makai side of the road. Seventy-five percent of it is on the bottom side, so when you're running heavy equipment and putting up the towers, how are you going to get around the sites? There's no way that they could put it in without destroying thousands of significant sites.

We oppose geothermal. We are saying it would interfere with our alternative lifestyle that gives Native Hawaiians more options. We have so much sites, sacred places over here that it does not matter if you put lines around us, you are still killing us!

\section{Economics and Land Value}

Informants were generally interested in how HGP would benefit them directly. They were aware of the potential negative impacts it might bring, but also sought information to help explain why anybody from the district would choose to support it. Some informants believed that proponents would argue that HGP would lead to lower energy costs. This argu ment, however, was disputed by those who believed that lower energy costs would be offset by increases in property and utility taxes to pay for the development. Many also questioned the notion that HGP would actually bring cheaper energy to those residing in the district; and even if it did, it would not be enough to compensate for the negative impacts. Many believed that the bulk of the benefits would go to $O^{\prime}$ ahu while they would be forced to assume the bulk of the problems.

Those who owned lands, or lands adjacent to where the power lines were proposed, were concerned about the decrease in their property value. Informants also expressed concerns about increased taxes as a means to compensate for the development costs. Hawaiians were over-represented in the lower income brackets and would be especially vulnerable to increased tax burdens. 


\section{Alternative Energy Sources}

Other informants took the position that all of this modern technology was unnecessary. Hawaiians had gotten along fine without modern conveniences. They relied on kerosene lamps and fuel for cooking, and generally appreciated the darkness of night. If alternative energy sources were to be developed, they should be consistent with land preservation. For example, numerous informants questioned why the government was not supporting solar or wind energy instead of geothermal. These approaches were thought to have minimal effects on the environment. One informant speculated that Hawaiian Electric Company would not support these endeavors because they would be less profitable.

\section{Geology, Noise, and Light}

Some informants expressed a great deal of concern about the prospect of drilling for geothermal energy on the slopes of Haleakala which is a dormant volcano. Although it was not a part of the immediate HGP plans, some believed it was a future possibility. Those who raised this issue had strong opinions that Haleakala should not be subjected to drilling. Among the reasons given, there was a belief that there was too little known about the consequences of geothermal in Hawai' $i$ (e.g., seismic activity, changes in sea level).

Noise was another concern expressed by informants, especially those who fished near Nu'u where the cable line would come onto land, and at 'Ahihi-Kina' $u$ where the cable would re-enter the ocean. Those that lived near the highway were. also concerned about the noise level and wondered how they would react in the long run to the buzzing sound being emitted by the electrical transmission line. Fishermen expressed concerns about how noise from HGP plants would obscure noises from the ocean that were important to gain one's bearings and avoid dangerous waves. One fishermen offered the following concern:

Night fishing depends on the sound of the ocean and the waves for safety. If there is a big generating plant there, what about [being able to hear the] important sounds for night fishing? Exactly. There are a lot of people who utilize the trails for fishing down here. You see them at night. The sounds of the waves can determine if the tide's coming up. But if the generator covers the sounds, you can't hear the waves. That's an important impact Not only that, but the power line's going to destroy your ears. Humming, high voltage humming.

Artificial light caused by HGP was a concern repeated by many informants. The lights emitted from the sea-to-land transfer stations or along the transmission route would bring subtle changes to peoples' lives. For example, stars would not be as visible, or experiencing the subtle changes in the colors of the sky as the sun sets and rises would be affected by light pollution. Fishermen and ocean gatherers, who relied upon darkness (moonless nights) and localized light as a condition for times when fish and kupe'e were most abundant, expressed concerns about how various forms of marine life would be affected. Overall, the pristine character of an undeveloped landscape would be subject to changes because of increased lighting. One informant offered the following:

We have taken the grandchildren out at night to study the stars. It is beautiful, the children love it. You cannot study nothing with too many lights. Crickets disappears with the light. 
One informant also envisioned a string of lights attached to the transmission towers running 17 miles across South Maui. Without the cover of trees, the artificial lighting would have a major visual impact at night and turn a rural, pristine landscape into an industrial or city-like atmosphere.

\section{Visual Impacts}

A lot of concern was expressed over the impacts of the geothermal towers and 17 miles of power lines on the aesthetic qualities of Southeastern Maui's landscape. Informants raised this concern after reviewing structural plans provided by the Department of Energy. 47 Many believed that the structures would destroy the physical beauty of the entire area which is one of the last remaining undeveloped areas on Maui. The cumulative loss of scenic and undisturbed landscapes on Maui placed a premium on what remained pristine. One informant suggested the following:

They [developers] need to re-design their plans so that it doesn't have the kind of effects that I can see before me. There is hardly any place on Maui that you can turn four corners and see everywhere, enjoy and appreciate the beauty. Nothing beyond two stories should be allowed here, and even that should be really set, not go to beyopd the natural flow of the land.

Some also questioned the appropriateness of the structural design and whether they would be able to withstand the climatic conditions of the area. For example, if the poles were as high as proposed in the design, they may have to be supported or reinforced by a series of smaller poles to sustain hurricane-force winds. The whipping wind of South Maui would necessitate either propping them up or lowering their height. The former would add to the severity of the visual impact.

\section{Electromagnetic Radiation and Concerns about Health}

There was a pervasive concern about electromagnetic radiation and its impacts on the health of people, livestock, and plants that lived within close proximity or under the power lines. Many informants believed that there was inadequate information available on the health risks and safety measures (e.g., buffer zone) that were essential to the planning of this project. For example, there were questions raised over whether radiation emitted from the lines had limited range or if it was possible that the strong winds could carry it and contaminate those living in distant areas. This concern led to the issue of how big buffer zones should be to protect people and other organisms from the potential harmful affects; and if the buffer zones were too large, they could effectively remove large tracts of land from traditional use.

Fears about electromagnetic radiation, whether actual or perceived, were thought to have an impact on subsistence and other economic cultural activities. The transmission line would sever traditional ahupua'a land division because of how people would respond to it being there. Some informants speculated that practitioners would avoid going near the lines because of fears of contamination. This would reduce cultural use of the area because it would disrupt traditional patterns of access and mobility.

${ }^{47}$ Illustrations of generic structures and transmission lines were provided by Oak Ridge National Laboratory, April 1993. 


\section{Marine Life and Ecology, and Fishing Grounds}

Informants who engaged in fishing expressed concerns about the impact of the underwater cable on marine organisms. If electromagnetic radiation were emitted by the cable, it could conceivably affect the health and behavior of fish. There was a lot of speculation over how fish might be affected. One informant suggested that limu would grow on the cable because it would emit warmth and would attract fish. Both would be contaminated by exposure to radiation. Humans who are at the top of the food chain would eventually suffer from eating fish caught in contaminated waters. Those who catch fish commercially may not reveal the location where the fish were caught, and people consuming the fish would fall ill without knowing why.

Another informant compared the potential affects of the cable line to other actions by the state which had detrimental affects on the marine ecology. He made the point that major mistakes were made in Hawai'i because scientists lacked an understanding of marine ecosystems and failed to assess negative outcomes. He shared the following information:

This geothermal project is a new untested thing in Hawai' $i$. They go right ahead, and guess what? It's too late-they wish they never done it. Scientist have imported the ta'ape (yellow perch) in the Hawaiian waters, now this fish destroys the eggs of other Hawailan fish and the eggs of the crab. Within three years the ta'ape has wiped out the Samoan Crab. This fish was only in 60-foot water. Now it is found in 500 foot of water. Fishermen get harder time catching paka [opakapaka] and naga [onaga].

A variety of concerns were expressed about the potential for damaging the cable and how it would be repaired. Unless it was somehow secured to the ocean floor, currents might sweep the cable from side to side causing damage. Another informant who engaged in bottom-fishing mentioned that boats in the area dragged anchor all the time. Boat anchors could damage the cable, or, depending on how lightweight it was, might accidentally pull it up. This would pose a threat to an unexpecting fisherman. A concern was expressed about how a cable lying 7,000 feet below the surface would be maintained and repaired. This informant believed that once the cable was laid, there would be no technology capable of repairing it.

\section{Wildlife and Vegetation}

Informants surmised that the power lines and structures would adversely affect wildlife and endangered plants in the area. Electromagnetic radiation would take its toll, along with power lines capable of electrocuting or damaging birds who unwittingly land on or fly into them. Some informants referred to situations on the mainland where power lines existed. Birds such as the bald eagle landed on lines and were killed. Informants suggested that sacred Hawaiian birds like the pueo (owl), ocean birds, and other birds that fly mauka-makai would meet the same fate. $A$ reduction in the ocean bird population would disrupt fishing practices that depended on circling birds to find schools of fish.

Informants feared that clearing the land for development and service roads would also mean destroying rare and endangered plants that lived within close proximity to the highway. Clearing the land would further diminish colonies of lama which were estimated to be 40-50 years old; kauwila (exact location was kept secret); 'iliahi estimated to be 20-30 years old and threatened; and various species of plants (e.g. nehe) which were also 
endangered. Concerns were expressed about endangered plants in the Auwahi ahupua'a where $60 \%$ of the plants were considered endangered. The route of the power lines would go through an area where many of the plants live.

A question was raised over why the proposed transmission line would go through two Natural Area Reserves. If the reserves were established in the first place, this meant that they were aimed at protecting endangered flora and fauna. For some informants, the development of transmission lines would signify that development would always take precedence over preservation. One informant shared the following thoughts:

In the ahupua'a of Kanaio, whereby the State has proclaimed 846 acres of land to be set aside as a Natural Area Reserve and the geothermal lines will cross right over the 846 acres. What does the state intend to do with it? Are they just going to say "oh, we made a mistake, that we should never have put this area into a Natural Area Reserve?"

\section{Construction, Maintenance, Traffic and Population Growth}

In general, the development of HGP in southeastern Maui would lead to a rise in existing levels of human activity. A variety of miscellaneous concerns were expressed regarding the impacts of construction and the maintenance of the transmission lines, additional traffic, and the in-migration of outsiders.

It was believed that the influx of newcomers would contribute to the degradation of significant cultural sites (e.g., heiau, graves). More people would mean more traffic on the roads and changes in driving behavior (e.g., faster drivers) leading to more accidents. Informants suggested that there should be careful planning aimed at regulating the number of people who intended to settle in the area and to control population growth in Southeastern Maui.

\section{MITIGATION}

\section{No Build Alternative}

The most common response in relation to the question about what could be done to mitigate HGP impacts was that it should not be built. Many informants were very adamant in their opposition to the project. HGP was not considered a native planning concept because it was perceived to be incompatible with existing cultural practices and lifestyles. Many informants stressed the importance of self-sufficiency among Hawaiians (by community or island) through the development of community-based economies. The idea of developing an inter-island energy source was viewed as another approach to encouraging economic dependency while at the same time ravaging the environment.

Despite the widespread opposition to HGP among informants, some suggestions were offered to mitigate the anticipated negative impacts. The suggestions generally fell into the categories that the cable line should not touch Maui or should not go over land. 
Suggestions to not touch Maui:

- The cable should bypass Maui altogether. If it was technologically feasible, the cable line should never touch land until it arrived on $O^{\prime}$ ahu.

- If a booster substation were essential to the transmission of power, it should pass over Lana'i or Kaho'olawe, not Maui.

Suggestions to not build over land:

- A booster station could be placed on a large ship anchored Southwest of Kaho'olawe-as far away from inhabited areas as possible. Coast Guard weather ships never leave their location at sea. Some have been anchored for over 20 years.

Still others believed that negative impacts could not be averted. If the cable remained exclusively under water, fish and migrating whales would be affected. This would be a detriment to those who relied on fishing. Choosing one route over another would boil down to choosing the lesser of two evils. This was not a predicament informants wanted to be in.

Management

A number of proactive suggestions were made by Hawaiian individuals and members of Hawaiian organizations (e.g., $\mathrm{Ka}$ 'Ohana o Kahikinui) who had intentions of resettling the area. They were as follows:

- Hawaiians should be given the opportunity to manage their own lands. Land management was their indigenous right and outsiders who were unfamiliar with the area should not make decisions that would ultimately affect their homelands.

- Traditional cultural and natural areas (e.g., heiau, endangered plants) should be respected and protected. The status of significant areas and sites should not be altered in order to accommodate new development proposals. These areas are sacred and no development should take priority over them.

- Cultural and natural sites should be managed by 'ohana or groups who live within close proximity or have genealogical ties to the area. In most cases, they are the nat ural caretakers because they have the most frequent contacts with and are most knowledgeable about the sites.

- A community advisory organization should be involved in the general planning for the South Maui area. This organization should be at least partially comprised of kupuna (elderly) who would advise others on appropriate cultural activities. Input would also come from 'ohana representatives from various ahupua'a on issues directly affecting them.

- The money spent on HGP would be better used promoting appropriate, smaller scale technology for homesteaders. Suggestions included solar energy and alternative water and sanitation systems. 
There are existing land use plans that are designed to promote the resettlement of Native Hawaiians at Kahikinui. In the past, the Department of Hawaiian Homelands (DHHL), who has jurisdiction over the district, leased the land for ranching. The leases expired in March of 1992, although extensions have been granted to enable the lessee to remove remaining cattle from the premises. In October of 1993, DHHL awarded 2,500 acres of undeveloped pastoral and homestead lots to Native Hawaiians on the waiting list.

Meanwhile, a community-based organization referred to as $\mathrm{Ka}$ 'Ohana 0 Kahikinui has occupied the land while waiting for the leases. With the aid of professional planning consultants, they have developed a master plan for Kahikinui. A document entitled The Conceptual Community Land Use Plan for the Ahupua' $a$ of Kahikinui ( $\mathrm{Ka}$ 'Ohana o Kahikinui, February 22, 1993) proposes the following land designations:

$\begin{array}{lr}\text { Land Use/Designation } & \text { Acres } \\ \text { Forest Reserve } & 7,300 \\ \text { Reforestation/ Horticulture } & 2,000 \\ \text { Pastoral Lots } & 4,000 \\ \text { Self-Sufficiency Homesteads and } & 4,000 \\ \text { Buffer Zones } & \\ \text { Community Center } & 500 \\ \text { Makai Access Areas } & 500 \\ \text { Cultural Management Zone } & 4,500 \\ \text { Total Acreage } & 22,800\end{array}$

In the plan, pastoral lots are located mauka of the Pi'ilani Highway and makai of the reforestation/horticultural zone and the forest reserve. Self-sufficiency lots are makai of the Pi'ilani highway. The cultural management zone extends all along the coast and shoreline. The 'Ohana has plans to undertake reforestation efforts (by propagating indigenous trees) in order to bring down the cloudline. First, the goats, pigs, cattle, and deer must be fenced out and eradicated. This plan is intended to give Native Hawaiians the option of choosing their own lifestyle and becoming self-sufficient.

The 'Ohana also plans to identify and restore archaeological sites. The idea is to a make them "living archaeological sites" which includes posting information and walkthroughs instead of an obscure site that is viewed by cars passing on the highway. The whole ahupua'a of Kahikinui would be a classroom where Native Hawaiian cultural practices, such as la'au lapa'au, would be taught. Children would also be taught Hawaiian approaches to land and resource management.

Finally, one kupuna summed up his feelings about land management and the ultimate rights of Native Hawaiians to the land:

From Kananena to Kaupo, from the ocean to the mountain, the Native Hawaiians have the rights to do whatever they see fit. This entire area, as far as hunting, preservation of Hawaiian historical sites, this all falls within their realm of claim, because they belong with it. This is their land. There should be no one to tell them that they have no right to cross this land. They have the right to do that. Everything is theirs. The entire ahupua'a of Kanaio and Kahikinui is theirs. Only the Native Hawaiians can manage their own land. 
We have had other agencies come in and say, "we're gonna manage this and that." A good example is right over this ridge here. There are 846 acres that the State set aside as Natural Area Reserve. They're not back there protecting it, taking care of it. The Hawaiians take from the land only what they need. They take from the ocean only what they can use. And that is to feed their families. This is not something that they learned today. This is something that was passed on down to them from their ancestors, from their kupuna. The makua to the mo'opuna. The land will give you the fruits and the food that you need to sustain life. The ocean will provide you with the fish and the food. The mountains, where the rain comes from provides the water. But all of this today, the Native Hawaiians are struggling to get back. So as far as all the fishing grounds go, I fish this entire area. I've hunted this entire area. There was no need for my father to go and say, "Ulupakalakua Ranch, I need your permission to cross your land to go hunting." When he wanted to, he saddled his favorite horse or mule and we went hunting. We didn't care who had the interest on the land, all he knew was that the land belonged to the Hawaiian people. If we are going to say who has the right to go out here any place they wanted to and get subsistence to live on, the Hawaiian people do. 


\section{CHAPTER 4}

\section{PELE BELIEFS, CUSTOMS, AND PRACTICES}

\section{INTRODUCTION}

The American Indian Religious Freedom Act of 1978 (42 U.S.C. 1996, P.L. No. 95341,1978 ) ensures that actions taken or licensed by federal agencies do not interfere with the inherent right of individual Native Americans (including American Indians, Eskimos, Aleuts, and Native Hawaiians) to believe, express, and exercise their traditional religions. These rights include access to religious sites, use and possession of sacred objects, and the freedom to worship through traditional ceremonies and rights. When a federal agency finds, upon consultation, that its proposed action would deny the free exercise of religion and yet determines that there is a compelling need for the action, the decision to proceed may be made, but appropriate mitigation measures to reduce interference with traditional religious practice to the lowest possible level must be included.

This chapter of the ethnographic study for the Hawai'i Geothermal Project describes and analyzes the beliefs, customs, and practices related to Pelehonuamea, Hawaiian female god of the volcano. The primary author for this part of the study was Pualani Kanakaole Kanahele who drew upon chants, legends, and traditions passed on to her through her family and information drawn from years of research in primary sources. Pualani's mother, Edith Kanakaole, in her lifetime, was a distinguished Hawaiian scholar and master of the Pele chants and dance. She founded Halau $\mathrm{O}$ Kekuhi, a traditional Hawaiian hula school, renowned in Hawai' $i$ and recognized by the National Endowment for the Arts as a premier hula school in the tradition of the Pele chants and dances. Pualani Kanakaole Kanahele continues as kumu hula or hula master for Halau O Kekuhi together with her sister, Nalani Kanakaole. Mrs. Kanahele is also a professor of Hawaiian language and culture at the Hawai'i Community College in Hilo and has conducted extensive research of the primary and secondary sources relating to the Pele clan. For example, in writing the manuscript Ka Honua Ola (The Living Earth) (see references) she collected 213 chants from the saga of Pele and Hi 'iaka by Nathaniel Emerson, the Bernice Pauahi Memoirs, Ka Leo O Kalahui newspaper, Ka $\mathrm{N}^{\prime a i}$ Aupuni newspaper, The Kuluwaimaka Chant Collection, the Puk'ui Collection, The Bishop Museum Bulletin, the Roberts Collection, the Lilivokalani Collection-Hawaiian Manuscript, and the Henriques Collection. Mrs. Kanahele is generally acknowledged as a foremost scholar of the Pele beliefs, customs, and practices.

On March 4-6, 1994, the Edith Kanakaole Foundation conducted a workshop retreat on the genealogy of the Pele fire clan, their migration and settlement in Hawai' $i$, the Hi'iaka and Pele cosmology, and the underlying spiritual meaning of selected chants. The presentations were given by the three Kanakaole sisters-Pualani Kanakaole Kanahele, Nalani Kanakaole and Ulunui Kanakaole Garman. The information presented represented a synthesis of years of research and study of the Pele and Hi'iaka chants and legends. Transcripts and the packet of materials from the workshop were used as the foundation of this report. An unpublished manuscript written by Pualani Kanakaole Kanahele, Ka Honua Ola (The Living Earth), also provided background material regarding the interpretation of certain Pele chants. Another major source of information were transcripts from Department of Land and Natural Resources administrative contested case hearings regarding the issuance of permits for geothermal energy development. In addition, directors of the Pele Defense Fund were 
interviewed. A complete bibliography of sources consulted by the two authors of this report is provided in the references section

The strongest and most articulate Hawaiian concerns about geothermal development have been voiced by certain practitioners of the Pele religion. From a religious standpoint, these Pele practitioners believe that geothermal energy is totally unacceptable in that it will have a fatal impact upon the continued manifestation of the volcanic deity in all her varied forms. They assert that geothermal development on the island of Hawai'i will have an irreversible and irretrievable impact on an irreplaceable resource.

It should be noted that other Hawaiian cultural experts have been called upon to provide their views on the appropriateness of developing geothermal energy. They were not Pele practitioners but trained in other traditions of belief and custom such as in Kamapua'a or were Christians who had been trained in a different belief system as their primary point of reference. There is a broad range of people, Hawaiian and non-Hawaiian, Christian and nonChristian, who acknowledge and respect Pele as deity of the Hawaiian volcano. However, they are not all active practitioners in the Pele customs, beliefs, and practices. This chapter has drawn upon and presented insights of the beliefs, customs and practices of the active Pele practitioners.

Pelehonuamea as akua (deity) is the pure and awe-inspiring energy of the volcano in all of its magnificent forms - the eruption, the flow, the earthquakes, the magma, the steam, the fireballs, etc. She is the maker of new land. She is an energy phenomenon which humans cannot reproduce.

Pele and her family migrated to Hawai' $i$ from Polynesia in "time immemorial." The family arrived on the northernmost islet of Nihoa and traveled through the chain of Hawaiian islands seeking a new home. Their joumey is marked by a series of eruptions that created new land and gave rise to new cinder cones, craters, and pu'u (hills). They finally decided to settle at the Kilauea volcano on the island of Hawai'i. From the earliest periods of Hawaiian history until today, Pele is believed to primarily reside in and embody the entire Kilauea volcano, the most active volcano in the world, which extends from Mauna Loa mountain through the $\mathrm{Ka}^{4} \mathrm{u}$ and Puna districts to the Pacific Ocean (Aluli, 1985; Kanahele, 1985).

As the home and embodiment of Pele, the entire Kilauea volcano is considered a sacred area of Pele practitioners. Pele takes the form and manifests herself in the magma, the heat, the vapor, the steam, the volcanic eruptions, and the land forms that it creates. $\mathrm{Na}$ tive plants, ferns, shrubs, and trees of the volcanic rainforests were considered to be the kino lau or body forms of other members of the Pele family (Aluli, 1985; Kanahele, 1985). They help to calm her more aggressive nature. The rainforest helps to filter out noxious gases. It also helps to regenerate the forest again after it is devastated by lava flows. The Pele fire clan deities and their connection with the Puna forest are acknowledged and honored in traditional Hawaiian chants. Gathering and weaving these plants for lei and ho'okupu (offerings) is an integral and indispensable part of the hula ceremony.

The Kilauea volcano, as the main form of Pele, is the source of spiritual power for Pele practitioners-descendants, hula masters, dancers, and worshippers, and they are obliged to protect it. Hawaiians believe that all the land is alive, especially the land which is hot, steams, and has magma under it. As long as there is steam coming out of the earth, Pele lives. The earth where the steam vents belongs to Pele and is sacred. 
Long ago, after migrating to Hawai' $\mathfrak{i}$, families who established themselves in Puna and $\mathrm{Ka}^{d} \mathrm{u}$ connected their genealogy to Pele and her family who appeared to them as the visible ancestors of the land. Through dreams these families were inspired to name their chil dren. Female children who were given Pele names passed these names on to their children. A carrier of Pele's name is obligated to honor the name. That person has a responsibility relating back to the god, the deity of that given name. The name also carries mana, spiritual force. The person is honor bound to protect the force, the spirituality, and enhance the strength of the deity through rituals, prayers, and protection of the deity (Aluli, 1985; P. Kanahele, 1985; E. Kanahele, 1985).

Aside from the living descendants of the Puna and $\mathrm{Ka}^{\prime} \mathrm{u}$ families who trace their ancestry to the Pele family, Pele is honored and perpetuated as a deity through hula dances and chants. The movements of the hula have to do with the movement of Pele herself and the movements of nature. The hula records a particular event or episode in history. Its re peated performance keeps the memory of that event and the person or deity being recognized alive through time. According to Mrs. Kanahele a new chant is composed for Pele whenever she erupts.

Pele survives as the last Hawaiian deity to be actively worshipped and honored despite over 200 years of contact. Thus, Pele is the heart and life of surviving Hawaiian religious beliefs and practices. She is central and indispensable to traditional Hawaiian religious beliefs and practices. Pele is a primary akua (god) and 'aumakua (ancestral deity) of Hawaiians today. Her blood relations continue to share traditions, genealogy, and aloha for the Puna and $\mathrm{Ka} u$ districts. Those who carry her family names; who live in her homeland of Ka'u or Puna; who worship her in chant, hula and ho'okupu; and who assume stewardship of lands in her homeland of Puna continue to feel conscience-bound to protect her life force, her body forms, and her domain in the Kilauea volcano.

The first section of this chapter describes who the Pele practitioners are today. The second section provides a genealogy of the Pele fire clan. The genealogy introduces the various members of the clan, the elemental forms that are their manifestations, and places the dominance of volcanic fire about 30 generations before Liloa, the high chief of Hawai' $i$ in approximately 1450 A.D. The third section relates the migration of the Pele fire clan from the south and through the Hawaiian islands until they finally settle in Puna, Hawai' $i$. The fourth section relates some of the recorded experiences, adventures, and exploits of the Pele fire clan in the Hawaiian islands. The fifth section describes beliefs, customs, and practices related to Pele and her family of deities. The final section discusses Hawaiian concerns about the effect of geothermal development on the Pele beliefs, customs, and practices.

\section{PELE PRACTITIONERS}

\section{Family Belief, Custom, Practice}

It is important to note that the primary practitioners of the Pele religion are those who trace their genealogy to the deity and her family. These are primarily families who are originally from $\mathrm{Ka}$ 'u and Puna. However, the Pele clan's migration chants indicate that members of the fire clan stayed behind and established themselves on other islands as the family migrated down the chain of islands. The families who migrated to Hawai'i established themselves under different deities. The families that came to Hawai"i and established themselves in Puna and $\mathrm{Ka}^{\prime} \mathrm{u}$ very quickly associated with Pele as their deity because she was 
very visible for them and readily available. They established their genealogy with her. Thus, they became part of her worship.

Hawaiian families have kept the stories which relate the history of their ancestors. Through their family history, their name lives on. When an ali' $i$ wiped out a family, their historians were wiped out too. When their family history was wiped out, their name disappeared. The Pele family has kept their family stories alive through the naming of their children, ancestor worship, chants, and hula. Thus, the Pele family name and their history lives on. Today the history of the family is still in the making because of the anestral worship. By calling upon Pele as deity and upon Hi'iaka and the rest of the clan for guidance and help, ancestral worship has continued to be a religion.

Most Hawaiian families in these districts converted to Christianity and may not continue to actively worship Pele. A few of these families stopped the active worship of the deity. Many of the informants interviewed for this ethnography described how their grandparents and elderly aunts and uncles had been dualistic in their religious practice. They would go to church on Sunday and pray to the Christian God in addition to conducting special rituals to Pele or family 'aumakua. Some kupuna passed on their beliefs, customs, and practices to the next generation and some did not. All families in Puna continue to respect the awesome power of the volcano and acknowledge the presence of Pele and her dominance over the land that she created. 48 However, they do not all consider themselves to be active Pele practitioners. Therefore, unlike the Pele practitioners, some of the Puna families accept geothermal development as part of the process of economic growth and development of Puna and the island of Hawaii.

According to Beckwith (1976), many heiau to the goddess Pele were erected in old days, particularly beside lava streams and at the edge of the crater. The bodies of the dead were offered to the goddess in the belief that their spirits will live again with Pele in a beautiful home beneath the burning pit which is the goddess' material body, and go forth as her messengers in bodies of flame to avenge any infringement of her tapus and to work her will in the land. Only those connected with the Pele family by being born with a human body from one of the Pele spirits, or a direct descendant of one of these, or one outside the family who has been adopted and given a name (in dream) by Pele herself have a right to such a burial.

Beckwith reported that the worship of Pele was not taught in the schools of the priesthood nor was her body deified. Pele's descendants alone worship her. Only actual relatives invoke her and become her keepers. Pele names are given to children born into her family, but such names belong to that individual alone and cannot be passed on to another, even to an own child.

\section{Family Names}

Those who believe in Pele and who are of the Pele family have maintained their ancestral names and the history of those names. Because they maintained those family names, the history of the Pele families live on. Names such as Ahiena, meaning intense, glowing fire, or Palikapuokamohoali' $i$, referring to the cliff in Halema'uma' $u$ Crater sacred to the

${ }^{48}$ Two earlier surveys in Puna also found that there is a strong continuity of belief and respect for Pele as the deity of the volcano (Burdette, Bostwick and Murton 1971; Puna Hui 'Ohana 1982). 
shark god brother of Pele, or Pele have been passed down from one generation to the next. The inspiration to give a child a particular family name usually comes through intense dreams and visions. Through the dream, the family member is contacted by a deity, usually Pele, or perhaps Hi' iaka. In the dream the deity says what kind of name the child is supposed to have.

Names which come through dreams are called inoa po or night names. One is obli gated to give the child the name in the dream, on pain of punishment to the child and/or the parents of the child.

The naming of a child with a Pele name establishes that these Pele people were worshipers of her. When the child is born, he or she is introduced to Pele and Pele is allowed to see him or her and accept the child. And if the child is denied, then the mother would continue to go up to the volcano with each successive pregnancy until one of the children was accepted from that family. That child would be the tender of Pele. She or he would be the one to give the offerings, say the different chants to Pele, and go to the crater whenever an offering needs to be given. That person does not have to go there all the time. Sometimes, it's only once a year. The offerings could include black pig, ohelo berries, or a chant.

A person who carries a Pele family name must honor the name. That person has a responsibility to the deity. The person must not desecrate the Pele family. The person must support the deity from which the name comes. The special family name carries a lot of mana or spiritual force from the deity. The person has to protect the force, the spiritualness that the deity has given to that particular person. Thus, they are honor-bound to enhance the strength of the deity through rituals, prayers, and protection of the deity.

A lot of times when names die, people die, and a bit of history dies because that family or that group of people have all been wiped out. When that line dies, the history of those people no longer lives. In the case of the Pele family, it has lived because there were a lot of people involved in the Pele family. They lived in and around the Pele family and saw the creation of the Pele family. They believed in this entity. So there is a lot of history in Pele.

\section{Pele Chants and Hula}

Pele can be spoken of at all different levels. The many Pele families have worshipped her differently. They are not all the same. The families look at her energy for different reasons. One line of Pele families are connected to the deity through the hula tradition. In the hula tradition, the saga of Pele and Hi'iaka has varying levels of meaning which not only convey the history of the family, their accomplishments, their natures, and their powers but also convey the history of the origin and growth of hula. In performing the hula, the dancer repeats the story and keeps the memory and knowledge of the family and the hula alive.

Chants, myths, and legends have different levels of meaning. They provide the pri mary record of the beliefs, customs, and practices special to the Pele deity. At one level the listener can enjoy the story. At another level, the stories relate history. They also pass on scientific knowledge about the environment. The stories have been passed on in order to convey values and lessons about how to treat one another. Understanding the symbolism within the chants is very important to the interpretive performance of the chant. In the hula tradition, adornments are also part of how the family story is retold. Together the hula and the change perpetuate the history of belief, custom and practice dedicated to Pele. 


\section{Hulihia Chants}

Hulihia are those kinds of mele about eruptions and eruptive phenomena. The only people who can keep those mele or who compose those mele are people who believe in that particular entity and what it has to offer. They are people in and around those areas, in those eruptive areas where it is taking place. When you read the Hulihia, they don't all have the same kind of words in them. It is because they treat the eruptive phenomena differently. It affects them differently. And it is not always the same kind of phenomenon. It may be a big mud flow, it may be only earthquakes, it may be those earthquakes that generate tidal waves. It may happen in that particular place or this particular-place. It may be an opening of the ground and then the lava flowing out, these different kind of phases. Thus, there is this idea of the different kind of history of the Pele family, the Pele religion.

\section{The Saga of Pele and Hiciaka}

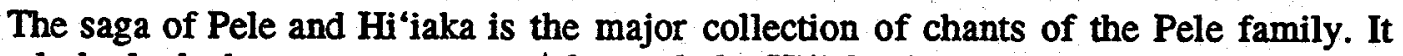
cannot only be looked upon as a process of growth for Hi'iaka, but also as the process for the growth of the hula. The saga reveals the nature and the primal power of the Pele clan by contrast to that of other natural forces, such as the Mo'o, and to other chiefly lines. Moreover, the saga reveals the existence of family members on other islands which had been touched upon by the Pele family in their migration to Hawai' $i$ island. In the beginning of the saga, Hi'iaka dances the simple hula for her sister, "Ke Ha'a La Puna I Ka Makani."

\section{Ke Ha'a La Puna I Ka Makani}

1. Ke ha'a la Puna i ka makani

Puna is dancing in the breeze

2 Ha'a ka ulu hala i Kea'au

The hala groves at Kea'au dance

3. Ha'a Ha'ena me Hopoe

Ha'ena and Hopoe dance

4. Ha'a ka wahine

The woman dances

5. 'Ami i kai o Nanahuki

(She) dances at the sea of Nanahuki

6. Hula le'a wale

Dancing is delightfully pleasing

7. I kai o Nanahuki

At the sea of Nanahuki

8. 'O Puna kai kuwa i ka hala

The voice of Puna resounds

9. Pae i ka leo o ke kai

The voice of the sea is carried. 
10. ... Ke lu la, i na pua lehua

While the lehua blossoms are being scattered.

11. Nana i kai o Hopoe

Look towards the sea of Hopoe

12. Ka wahine 'ami i kai o Nanahuki

The dancing woman is below, towards Nanahuki

13. Hula le'a wale

Dancing is delightfully pleasing

14. I kai o Nanahuki

At the sea of Nanahuki

The chant is very, very simple and it is done by a very young girl. By the time Hi' 'iaka reaches Kaua' $\mathbf{i}$, she is doing Kunihi ka mauna, the chant that is used by hula dancers to enter the halau. When dancers learn this kind of chant to enter into a halau they are at a formal stage in training. In the first stage of hula, the dancers are just reflecting movement. At the formal stage of training, the dancer is recognizing deities because they are asking permission to enter the halau.

The words in "Ke Ha'a La I Puna" have to do with movement of nature. The movements that are done in hula, the huki movement back and forth, has to do with very beginning of hula. The east represents the place of the very beginning of movement, the beginning of the movement of the winds. $\mathrm{Ha}^{\prime} \mathrm{a}$ is the archaic form of dance. The hula was called ha' $\mathrm{a}$ before it was called hula. Most images and idols are portrayed in a bent knee position, or ha'a. That concept came up from the South Pacific and is more prevalent in Hawaiian than in other images of the South Pacific. Ha'a hula is also a form of worship. $\mathrm{Ha}^{\prime} \mathrm{a}^{\prime}$ means humble/humility. This particular position gives one balance, makes one stable, brings one both negative and positive energy, and brings one balance. In sumo the bent knee position has to do with balance. 'Ai ha'a is necessary for balance. One needs to feel the ground. Hula is not danced on the toes. The ground has to do with balance and it has to do with connectedness. So the 'ai ha'a position is important in this way. The ha'a form of dance is itself in respect to what it is reflecting. The dance reflects a part of history. The dance reflects an occurrence. If the dance is performed over and over and over, then that part of history is kept alive, that occurrence is kept alive. Dancing is a reflection. If it is a reflection then it is a respect to that reflection. In hula, ha'a portrays a sense of humility. It does take on the meaning of that particular word.

The chant is one that is simple. It is for this very young girl. The imagery of ke ha'a la i puna is of the wind as it blows through Puna, through the grasslands. When one says $\mathrm{Ke}$ $\mathrm{Ha}^{\prime} \mathrm{a} \mathrm{La}$ I Puna and one watches the grass move in the wind and with the wind, it is not only dancing in the wind but it is also imitating the movement of that wind. It is not only imitating but also reflecting the movement of that wind. Looking at the movement of that grass and knowing where it's coming from and where it's going to is a reflection of that elemental form or that occurrence. In this, it is a ha'a.

The second line, "Ha'a ka ulu hala i Kea'au," refers to the hala grove down in Puna. As one nears the ocean, the sound of the waves as they hit against the sea cliffs can be heard within the grove. It gives one the nice sense of the sounding of an ipu or the resounding 


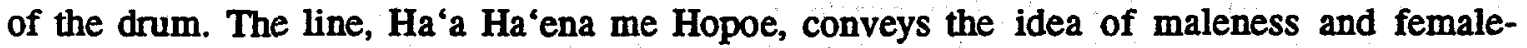
ness, the idea of the land and the flower. The idea of $\mathrm{Ha}^{\prime}$ ena is the intense first and last breath of the sun as it appears and disappears on the horizon. With that powerful breath comes the idea of Hopoe which is the dome of the sky. Hopoe, the lehua hopoe, is that perfect lehua that has that perfect dome.

In the line, "ha'a ka wahine, ka wahine" is a reference to the things from this earth, because it is from this earth. In "ami i kai o Nanahuki," we look at the different steps of the hula. 'Ami is a kind of a movement. Nanahuki is a different kind of movement. The "ami is a swirling movement. $\mathrm{Kai}$ is a pendulant movement, a pendulum movement, back and forth, such as with the kaholo and the paakauas. 'O Puna kai kuwa i ka hala, is, again, a resounding through the hala. In pae ka leo o ke kai, pae is a line, such as a line of dancers. Pae is also a line of islands. Looking at pae as a line of dancers, pae ka leo refers to how the line of dancers gets ready to go out to do their entrance, and the first thing they do is kahea, do the entry chant.

At Kaua'i, Hi'iaka meets Lohi'au who is an excellent dancer. By the time she brings Lohi'au back, Hopoe has died. Hopoe is no longer needed. The simplicity of her hula is no longer alive. It is not that she is a live person or anything, but the symbol of this is that hula has become very sophisticated and simplicity in the hula no longer exists. Hi'iaka has brought back a very sophisticated dancer with her. He doesn't come back with Pele. He doesn't come before it is ready. So Lohi'au goes down to Puna from Kaua'i, and on his way down he stops in at Pele'ula and he does a very sexual dance. All the women in the room got very excited, except Hi'iaka. That dance showed the sophisticated level of the hula at that point. Lohi'au was brought back to Hawai'i and a more sophisticated form of hula was introduced.

The Pele and Hi 'iaka saga also represents cycles. One cycle is going from east to west and then coming back to east. Another cycle has to do with hula and its growth process. There is also the replanting cycle, the cycle of death, and the re-creation and the growth pro cess. Hi'iaka herself represents the cyclical image of a lei. Within the story, at each level, the performer and the listener reach different levels of understanding through a spiral growth process. They come to a different understanding of who Pele and Hi'iaka are. Those who learn the chant, perform it, or experience its performance also come to know of and respect the powers, experiences, and nature of the different members of the Pele clan, particularly of Hi'iakaikapoliopele.

\section{Pele Defense Fund}

A contemporary form of continuing the respect, honor, and protection of the Pele fire clan is represented in the organization of Pele practitioners called Pele Defense Fund (PDF). Located on the island of Hawai' $i$, it was founded to perpetuate the Hawaiian religion and culture through recognition and revitalization of the beliefs, traditions, and practices to the Hawaiian deities, including and in particular the worship, habitats, forests, genealogy, oral histories, burials, lava tubes, places and sites, oli, haku mele, hula, and arts and crafts of Pele and her families in all forms. One of their major roles is to research and disseminate information gathered from such research concerning the significance of the Pele beliefs, traditions, and practices. They also sponsor the conduct of religious ceremonies and practices to Pele in accordance with Hawaiian religious beliefs and traditions (Pele Defense Fund, 1989). 
Through initial research and consultation with kupuna, kumu hula, and other bearers of the Pele traditions, the Pele Defense Fund developed a statement of perspectives of Pele to summarize the key tenets of the beliefs in Pele, the volcano. In part, the statement reads as follows:

1. Pele is the life force of the land and energizes the Hawaiian religious beliefs and practices today.

2. Pele has always been and is today central and indispensable to Hawaiian traditional religious beliefs and practices.

3. Nowhere in the geographical Pacific except Hawai' $i$ is there a recognized volcanonature god but Pele.

4. Pele is the akua and aumakua of Hawaiians today. Her blood relationships continue as shared traditions, genealogy, and aloha for particular 'aina and places in Hawai $i$. Pele is kupuna and "tutu" to many Native Hawaiians.

5. Pele is the inspiration, strength, and focus for those who are established in practices and performances of ancestral tradition and religion.

6. Pele influences daily spiritual and physical life activities, making it essential that Pele exist in pure form and environment.

7. Pele's person, her body - spirit, her power-mana, her very existence are the lands Hawa'' $\mathrm{i}$. Pele is the aina which she replenishes, nourishes, and protects. She is seen in special alternate body forms, along with those of her sisters and brothers, their kino lau: the native fern, the native shrub, the blossoms of the native trees.

8. Pele is a living god. She is tangible. She has a home on Hawai' $i$. She has been seen by many living in Hawai' $i$. She causes earthquakes, tidal waves, and lands to sink or surface from the ocean.

9. Pele is the magma, the heat, the vapor, the steam, and the cosmic creation which occur in volcanic eruptions. She is seen in the lava, images of her standing erect, dancing, and extending her arms with her hair flowing into the steam and clouds.

According to Noa Emmett Aluli, M.D., vice-president of the Pele Defense Fund, while Pele resides in Kilauea, wherever the earth is hot is an area sacred to the deity. The heat of Pele is an important natural resource for the constant evolution of the volcanic rainforest. Pele's warmth makes the forest dynamic and diverse genetically. Native plant and insect species continue to diversify under those conditions. Dr. Aluli visualizes Pele as being an important inspiration, protector, and healer of the Hawaiian people, especially the Pele families. In an interview he explained:

Her beauty is inspiring. The whole experience of seeing her, an ancestor; alive and active pulls you into identifying with being Hawaiian and part of this whole family. In the time of our kupuna, when Pele was erupting, flowing, steaming, her families would visit her. The kupuna speak of seeing her families, their different manifestations, and of seeing Pele. For the families she 
provides a real element of protection. They offer the bones of dead family members. They throw their hair or teeth into the volcano. They give these to Pele to permanently cover and protect. The healing too, the la'au that is gathered in the forests of Hi'iaka, the healer with the power of rebirth, is all part of the protection. Being part of the Pele line makes you part of a strong family system with connection to Pele, her sisters, her uncles, and the families today.

\section{Pele Acknowledged and Worshipped as Hawaiian Akua}

In addition to those who can trace their genealogy to Pele most people in Hawai' $i$, Hawaiian and non-Hawaiian alike, widely acknowledge and respect her as the premier Hawaiian deity of the volcano. The 1993 gathering of several hundred people around the Kilauea caldera, as discussed below in the section on beliefs, customs and practices, is one indicator of the breadth and extent of those still willing to actively participate in spiritual ceremonies focusing on Pele at the close of the twentieth century.

People not of the Pele clan also make offerings to Pele and perform her chants and dances. Arlo Nimmo in his article, "Pele, Ancient Goddess Of Contemporary Hawai' $i$ " recorded 108 newspaper and magazine articles which attribute the volcanic activity on Hawai ' $i$ to Pele. In the conclusion to his article Nimmo noted:

Pele is a significant ingredient in the culture of the contemporary Hawaiian Islands. Belief in the volcano goddess is widely held by a broad stratum of society-doctors, professors, scientists, writers, housewives, engineers, hotel managers, and countless others. Children in Hawai' $i$ are weaned on Pele stories and throughout their lives they hear of encounters with the goddess, see evidence of her wrath on the Big Island, and observe her periodic portrayal in island arts ... It is important to emphasize that the traditional belief in Pele as goddess of the volcanoes and special deity to Hawaiians in the volcano area is unbroken from the past.

He attributes the persistence of the beliefs in Pele to the continuity of beliefs and practices among Hawaiians, a revitalization of traditional culture among Hawaiians and other ethnic minorities, a renewed interest in the supernaturalism continuous volcanic eruptions and phenomena, media stories about Pele sightings, and the tourist industry (Nimmo, 1986).

At the time of Wakea, (Table 19) sky father and progenitor of the Hawaiian people, there was an existence of what was called the continual fire which was kept by the gods. This, however, was not a fire for the cooking of food. There was no cooking fire. Cooking fire came at the time of Maui a kalana, in generation 22.49

Cooking fire was brought into the culture by a person called Alaenuiahina. There are several renditions or variants to the story. Alaenuiahina had a bird form like an alae bird, and she started the mapele. Mapele is a type of tree whose branches are rubbed together in order to start a cooking fire. The term for getting fire by friction is called mapele ahi. The Hina legends speak of the origin of fire for cooking.

\footnotetext{
${ }^{4}$ Nalani Kanaka ole, workshop presentation, March 5, 1994.
} 
Table 19. Genealogy of the Pele fire clan

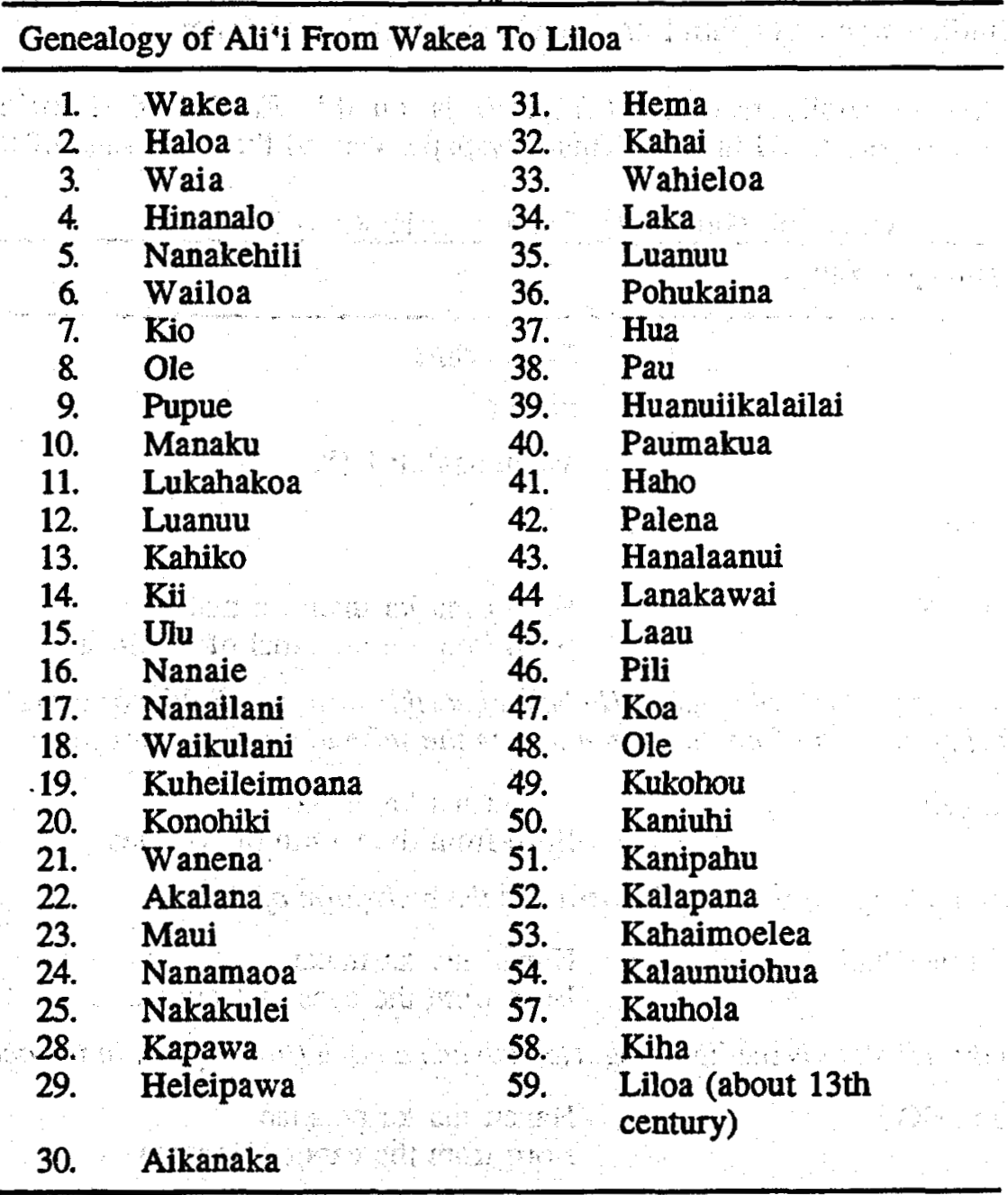

(Edith Kanakaole Foundation, 1994)

The origin of the Pele clan is after Hinanalo of the fourth generation when Kaikahinali' $i$ or kahinali' $i$, the great flood occurred. Every primitive people has a record of a great flood, and in Hawaiian mo'oku'auhau (genealogy) it occurs in the fourth generation after Wakea. 50

Volcanic fire is introduced into the culture at a later date, a later generation. Volcanic fire was called ahipele. In the genealogy chart, volcanic fire happens after the time of Maui in the twenty-third generation and before Kapawa of the twenty-eighth generation. Within those four generations ahipele became prevalent in the culture.

Pele came from several places. There are several genealogies that are recorded. In general knowledge, it is acknowledged that Haumea was the mother of Pele and all the fam-

${ }^{50}$ Some traditions suggest multiple floods. For example, Kepelino and the Kumulipo mention four floods. 
ily. Now Haumea was considered god-like, and it was usually a union of two gods that produced these children who had control or mana over either fire or water.

The following family genealogy (Table 20) is found in Ka Hoki O Hawai ${ }^{\prime}$, a Hawaiian language newspaper, based in Hilo. This newspaper carried the main saga of the Pele fire

Table 20. Genealogy from "Ka Hoku O Hawai'i ${ }^{\prime}$ "

(Ka Hoku O Hawai'i, 1908)

Makuahine
Mother
Haumea (W)
Na Keiki a Laua
Their Children

1. Kamohoali'i (K)

\section{Makuakane \\ Father \\ Moemoea'ali'i (K)}

Hanau ma ka manawa mai

Born from the fontanel of Haumea

His ocean form was the body of a mano. He had an earthly form of a Paliku or upright cliff which has lifted straight out from the ocean during the seismic shifting of the plates.
2. Kanehekili (K)
Hanau ma ka waha
Born from the mouth of Haumea

Kanehikili was in charge of thunder. He assumed the body form of thunder.
3. Kauwilanuimakehaikalani (K)
Hanau ma ka maka
Born from the eyes of Haumea

Kauwilanuimakehaikalani is the lightning. He also has a honu (turtle) form in the ocean.

4. Kuhaimoana (K)

He took the body form of a mano.

5. Kanemilohae (K)

He had the body form of a mano.
Hanau ma ka pepeiao

Born from the ears of Haumea

Hanau ma ka poholima akau

Born from the right palm of Haumea

6. Leho (K)

7. Kaneikokala (K)

8. Namakaokaha'i (W)
Hanau ma ka 'opu'upu'u lima Born from the knuckles of Haumea

Hanau ma ka manamanalima Born from the fingers of Haumea

Hanau ma ka umauma Born from the chest of Haumea

An ocean form. Also probably had a mo'o (dragon lizard) form. 
Table 20 (continued)

9. Pelehonuamea (W)

Hanau ma kahi mau e hanau 'ia ai ke kanaka

Born from the usual place of birth as people

Her body forms are the volcanic forces - eruptions, earthquakes, magma, flowing lava, steam, etc. She also took the form of an old woman or a beautiful young woman. Terms for various forms of volcanic matter are: pahoehoe-the smooth unbroken lava; $a$ 'a-the rough rocky lava; eleku-pumice; ana-cinders; ala-basalt; lauoho-Pele's hair; waimaka-olivine crystals; popoahi-giant lava balls emitted by a shield volcano, usually on the Mauna Loa ridge.

10. Kapo'ulakina'u (W)

Hanau ma na kuli

Born from the knees of Haumea

When she is worshipped as goddess of hula, the halapepe tree is her kino lau. Kina'u is a term used. for a certain type of puhi.

11. Kapokohelele (W)

Hanau ma ka 'opu'upu'u wawae

Born from the ankles of Haumea

Kapokohelele saved Pele from being killed by Kamapua' $a$. Kapokohelele means that she is able to throw her kohe (vagina). She was the one who enticed Kamapua' a away from assaulting Pele by throwing her kohe before him and up into the air. When it fell back down to earth it became Kohelepelepe, also known as Koko Head Crater on $O^{\prime}$ ahu.

\section{Hi'iakakalukalu (W)}

Kalukalu has to do with reforestation.
Hanau ma na manamanawawae Born from the toes of Haumea

\section{Hi'iakakuilei (W)}

Hanau ma na Kapua'iwawae

Born from the feet of Haumea

She was also a character that came along with Pele. She was the one that prepared the awa. The eldest usually prepares the awa.

14. Hi'iakaikapoliopele
Hanau ma na poholima ma ka ano me he hua moa ala

Born in the palm in the shape of an egg.

She is the muli, the youngest. She probably was the most talented of the family. She was able to be a kaula, a seer. She was a prophet. She had powers in anaana, not only snatching of life, but bringing life up from the dead. She had to do with the reforestation of lava flows. She was brought from Kahiki or Kapakapakaua or kapaahu in the form of an egg, and she was cared for when she came up with her family. In Fornander, the mother of Pele is Kaikahinali' $i$ and the makuakane as Kanehoalani. Kanehoali' $i$, rather than Moemoea'ali' $i$, is more widely known as the father of Pele. Fornander lists only three children: Kamohoali' $i$, Kahuilaokalani, and Pelehonuamea. 
Table 21. Genealogy of Pele

from Fornander's Collection of Hawaïian Folklore

Makuahine

Makuakane

Mother

Father

Kaikahinali'i

Kanehoalani

Na keiki a laua/Their Children

1. Kamohoali'i (K)

Hanau'ia i Hapakuela

Born at Hapakuela

2. Kahuilaokalani (K)

Hanau'ia i Hapakuela

Born at Hapakuela

3. Pelehonuamea (W)

Hanau'ia i Hapakuela

Born at Hapakuela

clan in Hawai' $\mathrm{i}$, Pele and Hi'iaka, from May 21,1908 , to September 10,1908 . In order to establish the birthright and lineage of the family the newspaper opened the story with the genealogy.

From the genealogy taken out of Ka Hoku O Hawai ${ }^{~} i$, the mother of Pele was Haumea and her father was Moemoe'ali' $i$. Among their children, Kamohoali'i is noted as the eldest. He was born from the fontanel which was considered to be a piko or navel on the top of the head. The genealogy lists down all of the children and from where they were born, an indication of the nature of the powers. Kamohoali' $i$ was considered godlike in many ways as far as the Pele family was concerned. He was higher than Pele. There was Kanehekili, Kauwilanuimakehaikalani Kuhaimoana, Kanemilohae, Leho, Kaneikokala, Namakaokaha'i, Pelehonuamea, Kapoulukina' $u$, Kapokohelele (these two are separated), and then Hi'iakakalukalu, Hi'iakakuuilei and Hi'iakaikapoliopele. Following each section of the genealogy is added in italics by the authors a brief explanation of the body forms and manifestations of the Pele family member.

The third genealogy, "The Genealogy of Pelehonuamea" (Table 22), lists six children: Kamohoali 'i, Kanehekili, Namakaokaha'i, Pelehonuamea, and Hi'iakaikapoliopele. These are the most important characters in the Pele and Hi'iaka saga which is set in the Hawaiian archipelago. 
Table 22. Genealogy of Pelehonuamea

\begin{tabular}{ll}
\hline $\begin{array}{l}\text { Mother } \\
\text { Haumea }\end{array}$ & $\begin{array}{c}\text { Eather } \\
\text { Kuwaha'ilo }\end{array}$ \\
1. Kamohoali'i (M) & Their children \\
2. Kanehekeli (M) & Born from the top of the head \\
3. Kauilanui (M) & Born from the mouth \\
4. Namakaokaha'i (F) & Born from the eyes \\
5. Pelehonuamea (F) & Born from the chest \\
6. Hi'iakaikapoliopele (F) & Born from the thigh \\
\hline
\end{tabular}

The following chant provides an overview of the akua and 'aumakua forms of Kane connected to each of the Hawaiian islands. In viewing the Pele family, the island of Hawai' $i$ and the Kilauea caldera are usually the focal point. This chant gives a different perspective on Pele and the fact that Kane is the focus of the family and Pele a by-product of this major God. Kaneikawaiola is the source of the subsurface waters which forms into the volcanic steam which is the life stream of the volcano deity, Pelehonuamea. Eastern parts of the islands are considered his traditional domain in his form as the rising sun. On the island of Hawai' $i$, the eastern part of the island is Puna and is also where the Pele clan found a wel come home in which to settle. In the Pele clan, Hi'iaka is the female counterpart to Kane of the rising sun.

Despite the Ku names, the chiefs are manifestations of Kane and most of the names in the chant are connected to one or other of the Pele genealogy. Pele is dominant for Hawai' $i$ because of the energy of magma and lava. Kahuilaokalani and Kanehekili are connected with electrical energy of the atmosphere displayed on Maui and Moloka' $i$ in the form of thunder and lightning. Kuhaimoana, $\mathrm{Ka}$ 'ahupahau and Kamohohali ${ }^{\text {' }} \mathrm{i}$ are all shark forms. During 'Hi'iaka's trip to and from Kaua'i to fetch Lohiau, she encounters other shark forms who she regards as paternal related kupuna who are Kane forms.

\section{'O Kane 'O Wai Ia Ali'i}

1. 'O Kane ' wai ia ali'i o Hawai' $i$ ?

Hey Kane, who is this chief of Hawa''i?

2 'O Pele ia ali'i o Hawai' 1 ,

Pele is the one who is chief of Hawai' $i$,

3. He li'i no La'auli, no La'akea,

Chiefess of sacred darkness and sacred light.

4. 'Au'au i ka wai polihua e Kane.

Hey Kane, bathe in the water Polihua.

5. Ina ke aloha e Kane, hele mai e Kane

If you have love, Kane, come 
6. He Kapua'i Akua, he Kapua'i kanaka.

Walk as a God, walk as a man.

7. 'O wai ia ali'i o Maui?

Who is this chief of Maui?

8. 'O Kanehikili keli'i o Maui.

Kanehikili is the chief of Maui.

9. 'O wai ia ali'i o Moloka'i?

Who is the chief of Moloka' $i$ ?

10. 'O Kahuilaokalani keli'i o Moloka'i.

Kahuilaokalani is the chief of Moloka' $i$.

11. 'O wai ia ali'i o Lana'i?

Who is that chief of Lana'i?

12. 'O Leapua ke ali'i o Lana'i.

Leapua is the chief of Lana' $i$.

13. 'O wai ia ali'ì o $O^{\prime}$ 'ahu?

Who is the chief of $\mathrm{O}^{\prime}$ ahu?

14 'O Ka'ahupahau ke ali'i o O'ahu.

Ka'ahupahau is the chief of $\mathrm{O}^{\prime} \mathrm{ahu}$.

15. 'O wai ia ali'i o Kaua'i?

Who is the chief of Kaua'i?

16. 'O Kamohoali'i ke ai'i o Kaua'i.

Kamohoali' $i$ is the chief of Kaua' $i$.

17. 'O wai ia ali'i o Ni'ihau?

Who is the chief of Ni'ihau?

18. 'O Kalalakea ke ali'i o Ni'ihau.

Kalalakea is the chief of $\mathrm{Ni}^{\text {'ihau. }}$

19. 'O wai ia ali'i o $\mathrm{Ka}$ 'ula?

Who is the chief of $\mathrm{Ka}$ 'ula?

20. 'O Kuhaimoana ke ali'i o $\mathrm{Ka}$ 'ula Kuhaimoana is the chief of $\mathrm{Ka}$ 'ula.

21. 'O wai ia ali'i o Kamokupapa?

Who is the chief of Kamokupapa?

22. 'O Ku ke ali'i o Kamokupapa.

$\mathrm{Ku}$ is the chief of Kamokupapa. 


\section{Migration Of The Pele Clan To Hawai'i}

As Pele begins her journey to Hawai' $i$ she asks permission of both mother and father, and finally the eldest brother Kamohoali' $i$. In response to questions about her destination she responds, "I am going to go to the island of Polapola (Borabora), Kahiki. From this island I will arrive at Kuaihelani, the land of Kanehunamoku. From this island I will travel to the island of Manamana and finally to the place of the ali iwahine Ka'Oahi." Her island was

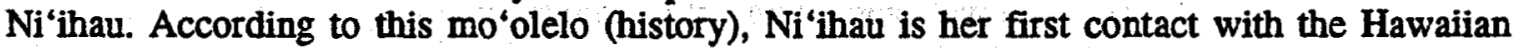
island chain. The island of Manamana proposes a question of location. Whether it is part of the southern Polynesian islands or a reference to the low laying island in the northwest section of the Hawaiian chain or the Hawaiian islands, themselves, is unclear.

This version of the migration chant of Pele starts from her homeland of Kahiki. The land of Polapola, or Borabora, is mentioned as a starting off point for the Pele clan. In the Beckwith narrative version of this migration saga Kahiki or Borabora was to be her first stop (Beckwith, 1976). She embarks upon this leg of her journey with the signs and splendor of the god Kane. This is her first trip to Hawai'i. The vessel made and secured for her by Kanekalaihonua, the carver, was named Honuaiakea.

After the carving of the canoe, as described in lines seven through nine, the time for sailing is right. Malau is given the task of emptying the bottom of the boat. The question is asked as to who should assume the prestigious position of steersman. Pelehonuamea is offered the prestigious task. Hi'iaka is the deity who enters the house of Pele. She bears no gifts.

The imagery of voyaging is abundant in this chant. The valuable information which this chant offers is the name of the canoe, the carver, the place of departure, and intended place of arrival. The names of the travelers are Pele, Hi 'iaka, Kamohoali'i, and Malau. Nontravelers mentioned are Lono and $\mathrm{Ku}$.

\section{He Oli Huaka'i A Pele}

1. Mai Kahiki ka wahine, 'o Pele, From Kahiki came the woman, Pele.

2 Mai ka 'aina i Polapola

From the land of Borabora

3. Mai ka punohu'ula a Kane, From the red rising mist of Kane

4. Mai ka ao lalapa i ka lani, From the flashing clouds in the heavens

5. Mai ka opua lapa i Kahiki.

From the flashing clouds of Kahiki.

6. Lapaku i Hawai'i ka wahine, o Pele;

The woman, Pele, bursts forth to Hawai's; 
7. Kalai i ka wa'a Honuaiakea, She carves the ship Honuaiakea,

8. Kou wa'a, e Kamohoali'i.

It is your ship, Kamohoali'i.

9. I apo'a ka moku i pa'a;

The ship was worked on until completed;

10. Ua hoa ka wa'a o ke Akua,

The ship of the God was secured,

11. Ka wa'a o Kanekalaihonua.

The ship of Kane the earth carver.

12. Holo mai ke au, a'ea'e Pelehonuamea;

The tide for sailing has arrived, Pelehonuamea rises upon it;

13. A'ea'e ka Lani, aipuni'a i ka moku

The royal one surmounts the waves, to circle the island.

14. A'e'e Kini o ke Akua

Followed by the many other gods

15. Noho a'e 'o Malau.

Malau sits.

16. Ua ka'ia ka liu o ka wa'a.

The bilge of the boat is emptied.

17. Ia wa ka hope, ka li'u o ka wa'a e nahoa li'i?

Who should steer, a skilled position of the canoe companions?

18. Ia Pelehonuamea

Pelehonuamea is suited for this job

19. A'ea'e kai hoe oluna o ka wa'a,

Rise to the large paddle on the canoe,

20. 'O ku ma, laua 'o Lono

$\mathrm{Ku}$ and Lono

21. Noho i ka honua 'aina

Will stay on shore

22. Kau aku i ho'olewa moku.

Stay upon dry land.

23. Hi'iaka, no'iau, he akua

Hi'iaka, goddess of great wisdom 
24. Ku a'e, hele a noho i ka hale o Pele. Rise, go and enter the house of Pele.

25. Huahaua'i Kahiki, lapa uila, e Pele. Bursting forth to Kahiki, lightning flashing, Pele.

26. E hua'i, e!

Pushing forward!

The following migratory story of Pele and her family begins in the Hawaiian archipelago. A safe canoe journey demands discipline, and people traveling together must be able to get along and each one must know their place on the canoe. This chant indicates a warmth among Pele family members which other chants do not have. It emotes caring for each other, nostalgia, respect, as well as the sense of carrying out responsibilities.

The first line sets the tone for the rest of the chant. The brothers and sisters traveling together were caring and compatible with each other. Kamohoali' $i$, the eldest and most revered brother of the Pele clan, is the navigator for this trip. The trust they have in the skill of their navigator in order to travel with him on uncharted and rough seas is described in lines two, five, six and seven.

The other person responsible for handling the canoe was Kaneapua whose task it was to turn the nose of the canoe about and push it out to sea. Kaneapua accomplishes this task but he was inadvertently left on Nihoa. Kamohoali $i$ was convinced by the family to turn the canoe about and rescue the younger sibling. After the rescue Kaneapua again takes his place upon the platform of the wa'a. Kanehoalani is another male character who has an important role in this migration. He is the father of the Pele clan, and Pele shares a moment of nostalgia with him in lines thirty-nine through forty-five.

Paoa is the divining rod used to search out new and appropriate land for this family. Paoa is a name used by different male characters in the Pele and Hi'iaka saga. Thus far, the names mentioned in this mele are those of the eldest and youngest male in the family as well as the makuakane. This story, however, is told in the first person, one of the few chants for which the implied persona of the storyteller is Pele.

The islands and special places upon the islands which they encountered are in the following order of arrival:

1. Nihoa

2. Lehua

3. Nihoa

4. Ni'ihau

5. Kaua'i

6. O'ahu - Ali'a pa'akai

- Peléula

- Kapo'ulakina'u

- Makapu'u

7. Hawai' $i$ - Makahanaloa

- Puna 
Information on the islands of Ka'ula, Moloka'i, Lana'i, Maui, and Kaho'olawe are not recorded in this chant but are mentioned in other narratives. The ending is rather abrupt and the entire chant seems fragmented, indications that the chant is probably incomplete.

\section{Ke Ka'ao A Pele I Ha'awi Ia Kamohoali'i I Ka Ha'alele 'Ana Ia Kahiki}

1. Ku makou e hele me $k^{\prime} \mathbf{u}$ mau poki'i aloha.

We started our journey, my siblings and $I$.

2. Ka 'aina a makou i 'ike'ole ai malalo aku nei, To a land below we had not seen before,

3. A'e makou me ku'u poki'i, kau i ka wa'a; Myself and my siblings climbed upon a vessel;

4. No'iau ka hoe a Kamohoali' $\mathfrak{i}$;

Kamohoali'i being the skilled navigator;

5. A'ea'e, kau i ka nalu,

Rising upon the wave,

6. He nalu haki kakala,

Riding the crest of a wave,

7. He nalu e imi ana i ka 'aina e hiki aku ai.

A wave in search of land to land upon.

8. 'O Nihoa ka aina a makou i pae mua aku ai';

Nihoa was the land upon which we arrived first;

9. Lele a'e nei makou, kau i uka o Nihoa.

We landed and went on shore.

10. 'O ka hana no a ko'u poki'i, a Kaneapua,

The task of my younger brother, Kaneapua,

11. 'O ka ho'oili i ka ihu o ka wa'a a n ou i ke kai

Was to turn the bow of the canoe and push it into the sea

12. Waiho anei o Kamohoali' $i$ ia Kaneapua i uka o Nihoa.

Kamohoali'i pushed off leaving Kaneapua on Nihoa.

13. No'iau ka hoe a Kamohoali'i

Kamohoali' $i$ was indeed the skilled navigator

14. A pae i ka 'aina i kapa 'ia o Lehua.

And we landed next on an island known as Lehua. 
15. Huli iho nei ka wa'a a Kamohoali' $i$

Kamohoali' $i$ turn the canoe about

16. E ki'i aku nei ko lakou poki 'i, ia Kaneapua, i Nihoa

To fetch our favorite Kaneapua at Nihoa

17. Pili aku nei ka wa'a o Kamohoali'i i uka nei o Nihoa,

The canoe of Kamohoali'i once again landed on Nihoa,

18. Kahea aku nei i ko lakou poki'i ia Kaneapua

They called out to their favorite one, Kaneapua

19. E kau aku ma ka pola o ka wa'a.

To climb onto the platform of the vessel.

20. Huli iho nei ka ihu o ka wa'a o Kamohoali' $i$;

The canoe of Kamohoali'i headed back out to sea;

21. He wa'a e holo ana i Ni'ihau

And sailed to Ni'ihau

22. Kau aku nei o Kamohoali'i i ka la'au, he paoa,

Kamohoali' $i$ consulted with Paoa the magical staff,

23. E imi ana i ko lakou 'aina e noho ai, o Kaua'i;

Searching for the land in which they could reside, perhaps Kaua' $i$;

24. 'A'ole na'e i loa'a

However, this was not favorable

25. Kau mai la o Kamohoali'i ka la'au, he paoa.

Again Kamohoali'i consulted the land searching rod, Paoa.

26. O'ahu ka 'aina

Perhaps 'Ahu (O'ahu) was the land

27. Ia $\mathrm{ka}$ ana iho nei o lakou i All'apa'akai

Ali'apa'akai was evaluated and surveyed by them

28. 'A'ole na'e he 'aina.

This was not the land suited for them.

29. Ke ku nei makou e imi kahi e noho ai

We started again in search for a suitable abode

30. A loa'a ma Pele'ula

Perhaps Pele'ula was the place

31. O Kapo 'ulakina'u ka wahine

The woman Kapo'ulakina'u 
32. A loa'a i ka lae kapu o Makapu'u.

Was found at the sacred cape of Makapu'u.

33. Iaila pau ke kuleana.

It was there where we thought it would end.

34. Imi ia Kanehoalani

We searched for Kanehoalani

35. A loa'a i ka lae o Makahanaloa

And he was found at the cape of Makahanaloa

36. He loa ka uka o Puna

The uplands of Puna was far in the distance

37. 'Elua kaua i ke kapa ho'okahi

At one time we shared one covering

38. Akahi au a 'ike haupu mau, walohia wale,

I began to recall those memories and called out,

39. E Kanehoalani, e! Kanehoalani!

40. E Kanehoalani, e!

Hey, Kanehoalani!

41. Aloha kaua!

Greetings to us!

42. Kau ka hoku ho'okahi, hele i ke ala loa!

Relying upon the star we traveled the long trail!

43. Aloha kama kuku kapa a ka wahine!

Greeting to the child of the kapa beating woman!

44. He wahine lohiau, nana i ka makani

An inactive woman, observing the wind

45. He makani lohiau, haupu mai oloko!

An inert wind, smouldering within!

On the island of Maui, Pele explored the western part of the island as well as Moloka'i and Lana'i to find a dry place for her eternal fires. She moved on to Haleakala. While there, Pele's enemy, her sister Namakaokaha'i who had doggedly trailed the migrating family from Kahiki, arrived with the sea dragon Ha-ui. At Kahikinui, on the slopes of Haleakala, Pele battled the two fierce sea monsters and her body was dismembered. Parts of her body were thrown to Hana near Kauiki and formed the hill called Kaiwiopele (the bones of Pele). Na-maka-o-ka-hai'i believed that she had finally destroyed her sister. However, Pele's spirit body lived and she became stronger in the transformed state of a goddess. Pele, 
now goddess, continued her search for a new home on the island of Hawai'i (Emerson, 1915; Beckwith, 1976).

The arrival of the Pele clan to the island of Hawai' $i$ and the deep sense of belonging to this island prompts this chant from Pele. She looks back over the cluster of islands to the northwest of Hawai' $i$ and bids farewell to them. The important information found in this chant and not found in other Pele migration chants are the names of the principal travelers belonging to this clan-Kamohoali' $i$, Pelehonuamea, Kane, Kanemiloha' $i$, Kaneapua, and Hi'iakaikapoliopele. The three kaikunane, or brothers, are of Kane descent. Kamohoali'i, also known as Kanemohoali' $i$, is the shark. He is the foundation upon which Pele builds. He is the exposed foundation or precipice and the navigator of Hunuaiakaea, the voyaging canoe, of the Pele clan. Kanemiloha'i, another champion and kunane of Pele, is the steersman of the canoe and is said to preside over Kamokupapapa or the low laying northwest islands of this archipelago. The younger kunane is Kaneapua is described in many different mo'olelo. He has the leading role in the story of Wahanui which takes place on the island of Lana' $i$. During the migration of the Pele clan he is left back on the island of Nihoa by Kamohoali' $i$ and is then rescued by his family.

The heroines are Pele and Hi'iaka. This chant shows a definite intent by Pele to establish her domain on Hawai'i during her southeast trek.

\section{Ke Ka'ao Na Pele, I Ha'alele Ai Ia Maui}

1. Aloha o Maul, aloha e!

Farewell to you Maui, farewell!

2. Aloha o Moloka'i, aloha e!

And you Moloka' $i$, farewell!

3. Aloha o Lana'i, aloha e!

Farewell to you Lana i, farewell!

4. Aloha o Kaho'olawe, aloha e!

Farewell Kaho'olawe, farewell!

5. Ku makou e hele, e!

We rise to travel

6. Hawai'i ka ka aina

To Hawai' $i$, our land

7. A makou e noho ai a mau loa aku;

Where we will reside forever;

8. Ke ala ho'i a makou i hiki mai ai,

We follow the path until we arrived,

9. He ala paoa ole ko Kamohoali' $i$,

A path not found by the paoa rod, 
10. Ko Pele, ko Kanemilohai, ko Kaneapua, But one traveled by Kamohoali'i, Pele, Kanemiloha'i, Kaneapua,

11. Ko Hi'iaka ka no'iau i ka poli o Pele, And Hi'iaka, the gifted one, in the bosom of Pele,

12. I hiki mai ai.

They have arrived.

The following chant not only tells of the migration of the Pele fire clan to Hawai $i$, it is also composed in the genre of a hulihia chant. Hulihia means overturned, overthrown, and upheaval. The hulihia chants describe volcanic eruptive phases and include words for earthquakes, moving lava, leaping fire caused by lava flows, the characteristic of fast or slow moving lava, clouds formed by steam or the heat of the volcano, the rising and falling of land, and all weather impacted by or produced from eruptive phases. The following chant describes creation, the abilities of the goddess Pele, her migration to Hawai ${ }^{\prime} i$, the establishment of her new home, and the laws sacred to the fire deity.

In the following chant Pele asks her parents for permission to leave her homeland which, however, is not revealed. Hi'iaka, the egg child, is given to Pele and she leaves with her wrapped in her skirt. She sketches a brief plan of her journey to her parents as well as her older brother, Kamohoali'i. She planned her first stop on the island of Polapola or Kahiki, then on to the island of $\mathrm{Ku}$ 'aihelani which she describes as being Kanehunamoku. From this place she planned to travel to Moku Manamana, a place close to the ali'iwahine Ka'oahi and her island of $\mathrm{Ni}$ 'ihau.

According to this chant Polapola is completely devastated and changed upon her departure. Kahiki is known as the land of the gods. Kahiki is a name used for any foreign land, but Kahiki in association with the gods existed from the beginning of time or as long as the gods were in existence. Kahiki may be different places at different time periods; however, in the Pele and Hi'iaka saga, Kahiki is the land she sails off to initially and remains long enough at this place so that Kahiki becomes synonymous with her family's ancestral home.

Haumea, the female deity of the land, is mentioned first. She is the mother of Pele and the one who represents female fertility. She would naturally be the one given credit for nourishing and nurturing land. This hulihia includes references to land existing from the beginning of time. The chant continues with the meeting place of sky and earth or male and female. This area is called Kahikiku or the horizon or more specifically the sky section of the horizon.

Lines twelve to fifteen gives an indication of a rebellion or a closing out of an era and the beginning of a new time period with the repetition of the word hina. Kukulu o Kahiki is a reference to the pillars which hold up and separate the sky from the earth. The concept of the pillar usually indicates an earlier period of time where domains, rights, laws, personalities, lineages, and responsibilities were established.

Pele's primary function, which is volcanic eruption, also impacts upon the atmosphere. Thus Pele's kinolau are also thunder, lightning, heavy rains, earthquakes, whirlwinds, smoke, steam, cloud forms, and fire. These are the kinolau which connect Pele to Kane and Lono. The tremors of Pele are also felt below the surface of the ocean to the coral beds to another dimension covered by the movement of Pele, referred to in lines 36 and 37. 
The sound of the pahu, or sacred drum, in line 50 is closely associated with the hula. It was the sound of the pahu which caused the spirit body of Pele to wander off to the island of Kaua' $i$ where she met and fell in love with Lohiau. The sound of the pahu on the luakini heiau reminds those who hear it that the kapu period has began. In lines 51 and 52, the eruption of Pele is not limited to the land but extends into the sea as well. It cuts into the ocean working its way towards a southeast direction. The path to Kane of the east and Kanaloa of the south becomes shorter.

The laws spoken of in lines 53, 54, 55, and 56 are literal. The back of Pele is kapu or sacred because it is hot. Therefore, no one stands at her back. The concept behind this idea is that if the earth is hot it still belongs to the Goddess and if it belongs to her it is sacred. If the earth steams or if any other sign of heat still exists on the land or the water surrounding the land because of volcanic activities, then the effect of the law still exists. Using ki as the intensifier before ho' $i k{ }^{\prime}$ ' $i$, the idea of immediate restoration of life after an eruption emerges. Restoration after an enuption is vital; therefore, the dependency on Hi'iaka and the responsibilities of the other siblings is utilized at this time in order to uphold this law. Restoration is done quickly and in the same sequence after each eruption. The effects of the rain and wind help bring life to the lava. Seedlings blown by the wind and moistened by the rain produce algae, lichen, moss, ferns, and then woody plants such as the 'ohi' $a$. The laws are observed out of respect for Pele and her creative abilities.

\section{Hulihia Ke Au, Ka Papa Honua O Kona Moku}

1. Hulihia ke au, ka papa honua o kona moku

The tide of time to be overturned is here, yes, the very foundation of Her island

2. Hulihia, kulia mai ka moku o Kahiki

A complete change, the island of Kahiki was outstanding

3. Aina no Kahiki i ka la kahi.

Kahiki, a land from the beginning of time.

4. Aina ho 'owall'a e Haumea

A land made supple by Haumea

5. Ho'omoe aku la Kahiki-ku

Then laid out towards Kahikiku, the horizon

6. Kulapa mai ka ulu wela, o mai ke ahi

The growing heat multiplies, as the fire digs forth

7. Ke'ehi aku la no e nalo kapua'i, e

Stamping out everything to conceal the footprints,

8. Kapua'i akua no Pele.

The prints of the Goddess, of Pele

9. Ke ke'eke'ehi wale la no i ka lani

Treading yonder towards the heavens 
10. Ha'ule, u'ina i Polapola

Finally falling, splashing at Borabora

11. Noho i ka lau ha'a o ka moku

To dwell in the low lying vegetation of the island

12. Hina kukulu o Kahiki

The pillars of Kahiki has fallen

13. Hina ka 'muku o ka makani

The wind shafts blew a straight course

14. Hina ka pae'opua ki'i ke ao

The light fetching clouds has dropped.

15. Hina ka 'onohi 'ula i ka lani

The red eyeball dwelling in the heavens has fallen

16. Kanewenewe'opua i ke kai

The billowy clouds are at sea

17. Ea mai ana ma Nihoa

Rising up at Nihoa

18. Ma ka mole mai o Lehua.

At the very foundation of Lehua

19. Mai Kaua'i nui o

From great Kaua'i

20. O'ahu, a Moloka'i

O'ahu to Moloka'i

21. Lana'i a Kanaloa, mai Maui a Hawai' $i$,

From Lana'i to Kanaloa, then Maui to Hawai' $i$

22. Ka Wahine-o Pele-i hi'a i kana ahi

Comes the woman, Pele, to spark here fires alive

23. A'a pulupulu, kukuni, wela ka lani

The kindled fire alites, blazes, heated are the higher extremities

24. He uwila ku'i no ka honua

Lightning strikes the earth

25. Hekili pa'apa'ina i ke ao

Thunder crackles at the light of day

26. Pohaku puoho, lele iluna

Stones exploding, flying upwards 
27. 'Opa'ipa'i wale ka Mauna

The mountain trembles

28. Pipili ka lani, pa'a ia moku

The heavens descend, firmly touches the land

29. Nalo Hawai'i i ka uahi a ka Wahine,

Hawai' $i$ is concealed in the smoke of the Woman,

30. I ka lili a ke Akua!

All because of the anguish of the God

31. Ke lauwili nei ka makani,

The winds are twisting

32. Ho'anoano mai ana na eho lapa uwila

The increasing flashing lightning are revered

33. Hekili wawahi ka lani

Thunder shatters the heavens

34. Ku loloku ka ua i uka

The rains fall in torrents in the uplands

35. Ku'i ka hekili, ne'i ka ola'i

With the crack of thunder, the earth rumbles

36. Lele kapu i kai

To the sacred altar at sea

37. Hiki lele ai i lalo o Kaneluhonua

Reaching below to the depths of Kaneluhonua

38. $O$ Kanepuahiohio, wili, Kanepuahiohio whirls

39. Wili 'ia i uka, wili 'ia i kai

Twists upland, twists seaward

40. Wili 'ia i luna, wili ia i lalo

Twists up and down

41. Wili ia i ka ua

And whirls through the rain

42. I ka ho'ole aku, ho'ole mana

Because of the denial, denial of power

43. Ka ho omalau, e, ka ho'0-maloka

The irreligious, neglecting the gods 
44. Ke 'Apapanu'u, ke 'Apapalani

Those of Keapapanu'u and $\mathrm{Ke}^{\prime}$ apapalani

45. 'O Manokalanipo. 'o ke aka leihulu

Manokalanipo, the reflection of royalty

46. Hulu o manu kiu, 'o manu ahiahi

Feathers from the birds who secretly observes and tattles

47. 'O manu 'aha'i lono

The birds who bring news

48. Haina a'e ana ka mana o ko'u Akua

Telling of the strength of my God

49. Iwaho nei la, e, ha'ina ho'i!

A declaration is made abroad, announce the news!

50. Kukulu ka pahu kapu a ka leo

The voice of the sacred drum is upheld

51. He ala hele, he ala muku

A pathway, a short path

52. No Kane, laua o Kanaloa

For Kane and Kanaloa

53. He ki ho'iho'i kanawai

A law provided for swift restoration

54. He kai 'okia kanawai

A sea separating edict

55. He kua a kanawai

A decree of the burning back

56. No Pele, no ko'u Akua, la!

For Pele, for my God!

\section{The Pele Clan In Hawai'i}

The Pele clan was responsible for several cultural innovations. They were responsible for elevating 'aumakua worship to a new level of significance. They were also responsible for mass education through the hula. It was not only mass education, it was also subliminal education. Through the Pele clan, hula went to a high form and gained a broad following. Before it was only done in little crowds. With the Pele clan, hula was used as an educating tool. The fire clan were also responsible for introducing dogs into the culture. Pork, a ritual food for men, was kapu to women. Dogs were introduced as the ritual food for women. They also introduced a recognition of dog forms in the clouds, those clouds which come and gather to bring on rain. The Pele clan introduced $\mathbf{k i}^{6} \mathrm{i}$ into the culture. Prior to that, Hawaiians utilized pohaku for the worship of the deities. The worship of images was a major innovation into the 
cuilture. Pele brought with her a whole family of Kalai or carvers such as Kalaiwa'a and Kalaiki 'i. ${ }^{51}$

A history of the life of the Pele clan in Hawai'i has been passed down from one generation to another to the present through chants, hula, and legends.

Chants and hula relating the epic saga of Pele, Hi 'iaka and Lohiau reveal the nature and power of the members of the Pele family and their role in the development and popu larization of the hula in Hawai'i. Chants and legends of Pele and Kamapua'a describe the elemental forces which naturally aligned against the fire clan and how these dynamic elemental forces of fire, air, forest, and water interacted to form the panoramic landscapes of Hawai' $i$ island. Legends of the battles of Pele and the various mo'o water forms relate how in the era following the migration of the Pele fire clan to Hawai' $i$, vulcanism became the primary natural energy which dominated the formation of the landscape in the Hawaiian islands. Legends of how Pele punished arrogant chiefs and mean-spirited folk taught humans to respect the forces of nature and to be kind to elderly women. Hulihia chants describe the enuptive phases of the volcano and praise the awe-inspiring pure and raw energy of Pele.

\section{Pele's Domain}

Pele's primary domain is acknowledged to be the Kilauea volcano which extends from Mokuaweoweo Crater on the top of Mauna Loa mountain through the Ka' $\mathrm{u}$ and Puna districts to the Pacific Ocean. The chants and legends describe the areas where she erupts and establishes herself. Most of her activity takes place in Puna. However, she is also active in the $\mathrm{Ka}^{\prime} \mathrm{u}$ district and occasionally in the Kona district. As discussed below, in the legend of Pele and Kamapua'a, upon reaching a truce, the island of Hawai' $i$ is divided between the two, with Puna, $\mathrm{Ka}^{\prime} \mathrm{u}$ and Kona going to Pele and Hilo, Hamakua and Kohala going to Kamapua‘a.

More broadly, the various craters and pu'u, or hills and summits, created by Pele in her migration down the chain of Hawaiian islands from Lehua to Hawai' $i$ also remain sacred to her.

The chant "Holo Mai Pele" tells about Pele moving to the east and establishing her religion in Hawai'i. She brought her $k i$ ' $i$, or her idols, that had been made by Ko' $i$, or the sacred adze. She went to Lele Iwi, the border between Hilo and Puna, and established that as one border of the area within which she would reign. She then went up to the crater and prayed after establishing her $\mathbf{k i}$ ' $\mathbf{i}$ there. There she prayed kanaenae, sent out a supplication to the deities to them for a safe journey to Hawai' 1 . She indicates that Hawai' $i$ will be her island where she will stay and establish herself. According to this chant, she then went and established herself in Papalawae which is a part of the Kilauea crater. She also established an area down in Puna in the Nanawale area.

\section{Holo Mai Pele}

1. Holo mai Pele mai Kahikina

Pele travels from the east

\footnotetext{
${ }^{51}$ Samuel Kamakau, however, attibutes the introduction of wooden $k i{ }^{i} i$ to Paao.
} 
2. A kau ka wa'a i Mo'okini And boards the canoe at Mo'okini

3. Noho i ka ua o Kumalae Sitting in the rain of Kumalae

4. Ho'oku Pele ma i ke Ki`i

Pele clan establishes the god image

5. Noho i ke ki'i a Pele ma

Living in the god image of the Pele clan

6. A ka pua o Ko'i

Are the followers of $\mathrm{Ko}$ 'i

7. 'Eli'eli kau mai e Pele e!

A profound reverence was produced!

8. Kanaenae Pele ma i laila

It was there that Pele asked for guidance

9. Aia ka huaka'i a Pele ma

Upon the journey of the Pele clan

10. A ka lae a Leleiwi

Until the foreland of Leleiwi

11. Ke honi i ke ala o ka hala

Where the fragrance of the pandanus purged the air

12. 'O ka lehua a Mokaulele

The lehua of Mokaulele

13. A ka kui a Pele ma

Was strung by the Pele clan

14. 'Eli'eli kau mai e Pele e!

A profound reverence was produced!

15. Ku nana hale a ka Pu'ulena

One stand and looks at the shelter of Pu'ulena

16. He hale moe o Papalauahi

A house of sleep is Papalauahi

17. He halau o Kilauea

Kilauea is the long house

18. Ha'ule mai Pele mai Kahiki mai e Pele has fallen from Kahiki 
19. Ka hekili ka 'ola'i ka ua loku

Noted by the thunder, lightning, and heavy downpour

20. Ka ua Papaoha'iha'ilaumeaiku

The rain of Papoha'iha'ilaumeaiku

21. 'Eli'eli kau mai e Pele e!

A profound reverence was produced.!

The chant "A popo' $i$ haki kaiko' 0 " further describes how Pele got established in Puna. It describes the inner motion of Pele as she erupts in different areas of Puna beginning with the area around Kilauea crater and working her way down to Kaniahiku which is below Leilani Estates or Keahialaka, and down to Kapoho at Waiwelawela or Warm Springs. This chant compares the movement of the lava to the movement of water. Most people are familiar with the movement of water and how it flows. The chant vividly describes how the lava, like water, goes around and encircles and makes a wave. It talks about the beauty of how the lava, being the deity herself, flows through the Puna district at these particular areas. The boundary again is from Leleiwi in Waiakea and over into Puna. Another chant describes how she covers the area from the border of Puna with Hilo and all the way over and down to Apua. When someone defies her, she goes out and covers everything.

\section{A popo'i haki kaiko'o}

1. A popo'i haki kaiko'o i ka lua

Covering, breaking, rough is the sea within the crater

2. Haki ku, haki kakala a ka 'ino

Breaking vertically, breaking jaggeredly like a storm

3. Paia kuli uwo lehua a Kaniahiku e

The sound is deafening to the lehua of Kaniahiku

4. Wahine ai lehua o $\mathrm{ka} u n u$

The lehua eating Woman is present

5. Kupukupu a 'eha i ka pohaku

Growing rock altar wrenched in pain

6. I ka uwalu a ke ahi

Clawed by the fire

7. I ka unu a ka Pu'ulena

Pulled up by the Pu'ulena

8. Huki ka moku, papa'a ka aina

The island stretches, the land is scorched

9. Ha'aha'a ka lani, Kaiko'o ka mauna e

The heavens are made low, the mountain is rough 
10. Ha ka moana popo'i Kilauea

The ocean breathes and covers Kilauea

11. Halelo o Papalauahi e

Papalauahi is jaggered with rocks

12. $O$ mai Pele i 'o na kino

Pele is in her many forms

13. Ka hakikili, ka ua mai ka lani

The light rain, the rain from heaven

14. Ne'i ka honua i ka 'ola'i $\mathrm{e}$

The earth moves with the quake

15. Haka Ikuawa ka poha ko 'ele'ele

Ikuwa breaks with the exploding storm

16. Ku mai Puna a ki' 'eki 'e

Puna grows until to great heights

17. Ha`a ka ulu i ka 'opua

The increase of clouds hangs low

18. Pua 'ehu maila uka o Keahialaka

Sprouting vigorously in the uplands of Keahialaka

19. $\mathrm{Pa}^{\circ} \mathrm{u}$ o keahi o Waiwelawela o ka lua e

The pit of Waiwelawela is encircled by fire

20. Aloha na po'e la o

Greetings to the people of the upland pit.

The chant "Kuololoa" is one of the earliest chants is learned by children. It is also taught to the beginning hula students. It teaches the performer and the listener about how Pele reacts. In teaching this chant to our children and young students, they learn about the nature of Pele, the deity. The children are also taught to respect the deity for what she is and respect the people who worship that particular deity and practice the different levels of honoring Pele. The first part of the chant talks about the mo'o who attempted to stop Hi'iaka in her journey through Panaewa forest. It describes the forest, the mountain ridge, and the shaggy pandanus trees. In the second part of the chant Pele erupts. She manifests herself in the eruption and rolls over everything and devastates Puna from the border with Waiakea and out to Apua, the other border of Puna. The last part of the chant describes how everything has been destroyed and turned to ashes. Everything has fallen and there is nothing that will stand in the way of Pele between the source of the eruption down to the ocean. Through the chant we learn that Pele is a deity of love. She creates new land. She is to be respected. Learning how she reacts to those who defy her, one must always be aware of her and her moods. 


\section{- Kuololoa}

1. Kuololoa Keaau i Ka nahelehele

Kea'au is a long range of forest

2. Hala kua hulu Pana'ewa i ka la'au

The bristly pandanus of Pana'ewa are the trees

3. Ino ka maha o ka 'ohi'a

Evident also are the severed 'ohi'a

4. Ku kepakepa ka maha o ka lehua

The severed lehua are straggly and ragged

5. Po'o hina i ka wela a ke akua

The blanket of gray is caused by the fire of the god

6. Uahi Puna i ka holoka a pohaku

Puna is blackened by the rolling stones

7. Na pe 'ia e ka wahine

Flattened by the will of the Lady

8. Nanahu ahi i ka papa 'Oluea

The consuming fire was found at the flats of Olvea

9. Momoku ahi Puna hala i Apua

Puna to past Apua is an island of ash

10. A ihu e a ihu la

Moving in this direction and that

11. A huli ia la i kai

Turning towards the ocean

12. A ihu e a ihu la

Moving in this direction and that

13. A huli ia la i uka

Turning towards the uplands

14. A ua wa'awa'a

Till it fissured, furrowed

15. A ua noho ha'aha'a

Until it is reduced to powder

16. A ua helei, helele' $i$, helele'i!

And crumpled to ashes and dust! 
Pele, Hi'iaka, and Lohiau

One day, after the Pele family settled in Kilauea, Pele and her sisters went down to the beach at Pu'upahoehoe along the coastline of Puna. They all gathered and started to talk about hula. They admired the hula of Hopoe and Pele asked if any of her sisters knew how to dance the hula. Hi'iaka said that she knew how to dance hula and performed "Ke Ha'a La Puna I Ka Makani." This is the first recorded hula in the Pele and Hi'iaka saga. It took place in the easternmost point of the Hawaiian archipelago and described $\mathrm{Ha}$ 'ena, Hopoe, Keaau, and Nanahuki which are all located in the district of Puna-Ka aina i ka houpu a Kane, Land in the heart of Kane. 'Ena refers to the heat of the sun. Ha is the breath. Ha'ena then refers to the first and last breath of Kane, the sun. The first breath of Kane is at Ha'ena in Puna.

After "Ke Ha'a La Puna" was danced, Pele fell asleep. In her dream state she heard the beating of pahu drums. Attracted to the sound, her ku'uwailua or spirit rose from her body and took flight. She went over to the Waiakea area and up through Makahanaloa to Kohala and across the Alenuihaha Channel to the island of Maui. On Maui, she went to Kauiki and continued across to Kahakuloa and on out to the island of Moloka'i. On Moloka'i she went to $\mathrm{La}^{\prime} \mathrm{au}$ Pt from where she went over to Makapu'u on O'ahu. On O'ahu she went over to $\mathrm{Ka}$ 'ena, the western point of the island, and then her wailua crossed the ocean to get to the

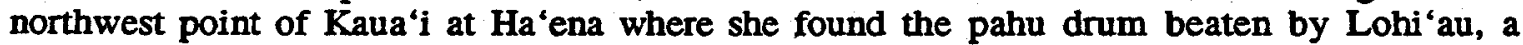
beautiful man in the midst of a large hula performance there at the halau. Thus, her journey

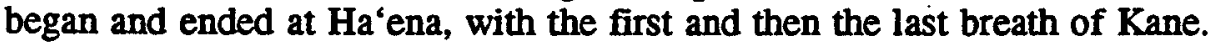

Pele assumed the form of a beautiful maiden. Mutually attracted, she remained with Lohiau for three days and nights. Upon leaving, she promised to send a messenger to bring Lohiau to her in Puna where they will consummate their passion for each other. The wailua of Pele returned to Puna. Upon awaking from her deep and extended sleep, Pele asked her sisters, one-by-one to journey to Kaua'i and fetch Lohi'au. Only Hi'iaka accepted the mission. Urged on by her family, Hi'iaka sets three conditions for facing the dangers and perils

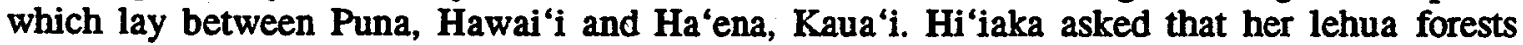
and her friend Hopoe not be ravaged and destroyed by Pele while she is on her journey; that she have a traveling companion, and that she be given the godly powers to overcome and subdue the foes who will rise up to oppose and defeat her. When Pele agreed to the three conditions, then Hi'iaka set out on her odyssey.

From that point, the epic chant eloquently and dramatically unfolds relating the saga of how the young and innocent Hi'iaka gradually assumed the powers of warrior, sorceress, and healer. As a side-purpose for her journey Hi'iaka exterminated the tribe of mo'o who inhabited the Hawaiian islands from one end to the other. Upon reaching $\mathrm{Ha}^{\prime}$ 'ena, Hi'iaka found that Lohi'au had hung himself in anguish over Pele. Hi 'iaka used her power of healing and over life and death to bring Lohi'au back from the dead. They traveled together back to Kilauea, encountering new obstacles and distractions. From a high mountain peak on $\mathrm{O}^{\prime}$ ahu, Hi'iaka observed that Pele, having grown impatient and jealous over how long it was taking to return with Lohi'au, had lashed out and destroyed Hi'iaka's lehua forests and her friend Hopoe. Upon finally reaching Kilauea crater, Hi'iaka, angry and seeking vengeance, compassionately embraced Lohi'au in front of Pele and the entire fire clan. Pele demanded that her family assist her in punishing Lohi'au for his betrayal. Lohiau is pursued, surrounded by lava, and entombed in stone. Hi'iaka, outraged and indignant, left Kilauea and went to $O^{\prime}$ ahu. The wailua of Lohiau wandered about and was finally found and restored to human 
life by Kane-milo-ha'i, a brother of Pele and Hi'iaka. Lohi'au followed Hi'iaka to O'ahu where they were finally reunited.

The story of Pele and Hi'iaka is really the saga of Hi 'iaka and her growth process, her experiences, and eventually how horrible she became. Through her odyssey up and down the island chain she found out who she was and the extent of her terrible powers over life and over death. Hi'iaka started out as the youngest. She was given the mana to rise to another level. Everything she learned along the way had another level of meaning as a lesson. At the end, she was almost at the same level as Pele. Her prowess and achievements has become known to all.

\section{Pele and Kamapua'a}

The legends also relate the dramatic struggles between the Pele and the forces of the storm and forest represented as Kamapua'a, the hog-man. Kamapua'a goes to the crater of Halema'uma'u attempts to woo the goddess in the form of a handsome man. Her sisters attract her attention to him. Pele refuses him with insult, calling him "a pig and the son of a pig." His love songs change to taunts and the two engage in a contest of insulting words. He attempts to approach her, but she sends her flames over him. Each summons his gods. Pele's brothers encompass him "above and below" and would have smothered him had not the lovemaking god of Kamapua'a lured them away with a beautiful woman. Kamapua'a threatens to put out the fires of the pit with deluges of water, but Pele's uncles, brothers, and the fire tender Lono-makua keep them burning. His sister, chiefess of Makahanaloa, comes to his aid with fog and rain. Hogs run all over the place. The pit fills with water. The love-making god sees that if Pele is destroyed Kamapua'a will be the loser. The fires are all out, only the fire sticks remain. These the god saves, Pele yields, and Kamapua'a has his way with her. They divide the districts between them, Pele taking Puna, Ka-u, and Kona (districts periodically overrun with lava flows) and Kamapua'a ruling Kohala, Hamakua, Hilo (the windward districts, always moist with rain) (Beckwith, 1976; Kahiolo, 1978).

Excerpts from the version by Kahiolo describe the struggle between Pele and Kamapua'a and reveal his various body forms:

There was no mercy in Pele as she ordered Lonomakua, "Fire!" The fire roared up and reached Kamapuaa above. It singed his bristles, the stench of which overwhelmed the islands ... Thinking that Kamapua'a was dead, (Kamapuaa had put himself into his tree body), the Hiiaka sisters stopped running when they reach Halemaumau. Pele asked, "What is this, your nunning here?" "What indeed! A tree fell down from up high. We barely es caped." Pele responded, "The bodies of Kamapuaa in the forest are the kukui, the amaumau, the hala, uhaloa, the olomea, and so forth." Pele ordered Lonomakua, "Fire!" The fire came up with such force that his tree bodies were destroyed. not even rubbish remained. The fire rose up and reached them above. Kilauea was burning everywhere. Since the gods saw that there was no place to escape, Kamapuaa was led up to the top of a cloud and placed there. This was the hog cloud spoken of (Kahiolo, 1978). 


\section{Pele Battles Other Forces of Nature}

The principal antagonists of the Pele family in Hawai' $i$ are those deities associated with surface water forms of nature-Namakaokaha' $i$ the fierce sister of the ocean, the mo'o who dwell in ponds and wetlands, and Poliahu the snow goddess. ${ }^{2}$

Both Pele and Hi'iaka battle various mo'o who had dominated the natural landscape prior to the migration and settlement in Hawai $i$ of the fire clan. The mo'o were usually turned into hills or small islets. For example, in Kaho'olawe, Pu'u-0-la' $\mathrm{i}$ took Lohiau for a lover. An angry Pele cut her in two and the tail became Pu'u-0-la'i hill along the shoreline of Makena and her head became Molokini island (Fornander, 1916-1920).

Hi'iaka, on her journey to Kaua' $i$ to accompany Lohi'au back to Hawai'i, ridded the islands of mo'o and monsters. She defeated the mo'o Panaewa in the forest between Hilo and Keaau, the evil shark Maka'ukiu at Waipi'o, the mo'o Mahiki of Waipi'o and Mo'olau of Kohala, Pili-a-mo'o and Noho-a-mo'o of the Wailuku river on the Hamakua side of Hilo, the mo'o Kiki-pua on Moloka' $i$, the mo'o Moko-li'i who forms the islet known today as Moko$l^{\prime}{ }^{\prime} i$, and Kili-oe-i-ka-pua and Ka-lana-mai-nu'u of Ha'ena, Kaua'i (Emerson, 1986).

Poliahu was the snow-goddess of Mauna Kea. She and her friends went down to a sloping hillside south of Hamakua for holua sledding. Pele appeared in the person of a beautiful woman and was welcomed to join in the games. Apparently Pele became angry at the superiority of Poliahu, threw off her disguise, and called for the forces of fire to burst open the subterranean caverns of Mauna Kea. Poliahu fled to the summit grasped her snow robe and threw it over the mountain. Earthquakes shook the island as the conflict between fire and snow raged on. Poliahu prevailed, chilling, hardening, and choking the flowing burning rivers. The ragged mass of Laupahoehoe and the arch of Onomea were formed during this volcanic episode (Westervelt, 1988).

\section{Pele and the Chiefs and People}

Legends relate how boastful chiefs were punished for arrogantly challenging the goddess or demeaning her before the people. Stingy and unkind persons receive retribution for treating Pele badly while she was disguised as either a beautiful young woman or a haggard old woman. Unfaithful lovers and those with whom they flirted were also punished. Trans gressors were either turned to stone or their land and homes were overrun with lava.

In $\mathrm{Kahuku}, \mathrm{Ka}^{\mathrm{c}} \mathrm{u}$, two young chiefs who had enjoyed games and sports, especially holua sledding with Pele in her form as a beautiful woman, had also become her lovers. Given her moods and capricious nature, they eventually suspected her true identity and then tried to avoid her. Angry she sought and pursued them, inundating Kahuku in lava and eventually building up two hills near the coast as their tombs called $\mathrm{Na}$ Pu'u O Pele or The Hills Of Pele (Westervelt, 1988).

Kumukahi was a chief of Puna who pleased Pele when she took her form as a beautiful young woman. However, one day, Pele appeared in the form of an old woman and de-

${ }^{52}$ As noted in Chapter 2, the mo'o dwell in mountain fresh water pools and brackish shoreline ponds and wetlands. They are not related to Kaneikawaiola who is the major Hawaiian god of springs and streams which originate from under the earth. 
manded to share. in the sporting games. He ridiculed her and she chased him to the sea and caught him on the beach where she poured lava over and all around him, far out into the ocean, forming Cape Kumukahi (Westervelt, 1988).

Kahawali, chief of Kapoho, refused to compete in holua sledding against Pele who was disguised as an old woman. She pursued him down the holua sled and into the ocean where he made his escape. However his family and his hula pupils were turned to stone (Pukui, 1949).

Kapapala, a chief of Ka' $u$, arrogantly challenged Pele, herself, to surf the waves of her own lava lake. Showing his contempt for Pele, he even stood on his head while he surfed the wave. Furious, Pele hurled more waves toward him and broke his wave's crest. He was hurled into the fiery lake (Westervelt, 1988).

Papalauahi was about to win a race to which Pele had challenged him. With victory in sight, he looked back over his shoulder and Pele overwhelmed in a flood of lava. The spectators were turned to stone figures (Westervelt, 1988).

Keliikuku, chief of Puna, visited the island of $O^{\prime}$ ahu and boasted how nothing could compare with Puna and its rich sandy plains and sweet-scented trees and vines. He met a prophet of Pele who ridiculed him and prophesied that he would find Puna burnt, desolate, and covered with lava upon his return. When the boastful chief returned and witnessed the destruction, he hung himself (Remy, 1868).

Paula was a beautiful girl who lived in $\mathrm{Ka}$ 'u. One day Pele found her lover playing the sport kimo (jackstones) with Paula. In a jealous fit of rage, Pele turned them both to stone (Beckwith, 1976).:

Pele, in the form of an old woman, appeared to two girls of $\mathrm{Ka}^{\mathrm{u}} \mathrm{u}$ who were roasting breadfruit. She asked them for food and drink. One girl kindly shared but the other girl refused. A flood of lava later came. The house of the stingy girls was destroyed. The kind girl had been warned and instructed by Pele to set up the necessary protection around her house. Her family's home was spared (Pukui, 1949).

The old man, Kalapana, went to Puna from Kaua i with a quest to see Pele. He had made a promise not to cut his hair until he had seen the goddess. He arrived by canoe and rested a few days before climbing the trail up to the Kilauea crater. Stormy weather prevented him from reaching his destination, and while he slept two mischievous boys cut his hair. The goddess appeared to him the next morning, but because his hair had been cut he was commanded to live the rest of his years in Puna rather than return home to Kaua' $i$. He lived among the people who named their district in his honor upon his passing away (Pukui, 1949).

In the story of the pounded water of Kekela, Pele appeared to an old couple of Kona in the middle of a drought. She showed their dog a pool of water in a cave in the middle of a lava field and, in turn, the old couple revealed its location to their chiefess. The whole vil. lage was grateful and acknowledged the pool as a gift from the goddess (Pukui, 1949).

In historic times, Pele destroyed a whole division of the army of Keoua, chief of $\mathrm{Ka} \mathrm{u}^{\mathrm{u}}$, as he was-retreating from battle with the army of Kamehameha. The people interpreted 
this as proof that Pele had favored Kamehameha in his quest to rule the entire island of Hawai' $i$ (Westervelt, 1988).

In the fourth year of the rule of Kamehameha, a lava flow started at Hu'ehu'e in North Kona and flowed to Mahai'ula, Ka'upulehu, and Kiholo. The people believed that Pele desired the awa fish from the fishponds of Kiholo and $\mathrm{Ka}$ 'upulehu and aku fish from $\mathrm{Ka}$ 'elehuluhulu; or that she was jealous of Kamehameha assuming wealth and honor for himself and giving only that which was worthless; or because he refused her the kapu breadfruit of Kaeha'ikana which grew in the uplands of Hu'ehu'e where the flow started. Kamehameha, in great distress over the destruction of his land and the threatened wiping out of his fishponds made offerings to Pele including cuttings of his hair. Appeased by the respect and offerings, the eruption ceased (Westervelt, 1988).

The village of Ho'opuloa was destroyed when the people dedicated only a portion of a pig to the goddess Pele and consumed the rest of it in a feast (Nimmo, 1986).

\section{BELIEFS, CUSTOMS, AND PRACTICES}

\section{Péle As Deity}

There are four major deities in the Hawaiian religion- Ku, Kane, Lono, and Kanaloa. All of the other deities that exist under them exist under the umbrella of one of the deities. Of these four major deities, Pele comes under the Ku deity because of her type of worship, her type of sacrifice, and her type of practice. She also comes under the Kane deity because she is a creator and Kane is a creator.

Pele is worshipped as a deity. She has been deified. She is associated with the land, geography, the clouds. The Pele family also has the power of healing. They are called upon to heal. People have associated with Pele as a deity. They have created a whole religion around her. She's not just here on surface level because she is deified.

Hawaiian ancestors, in order to live, had to be very well acquainted with the natural elements. They studied the elements and the seasons in order to survive. A constant observance of these elemental forms brought them to thinking that none of these elemental forms existed by itself. They were all interrelated some way or other. They understood the human form, and they understood the animate forms. What they were awed at and what they greatly admired was pure energy. After they had an idea of what these elemental forms were, they came to understand that what they could not reproduce themselves, as humans, was pure energy. These pure energy forms, which could not be made by humans, became their deities. When we talk about Kanenuiawakea we talk about the greater atmosphere. The idea that out of nothing comes something was awesome to them. It was godlike. That was a god, that which could produce something out of nothing. That was also energy, a pure form of energy.

When they talk about Kanaloa being water, surface water, earth water whether it was the salt water of the ocean or the fresh water that you find under earth, it was something that they could not produce themselves. The body that they sail on was the body of Kanaloa. It was an extension of the land. It is an extension of another deity form which is pure energy. If one were to sit and watch at the ocean during a storm one could get the idea of the pure energy that the ocean is. Humans cannot reproduce that kind of energy. 
When one looks at lightning and hears and feels the thunder, that is pure energy. That energy comes down from the sky. Humans cannot reproduce it. The pure energy forms became their gods.

When one looks at the eruption, there is the lava form. That is the energy that comes out of the earth. During the lava flow of 1985, when the eruptions at Mauna Loa and Pu'u Oo occurred at same time, large energy balls were set off from one volcano to the other. That was an awesome energy. Those are energy forms which are godlike. The energy coming out of the earth is Pele. Pele is the energy which produces the tangible material which comes out of the volcano, and she is the raw energy which produces the tangible material.

The Pele form is rock, flowing lava, bursting through the earth giving new life, earthquakes, projectiles, fire, steam, mana. She was a human form and she was deified. She went to other levels. Her relatives who were left back honored her as a deity.

Traditional chants reveal the tenet that whatever area of land which is hot or which still has the steam coming out of it is sacred to the deity. In the chant described above, "Hulihia Ke Au, Ka Papa Honua O Kona Moku" this tenet is referred to as the "law of the burning back." However, it is not only her back which is sacred, it is the whole part of the land that is hot which is sacred. The chant, "E komo maloko o Halema 'uma 'u," more clearly defines this when the chanter, in the first person persona of the deity, declares that whatever is hot is sacred to her. In the chant, the first person voice representing the deity invites the listener to go into Halema 'uma $u$ and see her display and her movements. The listener is invited to view her inner parts and how she dances and moves. However, the listener is admonished not to take what belongs to the deity and that whatever is hot belongs to the deity, that whatever is hot is sacred.

\section{E komo maloko o Halema'uma'u}

1. E komo ma loko 'o Halema'uma'u Come into Halema'uma'u

2 He mau na pu'u e 'ola'ola nei The cones continuously bubble forth

3. E Pele e Pele, e Pele e Pele It is Pele, Pele, Pele, Pele

4. E Pele i Pele hua i na hua i na ku It is Pele who flows upward and over until it stops

5. Pahu pahu una ma'i o ka lani ani! It explodes, bursts forth upward, hot!

6. Pahu pahu uha ma'i o ka lani ani! It explodes, bursts forth upward, hot!

7. Pahu pahu uha ma'i o ka lani ani! It explodes, bursts forth upward, hot! 
8. He inoa no Hi'iakaikapolioPele-mau loa no.

A name song of Hi'iakaikapoliopele-a never ending cycle.

Pele is creator of new land, and she is the destroyer. She is both. The flow of Pele goes out and makes new land. Who can make new land? Which is more valuable -new land or your house? What is rich-new land extending out into the ocean or the forest standing hundreds of years? In the Pele cycle, Hi'iaka comes behind Pele and helps with the regrowth of that land. There is quick restoration. One of the laws of Pele is that there is quick restoration. You can look at it as destruction or as being awesome. The volcano produces something of great value. It is pure energy; the energy is pure.

As long as there are practitioners who honor Pele and praise her, she will live. Like any other deity, so long as there are praises and worship of that deity, that deity lives. Should the worship die, then the deity will die. In the case of the Hawaiian culture, because Pele is the last of the Hawaiian deities to be actively worshipped and believed in, if the worship stops and the deity dies, then the Hawaiian culture will also die.

\section{Hulihia Chants}

One form of worship to Pele is the composing of chants in honor of her eruptive phases. Chants which specifically focus on volcanic eruptions and provide a description of volcanic eruptive phases are called "Hulihia" chants. Hulihia is a word meaning overturned, overthrown, and upheaval. These chants begin with this word. Hulihia projects a sense of sizable or major eruptions such as we have had within the last ten years or so involving the Hilo, Puna and $\mathrm{Ka}^{\prime} \mathrm{u}$ sides of Mauna Loa, the Kilauea caldera and its rift zones such as Pu'u $O$, Kupaianaha and $\mathrm{Pu}^{\prime} \mathrm{u}$ Kauka. As discussed above, these chants include words for all phases and aspects of eruptions. Whenever Pele has erupted, chants have been written for her and the beauty of the manifestation and that her followers know that she continued to exist.

The following chant was found in $\mathrm{Ka} H o k u$ Hawai ' $\mathrm{i}$, a Hawaiian language newspaper; however, different versions of this same chant may also be found in the saga of Pele and Hi'iaka by Emerson and also in the Helen Roberts collection of chants at the Bernice P. Bishop Museum. The length of the chant varies to great extremes with this version having thirty-seven lines and Emerson's version with ninety plus lines. Despite the differences it still appears to be the same chant. This shorter version possesses certain features which are important to focus and elaborate on.

There are five distinct sections to this chant: (1) lines one through seven clearly recognize earthquakes and the volcanic fires and eruption; (2) lines eight to fourteen diverts from fire to water which emphasizes the source of water and the rainy season; (3) lines from fifteen to nineteen are interesting because after preparation by fire and water the house is dedicated and given the name of Mauliola endowing it with health and long life. Hi'iaka's place of residence is also announced as the eastern gate; (4) lines twenty through thirty describes places such as $\mathrm{Ka}^{\prime} \mathrm{u}, \mathrm{Pu} \mathrm{u}^{\prime}$ 'oni'oni, Mokuaweoweo, and Kilauea that are affected by eruptions and its impact on the surrounding areas; and (5) lastly an acknowledgment of Pelehonuamea as the Deity honored and Kaleipaoa as the one to give honor to her.

The first two lines help one to visualize the immensity and intensity of the earthquake. It places the quake at Waiakea and exaggerates the magnitude of the quake by painting an image with the words ka mole honua which literally means the tap root of the 
earth. The tap root concept transfers you to the core of the earth; when used with hulihia it presents the listener an earthquake of intense seismographic quality:

An interesting point is the place name of Waiakea. Waiakea is a large ahupua'a in Hilo on the Hilo-Puna border. This would be the popular choice; however, another Waiakea can also be considered. This is a small bay in the Kapoho area just south of cape Kumukahi and ma kai of Pu'u ukae and Kuki'i.

The words ala in line three, meaning pathway, is spelled ale in Emerson's version, meaning wave. Both are compatible and maintain the thrust of the chant in describing the flow of lava. The red pathway or the red wave both project the picture of a sea of lava. Place names and land features are used to give direction; however, given their literal translation, it may also be the intention to refer to these places to add intensity to this particular eruption. Puko'a means to rise and blow, $\mathrm{ka}^{\prime} \mathrm{a}$ to twist and roll, aka is a reflection or shadow as in Hi'iaka, and keahua is a description of a mound. All of these features are also descriptive of eruptive characteristics.

Line six reminds one that the origin of this fire is from Kahiki. The name of Hinaulu'ohi'iakalani offers another deity outside of the Pele realm whose kinolau is the low growing ohi'a tree. The work hina or hina ulu is also significant at this time. Hina presupposes the falling over or flattening out of an area because of a wind storm or tidal wave or lava flow. Hina ulu portrays an area inundated with smoke, steam, ashes, or mist. In both cases, again we visualize the destruction from a lava flow in an area covered with growth.

Lines eight through thirteen announce that the heavy rains of winter that came from dark laden rain clouds are from Kulanihako'i, a mythical lake in the sky. Ho'oilo, in line ten, gives the reader a sense of time; however, 'Ikuwa, in line fourteen, states a more specific time period. It is the month of 'Ikuwa or the beginning of the rainy season. It is at this time period that the house of Pele will be consecrated. eleua is the door found on the ko'olau side of the house. The reference to eleua also reveals that the status of the house is kapu and not ready for occupation. Eleao is the door of a house facing the kona side of facing west. The 'eleao refers to the house after being consecrated when all kapu has been released and occupation of the house is allowed. According to line eighteen the name of Pele's house is Mauliola. The idea of residence continues to Hi'iaka and she is assigned living space at Ha'eha'e.

The chant resumes with the eruptive phases and focuses on the destruction of the forest of Hope at Kea'au. This particular eruption revamps the time when Hi'iaka returns from Kaua' $i$ to find her lehua grove and her friend Hopoe destroyed by lava. Lines 27 and 28 refer to the eruption's steam clouds which eventually reaches the apex of Mokuaweoweo. These lines suggest that the steam has become rain clouds and the elements of nature produced by and are directly connected to volcanic activities are indeed kinolau of Pele. The reference to creating rocks in line thirty again shows a kinolau o Pele. Some antithetical factors in line 29 such as lowland/upland or movements/stationary divides the line in half with the first half showing lowland and movement as the lava folds one wave over the other. The second half displays a majestic erect mountain ridge back which describes the district o Ka'u. These descriptions are also kinolau of Pele.

The last few lines reveal the artistry of word play. Line 31 focuses on Lono as the teacher. The line also draws attention to Kaleipaoa who is the chanter. The chanter, Kaleipaoa, is the servant of Lohiau. Kaleipaoa also becomes the lover of Pele. Paoa was the name 
of the divining rod used by Pele in search of a new home. This incident is an emphasis on the importance of this player, Paoa, in the drama of Pele and Hi'iaka.

The introduction of Paoa in this portion of the chant quickly switches attention from this male mortal to the female deity Pele. Pelehonuamea's name is earth connected; however, this chant of Paoa recognizes her heavenly kinolau and therefore a befitting title of Pualani is given. The title Pualani, or sometimes referred to as $\mathrm{Ka}$ Pualani, recognizes Pele's sacred connections with heavenly forms as found in line 27 . Line 27 also refers to some of the Hi 'iaka forms.

\section{Hulihia ke au ne'e i lalo o Waiakea}

1. Hulihia ke au ne'e i lalo o Waiakea

The time of upheaval arrives, the foundation of Waiakea is shifting

2 Hulihia i ka mole honua

Overturning to the very core of the earth

3. Hulihia i ke ala ula i ke ala lani

Overthrown by the red path, the exalted pathway

4. Ka pukoa i Kaaka i Keahua

To the coral heads of Ka'aaka at Keahua

5. I ka ala po'i e ka moku

To the point of rising and covering the island

6. Nawe ke aha 'a i Kahiki

The fire lit in Kahiki is on the move

7. Nawele ka maka o Hinauluohiakalani

The eyes of Hina of the low growing 'ohi'a is evident in this glow

8. Wahia ka lani uli paa ka lani

The dark sky erupts, the heavens are enveloped

9. 'Ele'ele ka lau Kahoalii

The Kahoali' $i$ clan is wrapped in darkness

10. Pohaku ku'i o ka Hooilo

The rumbling stones of winter

11. Noho mai Kulanihako'i

Abides at Kulanihako'i

12. Ke ha'aloloku nei ka ua

It is pouring rain

13. Ke ne'i nei ka 'ola'i

The land is trembling 
14. Ke Ikuwa mai la i uka o Kali'u When 'Ikuwa arrives in the uplands of Kali 'u

15. Ke 'o'oki mai la i ka piko o kona hale It is time to consecrate Her house

16. A mo ka piko i 'Eleua 'Eleao And the piko of 'Eleua and 'Eleao are severed

17. I ka wai 'eha o Kulamano At the four waters of Kulamano

18. E Pele e, eia ko hale ia 'o Mauliola Say Pele, here it is, your house, Mauliola

19. E Hi'iaka e, nau ka e noho ka la puka i Ha'eha'e

Say Hi'iaka, your residence is at the gate of the rising sun at Ha'eha'e

20. Ke 'ai holoholo la i ka uka o Hopoe

Traveling swiftly to the uplands of Hopoe

21. Pau a'e la ku'u lili kanahele ma uka o Kea'au My little forest above Kea'au is destroyed

22. A ka mahu a ka wahine i ka lua Vaporized by the Woman of the pit

23. 'Oni Pu'u'oni'oni hao a'e la ke 'a lele i luna Pu'u'oni'oni shimmers, the flame vigorously leaps above

24. Ne'i wale lalo Kilauea

The foundation of Kilauea vibrates

25. Ha'a ke one mahu'ehu'e o Kanaloa The exposed land of Kanaloa dances

26. Ke kui e nana ke alo o ka pohaku When aggressively pounded by the front of the lava flow

27. 'Opua au la a ka luna i Mokuaweoweo These steam clouds float until they are over Mokuaweoweo

28. Huki Pele i kona kino lawe ka ua lawe ke kaupu (kaupua) Pele gathers her manifestations which brought rain and clouds

29. 'Opi'opi kai a ke akua kuahiwi ku hao 'aina Ka'u The sea of the mountain God folds over and over, $\mathrm{Ka}^{4} \mathrm{u}$ is erect

30. E ho'opohaku mai ana kalua i kona kino The pit gives birth to rocks, Her manifestations 
31. Wela mai la ka maka o ka ulu o Lone e The favorite of Lono's protege is indeed hot

32. 'O ho'olono au o ho'okuli au I will listen or I will be made deaf

33. 'O Hooleilei au a 'o ka lei au 'o Paoa I give a lei, because I am the lei, Paoa

34. 'O Paoa au la i lono 'oe The paoa which you have heard

35. Ha'ina ka puana i ka inoa The name song is again repeated

36. 'O Pelehonuamea he Pua lani Pelehonuamea, a heavenly progeny

37. Ka lani ki'eki'e a eo mai! The progeny of highest esteem, answer to your name!

Aunty Edith Kanakaole, kumu hula and mother of Pualani Kanahele, composed a Hulihia chant for the 1977 flow at Kahaualea. Just before the flow there was an earthquake very early in the morning accompanied by a gigantic light which flashed in the sky. The light is a source of energy which also comes from Pele. At that time it was thought that flow was going to go over to Kalapana. The chant speaks about how the people who live in the Kalapana area felt about the deity. According to the chant, the people felt that if she wanted to come, then she could. It was her land. The people live on the land and are allowed to raise their families there, but because Pele made the land, the land belongs to her. Originally the Hawaiians had no concept of owning land. The land belonged to the deities. The people were loaned the land to live on. The chant also describes how people from the other islands come to know and experience Pele through the smoke and sulfur that she sends all across the chain of islands. Thus, even though people from the other islands cannot see it through the smoke and sulfur they are reminded that Pele is there ... she made the islands ... she is alive in Hawai' $i$, even if they may sometimes forget that she is alive. The chant also describes how when she does erupt, she flows to the ocean. Upon reaching the ocean she is hungry and she looks for food. In 1977, she did not reach the ocean; however, in the regular cycle of eruptions Pele usually reaches the ocean and when she does, she usually stops.

\section{Halulu ka honua i ka 'ola'i e}

1. Halulu ka honua i ka 'ola'i e

The earth quivers with the earthquake

2. Ilaila o uka o Kalalua

There in the uplands of Kalalua

3. 'Imi a'ela kahi o Pohakea

Searching for a place to break forth 
4. Wa'ele ka honua, puka a'ela

The earth separate, the exit is found

5. Ua po'ohina la e

The blanket of grey appears

6. Ho'i ka wahine i ka 'aina

It is the Woman who appears

7. Pololi no he 'ai he i'a

Hungry to consume, food, food

8. Ho'i ihola a pau ke kolu

After the third time she returns

9. Kani hou na manu

The sounds of the birds are again heard

10. Ho'olulu ka lehua e

The lehua becomes abundant

11. Na lehua i hoa me ka maile

The lehua and the maile are companions

12. Kau i pu'u Kauka e.

At the top of Kauka

13. Malamalama he au ua 'eha

An illumination ignited by a piercing energy

14. Eha ka mana'o he kupa o ka 'aina e

A worrisome sight for the people of the land

15. E nonome ana a ma'a mau

For the creeping flow of lava is evident

16. Uhi uha e manene ai

Groping, engulfing, fearsome

17. Ka hana ka wahine o ka lua

This primal force of the Woman of the pit

18. He e'epa ke akua ahienaena

The god of intense fiery glow is indeed extraordinary

19. Owaka ka lani naue ka honua

The heaven is rent the earth shakes

20. Poahi ka wahine, pouli e

The earth is obscure, dark 
21. Pa'apu ka moku o Keawe

The land of Keawe is concealed in smoke

22. Ke iho nei ka Pele 'au i ke kai e.

Downward marches Pele reaching to the sea.

\section{Honoring Pele at Kilauea}

The principal place to honor Pele is at her home at Kilauea. It is common practice to also offer ho'okupu to Pele when and where she is actively enupting. Park rangers at the Volcanoes National Park report observing numerous offerings being made or being left at Halema'uma'u Crater. They have also observed people placing offerings on top of moving tongues of lava, or leaving them where they could watch a moving tongue of lava consume them and know that Pele had accepted the gift. 53

Every family had their own special area at Kilauea to make their ho'okupu. Palikapuokamohoali'i Dedman, president of the Pele Defense Fund, explained how as a young child his family would leave Ka'u at night in the family's model $T$ and go up to the volcano to pay respect to Pele. His grandmother would spend a few hours chanting softly, moving her lips and hands with no sound coming out. Her offering was herself and an offering of her family's continued connection to the deity. Throughout the years he observed that other families had their own special place that they went to praise and honor Pele.

The following chants reveal five different approaches to the crater, given different situations. "E nihi ka hele" explains what not to do when one embarks on a task of confronting a deity. "Hele ho'i ke ala" is a chant when one has nothing to give except knowledge of the Pele clan, thus there is an offering of praises to the deity Pele within the chant. The chant, "E Pele weliweili," reveals some of the possible offerings which are taken and are acceptable to Pele. " $O$ Kapo'ulakina $u$ " indicates a formal approach to the crater." "O Pele o ke kumu" indicates an entrance by those of impressive rank and status with the elements of nature at one's command.

Except for the entrance rituals used by Haumea, the other entrances may be used when entering a wahi pana or sacred place where one may want to show respect. The wahi pana may not always be the crater, although the various entrance prayers and procedures gives insight into what was done and what is possible to do today.

This first chant is a popular contemporary mele tracing its origin to the saga of Pele and Hi'iaka. The mele describes Hi'iaka finding her way through the Pana'ewa forest to Hilo after being warned of the terrible mo'o. Pana ewa resides in this forest. The mele is a warning of the dangers of being distracted while on an important errand. This folk wisdom was a common cultural element and was a frequent admonishment when fetching medicinal herbs, delivering messages, and when on his way to a ceremony. Although common place enough, the caution is an important message intended for all tasks important enough to warrant complete concentration. Only after the task is completed are you allowed to notice or to tend to other matters. ${ }^{53}$ Russ Apple, former ranger at the Hawai'i Volcanoes National Park in the 1950 s, and historian
specializing on Hawai' $i$ island and Kilauea in particular. 


\section{E nihi ka hele}

1. Enihi ka hele i ka uka o Puna, Step carefully in the upland trail of Puna

2. Mai ako i ka pua,

Don't stop to pick flowers,

3. O lilo i ke ala o ka hewahewa

Or the trail will become unrecognizable,

4. Ua huna ia ke kinoi ka pohaku, The mischievous ones are hidden within the rocks

5. O ka pua na'e ke ahu ei i ke alanui The flowers that abound distract from the roadway

6. Alanui hele o ka unu kupukupu, e, The roadway of fern covers the stones.

7. Ka uli-a!

If there was a sudden accident!

8. A kaunu no anei 'oe o ke aloha la?

Would you not be yearning for compassion?

9. Hele a'e a komo i ka hale o Pele;

Go forward and enter the house of Pele,

10. Ua huahua'i i kahiki; lapa ulla, She burst forth to Kahiki, lightning flashing

11. Pele e, hua'i na ho'i!

Ever growing Pele!

In "Mele No Pele," the expert knowledge of the chanter about the Pele family is obvious. The chanter used this portion of the chant as a lead into the crater. The chanter's familiarity with the chants of the Pele family allowed the adaptation of this chant to fit the situation. The chanter's only gift was the voice and with this voice the repetition of the familiar chant. This practice of approach allows one to enter the crater area without benefit of gift except for songs of praise.

\section{Mele No Pele}

1. Hele ho'i ke ala ma uka o $\mathrm{Ka}$ 'u (I) traveled the upland trails of $\mathrm{Ka}^{\prime} \mathrm{u}$

2 Hele ho'i ke ala ma kai o Puna And traveled the lowland trails of Puna 
3. 'O ka ma'ema'e la o ka pua lei (I am) pure as a flower wreath

4. Aloha ka pi'ina i Kukala 'ula. Enjoying the climb at Kukala'ula

5. Ho'opuka aku la ka Pu'ulena, Pu'ulena enters into

6. 'Aina a e akua i noho ai. The residence of the god.

7. Ka'u makana ia o ka leo, My only gift is my voice,

8. 'O ka leo wale noe e -..Only the voice.

"Kanaenae O Pele" allows insight into the possible offerings to the fire deity. The style of the composition is presented in a straightforward manner without elaborate literary features. The chant context includes the following: (1) addressing the deity, (2) stating one's business, (3) presenting the gifts, (4) offering praises, (5) a wish of longevity to the deity, and (6) a formal closing.

The deity of importance is Pele and she is recognized in the first line. Lines two through five state that the purpose for being at the crater is to present offerings to Pele and to enjoy her presence. The chant continues and names three different articles which were brought to please the goddess. 'Ohelo berries, which grow in close proximity to the crater, are considered the kinolau of a younger sibling of Pele whose name is Ka'ohelo. The black pig is the best possible offering one can give to a god. The black rooster is also an impressive gift. The person giving the gifts has brought the best possible offerings and can now appreciate the performance staged by the deity. A wish of growth by the supplicant for Pele's continued gift of inspiration is left as a final gesture of admiration. The last line is a formal closing used in prayer chants. The offerings and the ritual must be formally delivered in a prayer.

\section{Kanaenae No Pele \\ Chant for Pele}

1. E Pele weliweli e.

Pele the great wonder.

2 Eia ka 'alana.

Here is an offering.

3. Eia na hua li'ili'i o ka 'ohelo.

Here are the 'ohelo fruits.

4. Eia ka mohai, he pua'a 'ele'ele.

Here is the formal offering, a black pig. 
5. Eia ka moa kane 'ele'ele

Here is a black rooster.

6. Ea ala, Pele e.

Arise Pele.

7. E lawe mai i kou kapa wahine.

Bring with you your female shroud.

8. Aia la! ke kamaha'o o kona alo e.

Over there! Her presence is astonishing.

9. Pi`i ana o Pele i ka lua ahi e!

Pele is rising from the fiery pit!

10. Pi $i$ ana o Pele $i$ kalua ahi e!

Pele is rising from the fiery pit!

11. Ho'ike mai la i keia wa i kona pua lapalapa.

Displaying now her dancing flames.

12. A ulu, e Pele!

And growing, e Pele!

13. Amama, ua noa.

It has ended, it is free.

"E Ho'i, E Komo I Kou Hale" is a portion of a longer chant by Pa'uopalai. The first half of this chant, which I did not include, describe the many aumakua and kinolau who are the defenders of Pele. The section of the chant reveals two definite purposes which deserve close investigation. The first purpose is an approach ritual to the crater to visit the fiery deity. The second purpose involves the kapu or laws put into effect because of Pele's existence and nature.

The first idea addresses Kapo'ulakina'u as one of high rank among the deities. A reference is made to the residence known as Kealohilani. This residence is in the east and refers to the brightness and brilliance of the sun. It is associated with Kapo at this time, although in the first half of the chant Kealohilani is mentioned with the presence of Uli. Accordingly, Kealohilani is a residence for both Uli and Kapo 'ulakina' $u$. The common function of these two female deities is sorcery.

The entrance ritual begins with an encouragement to enter into this abode. Then a sequence of action follows: (1) 'au'au or bath by immersion in a sacred pool known as Ponahakeone, (2) 'awa preparation and drink is offered, and the sacred black 'awa and 'awa papa are chosen, (3) a chant is offered for Moehaunaiki, (4) an invitation to enter the house of Pele is given, and (5) one then enjoys the exhibit of power and energy which Pele is capable of presenting. The rituals and action show a more formal approach to the deity of the crater.

Lines 14 through 21 announce the laws put upon Pele to preserve her mana and maintain her functions. Pele's primary function of creating new land has by the very nature of 
creation caused disruption among men and Gods alike. Therefore laws were created as a mechanism of protection for all concerned.

The law is very literal. Her back is kapu or sacred because it is hot; therefore, no one stands at her back. The concept behind this idea is that if the earth is hot it still belongs to the goddess and if it belongs to her it is sacred. If the earth steams or if any other sign of heat still exists on the land or the water surrounding the land because of volcanic activities, then the effect of the law still exists.

The eruption of Pele is not limited to the land but extends into the sea as well. It cuts into the ocean working its way towards a southeast direction. The trail to Kane of the east and Kanaloa of the south becomes shorter.

In line 20 , the use of $\mathbf{k i}$ as the intensifier before ho'iko' $\mathbf{i}$ conveys the idea of immediate restoration of life after an eruption emerges. Restoration after an eruption is vital; therefore, the dependency on Hi iaka and the responsibilities of the other siblings is utilized at this time in order to uphold this law.

Restoration is done quickly and in the same sequence after each eruption. The effects of the rain and wind help bring life to the lava. Seedlings blown by the wind and moistened by rain produce algae, lichen, moss, ferns, and then woody plants such as the 'ohi'a. Restoration is done in praise of Pele and her land-making abilities.

\section{E Ho‘i, E Komo I Kou Hale}

1. 'O Kapo'ulakina' $u$, he ali' $i$

Kapo'ulakina'u, a chiefly one;

2 E ho'i, e komo i kou hale,

Return, enter your house,

3. $O$ Kealohilani,

The brilliant abode, Kealohilani

4. E 'au'au' i kou ki'owai kapu,

Bathe in your sacred pool

5. 'O Ponahakeone;

The sacred pool of swirling sand, Ponahakeone;

6. E inu i kou pu'awa hiwa

Drink your black 'awa,

7. 'Awa papa a ke Akua,

Also the "awa papa, the 'awa of the Gods

8. I kanaenae no Moehaunaiki, e;

Present a chant for Moehaunaiki,

9. Hele a'e a komo

Then go and enter 
10. I ka hale o Pele

The house of Pele,

11. Ua huahaua'i Kahiki, lapa uwila:

(Pele) gushing outward to Kahiki, lightning flashing:

12. Pele e, hua'ina ho'i!

Pele lives with passionate outpour!

13. Hua'ina a'e ana

Bursting here, bursting there

14. Ka mana o ko'u Akua iwaho la, e!

My God's power is felt abroad;

15. 'O kukulu ka pahu kapu a ka leo;

The voice of the sacred pahu is powerful;

16. Ho'okiki kanawai;

It enforces the laws;

17. He kua 'a kanawai;

Which are, the law of the burning back;

18. He kai okia kanawai;

The law where the sea is cut into;

19. He ala muku no Kane me Kanaloa

A quick path for Kane and Kanaloa

20. He ki ho'iho'i kanawai

A law of restoration

21. No Pele, no ko'u Akua la, e!

For Pele, for my God!

" "O Pele O Ke Kumu O Kahiti" is another mele which describes an approach to the crater. The approach being made by one of great status which is Haumea, mother of Pele. The other name included in this chant besides Pele is Kane. Kane's function in this mele suggests clearing a path for the arrival of Haumea. Lines 11,12 , and 13 are repetitious of the other chants included in this section. We can conclude by the repetition that these lines are used when someone approaches the crater with the proper protocol who then is accepted by Pele and is given and impressive display of Pele's fiery moods.

There are several lines in this mele which strongly exhibit earth and sky movements, fiery displays of earth and sky, and finally the deep rumbling produced by elements of the earth and sky. The kinolau of earth and sky are directly related to Kane and Haumea. Unlike "Kanaenae No Pele" or "Mele No Pele" this chant does not pretend to bring any ho'okupu or gift for Pele. The deities are her superiors; therefore, the display of nature is warning of the coming of a deity of substantial significance. Another point of interest in this mele is line 
five. The characters of these mele are all deities; therefore, the word pili, or related to, is used as a recognition of equal or unequal status.

\section{O Pele O Ke Kumu O Kahiti}

1. 'O Pele o ke kumu o kahiti Pele, whose source is Kahiti

2 Nana i ho'olale ka pohaku, Hastens the growth of her lava

3. Ke kani ke, ku'i ke, Kahiki, Kahiki resounds and shudders,

4. Ka moku newa 'ula The island is red hot,

5. Inaila ka pili kua, ka pili alo, ka pili na hoali' 'i, There are the gods who guard the back and those who guard the front and the chiefly gods

6. Kawewe ka lani nehe i ko honua

The heaven reverberates the earth moves

7. Kohia e Kane ka moku ohi 'owaka i ka lani

The flashes of the young island is held back by Kane

8. Na Pele ia ahi ke 'a nei Kilauea

That fire burning at Kilauea is Pele's

9. Wakawaka ka niho o ke akua 'ai pohaku

It is like the serrated teeth of the stone devouring Goddess

10. A Haumea ke akua

Ah it is the Goddess Haumea who

11. Hele a'e a komo i ka hale o Pele

Comes and enters the house of Pele

12. Ua hua'i Kahiki lapa uila Pele

Kahiki bursts forth, Pele flashes her lightning

13. E hua' $i$, e haua'ina ho' $i$

Breaking out, displaying her forms

14. 'Eli'eli kau mai.

Produce and inspire. 


\section{Crater Ceremonies}

In addition to the private visits of families to honor Pele at Kilauea, there have also been public ceremonies conducted at the crater rim.

In March 1925, the Honolulu Advertiser reported on the preparations and conduct of traditional ceremonies to petition Pele to bring back fire to Halema'uma' $u$. The ceremonies were organized by Mrs. Helen Desha Beamer. Participating chanters included dancer Hananina Kelekolio, 70-year-old chanter, Philip Luahiwa, kahuna Akoni Mika, his pupil Kelilani Nakaula, 90-year-old kahuna George Kalama, and William Kalaiwa'a, among others. The newspaper reported that 2,000 people attended the traditional ceremonies which started at dusk and included chants, hula, and offerings of food, lei, awa, and tobacco. According the news article, "Madame Pele responded to the offerings and wooings at Kilauea firepit last night with clouds of steam and a slight avalanche in the wall of Halemaumau crater." One of the chants performed at the crater rim was, "He Pule Kapu No Pele." The Honolulu Advertiser of March 8, 1925, carried a translation of the chant by James E.K. Keola. It also noted that the reference in the chant to Mauilola is the old Hawaiian name for Pele's court at Kilauea and that Haumea who is mentioned in the chant was Pele's mother.

\section{He Pule Kapu No Pele}

O Pele, Thou goddess mine!

Heaven and earth in darkness dwell

A heavenly water, saline water,

Bring hither Hi'i's flowing awa bowl,

That I may drink and be satisfied;

O thou gallant Mauliola,

Pour forth sacred water to thine awa;

O Earth's mighty Pele, O Sun!

Here's thy gift, a prayer to thee,

Thou art of Haumea's female line,

Beauteous goddess Kilauea

Who dug a might fiery pit,

Abode for maids, of the Summer Seas;

Lovely woman of heaven,

Thou maid in fiery apparel aglow,

An awa bowl to grace a queenly maid

Here is the sacrificial pig;

A lengthwise striped pig:

Save me, thou Pele goddess mine,

Amen, 'tis free, fare thee well.

Annually, the investiture ceremonies for the Aloha Festival court is held at the crater. Halema 'uma' $u$ is a site of performances by the advanced classes of Halau $O$ Kekuhi to mark certain stages in the development of the class and for special occasions. 
Halema 'uma'u crater is a site for the personal introduction of members of the Kanaka'ole family and members of Halau O Kekuhi.

As part of the commemoration of the 100-year anniversary of the armed invasion of Hawai' $i$ by U.S. naval forces and the overthrow of the Hawaiian monarchy ceremonies were held around the Kilauea caldera. From noon on January 2, 1993, through noon on January 3, 1993, several hundred Hawaiian religious practitioners held vigil at four locations marking east, west, north, and south around the caldera. At every hour, the practitioners blew conch shells, pounded traditional pahu hula drums, and chanted from their designated location. One group hiked around the caldera, stopping to chant on every hour. The theme of the gathering was "Kamaka'eha." The name was chosen in remembrance of Queen Lili"uokalani Kamaka'eha whose throne was unjustly seized and the Hawaiian Kingdom was overthrown on January 17, 1893.

With Pele and Kilauea as the focal point, those who gathered around the rim of the Kilauea caldera honored Pele and all of the ancestors and 'aumakua of the Hawaiian people. The chants asked for guidance, strength, unity, and wisdom to move forward in fulfillment of the prophecy of Hawaiian Nationhood.54 Through the crater rim ceremonies the whole sovereignty movement was dedicated to Pele. It was placed under her protection to spark, fire up, and keep warm. All of the ceremonies were organized by Edith Kanakaole Foundation and the Halau $O$ Kekuhi as descendants of the Pele fire clan and a halau dedicated to the perpetuation of the chants and hula of the Pele family.

\section{Offerings at the Lava Flows}

When Pele erupts thousands of people are attracted and journey to the site. Pele practitioners who visit usually take offerings. Harry Kim, administrator of the Hawai'i Civil Defense agency since 1977, testified in court proceedings on February 19, 1991, that in the years of working with the volcano in the Puna district he had observed the chief deity acknowledged and honored by Hawaiians to be Pele. Families and individuals had requested permission to go beyond barricades to where the volcano was flowing to make offerings of lei, flowers, and gifts. News stories about the volcano usually include accounts of offerings made to Pele at the lava flows (Nimmo, 1986).

\section{Additional Acknowledgment}

The volcano, as well as the volcanic matter in the area of the volcano, is widely respected as belonging to Pele. According to park rangers, Hawai'i Volcanoes National Park

\footnotetext{
${ }^{54}$ The prophecy of Hawaiian nationhood was chanted at every hour during the vigil: E IHO ANA O LUNA

1. E iho ana o luna

That which is above, shall be brought down

2. E pi'i ana o lalo

That which is below, shall rise up

3. E hui ana na moku

The islands will be united

4. E ku ana ka paia

To stand strong as the wall of our nation
} 
receives a dozen to two dozen packages and letters a day addressed to Madame Pele (Haili, 1986). The packages usually contain pieces of rock or sand which were taken from the volcano during a visit. Having experienced mishaps or misfortunes which they attributed to having removed the volcanic material, the individuals mail the material to the park rangers to return to the volcano.

Arlo Nimmo, in his article "Pele, Ancient Goddess of Contemporary Hawaii," described many news accounts of sightings of Pele prior to an eruption or related volcanic activities.

\section{IMPACT OF GEOTHERMAL ENERGY}

Pele is the last Hawaiian deity to be actively worshipped, believed in, and revered at many levels after over 200 years of intense Western influence. Kumu Hula Pualani Kanahele explained this in the video, "Pele's Appeal:"

This energy of geothermal belongs to a deity. It belongs to a deity that has lived for hundreds of years and has been the only deity that has come down to us for many generations. It is still very much alive, still very much visible, still very much worshipped and thought of and believed at all different levels and respected.

The primary concern of those who continue to honor and respect Pele as deity be lieve that if geothermal energy is allowed to develop it will tap into the steam which is the life blood of the deity. This will deplete her energy and ultimately destroy her. She will stop manifesting herself to current and future generations. Testimony of Dr. Decker of the Hawai' $i$ Volcano Observatory in the 1985 geothermal contested case hearing provided a scientific foundation for this concern. It was his assessment that no more than 50 megawatts of geothermal energy could be produced annually without reducing the total geothermal present in the volcanic system year by year.

For Pele practitioners it is important to allow Pele to have her time on the island of Hawai' $i$ to create. Living on the island of Hawai' $i$, they smell Pele every day and see what she does for the people. As long as there is any steam coming out from the land; Pele is still creating. Pele should not be cut off by putting a cap on the steam and sending it off somewhere as geothermal energy. Once a cap is put on her steam, it is believed that Pele will move away and no longer manifest herself to the practitioners or their descendants. Pele is the only visible, life connection to the Hawaiian culture and that once a cap is put on the steam, that would be putting a cap on Hawailan culture.

Kumu hula Pualani Kanahele explained:

I am living today and I feel it, and I practice it. My children will live tomorrow and they will feel it and they will practice it if allowed to. If not allowed to, they won't see it and they won't practice. And you will have the responsibility of cutting off that part of the culture, and Hawai'i will be dead. And the Hawatians who will be living, this may as well be new California. Because we'll all be haoles, we'll all have the same goals as the haoles: make money. We would like to keep that part of our culture alive. Please, give us that chance. 
The continuing awesome and magnificent manifestations of Pele in the volcano is believed to be the primary reason for the active perpetuation of the Pele customs, beliefs, and practices throughout over 200 years of foreign influence. If Pele no longer manifests herself to current and future generations they will be unable to experience her and have their beliefs reinforced. This would ultimately lead to the disappearance of the Pele beliefs, customs, and practices. The sapping and depletion of the deity would not only have a negative impact on the customs and practices related to Pele, but upon Hawaiian custom and belief as a whole. Pualani and her husband, Edward Kanahele, professor of Hawaiian History at the Hawai'i Community College, each explained this point in their testimonies in the 1986 contested case hearing before the Board of Land and Natural Resources:

\section{According to Mrs. Kanahele:}

Once the geothermal is up, that will be, as far as I'm concerned, as far as practitioners are concerned, that will be the end of that part of the culture for us. And it's really the end of the living culture for us. What I have established from the beginning of the migration of Pele up until this time, Pele has always been a very vivacious deity that has been alive for us and has been kept alive because of the activity of the volcano. As long as there is steam in the air any of us who are practitioners or who live in the Puna/Ka'u area will know that the deity is alive. And once this steam is cut off from us and taken elsewhere, this part of our culture will die. Our culture itself will die. Because then we all become like everybody else. Because we will not have this connection to the past. We will remember what was done in the past, and we will remember what our grandmothers told us ... but it would not be a living part of them, and it will not be something that will still be alive, still have its connection from the old ... This is the only deity that is left. And she is left because of her manifestation, because of her eruptions, and because she has made herself known. But once this has been cut off from us, once geothermal comes and takes this steam away from us, takes this energy away from Pele, then Pele will die. And so will we, as Hawaiians, we will die and we will live like everybody else.

At another level the practitioners expressed concern that digging into Pele is a desecration and a direct defiance to the deity. They considered it an assault comparable to rape of the deity, of the religion of the first inhabitants of the islands, and of the Hawaiian culture, in general. They pointed out the similarity of the shape of the spiral geothermal drill and the spiral genitalia of a male pig, and alluded to the similarity between the assault upon Pele by the geothermal drills and the legendary rape of Pele by the mythical Kamapua'a.

The Pele religious doctrine centers on perpetuating a set of sacred rituals and cere monies conducted in accordance with the instructions handed down by oral tradition from generation to generation. Maintaining the physical integrity of sacred geography to enable Native Hawaiian religious practitioners to preserve the essential harmony with Pele is a critical attribute of the religious practice.

Practitioners are concerned that geothermal would spoil the imagery of Pele which inspires the performance of traditional chants and the composition of new chants. According to them, the practitioners need Pele to make connections, to get the inspiration, and continue the tradition customs and practices. The imagery is considered important to the composi tion of new chants and the re-enactment and celebration of traditional chants. If Pele doesn't 
come, the whole hula kahiko or traditional hula would be jeopardized. The hula would be performed in nightclubs, without any depth or spirit.

The entire Kilauea volcano is the literal home and body of the goddess Pele. In particular, those areas that are hot and are steaming are sacred. Plants, trees, and certain volcanic land forms are the sacred embodiment of Pele. Pele is the magma, the heat, the vapor, the steam, and the cosmic creation which occur in volcanic eruptions. She is seen by Pele people in the lava, images of her standing erect, dancing, and extending her arms with her hair flowing into the steam and clouds. The Kilauea volcanic area is the source of spiritual power for Pele practitioners which is essential for Pele religious ceremonies and in the daily lives of people who practice the Pele religion. Individual practitioners, when told to do so, go into the volcano area to conduct certain specific, private rituals and ceremonies. The kumu hula play an integral role in the Pele religion, translating messages and communicating them to others in the form of chants and dances.

Geothermal development would destroy practitioner access to and use of sacred land by turning a pristine, virgin rainforest into a spiderweb of pipelines, roads, geothermal wells, and production plants. Under the American Indian Religious Freedom Act, physical access to the land and its natural products must also include the preservation of the natural conditions which are the sine qua non of that access. The efficacy of the natural products and the spiritual well-being of the sacred sites are dependent upon physical conditions. The changing of physical conditions-the spraying and logging of trees, unlimited trapping or removal of original species, alteration of the terrain through river channelization, dams and other methods-not only damages the spiritual nature of the land but may also endanger the wellbeing of the native religious practitioners in their role and religious obligation as guardians and preservers of the natural character of specific land areas (Federal Agencies Task Force, 1979).

Palikapuokamohoalii Dedman is a descendant of the Pele fire clan. He provides insight into the personal responsibility born by those who carry a Pele family name to protect the deity. According to Dedman, when experimental geothermal wells and plants were built, he and other practitioners felt that Pele would take care of it. However, as the drilling continued and the plans for generating electricity expanded he and the other practitioners who eventually formed the Pele Defense Fund believed that they had to do something in their capacity to try to stop geothermal energy development. Mr. Dedman explained that he had been conditioned from the Western practice that one could simply go to church on Sunday and ask the god to clean up damage done during the week. However, one night it came to him that he, as a Pele practitioner, bearing a Pele name and tracing his genealogy to the deity, had to do something. He explained:

It comes upon you at night and grabs you by your neck and sits on your chest and tells you that, You go out and you do it as a Hawaiian because you intelligent, you got the ability, and this is Hawai'i.' You don't pass the buck or lay your rubbish down to your gods to clean it up. You clean it up yourself. You made it, you clean it. That's why I'm here today. If not I wouldn't have said nothing as I did years ago.

From a religious standpoint the Pele Defense Fund articulates what they perceive to be the impact of geothermal energy as follows: 
- We know geothermal development will adversely affect and personally injure the sacred body of the god Pele and that she would retaliate. We fear for the loss of our god, for the loss of the spirits of our ancestors, for the loss of the lives of our children, and for the loss of our places in Hawai' $i$.

- We believe that geothermal development will unduly burden those who are the family of Pele, her guardians, her worshippers.

- Geothermal development will severely impair those who depend on salient images of Pele, her viability, and her forests which are connections to the deity.

- Geothermal development would impinge upon the continuation of all essential ritual practices and therefore also impacts the ability of training young persons in traditional religious beliefs and practices and the ability to convey these to future generations.

- Geothermal development will take Pele and diminish and finally delete her creative force, causing spiritual-religious, cultural, psychological and sociological injury and damage to the people who worship and live with Pele.

From a religious standpoint, geothermal energy development is totally unacceptable to those who are descended from Pele and who continue to honor, respect, and worship her. They sincerely believe that geothermal energy will have a fatal and irreversible impact on the deity that they descend from, believe in, and worship. Moreover, Pele is singularly important to the survival of Hawaiian culture as a whole because she is the only Hawaiian deity to continue to be honored and worshipped by Hawaiians after over 200 years of contact. Thus, from that standpoint of the Pele practitioners, the development of geothermal energy would be tantamount to cultural genocide.

\section{Ceremonies to Heal Geothermal Damage}

In June 1989, True Geothermal began to bulldoze a road into the Wao Kele O Puna forest to establish a drill site for geothermal resource exploration. On October 14, 1989, approximately 350 Pele practitioners and supporters entered the Wao Kele O Puna forest in a religious procession and built an ahu or rock altar on the site where the geothermal drilling would start. They made offerings and chanted traditional oli (chants) to heal the wound in the forest. The drilling rig went into the forestone October 28,1989 , and on the following day Pele practitioners again conducted a religious ceremony at the drilling site. The drilling at the site began in November 1989.

On March 25, 1990, 1,500 Pele practitioners and supporters attempted to enter the forest to conduct a religious ceremony at the drilling site. The Campbell Estate and True Geothermal Energy $\mathrm{Co}$. called in the police. A total of 141 practitioners and their supporters were arrested. In the trials of the Pele practitioners, the testimonies they offered described how they felt an obligation to go into the forest to conduct ceremonies to heal the forest and the wound made by the geothermal drilling into the deity Pele. It also provided additional insights into the Pele beliefs, customs, and practices related to the volcanic rainforest and to the Puna district.

Punahele Lerma, a chanter and dancer of Halau $O$ Kekuhi, had conducted the healing ceremonies in Wao Kele O Puna in October 1989 and in March 1990. In his trial for 
trespass he described his sense of responsibility and obligation for protecting the forest. He explained that having been asked by a Hawaiian ahupua'a tenant to assist in the healing protocol, he had begun to prepare days and hours in advance. He felt obliged to help clear the forest of the desecration by the bulldozing. He explained the chants of healing which were performed in the March 1990 ceremonies. The first chant, "Na "Aumakua" was to link up each individual native person to the ancestral spirits of the area. The second protocol was the reaffirmation of the migration chant of the Pele line starting from Tahiti to the Northern islands of Hawai' $i$ and to Puna. He further explained that the deities of the forest are omnipotent in their form and ever changing, but when the lokahi or relationship of harmony and balance between the humans, the gods, and nature is upset, then it will be the humans living in the present and those yet unborn who will suffer the harm. The protocol he performed was to begin the process of restoring a relationship of lokahi between the people and the forest and the deities of the forest.

Pualani Kanahele, kumu hula for Halau O Kekuhi, provided expert witness testimony in the trial involving Mr. Lerma, one of the leading members of her halau. She explained that the district of Puna is the eastemmost district in the whole archipelago and that in the Pele cosmology, the Pele deity and her family are always in the east, and their travels are always toward the east. According to Mrs. Kanahele their eastward movement signifies that there will be new land. The creation of new land begins in the east. Everything that has to do with newness is in the east. The new day begins in the east. In Hawaii, the sun rises in the east over Point Kumukahi in Puna. Pele and her family are associated with creation of newness. Pele has to do with the creation of new land. Hi 'iaka has to do with the creation of greenery upon the new land. Mrs. Kanahele further explained that there is also a higher deity above Pele and Hi' ${ }^{\prime}$ 'aka, under whose guardianship they fall. That is Kane who has to do with the rising sun. She also described how the northeast trade winds which bring in the clouds and the rain also first arrive in the easternmost part of the Hawaiian archipelago at Puna. The word "Puna" also has to do with wellspring which again, is associated with creation. Puna not only has to do with the wellspring of water in the district but also the wellspring of land. When the volcano erupts and it overflows, it looks like the movement of water. The chants describe the movement of lava as the movement of water.

Mrs. Kanahele also explained how many of the chants that she is familiar with mention Keahialaka and the Wao Mau Kele O Puna. These are other manifestations of the Pele family. An aunt of Pele and Hi'iaka is $\mathrm{Ma}^{\prime} \mathrm{u}$. She has to do with the deep, wet forest. Hi'iaka has to do with the greenery that grows in the forest. Keahialaka means the fires of Laka It is so named because when the ohi'a trees are in bloom there, all one can see is red and it looks like fire. The chants reveal that Keahialaka is where the Hawaiians used to go and gather awa, the awa papa and the awa laulena. They speak of how the body form of Kane I Ka Wai Ola is used to make the awa and that when one goes to Keahialaka to gather awa you may come upon Pele also gathering lehua. The forest was important because it had awa in it and extensive groves of lehua. The wet forest is important to the deity Kane I Ka Wai Ola and its function is to attract rain and hold the water. She also explained that if the trees that the chants speak of are gone it will have a negative impact upon the tradition:

If all of these-all of the trees that-that our chants speak about are gone, all the trees that we use for many different reasons are gone, it no longer exist, and we don't see it, that particular part of our culture is gone. Because it's not visible anymore. And how can you teach a child only out of books, you know, and still expect that child to maintain or feel very-that that part of his culture is important when it doesn't exist anymore? So the culture doesn't 
have to only be something you believe in. The culture is also physical as well as spiritual. So if the physical part of it is gone, then ... the other part of it would dwindle.

Pualani Kanahele explained that Pele was a family or occupational deity. Those who use her forest to gather medicine or as a source of trees to make canoes or those who are chanters and dancers to Pele have an obligation to praise and respect the deity. If there was a disrespect to the deity, the burden of responsibility did not fall upon those who were unaware but upon the tradition bearers, those who have the responsibility to maintain the respect and the reverence that went to that deity. She also explained that when there is dese cration on the land a lot of ceremonies are necessary to heal the land and restore the balance. There must be a lot of giving back, of caring, and of showing sincerity and connecting to the spirits of the ancestors. Those who were raised in traditions related to.Pele and the forests of Pele feel a responsibility to try to protect the deity and her family and their manifestations.

In January 1983, Pele began to erupt in Kahauale'a. She built up Pu'u 'O'o. The areas slated for geothermal well drilling were buried under 15 feet of newly erupted lava. The eruption continued through 1994, flowing out of subterranean tubes from the Kupaianaha lava lake. Pele practitioners interpret the continuing eruption as a ho'ailona or supernatural sign of defiance by the deity against geothermal energy. The active manifestation of the deity inspires them to be resolute and determined in their efforts to protect the deity and shut down geothermal energy development.

Finally, Mrs. Kanahele explained that in order for the area which had been drilled to be completely healed, the drilling would have to stop; the equipment would have to removed; the area would have to be replanted with native vegetation; and a lot of offerings and prayers in connection with the ancestors of that area of Puna would have to be made. As the eruption which began in January 1983 continued into its 12 th year at the time of this study, the Pele practitioners remain resolute in their spiritual beliefs, dedicated in their customary practices, and convinced of their obligation to resist geothermal energy. 


\section{REFERENCE MATERIALS FOR REPORT AND APPENDICES}

Aiona, I. (1992). La'au Hawai'i: Traditional Hawaiian Uses of Plants. Honolulu:, HI: Bishop Museum Press.

Aiona, I. (1991). Major Plants Brought by Polynesians to Hawai'i. Handout \#3, EthnobotanyBotany 105. Honolulu, HI.: University of Hawai' $i$, Botany Department.

Allen, M. S. (1979). The Kalapana Extension in the 1800's, A Research of the Historical Records. Prepared for the National Park Service, Hawai'i Volcanoes National Park.

Alexander W. D. and F. S. Doger (1878-1884). Kipahulu and Kaupo Quadrangle. County of Maui. Honolulu: B.P. Bishop Museum. Honolulu: B.P. Bishop Museum.

Aluli, N. E. (1988). Aloha 'Aina: Without the Land We Are Nothing. Star Bulletin, Ho'olako Year of the Hawaiian Progress Edition, Alto, New Mexico: C.F. Boone Publishing Co.

Ashdown, I. (November 1970). Ke Alaloa o Maui: Authentic History and Legends of the Valley Isle told By Maui County's Historian Emeritus. Ulupalakua.

Ashdown, I. (1969-1977). Notes. Unpublished manuscript. Ulupalakua.

Baldwin, C. (1908). Geography of the Hawaiian Islands, New York: American Book Company.

Barrere, D. (1959). Political History of Puna. Unpublished manuscript for Archaeology Reconnaissance of the Kalapana Extension by Bishop Museum.

Beaglehole, J.C. (1967). The Joumals of Captain James Cook on his voyages of discovery, Vol. III. The Voyage of the Resolution and Discovery, 1776-1780. Cambridge: Haklut Society

Beckwith, M. (1970). Hawaiian Mythology. Honolulu: University of Hawai'i Press.

Beckwith, M. (1972). The Kumulipo: A Hawaiian Creation Chant. Honolulu: University of Hawai i Press.

Beckwith, M. (1976). Hawaiian Mythology, Honolulu: The University Press of Hawai'i.

Board of Land and Natural Resources, (1985-1986). Conservation District Use Application Contested Case Hearings, CDUA No. HA-12/20/85-1830, testimonies of Pualani Kanahele, Edward Kanahele, and Ka'iana Haili.

Board of Land and Natural Resources, (1985). Geothermal Subzone Contested Case Hearings, G.S. No. 9/26/85-5, testimony and exhibit of Noa Emmett Aluli, M.D.:

Bryan, E. H. (1954). The Hawaitan Chain. Honolulu, HI:: Bishop P. Museum Press. 
Bryan, E.H. (1980). Hawaiian Antiquities. Honolulu, HI.: Bishop Museum Spec. Pub. 2, 2025.

Burdette, Bostwick and Murton (1971). Puna Studies: Preliminary Research in Human Ecology. Honolulu, HI.: Department of Anthropology, University of Hawai' $i$.

Burtchard, Greg and Pennie Moblo (1994). Archaeology in the Kilauea East Rift Zone: Kapoho, Kama'ili and Kilauea Geothermal Subzones, Puna District, Hawai' $i$ Island. Report ORNL/SUB/94-SN150/1-2. Oak Ridge, Tennessee: Oak Ridge National Laboratory.

Cartwright, B. (1933). Some Allis of the Migratory Period. Bishop Museum Occasional Papers, Vol. X, No. 7, Honolulu.

Chapman, P. (July 5, 1966). Sam Po Interview: Native Use of the Land. Unpublished manuscript. Maui, Bailey Museum: 4.

Charlot, J. (1983). Chanting the Universe: Hawaiian Religious Culture, Honolulu: Emphasis International, 1983.

Chun, M. N. and Spriggs, M. (February, 1987). New Terms Suggested For Early Hawaiian History. In Ka Wai Ola O OHA, p. 4.

Cooper, G. and Daws, G. (1985). Land and Power in Hawai 'i. Honolulu, HI.: Benchmark Books.

County of Hawai'i (1989). The General Plan Hawai'i County. Hilo, HI.

Cuddihy, L. and Stone, C. (1990). Alteration of Native Hawaiian Vegetation: Effects of Humans, their Activities and Introductions. Honolulu, HI.: University of Hawai' $i$ Cooperative National Park Resource Studies Unit.

Davenport, William (1969). The Hawaiian "Cultural Revolution": Some Economic and Political Considerations. American Anthropologist LXXI, pp. 1-20.

Dean, Eckbo, Austin, and Williams with Morris Fox, (consultants) (1973). H-3 SocioEconomic Study: The Effects of Change on a Windward Oahu Rural Community. Unpublished report, 250.

Degener, O. (1975). Plants of Hawai' $i$ National Parks: Illustrative of plants and customs of the South Seas. Ann Arbor, MI.: Braun-Brumfield, Inc.

Documents in the Hawai'i Volcano National park Headquarters Library, "Transcriptions of a 1974 interview by Russell Apple with former Superintendent Wingate concerning the Kalapana Extension" and "Homesite Provisions of the 1938 Kalapana Act". by Russell Apple, January 5, 1971.

Earle, T.K. (1978). Economic and Social Organization of a Complex Chiefdom: The Halele' $a$ District, Kaua 'i, Hawai 'i. Anthropological Papers of the Museum of Anthropology, University of Michigan, No. 63. 
Edith Kanakaole Foundation, (1994). Unpublished transcripts of workshop on Pele and Hi'iaka by the Edith Kanaka'ole Foundation, March 5, 1994, Honaunau, Hawai'i.

Ellis, W. (reprint 1979). A Narrative of a Tour Through Hawai'i ... With Remarks on the History, Traditions, Manners, Customs, and Language of the Inhabitants, London, 1825.

Emerson, N. (1993). Pele and Hi iaka: A Myth From Hawaii, Honolulu: N.B. Emerson, 1915, reprinted Honolulu: 'Ai Pohaku Press.

Emerson, N. (1965). Unwritten Literature of Hawai 'i: The Sacred Songs of the Hula. Rutland: Charles E. Tuttle Co.

EPS (Elspeth Sterling) (April 22-25, 1968). "Talks with Mr. \& Mrs. Sam Po at their Home in Paukukalo, Maui." Unpublished manuscript. 1st Draft.

Erkelens, Conrad (1994). Phase I Archaeological Investigation Cultural Resource Survey, Hawaii Geothermal Project, Makawao and Hana Districts South Shore of Maui, Hawai $i$. Report ORNL/SUB/94-SN150/3. Oak Ridge, Tennessee: Oak Ridge National Laboratory.

Federal Agencies Task Force, (August 1979). American Indian Religious Freedom Act Report, at 54, prepared pursuant to Section 2, American Indian Religious Freedom Act of 1978, P..L. No. 95-341, 92 Stat. 469, 470, 42 U.S.C. 1996.

Fornander, A. (1880). An Account of the Polynesian Race. Vol. II. London: 1880, 35-36.

Fornander, A. (1916-1920). Fornander Collection of Hawaiian Antiquities and Folk-Lore. Honolulu: T.G. Thrum (ed.). BPBM Memoirs 4, 5, 6, 1916-1920.

Fornander, A. (1916-1919). Memories. Honolulu: B.P. Bishop Museum. Vol. IV.

Fuchs, Lawrence (1961). Hawaii Pono: A Social History. San Diego: Harcourt, Brace \& World, Inc.

Governor's Proclamation (June 29, 1911). In Hawai'i State Archives file of Governors' Proclamations.

Governor's Proclamation, December 22, 1928. In Hawai'i State Archives file of Governors' Proclamations.

Green, J. S. (Dec. 1835). Letter to Rev. R. Anderson. Missionary Letters Vol. 6:1730 67. Part Second XXVI: Remainder of Letter printed in 31 Missionary Herald, 463 Sandwich Islands 1831-1837. Honolulu: Mission House Museum Library.

Hall, Dana Naone (ed.) (1985). Malama Hawaiian Land and Water. Honolulu: Bamboo Ridge Press. 
Handy, E.S. Craighill and Elizabeth Green Handy, with Mary Kawena Pukui (1972). Native Planters in Old Hawaii: Their Life, Lore and Environment. Honolulu: BPBM Press, Bulletin 233.

Handy, S. C. (1940). The Hawaiian planter-Volume I: His plants, methods, and areas of cultivation. B.P. Museum Bulletin, 161, Honolulu: B.P. Bishop Museum.

Handy, E.S. Craighill and Mary Kawena Pukui (reprint, 1976): The Polynesian Family System in Ka'u, Hawai' $i$. Wellington: Polynesian Society, 1958; reprint Tokyo: Charles E. Tuttle Company, Inc.

Hawai'i State Archives (1897). Boundary Commission-Hawai 'i, 3rd \& 4th Circuits, In ReBoundaries, Ahupuaa of Keahialaka, Puna, Hawai'i, Brief of Hitchcock \& Wise, filed March 20, 1897, 2:10 pm.

Hawai'i State Archives (1911). File of Governors' Proclamations. Governor's Proclamation, June 29, 1911.

Hawai'i State Archives (1914). Boundary Commission-Hawai'i, 3rd \& 4th Circuits. Petitoners Exhibit B, "The Ahupuaa of Keaau, District of Puna, Island of Hawai'i, 3d, J.C. Before the Commissioner of Boundaries, Fourth Judicial Circuit. Territory of Hawai'i. In the Matter of the Boundaries of Waiakahekahe-'iki. Upon the Petition of W.H. Shipman, owner. Carl S. Carlsmith, attorney for petitioner. I.M. Stainback, Attorney General, Hilo, June 18th, 1914.

Hawai'i State Archives (1928) File of Governors' Proclamations. Governor's Proclamation, December 22, 1928.

Hawai'i State Archives. Place Name file for Puna.

Hawaiian Gazette (1910). Honolulu.

Hawaiian Ethnographical Notes (1885).

Hawaiian Sovereignty Advisory Commission (1994). Hawaiian Sovereignty Advisory Commission Report to the Hawai'i State Legislature. Honolulu, Hawai'i.

Holmes, T. (November, 1985). A Preliminary Report on the Early History and Archaeology of the Puna Forest Reserve/Wao Kele 'O Puna Natural Area Reserve. Prepared for Truel Mid-Pacific Geothermal, Inc.

Honolulu Advertiser, (1925). March 3, 1925, p. 1-2; March 8, 1925, p. 2; March 23, 1925, p. 1; March 24, 1925, p. 1, 7.

James, V. (1991). Ancient Sites of O'ahu: A Guide to Hawaiian Archaeological Places of Interest, Honolulu: Bishop Museum Press.

Johnson, R. K. (1981). Kumulipo: The Hawaiian Hymn of Creation, Volume One, Honolulu: Topgallant Publishing Co.. 
Ka Hoku O Hawai 'i, May 21, 1908, to September 10, 1908.

$\mathrm{Ka}$ 'Ohana o Kahikinui (February 22, 1993). A Conceptual Community Land Use Plan for the Ahupua'a of Kahikinui. Maui: Presented to the Hawaiian Homes Commission and the Department of Hawaiian Home Lands. Maui.

Kahiolo, G.W. Kahiolo (1978). He moolelo No Kamapua'a. The Story of Kamapua'a, translated by Esther T. Mookini and Erin C. Neizmen with the assistance of David Tom, Hawaiian Studies Program UH Manoa.

Kalakaua, D. (King of Hawaii) (1973). The Legends and Myths of Hawaii: The Fables and Folklore of a Strange People. Tokyo \& Rutland: Charles E. Tuttle.

Kamakau, S. (1961). Ruling Chiefs of Hawai'i. Honolulu: The Kamehameha Schools Press.

Kamakau, S. (1964). Ka Po'e Kahiko: The People of Old. BPBM Spec. Publ. 51.

Kamakau, S. (1976). The Works of the People of Old. BPBM Spec. Publ. 61.

Kamakau, S (1991). Tales and Traditions of the People of Old, na Mo'olelo a ka Po'e Kahiko. Translated from the Newspapers Ka Nupepa Kuokoa and Ke Au Okoa by Mary Kawena Pukui, Edited by Dorothy. Barrere, Honolulu: Bishop Museum Press.

Kamakau, S. (1992). Ruling Chiefs of Hawai ${ }^{i}$. Honolulu: The Kamehameha Schools Press.

Kanahele, P. K (1990). Ka Honua Ola (The Living Earth), unpublished manuscript, Honolulu: Center for Hawaiian Studies, UH, Manoa.

Kanahele, P. K. (May 2, 1990). Lecture to the student body of Kamehameha Schools.

Kelly, M. (1988). Majestic Ka'u. Mo'olelo of Nine Ahupua'a. Department of Anthropology Report Series 80-2, Honolulu: Bishop Museum Press.

Kent, Noel. (1983). Hawaii, Islands Under the Influence. New York: Monthly Review Press.

Kinney, H. W. (1913). The Island Of Hawai $i$. Hilo: Hilo Board of Trade.

King, Robert D. (1935). Districts in the Hawaiian Islands. In A Gazetteer of the Territory of Hawai $i$. Compiled by J. W. Coulter, University of Hawai'i Research Publication No. 11:214-230, Honolulu.

Kirch, P.V. (1985). Feathered Gods and Fishhooks: An Introduction to Hawaiian Archaeology and Prehistory. Honolulu: University of Hawai' $i$ Press.

Kroeber, A. L. (1948). Anthropology. New York: Harcourt, Brace.

Kuoko'a Newspaper (1922-24). Translated by Mary Kawena Pukul and Part of the Hawai'i Ethnographic Notes (HEN) in the B. P. Bishop Museum Library. 
Kuykendall, Ralph S. (1938). The Hawaiian Kingdom, Volume I, 1778-1854. Foundation and Transformation. Honolulu: The University of Hawai'i Press (1938). Reprint The University Press of Hawaíi (1980).

Langlas, C. (1990). The People of Kalapana, 1832-1950, Hilo: Charles Langlas.

Lind, A. (1938, reprint, 1968). An Island Community: Ecological Succession In Hawaii. Chicago: The University of Chicago Press (1938). Reprint New York: Greenwood Press, 1968.

Littler, Robert M. C. (1929). The Governance of Hawaii: A Study in Territorial Administration. Stanford: Stanford University Press.

Luomala, K. (1955). Voices on the Wind: Polynesian Myths and Chants. Honolulu, HI.: Bishop Museum Press.

Lyman, C. S. (1924). Around the Horn to the Sandwich Islands and California, 1845-1850. New Haven: Yale University Press.

Lyons, Curtis J. (1875). Land Matters in Hawai'i. The Islander. No. 2 Honolulu: Hawai'i.

Maciolek, J. (1973). Natural Area Reserve Proposal-Island of Maui Memo. Honolulu: U.S. Dept. of the Interior, Hawai'i Cooperative Fishery Unit.

Malo, D. (1839). Causes for the Decrease of the Population in the Islands. Translation with comments by Lorrin Andrews, The Hawaiian Spectator II, No. 2, p. 125.

Malo, D. (1951) \{1898\} Hawaiian Antiquities. Honolulu, HI: Bernice P. Bishop Museum Press.

Malo, D. (1971). Hawaiian Antiquities. Translation, Dr. Nathaniel B. Emerson, Honolulu: Bishop Museum Press, 53-54.

Malo, D. (1980). Hawaiian Antiquities. N.B. Emerson Transl. Publication 2. Honolulu, HI.: Bernice P. Museum Press.

Manupau, T. (6/1/1922-3/15/1923). Huaka'i maki'ka'i a Kaupo (Trip to Kaupo). Trans. M Chun. Kuokoa 6/1/1922-3/15/1923. Honolulu: B.P. Bishop Museum.

Marciel, J. (May 3, 1960). Interview by Mary Kawena Pukui, Kaupo, Maui. Audio-Recording Collection No. 85.7, Anthropology Department. Honolulu: Bernice Pauahi Bishop Museum.

McEldowney, Holly (1979). Archaeological and Historical Literature Search and Research Design, Lava Flow Control Study, Hilo, Hawai'i. Report prepared for U.S. Army Engineer Division, Pacific Ocean, Honolulu. Department of Anthropology, B.P. Bishop Museum. Honolulu.

McEldowney, Holly and Fred Stone (1991). Survey of Lava Tubes in the Former Puna Forest Reserve and on Adjacent State of Hawai' $i$ Lands. Prepared for the State Historic 
Preservation Division, Division of Water Resource Management, Department of Land and Natural Resources. State of Hawai 'i. Honolulu.

McGregor, D. (1980). Hawaiians: Organizing In The 1970's. Amerasia Journal, 7:2, $29-55$.

McGregor, D. (1989). Kupa'a I Ka 'Aina: Persistence On The Land. Unpublished doctoral dissertation, University of Hawai' $i$.

Mellen, K. (1956). The Gods Depart: A Saga of the Hawaiian Kingdom. New York, N.Y.: Hastings House.

Minerbi, L., McGregor, D., and Matsuoka, J. (1993). Hawai'i Environmental Risk Ranking: Native Hawaiian Assessment. Hawai'i State Department of Health.

Minerbi, L., McGregor, D, and Matsuoka, J. (1993). Native Hawaiian and Local Cultural Assessment Project Phase I: Problems/Assets Identification. Honolulu, HI.: University of Hawai'i.

Murphy, T, F. (1923). Keokeo Quadrangle Topographic Map. Territory of Hawai 'i. Honolulu: B.P. Bishop Museum.

Native Hawaiian Legal Corporation (1991). Native Hawaiian Rights Handbook. ed. by Mackenzie, M.., esq.

Newman, S. (1972). Man in the Prehistoric Hawailan Ecosystem. A Natural History of the Hawaiian Islands, 559-607.

Nimmo, A. (1986). Pele, Ancient Goddess of Contemporary Hawaii, Pacific Studies, Vol. 9, No. 2, March 1986.

Pacific Commercial Advertiser. (1910).

Pele Defense Fund, (1989). Charter of Incorporation.

Pukui, M. K. (November 30, 1961). Interview with Dolly Mahalo, Josephine Marciel and Francis Marciel. Audio Recording Collection, Anthropology Department, Bishop Museum, Kaupo, Maui, \#86.03.1,2,3.

Pukui, M.K (1983). Olelo No eau Hawaiian Proverbs \& Poetical Sayings. Honolulu, HI: P.B. Bishop Museum.

Pukui, M. K, and Curtis, C. (1949). Pikoi and Other Legends of the Island of Hawai ' $i$, reprinted Honolulu, HI: Kamehameha Schools Press.

Pukui, M. K and Elbert, S. H. (1986). Hawaiian Dictionary. Honolulu: University of Hawai'i Press.

Pukui. M. K., Elbert, S. and Mookini, E. (1974). Place Names of Hawai i. Honolulu: University of Hawai' $i$ Press. 
Puna Hui 'Ohana (1982). "Assessment of Geothermal Impact On Aboriginal Hawaiians." Washington D.C.: Department of Energy.

Rae, J. (1853). Joumal of a Tour Around East Maui Made by James Rae in 1853. Located in the Sterling Collection. Restricted File. Unpublished. Honolulu: B.P. Bishop Museum.

Ralston, C. (1984). Hawai'i 1778-1854: Some Aspects of Maka'ainana Response to Rapid Cultural Change. Joumal of Pacific History, XXIX No. 1, 23.

Remy, J. (1868). Contributions of a Venerable Savage to the Ancient History of the Hawaiian Islands. Translated from the French by William T. Brigham, Boston, MA.

Sahlins, Marshall (1981). Historical Metaphors and Mythical Realities: Structure in the Early History of the Sandwich Islands Kingdom. Ann Arbor: University of Michigan Press.

St. John, H. (1973). List of Hawaiian Plants. Pacific Botanical Garden, Lawai, Kaua'i.

Schmitt, Robert C. (1968). Demographic Statistics of Hawaii. Honolulu: University of Hawai‘i Press.

Schmitt, Robert (1973). The Missionary Census of Hawaii. Pacific Anthropological Records, No. 20, Bishop Museum Press, Honolulu.

Skolman, Roger (1976). Hawaii's Forest Products Industry, Proceedings of the 18th Annual Hawaii Forestry Conference held November 18-19, 1976, Honolulu.

Stannard, D. (1989). Before the Horror. Honolulu: University of Hawai'i Press.

State of Hawai'i. (1973). Department of Accounting and General Services (January 22, 1973). Ahihi-Kinau Natural Area Reserve Parts 1 and 2. Honolulu, HI.

State of Hawai'i (1981). Department of Land and Natural Resources. Title 13 Subtitle 9 Natural Area Reserve System V Chapter 209 Rules Regulating Activities Within Natural Area Reserves. Honolulu, HI.

State of Hawai 'i (1985). Section 7-1 (1985). Honolulu: State of Hawai'i. In Hawai'i Revised Statutes.

State of Hawai‘i (1991). Department of Business and Economic Development and Tourism, State of Hawai $i$ Counties and Districts. Honolulu, HI.

State of Hawai'i. (1992). Department of Business Economic Development and Tourism. State of Hawai' $i$ Data Book. Honolulu, $\mathrm{HI}$.

State of Hawai'i (1993). Subtitle $6 \mathrm{Ch}$. 195. Natural Area Reserve System. In Hawai'i Revised Statutes. Honolulu: State of Hawai'i, 239-243.

Sterling, E. (1968). Notes: Interview with Mr. and Mrs. Sam Po, April 22-25. Unpublished manuscript, Bishop Museum. 
Territory of Hawai'i (1924). Keoneoi 'io Quadrangle. Section \#16. Honolulu: B.P. Bishop Museum.

Territory of Hawai`i (1924), Luala'ilua Quadrangle. Section \#17. Honolulu: B.P. Bishop Museum.

Territory of Hawai'i (1924-25). Kaupo Quadrangle. Section \#17. Honolulu: B.P. Bishop Museum.

Territory of Hawai'i (1929). Indices of Awards by the Board of Commissioners to Quiet Land Titles in the Hawaiian Islands. Honolulu: Territorial Office Building.

Thrum, T. G. (1907). Hawaiian Folktales. Chicago.

Titicomb M. (1977). Native Fish Species in Hawaii. Honolulu: University of Hawai'i Press.

United States Bureau of the Census (1930). Fifteenth Census of the United States: 1930, Occupation Statistics Hawaii.

U.S. Congress. House. (1893). Intervention of United States Government in Affairs of Foreign Friendly Governments. 53rd Congress, 2nd Session. December 21, 1893. Washington: Government Printing Office.

U.S. Congress. Senate (1894). Hawaiian Islands. Report of the Committee on Foreign Relations With Accompanying Testimony and Executive Documents Transmitted to Congress from January 1, 1893 to March 19,1894. Volumes I and II. Washington: Government Printing Office.

U.S. Congress. Senate. Committee on Foreign Relations. Report No. 227. Report from the Committee on Foreign Relations and Appendix in Relation to the Hawaiian Islands, February 26, 1894. 53rd Congress, 2nd Session. Washington: Government Printing Office.

U.S. Congress. 56th Congress, 1st Session 1899-1900. Congressional Debates on Hawaii Organic Act, Together with Debates and Congressional Action on Other Matters Concerning the Hawaiian Islands. Washington: (photostat, reproduction from the Congressional Record, v. 33, pts. 1-8), 1899-1900.

U.S. Congress. Kalapana Extension Act, “52 Stat 781 et. Seq." Act of June 20, 1938.

U.S. Department of Energy (April 1993). Implementation Plan for the Hawai' $i$ Geothermal Project Environmental Impact Statement, Washington D.C.

U.S. Department of State. (1893). Papers Relating to the Mission of James H. Blount, United States Commissioner to the Hawaiian Islands. Washington: Government Printing Office.

U.S. Geological Survey (1993). Maps of Island of Maui. 1: 24,000. 
U.S. Department of the Interior. (n.d.) Guidelines for Evaluating and Documenting Rural Historic Landscapes. National Register Bulletin No. 30, National Park Service.

U.S. Department of the Interior. (n.d.) Guidelines for Evaluating and Documenting Traditional Cultural Properties. National Register Bulletin No. 38, National Park Service.

Uyehara, Mitsuo (1977). The Hawaii Ceded Land Trusts, Their Use and Misuse. Honolulu: Hawailana Almanac Publishing Company.

Wagner, W., Herbst, D. and Sohmer, H.S. (1990). Manual of the Flowering Plants of Hawai $i$, Vol. 1 \& 2. Honolulu, HI: University of Hawai'i Press.

Walker, W. M. (1931). Archeology of Maui. Unpublished manuscript. Honolulu: B. P. Bishop Museum.

Wall, W. E. (1922). Hawai' $i$ Territorial Survey Map.

Westervelt, W. D. (1910). Maui the DemiGod. Honolulu.

Westervelt, William (1988). Hawaiian Legends of Volcanoes, 1916, reprinted Tokyo: Tuttle.

Whistler, A. (1992). Flowers of the Pacific Island Seashore. Honolulu, HI: University of Hawai'i Press.

Wilkes, C. (1845). Narrative of the U.S. Exploring Expedition During The Years 1838-1842, Vol. IV. Philadelphia, PA. 
APPENDICES

. 
APPENDIX A

MATERIALS USED DURING INFORMANT INTERVIEWS 
NATIVE HAWAIIAN ETHNOGRAPHIC STUDY SURVEY

HAWAII GEOTHERMAL PROJECT

INDIVIDUAL INTER VIEW FORM

Name: Address:

Fh.

Age: ; Sex: F: ; $\mathrm{M}:$ ;

1. DESCRIBE YOUR RELATIONSHIP TO AND OR EXPERIENCE WITH THE PROJECT AREA?

2. DESCRIBE LENGTH OF TIME \& FREQUENCY OF CONTACT WTTH THE PROJECT AREA.

3. POINT OUT ON THE MAP AND DESCRIBE STTES AND AREAS OF CULTURAL AND HISTORICAL USE AND SIGNIFICANCE TO YOU IN THE PROJECT AREA. (refer to list of types of cultural sites and use areas)

4. IDENTIFY AND DESCRIBE NATURAL RESOURCES USED FOR CULTURAL, RELIGIOUSS AND SUBBSISTENCE PRACTICES.

5. DESCRIBE 'AUMAKUA AND DEITIES ASSOCIATED WITH THE AREA. PLEASE SHARE ANY LEGENDS, TRADITIONS OR CHANTS ASSOCIATED WITH THE DEITIES AND RELATED PLACES.

6. DESCRIBE HAWAIIAN CULTURAL AND SUBSISTENCE ACTIVITIES THAT HAVE BEEN OR CAN BE CONDUCTED IN THE AREA.

7. LOOKING AT THE PLACE NAMES (ATTACHED) PLEASE SHARE WHAT YOU KNOW TO BE THE MEANIIT, SIGNIFICANCE, OR STORY RELATED TO THE NAVE.

8. CAN YOU PLEASE SHARE INFORMATION ABOUT HISTORICAL EVENTS OR PERSONS ASSOCIATED WTTY THE AREA.

9. SHOLZD ALI INFORMATION ABOUT HAWAIIAN CULTURAL USE AREAS AND SITES BE INCLUDED IN THE ETHNOGRAPHIC REPORT? IS THERE ANY MFOR VIATION WHICH SHOLID NOT BE MIADE PLBLIC?

10. WIL THE HAWAI'I GEOTHERMAI PROJECT AFFECT THE HAWAIIAN CLSTOMS. BEIEES, PRACTICES, SITES OR USE AREAS WE HAVE DISCISSED?

1.. HOW COULD ANY OF THE IEGA TIVE IMPACTS BE REDLCED OR AVOIDED?

:- HOW WOULD YOL LIKE THE HAWAILAN HISTORICAL AND CIULTLRAL SITES AND USE AREAS THAT WE DISCLSSED TO BE W! ANAGED?

P:ease answer the following three items by circing the number whics corresponds to the approcriate question above.

A. MY OWNDIRECT KNOWLEDGE:

3. REPORTED TO ME BY RELATTVES:

C. REPORTED TO ME BY OTHERS:

$3,4,5,6,7,8$

$3,4,5,6,7,8$

$3,4,5,6,7,8$

Explain how qualified to be a respondent for this study:

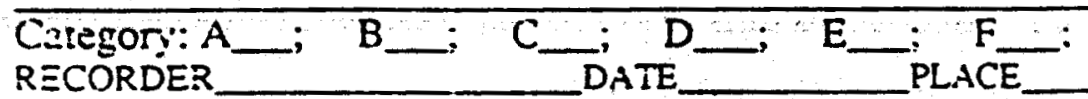


LAST NAME:

FIRST:

FULL ADDRESS:

ORGANIZATION OR OHANA:

PHONE:

AGE:

N. HAWAIIAN

TRADITIONAL

PRACTICES

EXERCISED

BY ME

SUBSISTENCE

Hunting

Fishing

Makai Gathering

Mauka Gathering

Planting

Öthers

CULTURE

Hula

Religious Pract.

Lapaiau

Lauhala/

Woodwork

Burials

Access Trail Ùse

Öthers

Explain how qualified to be a respondent for this study:

Category: $\mathrm{A}$ 


\section{AGREEMENT TO PARTICIPATE IN}

\section{A Native Hawaiian Ethnographic Survey \\ for the \\ Hawai'i Geothermal Project \\ Environmental Impact Statement}

\section{Sponsored by the U.S. Department of Energy}

Oak Ridge National Laboratory (ORNL) is currently assisting the Department of Energy (DOE) in identifying and evaluating the potential environmental impacts of the 500-megawatt Hawai' $i$ Geothermal project (HGP), a project proposed to Congress by the State of Hawai' $i$ in 1990. To assist DOE in complying with federal and State legislation on the protection of cultural resources and Native Hawaiian customs and religion, ORNL has subcontracted with a team of professional consultants located in Hawai' $i$ to conduct a survey of Native Hawaiian customs and religion. This team of consultants, who use the name Cultural Advocacy Network for Developing Options (CANDO), consists of Dr. Luciano Minerbi, Dr. Jon Matsuoka, and Dr. Davianna McGregor. Their fields of expertise at the University of Hawai'i include (respectively) planning, social work, and ethnic studies.

These consultants request your participation in a survey to gather information on Native Hawaiian customs, beliefs, and practices relating to culture, religion, and subsistence, and on potential impacts to those practices from the proposed geothermal project. They will conduct group meetings and individual interviews to gather the required information. Participation is completely voluntary, and you may withdraw for a group survey or interview at any time. You may also indicate, below, whether you wish to remain anonymous.

I certify that the survey approach for this project has been explained to me; that I have been given satisfactory answers to my questions about the project and the survey's intended purpose; and that I have been advised that I am free to withdraw my consent and to stop my participation in the project or acsivity at any time.

I wish my identify so remain anonymous.

Signature of Indivicual Participant

\section{Date}

Given the opportunity to first review any statement attributed to me, I would allow citation in a public document

Signature of Indivicual Participant

\section{Date}

For more informarion about the survey, please contact Dr. Jon K. Matsuoka, University of Hawai'i at Manoa, School of Social Work, 2500 Campus Road, Honolulu, Hawai'i, HI 96822, (808) $956-6123$. 


\section{Brief Description of the Hawaii Geothermal Project}

The proposed HGP would include a well field of approximately 155 production wells on 39 separate well sites requiring 195 acres, 37 injection wells requiring 74 acres, and 21 power plants requiring approximately 150 acres. According to a request for proposals issued by the Hawaiian Electric Company, Inc. (HECO) in 1989, these wells, power plants, and ancillary facilities could be located anywhere within the three geothermal resource subzones (GRS)-the Kilauea Middle East Rift Zone, the Kamaili Subzone, or the Kapoho Subzone-in the Puna District of the island of Hawaii. The total area of the three GRSs encompasses approximately 22,000 acre.

The HGP would also include overhead transmission lines from the well field at Puna to the north end of the island of Hawaii. The transmission route would follow one of the two proposed corridors, the first (the preferred route) being along the "saddle" between Mauna Loa and Mauna Kea, and the second being along the Hamakua coastal slopes on the northeastern shore of the Big Island. At a land-sea transition point located west of Mahukona Harbor at the north end of the islands, the transmission lines would connect with submarine cables designed to carry electricity across the Alenuihaha Channel to Maui.

As proposed, the submarine cables would resurface at a land-sea transition point between Apole Point and Huakini Bay on the southeast shore of Maui and connect with overhead transmission lines. The Maui overland transmission route would parallel the island's south shore for a distance of approximately 20 miles between State Highway 31 (the Pi'ilani Highway) and the Kings Trail. The transmission lines would then reconnect with submarine cables at a land-sea transition point located on the southwest shore of Maui between Ahihi Bay and La Perouse Bay. The cables would cross the Auau Channel, pass near the island of Molokai, and touch down on the island of Oahu at Waimanalo.

Alternative overland and submarine transmission routes will be examined in the Environmental Impact Statement (EIS). However, the GRSs on Hawaii and the south shore are of Maui constitute the two major, representative project areas for which cultural resources must be identified and potential impacts and mitigation strategies addressed. Therefore, the requirements outlined in this statement of work must address project areas in those two locations. The GRS project area includes all acreage that might provide evidence of prehistoric or early historic settlement, excluding only those areas covered by historic lava flows. The Maui project area consists of a $200 \mathrm{ft}$. corridor along the south coast of Maui, from Huakini Bay to Ahihi Bay. (Source: Oak Ridge National Laboratory 4/14/93 Statement of Work) 


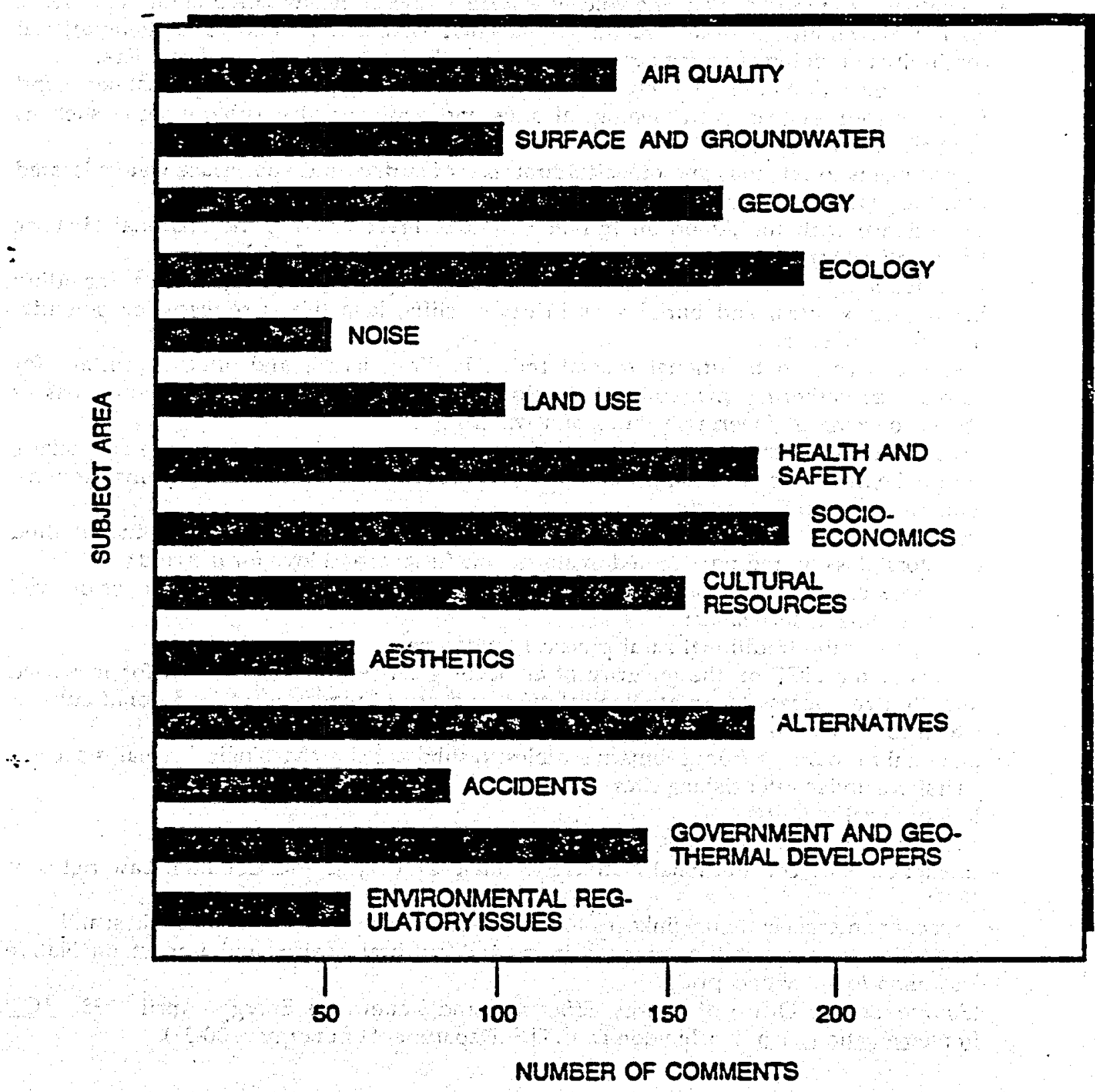

Fig. A. Number of oral and written scoping comments by subject area. About 1800 comments were received during the scoping process to identify significant issues related to the proposed HGP.

(Source Office of Energy Efficiency and Renewable Energy. April 1993. HGP Implementation Plan. Washington D. C. U.S. Department of Energy p. 16).

N. H. Ethnographic Study HGP Handout: Project Description January 6, 1994 


\section{List of Cultural Resources / Native Hawaiian Concerns Issues Identified in the HGP Scoping Sessions}

- potential desecration of Pele, the volcano-nature goddess, and impaired ability to observe Native Hawaiian religious practices associated with Pele; interrupted generational continuity in training of young persons in traditional religious and cultural practices;

- loss or desecration of religiously, spiritually, culturally, and socially unique habitats, land forms, resources (e.g. , archaeological sites and artifacts; atmospheric signs such as rainbows), and species;

- impediments to religious and other cultural uses of surface and subsurface waters located near the geothermal resources;

- compliance with the American Indian Religious Freedom Act, the National Historic Preservation Act of 1966, and other pertinent State and Federal legislation;

- confidentiality of Native Hawaiian practices and religiously significant sites, including heiau (sacred sites) and burial sites in caves, cliffs, lava tubes; concern for potential desecration of sites;

- reduced access to traditional coastal trails, healing places, and areas important for subsistence gathering, maricultural development, and medicinal use of plants; loss of ability to exercise gathering, fishing, and water rights;

- reduced contact with and access to marine resources: sanctuaries (coastal caves and heiau), spiritual emanations or hoailona (natural signs) such as waves, subsistence fishing grounds, gathering of limu (seaweed);

- reduced contact with fish, bird, and other wildlife identified as aumakua (deified ancestors); loss of traditions rooted in aloha 'aina (respect and love for the land);

- precluded use of Native Hawaiian homelands and ceded lands; loss of access to or delayed homesteading of such lands;

- alteration of the traditional rural physical landscape;

- effects of the HGP on the integrity of archaeological resources; potential for increased unauthorized access to archaeological sites and areas important to traditional culture, which could lead to their alteration or destruction;

- potential for damage from submarine cables to submerged archaeological remains such as nearshore underwater fishing sites;

- loss of racial identity;

- effects on subsistence lifestyles, including degradation of fishponds;

- impact on State constitutional Native Hawaiian legal rights and Common Law rights of 1892;

- impact on intergenerational linkages to ancestral lands and cultural/historic sites; and

- impact on quality of life, changes in mertal/cultural health, and impact on Native Hawaiian identity and pride.

(Source: Source Office of Energy Efficiency and Renewable Energy. April 1993. HGP Implementation Plan. Washington D. C. U.S. Department of Energy p. 30-31). 

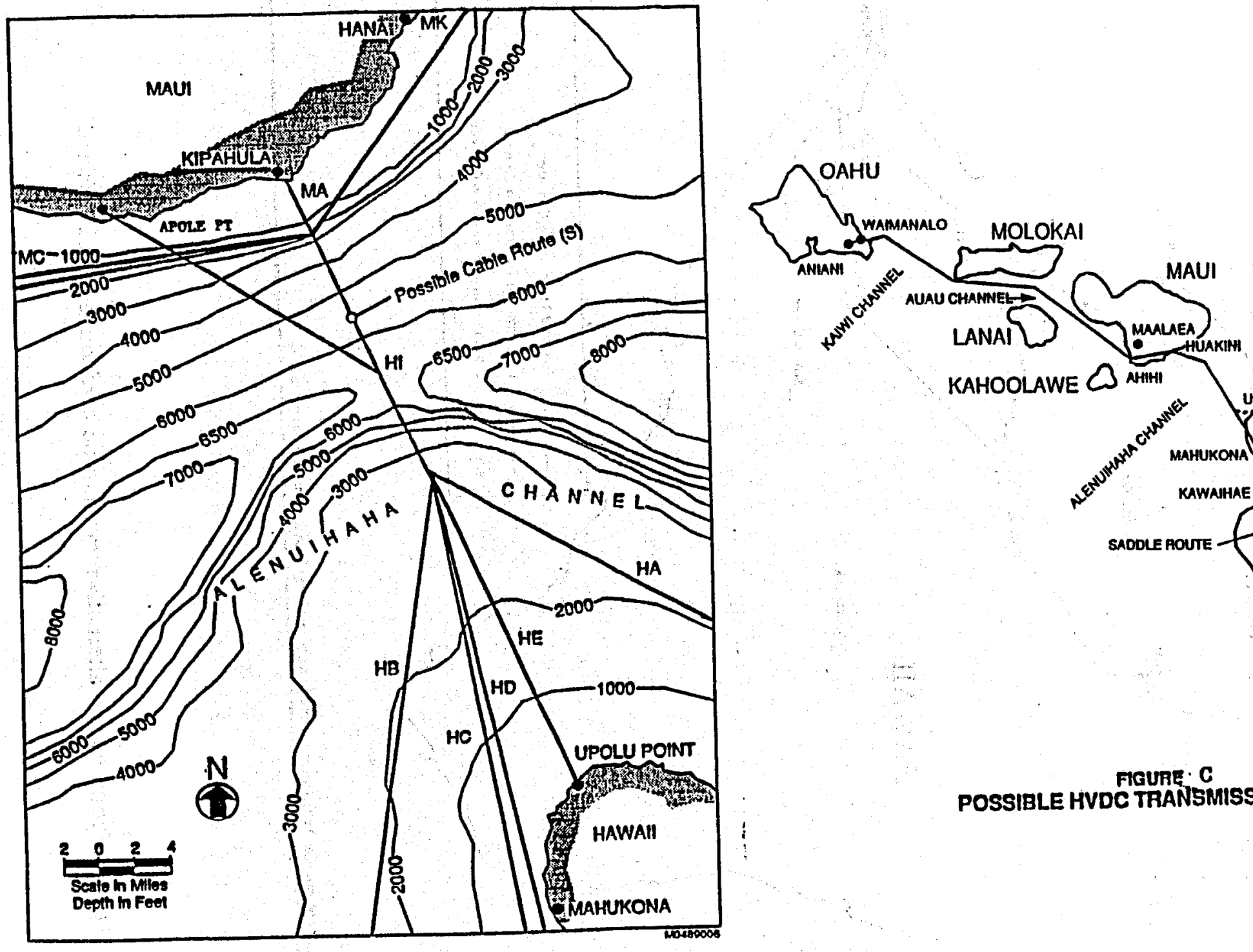

\section{FGURE $B$}

POTENTIAL haWAII TO MAUI CABLE ROUTES Heco 1909 


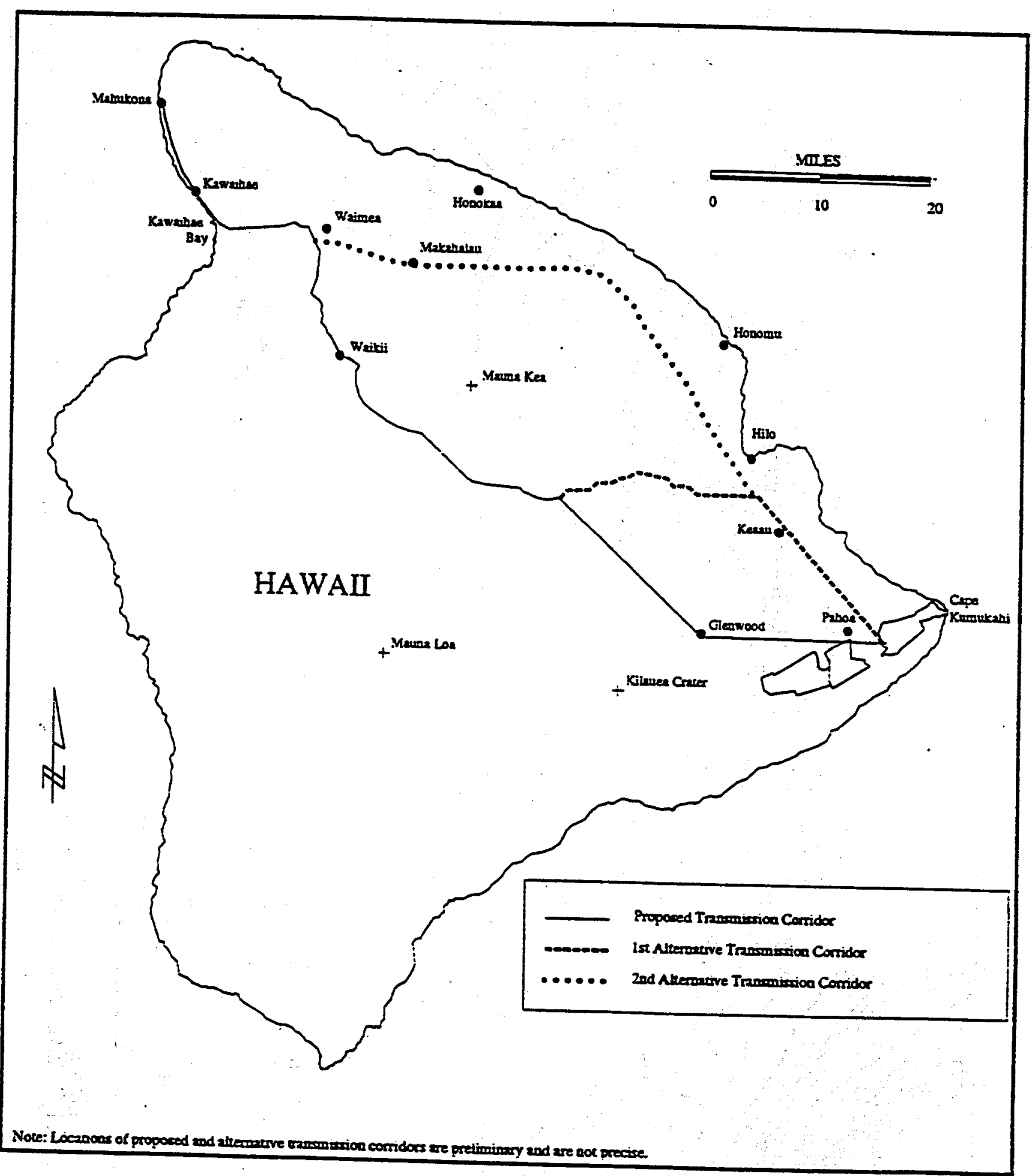

Figure 2 Proposed and alternative transmission corridors on the Big Island 
(11)

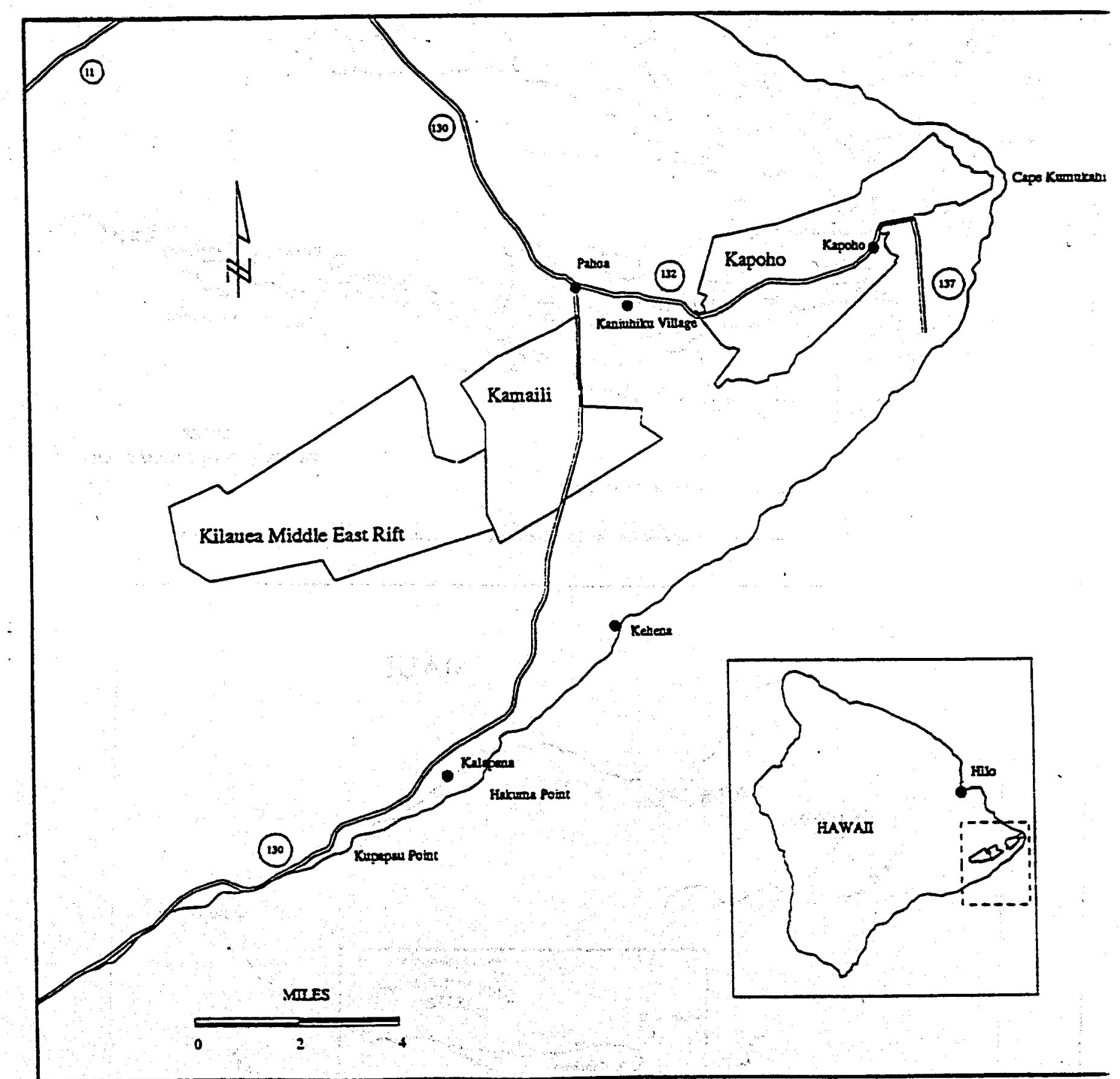

Figure 1. KERZ Geothermal Resource Subzones 


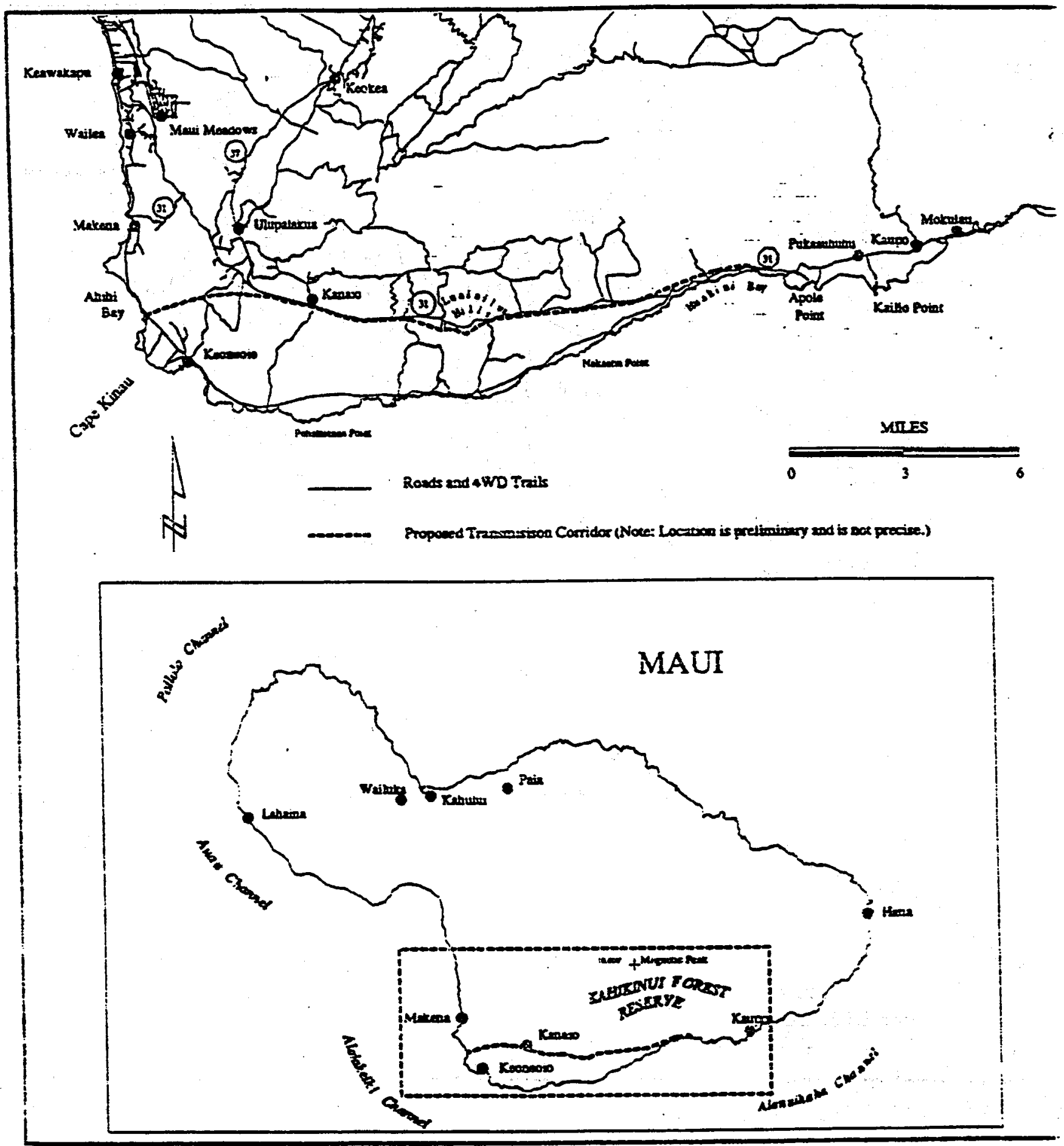

Figure I. The proposed transmission corridor on Maui 


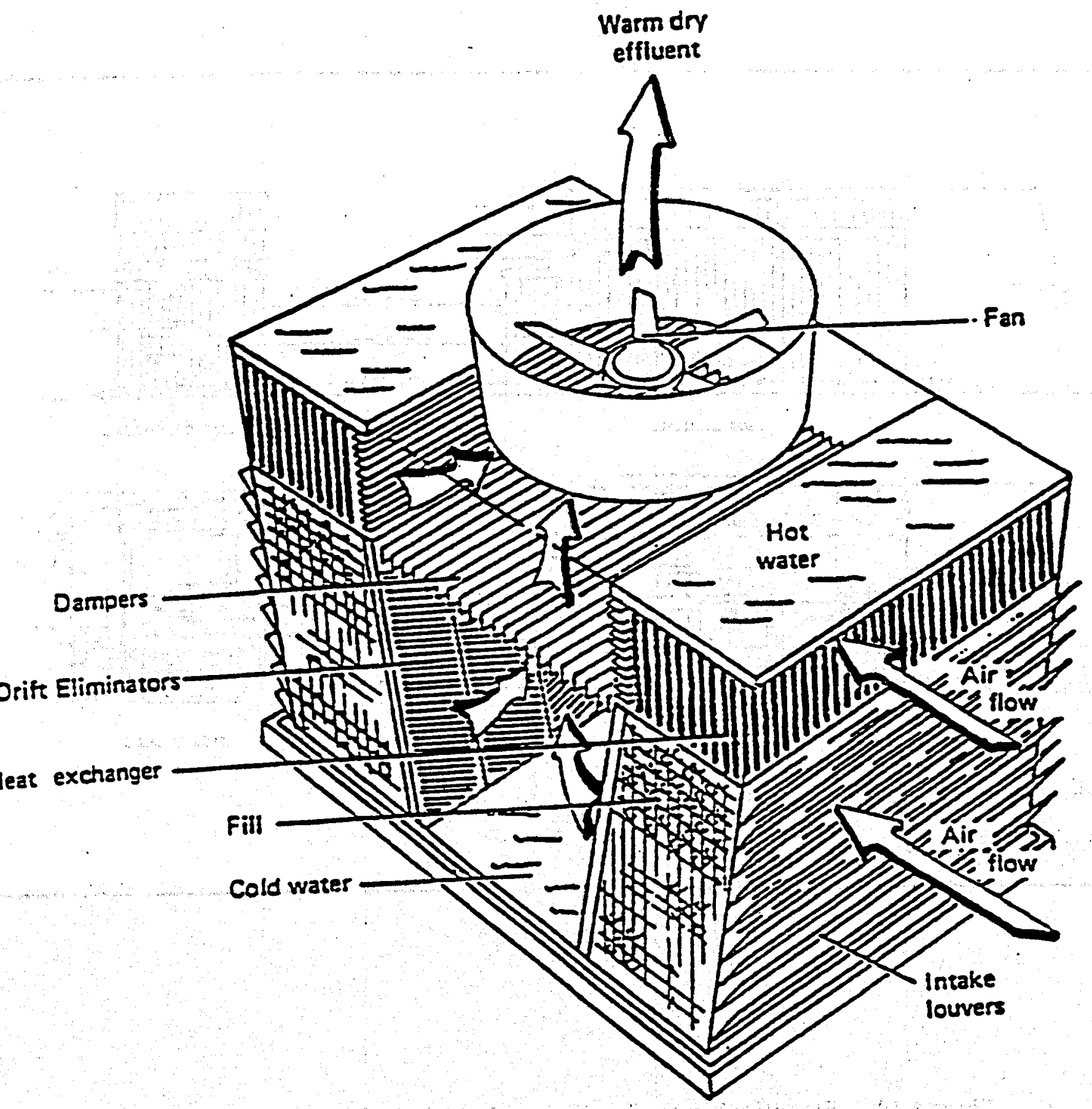

Figure 7. Cross-flow Mechanical Draft Cooling Tower.

(Source: Molenkamp, 1979) 

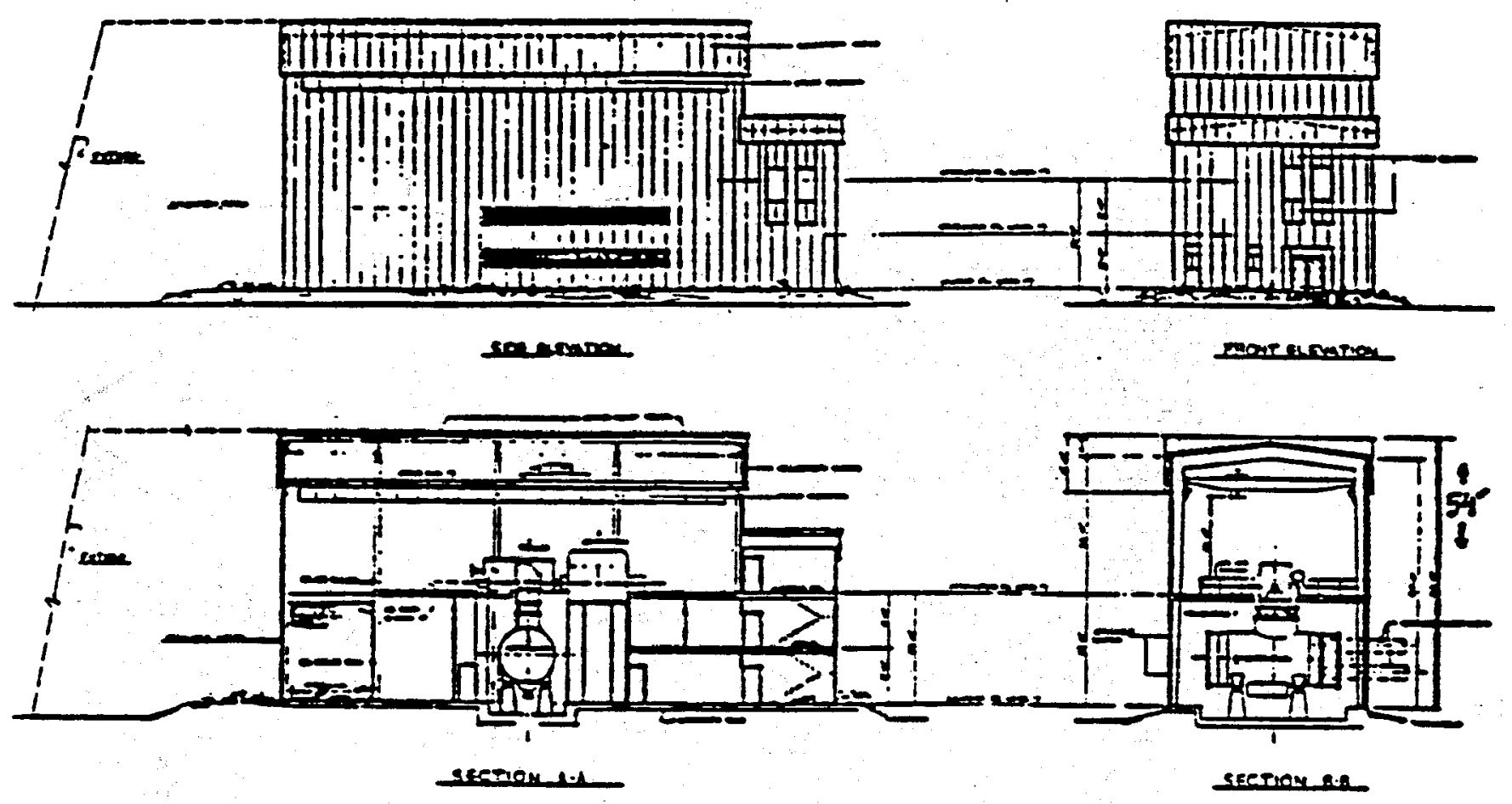

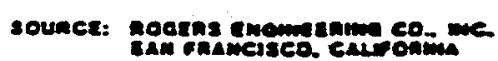

0

ceale in pert

Figure 10. Elevations and Sections - Initial 12.5 MWe Power Plant. 


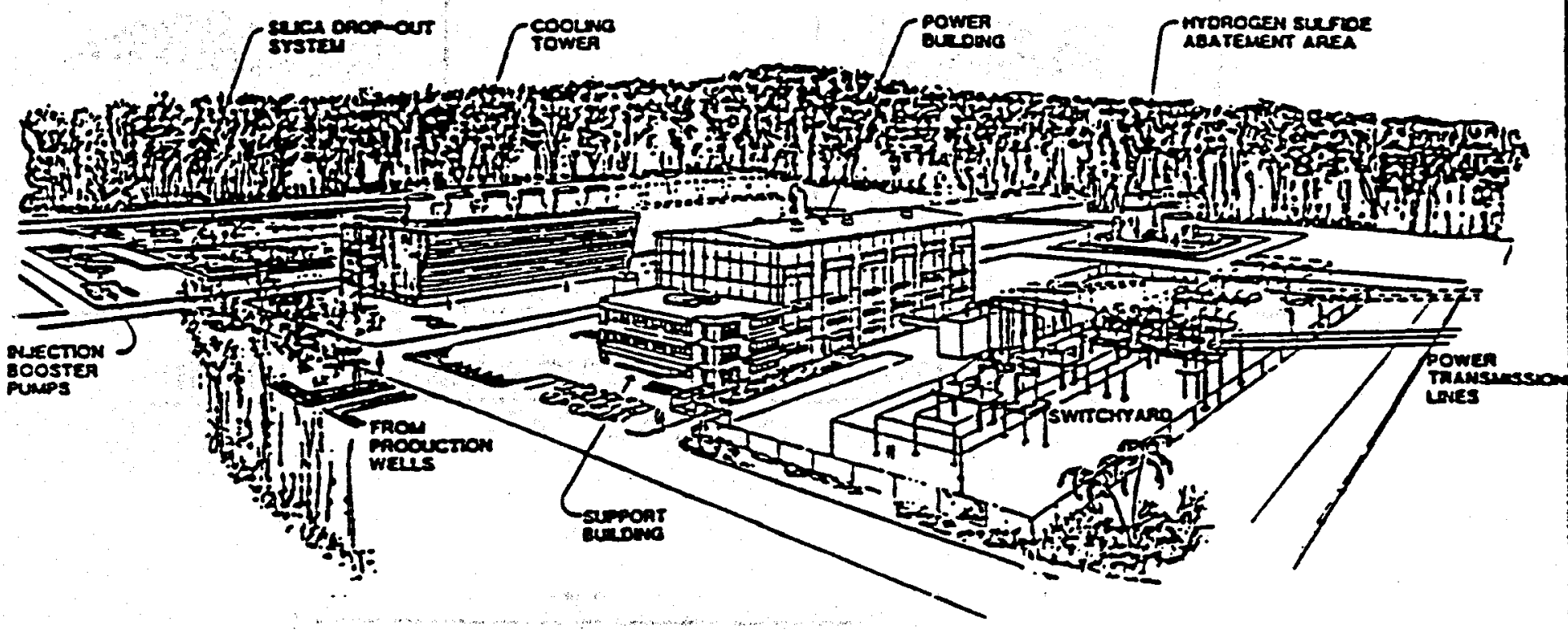

Figure 11. Perspective - 55 MWe Power Plant. (With Expansion to $110 \mathrm{MWe}$ ) 


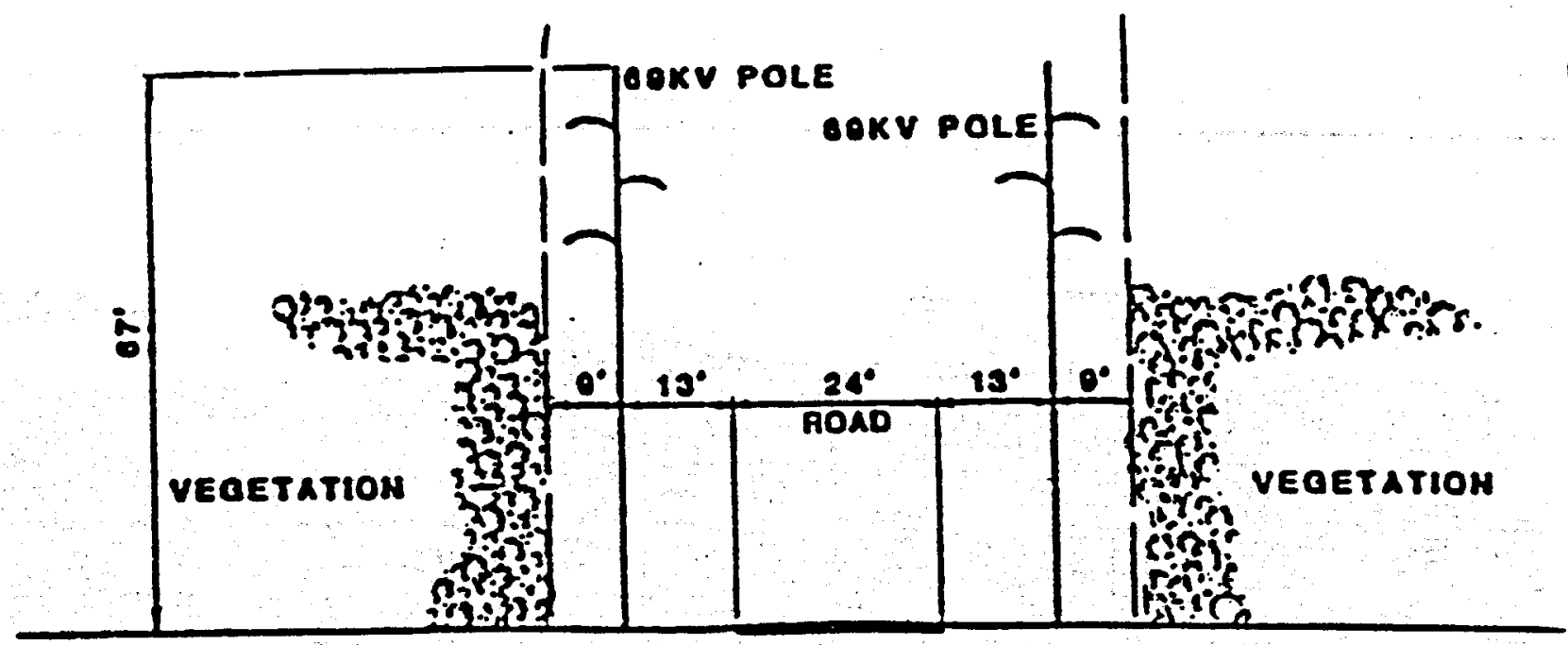

69KV POWER TRANSMISSION LINE CORRIDOR (DETAIL 'Aं)

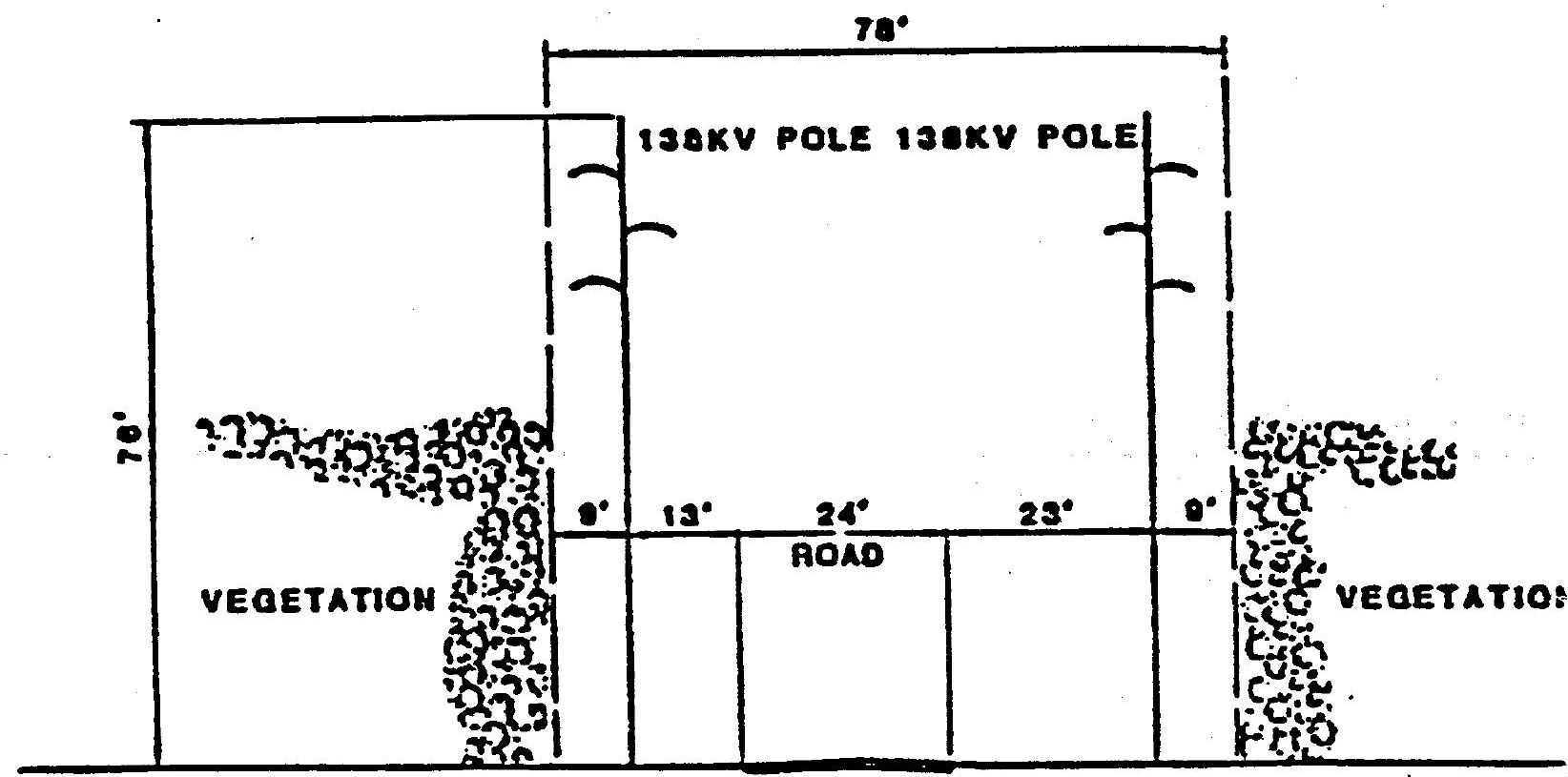

138KV POWER TRANSMISSION LINE CORRIDOR (DETAIL "B")

Figure 16. Power Transmission Line Corridors. (Source: HECO) 


\title{
APPENDIX B
}

\section{SENATE JOINT RESOLUTION 19}

\author{
$103 D$ Congress, 1st Session
}

(P.L. 103-150)

To acknowledge the 100th anniversary of the January 17,1893 , overthrow of the Kingdom of Hawai' $i$ and to offer an apology to Native Hawaiians on behalf of the United States for the overthrow of the Kingdom of Hawai'i.

Whereas, prior to the arrival of the first Europeans in 1778, the Native Hawailan people lived in a highly organized, self-sufficient, subsistent social system based on communal land tenure with a sophisticated language, culture, and religion;

Whereas, a unified monarchical government of the Hawaiian was established in 1810 under Kamehameha I, the first King of Hawai' $i$;

Whereas, from 1826 until 1893, the United States recognized the independence of the Kingdom of Hawai' $i$, extended full and complete diplomatic recognition to the Hawaiian Government, and entered into treaties and conventions with the Hawaiian monarchs to govern commerce and navigation in 1826, 1842, 1849, 1875, and 1887;

Whereas the Congregational Church (now known as the United Church of Christ), through its American Board of Commissioners for Foreign Missions, sponsored and sent more than 100 missionaries to the Kingdom of Hawai'i between 1820 and 1850;

Whereas, on January 14, 1893, John L. Stevens (hereafter referred to in this Resolution as the "United States Minister"), the United States Minister assigned to the sovereign and independent Kingdom of Hawai'i conspired with a small group of non-Hawaiian residents of the Kingdom of Hawai ' $i$, including citizens of the United States, to overthrow the indigenous and lawful Government of Hawai' $\mathbf{i}$;

Whereas, in pursuance of the conspiracy to overthrow the Government of Hawai' $i$, the United States Minister and the naval representatives of the United States caused armed naval forces of the United States to invade the sovereign Hawaiian nation on January 16, 1893, and to position themselves near the Hawaiian Government buildings and the 'Iolani Palace to intimidate Queen Lili'uokalani and her Government;

Whereas, on the afternoon of January 17, 1893, a Committee of Safety that represented the American and European sugar planters, descendants of missionaries, and financiers deposed the Hawaiian monarchy and proclaimed the establishment of a Provisional Government;

Whereas the United States Minister thereupon extended diplomatic recognition to the Provisional Government that was formed by the conspirators without the consent of the Native Hawaiian people or the lawful Government of Hawai'i and in violation of treaties between the two nations and of international law; 
Whereas, soon thereafter, when informed of the risk of bloodshed with resistance, Queen Lili 'uokalani issued the following statement yielding her authority to the United States Government rather than to the Provisional Government:

"I Lili'uokalani, by the Grace of God and under the Constitution of the $\mathrm{Ha}$ waiian Kingdom, Queen, do hereby solemnly protest against any and all acts done against myself and the Constitutional Government of the Hawaiian Kingdom by certain persons claiming to have established a Provisional Government of and for this Kingdom.

"That I yield to the superior force of the United States of America whose Minister Plenipotentiary, His Excellency John L. Stevens, has caused United States troops to be landed at Honolulu and declared that he would support the Provisional Government.

"Now to avoid any collision of armed forces, and perhaps the loss of life, I do this under protest and impelled by said force yield my authority until such time as the Government of the United States shall, upon facts being presented to it, undo the action of its representatives and reinstate me in the authori ty which I claim as the Constitutional Sovereign of the Hawaiian Islands."

Done at Honolulu this 17th day of January A.D. 1893;

Whereas, without the active support and intervention by the United States diplomatic and military representatives, the insurrection against the Government of Queen Lili'uokalani would have failed for lack of popular support and insufficient arms;

Whereas, on February 1, 1893, the United States Minister raised the American flag and proclaimed Hawai'i to be a protectorate of the United States;

Whereas the report of a Presidentially established investigation conducted by former Congressman James Blount into the vents surrounding the insurrection and overthrow of the January 17, 1893, concluded that the United States diplomatic and military representatives had abused their authority and were responsible for the change in government;

Whereas, as a result of this investigation, the United States Minister to Hawai'i was recalled from his diplomatic post and the military commander of the United States armed forces stationed in Hawai ' $i$ was disciplined and forced to resign his commission;

Whereas, in a message to Congress on December 18, 1893, President Grover Cleveland reported fully and accurately on the illegal acts of the conspirators, described such acts as an "act of war, committed with the participation of a diplomatic representative of the United States and without authority of Congress", and acknowledged that by such acts the government of a peaceful and friendly people was overthrown;

Whereas, President Cleveland further concluded that a' "substantial wrong has thus been done which a due regard for our national character as well as the rights 0 the injured people requires we should endeavor to repair" and called for the restoration of the Hawaiian monarchy; 
Whereas the Provisional Government protested President Cleveland's call for the restoration of the monarchy and continued to hold state power and pursue annexation to the United States;

Whereas the Provisional Government successfully lobbied the Committee on Foreign Relations of the Senate (hereafter referred to in this Resolution as the "Committee") to conduct a new investigation into the events surrounding the overthrow of the monarchy;

Whereas the Committee and its chairman, Senator John Morgan, conducted hearings in Washington, D.C., from December 27, 1893, through February 26, 1894, in which members of the Provisional Government justified and condoned the actions of the United States Minister and recommended annexation of Hawai' $i$;

Whereas, although the Provisional Government was able to obscure the role of the United States in the illegal overthrow of the Hawaiian monarchy, it was unable to rally the support from two-thirds of the Senate needed to ratify a treaty of annexation;

Whereas, on July 4, 1894, the Provisional Government declared itself to be the Republic of Hawai'i;

Whereas, on January 24, 1895, while imprisoned in Iolani Palace, Queen Lili'uokalani was forced by representatives of the Republic of Hawai'i to officially abdicate her throne;

Whereas, in the 1896 United States Presidential election, William McKinley replaced Grover Cleveland;

Whereas, on July 7, 1898, as a consequence of the Spanish-American War, President McKinley signed the Newlands Joint Resolution that provided for the annexation of Hawai' $i$;

Whereas, through the Newlands Resolution, the self-declared Republic of Hawai' $i$ ceded sovereignty over the Hawaiian Islands to the United States;

Whereas, the Republic of Hawai' $i$ also ceded $1,800,000$ acres of crown, government and public lands of the Kingdom of Hawai' $i$, without the consent of or compensation to the Native Hawaiian people of Hawai'i or their sovereign government;

Whereas the Congress, through the Newlands Resolution ratified the cession, annexed Hawai' $i$ as part of the United States, and vested title to the lands in Hawai' $i$ in the United States;

Whereas the Newlands Resolution also specified that treaties existing between Hawai' $i$ and foreign nations were to immediately cease and be replaced by United States treaties with such nations;

Whereas, the Newlands Resolution effected the transaction between the Republic of Hawai' $i$ and the United States Government;

Whereas, the indigenous Hawaiian people never directly relinquished their claims to their inherent sovereignty as a people or over their national lands to the United States, either through their monarchy or through a plebiscite or referendum; 
Whereas, on April 30, 1900, President McKinley signed the Organic Act that provided a government for the territory of Hawai' $i$ and defined the political structure and powers of the newly established Territorial Government and its relationship to the United States;

Whereas, on August 21, 1959, Hawai 'i became the 50th State of the United States;

Whereas the health and well-being of the Native Hawaiian people is intrinsically tied to their deep feelings and attachment to the land;

Whereas, the long-range economic and social changes in Hawai' $i$ over the nineteenth and early twentieth centuries have been devastating to the population and to the health and wellbeing of the Hawaiian people;

Whereas, the Native Hawaiian people are determined to preserve, develop and transmit to future generations their ancestral territory, and their cultural identity in accordance with their own spiritual and traditional beliefs, customs, practices, language, and social institutions;

Whereas, in order to promote racial harmony and cultural understanding, the Legislature of the State of Hawai' $i$ has determined that the year 1993 should serve Hawai' $i$ as a year of special reflection on the rights and dignities of the Native Hawaiians in the Hawaiian and a the American societies;

Whereas the Eighteenth General Synod of the United Church of Christ in recognition of the denomination's historical complicity in the illegal overthrow of the Kingdom of Hawai' $i$ in 1893 directed the Office of the President of the United Church o Christ to offer a public apology to the Native Hawaiian people and to initiate the process of reconciliation between the United Church of Christ and the Native Hawaiians; and

Whereas, it is proper and timely for the Congress on the occasion of the impending one hundredth anniversary of the event, to acknowledge the historic significance of the illegal overthrow of the Kingdom of Hawai' $i$, to express its deep regret to the Native Hawaiian people, and to support the reconciliation efforts of the State of Hawaiian and the United Church of Christ with Native Hawaiians:

Now, therefore, be it Resolved by the Senate-and House of Representatives of the United States of America in Congress assembled,

\section{Section 1. ACKNOWLEDGMENT AND APOLOGY}

\section{Congress-}

(1) on the occasion of the 100th anniversary of the illegal overthrow of the Kingdom of Hawai'i on January 17, 1893, acknowledges the historical significance of this event which resulted in the suppression of the inherent sovereignty of the Native Hawaiian people;

(2) recognizes and commends efforts of reconciliation initiated by the State of Hawai' $i$ and the United Church of Christ with Native Hawaiians;

(3) apologizes to Native Hawaiians on behalf of the people of the United States for the overthrow of the Kingdom of Hawai'i on January 17, 1898, with the participation of 
agents and citizens of the United States, and the deprivation of the rights of Native Hawaiians to self-determination;

(4) expresses its commitment to acknowledge the ramifications of the overthrow of the Kingdom of Hawai ${ }^{i} i$, in order to provide a proper foundation for reconciliation be tween the United States and the Native Hawaiian people;

(5) urges the President of the United States to also acknowledge the ramifications of the overthrow of the Kingdom of Hawai' $i$, and to support reconciliation efforts between the United States and the Native Hawaiian people.

\section{Section 2 DEFINITIONS}

As used in this Joint Resolution the term "Native Hawaiian" means any individual who is a descendent of the aboriginal people who, prior to 1778, occupied and exercised sovereignty in the area that now constitutes the State of Hawai ${ }^{6} i$.

\section{Section 3 DISCLAIMER}

Nothing in this Joint Resolution is intended to serve as a settlement of any claims against the United States. 


\section{APPENDIX C \\ COMPILATION OF INFORMATION FOR PUNA 55}

\section{INTRODUCTION}

Puna is a district which extends from 'Oki'okiaho on the $\mathrm{Ka}$ 'u side to Mawae on the Hilo side ("Olelo No'eau $\$ 2747$ ) and is distinguished as the district with the least amount of private land awards resulting from the 1848 Mahele and Kuleana Act. Only 19 awards of private land were made in the entire district: 16 of which were large tracts awarded to chiefs and 3 which were smaller to commoners. The bulk of the Puna lands were designated as public lands, left to either the monarchy as "crown" lands or to the government of the Hawaiian Kingdom.

Over the years the number of ahupua'a designated on maps for the Puna District varied greatly: 6 in 1838 which only listed those along the coast (Hawaiian Government Survey); 21 in the 1886 Government Survey which shows the ahupua 'a divisions before the Puna Forest Reserve is established; 58 on the 1901 map which shows public lands, homestead settlement tracts, and area of forest lands not in reserve; 37 on the 1904 map traced from the Government Survey Registered Map no. 2191, 60 division on the July 1927 map which includes forest reserve and homestead lands; 20 on the 1929 Hawai'i Territory Survey Map. It is hard to tell which are ahupua'a and which are 'ili (a subdivision of an ahupua'a) or some other division within the district. In addition, most of the maps available show the ahupua'a divisions stopping at the forest region now known as Wao Kele o Puna.

For purposes of this chart for the Puna District, it was decided to use the Assignment of Lands (Crown, Government and Fort Lands, Enumerated) of 1848 which was after the Mahele, or great land division: 4 designated as Crown Lands, one of which was listed as an 'ili; 39 Government Lands, 4 of which are listed as 'ili, 6 lands surrendered to the government in lieu of commutation due on other lands. Based on the above information, we have compiled the information according to the 63 ahupua'a (44 ahupua'a designations and 19 pri vate land awards) said to have existed in the Puna District at the time following the Mahele. We did not separate out any geographic feature such as the Kilauea Volcano or the Puna Forest Reserve, but followed the information provided in the Indices of Land Awards.

\section{NATURAL FEATURES}

- Wao Kele O Puna forest reserve: 19,850 acres were designated a forest reserve in 1911, and in 1928 the reserve was expanded to 25,738 acres.

- Numerous volcanic cones and craters, caves, ponds, and springs.

- Numerous lava flows that continue to cover the district today.

${ }^{55}$ Most of the place name meanings were derived from the Bishop Museum Oral History CollectionMary Kawena Pukui and Alvin Kaliko Kalama of Kapoho, recorded January 30, 1960. 


\section{OTHER FEATURES}

Fourteen heiau (Hawaiian religious structures) were identified by John Stokes in his early-1900 expedition through the Puna district:

- Waha'ula Heiau, land of Pulama

- Makaoiki Heiau and Punalu'u Heiau, land of Kahauale'a

- Waiaka Heiau, land of Kapaahu

- Unnamed Heiau, Niukukahi Heiau and Kekaloa Heiau, land of Kalapana

- Kamakaula Heiau, land of Kaimu

- Kue Heiau, land of Kehena

- Pulena Heiau, land of Ke'eke'e

- Waha'ula Heiau and Hali'ipalala Heiau, land of Kama'ili

- Mahinaakaaka Heiau, land of Keahialaka

- Kuki'i Heiau, land of Kula

- Railroad tracks and stations built for the sugar plantations

\section{LEGENDARY AND HISTORICAL FIGURES AND EVENTS}

Pele, Hawaiian goddess of the volcano, "stands at the fountain-head of Hawaiian myth and is the matrix from which the unwritten literature of Hawai'i drew its life-blood" (Emerson, p. v) and those to whose memory was committed to the keeping of the old mele considered it a sacred trust, a trust that required it be transmitted in its integrity. Because of these people, we of today are fortunate to have a history of Pele, one that is not only bound up in oli, mele, and pule but is a history of her adventures and travels that span the Pacific. Here in Hawai'i the Pele myth has given us such legendary figures as: Lohi'au, Pele's lover; Hi'iaka, Pele's younger sister who journeyed the island chain to bring Lohi'au to Pele; Kamapua'a, a legendary figures, half-pig and half-man who was desirous of Pele; and Hopoe, friend of Hi'aka and the one who taught her the hula.

It is said that Pele first landed in Puna at Ke-awa-o-Pele near Koa'e; from here she went to Keahialaka and Pohoiki where she dug craters. Following are only some of the many references to the legendary people of Hawai' $i$ :

'Olelo No'eau \#1639: Ka wahine 'ai honua.

The earth-eating woman, Pele.

'Olelo No'eau \#1640: Ka wahine 'ai la'au o Puna

The tree-eating woman of Puna.

'Olelo No'eau \#1641: Ka wahine 'ai pohaku.

The stone-eating woman, Pele.

'Olelo No'eau \#2019: Lohi'au Puna i ke akua wahine.

Puna is retarded by the Pele in her lava form.

'Olelo No'eau \#2044: Mai hahaki 'oe i ka 'ohelo o punia $i$ ka ua noe.

Don't pluck the 'ohelo berries lest we be surrounded by rain and fog and lose our way. A warning not to do anything that 
'Olelo No'eau \#2100: Maka'u ka hana hewa i ka uka o Puna.

Wrongdoing is feared in the upland of Puna, for it will bring the wrath of Pele.

‘Olelo No'eau \#2619: Pau Puna na ko'ele ka papa.

Puna is ravaged; the foundation crackles. Said of anything that is entirely consumed; from a chant by Lohi'au (Pele's lover) when Pele sent her sisters to overwhelm him with lava.

'Olelo No'eau \#2665: Po'ele ka ́aina o Puna. The land of Puna is blackened (by lava flows).

'Olelo No'eau \#1113: Hopoe, ka wahine lewa $i$ ke kai. Hopoe, the woman who dances in the sea. Hopoe was a dancer of Kea'au, Puna, who because of her dancing and her kindly nature was taken by the goddess $\mathrm{Hi}^{\prime}$ iaka as a favorite friend. When Pele sent Hi'iaka to Kaua'i to fetch Lohi' au, she requested that Pele be kind to her friend Hopoe. When Hi'iaka did not return as expected, Pele in a fit of rage destroyed Hi 'iaka's hala groves and her beloved friend Hopoe who was changed into a balancing stone that seems to dance in the sea.

Historical figures who traveled through or visited this area after Western contact included such explorers as Wilkes, Ellis, Lyman, and Coan, as well as Queen Emma and other members of royalty.

'Olelo No'eau \#2280: Na niu moe o Kalapana.

The reclining trees of Kalapana. In ancient times it was a custom in Kalapana, Puna, to force a young coconut tree to grow in a reclining position in commemoration of a chiefly visit. The last two such trees were made to bow to Chiefess Ululani and Queen Emma. While mounted on a horse, Queen Emma held a single coconut leaf growing from the tree while the people pulled and strained until the tree was bent. The tree was then fastened down so it would continue to grow in a reclining position. These trees have been made famous and memorialized in chants and songs of Puna.

\section{HAWAIIAN PROVERBS}

'Olelo No'eau \#79: Aina i ka houpo o Kane.

Land on the bosom of Kane, who is one of the four major Hawaiian gods. Refers to the Puna District, for it is said that 
‘Olelo No'eau \#360: E nihi ka helena i ka uka o Puna; mai pulale i ka 'ike a ka maka.

Go quietly in the upland of Puna; do not let anything you see excite you. Watch your step and don't let the things you see lead you into trouble. There is an abundance of flowers and berries in the uplands of Puna and it is thought that picking any on the trip up to the volcano will result in being caught in heavy rains. The picking is left until the return trip.

'Olelo No'eau \#397: Ha'alele i Puna na hoaloha e.

Left in Puna are the friends. Said of one who has deserted his friends. Originally said of Hi'iaka, Pele's younger sister, when she left Puna.

'Olelo No'eau \#994: Hilina'i Puna, kalele ia Ka'u.

Puna leans and reclines on $\mathrm{Ka}^{\prime} \mathrm{u}$. Said of one who leans or depends on another, for the ancestors of these two districts were originally of one extended family. When the time came for each district to have its own name, without breaking the link entirely, those in $\mathrm{Ka}^{\prime} \mathrm{u}$ referred to themselves as the Makaha and those in Puna as the Kumakaha. These names are mentioned in chants of the chiefs of $\mathrm{Ka}^{4} \mathrm{u}$.

'Olelo No'eau \#1458: Ka makani hali 'ala o Puna.

The fragrance-bearing wind of Puna. The district of Puna is famed for the fragrance of maile, lehua, and hala. It was said that when the wind blew from the land, even fishermen at sea could smell the fragrance of these leaves and flowers.

'Olelo No'eau \#1587: Ka ua moaniani lehua o Puna.

The rain that brings the fragrance of the lehua of Puna. Puna is known as the land of fragrance.

‘Olelo No'eau \#2036: Ma'ema'e Puna i ka hala me ka lehua.

Lovely is Puna with the hala and lehua.

'Olelo No'eau \#2278: Nani Puna po $i$ ke 'ala.

Beautiful Puna, heavy with fragrance. Praise for Puna where the breath of maile, lehua, and hala blossoms are everpresent.

'Olelo No'eau \#2316: Niniu Puna, po i ke 'ala.

Puna is dizzy with fragrance. Puna is a land heavily scented with the blossoms of hala and lehua. 
'Olelo No'eau \#2744: Puna, aina 'awa lau o ka manu.

Puna, land of the leafed 'awa planted by the birds. 'Awa, also known as kava, is a plant which is native to the Pacific islands. The root of the 'awa is the source of a narcotic drink used in ceremonies as well as for medicinal purposes.

'Olelo No'eau \#2745: , Puna kai nehe i ka ulu hala.

Puna, where the sea murmurs to the hala grove.

'Olelo No'eau \#2749: Puna paia 'ala $i$ ka hala.

Puna with walls fragrant with pandanus blossoms. Puna is the place of hala and lehua forests. In the olden days the people would stick the bracts of hala into the thatching of their houses to bring some of the fragrance indoors.

Hawaiian-English Dictionary p. 163: 'O Puna ia o ke kai koloa i ka ulu hala. This is Puna where the sea ever roars in the pandanus groves.

\section{CONCLUSION}

There are many place names and people mentioned in the accumulated literature of Hawai'i that are said to be a part of or are identified with the district of Puna, island of Hawai' $i$, but for which the exact location of the place or event has been lost. In many cases, the places have been given "foreign" names, the "foreign" name Hawaiianized, or the original name shortened or otherwise changed over time. Whatever the reason, the Hawaiian name of that place no longer exists, and gone with it is the meaning or significance once attached to the place. Many important names are so ancient that no translation at all is possible.

Mary Kawena Pukui, a noted scholar of Hawaiian culture and language, states that Hawaiians named everything: taro patches, rocks, and trees that represented deities and ancestors, sites of houses and heiau, canoes, adzes, drums, canoe landings, fishing stations in the sea, resting places in the forest, and even the tiniest spots where miraculous or interesting events are believed to have taken place (Place Names of Hawai ' $i$ by Pukui, p. $x$ ).

Added to this practice of naming is the fondness of Hawaiians for proverbial sayings and hidden meaning or kaona - a concealed reference to a person, thing, or place; words with double meanings that might bring good or bad fortune. Thus, sayings that incorporate place names are not just referring to that particular place but are also describing an emotional state or important event, as well as love for the land and sea (the source of life) and the people of the land whose job it was to take care of and respect these resources. These are important distinctions between Hawailan culture and language and that of the EuroAmericans and is the reason why the Hawaiian name of a particular place is so important (Place Names of Hawai ' $i$ by Pukui, p. 235-80). 


\title{
PUNA DISTRICT: INFORMATION BY AHUPUA'A \\ (alphabetical listing by ahupua'a)
}

\section{$\overline{\text { AHALANUI }}$}

Designated as Government Land in the Mahele Book of Land Awards 1848.

\author{
'APUA \\ (fish basket)
}

Designated as Crown Land in the Mahele Book of Land Awards 1848.

\section{Natural Features}

Several volcanic cones, also called hills or pu'u, are present in this area. As late as 19691970 "Alo'i and 'Alae Craters were active and the resulting lava flow covered large parts of this ahupua'a.

- 'Apua Pt.

- Pu'u Huluhulu

- Poliokeawe Pali

- Alealea Crater

- Makaopuhi Crater

- 'Alo'i Crater, named perhaps for Kahawali's pig, 'Alo'ipua'a

- Lava trees, cave, water, and shelter indicated on map.

\section{Other Features}

An ancient village known as 'Apua was swept away in the 1868 tidal wave.

\section{Hawaiian Proverbs}

'Olelo No'eau \#1898: Ku ke 'a o 'Apua.

Lava rocks were heaped down at 'Apua. Said of confusing untidiness, like the strewing of lava rocks, or of utter destruction, for 'Apua in Puna is a land of rocks.

\section{$\overline{\text { HALEPUA'A }}$ \\ (pig house)}

Designated as Government Land in the Mahele Book of Land Awards 1848.

\section{Natural Features}

Kahuwai Crater ("water tender") is near Halepua“a (Pukui, p. 67). 


\title{
Legendary and Historical Figures and Events
}

There is a story of a preacher who traveled through this area and because the people would only share their taro with the pigs instead of a hungry traveler like himself, he predicted that later the pigs would do the eating. A lava flow followed by a smallpox epidemic soon destroyed the town and its people. This story is said to illustrate the consequences of violating the Hawaiian code of hospitality.

\section{Hawaiian Proverb}

‘Olelo No'eau \# 755: Hele no ka wai, hele no ka 'ala, wali ka 'ulu o Halepua 'a. The water flows, the smooth stone (pounder) works, and the breadfruit of Halepua'a is well mixed (made into smooth poi). This is a play on words that means that everything goes smoothly when one is prosperous. This saying has come to refer to a generous donation.

\author{
HALONA \\ (peering place)
}

Designated as Government Land in the Mahele Book of Land Awards 1848.

\section{HAUKALUA 1 AND 2}

Designated as Government Land in the Mahele Book of Land Awards 1848.

\section{HONOLULU \\ (protected bay)}

Designated as Government Land in the Mahele Book of Land Awards 1848.

\section{Legendary and Historical Figures and Events}

William Ellis, who traveled around Hawai ' $i$ in $1822-1823$, wrote about this area of Puna:

“...we travelled in an inland direction to Honoruru [Honolulu] [from Kula and Kahuwai], a small village situated in the midst of a wood... we left Honolulu...and, travelling slowly towards the sea-shore, reached Waiakaheula about eight, where I was obliged to stop, and lie down under the shade of a canoe-house near the shore" (p.211).

\section{Natural Features}

- former landing for canoes in Puna (Pukui, p.49).

- bay. 
HONOMU

(silent bay)

Designated as Government Land in the Mahele Book of Land Awards 1848.

\author{
KAHAUALE'A \\ (hau tree or dew of Le'a)
}

This 26,000-acre ahupua'a was awarded to W.C. Lunalilo. (LCA 8559B, Bk. 10, Pg. 479; RP 8030, Bk. 32, Pg. 43).

\title{
Natural Features
}

Several volcanic cones, also known as hill, crater and pu'u are in the area:

- Kalalua Crater located in the east rift zone of Kilauea

- Napua Crater which last erupted in 1963 and 1965

- Pu'u 'O'O and the Kupaianalu Lava Lake, both formed in the 1983 to present flow are in Kahauale'a

Other natural features of the area (Pukui, p. 195):

- Punalu'u harbor landing

- Punalu'u black sand beach, beach park

- Punalu'u ancient surfing area

- Lava trees, water, shelter

- Pu'uloa, the old name for Queen's Bath, a large spring pool was located in Kahauale'a before the 1983 to present flow from $\mathrm{Pu}^{\prime} \mathrm{u}$ 'O'o

\section{Other Features}

- Village of Kahauale‘a (Pukui, p. 63).

- Panau, a village near Kahauale'a (T. Holmes).

- Heiau of Makaoiki located on an ' $a$ 'a prominence and thought to be an agricultural heiau. Stokes states that at the time of his survey it was occupied by graves (Stokes, p. 144) ( $T$. Holmes says that Hudson mentions an old trail across the lava flow south of this heiau).

- Heiau of Punalu'u is built on the pahoehoe lava over the Punalu'u spring which issues from seemingly solid rock and fills a long, deep cavity in the pahoehoe. According to Stokes' local account, the heiau is connected with the pool. Legend states that this heiau was built to commemorate the death of Punalu' $u$, a shark-man who devoured the girls who bathed in the pool. Another story is that the heiau was for securing good agricultural crops. This heiau is terraced and has a wall bordering two of its sides (Stokes, p. 144-146.)

- At least 4 trails traversed Kahauale'a: coastline trail, Kalapana trail (from Puna to Volcano area), Glenwood-Makaopuhi trail (Puna to the volcano in Makapuhi Crater, 
through Keeau (Keaau) and Ola'a and on to Hilo), Captain Wilkes' party trail (1840).

- Mauka-makai trails: Kapa'ahu trail, Chester Lyman reports one that starts in Kehauale'a, goes inland and then back to Hilo; Pulu export from 1851-1884 came from the Kilauea vicinity, this provided the need for extensive trails.

- Canoe ladder site (T. Holmes).

- 3 heiau: Waiaha heiau, Punalu'u, Makaoiki and burial cave called Kalua Makini.

- evidence of upland activity: cultigens, plantations; Captain Wilkes sighted an extensive upland taro patch; logging of koa trees.

\section{Legendary and Historical Figures and Events}

Informant Oulu Kamanui stated that people in Kahauale'a as well as Kamoamoa, Kealakomo, and other high places would snare birds for eating (Bishop Museum Oral History Collection, Oulu Konanui and M.K. Pukui, 10/26/59).

\section{KAHUWAI}

(water tender)

This 2869-acre parcel (Apana 12) was awarded to Victoria Kamamalu.

(LCA \#7713, Bk. 19, Pg. 437; RP \#6884, Bk. 25, Pg. 81).

\section{Natural Features}

- a crater near Halepua'a (Pukui, p. 67)

- Makaukui Point

- 21 and 22 Mile Stations (sugar cane train)

\section{KAIMU}

(gathering at the sea to watch surfing)

Designated as Crown Land in the Mahele Book of Land Awards 1848.

Kaimu is a land section as well as a village in the Kalapana area and is noted for its surf and its black sand beach, a beach which was formed by steam explosions that occurred when a lava flow entered the ocean in about 1750 . Much of Kaimu was covered by the recent lava flows of the early 1990 s which engulfed the black sand beach and forever changed the existing shoreline (Pukui, p. 69).

\section{Natural Features}

- black sand beach (Pukui, p. 69)

- surfing sites were formerly known as Ho 'eu ("mischief") and Kapoho but are now referred to as Kaimu.

- In Waiokolea, an ili in Kaimu, there is mentioned a fishpond which was at one time leased out to R. Kealikolani (The Kalapana Extension in the 1800s: A Research of Historical Records, June, 1979, p. 10). 


\section{Other Features}

Kumakaula Heiau is situated on Kaimu Bay near the sea. This was the heiau which Fornander said was "the best preserved specimen of the truncated pyramidal form" (Stokes, p. 147). Stokes thinks Fornander confused this with another nearby heiau as the structure that remained indicated it was a terraced heiau, level with the ground at one end and 10 feet high at the other.

\section{Legendary and Historical Figures and Events}

Rev. William Ellis and his party visited Kaimu on his trip around the island of Hawai' $i$ and were warmly received by the people there who numbered three to four hundred when assembled:

...could not believe that we had descended into the crater (Kilauea), or broken off pieces of Pele's houses, as they called the small craters, until the specimens of lava, etc. were produced, when some of them looked very significantly, and none of them cared much to handle them (Ellis, p. 194).

Ellis and his party also examined the effects of the earthquake that had happened a few months previously (in 1823). Of Kaimu he gives this description:

Kaimu is pleasantly situated near the sea shore, on the S.E. Side of the island, standing on a bed of lava considerably decomposed, and covered over with a light and fertile soil. It is adorned with plantations, groves of cocoanuts, and clumps of kou-trees. It has a fine sandy beach, where canoes may land with safety; and, according to the houses numbered to-day, contains about 725 inhabitants. Including the villages in its immediate vicinity, along the coast, the population would probably amount to 2000 . There are several wells in the village containing brackish water, which has passed from the sea, through the cells of the lava, undergoing a kind of filtration, and is collected in hollows scooped out to receive it. The natives told us that, at the distance of about a mile there was plenty of freshwater (Ellis, p.196-197).

\section{Hawaiian Proverbs}

'Olelo No'eau \#1446: Ka lipoa 'ala o Kalauonaona.

The most fragrant lipoa seaweed is found at Kalauonaona (Kalauonaone) in Kaimu.

'Olelo No'eau \#1475: Ka malu niu o Hu'ehu'ewai.

The coconut grove of $\mathrm{Hu}^{\prime}$ ehu'ewai. This coconut grove was located in Kaimu.

\section{KALAIHINA}

This 11.32 acre parcel / part of an ahupua 'a was awarded to Barenaba in the Mahele Book of Land Awards 1848. (L.C.A. 7713 B 10 p.437 / RP 7602 B 28 p. 345). 


\section{KALAPANA \\ (announce noted place)}

Land surrendered in lieu of commutation by Lunalilo; Mahele Book of Land Awards 1848. The recent lava flows of the early 1990s have covered much of the Kalapana area.

\section{Natural Features}

- Black sands beach (Pukui, p. 75).

- Surfing areas: 'Awili, Kalehua, Ho'eu (See 'Olelo No'eau \#2356).

_. Wai 'akolea pond ("fern water"); also the name of an 'ili (Pukui, p. 220).

- Halekamahina ("house of the moon"); a hill and land section (Pukui, p. 37).

- 'I'ilewa ("Ie'ielewa, "swinging 'ie'ie vine"); small crater (Pukui, p. 55).

- forest area of Malamaki ("bright ti plant") where the game "ho'olele ki" was played. A ti leaf was held in the hand while the player chanted " O kela ki, 'o keia ki, na Kamohoali' $i$ ka'u ki, lele!" ("That ti, this ti, my ti for Kamohoali' $i$, fly!"). Then the leaf was hurled, and if the chant had been said correctly and the wind was right, it returned to the sender. This game was played only here. Kamohoali' $i$, a celebrated shark deity, was Pele's older and favorite brother (Pukui, p. 143).

- Pu'uhonua'ala ("red place of refuge") spatter and lava cone built by a prehistoric eruption (Pukui, p. 197).

- Pu'ulena ("yellow hill") pit crater and ancient surfing area (Pukui, p. 200).

- Pu'ulena wind which comes from Pu'ulena Crater (Pukui, p. 200).

\section{Other Features}

- village of Kalapana (Pukui, p. 75).

- Brown Beach Park was thus named in 1953 for Harry Kaina Brown, Hawai'i County auditor (Pukui, p. 19).

- Hale Beach Park was thus named in 1951 for Isaac Hale who was killed in action in Korea (Pukui, p. 36).

- Homestead areas of Kaniahiku ("call of Hiku") (Pukui, p. 85), Ka'ohe ("the bamboo") (Pukui, p. 85), Kauka (Pukui, p. 92), Kikala puo ("hip").

- Land sections of $\mathrm{Ki}^{\prime}$ apu ("ti-leaf drinking cup") (Pukui, p. 109), Keokea ("white sand") (Pukui, p. 107).

- Maria, Hoku o ke Kai Catholic Church built by Father Evarist Gielen who came to Hawai' $i$ in 1927 and decorated the church's interior with religious paintings (Pukui, p. 147).

- Mauna Ke'a Congregational Church (Pukui, p. 149).

- Unnamed heiau is located on the flat between the road and the high ground at the sea. "This supposed heiau is a small enclosure, without features, in Kalapana village" (Stokes, p.146).

- Heiau of Niukukahi is situated in the uplands behind Kalapana village. The site of this heiau is covered by a grove of kamani and other trees. Local information indi cates it was built by Kapihe, "the famous kahuna who prayed the stillborn Kauikeaouli to life" (Stokes, p. 147). 
- Heiau of Kekaloa is located on the northeast side of Kalapana village, 400 feet from the sea. It is a small platform heiau on the northern bank of the Wai'akolea pond, secluded by groves of trees including pandanus and hau. Local information indicates it was built by Waukelenuiaiku, a kupua (wizard), and "to prove that he was a kupua, he planted some bananas. When the fruit was ripe, he would eat the pulp of the fruit, leaving the skin hanging on the stem. New pulp would then fill the skin up again" (Stokes, p. 147).

- Trails as listed in Kehauale'a section.

\section{Legendary and Historical Figures and Events}

Pele was attacked here by Kamapua'a, the pig man. According to Beckwith in her book on Hawaiian mythology:

At a place near the coast in Puna called Lua-0-Pele, where the earth is torn up as if there had been a struggle, he is said to have overtaken the reluctant Pele and forced the fire goddess to submit to his embraces. They say that this is why today the sacred lehua trees 'grow right down to the shore at this place alone'. Pele's sister Kapo, aware of Pele's peril, sends her own wandering vagina (kohe-lele) to light upon a tree and attract Kamapua'a from her sister (p. 212).

Another story involves a priest of Pele who may have been named for Kalapana. He had vowed that only Pele might cut his hair. One day, on his way to the volcano to visit with Pele he encountered a storm and returned to the shore where the people got him drunk on kava. When he fell asleep the people cut his hair. Later when Pele appeared at his doorway disguised as a woman she was angry because his hair had been cut and turned him to stone. $\mathrm{He}$ is said to be still there by a pool not far from where the Catholic Church once stood (Place Names of Hawai ' $i$ by Pukui, p. 75).

The Kalapana area was famous for riddling and Beckwith, on pages $456-458$, gives a detailed example of a riddling match pitting a child against the chief's riddlers. The riddle plays upon the work "hua" which refers to an offspring or fruiting. Another example from Beckwith and attributed to Mary Kawena Pukui, a renowned scholar of Hawaiian literature, culture and language, has to do with a Puna chief who, because of his fondness for riddling, send his men in search of fresh riddles. When the men return the chief then poses a riddle to them. Because they do not understand what is being asked they are put to death until at last one young men is given help by the old court jester who teaches him the answer and how to turn the riddle against the chief himself. Thus the chief is slain and the practice of riddling in Puna is ended (Beckwith, p.461).

The legend of the "recumbent coconuts of Kalapana" is related by Beckwith (p. 95) and involves two young chiefs of Puna named Hinawale and Owalauahi (-wahie) who stole away incognito to tour the island. Upon their return they discovered a group of men who were testing their strength by attempting to bend to earth two full-grown coconut trees. The two chiefs waited until all attempts had failed and then they too attempted and succeeded in laying them low. Visitors to the coconut grove prior to the latest lava flow were able to see the "Naniu-moe-o-Kalapana" (the recumbent coconut trees of Kalapana) although it was said that the two original trees had been replaced. It is told that Queen Emma, when she found the trees dead, asked her men to bend two more to take their place, but none could do so until the queen herself held a leaf of each, at which time they bent easily. 
William Ellis, an English missionary who visited Hawa' $i$ in 1822-1823, wrote this in his journal about the Kalapana area:

... we passed on to Kalapana, a small village on the sea-shore, distinguished as the residence of Kapihi, the priest, who, in the days of Tamehameha [Kamehameha], told the king, that after death he and all his ancestors would live again on Hawaii. We saw a large heiau, of which he was chief priest, but did not see many people in the houses as we passed by ... we approached Kaimu" (p. 191).

\section{Hawailan Proverbs}

'Olelo No'eau \#1347: Ka i'a ka'a poepoe o Kalapana, ina'i uala o Kaimu. The round rolling fish of Kalapana, to be eaten with the sweet potato of Kaimu. This is a riddling chant, the answer being the kukui nut, cooked and eaten as a relish. This is from a ho'opapa riddling chant in the story of Kaipalaoa, a boy of Puna, who went to Kava'i to riddle with the experts there and won.

'Olelo No'eau \#2280: Na niu moe o Kalopana.

The reclining coconut trees of Kalapana. This was last done to commemorate the visit of Queen Emma.

'Olelo No'eau \#2356: 'O 'Awili ka nalu, he nalu kapu kai na ke akua.

'Awili is the name of a surf reserved for the ceremonial bath of the goddess Pele. There were three noted surfs at Kalapana: Kalehua for children and those just learning to surf; Ho'eu for experienced surfers; and 'Awili which none dared to ride, and when it was rolling dangerously high (this being a sign that the gods were riding), all surfing and canoeing ceased.

\section{KAMA'ILI \\ (the pebbles)}

Designated as Government Land in the Mahele Book of Land Awards 1848.

\section{Legendary and Historical Figures and Events}

William Ellis, who traveled around Hawai'i in 1822-1823, said this about the area:

Leaving Kehena, we walked on to Kamaili, a pleasant village, standing in a gently sloping valley, cultivated and shaded by some large cocoa-nut trees. Here we stopped to take breakfast, having travelled about four hours and a half. The hospitable inhabitants, at the request of our guide, soon brought us some fresh fish, a nice pig, with potatoes and taro, and a calabash of good water ... Our path from Kaimu had been smooth and pleasant, but shortly after leaving Kamaili, we passed a very rugged tract of lava nearly four miles across ... On our way, our guide pointed out Karepa, an ancient heiau, 
formerly dedicated to $\mathrm{Tu}$ [Ku] and Rono [Lono], and built in the days of Teavemauhiri, or Tanakini, king of this part of the island. We could not learn whether this was the heiau of Rono, in which the bones of Captain Cook were deposited, and worshipped (p. 199-200).

\section{Other Features}

Heiau of Waha'ula was probably an enclosure. Local informants claimed that this was the site of the original heiau of Waha'ula and that later the stones were taken to Pulama to built the heiau at that place. Stokes could never confirm this (p. 149).

Heiau of Hali'ipalala (land of Kama'ili, Puna) is said to have been small and for agriculture (Stokes, p. 149).

\section{KAMALOMALO}

Land surrendered by Lunalilo in commutation due on other lands.

\section{KAMOAMOA}

Ahupua'a awarded to M. Kaoanaeha as "inherited lands"; Mahele Book of Land Awards 1848.

\section{Other Features}

Site of an ancient village destroyed in the 1868 tsunami.

\section{KANEKIKI}

Designated as Government Land in the Mahele Book of Land Awards 1848.

$\mathrm{KA}^{\circ} \mathrm{OHE}$

(the bamboo)

Designated as Government Land in the Mahele Book of Land Awards 1848.

\section{KAPA'AHU}

Designated as Government Land in the Mahele Book of Land Awards 1848.

- Waiaka pond.

Natural Features

- Waikupanaha pond. 


\section{Other Features}

- Heiau of Waiaka is said to be a temple for "ho"ouluulu "ai", or food growing. On its western side is Waiaka pond and at its southern end is Waikupanaha pond (Stokes, p. 146).

\section{KAPOHO}

(the depression)

Ahupua'a, consisting of 4060 acres, was awarded to C. Kanaina; Mahele Book of Land Awards 1848.

\section{Natural Features}

- cinder cone called Kapoho Crater (Pukui, p. 89).

- Pu'ukea ("white hill")(Pukui, p. 199).

- Pu'ukukae ("excreta hill”) is a cinder cone in Kapoho (Pukui, p. 200).

- Pu'ulaimana ("Lyman's hill") is a cone built by the 1960 Kapoho eruption named for the owner of the land, Richard Lyman Jr.

- Kaholua-o-Kahawali ("the sledding course of Kahawali") is a crater, cinder and spatter cone on Kilauea volcano's east rift zone; also called Pu'u a Kahawali (Pukui, p. 89).

- Pu'u Ki (Pu'u Ki'i) Kahawali rode from Pu'u Kahawali ki to Pu'u Ki (Bishop Museum Oral History Collection, Alvin Kaliko Kalawe tape, 1/30/60).

- Ancient village which was buried in the 1960 eruption of Kilauea.

- Waiwelawela (meaning "warm water" was a warm spring pool near Kapoho which was covered in the 1960 eruption. It was also called Warm Springs. It is said by people of the area that Pele covered the springs because people were charging others, namely Hawaiians, for use of the warm springs. In former days these warm springs were available to everyone (Pukui, p. 228).

- Wai-a-Pele is the old name for Green Lake (Pukui, p. 221).

- Lekia (kane pohaku) and Hanalei (wahine pohaku), a pair of twins who whispered during a thunderstorm (taboo at that time) and were turned into stones; in another version these two figures were married to each other; they sit on the rim of the lake (Pukui, p. 221). See 'Olelo No'eau \#334 and see Folktales of Hawai' $i$ by Pukui \& Green, p. 21).

- Higashi Pond.

- Kapele (Kaoko Point) -lava flow went into the sea here between Kapele and Ipoho-at Kapele was the burial place for inhabitants of Koa'e.

\section{Legendary and Historical Figures and Events}

William Ellis, an English missionary who traveled the Pacific, visited Hawai' $i$ in $1822-1823$ and wrote about Kapoho:

A cluster, apparently of hills three or four miles round, and as many hundred feet high, with deep indented sides, overhung with trees, and clothed with herbage, standing in the midst of the barren plain of lava, attracted our atten tion. We walked through the gardens that encircled its base... The sides of the 
valley ... were almost entirely laid out in plantations, and enlivened by the cottages of their proprietors...a beautiful lake of brackish water, whose margin was in a high state of cultivation, planted with taro, bananas, and sugarcane ... the bread-fruit, the kukui, and the ohia trees... They told us the name of the place was Kapoho (the sunken in) and of the lake, $\mathrm{Ka}$ wai a Pele (the water of Pele). The saltness of the water in this extinguished volcano proves the connexion of the lake with the sea, from which it is about a mile distant...The natives also told us that it was one of the places from which the volcanic goddess threw rocks and lava after Kahavari [Kahavali], for refusing his papa, or sledge, when playing at horua [holua]...(p. 207).

The handsome young chief Kahawali lived near Kapoho in Puna district. Kahawali, an expert in hula and in riding the holua (sled), lived near Kapoho in the Puna district. During the time of the Lono festival, a sled race is arranged and Pele, disguised as an old woman, offers to compete with him. Angry at the chief's rebuff, Pele pursues Kahawali down the hill in the form of fire. Kahawali first flees to the hill Pu'ukea, bids farewell to his wife, children and favorite pig 'Alo'ipua'a, greets his sister at Kula, and escapes to the sea in a canoe (Beck with, p. 191). The sledding course of Kahawali is a line of small spatter cones which marks Pele's barrage of hot rocks that followed him.

Uwekahuna is the name of one of Kahawali's priests who challenged Pele after Kahawali's defeat in holua sledding.

\section{Hawaiian Proverbs}

'Olelo No'eau \#334: EL Lekia e, 'onia i pa'a.

Make a move to give yourself a secure hold. Lekia and Hanalei are stones in Puna. When the demigod Kaleikini came to the district, he dug around Lekia with the intention of toppling it off the hill. Before he could uproot it, however, he got hungry and departed. It was then that the other stone, Hanalei, cried out the above, and in response, Lekia moved downward and held fast. Kaleikini tried in vain after that but was unable to remove Lekia.

\section{KAUAEA}

Ahupua'a, consisting of 1568 acres, was awarded to V. Kamamalu; Mahele Book of Land Awards 1848.

\section{Legendary and Historical Figures and Events}

William Ellis, a missionary, passed through this area on his trip around Hawai'i in 18221823:

We then proceeded about two miles, principally through cultivated grounds, to Kauaea [from 'Opihikao]...We afterwards sat down and talked with them, and then resumed our journey through the district of Malama..." (p. 201). 


\section{KAUELEAU}

Designated as Government Land in the Mahele Book of Land Awards 1848.

\section{KAUKULAU}

Designated as Government Land in the Mahele Book of Land Awards 1848.

\section{KAUWALEHUA}

This 5562-acre parcel was awarded to V. Kamamalau in the Mahele Book of Land Awards 1848 (L.C.A. 7713 B.10 p. 437 / RP 8199 B 35 p. 417 / NR v.5 p. 443).

\section{KEA'AU}

Ahupua'a awarded in two parts: 13.64 acres to Hewahewa and 64.275 acres to Wm. C. Lunalilo; land award also included Halauloa; Mahele Book of Land Awards 1848.

\section{Natural Features}

- Hopoe is a stone, formerly in the sea at Kea'au. It was believed to be Hi'iaka's companion who was turned to stone by Pele. It was moved by the tidal wave of 1946 (Pukui, p. 52).

- At Hopoe, fringes of lehua fall into the sea and are washed up over the rocks, thus hiding the 'opihi (See Olelo No'eau \#1567, \#2534, and \#474).

\section{Other Features}

Kuolo ("to rub") is an area near Kea'au where the Puna chief, Hua'a, was defeated, thus giving control of Puna to the chief Umi (Pukui, p. 125).

\section{Legendary and Historical Figures and Events}

William Ellis wrote in his journal about the village of Kea'au which he visited in 1822-1823:

... we reached Kaau, the last village in the division of Puna. It was extensive and populous, abounding with well-cultivated plantations of taro, sweet potatoes, and sugar-cane; and probably owes its fertility to a fine rapid stream of water, which, descending from the mountains, runs through it into the sea... Before we left the place, the people offered for sale some curious deep oval baskets, with covers, made of the fibrous roots of $\mathrm{ie}^{\prime \prime}$ (p. 212-213).

Kepaka-ili-ula ("born with red skin") is born in Kea'au, child of Ku and Hina. He is born in the form of an egg but after being wrapped in a feather cape for ten days and ten nights he emerges as a beautiful child. At the end of forty days being wrapped in a red feather cloak, his skin and eyes have become red. His foster parents raise him in Pali'uli. When 
Kepakailiula leaves Pali'uli to court his wife, the place is shut up and no one has seen it since. Eventually, Kukui-pahu marries his daughter to the red-skinned kupua (Beckwith, p. 423-424).

\section{Hawaiian Proverbs}

'Olelo No'eau \# 624: He iki hala au no Kea'au, 'a'ole pohaku 'ala e naha ai. I am a small hala fruit of Kea' au, but there is no rock hard enough to smash me. This is the boast of a Puna man-I am small, perhaps, but mighty.

Olelo No'eau \#1560: $\quad$ Ka ua kahiko hala o Kea'au.

The rain that adorns the pandanus trees of Kea'au. This saying refers to the pandanus grove of Kea'au, Puna.

'Olelo No'eau \#1638: Kauwa ke aloha i na lehua o Ka'ana.

Love is a slave to the lehua blossoms of $\mathrm{Ka}^{\text {'ana. }} \mathrm{Ka}$ 'ana is a place between $\mathrm{Kea}^{\prime} \mathrm{au}$ and 'Ola'a where travelers used to rest and make a lei of lehua. It took many blossoms and much patience to complete a lei, which was later given to a loved one.

'Olelo No'eau \#1668: $\quad K e a ' a u, i$ ke kai nehe i ka 'ili'ili.

Kea'au, where the sea murmurs over the pebbles.

'Olelo No'eau \#2070: Mai ke kai kuwa e nu ana i ka ulu hala o Kea'au a ka 'aina ka'ili la o lalo o ka Waiku'auhoe.

From the noisy sea that moans to the hala groves of Kea'au, to the land that snatches away the sun, below Waiku'auhoa. From Puna, where the sun was said to rise, to Lehua, beyond Waiku'auhoe, where it vanishes out of sight.

\section{KEAHIALAKA}

(a fire made by Laka, the goddess of hula)

Ahupua 'a, consisting of 5562 acres, awarded to W.C. Lunalilo; Mahele Book of Land Awards 1848. L.C.A. 8559-B, B10, p. 479 / RP 8094 B 35 p. 1, and RP 8088 B 32, p. 55).

\section{Other Features}

Heiau of Mahinaakaaka is an unusually high-platformed heiau built on an old sea-boulder beach, which has been gradually moving seawards. At the western corner of the platform was originally a pond. The platform itself is built of the rounded, water-worn stones called "'ala" which are plentiful in the vicinity. This is an example of a truncated pyramidal form heiau, probably as a result of these stones which were used. Local informants claimed that the heiau was used for human sacrifice and was dedicated to Kamehameha's god Ka'ili (Stokes, p. 149-151). 


\section{Legendary and Historical Figures and Events}

It is said that Pele dug a crater here.

William Ellis, a missionary who toured the islands in 1822-1823, wrote about what he saw:

... we reached Keahialaka [from Malama], the residence of Kinao, chief or governor of Puna. We found him lying on a couch of sickness ... I therefore remained with the sick chief, while Messrs. Thurston and Bishop went on to a village at the east point, about two miles distant [called Pualaa] ... The country had been much more populous than any we had passed since leaving Kona ... (p. 201).

\section{KEALAKOMO/KILAUEA 56 \\ (the entrance path/spewing, much spreading as volcanic eruptions)}

Designated, in conjunction with Kilauea, as Government Land in the Mahele Book of Land Awards 1848.

\section{Natural Features}

- a lava flow from Mauna Ulu vent poured into the sea near here in 1971 and created 97 acres of new land (Pukui, p. 102).

- Kilauea is an active volcano on the flank of Mauna Loa, nearly continuously active 1823-1894 and 1907-1924; eruptions began again in 1952 and have been active most of the years since then (Pukui, p. 111).

- Kilauea Iki ("small Kilauea") is a small crater just outside Kilauea Crater (Pukui, p. 111).

- Alae is a pit crater near Kilauea Crater and was last active in 1969. A lava flow from 'Alo' $i$ and 'Alae craters reached the sea 1000 feet west in 1970; an ancient village known as Kahue ("the gourd") was destroyed at this same site in the 1868 tidal wave (Pukui, p. 8\&66).

- forest reserve (Pukui, p. 111).

- crater of Keanakakoi ("the adze making cave"), quarry buried by 1877 flow (Pukui, p. 103).

- Nahuku ("protuberances") is a lava tube near Kilauea Crater. It is now referred to as Thurston Lava Tube (Pukui, p. 160).

- Namakanipaio ("conflicting winds") is a place in the Hawai'i Volcanoes National Park in Kilauea (Pukui, p. 161):

- Palikapuokamohoali'i ("sacred cliff of Kamohoali' $i$ ") is a cliff at Kilauea which was allotted by Pele to her favorite brother Kamohoali' 1 ("the royal selected one"). Regardless of wind direction, volcanic smoke is believed never to fly over this cliff (Pukui, p. 177).

\footnotetext{
56For consistency with our system of using the land divisions designated by the Mahele Land Awards, we are placing the information related to Kilauea and its many features in this section rather than in a section of its own. While some sources place Kilauea in Keauliou, the source which we used places it within Kealakomo.
} 
- Peleli'ili' $i$ is a gulch and small lava flow in Kilauea (Pukui, p. 183).

- Puakalehua ("the lehua blooms") is a land section in Kilauea. The reference is to pretty girls there (Pukui, p. 191).

- Puhimau ("ever smoking") is a $3623 \mathrm{ft}$. crater in Kilauea (Pukui, p. 193).

- Pu'ukaone is a $787 \mathrm{ft}$. hill in Kilauea (Pukui, p. 198).

- Pu'ukoa ("koa tree hill") is a land section in Kilauea (Pukui, p. 199).

- Pu'ukoa "e ("tropic bird hill") is a $3250 \mathrm{ft}$ hill in Kilauea (Pukui, p. 199).

- Pu'upua'i ("gushing hill") is a 3885 ft. peak in Kilauea (Pukui, p. 205).

- Pu'uone, or Sand Hill, a 3700 ft. peak in Kilauea (Pukui, p. 210).

- Uwekahuna is a cliff and bluff at Kilauea. A house stood over a pit here. When a curious person entered, the priest would pull ropes making the floor collapse. The people fell to their deaths in the pit. Kamiki set the house on fire and the priest wept, thus the name "uwe (crying) kahuna (priest)" (Pukui, p. 216).

- Uwewale ("crying without cause") is a gulch in Kilauea (Pukui, p. 216).

- Wahinekapu ("sacred woman" referring to Pele) is a bluff near Kilauea and taboo residence of the god Kamohoali'i, Pele's brother (Pukui, p. 218).

\section{Other Features}

- The Volcano House Hotel was built on the brink of Kilauea caldera in 1846 by Benjamin Pitman, Sr. (Pukui, p. 217).

- Uwekahuna is the name of the volcano observatory which sits at Kilauea at $4077 \mathrm{ft}$. (Pukui, p. 216).

\section{Legendary and Historical Figures and Events}

Hawaiians believe that the volcano at Kilauea is inhabited by a family of fire gods presided over by the goddess Pele who governs the activities of lava flows. The Pele myth is believed to have developed in Hawaii, though Pele is said to have traveled to Hawai'i from Kahiki somewhere in the South Pacific, where it is closely associated with 'aumakua worship of the deities of the volcano, with the development of the hula dance, and with stories in which odd rock or cone formations are ascribed to contests between Pele and her rivals, be they human or divine (Beckwith: 168-170).

William Ellis describes a weekend visit in 1823 to the crater at Kilauea during his travels around the island:

Strawberries, as well as raspberries, are indigenous plants, and are found in great abundance over most of the high lands of Hawaii ... The ground over which we walked was composed of ancient lava ... The surface was covered with ohelo bushes ... Within a few miles of Kirauea [Kilauea], we passed three or four high and extinct craters. One of them, Keanakakoi, the natives told us, sent forth, in the days of Riroa [Liloa], king of Hawai'i about fourteen generations back, most of the lava over which we were traveling (p. 182).

William Ellis also writes about his descent from the crater of Kilauea:

As we approached the sea, the soil became more generally spread over the surface, and vegetation more luxuriant ... we descended, by following the 
course of a rugged current of ancient lava, for about 600 feet perpendicular depth, when we arrived at the plain below, which was one extended sheet of lava. ... the natives gave us the fabulous story of the combat between Pele and Tamapuaa [Kamapua'a], as the origin of this flood of lava ... we crossed it in about two hours, and anrived at Kearakomo [Kealakomo], the second village in the division of Puna ...

The natives brought us a calabash-full [of water], of which we drank most hearty draughts, though it was little better than the water of the sea, from which it had percolated through the vesicles of the lava into the hollows from nine to twelve feet distant from the ocean...After walking about a mile along the beach, we came to a house ... it was a miserable hut ... Mauae told us it was the only one in the place that was not crowded with people ... The village is populous ... When they learned that we had been to Kirauea [Kilauea], they were unwilling to believe we had broken the sulphur banks, eaten the ohelo berries, descended to the craters, or broken any fragments of lava from them, as they said Pele ma, Pele and her associates, would certainly have avenged the insult .... In the evening, we were so favoured as to procure a calabash-full of fresh water from the caves in the mountains ,... Leaving Kearakomo [Kealakomo] we travelled several miles in a northeasterly direction along the same bed of lava that we had crossed on Saturday evening ... The population of this part of Puna, though somewhat numerous, did not appear to possess the means of subsistence in any great variety of abundance; and we have often been surprised to find the desolate coasts more thickly inhabited than some of the fertile tracts in the interior (p. 182-190).

\section{Hawaiian Proverbs}

'Olelo No'eau 1511: Ka 'ohi'a hihipe'a o Kealakomo.

The entwining ohi'a branches of Kealakomo. In Kealakomo 'ohi'a trees grown thickly together.

\section{KEAUOHANA}

Designated as Government Land in the Mahele Book of Land Awards 1848.

Legendary and Historical Figures and Events

William Ellis who traveled around Hawai 'i in 1822-1823 mentioned this area in his journal:

After traveling nearly two hours [from Kaimu], we arrived at Keouohana, where we sat down to rest beneath the shade of some cocoa-nut trees (p. 198).

\section{KEHENA \\ (place for refuse)}

Ahupua'a, consisting of 7.37 acres, was awarded to Haka; Mahele Book of Land Awards 1848 (L.C.A. 1-M b 7, p. 677 / RP 8029 B 34, p. 293). Haka was possibly the former house 
servant of Mr. Coan and kept a house ready for him in Keekee just $11 / 2$ miles north of Kehena (Lyman, 1846 July 10).

\section{Other Features}

Heiau of Kue is said to have been a platform heiau for human sacrifice. Unfortunately it was not seen by Stokes (p. 149) but was said to be located "mauka of Loebenstein's house".

\section{Legendary and Historical Figures and Events}

Kehena is the birthplace of the Reverend J.W. Kanoa, a man of chiefly rank and the first Hawaiian missionary to the Gilbert Islands (Pukui, p. 105).

William Ellis, an English missionary, traveled around Hawai' $i$ in 1822-1823 and wrote in his journal:

After traveling a mile and a half along the shore [from Keouohana], we came to Kehena, a populous village; the people seemed, from the number of their canoes, nets, \&c. to be much engaged in fishing. Their contrivance for launching and landing their canoes, was curious and singular ... The canoes of the place were light and small, seldom carrying more than one man in each (p. 199).

KEOKEA

(the white sand)

Designated as Government Land in the Mahele Book of Land Awards 1848.

\section{KEONEPOKO}

(the short sand)

Designated as Government Land in the Mahele Book of Land Awards 1848.

\section{Natural Features}

'Opihi is an offshore rock near the north boundary of Keonepoho Nui; it is sometimes called Moku'opihi (Pukui, p. 171).

\section{KI}

(ti plant)

Designated as Government Land in the Mahele Book of Land Awards 1848.

\section{KIAPU}

Designated as Government Land in the Mahele Book of Land Awards 1848. 


\section{KIKALA 1 AND 2}

Designated as Government Land in the Mahele Book of Land Awards 1848.

\section{KOA'E 1 AND 2}

Land surrendered by Lunalilo in lieu of commutation due on other lands.

\section{Legendary and Historical Figures and Events}

Village or land section named perhaps for Puna 'aikoa'e ("Puna ruled by the tropic bird"), a supernatural being with a tropic bird form who once lived near here at Pu'ula and is seen today flying over Kilauea Crater (Pukui, p. 110). The story goes that the Kiki bird nested together with the Koa'e bird - the koa'e bird faced the area known as Koa'e and the kiki bird faced towards kiki. According to some, both birds stole wild taro and were destroyed by the demigod Pikoiaka'alala.

(Pikoi and Other Legends of Hawaii, M. K. Pukui and C. Curtis, p. 20-22).

\section{KULA \\ (plain)}

Not listed in the Mahele Book of Land Awards 1848 but appears on maps and in references; land perhaps changed names or became a part of another ahupua'a.

\section{Natural Features}

Cape Kumukahi ("first beginning"), the place where the wind divides and blows to Hilo and $\mathrm{Ka}$ 'u; it also marks the span of day from sunrise at Kumukahi until sunset at Lehua Island. It is the easternmost cape in Hawai i, named for a migratory hero from Kahiki who stopped here and is represented by a red stone. It is believed that two of his wives, also in the form of stones, manipulate the seasons by pushing the sun back and forth between them. One of the wives was named $\mathrm{Ha}^{\prime}$ eha' $\mathrm{e}$. Sun worshippers bring their sick here to be healed. Another Kumukahi, the favorite younger brother of Kamalalawalu, lived near here. Kumukahi was also the name of a chief who pleased Pele but who ridiculed her. As a result, she heaped lava over him forming the cape (Bishop Museum Oral History Collection, M.K. Pukui and Alvin Kaliko Kalawe of Kapoho, recorded January 30, 1960).

Makanoni ("mixed or speckled face") is a large stone near Cape Kumukahi (Pukui, p. 141).

\section{Other Features}

Heiau of Kuki'i ("standing image") crowns Kuki'i Hill. Natives of the area described this heiau as having a platform constructed of hewn stone and laid so closely that 'an ant could not crawl between'. Stokes found this heiau disappointing in this regard. None of the ancient features remained. Local informants said that the heiau was built by 'Umi; another stated that Pakaa, one generation later, was the builder. Many of these stones have been carried off, some by local residents, others by Honolulu people. One of the paving blocks, obtained 
by Mr. Rufus Lyman whose estate is nearby, is now in Bishop Museum and is described by Stokes (Stokes, p. 151-153). It is said that one was brought to Honolulu by Kalakaua in 1877 and used in the construction of 'Iolani Palace. Others were moved to Kalapana Park where it is said they cried to be returned (Pukui, p. 121).

\section{Legendary and Historical Figures and Events}

Kula is the place where Kahawali, who had been holua sledding with Pele, bid farewell to his sister (See story of Kahawali under Kapoho).

William Ellis, a missionary, traveled through this area and wrote in his journal:

About three o'clock we resumed our journey [from Kapoho] and soon reached Kula, a romantic spot, where Kahavari took leave of his sister...The natives pointed out a number of rocks in the sea, which, they said, were thrown by Pele to sink the canoe in which Kahavari escaped ... Our way now lay over a very rugged tract of country ... we reached Kahuwai ... we travelled in an inland direction to Honoruru [Honolulu] (p. 210-211).

\section{Hawaiian Proverbs}

'Olelo No'eau \#990: Hiki mai ka la ma Ha'eha'e, maluna mai o Kuki'i. The sun rises at $\mathrm{Ha}^{\prime}$ eha'e, above Kuki'i. Ha'eha'e is often called the gateway of the sun.

'Olelo No'eau \#2063: Mai ka la 'o'ili i Ha'eha'e a hali'i ka mole o Lehua. From the appearance of the sun at $\mathrm{Ha}^{\prime}$ eha'e till it spreads its light to the foundation of Lehua. Refers to Kumukahi as the gateway of the sun.

'Olelo No'eau \#2064: Mai ka 'o'ili ana a ka la i Kumukahi a ka la iho aku i ka mole 'olu o Lehua.

From the appearance of the sun at Kumukahi till its descent beyond the pleasant base of Lehua.

'Olelo No‘eau \#2058: Mai ka hikina a ka la i Kumukahi a ka welona a ka la i Lehua. From the sunrise at Kumukahi to the fading sunlight at Lehua. Kumukahi was called the land of the sunrise and Lehua, the land of the sunset. This saying also refers to life span, from birth to death.

\section{KUPAHUA}

Designated as Government Land in the Mahele Book of Land Awards 1848. Three ili in Kupahua are also designated as an ahupua'a or part thereof. 


\section{LAE'APUIKI / LAE'APUKI (short point)}

Land surrendered by Lunalilo in lieu of commutation; Mahele Book of Land Awards 1848 (Bishop Museum Oral History Tape Collection, 'Oulu Konanui \& M.K. Pukui, recorded 10/26/59). According to informant 'Oulu Konanui, he says that Panauiki could be another name for Lae'Apaki and that Pali'ula, located directly above Lae 'Apuki, could also have been another name for Panauiki.

\section{Natural Features}

- an overlook

\section{Other Features}

- ancient village site (Pukui, p. 126).

\section{LAEPAO'O \\ (pao'o fish point)}

Land surrendered in lieu of commutation by Lunalilo: Mahele Book of Land Awards 1848.

$$
\begin{gathered}
\text { MAKENA } \\
\text { (abundance) }
\end{gathered}
$$

Designated as Government Land in the Mahele Book of Land Awards 1848.

\section{Legendary and Historical Figures and Events}

William Ellis, an English missionary who traveled through Hawai'i in 1822 and 1823 reported this in his journal:

In the afternoon, Messrs. Thurston and Bishop walked over to Makena, a pleasant village about a mile to the southward of Kaimu...Mr. Bishop numbered the houses in the village, and found them, including Makena, to be 145 (p. 196).

$$
\begin{gathered}
\text { MAKUU } \\
\text { (canoe end-pieces) }
\end{gathered}
$$

Designated as Government Land in the Mahele Book of Land Awards 1848. 


\author{
MALAMA \\ (month / moon)
}

Designated as Government Land in the Mahele Book of Land Awards 1848.

Natural Features

- inland crater

- sea area

\title{
Legendary and Historical Figures and Events
}

William Ellis, on his trip around the island in 1822-1823, wrote this about the area in his journal:

... and then resumed our journey through the district of Malama [from Kauaea], the inland part of which was inundated by a volcanic eruption about thirty years since. The part over which we passed, being nearer the sea than that which the lava had overflowed, was covered with soil, and smiling with verdure (p. 201).

\section{Hawaiian Proverbs}

'Olelo No'eau \#1950: Lauahi Pele i kai o Puna, one 'a kai o Malama.

Pele spread her fire down in Puna and leaves cinder down in Malama. There are two places in Puna called Malama, one inland and one on the shore where black sand (one 'a) is found.

'Olelo No'eau \# 2563: Pa'apa'akai o Malama.

Crusted with salt is Malama. Said of a sour situation.

'Olelo No'eau \# 2673: Pohaku 'ai wawae o Malama.

Feet-eating rocks of Malama. Said of sharp ' $a$ 'a rocks that make walking with bare feet very painful. This saying comes from a chant by $\mathrm{Pa}^{\prime} \mathrm{Oa}$, a friend of Lohi'au, who went to Kilauea to seek his friend's lava-encased remains.

\author{
NANAWALE \\ (just look around)
}

Designated as Government Land in the Mahele Book of Land Awards 1848.

\section{Hawaiian Proverbs}

'Olelo No'eau \# 1770: Ka nana la i Nanawale.

Just looks at Nanawale. Said of one who has nothing or no one to look to for help. 
'Olelo No'eau \# 233: Apiki Puna i Lele'apiki, ke nana la i Nanawale, Puna is concerned at Lele'apiki and looks about at Nanawale: The people are followers, obedient to their rulers. The people of Puna were not anxious to go to war when a battle was declared between Kiwala'o and Kamehameha, but it was the will of their chief. Lele apiki and Nanawale are places in Puna.

Place Names p. 162: Ua pae ka wa'a i Nanawale.

Unsuccessful fishermen would say that their canoe landed at Nanawale.

OLA'A /LA'A

(dedicated)

Designated as Crown Land in the Mahele Book of Land Awards 1848.

\section{Natural Features}

- Forest reserve (Pukui, p. 169).

- a legendary area for collecting bird feathers (Pukui, p. 126 \& 169).

\section{Other Features}

-Kurtistown is a village here named for A.G. Curtis, a pioneer at 'Ola'a (1902) when the 'Ola'a Sugar Company began operations (Pukui, p. 125).

- Glenwood is a village in Puna built in 1901 as a terminal for the Hilo Railroad. Kap"ueuhi ("yam mound") is the old name for this place (Pukui, p. 32).

\section{Legendary and Historical Figures and Events}

William Ellis wrote in his journal during in travels in Hawai' $i$ in 1822-1823 about Ola'a:

The distance is probably between thirty and forty miles, and the ascent gradual from the shore [at Waiakea near Hilo] to the volcano. The soil is generally rich and fertile ... we travelled through two or three extensive woods, in which were many large trees, and saw also several pools and small currents of excellent fresh water. The construction of the swineherds' house at the village of Kapuokaahi ("the hill of the fire") was singular ... we also saw hedges of raspberry bushes, which the natives informed us bore white berries ... Nine or ten miles from the sea, we met with ohelo bushes and after we had travelled about twenty miles, we found strawberry plants in abundance (p.213-214).

Dr. Russell noted that Hawaiians near Ola'a make kapa of mamake, gathered olona fiber for fishing nets, and captured ' 0 ' 0 (a black honey eater with yellow feathers in a tuft under each wing which were used for featherwork; these birds were endemic to the island of Hawai' $i$ but are now extinct) for feathers. He also noted extensive patches of banana and taro as well as heaps of stones in the forest which would indicate a place of former habitation and industry. 
Kapuaeuhi, an olohe (a hairless professional robber trained in lua) of Ola'a, uses his two strong daughters to decoy travelers to his cave where he kills the traveler. Finally two cousins of a plundered man kill the daughters and then the old man whom they leave in the cave. Some say he remains there yet (Beckwith, p. 344).

Travelers between $\mathrm{Ka}^{\mathrm{u}} \mathrm{u}$ and Puna were attached and killed by a band of robbers (Folktales of Hawaii, M.K. Pukui \& Green, p. 91).

\section{Hawaiian Proverbs}

'Olelo No'eau \# 1707: Keiki kiamanu o La'a.

Bird-catching lad of La'a. Said of a person whose charm attracts the opposite sex. 'Ola'a was once known as La'a. Birdcatchers often went into the forest there for feathers. This expression is used in a chant composed for Kalakaua.

ONELOA

(long sand)

Designated as Government Land in the Mahele Book of Land Awards 1848.

\section{OPIHIKAO \\ (crowd gathering limpets)}

Designated as Government Land in the Mahele Book of Land Awards 1848.

Limpets are better known as 'opihi, but because of robbers, people were afraid to gather 'opihi alone; thus a crowd gathered to do it.

\section{Other Features}

- village.

\section{Legendary and Historical Figures and Events}

In June 1823, Rev. William Ellis and three American missionaries (Asa Thurston, Artemas Bishop, and Joseph Goodrich) proceeded on a two-month tour of the island of Hawai' $i$ for the purpose of learning more of the country and people, with a view to establishing mission stations there. So far as the records show, these were the first white men to do this, as well as to visit the volcano at Kilauea. In the Journal of William Ellis it states:

...we arrived at Opihikao [from Kamaili], another populous village, situated within a short distance of the sea. The head man, Karaikoa, brought out a mat, spread it under the umbrageous shade of a kou-tree in front of his door, and invited us to sit down and rest... We then proceeded about two miles, principally through cultivated ground, to Kauaea..." (p. 200-201). 


\begin{abstract}
Hawailan Proverbs
Hawaiian nane (riddle): He i'a ka'u i ke kai; he i'a ka'u i ka 'aina E ha'i mai i ka inoa o $k u ' u$ 'aina. Pane (answer): Opihi ko ke kai, kao ko ka 'aina. 'O 'Opihikao ka inoa o ka 'aina.

Riddle: It is a fish from the sea; it is a fish from the land. Tell me the name of my land. Answer: Opihi from the sea; goat (kao) from the land. 'Opihikao is the name of the land (Riddle from Oulu Konanui interview with Mary Kawena Pukui, Bishop Museum Oral History Collection).
\end{abstract}

\author{
PANAU \\ (uneasy/restless) (Pukui, p. 178)
}

This section of Puna is divided into Panauikj (small Panau) and Panaunui (large Panau). Panau extends from shore, upland to Makaopuhi Crater, a place mentioned in one of Queen Emma's mele. Panaunui extends from the shore to the volcano. Panauiki could be another name for (Ka) Lae 'Apuki (Bishop Museum Oral History Tape Collection, M.K. Pukui \& O. Konanui, recorded 10/26/59).

A part of this ahupua'a was awarded to M. Kekauonohi (L.C.A. 11216, Bk. 9, Pg. 661; RP 8095, Bk. 35, Pg. 5).

Panauiki was designated Government Land in the Mahele Book of Land Awards 1848.

\title{
Natural Features
}

Makaopuhi Crater ("eye of eel") is a large double pit crater which was last active in 1969. It is one of the Chain of Craters (Pukui, p. 141).

\section{Other Features}

Pu'uloa is the site of the most concentrated complex of petroglyphs (drawings by ancient Hawaiians) in Hawai'i (Pukui, p. 200-201).

Pu'uloa ("long hill") also contains a mound which was used as a depository for the piko (umbilical cord) of infants (Pukui, p. 200-201).

Paliuli ("green cliff") is a legendary paradise of plenty, usually thought to be in the Puna district, is also one of the assumed homes of the sacred princess Laieikawai. Many Island places are named Paliuli including a land section with a water cistern in Puna (Pukui, $p$. 178).

Chain of Craters is a land section as well as a road in Puna. Recent eruptions from the craters of 'Alo'i, Alae, Kanenuiohamo, Makaopuhi and Napua, however, have covered much of the upper section of the road. 


\section{Legendary and Historical Figures and Events}

In June 1823, Rev. William Ellis and three American missionaries passed through this part of Puna:

... surprised to find the desolate coasts more thickly inhabited than some of the fertile tracts in the interior; a circumstance we can only account for, by supposing that the facilities which the former afford for fishing, induce the natives to prefer them as places of abode; for they find that where the coast is low, the adjacent water is generally shallow... This latter article (quantities of dried salt fish, principally albacores and bonitos), with their poe (poi) and sweet potatoes, constitutes nearly the entire support of the inhabitants, not only in this vicinity, but on the sea-coasts of the north and south parts of the island...When we had passed Panau, Leapuki, and Kamoamoa, the country began to wear a more agreeable aspect. Groves of coca-nuts ornamented the projecting points of land, clumps of kou-trees appeared in various directions, and the habitations of the natives were also thickly scattered over the coast (Journal of William Ellis, p. 190).

Wilkes, in 1841, left Panau and passed on towards the east. After traveling about three miles he came in sight of the ocean. He then changed to a northeast direction and soon reached an extensive upland taro patch.

Panau is said to be the home of 'Opelukahi, a robber in the time of Kamehameha I who knew the art of lua, a type of dangerous hand-to-hand fighting. He robbed and murdered a Kohala man whose brother then swore revenge. The brother first oiled his body and at Kealakomo fought and killed 'Opelukahi (Pukui, p. 178).

A shark god called $\mathrm{Ka}$ 'ehuikamanoopu'uloa (the little red-headed shark of Pearl Harbor, formerly called Pu'uloa) was born at Panau in Puna and named after the red hair of the shark goddess Kaahupahau. He was fed 'awa and milk by his parents before he is put out to sea where he pays a visit to each of the king sharks of Hawai' $i$ and travels to many places in the South Pacific. He arrives home a hero after successfully battling with the man-eating shark Pehu (Beckwith, p. 140).

\section{POHOIKI \\ (small depression)}

Designated as Government Land in the Mahele Book of Land Awards 1848.

\section{Natural Features}

- Surfing area (Pukui, p. 187).

- Laeokahuna ("point of the secret place") is a point near Pohoiki (Pukui, p. 127).

- natural warm springs.

\section{Legendary and Historical Figures and Events}

Pele is said to have dug a crater here (Pukui, p. 187). 


\title{
POPOKI \\ (ti leaf bundie)
}

Designated as Government Land in the Mahele Book of Land Awards 1848.

\section{POUPOU 1 / POUPOU 2 \\ (stout)}

Designated as Government Land in the Mahele Book of Land Awards 1848.

Natural Features

- Kupapau Point.

\author{
PU'ALA'A \\ (a type of 'ala'a tree)
}

Ahupua'a, consisting of 1110 acres, was awarded to William P. Leleiohoku; (L.C.A. 9971, Bk. 10, Pg. 609; RP 7714, Bk. 29, Pg. 53); Mahele Book of Land Awards 1848.

\section{Natural Features}

- Pohakupaia.

- Hala Point named for the ' $a$ 'ala tree which is common here but rare elsewhere (Pukui, p. 191).

\section{Other Features}

_ ancient village site discovered here by archaeologists in 1971 (Pukui, 191).

\section{Legendary and Historical Figures and Events}

In the Journal of William Ellis, Rev. Ellis explains that when his party reached Keahialaka, the residence of Kinao who the chief or governor of Puna, they found him to be sick and thus he stayed to aid in his comfort while his colleagues:

... went on to a village at the east point, about two miles distant. When they reached Pualaa, the abovementioned village, they were kindly welcomed by the head man ... [he rejoined his group at Pualaa] we took leave of them, and directed our way across the eastern point. A most beautiful and romantic landscape presented itself on our left as we travelled out of Pualaa. The lava was covered with a tolerably thick layer of soil, and the verdant plain, extending several miles towards the foot of the mountains, was agreeably diversified by groups of picturesque hills, originally craters, but now clothed with grass, and ornamented with clumps of trees. The natives informed us, that three of these groups, Honuaura, Malama, and Mariu, being contiguous, and joined at their base, arrested the progress of an immense torrent of lava, 
which, in the days of Taraiopu, the friend of Captain Cook, inundated all the country beyond them. We soon left this cheerful scenery, and entered a rugged tract of lava... when we reached Kapoho" (pages 201-205).

\section{PULAMA}

(to cherish)

Not listed in the Mahele Book of Land Awards 1848 but appears on maps and in references; land perhaps changed names or became a part of another ahupua'a.

According to T. Holmes, on old maps this ahupua'a bordered Kahauale'a in the west. Hudson reported a heiau, Makaiwa here 3 miles from the sea. Thrum called this heiau an ipuolono or agricultural heiau.

\section{Natural Features}

Holoinaiwi ("bone washer") is a small cove, deep down the jagged bluffs of Puna's coastline at the southern end of Waha'ula where the bones of the slain were washed (Stokes, p. 144).

\section{Other Features}

Waha 'ula Heiau ("red mouth") was the first walled heiau built in Hawai'i and the first to be built by $\mathrm{Pa}^{4} \mathrm{ao}$, a Polynesian from the south who migrated to the Hawaiian Islands around the 11th Century. $\mathrm{Pa}^{\prime} \mathrm{ao}$ is credited with introducing changes in religious forms and probably human sacrifices. Thrum says: "The heiau of Waha'ula is built on an aa flow, and the ascent to it is by terraces. Upon the first terrace the female members of the royal family were allowed to come and bring their offerings which were then taken by the priests. Beyond this first terrace no female was allowed to pass. Two more terraces bring the traveler to the enclosure or temple" (Stokes, p. 139). Fornander states, on the authority of Kamakau, that "in the original enclosure of the heiau of Waha"ula was a sacred grove, said to contain one or more specimens of every tree growing in the Hawaiian group, a number of which, or their descendants, has survived when he visited the place in $1869 .$. It was built in the quadrangular or parallelogram form which characterized all the heiaus built under and after the religious regime introduced by Paao" (Stokes, p. 139).

\section{Legendary and Historical Figures and Events}

Tradition ascribes to $\mathrm{Pa}^{\prime} \mathrm{ao}$, a priest who traveled to Hawai' $\mathrm{i}$ in about the 13 th century from Kahiki in the South Pacific, the introduction of human sacrifice into the temple ritual, the walled heiau, and the red-feather girdle as a sign of rank. It is said that $\mathrm{Pa}$ 'ao first landed in Puna where he built the heiau at Pulama (Waha'ula), then goes to Kohala and erects the famous heiau of Mo'okini at Pu'uepa. $\mathrm{Pa}$ 'ao brought with him several mo'o kupua (demi gods) with him from Kahiki, all of which are worshipped, some as sacred stones. (Beckwith, p. 370-372) The temple was used by Kamehameha I and dedicated to his war god Kuka'ilimoku and was the last major temple where public worship was held (Place Names in Hawai $i$ by Pukui, p. 218).

Beckwith relates a story told of the heiau of Waha'ula: "The smoke from the altar at Waha'ula is regarded as the shadow cast by the god of the heiau and hence to cross through the smoke is sacrilege. A young chief, forgetful of the tapu, allows himself to be touched by 
the smoke and is accordingly seized and sacrificed and his bones thrown into the bone pit. His spirit comes in dream to his father, who is the high chief of $\mathrm{Ka}-\mathrm{u}$, and the father sets out at once to recover his son's bones. After first encountering and killing the olohe [a wellrecognized class of people who were skilled in wrestling and bone-breaking, or lua, and had hairless bodies; legend portrays them as professional robbers] who slays travelers along the sea road out of Kalapana, he arrives at the heiau. As the spirits dance at night, he recognizes and seizes the spirit of his son, who points out to him where the bones are to be found. Some say that the father restores his son to life, others that he merely gives the bones a proper burial" (p. 343-346).

William Ellis, an English missionary to the South Pacific islands, visited Hawai'i in 1822 and 1823 and had this to say about this area in his journal:

At noon we passed through Pulana, where we saw a large heiau called Wahaura, Red Mouth, or Red-feather Mouth, built by Tamehameha, and dedicated to Tairi, his war-god. Human sacrifices, we were informed, were occasionally offered here. Shortly after, we reached Kupahua, a pleasant village, situated on a rising ground, in the midst of groves of shady trees, and surrounded by a well-cultivated country...Leaving this interesting place, we passed on to Kalapana, a small village on the sea-shore (p. 190-191).

\section{PUUA}

Ahupua 'a, consisting of 4919 acres, was awarded to A. Keohokalole; (L.C.A. 8452, Bk. 10, Pg. 431; RP 7788, Bk. 29, Pg. 125); Mahele Book of Land Awards 1848.

\section{Natural Features}

- Kipu Point.

WA'AWA'A

(Wa'awa'ia)

Designated as Government Land in the Mahele Book of Land Awards 1848.

\section{Other Features}

- canoe landing.

- fishing harbor.

\section{WAIAKAHEKAHE / WAIKAHEKAHE \\ (Waikahekaheiki and Waikahekahenui)}

Ahupua'a was awarded to Kale (Dale Davis) (w) (L.C.A. 8522, Bk. B-10, Pg. 465; RP 2236, Bk. 9, Pg. 605; Apana 3) and Gini M. Lahilahi (w) (L.C.A. 8520, Bk. B-10, Pg.5-6; RP 1668, Bk. 6, Pg. 279); the latter is designated as inherited land; Mahele Book of Land Awards 1848. 


\section{WAIAKAHIULA \\ (red water)}

Ahupua'a, consisting of 2927 acres, was awarded to M. Kekauonohi; (L.C.A. 11216, Bk. 9, Pg. 661; RP 8095, Bk. 35, Pg. 5; 2 Apana); Mahele Book of Land Awards 1848.

\section{Other Features}

- town

\section{Legendary and Historical Figures and Events}

William Ellis, a missionary who traveled through the islands in $1822-1823$, noted in his journal that he had stopped briefly at Waiakaheula [Waiakahiula] where he rested before continuing on to Kea'au and Hilo (p. 211).

\section{OTHER PLACES AND EVENTS57 \\ (associated with the Puna District)}

'A'alamanu is a place where the best pebbles of the Puna district were found; they were much liked by chiefs for the game of konane. See 'Olelo No'eau \# 1405.

Halalu is a heiau in Puna, probably named for the legendary man-eating bird.

Halape is an area as well as a trail in the Puna district near the $\mathrm{Ka}$ ' $\mathrm{u}$ border. Gourds growing here were completely buried by shifting winds. People not knowing this would miss them entirely; thus the saying "I Halape aku nei paha" (maybe at Halape), said when things were not found (Pukui, p. 36).

Hale-o-Lono ("house of Lono") is a land section that sits on top of Holei Pali. In ancient times the rain was so heavy here that it washed away all growing plants. The angry people caught some rain, put it in an oven, and watched it escape as a cloud at Pu'ukapukapu ("regal hill"), a $1050 \mathrm{ft}$. hill at Kilauea. On all islands there are ancient heiau (pre-Christian place of worship) of this name for the worship of Lono, which include ceremonies to bring rain and growth. Lono was one of the four major gods brought from Kahiki (Pukui, p. 38).

Holei is a pali (cliff, precipice, steep hill) and an ancient village in Puna. A supernatural rat named 'Apua lived here and was shot by Pikoiaka'alala (Pukui, p. 47).

Imukaluaua ("rain-baking oven") is a land section in Puna (Pukui, p. 56).

Ka'awaloa ("the distant kava") which refers to runners who went to Puna or Waipi 'o to get kava for their chiefs.

Ka'ena is a point and land section in Puna (Pukui, p. 61).

${ }^{57}$ The exact location within the ahupua'a designations of the Mahele Land Awards are uncertain. 
At Kaueleau in Puna is a hard rock called the 'ala pa'a. The reference is to a hard, unyielding person. See 'Olelo No'eau 1278.

Ka'ili'ili ("the pebble") is a land section and village in Puna (Pukui, p. 68).

Kalalani ("the row"), Kalaloa ("very rough"), and Kalehua ("the expert") are ancient surfing places in Puna (Pukui, p. 73).

Kali " $u$ ("the well salted")(also a hill in Kalapana) is a place in Puna where good "awa is grown (Pukui, p. 77). See 'Olelo No'eau \# 1281.

Kaloaoka'oma ("length of the oven") is an ancient surfing area in Keau (Pukui, p. 77).

Kamilo Point ("twisting, of currents") is located at $\mathrm{Ka} \mathrm{Lae.} \mathrm{Ka}$ 'u people traveling to Puna would cast leis tied with loincloths and pandanus clusters into the sea at Puna. When the leis drifted back to Kamilo the Ka'u people knew that the travelers had reached Puna (Pukui, p. 81-82).

Kamiloholu ("the swaying milo tree") is a land division in Puna (Pukui, 82).

Keahole ("the ahole fish") is a land section in Puna (Pukui, p. 100).

Keau ("the current") is a land section and coastal area (Pukui, p. 104).

Keauhou ("the new era or the new current") is a land section in Puna and the site of an ancient village which was washed away in the 1868 tsunami (Pukui, 104).

$\mathrm{Ki}^{\prime} \mathbf{i}$ ("image") is an area in Puna (Pukui, p. 110).

Kiki is a land area near Koa'e in Puna and is named for the kiki bird that nested together with the koa'e bird. The kiki bird faced the area known as Koa'e and the kiki bird faced the Kiki area. According to legend, both birds stole wild taro and were subsequently destroyed by the demigod Pikoiaka'alala (Pukui, p. 110).

Kipuka-papalina-moku ("cut-cheek kipuka") is a kipuka (an opening in the forest or a clear place or oasis within a lava bed where there may be vegetation) in Puna (Pukui, 113).

Ko'oko'olau is a land section in Puna named for the plant used by Hawaiians for tea (Pukui, p. 117).

Lelekawa ("jump from a high place into the water") is a sea arch in Puna (Pukui, p. 131).

MacKenzie State Park was established in Puna in 1934 and named for Albert J. MacKenzie, a forest ranger (Pukui, p. 137).

Maka'ukiu is a point in Puna (Pukui, p. 142).

Napali ("the cliffs") is an overlook at Holei Pali. It was covered by lava in the 1968+ eruption (Pukui, p. 163). 
Napua ("the endings") is a pit crater which erupted in 1963 and 1965 as well as a trail in Puna.

Napu'ukulua ("hills standing in twos") is the name of lava flows and hills:

Naulu ("the groves") is a forest area cut off from the road and partially destroyed by the 1972 flow in Puna (Pukui, p. 164).

Oloua ("sounding rain or rainy hill") is a cave in Puna where fishermen found shelter (Pukui, p. 170).

Pauahi ("destroyed by fire") is a pit crater in Puna (Pukui, p. 181).

Pi 'ikea ("to become light, as the day") is a gulch in Puna (Pukui, p. 184).

Pilau ("stench") is a $2158 \mathrm{ft}$. hill in Puna (Pukui, p. 184).

Poliokeawe ("bosom of Keawe") is a cliff in Puna (Pukui, p. 188).

Pua'i'alua ("to flow out twice") is a crater in Puna (Pukui, p. 191).

Pula'a in Puna was known for its movable mounds of sweet potatoes: Na pu'e 'uwala ho'ouwai. It was the custom here to remove the best mounds of sweet potato, earth and all, and place them on wide strips of thick, coarse lauhala mats stretched out on racks. When a chief came for a visit, these mats were then placed on the right-hand side of the road and made kapu. Should the chief return, the mat-grown potato fields were carried to the opposite side of the road so that it would still be on the right side of the traveling chief. See "Olelo No“eau \#2290.

At the sea in Puna are two stones which were made thus by Pele who was once annoyed with Mali'o and her brother Halaaniani. It was at the bay named after Halaaniani that clusters of pandanus were tossed into the sea with tokens to loved ones. These tokens were then borne by the current to Kamilo in $\mathrm{Ka}^{\prime} \mathrm{u}$. Mali'o is a mythical woman of Puna whom Pele once snubbed, thus the saying, "A'ohe "alawa wale iho ia Mali'o ("not even a glance at Mali'o") which is said of a haughty person. 'Olelo No'eau \#127.

Pu'u'eo is a pali in Puna (Pukui, p. 196).

Pu'uholei and Pu'uhuluhulu (3,440 ft.) are both hills in Puna (Pukui, p. 196-197).

Pu'ula is a Congregational church and village near Koa'e. In the early days a church service was announced by a red conch shell (pu 'ula). When a bell was obtained, the conch was buried and a funeral held for it. Later the conch was stolen. Pele's first landing in Puna was at Keawaopele near here. From here she went to Keahialaka and Pohoiki where she dug craters.

Waiaka "ea ("water used by the turtle") is a pond and land division in Puna (Pukui, p. 219).

Waiko"olihilihi ("water supporting eyelashes") is a pool at Puna. Lehua flowers were fastened on reeds here in honor of visiting chiefs so that when they kneeled to drink, the 
blossoms touched their eyelashes. The last royal person to visit here was Keohokalole, the mother of Kalakaua and Lili'uokalani (Pukui, p. 224). See 'Olelo No'eau \#255.

Note:

This appendix presents information about the Puna District that was gathered in the course of the literature search. The information is categorized according to "natural features", "other features", "legendary and historical figures and events", and "Hawaiian proverbs" for the Puna district as a whole, and then by ahupua'a (where information is available). The trans lation of the place name is provided in the parenthesis under the ahupua'a name. There are many place names and people mentions in the accumulated literature of Hawai' $i$ that are said to be part of, or are identified with the district of Puna, island of Hawai' $\mathbf{i}$, but for which the exact location of the place or event has been lost. In many cases, the places have been given "foreign" names-the "foreign" names Hawaiianized, or the original name shortened or otherwise changed over time. Whatever the reason, the Hawaiian name of that place no longer exists, and gone with it is the meaning or significance once attached to the place. Many important names are so ancient that no translation at all is possible.

Mary Kawena Pukui, a noted scholar of Hawaiian culture and language, stated that Hawaiians named everything: taro loi, rock and trees that represented deities and ancestors, sites of houses and heiau, canoes, adzes, drums, canoe landings, fishing stations in the sea, resting places in the forest, and even the tiniest spots where miraculous or interesting events are believed to have taken place (Place Names in Hawai' $i$ by Pukui, p. $x$ ).

Added to this practice of naming is the fondness of Hawaiians for proverbial sayings and hidden meaning or kaona-a concealed reference to a person, thing, or place: words with double meanings that might bring good or bad fortune. Thus sayings that incorporate place names are not just referring to that particular place but are also describing an emotional state or important event, as well as love for the land and sea (the source of life) and the people of the land whose job it was to take care of and respect and that of the Euro-Americans and is the reason why the Hawaiian name of a particular place is so important (Place Names of Hawaii, p. 235-280). 


\section{APPENDIX D \\ COMPILATION OF INFORMATION FOR SOUTHEAST MAUI DISTRICT HONOLUA'ULA LAND SECTION}

\section{NATURAL FEATURES}

\section{Volcanic Cones}

Several volcanic cones or hills are in the area. They represent the powerful activity of Goddess of the volcano, their caves are the dwelling places of mythical beings, or are used as burial. On top of some of them there are observation and religious sites. The pu'u are also important landmarks for locating fishing grounds at sea (Ashdown, 1969-1977):

- Kaumahina over 1,000 years old.

- Keonehunehune (land may be impoverished but always will persist if treated well and loved.

- Ke'eke "ehia Hill (follow the pathway of life and entrust to a fair judgment at death).

- Pu'u 'To.

- Púu Kalualapa.

- Pu'u Kanahau.

- Pu'u Kanaloa, the god of healing, a chief of long ago.

- Pu'u Keonehuna, is about 700 year old.

- Púu Lalani was made by Pele.

- Pu'u Lua Palani 300 years old.

- Pu'u Mahoe.

- Pu'u Makua is about 600 year old.

- Pu'u Naio about 300 years old.

- Pu'ui o Kali.

- Púu Ola'i.

- Pu'u Pimoe 200 years old, where Pele went inland to sleep. A burial place.

- Pu'uKaco.

The dates of the $P u^{\prime} \mathrm{u}$ and lava flows are significant because they may represent different geological ages of hills. These hills were used by Hawaiians as landmarks, temples, observation points and burial grounds. The lava flows delineate areas of possible coverage and destruction of Hawaiian settlements and utilization by Hawaiians of lava land for many purposes including dwellings and cultivation (in the lava holes).

\section{Fishing, Fishponds, and Fishing Grounds}

The area is plentiful of near shore fishing, sharks and mermaids dwell in caves, there are good fishing trails, fishponds, and there are ko'a to mark good fishing grounds (Ashdown, 1969-1977; HENI 199-200): 
- The Ahole fish had to do with magic, such as Hana aloha (love work), or causing people to love each other.

- The Kumu fish frequent the sacred loko (fishponds) at Keone'o'io.

- The $A^{\prime} u$ (Swordfish) the 'Ahi (Tuna), the ulua and its young papio (Jackfish family) are closely associated with the Kingdom of Maui.

- The Makena Bay which should be called Keawala'i, the Calm Harbor, is a fine fishing place. Ku-Makena, like $\mathrm{Ku}-\mathrm{He}^{\prime} \mathrm{eia}$, is a place where fish run in schools $k e-$ he' $e$, or ke-hei.

- The Mermaid favorite haunts is Keone'oi'o and the sacred fishponds there on Lae Kina'u.

- Ku-Makena and 'Ahihi bays, each had a fishpond. Keone'oi'o had a huge one. Here the 'Ama'ama, Awa, and 'Oi'o are found in large numbers. At certain times the spirits of the dead chiefs are heard, and often seen, at certain places. This procession is called as 'oi' $O$ or as huaka'i-po, the Marches of the Night. The two main ponds are named Halua and Kauhioaiakini and here dwell the mermaids and the benign sharks, such as Kamo'oali'i and Kaneikokala, their spirit mates of the sea.

- Hana-huapala is a shark who can come ashore as a handsome man. He lives in the Ana Mano or Shark cave beneath Pu'u Ola'i. One of the spirits in the area is Inaina and her sweetheart was 'Ilolo. Her form is a certain white eel with yellow spots. This white eel has also the name of Puhi Kina'u on Lae Kina'u. This was in 1100s or the era when Kauholanuimahu dwelt in Honua'ula with his mother, La'akapu.

- Kaneikokala is a benign shark or 'aumakua as also Wewehe, his sister Mermaid, who frequent Wailea.

- Pahua are the fishing grounds out in the sea at Kanaio. Its upper markers are Laeloa and Holu point. Puwai cave is the lower mark.

- Hui is a fishing ground and on the seaward side is the islet Molokini, which is the first landmark. The other mark is red hill, Pu'u Okali which appears to be the point on the Western side of Molokini. That would be Lae Lalelale, while the opposite point is of the islet of Kahaki.

- The two ko' $a$ at Kanahena show the good fishing grounds of Molokini and toward Canape Bay of Kaho'olawe.

- The Ko'a atop Pu'u Ola'i for Maka Kilo i'a and its mates along the coastline indicates fishing areas between Maui, Molokini, and Kaho'olawe.

- Keahua is a fishing ground. Nihomole sands are the upper mark lined up with Pahe'eo-Lono at East Molokini. Pohaku-olo near to Kauke Point at Kohe-o-Hala, the blowhole is the lower mark.

- Kalawa is a fishing ground. Nihomole sands lined up with Pahe'e-o-Lono at East Molokini is the upper mark. Kalawa point, Kala hills and Kaule are the lower mark.

- Pohakulula is a fishing ground. The stone by that name is the upper mark with Molokini and Pahe'e-o-Lono. Kala Hills and Kaule Point is the lower mark.

- At the base of Pu'u Ola' $i$ on the land side there are two ponds. One is a salt pond, or makapa pipi, where pa'akai (salt) was gathered. The pa'akai of this pond was valuable because it contained lepo alae (the ocherous red earth full of iron).

- Two fishing grounds are at Kanaio and Papaka-kai. 


\section{Caves}

Sea caves are the dwelling places of sea gods and guardian spirits. Dry caves are family burial places, underground sheltered trails, ancient hiding places in case of war, or meeting places. The following caves (ana) are noted in the area:

- Ke Ana Mano, the shark cave, is under Pu'u Ola' $i$ in Keawala ' $i$ in Makena, where the guardian spirit shark dwells.

- One Cave is under Lae Mahuna where the guardian spirit shark dwells.

- Kalua 'Opala is below Pu'u Naio in the 'Ili of Kalihi, mauka of Keone"o'io.

- Kalua Papaka is in upper Kanaio, Papaka area. Once one could reach "Ahihi Bay from here.

- Ke-ana-wa'a burial cave is below Kanaio; it is a canoe cave.

- Alala-keiki is the Weeping Child cave where children and older people were hidden when the Maui defenders met in canoes in the channel, between Maui and Kaho olawe the invading army from the Hawai'i (Ashdown, 1969-1977).

- Ala-lo'ihi is a lava tube below Pamano at Kanaio which was used as a school to teach students fishing, planting etc. in early 1900 . The teacher at this school in the cave was Kauwa and Sam Po briefly attended this school as a child, but was expelled for not following its strict rules. This cave connects at Ala-lo'ihi with Ala poepoe cave where the bodies of those fallen in battle where thrown in the old days (Po in EPS, 1968:13).

Winds, Rains, and Springs

The followings are winds, streams and springs are known in the area:

- Kowelo'e'a, dust streamers blowing from Kaho'olawe.

- Ualanipili rain makes cloudburst in Honua ula.

- Ualanipili rain of Ulupalakua.

- Naulu is a sudden shower.

- Papa is a wind associated with Honua ula (Pukui \& Elbert, 1986: 316).

- Poiki is the black dog of Pele associated with Wai-a-ka-'llio Springs.

\section{OTHER FEATURES}

\section{Temples and Other Structures}

In the area there are many heiau and little altars of stones where people prayed to Lono and to Hina for rain and ample crops. Other temple include many fishing shrines $\left(k 0^{\prime} a\right)$, a hula platform (halau) and a place of refuge (pu'uhonua), etc::

- Pohakunahaha Heiau is a small well preserved walled structure at Makena.

- The heiau called Onipa'a or Onepa'a provided King Kamehameha V and Queen Liliu'okalani with the motto "Firmly Established." It is located upon land presently owned by Seibu Corp., mauka of the Pu'u Ola'i Gate by Ulupalakua Ranch. The other part of the heiau called Oniuli or Oneuli, or Oneuliuli, is on Sam Garcia's land, Makena side. It was a school for kahuna (priests). There was the halau where 
students of hula performed for the ali' $i$ and ali' $i$-nui during the ho'ao marriage ceremony and during the makahiki (new year), when games where enjoyed there.

- Heiau Papakea a large shrine to Ku'ula-kai and other fishing deities stood at Pu'u Ola $i$ in Makena.

- Oneuliuli and Onepa'a Heiau at Makena and the fishponds Maonakala village were sacred to Queen La'akapu and her son, Kauholanuimahu.

- Ko'a and shrine on top of Pu'u Ola'i.

- Kalani Heiau is a large temple on David Chang's property in Makena

- Popoki Heiau is nearby; the cemetery of Kukahiko family.

- Heiau at Luala ilua looking North.

- Ko'ula Heiau in a good size high platform in Kanahena.

- The Heiau Ko'ula at Kanahena was said to be a ho'oulu'ai, or place where offerings were placed while prayers were said for blessing of plentiful food.

- Below to the Northward is a large ko $a$ by the sea said to be a place for deification of souls of beloved dead. The corpse would be wrapped in a covering with a family pattern on it. and the body was placed in the sea. When a shark having similar marking to the cloth pattern appeared, the people knew that the dead one's soul would be a sharkbody 'aumakua or guardian spirit who would help family members at sea.

- Heiau at Kalihi near Keone'o'io.

- Kauholamahu, son of Kahoukapu and La'akapu of the Maui ali $i$ with the Burning $K a p u$ of the Sun, came to Honua'ula from Hawai'i. He built the Oneuli Heiau mauka of Keawalai Church in Makena and his sacred fishpond at Keone'o'io.

- One of the larger heiau structures is at Make'e near Ulupalakua Ranch, where children were taught the arts of good living and industry, until King Kalani 'opu'u invaded the area from Hawai' $i$.

- Pu'u Naio Heiau is at Papakuka or upper Papaka above Keone'o'io, the sand or land of the ghost of a departed chief and his companions; it is located above La Perouse Bay.

- There is one pa heiau and kahua (an arena or a slide) and the Nahawale village sites and the water spring called Waipe'epoli.

- There is a fishing shrine, sacred $k 0^{\prime} a$, at Keone'o'io, known today as La Perouse Bay, and the four sacred pools above the undersea cave, near Pu'u Kanaloa. Kamohoali' $i$, shark brother of Pele and 'aumakua of the Yoshikawa and Po families used to be fed here.

- Papa Pueo, the Owl Flat by Pu'u Ke'eke'ehia held the Hale Pueo, now Mausoleum Hill. The Hale Pueo was a place to pray for enlightenment and for the souls of the dead. Ke'eke'ehia was the pu'uhonua, or place of refuge for this area of Honua'ula. The Pueo-kahi and Pueo-nui-akea are two names for the akua, or God. Pueo is symbolic of Wisdom and the whole universe, light and enlightenment. It is an 'aumakua or ancestral guardian spirit (Ashdown, 1970).

- Nahaleloulua Kane Heiau was dedicated to Kane and built in remote antiquity.

- Kaaiea Heiau was built in remote antiquity to multiplying and producing food.

- Pa'alua Heiau is a good sized L shaped enclosure in Kalihi. Pa'alua Heiau is in the land division, or 'Ili of Kalihi in Honua'ula, above La Perouse Bay. It was for rain. Below was a $k o^{\prime} a$ or Maka-kilo-i'a, or both.

- Kaulena is the name of the ko' $a$ near Keone 'o'io.

- Heiau near the shore at Keawanaku in Kaloi. Probably a ku'ula. 
- Kahemanini Heiau was built in remote antiquity to multiplying fish.

- Kuahuka is a small heiau at Kaunukeaha in Kanaio at $\mathbf{2 7 0 0}$ feet.

- Kohala Heiau is a rough platform South of the Kula Pipe in Kanaio.

- Manonokohala Heiau is a platform at Puki in Kanaio East of the Honua'ula Congregational Church.

- Manoka'ahia Heiau is at Puki, west of the Church at Kanaio.

- Papanuiokane Heiau at Hulapapa is above the upper Kanaio Trail.

- Heiau at $\mathrm{Kj}$ 'ipuna, Ninaulua Nui in Kanaio is makai of the trail between Wai-a-'ilio and Wahene. It is a large platform (Ashdown, 1969-1977).

\section{Ancient Villages and Sites}

There are a number of Hawaiian villages from 'Ulupalakua to Kanaio:

- At the Nahawale village there was a tapa making platform, a temple and the halau for canoe finishing and launching. The cold water well there is called Waipe'epoli.

- The Nahawale village and the sacred coconut grove is nearby Pu'u Ola' $i$.

- Maonakala village was near Keone'o'io, now La Perouse Bay.

- Waile'a village was to the north.

- Kanaio village had pili or pili-grass thatched homes still in 1925 . It was partially de stroyed by the 1736 lava flow at the time of the birth of Kamehameha. The village once went down to Na'upaka beach by $\mathrm{Pu}^{\prime} \mathrm{u}$ Ola' $\mathrm{i}$ and was called there Nahawale Village. There are Hawaiians living in Kanaio now and more Hawaiians plan to settle there on family lands.

\section{LEGENDARY AND HISTORICAL FIGURES AND EVENTS}

- There is a East Maui version of the birth of Maui, finding of fire, fishing up the islands, and snaring the sun. It involves places in Hana, Kipahulu, Pimoe and Haleakala (Beckwith, 1940: 229-330).

- 'Ai'ai, son of Kuulakai, the fishing god, traveled about the island establishing ko'a (fishing stations) at ko' $a$ aina (fishing grounds) and setting up kuula (altars). Many of them are at Honua'ula (Beckwith, 1940: 18).

- Kalani'opu third invasion of Maui took place at Honua'ula. He ravaged it from Keone'o'io to Makena (Walker, 1931:28).

- Kanaloa could not make his figures of the first man and woman come to life using the Honua'ula earth, while Kane was able to do so.

- La'akapu of Honua'ula married Kahoukapu chief of Hawai' $i$ in the 12th century A.D. She gave her Houa'ula land to his beloved son who ruled from Makena to Nu'u. He built the temple in Makena.

- Honua'ula was the residence of Queen Kalola, a daughter of King Kekakulike, who ruled Muai until 1736. She was the last Ali' $i$ to pronounce the kapu of the burning sun.

- In Honua'ula, King Kahekili gave permission to a chief named Ku-keawe to run pigs in the uplands. See 'Olelo No'eau \# 88 for the proverb derived from this story (Ashdown, 1969-1977).

- The Chief Aikanaka (Man-eater) was born in the Hana district died at Honua'ula. He was a good man. His wife is Hina (fed on the Moon), who escaped on the moon 
because her children made too much excrement, which was difficult to dispose of it according to the kapu. There are various versions of this legend including some from the South Pacific. (Beckwith, 1940).

\section{CHANTS AND SONGS}

Honua'ula, pitted back,

Hills of Doubly peaceful

A greeting

For my famous land,

For scaling squid suction cups,

Gusty mists.

The rain hiding [behind] stone walls,

Distinguished by tapoo fish,

Famous stones,

Auwahi hot in the sun.

O Bays of Pi'ilani

In the Valley shade.

O rain that stings the skin

And the rain and Kili'o'opu wind.

You block Ka'uiki,

Streams mingling with seas

In the Lowlying rain

And windward cliffs.

(David Kapohakimohewa in Pukui, Helbert and Mookini, 1974: 276-277)

\section{HA WAIIAN PROVERBS}

'Olelo No'eau \# 88: 'Ai pua'a a Kukeawe.

The pork eating of Kukeawe. Said of a person who is not satisfied with the number of his own pigs and so he robs his neighbors of their. (See the story of Kekeawe).

'Olelo No'eau \# 1058: Honua'ula, e paluku 'ia ana na kihi po'ohiwi e na 'ale o ka Moa'e.

Honua 'ula whose shoulders are pummeled by the Moa' wind. Honua 'ula is a windy place.

'Olelo No'eau \# 1059: Honua'ula kua La'ola'o.

Callous-backed Honua'ula. Said of the people of Honua'ula, who were hard workers and carried loads on their back.

'Olelo No'eau \# 1579: Ka ua Lanipa'ina o 'Ulupalakua.

The sky-crackling rain of 'Ulupalakua.

'Olelo No'eau \# 2094: Makali'i puainawele ke kai o Keone'o'io.

The sea of Keone'o'io is dim and distant. Said of one who fees himself too good for his associates. 
'Olelo No'eau \# 1817: Kohu 'ole kahi wai o Kanaio.

Unattractive is the water of Kanaio. A contemptuous expression meaning that another person has said or done something worthless.

Table D1. Place names Honua'ula: Red Land, Sacred Land

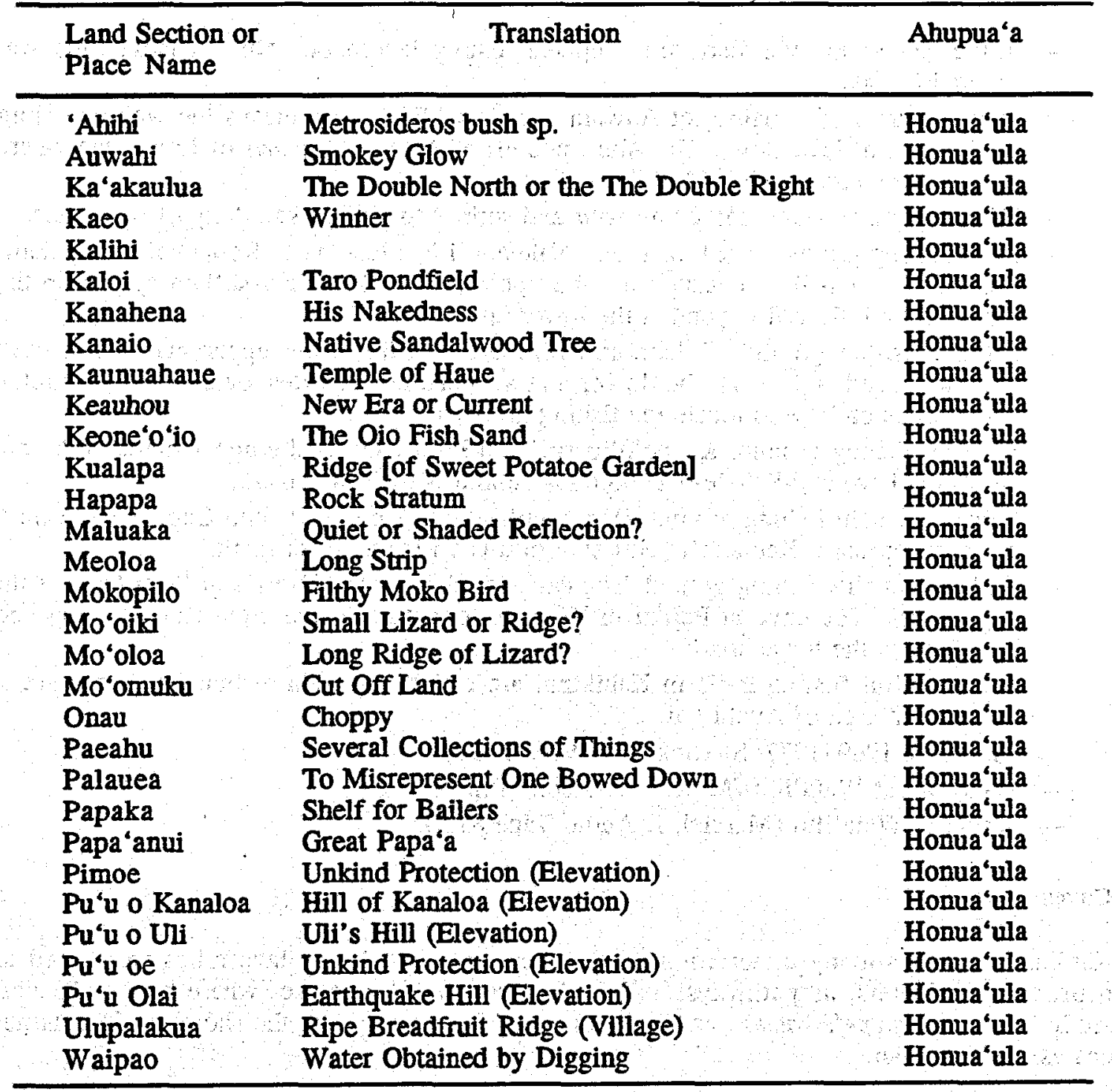

Source: (Walker, 1931: 27-36; Pukui, Elbert, and Mookini, 1974; Pukui, Elbert, 1986)

\section{KAHIKINUI LAND SECTION NATURAL FEATURES}

Fishing, Fishponds, and Fishing Grounds

The ocean along the shoreline has abundant marine life and is a source of sustenance for many people. The fresh water seeping into the ocean at the shoreline produces a large array 
of sea life. The gods Kane and Kanaloa went about the islands to establish springs of fresh water, and to keep them clear for drinking and for the chiefs. These gods open the fishpond Kanaloa at Luala'ilua (Beckwith, 1970). The first akua made the a fishpond for spawning fish, at Luala'ilua-kai into which flowed the Waiokou stream from Kaupo side where the ignorant priest Koino was destroyed because he desecrated the pure waters and had bad manners.

- In the Kahikinui side there are deep-sea fishing landmarks. One in Honua'ula was covered by lava.

- The Ahupua'a of A'uahi (not Auwahi as it is spelled now), means the white swirling smoky mist of lava flows. The Ahu (mound) of Aiea was mauka of Luala'ilua where the boundary crossed the old alaloa (road).

- Fishing grounds were marked by $k o^{\prime} a$ and shrines to Ku'ula-kai, deity of fishermen.

- Kiele fishing ground is at Luala 'ilua. Kalenawai is a landmark. Koukouai at Kipahulu and Ka-lae-o-ka-'ilio at Kaupo are the upper landmarks. Wa'a-ke'kua spring on the beach and a little hill beyond is the lower landmark.

- Palua'a fishing ground. Kalena and Ka-lae-o-ka-'ilio is the upper mark. The cave Puhimake and a hill is the lower mark Sterling provides detailed topographic descriptions on how to locate the fishing grounds.

- Ko'ahau fishing ground. Keone'o'io Hill and Pu'u Ola'i is the upper mark. Kaka hill on Kaho'olawe and Pahe'e-o-Lono on Molokini is the lower mark.

- NaiaaKamahalu fishing ground. Hoaka upland on Kaho'olawe and Cape Kealaikahiki is the upper mark. Keone'o'io Hill and Pu'u Ola' $i$ is the lower mark.

- Nai'a-a-kamali'i fishing ground. The cave on Makena and Paopoa at Pu'u Ola'i is the upper mark. The cave at Paliku in Keone'o'io with the two stones at Mokuha and Kanahena is the lower mark.

- The beautiful fishing trails in Kahikinui are called maka'ala or makala. Some are at Anamauloa area of Auahi-kai (Ashdown 1969-1977; Sterling HEN Vol. I: 199).

- Make salt at Waia'ilio (Marciel, J. Audio Tape 87.5).

- Spring at Waia'ilio (Marciel, J. Audio Tape 87.5).

\section{Caves}

Kahikinui contains many underground lava tubes, or caves. Many lava tubes were used as pathways, as shelters, as pathways, as burial places, awaloa, places where bones of chiefs are hidden; and ana pe 'e kaua, war hiding caves". Many caves near the shore are in continuous use in Kahikinui.

- Many large caves near Hanamauuloa village at the shore below Luala'ilua Hills were used for shelter in ancient times and now by fishermen.

- Many small caves at Kamoamoa used as shelter or storage places, and at the shore there is a large cave with sign of ancient occupation and current use by hunters and fishermen (Walker 1931: 88).

Burials in inaccessible sea cliffs were described to Walker in the 1930s. 
Winds, Rains, and Springs

The Wai-a-'Dio fresh water spring, is located near the Uliuli village. This is the spring named in the legend of the of the old woman and the little dog previously mentioned (Walker, 1931).

In one or two places along the Kahikinui shore, small rivulets had been dammed to impound some of the water which came down with the freshet. (Walker, 1931).

\section{OTHER FEATURES}

\section{Temples and Other Structures}

In Kahikinui there are heiau and many little altars built of stone where people prayed to Lono and to Hina for rain and ample crops. Many of these remain.

- Kahuahakamoa is a heiau. Kahua is course, or arena; hakamoa is a type of wrestling without the use of the hands. In another version Hakamoa is the constellation of "Chicken Roost." This heiau was just makai of Luala'ilua. Another theory was that it was a temple for Kilo (star gazer) to study the heavens. Others say that it is the temple where the mango trees stand. Ashdown thinks that it is associated with Moa'ula on Kaho'olawe since the latter also was a place for Kilo Hoke or the kahuna of astronomy and navigation. Kuamoanaha taught on 'Aina Kanaloa (now Kaho'olawe) and that isle is associated with the two Kanaloa on Maui at Keone ' 0 'io and Auahi at the coast (present point of division between Makawao and Hana district in Honua' ula. Kahuahalamoa Heiau is a walled enclosure of large size and here ceremonies of marriage etc. were held. Nearby was the arena where wrestling and other games for the Makahiki were enjoyed by the populace. This temple was also for planting ceremonies on the Night of Hua. Makai, down the slope of Luala ilua was the He'e Holua or the largest holua slide, and above it was another temple. The kahua or track for playing the game with the "ulu stone or game of 'ulu maika is mentioned in the Ashdown's notes for this area.

- The Heiau Make'e Kanawai, law abiding and zealous, is located in lower Auahi, Kahikinui side.

- Unnamed heiau is West of Luala ilua Hills near the beach trail at Auwahi.

- The heiau at Koholuapapa is located northwest of Luala ilua Hills. It is a large walled structure.

- Puoho-ka-Moa Heiau is near Saint Ynez Church. It means blaze up, to lift up or to bloom and ka meaning the, and Moa the Cock of dawn. Or puoho, to be awaked by the god, sun. Here boxing and wresting games were held and warriors were "fighting cocks". The place apparently was dedicated to Lonomakaihe as the god of warriors. It was bulldozed.

- Hakalauai heiau was a temple for multiplying plant food in the Lapueo ahupua'a. Uluao Keakakilohi was the chief who built it and Mana was the priest.

- Kaooa was the ancient heiau for human sacrifices in the Alena Ahupua'a.

- Momoku was the heiau at Luala'ilua Ahupua'a built by the Menehune at Kapapaiki.

- From above the present road and down to the beach are trails ala hele or paved trails to fishing grounds, or kai lawai' $a$ and several $k^{\prime}{ }^{\prime} a$ for $\mathrm{Ku}$ 'ula to indicate the deep fishing grounds.

- There are petroglyphs are in Kahikinui at Pahihi Gulch. 
- Rock circles of possible astronomical use similar to those on Kaho'olawe are located near Science City at the crater summit and below Luala'ilua Hill in Kahikinui (Ashdown 1969-1977; Hms K8, Oct.13, 1885 HEN: 374).

\section{Ancient Villages and Sites}

The villages, whose ruins are now easily seen, date back to the time of Pi'ilani in the 1500 s. The Kahikinui villages were quite numerous and indicated extensive population where now none live. Walker estimated a population of 1500 or 1800 based on a count of sites in the South Coast of Kahikinui. Burial platforms of rough stone are common features of the villages along the shore including individual and family burial (Walker 1931: 66, 67, 68, 86). The entire Kahikinui region is dotted with structures, house foundations, stone walls, animal pens and so on. The population count inclusive of the mauka villages would be then higher than quoted.

- Make'e is the site of a larger village with 11 large dwelling sites and one heiau.

- Above and below Pu'u Luala'ilua stood a huge village which was destroyed in part before Pele left Maui for Hawai'i.

- The largest village Hanamauuloa is the one situated below Luala'ilua Hills near Kiakeana Point. It contains 80 sites.

- Wai-a-"Tlio is the village at the foot trail at Luala'ilua with 27 sites of which 15 house sites, pens, canoe-sheds, and other enclosures. A stone house with grass roof still in place in the 1930 s. Other villages are near the heiau sites.

- West of Waiailio there are 5 house sites.

- North of Luala'ilua Hills near the trail is a small villages with 5 houses and a small heiau.

- Between Hanamauuloa and Alena there are 30 sites.

- Between Kipapa and Alena there are 30 sites scattered in the ' $a$ ' $a$ lava flow. A possible small heiau and $k o^{\prime} a$ are there.

- At Papaula there are 14 sites on the ridge.

- At Waiapea there are 10 sites on the extensive ' $a$ ' $a$ lava flow.

- The Kahikinui village, like all those situated from Ulupalakua and Makena to $\mathrm{Nu}^{\prime} \mathrm{u}$ and Wai' $u$ on the present road to Kaupo, thrived. It is located at Nakahohu.

- West of Nakahaka is the village of Ka-Lae-o-Ka-Pulou with 18 sites of which 11 are house sites. It also includes a heiau and $k 0^{\prime} a$ shrine.

- Old villages with 36 sites of which 17 house sites are along the shore in the Nakahaka region.

- The Uliuli village is located near Kahawaipapa Point. 21 sites include 11 house sites. and a well-built $k 0^{\prime} a$. (It is also the site of the old windmill).

- Kamoamoa is a village with 20 sites, with a large heiau, a possible kahuna house, and 8 house sites.

- At Kalaniana in Mahamenui, just below Palaha Gulch on the shore trail, is an ancient village of 21 sites with fishing shelters, 15 house-sites, a heiau, a possible $k o^{\prime} a$ shrine, pens and burial platforms.

- At the mouth of Manawainui Gulch is located a fishing village with two large sites, several small shelter sites, a canoe-shed, a large $k o^{\prime} a$, and a burial platform

(Walker, 1931). 


\section{LEGENDARY AND HISTORICAL FIGURES AND EVENTS}

- Moikeha of Tahiti-Named Kahikinui or Great Tahiti in honor of his homeland (Marciel, J.' Audio Tape 87.5).

- Moikeha, son of Mulieleali' $i$, son of Maweke of Tahiti. Moikeha retire to Kahiki (Beckwith 1940: 352-353).

- La'a settles at Kahikinui on Maui but, finding its too windy, moves to Kaho'olawe, whence sails back to Kahiki. La'amaikahiki introduces image worship and he is most famous as the bringer of the kaeke drum and the hulka dance to Hawai' $i$ (Beckwith 1940: 358-359).

- Tahitinui, a grandchild of $\mathbf{K i}$, from Tahiti, lands at Kaho'olawe and settles East Maui, hence the name Kahikinui for a district on Maui. Thus the descendants of Ki and Hawai'iloa people the whole group (Beckwith 1940: 363-366). The name of Hawai'iloa is associated with sites at Kahikinui.

- Makali'i (the Eye of the chief) is the navigator of Hawai'iloa. During the Makahiki ceremony the scattering of edible plants, to decide the food supply for the coming year, is done using the net of Makali'i. His knowledge of the stars, made him the regulator of successful planting seasons (Beckwith 1940: 367).

- Anianikalani is the father of Hawai'iloa, the ancestors of the Hawaiian peoples. Places in Kahikinui are reported to be associated with Anianikalani.

\section{CHANTS AND SONGS}

There is a mele hoipoipo (love song) about Kahikinui for the Hula Ka'eke'eke, or the hula for the kneeling position, celebrating a woman lover looking from Kahikinui on Maui across the channel to Kona on the Big island, which represents her beloved:

Kahikinui, land of wind driven smoke!

Mine eyes gaze with longing on Kona;

A firewreath glows aback of the district, And a robe of wonderful green

Lies the sea that has aproned my loins

Off the point of Hanamaolo"

A dark burnished form is Hawai' $i$,

To one who stands on the mount

A hamper swung down from heaven,

A beautiful carved shape is the islands

Thy mountains, thy splendor of herbage:

Maunakea and Loa stand (in glory) apart.

To him who looks from Mailehahei;

And Kilohana pillows for rest

On the shoulder of Hu' ${ }^{\prime}$ ehu'e. (Emerson, 1965: 124-125.)

Recently a Hula Halau enacted hula dances using the Kahikinui Chant and have been filmed by an European video crew on site at Kanaio. 


\section{HA WAIIAN PROVERBS}

'Olelo No'eau \# 88: $\quad$ 'Ai pua'a a Kukeawe.

The pork eating of Kukeawe. Said of a person who is not satisfied with the number of his own pigs and so he robs his neighbors of their. (See the story of Kekeawe).

'Olelo No'eau \# 2866: Uliuli kai pali o Kahikinui, kokolo mai ka 'ohu he 'ino.

Dark are the sea cliffs of Kahikinui; when the mist creep, it is a sign of a storm. Trouble is approaching, from the legend of Pamano who saw his own dead approaching.

Table D2. Place names-Kahikinui: Great Tahiti

\begin{tabular}{|c|c|c|}
\hline $\begin{array}{l}\text { Land Section or } \\
\text { Place Name }\end{array}$ & Translation & Ahupua'a \\
\hline Alena & Boerhaavia repens weed? & Kahikinui \\
\hline Auwahi & Smoldering Fire & Kahikinui \\
\hline Huakini & & Kahikinui \\
\hline Kahaleaimakani & The Windy House & Kahikinui \\
\hline Kahalulu & Peaceful Place? & Kahikinui \\
\hline Kahawaihapapa & Shallow Aqueduct & Kahikinui \\
\hline Kaipapa & Shoal (Section)? & Kahikinui \\
\hline Kaipapa & Shoal Reef & Kahikinui \\
\hline Kamole & The Main Root & Kahikinui \\
\hline Kamuku & Cut Short & Kahikinui \\
\hline $\mathbf{K a}$ & To Overthrow & Kahikinui \\
\hline Kepuni & & Kahikinui \\
\hline Kolanai & & Kahikinui \\
\hline Lanipo & Darkened Heavens & Kahikinui \\
\hline Louluape & Fan Palm Plant & Kahikinui \\
\hline Luala'ilua & Two Fold Tranquillity (Hills) & Kahikinui \\
\hline Mahamenui & Large Mehame Tree & Kahikinui \\
\hline Makamoku & District Observer & Kahikinui \\
\hline Makee & & Kahikinui \\
\hline Mamuku & Cut Short & Kahikinui \\
\hline Manawainui & Large Water Branch & Kahikinui \\
\hline Manukani & Bird Sound? & Kahikinui \\
\hline Naioli'ili' $\mathbf{i}$ & Small bastard Sandalwood & Kahikinui \\
\hline Nakaohu & Trembling Mist & Kahikinui \\
\hline Naka'aha & Quivering Prayer? & Kahikinui \\
\hline Nakukuikea & White Kukui Tree & Kahikinui \\
\hline Nakula & Uplands & Kahikinui \\
\hline Navini? & & Kahikinui \\
\hline Ninialii & Balm of Ali' $i$ & Kahikinui \\
\hline Pakowai & & Kahikinui \\
\hline Pohaku Eaea & Spray Rock (Point) & Kahikinui \\
\hline Polala & Warming Night & Kahikinui \\
\hline Polo‘ai & To Summon & Kahikinui \\
\hline Popoo & & Kahikinui \\
\hline
\end{tabular}


Table D2 (Continued)

\begin{tabular}{lll}
\hline Pukai & Parading Trumpet & Kahikinui \\
Pu'u Pane & Answering Hill? & Kahikinui \\
Wailaulau & Very Many Waters? & Kahikinui \\
Waiopai & Trembling Water & Kahikinui \\
\hline
\end{tabular}

Source: Walker, 1931: 27-36; Pukui, Elbert, and Mookini, 1974; Pukui, Elbert, 1986.

\section{KAUPO LAND SECTION}

\section{NATURAL FEATURES}

\section{Fishing, Fishing Grounds}

- There is a deep sea at Kaupo and no fishing grounds (Sterling, 1966: 3/ 3.13)

- Paiena Fishing Grounds, "Waiopai is the fishing ground, extending from the hollow where the breadfruit trees grow at pu'u Kaaahuahu down to the point at Kalaniwahine. That is the ground. It is 120 fathoms deep" (Hms. K. 8. HEN Vol. 1 :405 in Sterling, 1966: 8/9.7).

- Manowaiopae-about 50 feet from the shore and the canoe landing is a small pool for Opae (Manupau 1992-1993: 17).

- People of Kaupo gathered Hihiwai, 'Opihi, and Sea urchins (Ha'ue'ue) (Marciel, J. Audio Tape 87.5).

- "All take a turn at fishing at times and the toothsome aweoweo is so abundant hereabouts that it helps out the commissary problem materially during the moonlight season."

(Hawaiian Gazette September 6, 1910: 6; and Pacific Commercial Advertiser, September 5 1910: 6 and September 9 1910:6 in McGregor Dec. 1989: 366-367).

- Nu'u Bay with its beach was a traditional landing places for Hawaiian fishing canoes and a fishing village. It was also a recent landing for shipping cattle by the ranch. In 1922 Manupau and Emory noted:

"When we came to level land, that was Nu'u proper. It is a seaport and cattle are shipped from here. This was a landing place for fishermen in the olden days and even down to the present. There are about five houses at $\mathrm{Nu}$ ' $\mathrm{u}$ and the inhabitants are all Hawaiians" (Kuoko'a Newspaper June 20, 1922).

- Nu'u is a sea port and cattle are shipped from here. This was also a landing place for fishermen (Manupau 1992-1993: 15).

- Salt gathering pond at Nu'u by the beach (Malo'0?? in Marciel, J. Audio Tape 87.5)

- The chief lived here at $N u^{\prime} u$ so that he could fish and so he made the path from the canoe landing to his house (Manupau, 1992-1993: 24).

- Fishing ko'a at Nu'u-on West side of canoe landing close to a rocky base (Manupau, 1992-1993: 23).

- Fishing and 'Opihi gathering at Nu'u (Marciel, J. Audio Tape 87.5).

- Loko i'a (Fish pond) called Malo'o-this fish pond had akule, opelu, ahole. Mrs. Marciel remembers cleaning it with her father (Marciel, J. Audio Tape 87.5). 
Caves

- There are several caves in Kaupo. Alala-keiki is a burial cave at Nu'u which was still in use when was partially destroyed by road builders, as were the beautiful petroglyphs in them. During the raid of Kalani 'opu' $u$ the Maui men could hear the weeping of old folks, women and children from the cave of $\mathrm{Nu}$ ' $u$. By the time they came back from the battle their people had died in the cave and that it is how it first became a burial cave.

- The heiau at $\mathrm{Nu}^{\prime} \mathrm{u}$ has petroglyphs as well as the cave wall at Nu'u (Manupau, 19921993: 23).

\section{Winds, Rains, and Springs}

The forces of nature were as much part of the community as the people. The winds and rains are prominent features and an integral part of the lives of the residents. The Hawaiians of the district have observed set patterns in the wind and the rain as it moves across the land and the ocean. By observing changing patterns in the weather, the Hawaiians were able to adjust their activities to accomplish what was appropriate to the conditions. Because of their dependence upon the land and ocean for survival, knowledge about the winds, rains, the habitats and the life cycles of marine animals and birds, and the mythical origins of Hana's rich resources enable them to live simple yet comfortable lives (McGregor, Dec. 1989: 385).

The famous winds of Kaupo include:

Kualau or Kuakualau-is the strong wind and the rain out in the ocean. In Kona this wind brings in the ohua like fish along the beaches. It is customary for it to blow in the evening and in the morning but it also blows at other times-"Where are you, O Kualau, Your rain goes about at sea."

Moa ${ }^{\prime} \mathrm{e}-$ This is a customary wind. It blows strongly but pleasantly from the sea and sometimes from the land. It is sung about, thus: "Where are you, 0 moa'e wind? You're taking my love with you."

Moa'eku-This is a customary wind like moa'e but much stronger. This wind was said to have been born in Hana, grew up in Kipahulu, attained maturity at Kaupo, became aged in Kahikinui, grew feeble at Kanaio, rested and let its burden down at Honua ula. Here is a song for this wind: "Where are you. O Moa'eku/You make much work on a stormy day".

Kupele-This wind comes with the rain. It is strong and blows out to sea from the lands.

Kaomi-It was strong, blustering wind whose strength does not last long but blew like a gentle pressure. It is sung of thus: "The wind blows in a gale, Then it gently presses."

Naulu-This wind goes with the Naulu clouds. The Naulu is the wind, It bears the Naulu clouds along. 
Kiu-It is a wind that flies along and seems to sneak by the mountain of Haleakala. It is called the Kiu of Haleakala. Here is a song of this wind: "The Kiu is the wind that lives on the mountain."

Makani ka ili aloha o Kipahulu-The love-snatching wind of Kipahulu is the usual Kipahulu wind. It blows down the mountain and goes out to sea (Kuokoa Newspaper, June 15, 1922).

Ka ua pe'e pa pohaku-The rain that makes you hide behind rocks (Marciel, J. Audiotape 87.5).

\section{OTHER FEATURES}

\section{Temples and Other Structures}

Many large and small temples, some of them very ancient are reported in the area including:

- Loaloa was a very ancient heiau, it was built by the Menehune and not by the chiefs in the Manawainui ahupua'a. It belonged to the ancient gods. It is longest on Maui. Kukui tree from Lanikaula on Molokai was planted at this temple in Kaupo (Marciel, J. Audio Tape 87.5).

- The Loaloa Heiau on Kaupo Ranch, is thought to have been rededicated by King Kekaulike about 1730.

- There are 7 heiau sites in the Nu'u region: unknown name near site 9, heiau at Anakalehua, Halekou, a large heiau at Ka'ili'ili, Site 160, at Ka'ili'ili, Papakea Heiau near the salt pond, Oheohenui near Halekou, and unknowns Northwest of Halekou.

- Pili-o-Kane was the ancient heiau where human sacrifices were offered in the Nu'u Ahupua'a.

- Papa'akea was the ancient heiau for the multiplication of food crops in the Nu'u Ahupua'a. A burial platform nearby may have contained the remains of the kahu (keeper) of the temple.

- The most interesting $k o^{\prime} a$ or fishing shrine at $\mathrm{Nu}^{\prime} \mathrm{u}$ is close by a high rock ledge on which petroglyphs can be seen. The road has damaged them.

- The Heiau Ohelo at $\mathrm{Nu}^{\prime} \mathrm{u}$ stands near the two caves of Alalakeiki.

- Ukulaelae was the ancient heiau for the multiplication of fish in the Nu'u Ahupua'a.

- There are 2 heiau in the $\mathrm{Pu}$ ' $\mathrm{u}$ Maneoneo region: A heiau at Opihi above Pu'u Maneoneo, and another heiau above the hill of Keanawai.

- Near the village of Kou there is a very large heiau; another heiau at Kou is on the ridge at Pu'u Maneoneo.

- Popoiwi was the heiau built by the Menehune in remote times in the Popoiwi Ahupua'a. Popoiwi is not the real name of the heiau, it is known as Keakalauai (Name given by Josua Ahili'i) Popoiwi is the name of the area (Manupau, 19921993: 6):

- Hale-0-Kane was the heiau were human sacrifices were offered in the Kumunui Ahupua'a. Nakuli was the chief of Kaupo in very ancient times. This heiau belonged to him. After his death Kaiuli became chief of Kaupo. Near Marciel House (Marciel, J. Audio Tape 87.5).

- Lonoaea Heiau is located near Hale-0-Kane. 
- Hala was the heiau for the multiplication of the food crops in Kakio Ahupua'a. Chief Kaiuli owned it and Hala was the kahuna who dedicated it.

- Pu'ulakua was the heiau for human sacrifices in Maipalaha. Chief Kekaulike lived there and the heiau belonged to him. His royal son Kakaalaneo of Lahaina of the high lineage of Kaalaneo was born there, the chief Kamehameha. The mother was Kekui (Kekuiapoiwa). Mother and father were kapu chiefs (Marciel, J. Audio Tape 87.5).

- A ko'a shrine is located between Ka-Lae-o-Ka-'Nlio and Kamanawa Points in Naholoku. The last kahu of the place was Mikikolo Ahuli'i who used the structure until the year 1924.

- Lanikaula (?) Heiau is located just beyond the Kaupo Post Office.

- Pu'umakaa Heiau is located mauka of the school-house in the Kumunui region in Kaupo.

- A small heiau at Kaumakalua above the road.

- The heiau at Puhilele is at Kepio on top of a hill. Another heiau is near the shore.

- Pua'akolo is a small heiau near the beginning of the upper trail to Nu'u in Naholoku.

- Laia? is a small heiau on the Pu'u-o-Kaupo hill near the Catholic Church between the road and Kamanawa Point in the Pu'u-o-aiai region.

- Pu'uakua is a small heiau near the trail leading down to $\mathrm{Nu}$ ' $\mathrm{u}$ road at 850-foot elevation.

- Waihi Heiau at is at $\mathbf{1 2 0 0}$ feet elevation south of the upper $\mathrm{Nu}^{\prime} \mathrm{u}$ trail.

- Halileo was the heiau were human sacrifices were offered in the Kalepa Ahupua'a.

- Petroglyphs at Nu'u are on Waiopai side of Nu'u (Marciel, J. Audio Tape 87.5).

(Hawaiian Eth. Notes Aug. 12, 1885:3/404; Walker 1931, 102,127, 215)

\section{Ancient Villages and Sites}

- Along the shore from Ka-Lae-o-Ka-'Tlio (the cape of the dog) to Moku-lau (many islets) are the ruins of many house sites, large and small. The old school house was located also at Moku-lau. Stone with petroglyphs are at Nu'u, Wai'u Bay, Kaupo, and also at Kipahulu and Hana.

- "Along the trail leading to Keoneoio from Kaupo are several large rocks encircled with low platforms and pebbles and bit of coral. These are the tombs of certain chiefs who fell during one of the numerous fights that occurred between raiding parties from West to Kaupo region. Less pretentious graves in the vicinity were those of common fighting men. Fifty-seven of those graves were seen at one place in the midst of a rough broken lava flow. Due to insufficient protection from the weather most of the bones have long since mouldered into dust" (Walker :71 in Sterling, 1966).

Food

- People of Kaupo ate sea cucumbers (Manupau, 1992-1993: 176; Pukui, Olelo No'eau \#1635).

- People cultivated sweet potato, onion and maize (Sterling, $1966: 3.13$ ).

- Where villages of Kaupo district are located and how to identify agricultural areas (Walker, in Sterling, 1966: 9.7). 
- "Kaupo has been famous for its sweet potato, both in ancient times and recent years. Sweet potato can be cultivated from sea level to about 2000 feet in the rich pulverized lava of the district" (Handy, 1970: 161).

- The people of Kaupo used to catch u'au birds in Haleakala (Manupau, 1992-1993: 23).

- Kaupo known for two types of taro that makes white poi, called papapueo \& haoku (Marciel, J. Audio Tape 87.5).

- People of Kaupo and also planted Ipu (gourd) and pumpkin (Marciel, J. Audio Tape: 87.5).

- Palaha wale-place to go pick the best kukui, the kukui was sent to Honolulu (Marciel, J. Audio Tape: 87,5 ).

- "Excellent oranges and limes are grown at Kaupo, the former being sweet and finely flavored" ... "The Kaupo people suffer in another way by lack of a regular steamer services".

- People of Nu'u plant sweet potato, Ipu, and pumpkin (Marciel, J. Audio Tape: 87.5).

- Planting enclosure at Nu'u (Marciel, J. Audio Tape: 87.5).

(Hawaiian Gazette September 6, 1910: 6; and Pacific Commercial Advertiser, September 5, 1910: 6 and September 9, 1910:6 in McGregor Dec. 1989: 366-367).

\section{Cultural Practices}

- The wiliwili is plentiful at Nu'u (Marciel, J. Audio Tape 87.5).

- People of Kaupo and $\mathrm{Nu}^{\prime} \mathrm{u}$ are known for their woven hats made from Nanaku (sedge) and Iwa. These were best known on Maui (Marciel, J. Audio Tape 87.5).

- The yellow wiliwili is indigenous to the area of Kaupo. The wiliwili wood was for merly used for canoe outriggers. The wiliwili was planted for posts. When the wiliwili blooms stay out of the water because the sharks are mating and they will attack (Marciel, J. Audio Tape 87.5).

In 1922, Manapau and Emory describe the fine setting of Kaupo:

"Kaupo is indeed a green land and so is Hana. They look so open and pleasant to live in because the wind is always blowing. The coast is good to look at and fine for inshore fishing. The whole of Kaupo faces West Hawai' $i$. Looking upward one sees the majestic Haleakala mountain, the Kaupo Gap and many small waterfalls (Kuoko'a Newspaper June 1, 1922).

\section{LEGENDARY AND HISTORICAL FIGURES AND EVENTS}

- Pamano is the demigod of Kaupo (Manupau 1922-1923: 5)

- The legend of Laiekawai is associated with Kaupo (Manupau 1922-1923: 30).

- Kane and Kanaloa made Waiu pond in Pu'u, The version Hina and Ku made the pond (Manupau 1922-1923: 24).

- Chief Kalaniopu'u and his warriors camped at Mokulau and slaughtered the people of Kaupo. Kamehameha and Kekuhaupi 'o were the famous warriors of Kalaniopu'v at this battle (Manupau 1922-1923: 6).

- The pool of Kapunahoa-Pamano swam and bathed here (Manupau, 1922-1923: 6). 
- Paukela was a chiefess of Kaupo in the legend of the high chiefs of Maui (Sterling, 1966: 9.7).

- Chief of Kaupo is Kahekahiali'i (Manupau, 1922-1923: 1).

- Kauakahiakua, Chief of Kaupo (Pukui, Olelo No'eau \#1635).

- Keli'imaika' $i$ Kamehameha's younger brother was kind to the people of Kaupo, in gratitude they hid him when he was sought to be killed (Marciel, J. Audio Tape 87.5).

- Chief Kekaulike lived in Kaupo, his son is Kakaakaneo of Lahaina (Marciel, $J$. Audio Tape 87.5).

- Queen Kapi'olani owned land where $\mathrm{Nu}^{\prime} \mathrm{u}$ wharf is today (Moses Manu in Sterling 9.7 also found in Ka loea Kalaiaina 9/9/1899, HEN Vol. 11:942).

- Nu'u means the high place, or second platform in a temple, is a place of sacredness and is a village site. It is so named because it was the landing place of $\mathrm{Nu}$ ' $u$, a great kahuna, navigator and ancestor twelve generations from the beginning of the race on the genealogy of Kumuhonua (Beckwith, 1970:314).

- Keli'iahonui, younger brother of Kaleimoku chief of Lahaina was the one who built the ala stone to $\mathrm{Nu}^{\prime} \mathrm{u}$.

\section{CHANTS AND SONGS}

Kaupo 'aina pali huki i luna -

Huki a'ela e like me Kahikinui

He nui no wau nau, e ke aloha

(For. Sel. in Pukui, Elbert, Mookini, 275 274-275).

Kaupo land of cliffs rising high, Rising upward like Great Tahiti, Great was I, you [thought], 0 love.

\section{HAWAIIAN PROVERBS}

'Olelo No'eau \# 460: Hana, mai Ko'oolau a Kaupo.

The extent of the district of Hana, Maui.

'Olelo No'eaư \# 1259: Ipu pa'u lena i ka uahi.

Soot containers yellowed by smoke. A term of contempt applied to the kauwa at Kaupo.

'Olelo No'eau \# 1595: Ka ua pe 'e pohaku o Kaupo.

The rain of Kaupo that makes one hide behind a rock.. It falls so suddenly that one flees behind rocks for shelter.

'Olelo No'eau \# 1635: Kaupo'ai loli.

Kauakahiaka, a chief of Kaupo, is said to have been fond of the loli and to have once built a large imu for roasting them. Since that time the people of Kaupo have a reputation for being especially found of this sea creature. 
'Olelo No'eau \# 1897: Ku ke 'a ka hale o Kaupo.

The lava is heaped at the house of Kaupo. A saying denoting great distress from the legend of Pamano.

'Olelo No'eau \# 2519: 'Onea Kaupo ua ka ka'ai i ka lua.

Barren is Kaupo; the eating in the cavern has begun. Fatal shark attacks were common at one time at Kaupo. As a result, the people moved elsewhere, after which a maneating shark peered at Kaupo and said these words at the place called $\mathrm{Ki}$ 'ei (peer), later used to mean destitution.

Table D3. Place names-Kaupo: Landing [of Canoe] at Night

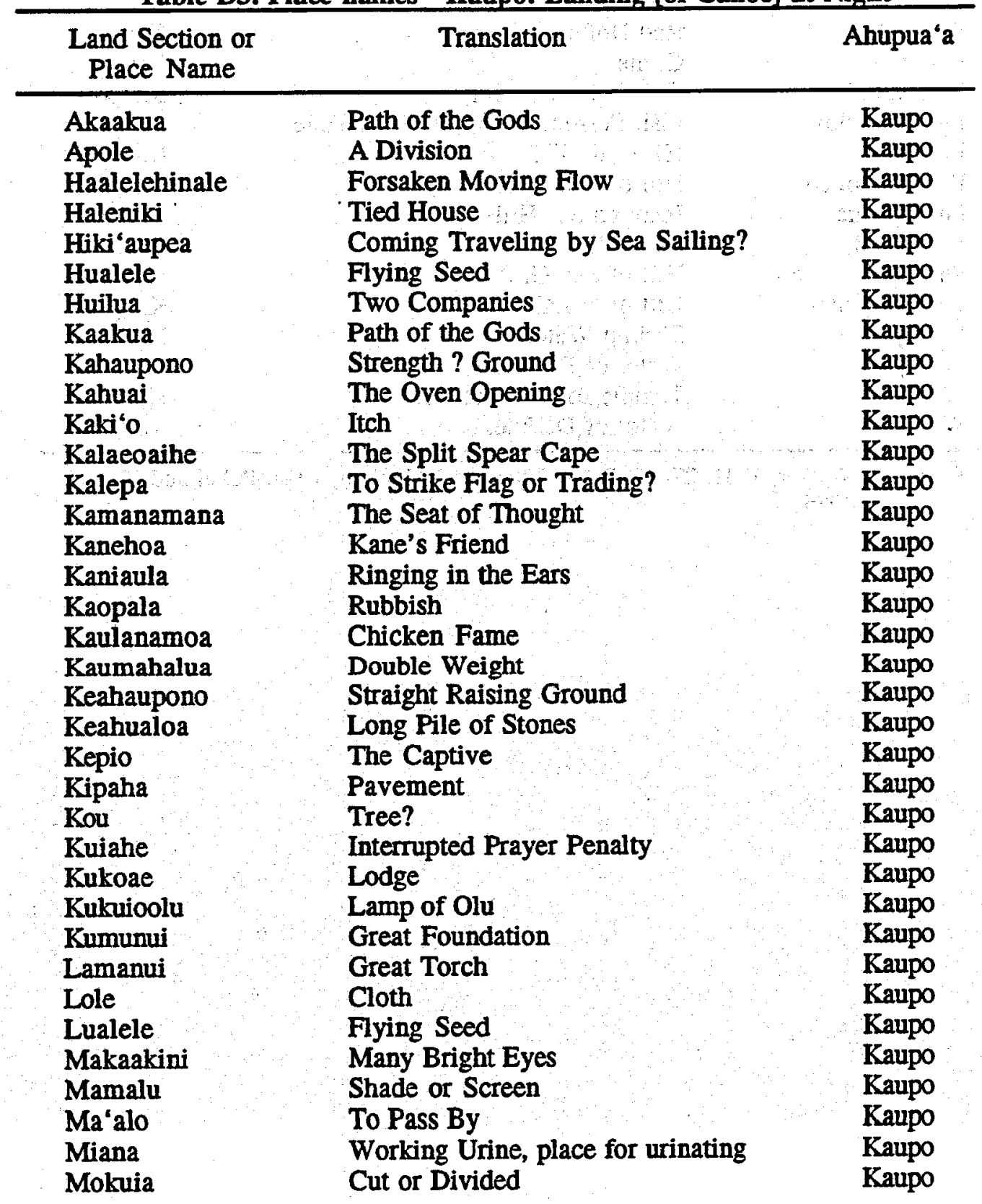


Table D3 (Continued)

\begin{tabular}{lll}
\hline Mokulau & Leafy District (Many Islands) & Kaupo \\
Naholuku & Garments & Kaupo \\
Nakula & Uplands & Kaupo \\
Naniumalu & Shady Coconut Trees & Kaupo \\
Nau & Craig niche & Kaupo \\
Niniao & Pouring Cloud & Kaupo \\
Nu'u & High Place; Craig Niche & Kaupo \\
Opupao'o & Collecting of Pao'o Fish & Kaupo \\
Paina & Eating & Kaupo \\
Pauku & Piece? & Kaupo \\
Poe & Round & Kaupo \\
Poho'ula & Red Hollow & Kaupo \\
Popoiwi & Come & Kaupo \\
Pukaauhuhu & Fish Poison Outlet & Kaupo \\
Puka'auhuhu & Fish Poisoning Outlet, Plant Hole & Kaupo \\
Puulani & Heavenly Hill & Kaupo \\
Puumaneoneo & Hill of Sea Grass & Kaupo \\
Pu'u Lakua & Incongruous Hill & Kaupo \\
Pu'u Lani & Sky Hill & Kaupo \\
Pu'u Mane'one'o & Hill of Sea Grass & Kaupo \\
Pu'u O Maiai & Hill of Maiai & Kaupo \\
Waiopai & Shrimp Water & Kaupo \\
Waiopuli & Water of Darkness & Kaupo \\
Waipule & Temple for Purification & Kaupo \\
Waipuli & Water of Darkness & Kaupo \\
\hline
\end{tabular}

Source: Walker, 1931: 27-36; Pukni, Elbert and Mookini, 1974; Pukui and Elbert, 1986. 


\section{APPENDIX E}

WORKING LIST OF ARCHAEOLOGICAL SITES IN PUNA, HAWAI'I 


$$
\text { in Puns, Hawal i }
$$

50-HA-A01-011

SO-HA-A01-012

50-HA-A01-013

50-HA-A01-017

50-HA-A01-018

50-HA-A01-020

50-HA-A01-021

SO-HA-A01-022

50-HA-AO1-024

50-HA-A01-025

50-HA-A.01-026

50-HA-A01-027

SO-HA-A01-028

SO-HA-A01-029

S0-HA-AOT-030

50-HA-A01-031

50-HA-A01-035

50-HA-1.01-040

50-HA-A01-041

50-HA-AOZ-016

50-HA-AO3-020

50-HA-A03-024

SO-HA-AO4-003

50-HA-AO4-004

50-HA-A04-005

50-HA-A04-006

50-4A-104-007

S0-HA-AO4-008

50-HA-A04-009

50-HA-A04-010

50-HA-AO4-011

SO-HA-A04-012

50-HA-AO4-013

SO-HA-A04-014

50-HA-A04-015

50-HA-104-016

50-HA- $204-019$

SO-HA-AO4-026

50-HA- $104-027$

SO-HA-104-028

50-HA-104-029

50-HA-104-030

50-fA-104-031

50-1A- $104-032$

50-1A- 104-033

50-HA-A04-034
MCELDOUNEY 1979:11 (H-127) MCELDOWNEY 1979:11 (H-127) MCELDOWNEY 1979:11 (H-127) MCELDOLNEY 1979:11 (H-127) MCELDOUNEY 1979:11 (H-127) MCELDOUNEY 1979:11 (H-127) MCELDOHNEY 1979:11 (H-127) MCELDOHNEY 1979:11 (H-127) HCELOOWNEY 1979:11 (H-127) HCELOOWNEY 1979:12 (H-127) MCELOOUNEY 1979:12 (H-127) RCELDOUNEY 1979:12 (H-127) MCELDOWNEY 1979:12 (H-127) HCELDOUNEY 1979:12 (H-127) HCELDOUNEY 1979:12 (H-127) MCELDOUNEY 1979:12 (H-127) HCELDOUNEY 1979:12 (H-127) HCELDOWNEY 1979:13 (H-127) HCELDOLNEY 1979:13 (H-127) HCELDOUNEY 1979:17 (H-127) MCELDOWNEY 1979:17 (H-127) HCELDOUNEY 1979:17 (H-127) HCELDOUNEY 1979:18 (H-127) NCELDOUNEY 1979:18 (H-127) HCELDOWNEY 1979:18 (H-127) MCELDOHNEY 1979:18 (H-127) NCELDOWNEY 1979:18 (H-127) MCELDOWNEY 1979:18 (H-127) MCELDOUNEY 1979:18 (H-127) MCELDOUNEY 1979:18 (H-127) MCELDOINEY 1979:18 (H-127) MCELDOUNEY 1979:18 (H-127) MCELDOWNEY 1979:18 (H-127) MCELDOUNEY 1979:18 (H-127) MCELDOWNEY 1979:18 (H-127) HCELDOUNEY 1979:18 (H-127) NCELOOWNEY 1979:19 (H-127) HCELDOWNEY 1979:19 (H-127) HCELDOWNEY 1979:19 (H-127) HCELDOUNEY 1979:19 (H-127) MCELDOHIEY 1979:19 (H-127) HCELDOWNEY 1979:19 (H-127) NCELDOUNEY 1979:19 (H-127) HCELDOUNEY 1979:19 (H-127) NCELDOUNEY 1979:19 (H-127) MCELDOUNEY 1979:20 (H-127) 
State site

\begin{abstract}
BPEM site
SO-HA-A04-036

5O-HA-AO4-041

50-HA-AO4-0.42

5O-HA-AO4-O43

SO-HA-AO4-O44

50-HA-AO4-045

50-HA- $-104-048$

50-HA-AO4-049

50-HA- $104-050$

50-HA- $104-053$

50-HA-104-056

50-HA- $104-057$

50-HA- $-104-058$

50-HA- $104-059$

50-Ha- $104-060$

50-HA- $104-061$

50-Ha- 104-062

50-14A- $-104-063$

$50-4 \mathrm{~A}-\mathrm{-104}-066$

50-HA- $-104-067$

50-HA-A05-002

50-HA-A05-003

50-HA-A06-024

50-HA- $106-025$

SO-HA-A08-005
\end{abstract}

50-10-34-10307 50-10-36-01845

50-10-36-01846

50-10-36-18938

50-10-36-18939

50-10-36-18940

50-10-36-18941

50-10-36-18942

50-10-36-18943

50-10-36-18944

50-10-36-18945

50-10-36-18946

50-10-36-18947

50-10-36-18948

50-10-36-18953

50-10-36-18954

50-10-36-18955

50-10-36-18956

50-10-36-18957

50-10-36-18958

50-10-36-18959

50-10-36-18960

50-11A-101-014
$50-11 A-101-049$

50-Ha-101-052

50-HA-A01-053
Reference

MCELDOUNEY 1979:20 (H-127)

MCELDOUNEY 1979:20 (H-127)

MCELDOUNEY 1979:20 (H-127)

MCELDOWNEY 1979:20 (H-127)

HCELDOUNEY 1979:20 (H-127)

MCELDOUNEY 1979:20 (H-127)

MCELOOWNEY 1979:21 (H-127)

HCELDOUNEY 1979:21 (H-127)

MCELDOUNEY 1979:21 (H-127)

MCELDOUNEY 1979:21 (H-127)

MCELDOUNEY 1979:21 (H-127)

MCELDOUNEY 1979:21 (H-127)

MEELDOWNEY 1979:21 (H-127)

NCELDOWNEY 1979:21 (H-127)

MEELDOUNEY 1979:21 (H-127)

NCELDOUNEY 1979:22 (H-127)

MCELDOWNEY 1979:22 (H-127)

MCELDOUNEY 1979:22 (H-127)

MCELDOUNEY 1979:22 (H-127)

MCELDOWNEY 1979:22 (H-127)

MCELDOWNEY 1979:22 (H-127)

MCELDOUNEY 1979:22 (H-127)

MCELDOUNEY 1979:25 (H-127)

MCELDOUNEY 1979:25 (H-127)

HCELDOINEY 1979:26 (H-127)

SHPD SITE FOLDER (NO MAP)

MALL

SHPD SITE FOLDER; MCELDONMEY 1979 (H-127 ENCLOSURE

SHPD SITE FOLDER; MCELDOUNEY 1979 (H-127 LAVA BUBBLE ENCLOSURE

HCELDONNEY 1979:11 (H-127)

HCELDONNEY 1979:11 (H-127)

MCELDOUNEY 1979:11 (H-127)

MCELDOWNEY 1979:11 (H-127)

RCELDOWNEY 1979:12 (H-127)

MCELDOWNEY 1979:12 (H-127)

MCELDONNEY 1979:12 (H-127)

MCELDONNEY 1979:12 (H-127)

KCELDOHNEY 1979:13 (H-127)

MCELDONNEY 1979:13 (H-127)

HCELOONNEY 1979:13 (H-127)

HCELDOUNEY 1979:13 (H-127)

MCELOONNEY 1979:13 (H-127)

MCELDOHNEY 1979:13 (H-127)

HCELOOWNEY 1979:13 (H-127)

RCELDOUNEY 1979:13 (H-127)

WCEL DONNEY 1979:13 (H-127)

MCEL DOUNEY 1979:13 (H-127)

MCELDOWNEY 1979:14 (H-127)
Name/Type 
$8 / 23 / 94$

\begin{tabular}{cc} 
State site & BPBM site \\
\hline $50-10-36-18961$ & $50-H A-A 01-054$ \\
$50-10-36-18962$ & $50-H A-A 01-055$ \\
$50-10-36-18963$ & $50-H A-A 01-056$ \\
$50-10-36-18964$ & $50-H A-A 01-057$ \\
$50-10-36-18965$ & $50-H A-A 01-058$ \\
$50-10-36-18966$ & $50-H A-A 01-059$ \\
$50-10-36-18967$ & $50-H A-A 01-060$ \\
$50-10-36-18968$ & $50-H A-A 01-061$ \\
$50-10-36-18969$ & $50-H A-A 01-062$ \\
$50-10-36-18970$ & $50-H A-A 01-063$ \\
$50-10-36-18971$ & $50-H A-A 01-064$ \\
$50-10-36-18972$ & $50-H A-A 01-065$
\end{tabular}

50-10-44-07374

50-10-44-07375

50-10-44-07376

50-10-44-07378

50-10-44-07379

50-10-44-07389

50-10-44-18952

50-10-45-04221

50-10-45-04222

50-10-45-07476

50-10-45-18949

50-10-45-18950

50-10-45-18951

50-10-45-18973

50-10-45-18974

50-10-45-18975

50-10-45-18976

50-10-45-18977

50-10-45-18978

50-10-45-18979

50-10-45-18980

50-10-45-18981

50-10-45-18982

50-10-45-18983

50-10-45-18984

50-10-45-18985

50-10-45-18986

50-10-45-18987

50-10-45-18987

50-10-45-18988

50-10-45-18989

$50-10-45-18990$

50-10-45-18991

50-10-45-18992

50-10-45-18993

50-HA-A07-042

SO-HA-A01-043

50-HA- $401-044$

SO-HAA-AOZ-DOO

5O-HA-AOZ-COZ

50-HA-AO2-CO3

50-HA-AO3-DO1

50-HAA-A03-DO2

5O-HA-AO3-OO3

SO-HA-A03-004

50-HA-AO3-CO5

SO-HA-AO3-DOS

SO-HA- $-103-007$

SO-HA-AO3-008

$50-11 \mathrm{~A}-1.03-010$

50-HA-103-014

SO-HA-A03-015

SO- $+1 A-A 03-018$

50-41A-103-019

SO-HA-AO3-025

50-HA-A03-026

SO-HA-A03-027

SO-HA- $-103-028$
Working List of Archaeological sites

in Puna, Hawai $i$
Reference $\quad \therefore \quad$ Name/Type

MCELDOUNEY 1979:14 (H-127)

MCELDOUNEY 1979:14 (H-127)

MCELDOWNEY 1979:14 (H-127)

HCELDOUNEY 1979:14 (H-127)

MCELDOUNEY 1979:14 (H-127)

MCELDOWNEY 1979:14 (H-127)

HCELDOUNEY 1979:14 (H-127)

MCELDOUNEY 1979:14 (H-127)

MCELDOUNEY 1979:14 (H-127)

MCELDOUNEY 1979:14 (H-127)

MCELOOUNEY 1979:14 (H-127)

HCELDOWNEY 1979:14 (H-127)

MCELDOUNEY 1979:15 (H-127)

MCELDOWNEY 1979:15 (H-127)

MCELDOUNEY 1979:15 (H-127)

MCELDOUNEY 1979:15 (H-127)

HCELDOUNEY 1979:15 (H-127)

MCELDOWNEY 1979:15 (H-127)

50-HA-301-045 MCELDOWNEY 1979:13 (H-127)

SHPO SITE FOLDER; MCELDOUNEY 1979 (H-127 HON. LANDING HAB. COHPLEX SHPD SITE FOLDER; MCELDOLNEY 1979 (H-127 MAKAU PETROGLYPHS

- P. AMELDOWHEY,A979. (H-127)

$50+1 a-103-017$

MCELOOUNEY 1979:13 (H-127). . _ 39

NCELDOLNEY 1979:13 (H-127)

MCELOOWNEY 1979:13 (H-127)

MCELDOUNEY 1979:16 (H-127)

HCELDOUNEY 1979:16:(H-127)

NCELDOUNEY 1979:16 (H-127)

HCELDOWNEY 1979:16 (H-127)

HCELDOLNEY 1979:16 (H-127)

HCELDOUNEY 1979:16 (H-127),

MCELDOUNEY 1979:16 (H-127)

HCELDOWNEY 1979:16 (H-127)

MCELDOUNEY 1979:16 (H-127)

HCELDOWNEY 1979:16 (H-127)

MCELDOWNEY 1979:16 (H-127)

NCELDOWNEY 1979:16 (H-127)

HCELOOLNEY 1979:17 (H-127)

MCELDOHNEY 1979:17 (H-127)

HCELDOLNEY 1979:17 (H-127)

HCELDOWNEY 1979:17 (H-127)

MCELDOWNEY 1979:17 (H-127)

MCELOOLNEY 1979:17 (H-927)

HCELDOWNEY 1979:17 (H-127)

NCELDOWNEY 1979:17 (H-127)

MCELDOWNEY 1979:17 (H-127)

HCELDOLNEY 1979:18 (H-127) 
in Puna, Hawa ' $i$

state site

50-10-45-18994

142

143

144

145

146

147

148

149

150

151

152

153

154

155

156

157

158

159

160

161

162

163

164

165

166

167

168

169

170

171

172

173

174

175

176

177

178

179

180

181

182

183

184

185

186

187

50-10-46-02501

50-10-46-02503

50-10-46-02505

50-10-46-02505

50-10-46-02506

50-10-46-02507

50-10-46-02510

50-10-46-02512

50-10-46-02515

50-10-46-02516

50-10-46-02517

50-10-46-02518

50-10-46-02519

50-10-46-02520

50-10-46-02521

50-10-46-02522

50-10-46-02524

50-10-46-02526

50-10-46-02529

50-10-46-02530

BPBM site:

50-HA- $104-002$

50-HA-AO4-021

50-Ha-104-022

50-HA-104-023

50-HA-104-024

50-HA-104-025

50-HA-104-035

50-HA-104-038

50-HA-104-039

50-HA- $04-040$

50-HA-104-046

50-HA- $04-047$

50-11A-104-051

50-HA-A04-052

50-14A-104-054

50-HA-104-055

50-HA-104-064

50-HA-. $.05-001$

50-HA- $105-004$

50-HA- $105-005$

50-HA- $.05-\infty 06$

50-th-105-007

50-HA- $105-008$

50-HA-AOS-COS

50-HA-105-010

SO-HA-A08-001

50-HA-A10-003

50-HA-A10-005

50-HA-A11-001
50-HA-104-037

Reference

MCELDOWNEY 1979:18 (H-127)

MCELDOWNEY 1979:19 (H-127)

RCELDOWNEY 1979:19 (H-127)

RCELDOWNEY 1979:19 (H-127)

HCELDOWNEY 1979:19 (H-127)

MCELDOWNEY 1979:19 (H-127)

RCELOOWNEY 1979:20 (H-127)

HCELOOLNEY 1979:20 (H-127)

HCELOOWNEY 1979:20 (H-127)

KCELDOHNEY 1979:20 (H-127)

MCELDOUNEY 1979:20 (H-127)

HCELDOWNEY 1979:20 (1-127)

HCELDOUNEY 1979:21 (H-127)

HCELDOWNEY 1979:21 (H-127)

HCELDOWNEY 1979:21 (1-127)

HCELDOWNEY 1979:21 (H-127)

MCELDOWNEY 1979:21 (H-127)

HCELDOLNEY 1979:22 (H-127)

MCELDONNEY 1979:22 (H-127)

MCELDOLNEY 1979:22 (H-127)

HCELDOWNEY 1979:22 (H-127)

HCELDOWNEY 1979:22" $(H-127)^{\circ} \mathrm{m}$

MCELDOUNEY 1979:22 (H-127)

MCELDOWNEY 1979:23 (H-127)

MCELDOWNEY 1979:23 (H-127)

MCELDOUNEY 1979:23 (H-127)

SHPD SITE FOLDER

SHPD SITE FOLDER

SHPD SITE FOLOER

SHPD SITE FOLOER

SHPO SITE FOLDER

SHPD SITE FOLDER

SHPD SITE FOLDER

SHPD SITE FOLDER

SHPD SITE FOLDER

SHPD SITE FOLDER

SHPD SITE FOLDER

SHPD SITE FOLDER

SHPD SITE FOLDER

SHPO SITE FOLDER

SHPO SITE FOLDER

SHPO SITE FOLDER

SHPD SITE FOLDER

SHPD SITE FOLDER

SHPD SITE FOLDER

SHPD SITE FOLDER

SHPO SITE FOLDER
(NO MAP)

(NO MAP)

(NO MAP)

(NO MAP)

(NO MAP)

(NO MAP)

(NO MAP)

(NO MAP)

(NO MAP)

(NO MAP)

Name/Type

KUKII HEIAU

KAPOHO PETROGLYPHS

AHALANUI COMPLEX 1

AHALANUI COAPLX 2: PLTFRH

AHALANUI COAPLX 2: PENS

LAEPAOO ENCLOSURE

POHOIKI NORTH COHPLEX

POHOIKI WARM SPRING

POHOIKI ENCLOSURE

HALE PARK COHPLEX

COHPLEX

MAHIKMAKAKA. HELAU

KEAHIALAKA SPRING $\&$ POND

MLE FAMILY (GRAVES)

COMPLEX

ENCLOSURE

CONPLEX

COMPLEX

LAVA TUBE

(NO MAP)
MACKENZIE PETROGLYPHS 


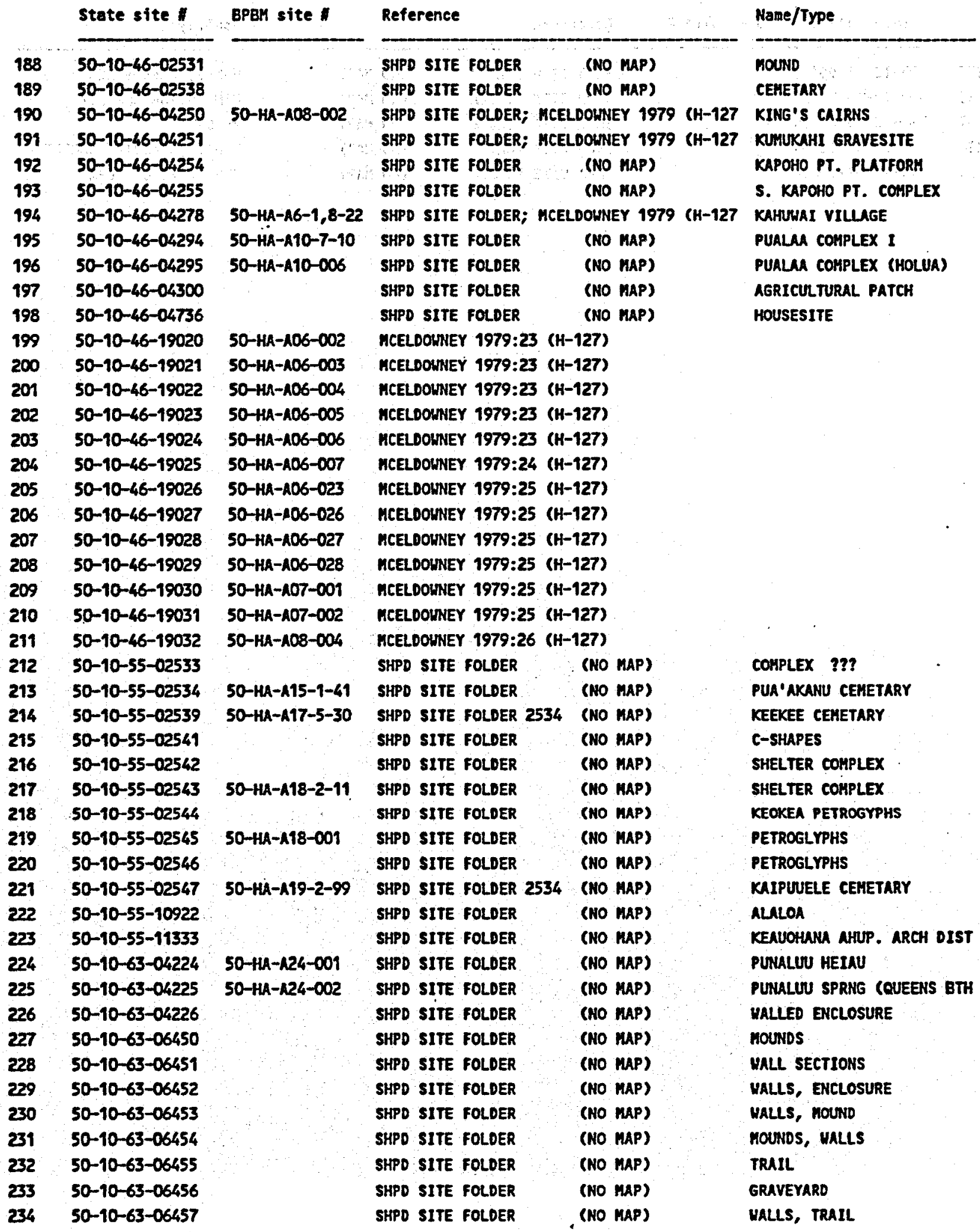




\begin{tabular}{|c|c|c|c|c|c|}
\hline \multirow[b]{2}{*}{235} & \multirow{2}{*}{$\frac{\text { state site }}{\text { 50-10-63-06458 }}$} & \multirow[t]{2}{*}{ BPBM site } & \multicolumn{2}{|l|}{ Reference } & \multirow{2}{*}{$\frac{\text { Name/TYPe }}{\text { WALLS, ENCLOSURE }}$} \\
\hline & & & SHPD SITE FOLDER & (NO MAP) & \\
\hline 236 & $50-10-63-06459$ & & SHPD SITE FOLDER & (NO MAP) & HABITATION COMPLEX \\
\hline 237 & $50-10-63-06460$ & & SKPD SITE FOLDER & (NO MAP) & WALL \\
\hline 238 & $50-10-63-06461$ & & SHPD SITE FOLDER & (NO MAP) & HABIT. AGRIC. COMPLEX \\
\hline 239 & $50-10-99-10000$ & & SHPD SITE FOLDER & (No MAP) & PUNA CAVE COMPLEX \\
\hline
\end{tabular}




\section{APPENDIX F}

WAO KELE 'O PUNA NATURAL AREA RESERVE 
George n. AnTrosily

Cuvermet of ollowolo

USTOPIIEA COBB, CHAAMMAN

ard of Land and Nithas thesnueces

Elloari a. ILAMASU

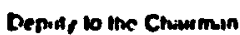

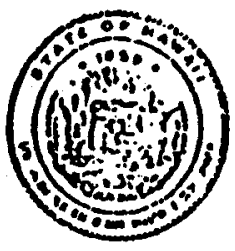

STATE OF HAWAII

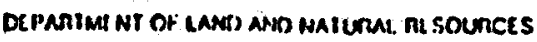

NATURAL AREA RESERYES SYSTEM COMMISSION

P.O Box 621. Monolulu, Huwan 06009

Room 313. Matanuri.noku 8:ag

1151 Punchexul Sr. In SAB 255

NOV 121976

Board of Land \& Natural Resources

Honolulu, HI

Gentlemen:

Subject: Wao Kele 0 Puna Natural Area Reserve, Hawaii

At its meeting of Octobcr 21, 1976 the Natural Area Reserves system Commission recommended that a 6,500-acre portion of the Puna Forest Reserve be established as the "Wao Kele $O$ Puna Natural Area Reserve" as detailed in the attached proposal. The Draft Regulation No. 13 governing its use must receive a public hearing. Becalise the proposed liutural Area Reserve is now a part of Puna Forest Reserve, it is also necessary to withdraw this land from forest reserve stutus, which action requires a hearing pursuant to Chapter 183 , HRS.

During the past three months the Commission has made a serious examination of its functions and position in the stite Governmert. We find that there is a cubetantial back-loe of field data concerning the nomination of candidate Natural Area Reserves and in preliminar ment of proposals for selected reserves. However, the work of the Commission is severely hampered by shortages of staff and budgeting fo: carrjing these proposals to final draft form.

The current puna proposal was produced only by volunteer essistance in research and prepuration by several of our Commissioners, and by taxint beyond reasonable limits the expertise and time of our Natural dreas specialist who serves in a half-time capacity.

The creat need of the comission at this juncture in the development of a meaningrul state Natural Area Reserves System is for a Iull-time Executive officer to finalize and expedite additional proposals of the quality reflected in the one we are submitting at this time.

RECOIALENDIIOH:

Shat the Boari:

1. Approve and recommend to the Governor of havaii that a jublic hearine be lacld on the island of luwail covering the proposed reculation and withdrawil of the subject urea from puna Forest fieserve ard that 
GEORGE R. ARIYOSH

Govorant of Mawaii

TOPHEN COBB, CHAJRMAN ol Land and Nalunat Resources

EDGar A. HAMASU

Depuly to the Chairman

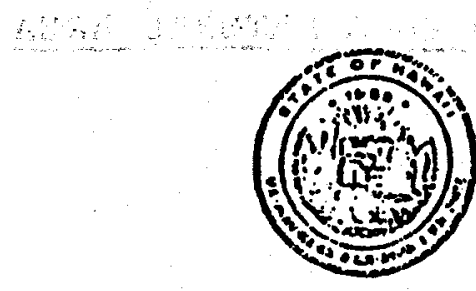

STATE OF HAWAII

DCPAnIMENI OI LaAn aNO NAIIHAI IH SOIRCI:

NATURAL AREA RESERVES SYSTEM COMIMISSION

P.O. Box 621. Honolulu. Itowan gioug

Rooni 313 . Kalenimoku Bito

IISt Punclibowl SL. Ph 513.2529
Commission AJembers

P. Ouentin Ionwen, Chairman

D Elimo Hardy

Robert a Kinz1o, II

Gotuon A Ma. donsio

Cihrin 1 Vianideluta

\section{RECOMMENDATION}

The above constitutes the report and recommendation of the undersigned commissioners to the Board of Land and Natural Resources, and has been approved by all members.

Approved by the Natural Area Reserves System Commission

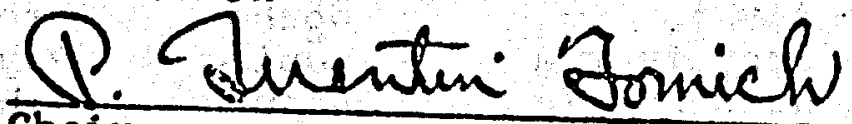

Chairman

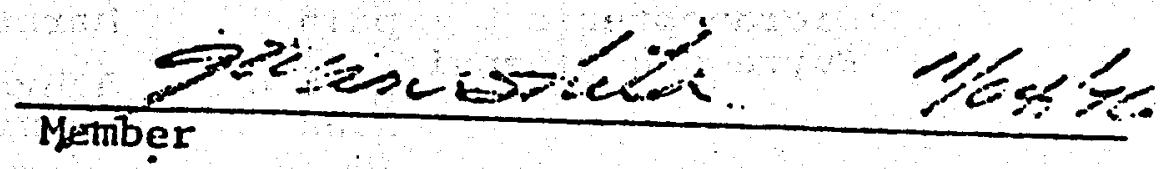




\section{IAO KILLE 'O PUi:A FiATURAL AIEBA}

Introduction

Commission

Reserve Purpose

The Proposal

Representative Rather Than Unique

General Description

Management

General

Allowable Uses

Special Foatures

Relationship to Hawaiian Culture

Scientific Interest, Botanical lidaptations

Relationship to Eadangered Species nct

ITATIVE PLANTS IDENTIFIED TO DNTE IN THE MAO KELE 'O PUHA INTURAL MRFA RESERVE

Glenrood, or maulia sicle

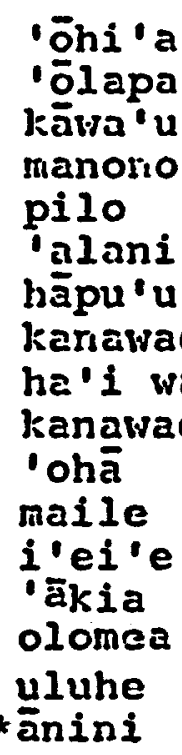

Cyrtandra
Metrosideros

Cheirodendron

IJ.ex

Gouldia

Coprosma

Pelea

Cibotiun

Cyrtandra

Broussaisia

Clermontia

Alyxia

Freycinetia

Wikstroemia

Perottetic

Dicranopteris

Euyra sandwicensis hō'i'o

hāhā

lama

mänaki

olonea

pilo

-alani

maile

oppuhe

kopiko

häpu'u

uluhe

pala
Kalepana, or makai side

-ōhi'a lietrosideros

'alia Vilistroenia

i'ei'e Freycinctia

*.' ahàkea

* 'ahakea

Diospyros

Pipturus

Perottetia

Coprosma

Bobea sanduicensis

Bobea tinonioides

Pelea

Alysia

Urera

Psychotria

Cibotium

Dicranopteris

Marattia

ithyrium

Cyanea pilosa

* Indicates plant is on the smithsonian list of Endangered Species.

Spelling according to John Porter list of Hawaiian names.

$$
\begin{aligned}
& \text { snici=l } \\
& \text { inr st } \\
& \text { ofreinel } \\
& 11 / 1 / 70^{\circ} \quad \text { ifst }
\end{aligned}
$$


WAO KELE $O$ PUNA HATURAL AREẌ RESERVE

Introduction

The Natural Area Reserves System Commission was created in 1970 by State Act 139 and consists of six scientists appointed by the Governor and five ex-officio nembers: the heads of the Departments of higriculture, Education, Land and Natural Resources, Planning and Economic Development, and the President of the University of Hawali.

According to Legislative intent, the comnission has adopted criteria for recommending Hatural irea Reserves and has clarified the purpose, scope and composition of the system. The purpose is to preserve for future generations irreplacable examples of the Hawaiian environment. The Reserves will serve as benchmarks against which to measure change in the natural environment and will preserve biological gene pools. The scope is statewide, and the composition will include both unique and representative areas of zoological, geological, and botanical value.

A Statewide plan has identified about 70 possible candidate areas and the first two, the Waiakea 1942 Lava Flow Reserve and the Ahhihi-Cape Kinau Reserve have been set aside by Executive order.

\section{The Proposal}

The proposed yzo liele 10 puna Hatural Area is a portion of tis State owned Puna forest, located in the southeastern part of the Island of Havai'l and will preserve a representative ohi'a-fern forest much as it cxisted before the arrival of Captain cook. The entire puna Forest of about 25,700 acres vas at one time suggested by the Division of Forestry as a llaturel Area but subsequent investigation showed that the purpose of preserving this type of ecosystem could be achieved in a Reserve of 6,500 acres, leaving the renaining forest for multiple use as needed.

Although the ohi'a-fern association is the predominent feature in this native Havaitan forcst, there are numerous other native plants to be found, some of then being on the Endangered Species list. Older and more varied plant communities survive in the kipuka which arc islands of vegetation surrounded by lava flows. 
The Puna forcst is locatel in the center of the l'una bistrict near the castern tip of the Island of lawai' $i$. It is on the cast slope of the kilatuea shicld volcano and was formed by a succession of prehistoric and historic basalt lava flows fron the luna volcanic scrics.

This cast rift of the kilauca volcano cxtends froli the caldicrat at 4,000 fect elevation to Cape liunukihi. It is slashed with great crilcks, or fissures, pimpled with cinder and spatter cones, and blickened witli recent flows. volcanic activity along the rift in 1963 resultad in sevcral hundred acres of new lava and added another interesting kipuka, lihere vegetition existing beforc the lava flow stands tall and green, surrounded by sterile 1ava. Due to these volcanic conditions vegetation ranges from the ferns wich move in as the lava cools, to exanples of a mature native ohia-fern ecosysten.

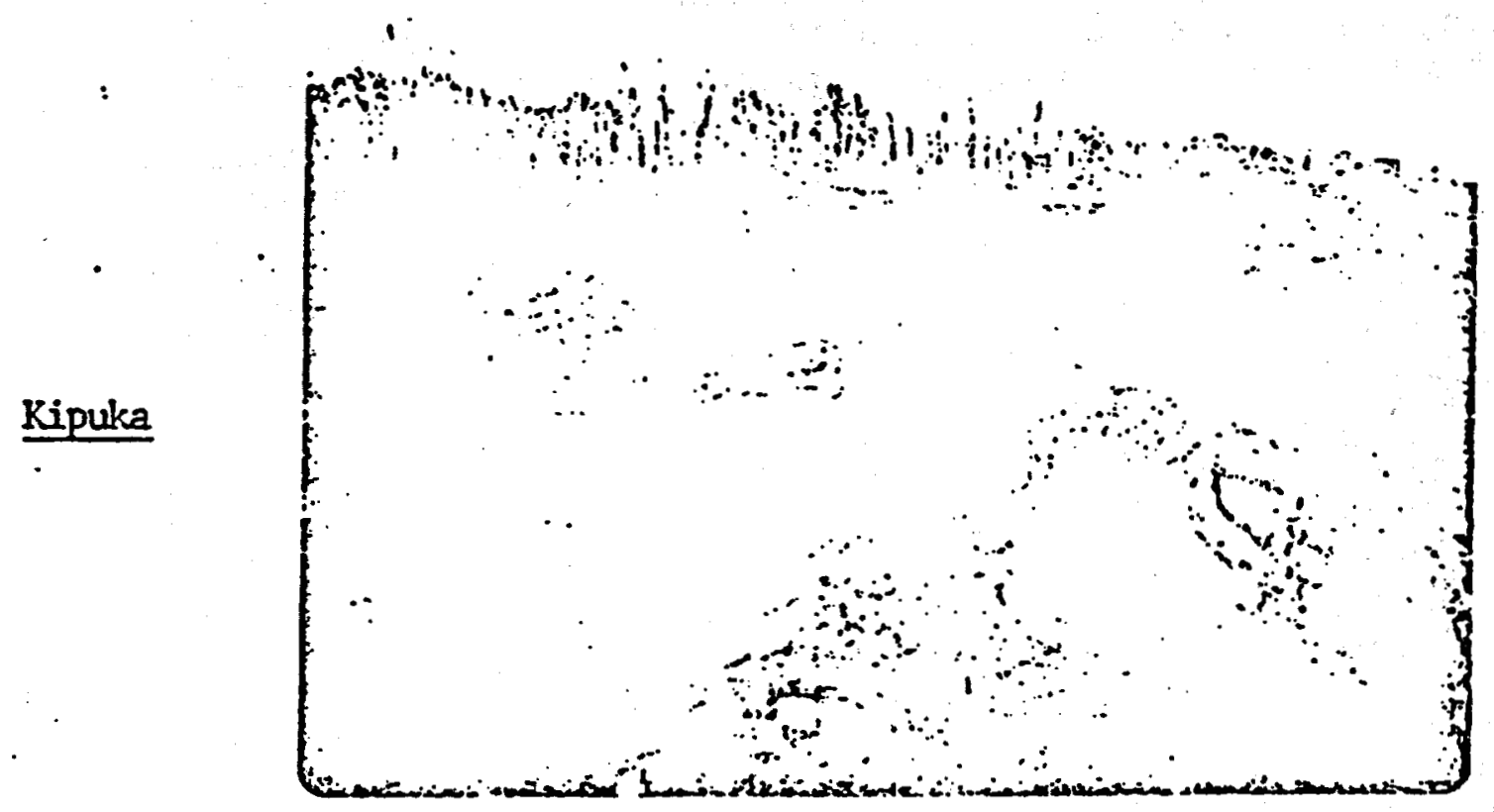

Soils in the proposed Rescrve are basically histusols, which consist of thin layers of organic material on geologically young lava rock. The elevation rises from 1,380 feet to 2,300 feet, and the avcrage annual rainfall ranges from 125 inches at the lower elevation to 150 inches at the Glentood end near 22 mile road. It is this amount of rainfall conbincd with a warm climite which makes possible the relatively rapid concback of plant life on the new lava.

Acrial photographs and ground surveys have shom that the proposed Reserve is predominantly a fern-ohia ecosystem. While the ohia belongs to a genus which has representatives in many parts of the Pacific, all of the species of olia occurring naturally in Ihatw'i arc unique to the Islands and, according to the botanist Joseph F. Rock, Puna is one of the prine arcas where the ohia reaches its largest size, sometinics 100 fect. liliile different forns of the ohia occur from sca-level to as high as 9,000 feet, this Puna area presents the ohia-fern association which is a very stable llawaii ecosystem when eudisturbed. In the higher, wetter area of the Reserve the fern associated with the olia is the majestic hapuu, while on 


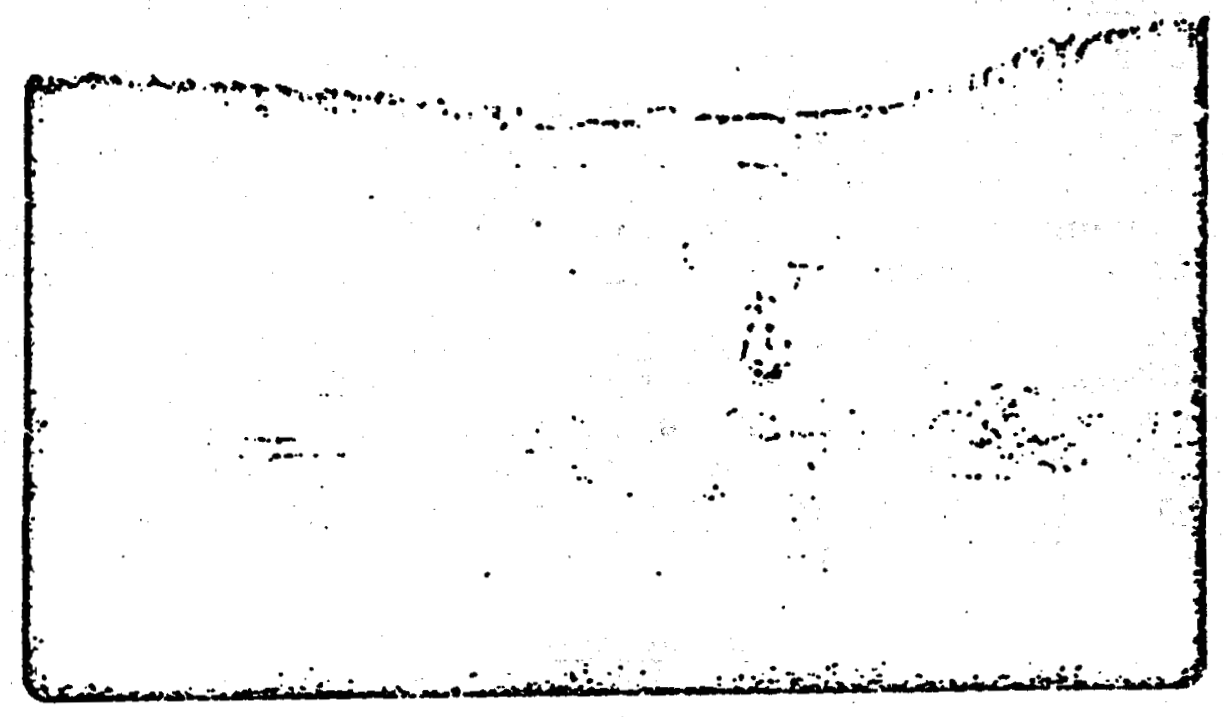

\section{Hikers}

Due to the rugged lava, large cracks, and the wilderness clasracter of the area, manacement may require some provision for user safety. Interpretive displays, handout material, and special trails for vicwing native plants might be developed in certain portions of the Reserve.

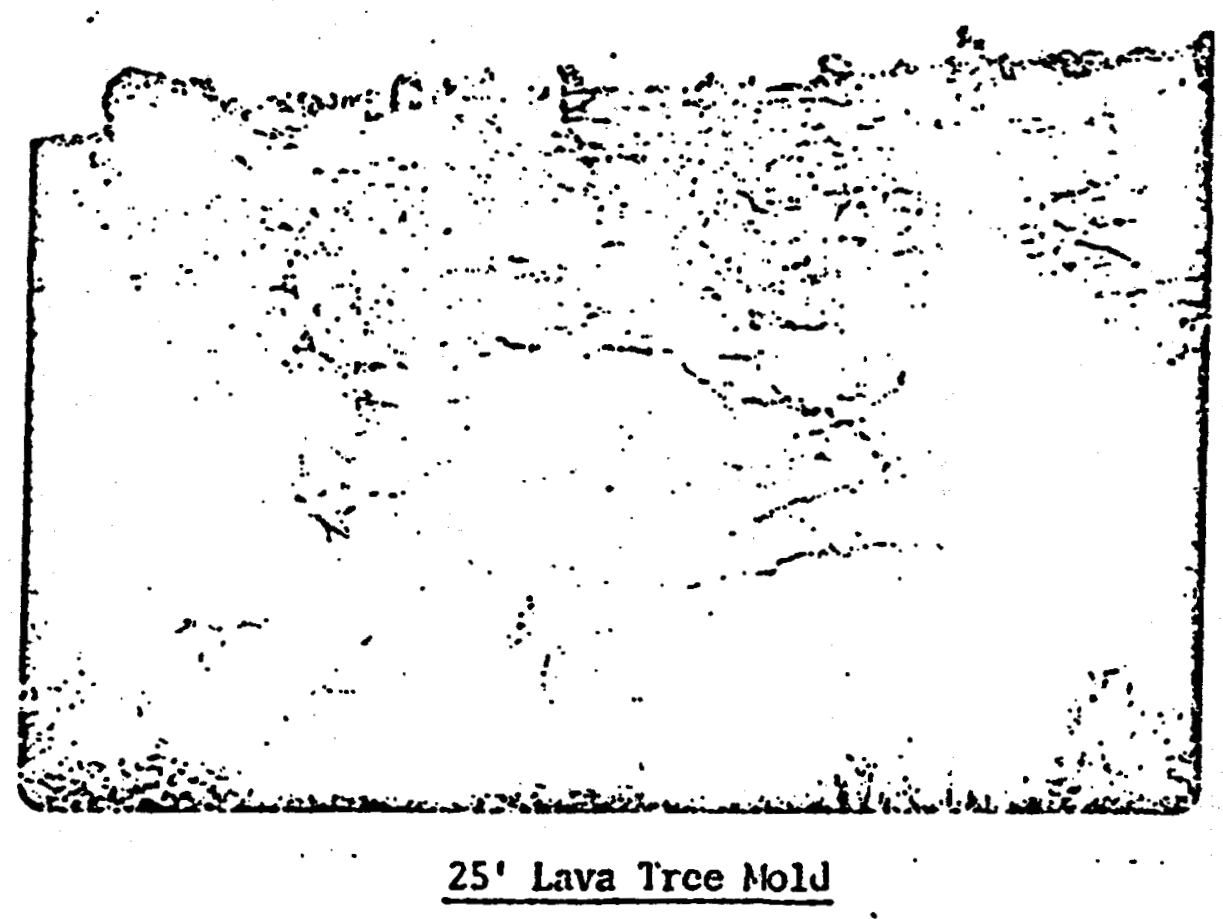




\section{Ihakea (Bobea)}

The llawailans, through long experience, knew the characteristics of the various plants which were available to them. The 'ahakea, which is found in the proposed Reserve area, is a tree 30 fect or so tall with a trunk which often reaches $1 / \xi$ feet in diameter. Being a very hard, durable wood it was utilized for canoe gunwales. To this day canoe gunwales, whatever the material, are painted yellow to initate the typically yellowish color of the ahakea.

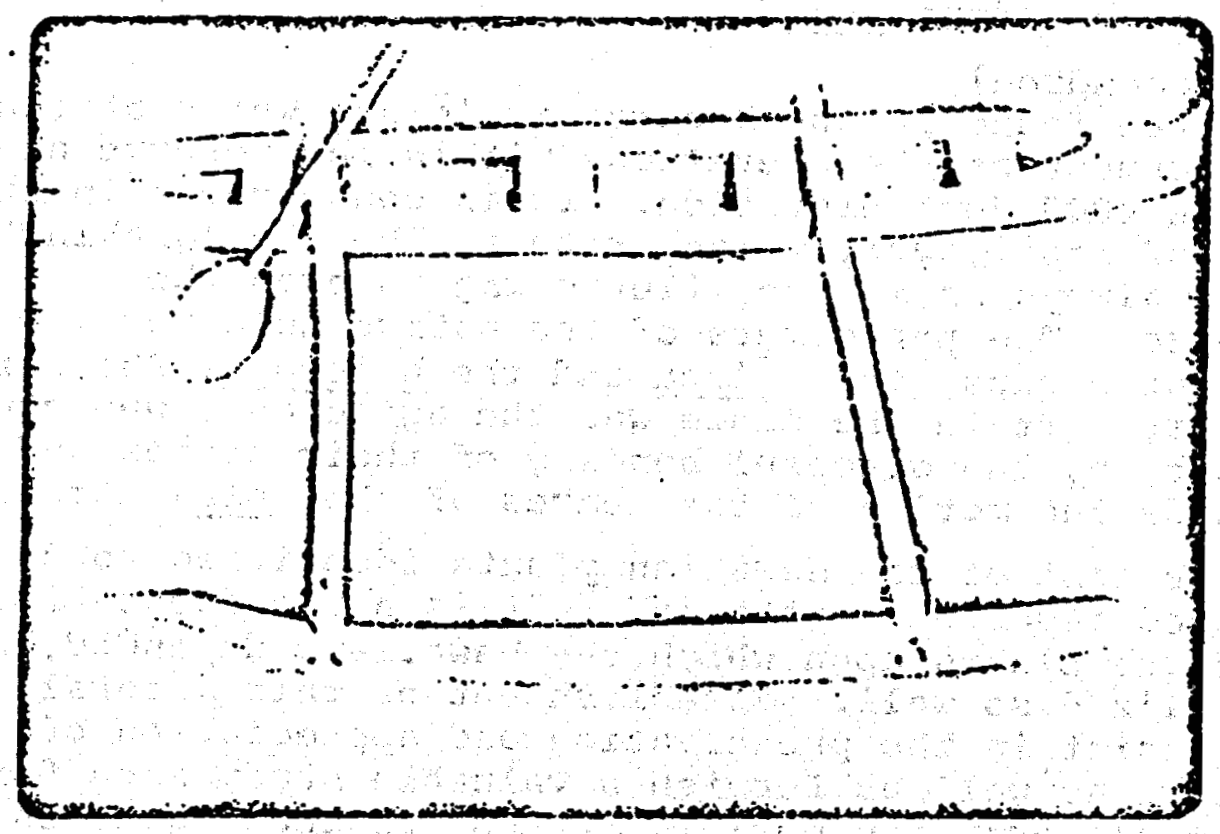

Hawailan Canoe with I Ahakea Gunwale

\section{Lama (Diospyros)}

Lama belongs to the genus Diospyros and the species found in Puns is an endemic one, found nowhere in the world except in Hawai'i. It is a medium sized tree whose wood is very hard, close grained, and of a rich reddish brown' color when old.

The lama wood was used in the construction of religious temples and a block of lama urapped in choice yellow tapa and scented with tumeric was always placed on the alter of Laka, goddess of the sacred hula.

Another use of lama was for a kapu enclosure, palama, within which an alii chiefess was consecrated and where she awaited the alii chief chosen as her first mate.

The word ma-lamalama, which refers to the lama tree, occurs in the motto of the University of Hawaii and refers to a state of enlightenment.

'rikia (Hikstro emia)

The a akia is a large shrub or small tree and is widely found on the lava fields of the Island of Hawai'i. The native Hawailans used a rope made from the tough, fibrous bark of the 
'ākia, a rope almost as good as that made from olonā, which was greatiy prized by whalers for its strength. Tho 'akia is somewhat poisonous and when pounded to a pulp and thrown into the water it had a stupefying effect on the fish, making them easier to catch.

olomea (Per ottetia)

The olomea is an attractive tall shrub or small tree, whose bright red berries droop gracefully from every branch. The wood was used by native Hawailians for proclucing fire by friction. Two sticks called aunaki were used, one of which was olomea and the other the much softer hau.

- Olapa (Cheirodendron)

Inother tree found in the Reserve is 'olapa which attains its best developmint at the elevations within the Reserve and up to about the 4000 foot elevation. It is conspicuous in the woods because of its leaves, which, rather like the "qualing" aspen tree are always in motion, fiuttering in even the slightest breeze. The performers of the native hula were divided into two groups, the 'olapa and the ho'opa'a. The former were those whose part in the dance was the agile one, who could best illustrate, by the graceful bending of their bodies and fluttering hands the motion of the leaves of the oflapa tree.

A complete list of the Hawailan plants identified to date in this proposed reserve is attached. It is a representative assortment of the plants upon which the Hawaiians depended, and which they utilized so well. Establishment of this liatural isrea Reserve will assist in the preservation and appreciaticn of Hawaiian culiure as well as firnish a valuable study arca for botanists from all over the world. If some of these species are added to the Federal Endangered specics List, the protection assured by management in a Natural Area Reserve will help fulfull the intent of State and Federal endangered species laws, and will facilitate cooperatively funded programs.

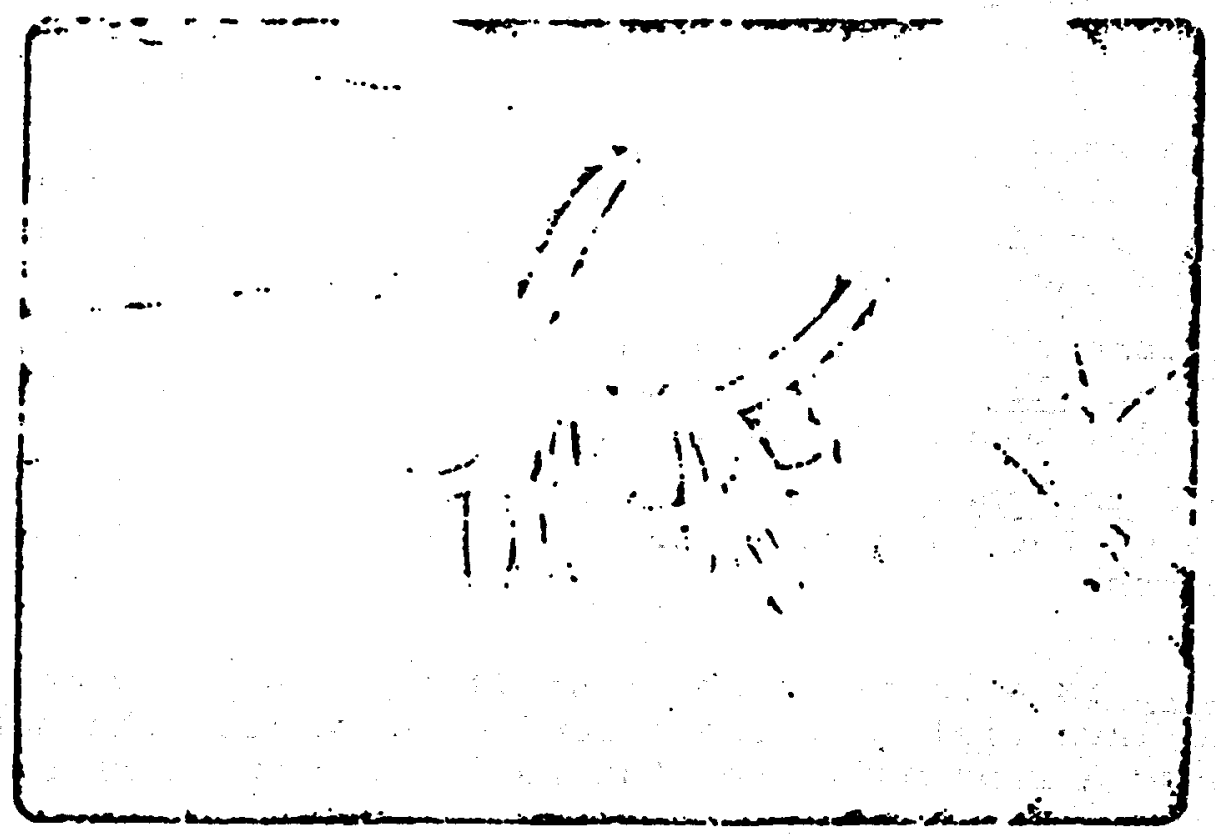


WAO KELE 'O

\section{PUNA NATURAL AREA RESERVE}

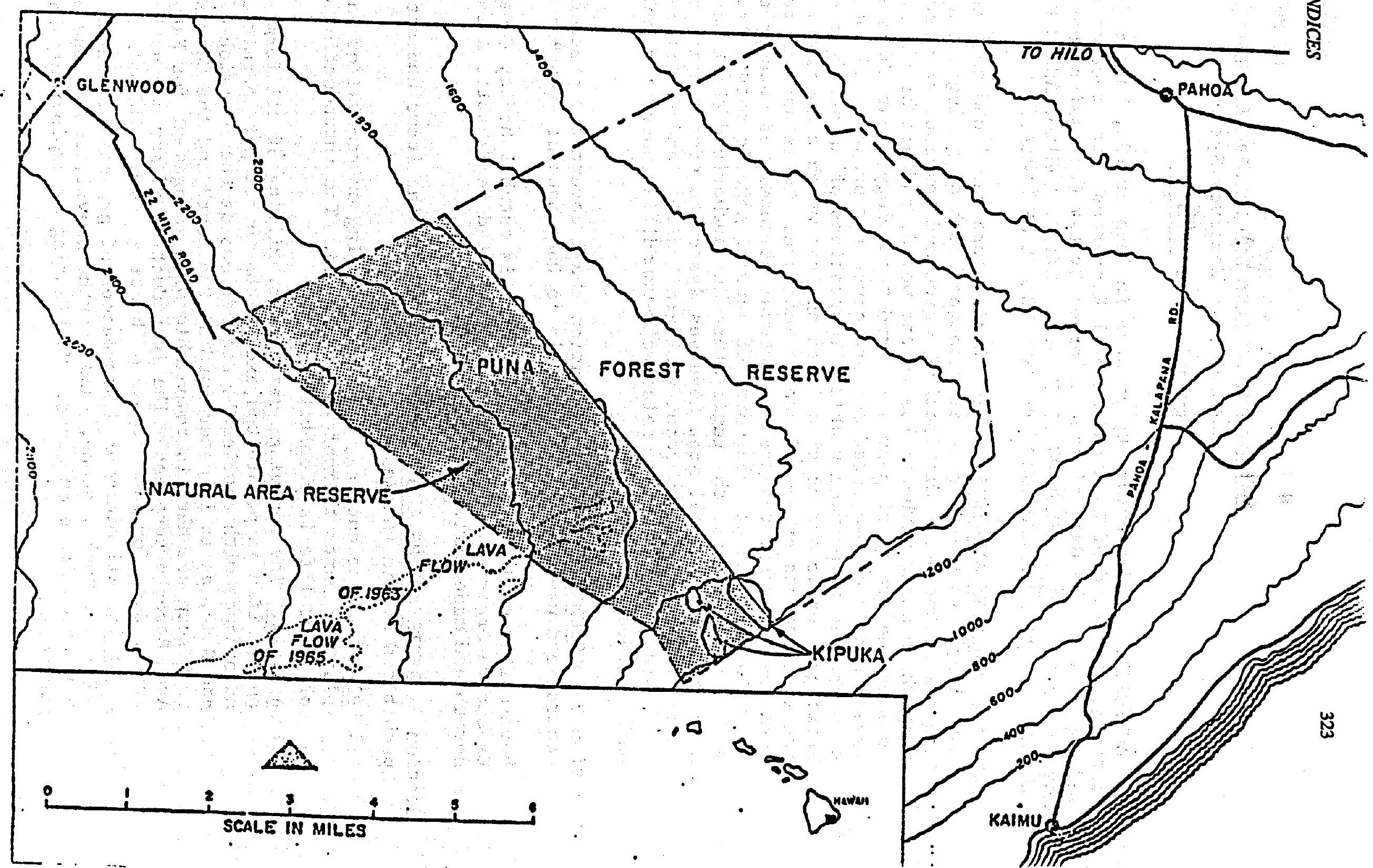


STATE OF HANAII

for Public Con:mente

DEPAPTIENT OF LAND AND NATURAL RESOURCES

Natural Area Reserves System

Regulation No. 13

AUTHORITY. Under authority granted in Chapter 195, Hawaii Revised statutes, the Board of Land and Natural Resources after recomendation and approval of the Natural Area Reserves System Comnission, hereby adopts Regulation No. 13 , RELATING TO THE PROTECTION, CONTROL AND USE OF THE WAO KELE 'O PUNA NATURAL AREA KESEKVE, ISLAÑD OF HAWAII.

Section 1 PURPOSE AND INTENT. The Legislature has found that the state of Hawail possess unique natural resources such as geological and volcanological features and distinctive marine and terrestrial plants and animals many: which occur nowhere else in the world, and are highly vulnerabie to loss by the growth of population and technology; that these unique nacurai assets should be protected and preserved for present and future gencrntions of man to provide viable illustrations of an original natural heritage, and to act as base lines against which changes being made in the environments of Hawaii can be measured. These natural resources serva when feasible, for research in natural sciences, as outdoor teaching laboratories, and as reservoirs of natural genetic materials. In keeping with these findings, the Legislature has authorized the establishment of a statewide Natural Area Reserves System to preserve in perpetuity endangered species, important geological sites, and specific land and water areas which support relatively unmodified natural conmunities of native flora and fauna.

Section 2 DESIGNATION. This regulation shall govern the protection, control and use within the wao Kele 'o Puna Natural Area Reserve.

hereinafter called the "Reserve" which is established by Governor's Executive Order No. hereto and made parts thereof.

Section 3 RESTRICTIONS AND CONTROL. The following items and activities are prohibited within the Reserve:

(1) Plants. The cutting, killing, damaging or removal of any rative plant or parts thereof is prohibited. The introduction of any form of plant life is prohibited.

(2) Animals. The removing, damaging or killing of all forms of animal life is prohibited, except that hunting is permitted in accordance with applicable regulations of the Division of Fish and Game, as it is determined by the Board and the Conmission that such use here is compatable with management for Natural

- Area Reserve purposes. The introduction of any non-native animal, except dogs for the purpose of hunting, is prohibited.

(3) Minerals. All miningor disturbances of geological features such as minerals, rocks, stone, sand, earth, gravel, fossils and other reiated substances are prohlbited. No blasting or explosions shall be permitted. 
(4) Artifacts. The appropriation, excavation, Injuring or destroying of any historic or prehistorlc ruin or monument or ary object of antiquily is prohibited.

(5) Property. The willful destruction, defacing, or disturbing of any

(6) public notice or sign, fence or gate, or other property is prohibited. Improvements. All improvements including but not limited to structures, tralls and roads are prohibited.

(7) Campino. Camping activity defined as the setting up of a tent or other temporary shelter is prohibited:

(8) Fires. The setting or building of a fire is prohiblted.

(9) pollution. The depositing of refuse, litter or any other substance which poliutes or is llable to cause pollution within the grounds or vaters within the Reserve is prohibited.

(10) Vehicles. Vehicles are prohibited within the Reserve except on designated roadways.

jection 4 EXCEPTED USES AND PERMITS. The Board of Land and Natural Resources or its authorized representative may issue permits granting exceptions to the restrictions of this regulation for research or educational purposes subject to approval of the Commission. Each permit application shall be made to the Board in writing and shall be considered on its own merits, particularly as regards its effect on the Reserve. Permits shall be non-transferable and subject to cancellation.

ection 5 PENALTY. Any person who violates any of the provisions of this regulation shall, upon conviction thereof, be fined not more than one Hundred Dollars $(\$ 100.00)$ or imprisoned not more than 30 days, or botn, for each offense.

Adopted this day of by the Board of Land and Natural Resources. Board of Land and Natural Resources By:

And by:

pproved this day of 1976

3overnor of Hawail

Approved as to form:
Approved by the Natural Area Reserves System Commission. 


\section{State of Jlaumii}

\section{Offire of the Titutenant Gavernne}

Ohis ts to Orrtify That the within is a true copy of Executive Order No..........? setting aside land for public purposes, the original of which is on tile in this office.

In Orglmony İhrreaf, the Lieutenant Governor of the State of Hawaii, has hereunto subscribed his name and caused the Great Scal of the State to be affixed. day of

A.D. 19

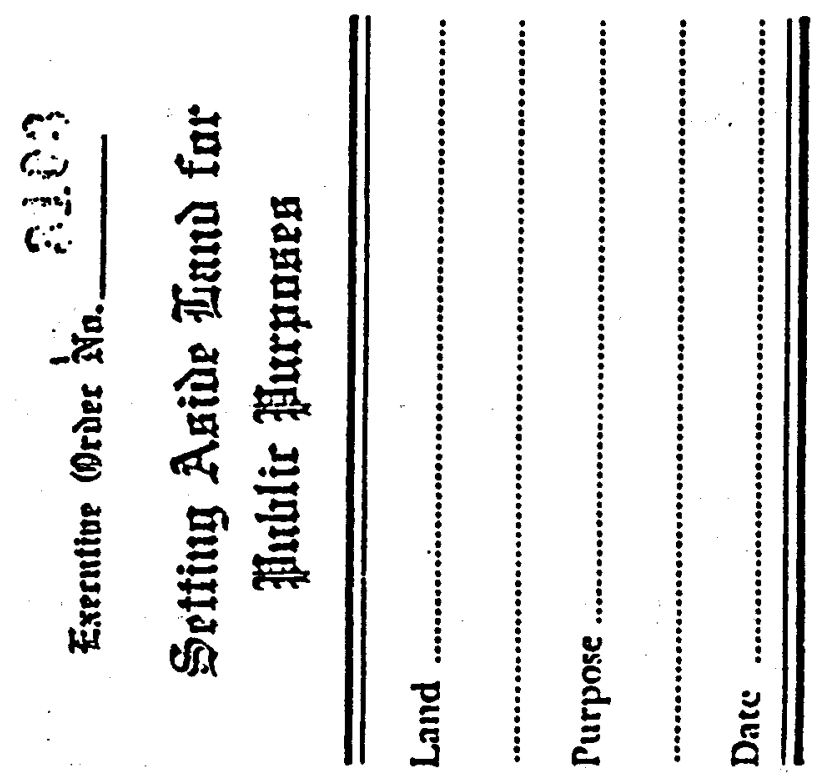




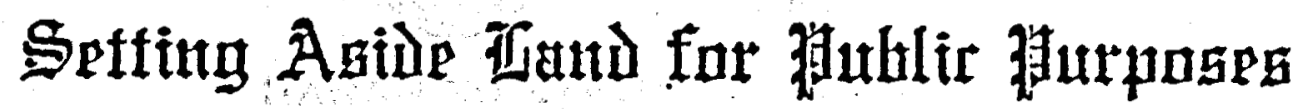

Thy this Executlue Bropr. J. thr underolgned. Gourrnor of the Elats of Huwail. by virtue of the authority in me vested by Section 171-11, Hawaii Revised Statutes, and every other authority me hereunto enabling, do hereby order that the public land hereinafter described be, and the same is, hereby set aside for the following public purposes:

FOR NATURAL AREA RESERVE, to be under the control and management of the Department of Iand and Natural Resources, state of Hawaii, being the lands situate at Puna, Island of Hawail, Hawail, and designated as WAO KELE O PUNA NATURAL AREA RESERVE, containing an area of 16,843.891 Acres, more or less, all more particularly described in Exhibit " $A$ " and delineated on Exhibit "B", both of which are attached hereto and made a part hereof, said exhibits being, respectively, a survey description and survey map prepared by the survey Division, Department of Accounting and General Services, state of hawail, both being designated C.S.F. No. 18,647 and dated May 4.1979.

SUBJECT to disapproval by the Legislature by two-thirds vote of either the senate or the House of Representatives or by majority vote of both, in any regular or special session next following the date of this Executive order.

In Mitnege Mhpreof. I have hereunto sct my hand and caused the Great Seal of the State of Ilawaijto be affixed. Done at the Capitol, at Honolulu this ....................... day of

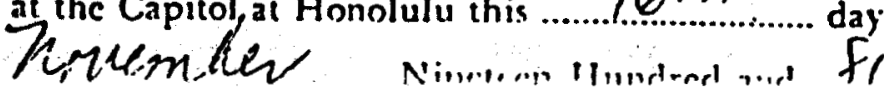




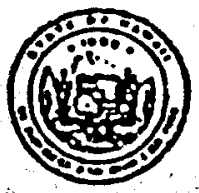
DEPT. OF ACCOUNTING AND GENERAL SERVICES HONOLULU

- WAO KELE O PUNA

NATURAL AREA RESERVE

Puna, Island of Hawa11, Hawa11

Being portlons of the Government Lands of Makuu-Kaohe, Raimu-Kehena and Rapashu-Kama111.

Beginning at the west corner of this parcel of land and at an angle on the south side of Land Court Application 1053, the coordinates of said point of beglnning referred to Government Survey Iriangulation Station "OLAA" being 55,748.7 feet South and 22,096.9 feet West, thence running by az1muths measured clockwlse from True South:-

1. $240^{\circ} 0^{\prime} 12^{\prime \prime} 16,000.00$ feet along. Land Court Application 1053;

2. $320^{\circ} 23^{\circ} 16,220.18$ feet along the remainder of Puna Forest Reserve (Governor's Proclamation dated December 22, 1928); .

3. 240" $05^{\prime} 12^{\prime \prime} 25,840.22$ feet along the remainder of Puna Forest - Reserve (Governor's Proclamation dated Decebwer 22, 1928);

4. $338^{\circ} 15^{\circ}$

5. $340^{\circ} 23^{\prime}$

6. $342^{\circ} 31^{\prime}$

7. $337^{\circ} 27^{\prime}$

8. $347^{\circ} 14^{\prime}$

9. $348^{\circ} 38^{\prime}$

10. $353^{\circ} 51^{\circ}$

11. $359^{\circ} 30^{\circ}$

12.. $358^{\circ} 59^{\prime}$

13. $332^{\circ} .38^{\prime}$
3262.76 feet along the west s1de of the 20-Foot Road; 19.26 feet along the west side of the 20-Foot Road; 250.51 feet along the west side of the 20-Foot Road; 156.17 feet along the west side of the 20-Foot Road; 271.04 feet along the west side of the 20-Foot Road; 331.85 feet along the west side of the 20-Foot Rosd; 125.10 feet along the west side of the 20-Foot Road; 1278.10 feet along the west side of the 20-Foot koad; 2128.77 feet along the west side of the 20-Foot Road; 221.69 feet along the west side of the 20-Foot Road; 
14. $315^{\circ} 33^{\prime}$

15. $258^{\circ} 17^{\prime}$

16. $352^{\circ} 29^{\prime}$

17. $56^{\circ} 27^{\prime}$

18. $39^{\circ} 38^{\circ}$
287.92 feet along the west side of the 20-Foot Road;

9.45 feet along the west side of the 20-Foot Road;

6915.35 feet along the Government Land;

1460.6 feet along Lots $3-B$ and $3-A$ of Upper Kaimu Homesteads;

3534.1 feet along Lot 3-A of Upper Kalmu Homesteads and also along Grants 6571 to K. Kamakan1, 6330 to S. Kamelamela and 6238 to D. Ramelamela;

19, $53^{\circ} 04^{\circ}$

10,520.9 feet along Government Land;

20. $53^{\circ} 31^{\prime} 30^{\prime \prime}$

21. $148^{\circ} 00^{\prime}$

22. $116^{\circ} 00^{\circ}$

23. $126^{\circ} 59^{\circ}$
9863.3 feet along Grant 9275 to James Campbell Estate;

4100.0 feet along R.P. 8030, L.C. Award 8559-B, Apana 14 to W1lilam C. Lunal1lo;

8150.0 feet along R.P. 8030, L.C. Award 8559-B, Apana 14 to William C. Lunal1lo;

25,105.3 feet along R.P. 8030, L.C. Award 8559-B, Apana 14 to Williem C. Lunelllo, to the point of beginning and contalning an AREA OF 16,843.891 ACRES.

\section{SURVEY DIVISION}

DEPARTMENT OF ACCOUNTING AND GENERAL SERVICES

STATE OF HAWAII

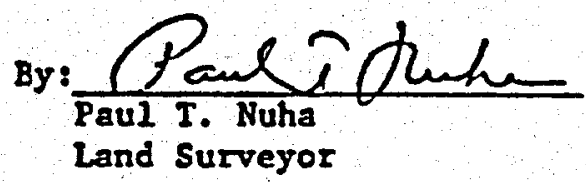

Complled from Govt.

Survey Records. 
ATTACHMENT $A$. Documents relating to the establishment of the Wao Kele $q$ Natural Area Reserve (Negative Declaration, Recommendation the BLNR from the NARS Commission, and Governor's Executive Order). State of Hawail

Department of Land and Natural Resources NATURAL AREA RESERVES SYSTEM COMMISSION NOTICE OF DETERMINATION

Negative Declaration:

for

Wao Kele 'O Puna Natural Area Reserve 


\section{Contents}

PROPOSING AGENCY........................

AGENCIES CONSULTED......................

INTRODUCTION............................

DESCRIPTION OF THE ACTION....................2

DESCRIPTION OF THE AFFECTED ENVIRONMENT..........6

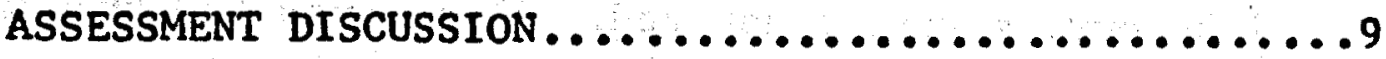

NEGATIVE DECLARATION AND REASONS THEREOF.........10

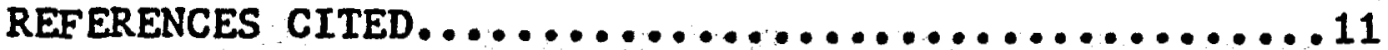

APPENDIX

I. Plant List........................12

II. Earlier drafted regulation (Reg. 13) ......13

III. Letter, Attorney General's office........15

IV. Regulation drafted $12 / 28 / 77 \ldots \ldots \ldots \ldots \ldots \ldots 17$

FIGURES

1. Location of Wao Kele 'o Puna Natural Area

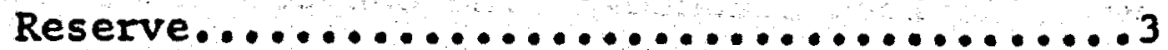

2. Land ownership adjacent to Wao Kele 0 Puna Natural Area Reserve...................8 
NEGATIVE DECLARATION FOR

WAO KELE 'O PUNA NATURAL AREA RESERVE

PROPOSING AGENCY

Natural Area Reserve System Commission, Department of Land and Natural Resources, State of Hawa11. AGENCIES CONSULTED

All divisions within the Department of Land and Naturai Resources were consulted. Also consulted through their ex-officio membership in the Natural Area Reserves System Commission were the Department of Agriculture, Department of Education, Department of Planning and Economic Development, and University of Hawaii (President's office).

\section{INTRODUCTION}

The need to protect natural areas, as cultural and scientific assets, against intense population and economic pressures on a limited natural environment was recognized by the 1970 state Legislature in enacting Chapter 195, Hawail Revised statutes. The Chapter authorized the establishment of a Natural Area Reserves System to strengthen the existing conservation programs of preserves, sanctuaries, and refuges. The natural areas selected (primarily from State-owned land) would be irreplaceable examples of all aspects of the unique and varied, original Hawailan ecological system. Their undisturbed condition would be perpetuated by allowing natural processes to prevail over human influences. As specified by the Chapter, an 11-member Commission, administratively within the Department of Land and Natural Resources (DLNR), functions as an advisory and 
policy recommending body to the Governor and the DLNR.

Two Natural Area Reserves thus far established are the Ahihi-Kinau Natural Area Reserve on Maul and the Waiakea 1942 Lava Flow Natural Area Reserve on Hawail. What follows is a Notice of Determination on the potential environmental effect of placing a parcel of Forest Reserve land within the Hawaif Natural Area Reserves System. It is the result of the assessment process conducted in compliance with Chapter 343, HRS, and the Regulations of the State's Environmental Quality Comission. DESCRIPTION OF THE ACTION

The Natural Area Reserves System Comission is reconmending that a 6,500 acre portion of the 25,700 acre Puna Forest Reserve (TMK 1-2-10:2) be established as the . Wao Kele 10 Puna Natural Area Reserve (Fig. 1). The Puna Forest Reserve, situated in the Puna District near the eastern tip of the is land of Hawaii, is in the state's Conservation District, under the jurisdiction of the DLNR.

The purpose of the proposed Natural Area Reserve is to preserve for present and future generations a representative ohi'a-fern forest ecosystem much as it existed before the arrival of Captain Cook. As much as possible to be maintained so as to allow natural processes to dominate, the Natural Area Reserve would be a living example of a natural heritage. It would serve as a long-term control against which to measure man-introduced stresses in adjacent or similar ecosystems elsewhere. It would provide an environmental and natural heritage appreciation site for citizens, teachers, and students. It would provide a research site for scientists studying the natural environment, its components, and the particular type of undisturbed ecosystem it represents. It 
WAO KELE :O

\section{PUNA NATURAL AREA RESERVE}

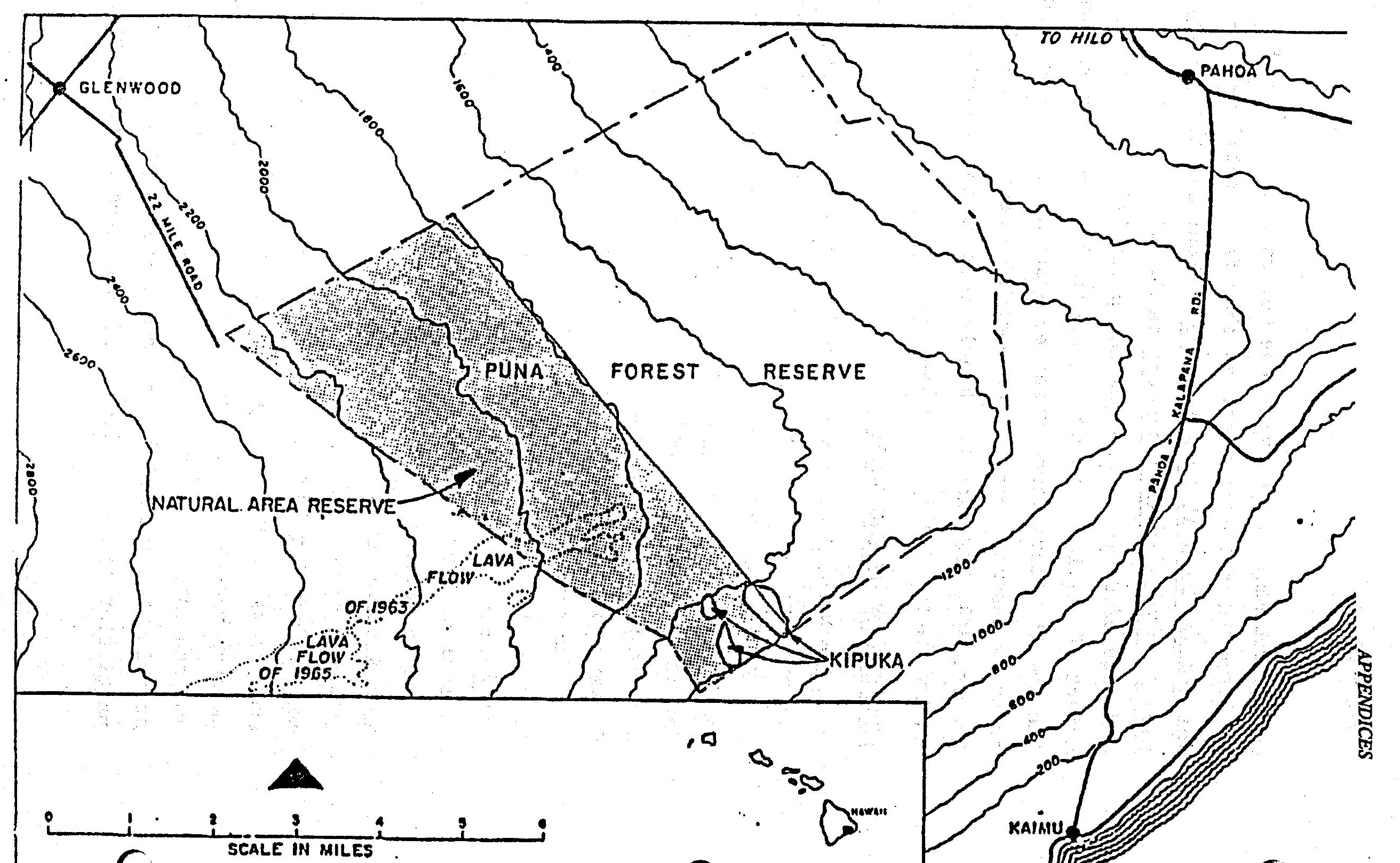


would preserve a gene pool of natlve plant and animal species, particularly of rare and endangered species.

In accordance with the requirements of Chapter 195, HRS, the Commission-recommended site is established as a Natural Area Reserve by DLNR resolution and a governor's executive order that sets aside the land for that purpose. The DLNR has the responstblility of control and management, including the formulation of the use regulation. The proposed regulation must have a public hearing and be approved by the Commission before it can be adopted by the DLNR.

A public hearing on an earlier drafted regulation (Appendix II) on the Weo Kele 'o Puna Natural Area Reserve was held in Hilo, Hawal1, Jan. 11, 1977. Mr. Steven Morse, representing the Hawailan Coalftion of Native Claims, was . the only person to testify. His written testimony requested an amendment to the proposed regulation that would "acknowledge the aboriginal rights of native Hawaiians of Puna to use Wao Kele $O$ Puna for hunting and gathering purposes." The Commission subsequently obtained a legal opinion on this matter from the Attorney General's office (Appendix III).

The regulation has since been redrafted (Appendix IV), whereby section 4 has been restructured so that any agency, citizen group, or Individual may submit an application to conduct activities prohibited by the regulation. As stated in the regulation, the application could be for research, education, management, or any other purpose. Thus, Mr. Steven Morse and other individuals may be allowed by DLNR permit to retain traditional follage or food gathering privileges. Similarly, DLNR's Division of Water and Land Development, who has expressed the desire to have water and 
geothermal development rights, could apply for a permit to develop such resources should the need arise. A well-considered decision to allow development would require comprehensive knowledge of the ecosystem and an objective evaluation of the project's impact on the environment. Its effect on the integrity of the natural preserve would be weighed against avallable alternatives and the urgency of the project in terms of public need.

Pursuant to Section 183-12, HRS, another public hearing was held to hear opinions regarding the withdrawal of 6,500 acres of land from the Puna Forest Reserve. A main concern expressed was that all or a larger portion of the Puna Forest Reserve should be designated a Natural Area Reserve. The entire Puna Forest of about 25,700 acres was at one time suggested by the Division of Forestry as a Natural Area Reserve. However, subsequent investigation showed that the purpose of preserving this type of ecosystem could be achieved with 6,500 acres, leaving the remaining forest for multiple use as needed.

With preservation as the primary objective of Natural Area Reserves, the guiding principle in the formulation of use regulations is the prevention of unnatural encroachment. Maintaining to posterity the natural state of the ecosystem can be assured only by imposing restrictive uses. Besides the explicit prohibition of destructive or damaging activities to the biological and physical elements, the proposed regulation forbids camping or the setting of a fire. The only consumptive recreation allowed is hunting, subject to applicable regulations of the Division of Fish and Game. Controlling feral pig populations is considered necessary because of the damage they cause to the vegetation and terrain (see review by Smith and Diong 1977). Enforcement of the proposed regulation will likely be 
by a forester or fish and game warden. Signs will be posted at strategic locations.

DESCRIPTION OF THE AFFECTED ENVIRONMENT

The Puna Forest Reserve is located in the center of the Puna District near the eastern tip of the island of Hawail. It is on the eastern slope of the Kilauea shield volcano that was formed by a succession of prehistorlc basalt lava flows from the Puna volcanic series (Macdonald 1949).

This eastern rift of the Kilauea volcano extends from the caldera at the 4,000 feet elevation to Cape Kumukahi. It is slashed with great fissures, pimpled with cinder and spatter cones, and blackened with recent flows. Volcanic activity along the rift in 1963 resulted in several hundred acres of new lava (Fig. 1) and added another interesting kipuka, or pocket of vegetation surrounded by barren lava. An arm of a 1977 lava flow entered the lower section of the proposed Natural Area Reserve. Because of the active volcanic condition, the vegetation cover ranges from ferns, which are among the first apparent plants to appear on fresh lava rocks, to mature forests dominated by ohi'a trees.

The soil in the proposed Natural Area Reserve is of organic composition (histosols) present as a thin layer on geologically young lava rock. The elevation rises from 1,380 feet to 2,300 feet, and the average annual rainfall ranges from 125 Inches at the lower elevation to 150 inches at the Glenwood end near 22 Mile Road. This high amount of rainfall facilitates the rapid appearance of plant life on the new lava.

The "22 Mile Road" transecting the Mamalahoa Highway at Glenwood ends about 1000 feet from the westernmost corner of the proposed Natural Area Reserve. Glenwood itself, with a 
population of about 100 , is about 4 miles away. The Natural Area Reserve would be bounded (Fig. 2) by James Campbell Trust Estate land along all of its southwestern side and by Hawaii's Eden Rock Estate (Mountain View Development Corporation) and Fern Forest Vacation Estates (Finance Realty Ltd.) at the northwestern face. The latter two estates are selling subdivision plots amid a road system that has been constructed up to the present Forest Reserve boundary. The remaining sides of the proposed Natural Area Reserve would adjoin state-owned land. This section could be approached by vehicles using an existing jeep trail that would skirt the easternmost corner of the Natural Area Reserve. The jeep trail originates from the end of a $4-\mathrm{mile}$ arm of the Pahoa-Kalapana Road.

Aerial photographs and ground surveys show that the area is predominantly an ohi'a-fern ecosystem. While the ohi'a belongs to a genus that has representatives in many parts of the Pacific, species of ohi'a occurring naturally in Hawali are considered by some botanists (e.g. St. John 1973) to be unique to the Islands. It can be found at sea level to near the 9000 foot elevation, within which it grows as a low creeper to tall trees (Rock 1913). The most extensive forests and its best development, with heights of nearly 100 feet and a trunk diameter of several feet, occur on the volcanic slopes of Hawail Island (Rock 1913). In the higher, wetter area of the proposed Natural Area Reserve, ohi'a and hapu'y or tree fern, is a common association; in the newer and drier areas ohi'a is usually found with uluhe, the false staghorn fern.

The flowers of the ohi'a are usually bright red, matching the plumage of the native i'iwi bird which feeds on the flowers' nectar (Rock 1913). Birds are not as numerous as at 
APPENDICES

higher elevations but, besties the 1liwl, the elepaio, amakihi apapane, and oma'o have been recorded (James Jacobi, pers. commun.).

Although the ohi'a-fern association is the predominant feature of this native Hawailan forest, there are numerous other native plants to be found (Appendix I), some of which are endangered species. In the absence of an extensive biological survey, the plant list is merely a general indication of what is present.

\section{ASSESSMENT DISCUSSION}

The assessment process consisted of identifying and evaluating potential impacts after a discussion of the proposed action, its objectives, and a description of the site involved. Agencles and Individuals having some expertise and familiarlty with the area were consulted.

It was determined that, as the purpose of having a Natural Area Reserve is to protect and preserve the existing natural habitat and all the natural things that occur in it and act upon it, the proposed action would neither destroy nor degrade the quality of the physical and biological environment. This favorable impact on the environment, in turn, would afford the equally beneficlal Impact of retalning an original natural resource that would always be available for such things as heritage appreciation, environmental awareness, scientific study, and education. Establishing the site as a Natural Area Reserve would not adversely alter current opportunities for public use. Presently a part of the Puna Forest Reserve, the proposed site is being administered according to conservation measures outlined in Regulation No. 1 of the Division of Forestry. But the more stringent preservation demands of the Wao Kele o Puna Natural Area Reserve would exclude camping; fires, 
and nearly all "special use" activities that can take place in a Forest Reserve. Hunting, which would be allowed as it is considered a desirable management tool, is the present major recreational activity.

Non-destructive and non-consumptive uses, such as hiking, photography, and environmental education and appreciation, are generally encouraged in Natural Area Reserves. However, accessibility is a problem and, according to the DLNR Division of Fish and Game and Division of Forestry, public use (other than hunting) of the Puna Forest Reserve has been practically nil, largely because of hazards of the clinker a'a lava terrain and the entangled uluhe cover.

With respect to the desire of aboriginal Hawailans to have the right by tradition to gather plant material for home use and consumption, such practice could be allowed in the Natural Area Reserve by an excepted use permit. In considering what the effect may be should a permit be denied, it should be noted that the proposed Natural Area Reserve regulation dealing with protection of the vegetation is basically similar to that already prescribed in Regulation No. 1 for Forest Reserves:

NEGATIVE DECLARATION AND REASONS THEREOF

The environmental assessment has indicated that an environmental impact statement is not required. The proposed action is not expected to have an adverse effect on the economic or social welfare of the area. Its objective being to preserve and maintain natural features, the proposed action does not involve any modification to the physical or binlogical environment. 


\section{References Cited}

Macdonald, G. A. 1949. Petrography of the island of Hawai1. U. S. Geological Survey, Professional Paper 214-D.

Rock, J. F. 1913. The indigenous trees of the Hawaiian Islands. (Privately published.)

St. John, H. 1973. List and summary of the flowering plants in the Hawailan Islands. Pacific Tropical Garden Memoir No. 1.

Smith, C. W. and Diong, C. H. 1977. Proposal to study feral pigs in Kipahulu Valley, Haleakala National Park. National Parks Service, Cooperative National Park Resources Studies Unit/University of Hawaii, Technical Report 19. 


\section{APPENDIX I}

NATIVE PLANTS IDENTIFIED TO DATE IN THE WAO KELE 'O PUNA IIATURAL AREA RESERVE

Glenwood or mauka side

ohi'a

olapa

kawau

manono

pilo

alani

hapu'u

kanawao-ke'oke'o

kanawao

oha

maile

i'el'e

akia

$\because$ olomea

tanini
Metrosideros

Cheirodendron

Ilex

Gouldia

Coprosma

Pelea

Cibotium

Cyrtandra

Broussais ia

Clermontia

Alyxia

Freycinetia

Wikstroemia

Perrottetia

Eurya
Kalapana or makai side

ohi'a

akia

i'ei'e

lama

mamaki

olomea

pilo

*ahakea

alani

maile

opuhe

kopiko

hapu'u

uluhe

hoio

haha
Metrosideros

Wikstruemia

Freycinetia

Diospyros

Pipturus

Perrottetia

Coprosma

Bobea

Pelea

Alyxia

Urera

Psychotrla

Cibotium

Dicranopteris

Athyrium

Cyanea

*On the Smithsonian list of endangered species.

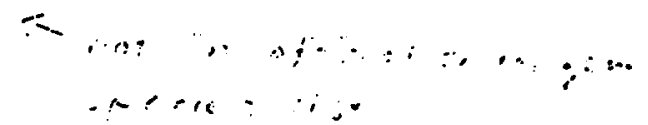




\section{DEPARTRENT OF LAND AND NATURAL RESOURCES}

Natural Area Reserves.System

Regulation No.

AUTHORITY. Under authority granted in Chapter 195, Hawaii Revised utes, the Board of Land and Natural Resources after recommendation approval of the Natural Area Reserves System Comission, hereby adopts lation No. 13, RELATING TO THE PROTECIION, CONTROL AND USE OF THE KELE 'O PUNA NATURAL AREA KESEKVE, ISLA:ID OF HAWAII.

Ion 1 PURPOSE AND INTENT. The Legislacure has found that the state of Hawaii possess unique nacural resources such as geological and volcanological features and distinctive marine and terrestrial plants and animals. many which occur nowhere else in the world, and are highly vulnerable to loss by the growth of population and technology; that these unique natural assets should be protected and preserved for present and future gererations of man to provide viable illustrasions of an original natural heritage, and to act as base lines against which changes being made in the environments of Hawali can be measured. These natural resources serve. when feasible, for research in natural sciences, as outdoor teaching laboratories, and as reservoirs of natural genetic materials. In keeping with these findings, the Legislature has authorized the establishment of a statewide Natural Area Reserves System to preserve in perpetuity endangered species, important geologicai sites, and specific land and water areas which support relatively unmodified natural communities of native flora and fauna.

Ion 2 DESIGNATION. This regulation shall govern the protection, control and use within the wao Kele 'o Puna Natural Area Reserve.

hereinafter called the "Reserve" which is established by Governor's Executive Order No. hertto and made parts thereof. and designated in. Exhibits $A$ and $B$, attached

Ion 3 RESTRICTIONS AND CONTROL. The following items and activities are prohibited within the Reserve:

(1) plants. The cutting, killing, damaging or removal of any native plant or parts thereof is prohibited. The. introduction of any form of plant life is prohibited.

(2) Animals. The removing, damaging or killing of all forms of animal life is prohibited, except that hunting is permitted in accordance with applicable regulations of the Division of Fish and Game, as it is determined by the Board and the Commission that such use here is compatable with management for Natural Area Reserve purposes. The introduction of any non-native animal. except dogs for the purpose of hunting, is prohibited.

(3) Minerals. All minirgor disturbances of geological features such as minerals, rocks, scone, sand, earth, gravel, fossils and other reiaceu substances are prohibited. No blasting or explosions shall be permitted. 
antiquity is prohibited.

(5) Property. The willful destruction, defacing, or disturbing of any Fublic notice or sign, fence or gate, or pther property is prohibi

(6) Improvements. All improvements including but not limited to structur trails and roads are prohibited.

(7) Camping. Camping activity defined as the setting up of a tent or other temporary shelter is prohibited.

(8) Fires. The setting or building of a fire is prohibited.

(9) Pollution. The depositing of refuse, litter or any other substance which pollutes or is liable to cause pollution within the grounds or waters within the Reserve is prohibited.

(10) Vehicles. Vehicles are prohibited within the Reserve except on designated roadways.

jection 4 EXCEPTED USES AND PERMITS. The Board of Land and Natural Resources or its authorized representative may issue permits granting exceptions to the restrictions of this regulation for research or educational purposes subject to approval of the Commission. Each permit application shall be made to the Board in writing and shall be considered on its own merits, particularly as regards its effect on the Reserve. Permits shall be non-transferable and subject to cancellation.

iection 5 PENALTY. Any person who violates any of the provisions of this regulation shall, upon conviction thereof, be fined not more than One Hundred Dollars $(\$ 100.00)$ or imprisoned not more than 30 days, or both, for each offense.

Adopted this day of by the Board of Land and Natural Resourc Board of Land and Natural Resources By:

And by:

pproved this day of 1976 Approved by the Natural Area Reserves System Commission

Governor of Hawaii

Chairman

Approved as to form: 
(3) Minerals and fossils. To retnove, damage, dig or otherwise disturb any geological or paleontological feature or substance.

(4) Artifacts. To remove, damage or destroy any historic property.

(5) Property. To remove, damage or disturb any notice, marker, structure or any other property.

(6) Improvements. To engage in any improvement or construction, except that related to the establishment and repair of interpretive signs and associated foot trails.

(7) Camping. To engage in any camping astivity defined as the setting up of a tent or other temporary shelter.

(8) Fires. To set or maintain a fire.

(9) Pollution. To deposit refuse, litter or Introduce any substance which pollutes or is. Ilable to cause pollution.

(10) Vehicles. To land any aircraft or operate any land vehicle.

SECTION 4. Excepted Uses and Permits. The Board of Land and Natural Resources or its authorized representative, subject to approval of the Commission, may issue permits to engage in activities prohibited in this regulation for research, education, management or other purposes. All permit applications shall be made to the Board in a written statement that Includes the project's purpose and the potential effect of its activities on the protected environment. Each application shall be considered on its own merits as related to the project's impact on the environment.

SECTION 5. Penalty. Any person violating any of the provisions of this regulation shall, upon conviction thereof, be fined not more than $\$ 100,00$ or imprisoned not more than 30 days or both, as provided under sec. 195-8, Hawail Revised Statutes. 
Under authority granted in Chapter 195, Hawaii Revised Statutes, as amended, the Board of Land and Natural Resources after recommendation and approval of the Natural Area Reserves System Commission, hereby adopts the following regulation for the protection and preservation of the Wao Kele 'O Puna Natural. Area Reserve.

REGULATION_— CONCERNING THE PRESERVATION AND PRDTECTION OF THE WAO KELE 'O PUNA NATURAL AREA RESERVE, ISLAND OF HAWAII.

SECTION 1. Purpose. The Legislature, recognizing that the State of Hawail possesses unigue natural resources which are highly vulnerable tc loss by the growth of population and technology, has authorized the establishment of a statewide Natural Area Reserves System to preserve in perpetuity endangered species, important geological sites, and specific land and water areas supporting relatively unmodified communities of native flora and fauna. This regulation preserves and protects the biological and geological features within the Wao Kele 'o Puna Natural Area Reserve.

SECTION 2. Applicability. This regulation shall apply to all persons entering, visiting, hunting, or who are otherwise within the boundaries, described in Exhibit $A$, of the Wao Kele 'O Puna Natural Area Reserve, established by Governor's Executive Order No.

SECTION 3. Preservation of the Natural Environment. Everything is protected, except for game animals hunted according to Division of Fish and Game regulations. Walking, observing, and nature study are permitted activities. Unlawful activities are:

(1) plants. To remove, injure or kill any form of native plant. To introduce any form of plant life.

(2) Animals. To remove, in jure or kill any form of native animal life. To introduce any animal, except dogs when permitted by applicable Division of Fish and Game hunting regulations. 


\section{STATE OF HAWAII}

\author{
STARE CAPITOL \\ ATH FLOOR \\ MONOLULU. MAWAII gop1s
}

March 31, 1977

\section{MEMORANDUM}

TO: Christopher Cobb, Chairman and Member Board of Land and Natural Resources

ATTN: Steve Montgomery, Commission Staff Specialist

FROM: Susan Y. M. Chock, Deputy Attorney General

SUBJECT: Draft of Proposed Regulation 13 for

Proposed Wao Kele 'O Puna Natural Area Reserve

In response to your letter of March 2. 1977, we understand your first question to be whether native Hawaiians are exempt from the Rules and Regulations of the Natural Area Reserve Systems Commission.

From the attached copy of testimony, it seems that stephen Morse is referring to Section 7-1. Hawaii Revised statutes, also known as rights of the native tenants. The statute and wording have a history that predates the Territory of Hawaii. While there are studies and articles discussing the native tenant rights, there has been no case law defining the rights explicitly or illustrating the applicability in our modern private property system.

However, in this instance, we do not reach such questions as can be formulated from the above problems because there is no conflict with the rulemaking power of the Department of Land and Natural Resources under Section 175-5. Hawaii Revised statutes. The purpose of the rules and in fact. Chapter 195, H.R.S.. is to control 
MEMORANDUM TO:

Christopher Cobb, Chairman

and Member

Page 2

March 31, 1977

and protect the areas in the reserve system. They do not address themselves to the right to use the area, which includes the picking of ti leaves, firewood and other plants for home use and also, the right to the water and use of roadways. Instead, the rules and regulations set up procedures for the regulation and control of the use of the natural area reserves. All person desiring to use the area are subject to the regulations. In this way, any and all persons in Hawai. are able to use and enjoy the natural area reserves.

Persons wishing to participate in the seemingly unrestricted right given in section 7-1, H.R.S., must then. prove that they are one of the people covered by Section 7-1.

Accordingly, we answer your first question in the negative. Native Hawaiians who wish to be exempt from the Rules and Regulations under Section 7-1, H.R.S., must be able to prove that they are covered and intended to be benefited under Section 7-1, H.R.S.

As for your second question dealing with the language of Section $3(1)$ and $(6)$, we find no legal objection. However, we suggest that you substitute "permanent or improved" for "improved" in section $3(6)$.

Sus-ỹ Cro

Deputy Attorney General

SYMC : msk

Enc. 


\section{APPENDIX G}

\section{CLASSIFICATION OF PUNA INFORMANTS}

Table G1. Classification of Puna informants

\begin{tabular}{rcc}
\hline \multicolumn{3}{c}{ Age Group Distribution } \\
\hline & Number & Percent \\
\hline Under 20 years & 14 & 29 \\
$20-39$ years & 13 & 27 \\
$40-59$ years & 12 & 24 \\
60 and over & 10 & 20 \\
Total & 49 & 100 \\
& & \\
\hline Gender Group Distribution \\
\hline Male & 29 & 59 \\
Female & 20 & 41 \\
Total & 49 & 100 \\
& & \\
\hline Respondent's Qualifications by Category & \\
\hline Category A & 43 & 88 \\
Category B & 0 & 0 \\
Category C & 4 & 8 \\
Category D & 0 & 0 \\
Category E & 2 & 4 \\
Category F & 0 & 0 \\
Total & 49 & 100 \\
\hline
\end{tabular}

a Categories are not mutually exclusive, qualifications were based on respondent's primary identification. Categories are defined in Chapter 1 , pp. 6-7. 


\title{
APPENDIX H
}

\section{FISH SPECIES CAUGHT IN PUNA 58}

\begin{abstract}
Akule -is also referred to as the big-eyed scad; swims in school from place to place, but prefers large bays; the juveniles are referred to as halalu; common in the spring and early summer; are caught by hook or net.
\end{abstract}

Aholehole-is a small perch-like fish; the young are relatively common along sandy beaches, older ones inhabit rocky or coral areas; are found in salt, brackish, and fresh water; are caught by hook and net.

Ahi-also known as yellow-fin tuna; are often found in schools in deep water and are more common during the spring and summer; can weigh up to 200 pounds; are caught on hook and known for their immense strength.

Aku -is also referred to as bonito or skip-jack; tend to school in the deeper ocean areas and are more common during the spring and summer; can weigh up to about 25-30 pounds; are caught in abundance on hook and line.

Aweoweo-sometimes referred to as big-eye and are found to grow up to 12 inches long (a larger variety up to 20 inches); they have a brilliant red color and are generally caught at night on hook and line; have a prized white meat and are sometimes found in schools in the shallow reef areas.

Ehu -is a type of reddish snapper that swim in deeper waters; is a relatively rare fish, but found in waters sumounding the Big Island; is caught on hook and line and eaten a variety of ways-raw, cooked in imu, etc.

Enenue -is also known as a rudder or pilot fish and has a flat, solid body; is caught with spear or net, is difficult to catch because it leaps over nets; its habitat is the nearshore reef where it feeds on limu (seaweed) and its entrails have a strong odor; was one of the most popular fish with Hawailans.

Kala - is also known as a unicorn fish because of distinguished horn-like spine on the forehead; it has a very tough scaleless skin that is used for small knee-drums; it inhabits the reefs, has a strong odor, and is a very popular fish among Hawairans.

Kole-it is a small dark brown fish that is relished for its flavor; they live in schools in the reef areas.

Kumu -it is also known as a goat-fish and has a bright reddish color; it caught in the nearshore and deep sea regions; it is prized for its flavor and was used extensively as an offering to the gods.

${ }^{58}$ Information regarding fish species was provided by informants and the reference book, Native Fish Species in Hawaii, M. Titcomb (1977), University of Hawai' $i$ Press. 
Manini-it is also known as a surgeon-fish; it is a small yellow, black-banded fish that inhabits the nearshore reefs; is one of the most common and sought after fish that is caught with net or spear; they were traditionally caught by the thousands, dried, and taken inland for trade.

Moi-is also known as the thread-fish; is a silvery fish with whiskers that are caught with pole or net; it is the most delicious fish that was consumed by the ali' $i$ and commoners were not allowed to eat it; they travel in large schools and lives in the foamy white-water along the waters edge.

Opakapaka - is also known as the blue snapper and inhabits the deeper regions of the ocean; they are generally caught by hook and line; they are a long, thick, fleshy fish that is traditionally preferred more by non-Hawaiians than Hawaiians.

Opelu-is also known as the mackerel scad; they live in large schools that inhabit offshore and bay areas; are perhaps the "staple" fish for Hawaiians; are generally caught by net or pole by the thousands and often dried.

Papio/Ulua -is also referred to as the crevally; the juvenile version (under 10 pounds) is referred to as papio, and the adult version referred to as ulua can exceed 100 pounds; they inhabit areas inside and outside the reef, are voracious feeders with great strength; are generally caught with pole or spear, and are prized for eating.

Uhu-is also known as the parrot-fish; they live in the reef areas and feed on coral; they are a favorite eating fish for Hawaiians and have soft, white flesh that is somewhat mushy; often caught by spear.

Uouoa-is also referred to as the false mullet; they are silvery fish that live in schools in the brackish or shallow reef areas and are generally caught by net; they have been described as a small, yet tasty fish.

'U'u-is also known as the squirrel-fish or menpachi; it often lives in schools in the reef areas; they bite vigorously and are caught in abundance by net or pole at night during the summer months; has a distinct reddish color.

Weke-are multiple species of surmullets; they live in schools in shallow waters with sandy bottoms; are caught by net, spear, or pole and noted for their tender white flesh. 


\section{APPENDIX I}

\section{OCEAN RESOURCES GATHERED IN PUNA 59}

A'ama Crab-is a small, crab that scurries along the rocky shoreline; the rugged lava shoreline provides an excellent backdrop for these black crabs; they are easier to catch at night than during the day when they are alert; its meat is delicate and often prepared with Hawaiian salt and kukui nut.

Kupe'e-these sea snails prefer the darkest, moonless nights to emerge from the sand and crevices to crawl and feed on the rocks; the meat is a delicacy and the shells are made into necklaces.

Limu-is a generic term for a variety of subspecies of edible seaweed or algae; they are picked by hand and prefer certain water conditions (e.g., where freshwater mixes with saltwater); to prepare limu, one must clean them and they are often mixed with fish, opihi, etc.; they are also the primary food of the turtle and some species of fish.

Opae Ula-is a very small red shrimp that lives in anchialine ponds and where freshwater enters the ocean; during the day they sun themselves and are often scooped up and used as palu or chum to attract fish.

Opihi-is a limpid that lives in rocky shoreline areas that are pounded by waves; they have a very strong suction or grip when disturbed and must by quickly chipped from the rock; they are a delicacy that has become increasingly rare.

Ula-is also known as spiny lobster; they live in crevices along the rocky shoreline and are most active at night; they are usually grabbed by divers, but are sometimes caught by hook and line.

Wana - is also known as sea urchin; they live attached to rocks in the shallows and are caught by hand although getting pricked by their spines is very painful; the shell is cracked open and the orange eggs are consumed.

\footnotetext{
${ }^{59}$ Most of the information regarding the various species was provided by informants
} 


\section{APPENDLX J}

\section{PLANTS GATHERED IN PUNA 60}

$A^{\prime}$ 'ali' $i$-is a shrub that grows abundantly in the vicinity of Kilauea; it is sacred to Laka and Kapo, the goddess of hula; various parts of the plant were used by Hawaiians-the brilliant red flowers were collected and used in adornments for hula, and was used as ink and in dyes.

Awa kolo-is a member of the pepper family; it has a strong narcotic affect and was valuable medicine for Hawaiians as it was used as a basic ingredient in remedies for a variety of problems.

Flowers-the informants mentioned that they picked a variety of flowers that often grew along the trails edge in the forest; these flowers were used in making leis.

Guava - the young shoots are used to make medicine for remedying stomach problems such as constipation or for cleaning out the system.

Hapu' $u$-is also known as the tree fern and grows in the dense rain forest; it can reach enormous heights (over twenty feet) and was heavily harvested for its pulu or brown silky hair that was once exported for making pillows and mattresses; pulu is still used and the young fronds are cooked and eaten.

Ko'oko'olau-is a plant that grows from the shoreline to higher mountain elevations; is greatly valued by Hawaiians who stripped leaves from the plant and dried them, and made tea that was considered a tonic or blood purifier.

'Ie'ie - is also known as the climbing screwpine; the flower is used to make medicine that strengthens the body and alleviates aching backs and joints.

Laua' $\mathrm{e}$ - is characterized by a short rootstock from which arise flat, finger-like fronds; some varieties have brown spores on the underside, others do not; is used for hula adornments and lei po'o (head leis); it is also used for medicinal purposes to treat kidney ailments.

Lauhala -is also referred to as pandanus and lives in the coastal regions; its greatest value are its reddish-brown leaves that are used in thatched roofs, floor covering, mats, and for making baskets, hats, and adormments. The lauhala from Puna is known for its fine quality.

Maile -is a twining vine that bears smooth, shiny leaves that are arranged in twos, threes, or fours; it is one of the favorite plants of Hawaiians who use the fragrant leaves to weave leis. The Puna Maile in known for its strong fragrance.

\footnotetext{
${ }^{60}$ Most of the information was provided by informants and reference was made to Plants of Hawai ${ }^{\circ} i$ National Park: Illustrative of Plants and Customs of the South Seas. O. Degener (1975), Ann Arbor, MI.: Braun-Brumfield, Inc.
} 
Mamake-is a shrub that is found growing in open wooded areas; its leaves are picked are dried for making tea and dies, and the fruits are occasionally eaten by Hawaiians as a laxative.

Mango-is the fruit from trees that were planted by Hawaiians along trails in Puna; some informants stated that they still ventured along the trails and picked mango for consumption.

$\mathrm{Niu}$-is also known as the coconut; most the trees grew naturally or were planted along the coast; the fruit provided materials for a multitude of uses-fibers were made into rope used in building and mending; the shell was used for drinking cups and art-work; and the coconut flesh and milk was used for haupia (pudding), and added to other dishes that were cooked.

Noni-is a small tree with large green leaves that is believed to be brought to Hawai $i$ by the progenitors of the Hawaiian race during their great migrations; the fruit is generally used medicinally and it made into a drink that is believed to cure a variety of problems including kidney and lung diseases; it is generally found in the low-lying coastal areas in Puna.

Ohia Lehua-is the commonest tree in Puna and ranges from the coast to the higher rainforest; is recognized by its green-gray leaves and clusters of scarlet or yellow flowers; the flower is considered sacred to Pele and are used along with new shoots of leaves in leis and hula adornments; its wood is used in building structures and making bowls and other art forms.

Orange-is the fruit from trees that were planted by Hawaiians along trails in Puna; some informants stated that they walked the trails and picked oranges from trees planted long ago.

Pa'iniu-is a member of the lily family; the skin of the plant was often stripped and used to make lei; the juices from this plant were also used to make medicine for the treatment of hemorrhaging in women.

Pala'a - is a fern that dwells on the forest floor; it has long pinnate fronds that are used for leis and hula adornments.

Palapalai-is a fern that dwells on the floor of the forest; it has long fronds that are used for leis and hula adornments.

Pink opiko - a plant that had medicinal qualities; it was used to make tea for women after miscarriage and helps strengthen the womb so the women can hold the fetus.

True koli-is also referred to as the castor bean plant; it is used in the treatment of diabetes and saves appendages from being amputated. 


\section{APPENDIX $\mathrm{K}$}

\section{CLASSIFICATION OF SOUTH MAUI INFORMANTS}

Table K1. Classification of South Maui informants

\begin{tabular}{|c|c|c|}
\hline \multicolumn{3}{|c|}{ Age Group Distribution } \\
\hline & Number & Percent \\
\hline $\begin{array}{r}20-39 \text { years } \\
40-59 \text { years } \\
60 \text { and older } \\
\text { Total }\end{array}$ & $\begin{array}{r}8 \\
22 \\
7 \\
37\end{array}$ & $\begin{array}{r}22 \\
59 \\
19 \\
100\end{array}$ \\
\hline \multicolumn{3}{|c|}{ Gender Group Distribution } \\
\hline $\begin{array}{r}\text { Male } \\
\text { Female } \\
\text { Total }\end{array}$ & $\begin{array}{l}25 \\
12 \\
37\end{array}$ & $\begin{array}{r}68 \\
32 \\
100\end{array}$ \\
\hline \multicolumn{3}{|c|}{ Respondent's Qualifications by Category } \\
\hline $\begin{array}{l}\text { Category A } \\
\text { Category B } \\
\text { Category C } \\
\text { Category D }\end{array}$ & $\begin{array}{r}7 \\
5 \\
27 \\
3\end{array}$ & $\begin{array}{r}33 \\
14 \\
73 \\
8\end{array}$ \\
\hline $\begin{array}{r}\text { Category } \mathrm{E}^{a} \\
\text { Category } \mathrm{F} \\
\text { Total }^{b}\end{array}$ & $\frac{12}{54}$ & $\frac{33}{161}$ \\
\hline
\end{tabular}

a A majority of the respondents belonged to a Hawaiian organization. None of them, however, qualified for the study based on this criterion alone.

$b$ The percent exceeds 100 due to multiple qualifications of respondents. 


\section{APPENDIX L}

\section{HAWAIIAN PLANTS IN SOUTH MAUI 61}

'A'ali'i (Dodonaea viscosa) -hardwood used in house building; leaves or bark used to make a lotion for rashes and skin eruptions.

'Ae (Polypodium pellucidum)—native fern, wood used in spear making.

A'e Manele (Sapindus saponaria) - seeds strung into lei and necklaces.

'Ahakea (Bobea elatior)-a smaller trees used in canoe-making (carved pieces at the bow and the stern), poi boards, paddles, etc.

Ahuhu (Teprhosia purpurea)-poisonous plant used to catch fish.

Ahu'awa (Mariscus javanicus)_-a sedge, used for cordage and for making fiber strainers.

Akia (Wikstroemia sandwicensis)-poisonous plant used to catch fish; the bright orange or gold berries are used in making lei; also used for cordage.

Ala'alawainui (Peperomia species)_endemic medicinal plant used to make a tonic for debility, tumors, various internal ailments and uterine problems.

'Alahe'e, 'Ohe'e, Walahe'e (Canthium odoratum) -indigenous tree or shrub used in place of kauila; hardwood used in making an adze to cut the soft wili-wili wood; used for tools to till the soil, o'o digging sticks; it also furnished the small poles for keeping open the mouth of the bag net; the leaves produce a black dye.

'Aweoweo (Chenopodium)-subalpine shrub.

Awikiwiki (Canavalia galeata)-vine for making fish traps.

Ha'a (Antisdema platyphyllum)_or Hame, native tree, used in house building; suitable for fuelwood.

Ho'awa, Ha'awa (Pittosporum terminalioides) - suitable for fuelwood.

Holei (Ochrosia species)_used as yellow dye for tapa.

${ }^{61}$ This is the list of Hawaiian plants found in Southeast Maui according to expert botanist and informant Renee Silva. A longer list of Hawaiian plants and cultural uses is contained in a report by L. Minerbi, D. McGregor, and J. Matsuoka, June, 1993. The report is entitled, Native Hawaiian and Local Cultural Assessment Project Phase I: Problems/Assets Identification. Honolulu, HI.: University of Hawai' $i$. This list of Hawaiian plants was used as a checklist in the interview with Mr. Silva who described Hawaiian plants and their geographical location and range (See Appendix M, Interview with Renee Silva). 
'Ihi (Portulaca vilosa)-prostrate to ascending, succulent, perennial herb with yellow flowers. Grows on lava and on shores. Edible, leaf infusion used to treat tuberculosis and asthma; medicinal root.

'Ili-ahi, 'Iliahialo'e (Santalum) - sandalwood, shrub, used as fragrance to scent tapa and later on for other commercial uses.

'Ili'e (Plumbago zeylanica)-the juice from the roots was used to make tattooing pigments.

'Ilima (Sida fallax) - used to decorate the altar of the halau Hula; the flowers are used to make lei and for mild laxative for babies.

Kauila (Alphintonia ponderosa or Colubrina oppositifolia) - hard wood excellent for spears, tap beaters; for making ' 0 ' 0 , digging sticks; for making fish baited sticks to trail from a canoe, for making fine 'auamo, carrying poles, etc.; now this plant is rare.

Kauna'oa Pehu (Cassytha filiformis)-leafless, herbaceous, parasitic vine coastal and lowland. various medical use, shampoo/hair conditioner use in Polynesia.

Kauna'oa (Cuscuta sandwichiana) - stem infusion used to treat different ailments.

Koa (Akacia koa) -the largest trees, canoes, surf-boards, hoe, or paddles, spears and calabashes.

Koali 'awa (Ipomoea indica)-medicinal plant used as purge and in treating broken bones and body aches.

Ko'oko'olau (Bidens) _endemic medicinal plant used as a tonic and for throat, stomach and asthma; an herb used to make a tonic tea.

Kupaoa, Na'ena'e, Hanupaoa, Hina'aikamalama, Ne'ine‘i (Daubatia subgenus raillardia)-its leaves were used to scent tapa.

Lama (Diospyros sandwicensis) —endemic ebony, its wood was used in house construction and for erecting enclosures for certain idols; used on the altar for Laka, the goddess of Hula. Fruits were eaten.

Maile (Alyxia oliviformis)_associated with the worship of the gods; represented the four Maili sisters, legendary sponsor of Hula; used to make lei and scent tapa.

Makaloa (Cyperus laevigatus)—sedge, used for making sleeping mats.

Mai'a (Musa acuminata)_banana, used to decorate the altar of the halau Hula.

Moa (Psilotum nudum)-stems brewed into a tonic for body pains and as a laxative.

Naio (Myoporum sandwicense)-hard wood and sweet scented wood; used for hale posts and thatching poles.

Naupaka Kahakai (Scaevola taccada)_littoral shrub, medicinal plant; root bark pounded to treat cuts and punctures. 
Nehe (Lipochaeta)-Shrub.

Nena, Kipukai (Heliotropium curassavicum)-perennial coastal herb. No recorded use.

$\mathrm{Niu}$ (Cocos nucifera) -the coco palm tree; kinolau (body form) of the god $\mathrm{Ku}$; its fruits are eaten; offered in religious ceremonies; the juice is a drink; the husk is used for rope, cordage aha, the stem is used for making drums; the leaves to make fans, pa'ahi launiu; the puaaniu, niu flower, laua'e leaves, or kupaoa were used to impregnate the $\mathrm{pa}^{\prime} \mathrm{u}$ dyes.

Nohu (Tribulus cistoides)-prostrate perennial herb.

Noni (Morinda citrofilia) - a small tree or shrub, its bark furnish a yellowish-brown dye to stain the tapa yellow; its fruits were eaten in case of famine; also of medicinal use for skin eruptions and cuts and stomach problems and diabetes.

'Ohai (Sesbania tormentosa)-shrub.

'Ohe (Raynoldsia sandwicensis)—reputed to be a poisonous aladian tree, used for making poisonous images.

'Ohe (Bambusa glaucifolia)-the bamboo, used as a fishing pole, when splintered, it is used as a knife.

'Ohi'a (Metrosideros polymorpha)-same as Lehua, a large tree where birds were caught. It grows on the lower mountain slope, it represented the god Kuka 'ohi'a Laka. Its wood was used for: idol making, posts, rafters for houses, enclosures of temples, fuel, sticks to couple double canoe, etc.

'Ohia Lehua (Metrosideros polymorpha)—used for house rafters; bark or young leaves used as a gargle for sore throat.

Olopua (Nestegis sandwicensis)-see: Pua.

Papala Kepau (Pisonia species) - the exudate around seeds was used to catch birds.

Pa'uo Hi'iaka (Jacquemontia ovalifolia)-Prostrate vine with stem, found in rocky and sandy shores. Named by the Goddess Pele "the skirt of Hi 'iaka", as it had grown to cover her baby sister.

Pili (Heteropogon contortus) - a grass used for thatching houses, used in the hula altar to Laka.

Pohuehue (Ipomoea pes-caprae) - the beach morning glory, was used for cordage.

Po'ola (Claoxylon sandwicense)-small native tree; wood used in spear making.

'Uhaloa, or Hi'aloa (Waltheria indica)-weed, medicinal plant, root bark chewed and the juice swallowed or gargled for sore throat and coughs.

'Ulei (Osteomeles Anthyllidifolia)—a tough tree or shrub, used to make thick, heavy darts for skating over the ground in the ihe-pahe'e game; for fish spears; it also furnished the small 
poles for keeping open the mouth of the bag net; used to make 'o'o digging sticks; leaves, flowers and fruits were used in lei will. Fruits were eaten.

Wiliwili (Erythrina sandwicensis) - a leguminous tree, found on dry coral plains and lava flow; it is a very buoyant wood used for making surf-boards and outrigger floats; its seeds are used in the lei wiliwili. 


\section{APPENDIX M}

\section{INTERVIEW WITH RENEE SILVA62}

The back side is very historical, there are many archaeological sites. These sites show how the Hawaiians survived in an extremely dry place. Extreme hardship, with no running streams and hot weather, and a harsh ocean. Hawaiian culture was based on the use of the plants. No matter what the Hawaiians did, plants were involved: fishing, the canoe is from plants, the net, the spears, the ropes, the sail - they're all from plants. Hawaiians could not have survived without the plants, particularly in South Maui. Plants played a major role. One of the value of protecting the plants, aside from scientific and medical use, is that they are closely associated with the Hawaiian culture. So Hawaian culture cannot exist without the plants. Hawailans were planters, expert cultivators. The area has been designated by the Department of Land and Natural Resources a Natural Area Reserve:

The biggest concentration of native plants in South Maui is right in the Auwahi forest. A famous forest, when the scientist Rock went to Auwahi in 1910 is was very impressed. He even found the creeping ohia tree. It's not there anymore. This concentration of plants is famous .... it crosses the road, on both sides. It flourished because of the cloud cover, being fed by the clouds. It's one of the best dry forests in Hawaii. Rock said that it's still a good forest, if we leave it alone. But if we keep putting power lines and houses and goats and cattle, then that's not compatible with the native forest. We'll lose it.

The grass is in the Kanaio area, and underneath the power line there is even Maile, makai side of the highway, in the lava. The Sugar Cane, Acacia Koa, are right behind Lualailua Hills. All Haole koa and Lantana, grow even up to the hill. From the hill, there is a big colony of 'A'ali'i. A rare fern, and Sandalwood, and all kinds of Hawaiian trees, $\mathrm{Ha}^{\prime} \mathrm{O}$, Orohopia, are all in this area. The hill might be slowing down the clouds, there is moisture there. There's a species of Ko'oko'olau at Waiopai, right on the beach. Ahakea, Koa, are trees for canoe-building. There is few Koa trees. The best elevation is about 2,600 feet way up in the clouds. There's a small colony right behind Lualilua Hills. Kupimoi, a nice healthy colony. The Natural Area Reserve is there, because of the Kupaoa plant. Raillardia belongs to this genus. Lineris is the species. Some of them have different names. That is the only colony on Maul. It is right next to the road, so the power line is going right on there. Lama is all along that trench on the side of Okukano Mountain. There is Maile, Mamane, Makaloa, is along the beach. Aki is common grass. At Manowainui there is a nice colony on the beach. Mamaki is way up in Auwahi. Rare Naupaka is at Kamoli Gulch. The one with the yellow flower. That's the only colony on East Maui. Right next, makai side of the road. There's also Nehe, right above it, that's an endangered shrub. Milo is down at Kanaio Beach. Had to be planted, because it's a Polynesian-introduced. Moa, a fern with no leaves, very ancient, 300 million years old. A big colony scattered all around near Kanaio Church. Naio is found makai of the road. Nena is at Waiopai. There was about 10 plants. There's a Hawaiian coconut ... there's several trees on the outside of Pu'ulai, right in middle of La Perouse Bay. But that tree is doomed it cannot pollinate itself. There is Nehe. Another endangered species, not listed. There's one more in Lualilua Hills, inside the road..Forbesiai, is makai the road, near

${ }^{62}$ Renee Silva is recognized as a botany expert who specializes in native Hawaiian plants. He manages a nursery that germinates and grows native plants for replanting in the wild. 
the water tank. Another 1/4 mile on the Kaupo side of Lualilua, near the sandalwood, another Nehe. Nohu grows on the beach at La Perouse Bay. Noni is in La Perouse Bay, in the middle. Ohai, they found a colony just recently at Pu'u Pimoi-it's endangered, close to the power line. It's a beautiful red flower, found especially in Kanaio area. Ohia is right on the highway next to Lualailua Hills, 15-20 quite a few scattered all over. There is Lehua unusual for dry places. It protects all the Hawaiian forests. Underneath the Ohia, there is Maile, ferns, creepers, vines, shrubs-it protects all that. It saves $10-15 \%$ more soil in the ground and almost every native bird feeds on it or nests on it, but at different elevations. One is the canopy, one is half-way; almost all of them use the Ohia, all the hepapites are on the branches. Even the parasites are on the branches. Even small ferns, not moss, not lichen, all grow on the branches and stems. All the insects like it, too. Olopua is all over, actually. Behind Lualailua Hills, there is a nice big colony. All the branches come out from the bottom. That's the one you use to make spears, the digging sticks. Opahi is the one they use to make. Papala Kipau, a tree, used to catch the birds - it is sticky. Haluohiiaka, a vine, is in Waiopai, all along the shoreland. Pia is a Polynesian arrowhead. Pohinahina is along the shoreline at Nu'u. Phuihui is the big one ... it's indigenous at Kanaio Beach. A big stretch in Kanaio Beach. Puola-one or two trees. They're disappearing, they're not endangered yet. By the time you put it on the endangered list, the tree is gone already. Puakala, the poppy with white flowers. Uhaloa there's lots of them all along the Lualailua Hills and the Church. Uhiuhi is a rare tree. It was found all in the back slope and now it's gone. Hardwood tree, throw in the ocean, it sinks. It was on both West and East Maui, but now it's gone. Ulei is at any place along the road. Wiliwili is a leguminous tree, with red seeds. Thousands of them. A very rare grass on the East Coast, Iscamelia brioli, is an endangered species. There's one named Tetramalopium Sylviai-found on Maui and Molokai, on the Halawa end, and the Kanahena the line is going through one sensitive place. The blind shrimp is found there. There's a little pond there, about $1 / 2$ to $1 / 4$ of an acre, inside the Natural Area Reserve. Ahakea is in the Kanaio forest. That's a rare tree you don't find in Auwahi. Ahuhua is on the coast, on this side of La Perouse Bay. Ahuava is at Waiopai, close to the ocean, just past Manowainui, it is used for fiber strainers. There's plenty Akia. Poisonous plant used to catch fish; bright orange gold berries used in making leis. The scientific name is Montekoala. Akia is scattered here and there right next to the road, on both sides, hundreds. At Manavainui and Lualailua there are some. There's lots of species, about 15 or 20 . That's a species found in Awahi and comes from St. Johns. Mauka of the road, that one is indigenous. The endemic one, those only found in Hawai' $i$, are most important. Alahe' $e$, there are many around the road from Lualailua running toward Hana. Mauka of the road, mainly. There's one or two scattered ones between Manowainui and the Church. Aumaumau, a ferns. The only place is on Lualailua Hills. Alani is way up mauka. Auwahi has many rare trees. Alena is a medicinal plant that grows on the beach at Kanaio Beach. Ahuhu, Awapuhi are in the area. Aweoweo is up at Auwahi, a very rare vine. One is named for Forbes in 1920, found on this side of Lualailua hills. One is in Kanaio. The Hawaiian name is Awikiwiki. There's a second one called Cantavelia Haleakelentis - found on the backside of Haleakala. One Forbesiai plant is at the East end toward Kanaio, but they think it's extinct. it is in the opposite end of the Awahi forest. Forbes found it one at the Kaupo end.

A rare sage is at Lualilua Hills, it will be in the updated endangered list. The Mehami, one to three at the most, are next to Lualilua Hills. Makaloa, Ma'ipilo, a rare tree is all along the beach at Kanaio. A little bush about $3-4$ feet high. Naio is sandalwood, all along the beach. Nehe is there on the Kanaio Beach. Kanaio is most untouched, a very big area. There is a rare Portulaca at the bottom, Ihi is the Hawaiian name. Lute is not found on the beach ... it's endemic one. ... Halapepe - there's hundreds in Auwahi forest, next to Lualailua. The regular Hau is found in La Perouse Bay. Ho'olei is a rare tree. Awahi, only few trees left. I have 70 
seeds, ripe. I planted them all. Hunakai we planted this. Pornetunatum is a red flower 1,900 feet, parallel with the hill, Mliahi is the rare one. The rare, red one is found on this side of Maui. Dima is on the beach, whole stretch, a rare one. Kahuna noi is called Kauna'oa, right next to the road here, under the power line. Kuskuta is a parasitic plant. Kau'una'oa is makai and mauka of Lualilua Hills. It feeds off other plants. The mountain one isn't orange. The best way to tell the pili is the flower, it's pointed and twisted. It doesn't open up, it lays like that. This crawling one is a different variety. Most of them are upright. This colony is found here. Some creeping ones are in Kahoolawe. That's pili. There was a sedge called Ahu awa, they used it to strain the awa. Mome Mahi pilo grows here. Ahuawa is here. 


\section{INTERNAL DISTRIBUTION}

1. G. E. Courville

2. F. M. Glenn

3-12. R. M. Reed

13. D. E. Reichle

14. J. W. Saulsbury

15. A. C. Schaffhauser
16. R. B. Shelton

17-18. Laboratory Records

19. Laboratory Records-RC

20. Document Reference Section

21. Central Research Library

22. ORNL Patent Section

\section{EXTERNAL DISTRIBUTION}

23. ORNL Site Manager, U.S. Department of Energy, Oak Ridge National Laboratory, P. O. Box 2008, Oak Ridge, Tennessee 37831-6269

24. Andrea Campbell, Department of Energy, Oak Ridge Operations, Bldg. 1714-J, SE-311, Oak Ridge, TN 37831-8739

25. Ross Cordy, State Historic Preservation Division, 33 S. King Street, 6th Floor, Honolulu, HII 96813

26. Theresa Donham, State Historic Preservation Division-Maui, 1325 Lower Main St., Suite 108, Wailuku, HI 96793

27. Virginia H. Goldstein, Director, Hawaii County Planning Commission, 25 Aupuni Street, Room 109, Hilo, HI 96721

28. Hugo Huntzinger, Superintendent, Hawaii Volcanoes National Park, P. O. Box 52, Hawaii Volcanoes National Park, HI 96718-0052

29. Maurice H. Kaya, Energy Program Administrator, Department of Business, Economic Development \& Tourism, 335 Merchant Street, Suite 108, Honolulu, HI 96813

30-34. Allan J. Jelacic, Office of Renewable Energy Conversion (EE-12), U.S. Department of Energy, Forrestal Building, 1000 Independence Ave. SW, Washington, DC 20585

35. Kalvin K. Kobayashi, Energy Program Administrator, Department of Planning, Energy Extension Service Division, County of Maui, 250 S. High Street, Wailuku, HI 96793

36. Mike Lee, Chief, Operations Division, Honolulu Engineer District, Building 230, Fort Shafter, HI 86858-5440

37-46. Jon K. Matsuoka, 2367 Kaululaau St., Honolulu, HI 96813

47. Holly McEldowney, State Historic Preservation Division, 33 S. King Street, 6th Floor, Honolulu, HI 96813

48-52. Davianna McGregor, 1942 Naio St., Honolulu, HI 96817

53-57. Luciano Minerbi, 2444 Hihiwai St. \$2005, Honolulu, HI 96826

58. John Naughton, Pacific Area Office, National Marine Service, National Oceanic and Atmospheric Administration, 2570 Dole Street, Honolulu, HI 96822-2396

59. Manuel Nathenson, U.S. Geological Survey, Geologic Division, Branch of Volcanic and Geothermal Processes, 345 Middlefield Road, M/S 910, Menlo Park, CA 94025

60. Robert Smith, Director, Pacific Island Office, U.S. Fish and Wildlife Service, Prince Kuhio Building, Room 6307, 300 Ala Moana Boulevard, Honolulu, HI 96850

61. Judith C. Stroud, ER-10, Department of Energy, Oak Ridge Operations Office, P. O. Box 2001, Oak Ridge, TN $37831-6600$

62. Lillian D. Trettin, 712 Wakendaw Blvd., Mount Pleasant, SC 29464

63-64. OSTI, U.S. Department of Energy, P. O. Box 62, Oak Ridge, TN 37831 